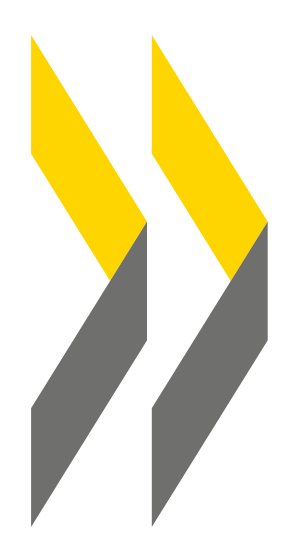

\title{
Pallier la pénurie d'entrepreneurs 2014
}

POLITIQUES D'ENTREPRENEURIAT INCLUSIF EN EUROPE

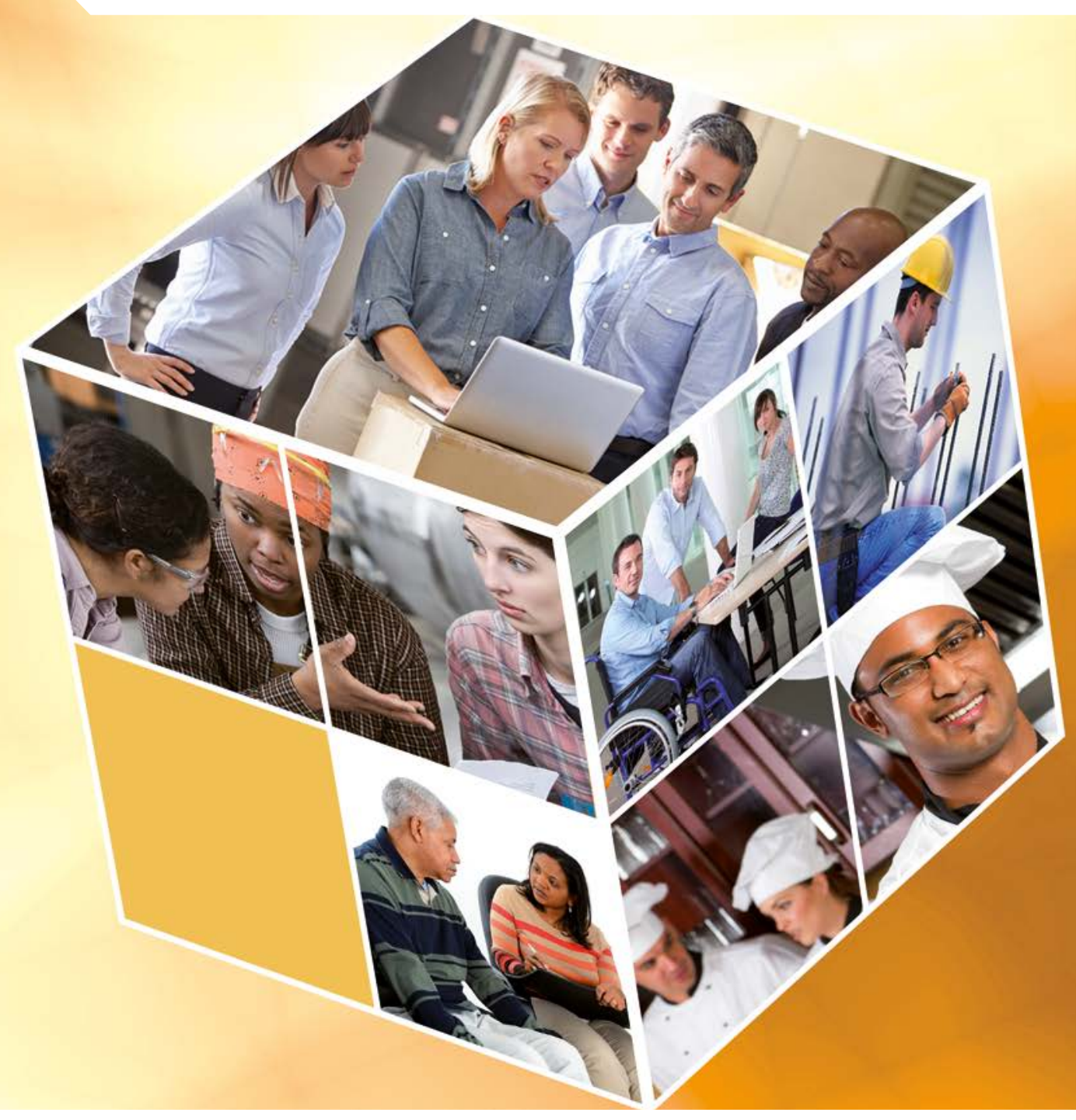

D) $O C D E$

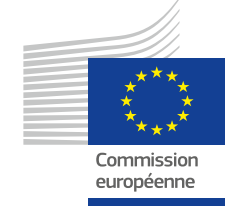




\title{
Pallier la pénurie d'entrepreneurs 2014
}

\author{
POLITIQUES D'ENTREPRENEURIAT \\ INCLUSIF EN EUROPE
}
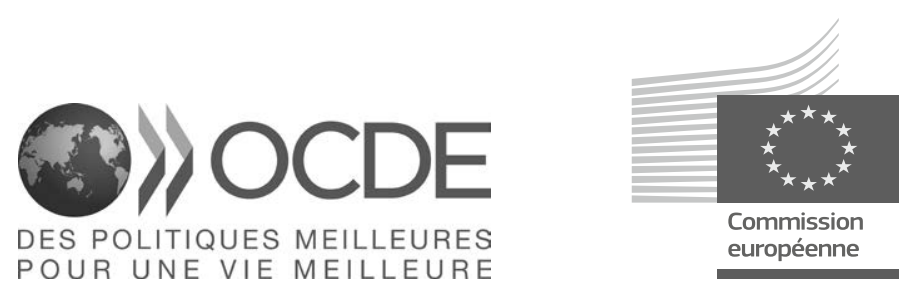
Les opinions et les interprétations exprimées dans cette publication sont la seule responsabilité des auteurs et ne reflètent pas nécessairement les vues de l'Organisation de coopération et de développement économiques (OCDE) ou des gouvernements de ses pays membres ou des États membres de l'Union européenne (UE).

Ce document et toute carte qu'il peut comprendre sont sans préjudice du statut de tout territoire, de la souveraineté s'exerçant sur ce dernier, du tracé des frontières et limites internationales, et du nom de tout territoire, ville ou région.

\section{Merci de citer cet ouvrage comme suit:}

OECD/The European Commission (2015), Pallier la pénurie d'entrepreneurs 2014: Politiques

d'entrepreneuriat inclusif en Europe, OECD Publishing.

http://dx.doi.org/10.1787/9789264230842-fr

ISBN 978-92-64-23083-5 (print)

ISBN 978-92-64-23084-2 (PDF)

Commission européenne

ISBN 978-92-79-38533-9 (print)

ISBN 978-92-79-38530-8 (PDF)

Numéro de catalogue

KE-02-14-710-FR-C (print)

KE-02-14-710-FR-N (PDF)

Crédits photos: Couverture @ ririro/Shutterstock.com, @ auremar - Fotolia.com, ๑ Rob - Fotolia.com, ๑ michaeljung Fotolia.com, ๑ Monkey Business Images/Shutterstock.com, ๑ Stockbyte/Collection/Getty Images, ๑ jetta production/ Collection/Getty Images

Les corrigenda des publications de l'OCDE sont disponibles sur: www.oecd.org/publishing/corrigenda.

๑) OCDE/Union européenne 2015

La copie, le téléchargement ou l'impression du contenu OCDE pour une utilisation personnelle sont autorisés. Il est possible d'inclure des extraits de publications, de bases de données et de produitsmultimédia de l'OCDE dans des documents, présentations, blogs, sites Internet et matériel pédagogique, sous réserve de faire mention de la source et du copyright. Toute demande en vue d'un usage public ou commercial ou concernant les droits de traduction devra être adressée à rights@oecd.org. Toute demande d'autorisation de photocopier une partie de ce contenu à des fins publiques ou commerciales devra être soumise au Copyright Clearance Center (CCC), info@copyright.com, ou au Centre français d'exploitation du droit de copie (CFC), contact@cfcopies.com. 


\section{Préface}

Selon les prévisions, l'économie mondiale devrait repartir au cours des prochaines années et retrouver sa croissance passée. La crise laisse néanmoins dans son sillage un certain nombre de défis économiques et sociaux majeurs, parmi lesquels un chômage durable et des inégalités grandissantes. Près de 26 millions de citoyens de l'Union européenne n'avaient pas d'emploi fin 2013, dont 12,6 millions depuis plus d'un an. En outre, un quart de la population de l'Union européenne est menacée de pauvreté.

Le moment est venu d'agir. Nous avons besoin de politiques qui favorisent la croissance et créent à la fois des opportunités pour tous, afin que les bénéfices de l'activité économique soient largement partagés et que l'ensemble des catégories de la population, y compris les jeunes, les femmes, les personnes âgées, les pauvres et les immigrés, voient leur niveau de vie s'améliorer. La bonne nouvelle est qu'il n'est plus question pour les responsables politiques d'éviter la catastrophe, mais bien de relever ces défis.

Cet ouvrage analyse le rôle que l'entrepreneuriat peut jouer en tant que facteur d'inclusion, en particulier au sein de l'Union européenne. Il décrit l'ampleur et la portée des activités d'indépendant et d'entrepreneuriat exercées par des groupes défavorisés ou sousreprésentés tant au niveau de ces activités que du marché du travail. Il passe également en revue les différents obstacles et conseille les décideurs politiques sur la manière de les surmonter, en mettant l'accent sur la création d'entreprise par les chômeurs, l'entrepreneuriat des minorités ethniques, la conception de services au développement des entreprises et en adaptant les systèmes de sécurité sociale à l'entrepreneuriat et au travail indépendant.

Le message essentiel à retirer de cet ouvrage est que les responsables politiques peuvent faire évoluer les choses, aussi bien du point de vue de l'augmentation du nombre d'entreprises créées par des personnes issues de groupes de population défavorisés et sous-représentés dans le domaine de l'entrepreneuriat, que de l'amélioration de la qualité de leur activité entrepreneuriale. Nombreux sont les exemples de programmes publics ayant soutenu avec succès la création d'entreprises par des personnes défavorisées qui soient viables pour ellesmêmes. Parmi les facteurs déterminants de leur réussite figurent la définition d'objectifs clairs et précis dans le cadre des mesures d'aide destinées à éliminer les obstacles à l'entrepreneuriat auxquels chaque groupe est confronté, et le fait de s'assurer que les bénéficiaires ciblés ont connaissance de l'aide mise à leur disposition et peuvent y accéder facilement.

Malgré les exemples de réussite, les attentes doivent être contenues. L'entrepreneuriat ne convient pas à tout le monde. Il ne constitue pas non plus la réponse universelle au problème du chômage auquel doivent faire face les pays de l'Union européenne. Mais les coûts de l'inaction sont extraordinairement élevés. 
Je voudrais remercier la Commission européenne d'avoir collaboré avec l'OCDE sur ce programme de travail important. J'espère par ailleurs que les responsables politiques aux niveaux national, régional et local mettront à profit les conseils politiques prodigués dans cet ouvrage au moment d'élaborer et d'entreprendre des actions de promotion et de soutien en faveur de l'entrepreneuriat inclusif.

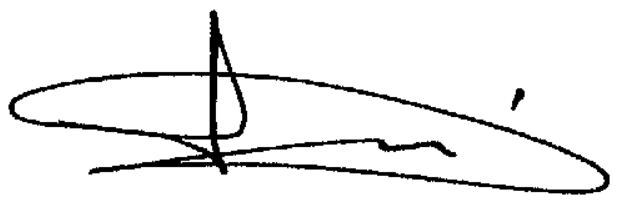

Sergio Arzeni, directeur,

Centre pour l'entrepreneuriat, les PME et le développement local, Organisation de coopération et de développement économiques

La promotion d'un climat favorable à l'entrepreneuriat est essentielle à la création d'emplois. Elle permet de répondre la crise de l'emploi actuelle et de lutter contre l'exclusion sociale. Les effets de la crise économique et financière mondiale nécessitent de renforcer le rôle de l'entrepreneuriat et du travail indépendant dans les politiques de développement économique et social.

La Commission européenne soutient depuis longtemps l'entrepreneuriat, qui constitue l'un des éléments clés de la stratégie Europe 2020. Plus récemment, le plan d'action «Entrepreneuriat 2020» a défini les grandes lignes d'une action décisive destinée à libérer le potentiel entrepreneurial de l'Europe, éliminer les obstacles et révolutionner la culture de l'entrepreneuriat en Europe. L'aide à l'entrepreneuriat et au travail indépendant auprès des personnes les plus exposées au risque d'exclusion sociale est l'un des aspects importants de ce plan. Cette approche de l'entrepreneuriat inclusif n'est pas suffisamment prise en compte en Europe.

Le Fonds social européen constitue un outil majeur que les décideurs politiques peuvent utiliser pour appuyer les mesures en faveur de l'entrepreneuriat inclusif. Le Fonds social européen aide les personnes qui veulent créer leur propre entreprise et travailler comme indépendant. Cette priorité est toujours d'actualité. Dans le cadre de la nouvelle période de programmation 2014-2020, la Commission a encouragé les États membres et les régions à prévoir des mesures ciblées en faveur de l'entrepreneuriat inclusif dans leurs programmes opérationnels au titre de la priorité d'investissement «Travail indépendant, entrepreneuriat et création d'entreprise».

Cet ouvrage, réalisé en partenariat avec l'OCDE, doit être une base de connaissances et une source d'inspiration pour les responsables politiques. Je les invite à utiliser les orientations politiques et les exemples qui y sont développés pour élaborer des mécanismes de soutien à l'entrepreneuriat inclusif.

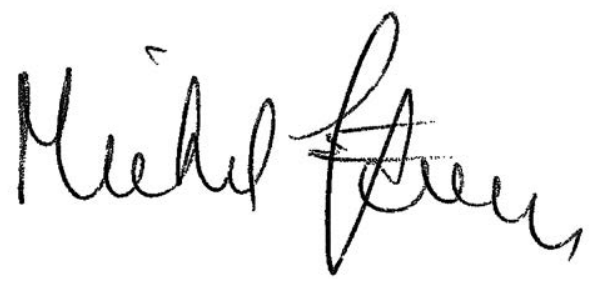

Michel Servoz, directeur général de la direction générale de l'emploi, des affaires sociales et de l'inclusion Commission européenne 


\section{Remerciements}

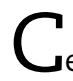

eci est le deuxième rapport issu d'une collaboration de longue haleine entre le Programme pour le Développement économique et la création d'emplois au niveau local (LEED) du Centre pour l'entrepreneuriat, les PME et le développement local de l'OCDE et la Direction générale Emploi, affaires sociales et inclusion de la Commission européenne portant sur les politiques d'entrepreneuriat inclusif en Europe.

Ce rapport a été préparé et publié sous la direction de Jonathan Potter, économiste en chef du Centre pour l'entrepreneuriat, les PME et le développement local de l'OCDE, assisté par David Halabisky, économiste à la Division LEED de l'OCDE, qui s'est chargé d'une bonne partie de la rédaction et de la préparation et qui a coordonné les contributions écrites de divers auteurs.

Les membres du Secrétariat de l'OCDE et les experts externes suivants ont fourni du matériel: Marco Goli, Francis Greene, David Halabisky, Jonathan Potter, Shahamak Rezaei, Jacqueline Snijders, Stuart Thompson, Amber van der Graaf et Karl Wennberg. Sergio Destefanis, Heike Grimm, Giuseppe Lubrano Lavadera et Nadine Levratto y ont également contribué.

Ce rapport a bénéficié de commentaires et d'apports de la Commission européenne, Direction générale Emploi, affaires sociales et inclusion, ainsi que de contributions majeures de Ciprian Alionescu, Anstasios Bisopoulos, Laura Catana, Marco Fantini, Katarina Lindahl, Andrea Maier, Frédéric Merméty, Michal Petrik, Isabelle Prondzynski et Filip Tanay. Quant à l'OCDE, elle a instauré un comité directeur composé de Carin Holmquist, Iñaki Peña, David Smallbone, Roy Thurik et Friederike Welter en vue de guider la publication; ce comité a par ailleurs émis des remarques et des suggestions précieuses.

Nous remercions la Direction Statistiques de l'OCDE ainsi que Niels Bosma et Jonathan Levie de la Global Entrepreneurship Research Association pour leurs données pertinentes.

Un certain nombre de correspondants nationaux ont contribué aux descriptions de politiques des chapitres II et IV de ce rapport, à savoir: Leonie Baldacchino, Inga Blaziene, Sergio Destefanis, Anca Dodescu, Ladislav Faigl, Paula Fitzsimmons, Elias Hadjielias, Henri Hakala, Eva Heckl, Carin Holmquist, Annemarie Jepsen, Marina Kaas, Dimitris Karantinos, Teemu Kautonen, Giuseppe Lubrano Lavadera, Jonathan Levie, Nadine Levratto, Augusto Medina, Rui Monteiro, Iñaki Peña, Anna Pilková, Panikkos Poutziouris, Shirley Pulis-Xerxen, Olga Rastrigina, Petra Reszkető, Slavica Singer, Karin Širec, Jacqueline Snijders, Patrick Thill, Douglas Thompson, Kiril Todorov, Amber van der Graaf, Elisa Veronesi, Krzysztof Wach, Friederike Welter et Patrizia Zanoni. 



\section{Table des matières}

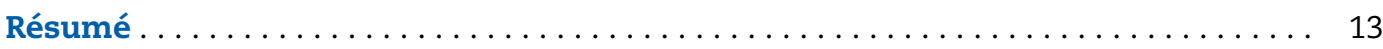

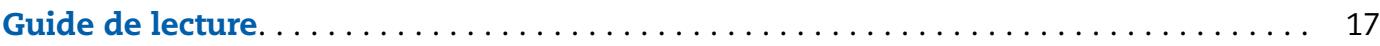

Chapitre 1. La politique d'entrepreneuriat inclusif de l'Union européenne ......... 23

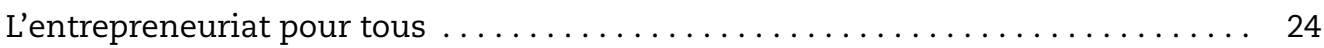

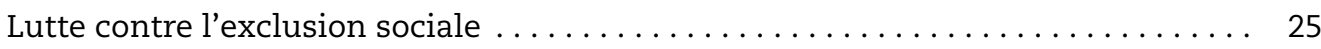

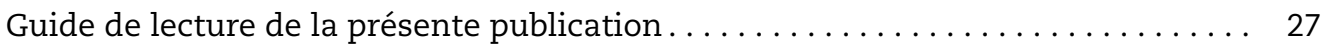

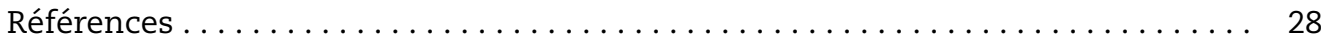

Partie I

Les activités d'entrepreneuriat inclusif en Europe

Chapitre 2. Le travail indépendant et l'entrepreneuriat chez les femmes......... 31

Le travail indépendant chez les femmes. . . . . . . . . . . . . . . . 32

Activités exercées par des femmes tout au long du cycle de vie entrepreneuriale . 36

Entraves à la création d'entreprise par des femmes . . . . . . . . . . . . 39

Heures de travail des femmes indépendantes.................. 41

Revenu des indépendantes . . . . . . . . . . . . . . . . . . . . 43

Prévisions de croissance chez les femmes entrepreneurs . .............. 45

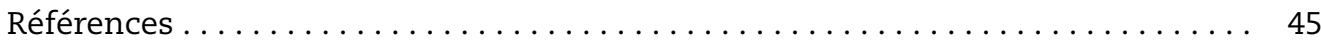

Chapitre 3. Le travail indépendant et l'entrepreneuriat chez les jeunes . . . . . . . 47

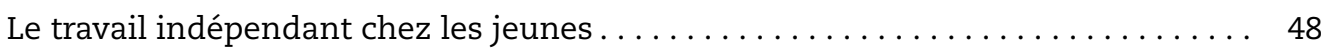

Activités exercées par les jeunes tout au long du cycle de vie entrepreneuriale . . . 52

Entraves à la création d'entreprise par des jeunes ................. 55

Revenu des jeunes indépendants. . . . . . . . . . . . . . . . . . 57

Prévisions de croissance chez les jeunes entrepreneurs . . . . . . . . . . . 57

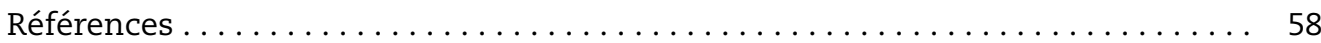

Chapitre 4. Le travail indépendant et l'entrepreneuriat chez les seniors . . . . . . . . 59

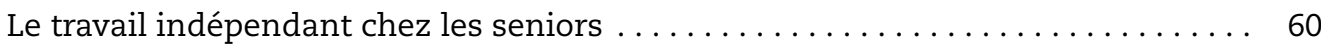

Activités exercées par les seniors tout au long du cycle de vie entrepreneuriale. . . 64

Entraves à la création d'entreprise par des seniors................ 67

Revenu des seniors indépendants . . . . . . . . . . . . . . . . . 69

Prévisions de croissance chez les entrepreneurs seniors. . . . . . . . . . . . 69

Références ............................................. 70

Chapitre 5 . Localisation des activités entrepreneuriales................. 71

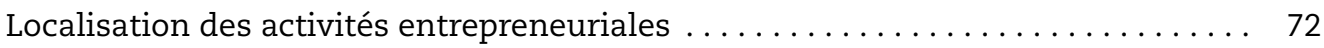

Localisation des activités entrepreneuriales au stade précoce par sexe et par âge $\quad 73$

Références ...................................... 75 


\section{Partie II \\ Les politiques d'entrepreneuriat inclusif}

Chapitre 6. Politiques en faveur de l'entrepreneuriat des chômeurs

Potentiel de créateurs d'entreprise et de travailleurs indépendants

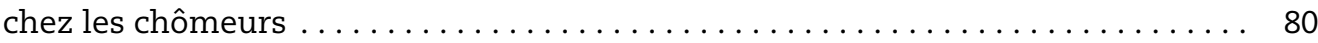

Entraves à la création d'entreprise par des chômeurs . . . . . . . . . . . 83

Mesures politiques en faveur de l'entrepreneuriat des chômeurs .......... 86

Conclusions et recommandations politiques. . . . . . . . . . . . . . . . 96

Annexe 6 A1. . . . . . . . . . . . . . . . . . . . . . . . . . . . . . . 99

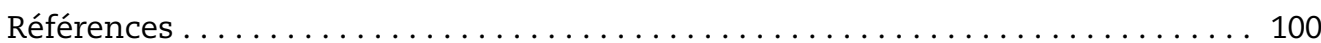

Chapitre 7. Soutien politique en faveur de l'entrepreneuriat des minorités ethniques. . 105

Potentiel de création d'entreprise et de travail indépendant

chez les minorités ethniques . . . . . . . . . . . . . . . . . . 106

Entraves à la création d'entreprise par des minorités ethniques . . . . . . . . 111

Actions politiques en faveur des entrepreneurs issus de minorités ethniques . . . 117

Atteindre les bénéficiaires au sein des minorités ethniques . . . . . . . . . . . . 125

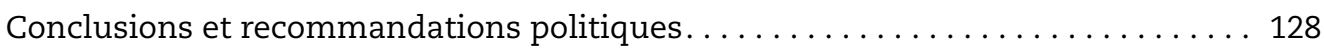

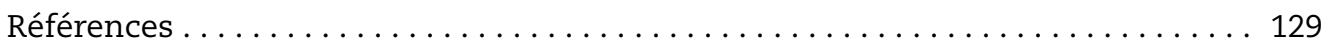

Chapitre 8. Services d'aide au développement des START-UP . . . . . . . . . . . . 133

Justification des services d'aide au développement des start-up . . . . . . . . . . 134

Approches de politique publique concernant la prestation des services d'aide

au développement des entreprises . . . . . . . . . . . . . . . . . . 135

Offrir des services d'aide au développement des entreprise . . . . . . . . . . . 144

Conclusions et recommandations politiques. . . . . . . . . . . . . . . . 149

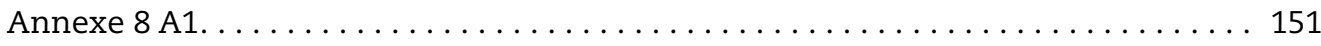

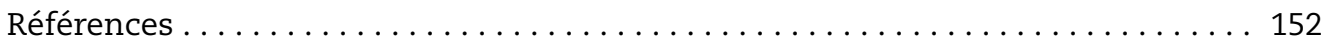

Chapitre 9. Sécurité sociale et Entrepreneuriat inclusif. .................. 155

Systèmes de sécurité sociale. . . . . . . . . . . . . . . . . . . . . 156

Influence des systèmes de sécurité sociale sur l'entrepreneuriat. . . . . . . . 156

Approches politiques destinées à atténuer les effets dissuasifs

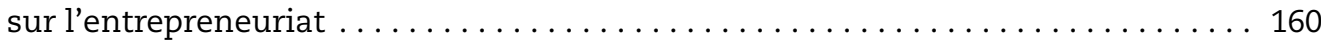

Conclusions et recommandations politiques................... 168

Références ... . . . . . . . . . . . . . . . . . . . . . . . . . . . . . . . . . . . . 169

Partie III

Profils des pays

Chapitre 10. Données et pratiques instructives en matière de politique

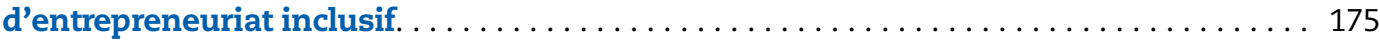

Autriche: programme d'aide à la création d'entreprise UGP

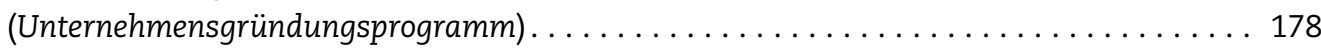

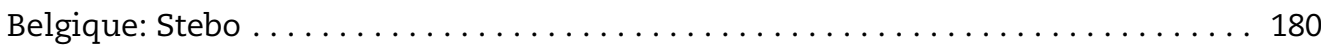

Bulgarie: Social Entrepreneurship — Popularisation and Support

for Social Enterprises . . . . . . . . . . . . . . . . . . . . . . . . . . . . . . 182 
Croatie: «It's time for women» . . . . . . . . . . . . . . . . . . . . . . . . 184

Chypre: Grant Scheme for the Enhancement of Youth Entrepreneurship . . . . . . 186

République tchèque: Build your own enterprise as a way to connect

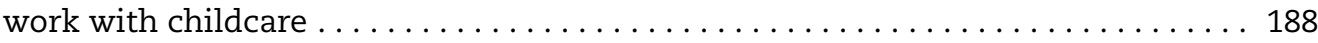

Danemark: promotion de l'entrepreneuriat à Bornholm . . . . . . . . . . . . . 190

Estonie: programme de microcrédit de l'ETNA pour les femmes entrepreneurs

des zones rurales . . . . . . . . . . . . . . . . . . . . . . . . 192

Finlande: Women's Enterprise Agency . . . . . . . . . . . . . . . . . . 194

France: Fonds de garantie pour la création, le rachat ou le développement

d'entreprises initiées par des femmes . . . . . . . . . . . . . . . . . . . . . 196

Allemagne: Schüler-Institut für Technik und angewandte Informatik (SITI). . . . . . . . 198

Grèce: coopératives sociales à responsabilité limitée pour les personnes

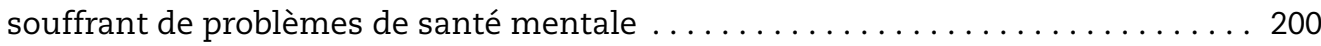

Hongrie: programme MeXX, 2004-2009 . . . . . . . . . . . . . . . . . . . . 202

Irlande: National Women's Enterprise Day. . . . . . . . . . . . . . . . . . . . . . 204

Italie: Programme Starting a Business (dans le cadre de la stratégie Giovanisì

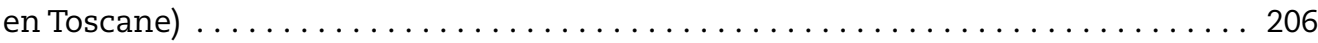

Lettonie: Business incubators in the Latvian regions . . . . . . . . . . . . . . . 208

Lituanie: First business year baskets for youth $\ldots \ldots \ldots \ldots \ldots \ldots \ldots \ldots \ldots \ldots$

Luxembourg: Jonk Entrepreneuren Luxembourg. . . . . . . . . . . . . . . . . . . 212

Malte: projet Hands-on . . . . . . . . . . . . . . . . . . . . . . . . . 214

Pays-Bas: «IkStartSmart», Gueldre . . . . . . . . . . . . . . . . . . . . 216

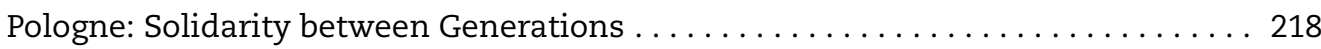

Portugal: Best Form — Boosting Entrepreneurship Tools for Migrants . . . . . . . . 220

Roumanie: A chance for those in rural areas . . . . . . . . . . . . . . . 222

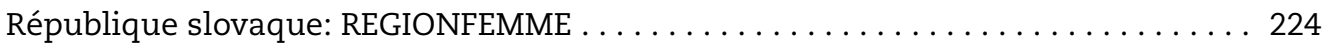

Slovénie: Entrepreneurially into the world of business $2013 \ldots \ldots \ldots \ldots \ldots 226$

Espagne: Programa operativo de la Comunidad Foral de Navarra 2007-2013

(soutenir le travail indépendant en Navarre 2007-2013) . . . . . . . . . . . . . 228

Suède: Ambassadors for Women's Entrepreneurship . . . . . . . . . . . . . . . . . 230

Royaume-Uni: programme Local Enterprise Growth Initiative (LEGI) . . . . . . . . 232

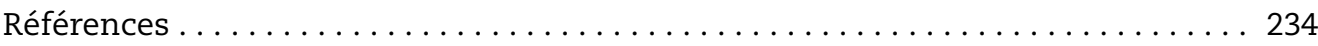

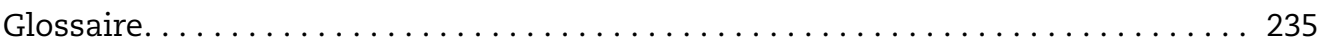

Tableaux

6.1. Types de compétences requises de la part des entrepreneurs . . . . . . . . . . . . 85

6.2. Évaluation du succès des aides aux start-up ......................... 93

9.1. Taux de cotisation aux régimes de sécurité sociale, 2010 (en \% du salaire) . . . . . . . 157

9.2. Vue d'ensemble des principales politiques de pont social en Europe. . . . . . . . . . . . 162

10.1. Inventaire des mesures politiques décrites . . . . . . . . . . . . . . . . . . . 177 
Graphiques

1.1. Proportion de la population menacée de pauvreté ou d'exclusion sociale,

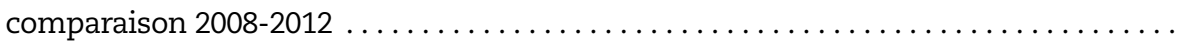

1.2. Part du soutien aux start-up dans les dépenses de la PAMT au sein de l'UE-28,

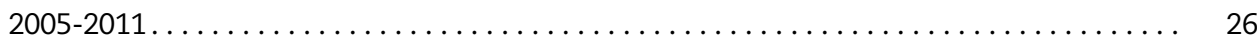

1.3. Part du soutien aux start-up dans les dépenses de la PAMT, 2011. . . . . . . . . . 27

2.1. Taux de travail indépendant des hommes et des femmes dans l'UE-28, 2002-2012 ... 32

2.2. Taux de travail indépendant des hommes et des femmes, 2002-2012 . . . . . . . . . 33

2.3. Proportion des indépendants (hommes et femmes) employant des salariés dans l'UE-28, 2002-2012. ......................................

2.4. Proportion des indépendants (hommes et femmes) employant des salariés,

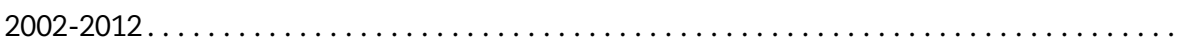

2.5. Répartition des hommes et femmes indépendants par secteur professionnel

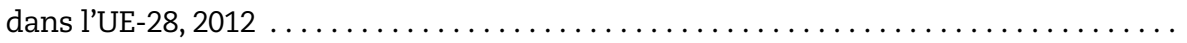

2.6. Taux d'entrepreneuriat naissant chez les hommes et les femmes, 2008-2012 (combinés)

7. Taux de détention de nouvelles entreprises chez les hommes et les femmes, 2008-2012 (combinés)

Taux de détention d'entreprises établies chez les hommes et les femmes, 2008-2012 (combinés)

2.9. Attrait pour le travail indépendant et faisabilité chez les hommes et les femmes

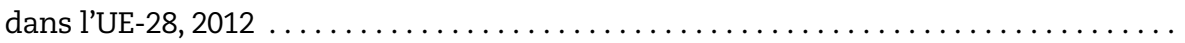

2.10. Entraves au travail indépendant des hommes et des femmes dans l'UE-28, 2012. . . .

2.11. Nombre moyen d'heures de travail hebdomadaires chez les indépendants (hommes et femmes) dans l'UE-28, 2002-2012. ........................

2.12. Nombre moyen d'heures hebdomadaires travaillées chez les hommes

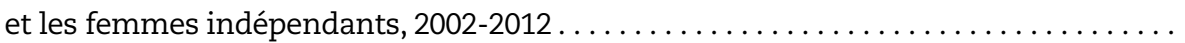

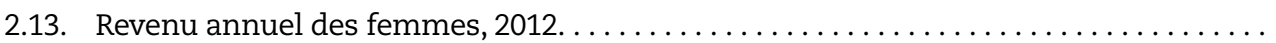

2.14. Revenu du travail indépendant des hommes et des femmes, 2012 ..............

2.15. Principales sources de revenu des indépendants (hommes et femmes)

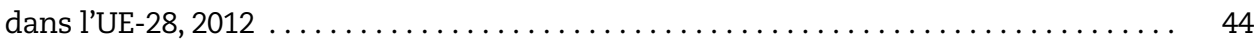

2.16. Prévisions de croissance chez les entrepreneurs (hommes et femmes), $2008-2012$ (combinés) . . . . . . . . . . . . . . . . . . . . . . . . . . . . 45

3.1. Taux de travail indépendant des jeunes dans l'UE-28, 2002-2012 . . . . . . . . . . 48

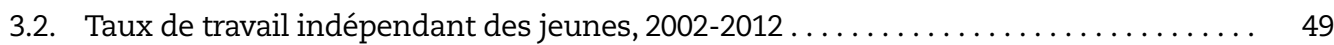

3.3. Proportion des jeunes indépendants employant des salariés dans l'UE-28,

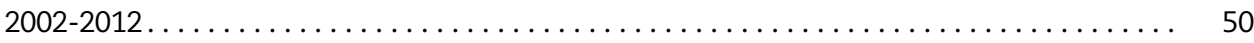

3.4. Proportion des jeunes indépendants employant des salariés, 2002-2012 . ........ 51

3.5. Répartition des jeunes indépendants par secteur professionnel dans l'UE-28, 2012 .. 52

3.6. Taux d'entrepreneuriat naissant chez les jeunes, 2008-2012 (combinés). ......... 53

3.7. Taux de détention de nouvelles entreprises chez les jeunes, 2008-2012 (combinés). . . 54

3.8. Taux de détention d'entreprises établies chez les jeunes, 2008-2012 (combinés) . . 55

3.9. Attrait pour le travail indépendant et faisabilité chez les jeunes dans l'UE-28, 2012 .. 56

3.10. Entraves au travail indépendant des jeunes dans l'UE-28, 2012 . . . . . . . . . . 56

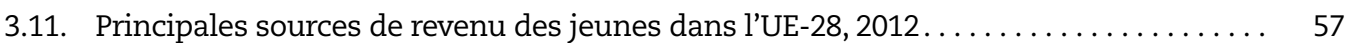

3.12. Prévisions de croissance chez les jeunes entrepreneurs, 2008-2012 (combinés) ... 58

4.1. Taux de travail indépendant des seniors dans l'UE-28, 2002-2012 ............. 60 
4.2. Taux de travail indépendant des seniors, $2002-2012 \ldots \ldots \ldots \ldots \ldots \ldots \ldots \ldots \ldots \ldots$

4.3. Proportion des seniors indépendants employant des salariés dans l’UE-28, 2002-2012. . 62

4.4. Proportion des seniors indépendants employant des salariés, 2002-2012 . . . . . . 63

4.5. Répartition des seniors indépendants par secteur professionnel dans l'UE-28, 2012 . . 64

4.6. Taux d'entrepreneuriat naissant chez les seniors, 2008-2012 (combinés) . . . . . 65

4.7. Taux de détention de nouvelles entreprises chez les seniors, 2008-2012 (combinés) .. 66

4.8. Taux de détention d'entreprises établies chez les seniors, 2008-2012 (combinés) . . . . 67

4.9. Attrait pour le travail indépendant et faisabilité chez les seniors dans l'UE-28, 2012 . . 68

4.10. Entraves au travail indépendant des seniors dans l'UE-28, $2012 \ldots \ldots \ldots \ldots \ldots \ldots$

4.11. Principales sources de revenu des seniors dans l'UE-28, $2012 \ldots \ldots \ldots \ldots \ldots \ldots \ldots$

4.12. Prévisions de croissance chez les entrepreneurs seniors, 2008-2012 (combinés) . . . . 70

5.1. Localisation des activités entrepreneuriales dans l'UE, $2012 \ldots \ldots \ldots \ldots \ldots \ldots \ldots$

5.2. Localisation des activités entrepreneuriales au stade précoce (hommes et femmes)

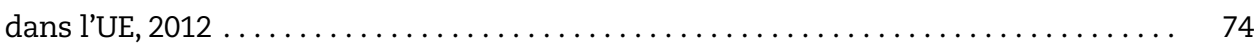

5.3. Localisation des activités entrepreneuriales au stade précoce par âge dans l'UE, 201274

6.1. Taux de chômage par État membre, $2012 \ldots \ldots \ldots \ldots \ldots \ldots \ldots \ldots \ldots \ldots \ldots \ldots \ldots$

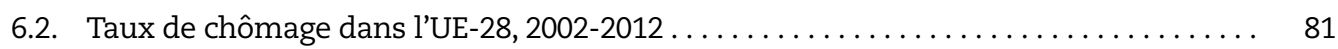

6.3. Potentiel de travailleurs indépendants chez les chômeurs, $2011 \ldots \ldots \ldots \ldots \ldots \ldots . \quad 82$

6.4. Potentiel de travailleurs indépendants chez les chômeurs dans l'UE-28, 2002-2011 .. 83

6.5. Une réponse politique globale en faveur de l'entrepreneuriat des chômeurs. . . . . . . 87

7.1. Proportion des travailleurs indépendants nés en dehors de l'UE, $2012 \ldots \ldots \ldots \ldots$. . . 107

7.2. Taux de travail indépendant par lieu de naissance et par État membre, 2012 . . . . . 108

7.3. Proportion des indépendants nés à l'étranger, comparaison 2004-2006 et 2009-2011. . 108

7.4. Proportion d'indépendants employant des salariés par lieu de naissance, 2012 . . . . 109

7.5. Taux de survie des entreprises gérées par des immigrés (France) . . . . . . . . . . 110

7.6. Proportion d’indépendants ayant suivi des études supérieures

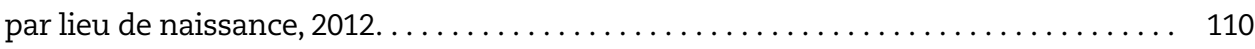

8.1. Services d'aide au développement des start-up . . . . . . . . . . . . . . . 136

11.1. Données relatives à l'entrepreneuriat et au travail indépendant en Autriche . . . . . . 179

12.1. Données relatives à l'entrepreneuriat et au travail indépendant en Belgique . . . . . . 181

13.1. Données relatives à l'entrepreneuriat et au travail indépendant en Bulgarie. . . . . . . 183

14.1. Données relatives à l'entrepreneuriat et au travail indépendant en Croatie. . . . . . . . 185

15.1. Données relatives à l'entrepreneuriat et au travail indépendant à Chypre . . . . . . . . 187

16.1. Données relatives à l'entrepreneuriat et au travail indépendant

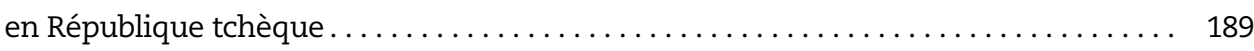

17.1. Données relatives à l'entrepreneuriat et au travail indépendant au Danemark. . . . . 191

18.1. Données relatives à l'entrepreneuriat et au travail indépendant en Estonie . . . . . . . 193

19.1 Données relatives à l'entrepreneuriat et au travail indépendant en Finlande . . . . . . 195

20.1. Données relatives à l'entrepreneuriat et au travail indépendant en France . . . . . . . . 197

21.1. Données relatives à l'entrepreneuriat et au travail indépendant en Allemagne . . . . . 199

22.1. Données relatives à l'entrepreneuriat et au travail indépendant en Grèce . . . . . . . . 201

23.1. Données relatives à l'entrepreneuriat et au travail indépendant en Hongrie . . . . . . . 203

24.1. Données relatives à l'entrepreneuriat et au travail indépendant en Irlande. . . . . . . 205

25.1. Données relatives à l'entrepreneuriat et au travail indépendant en Italie. . . . . . . . . 207

26.1. Données relatives à l'entrepreneuriat et au travail indépendant en Lettonie. . . . . . . 209

27.1. Données relatives à l'entrepreneuriat et au travail indépendant en Lituanie. . . . . . . 211

28.1. Données relatives à l'entrepreneuriat et au travail indépendant en Luxembourg . . . . . 213 
29.1. Données relatives à l'entrepreneuriat et au travail indépendant à Malte . . . . . . . 215

30.1. Données relatives à l'entrepreneuriat et au travail indépendant aux Pays-Bas . . . . . 217

31.1. Données relatives à l'entrepreneuriat et au travail indépendant en Pologne . . . . . . . 219

32.1. Données relatives à l'entrepreneuriat et au travail indépendant au Portugal. . . . . . . 221

33.1. Données relatives à l'entrepreneuriat et au travail indépendant en Roumanie. . . . . . 223

34.1. Données relatives à l'entrepreneuriat et au travail indépendant en République slovaque .............................. 225

35.1. Données relatives à l'entrepreneuriat et au travail indépendant en Slovénie . . . . . . 227

36.1. Données relatives à l'entrepreneuriat et au travail indépendant en Espagne. . . . . . . 229

37.1. Données relatives à l'entrepreneuriat et au travail indépendant en Suède. . . . . . . . 231

38.1. Données relatives à l'entrepreneuriat et au travail indépendant au Royaume-Uni. . . 233

\section{Suivez les publications de l'OCDE sur:}

http://twitter.com/OECD_Pubs

f http://www.facebook.com/OECDPublications

in. http://www.linkedin.com/groups/OECD-Publications-4645871

You $h$ tube $h: / / w w w . y o u t u b e . c o m / o e c d i l i b r a r y$

OECD http://www.oecd.org/oecddirect/

\section{Ce livre contient des...}

En bas des tableaux ou graphiques de cet ouvrage, vous trouverez des StatLinks तiाs de retranscrire dans votre navigateur Internet le lien commençant par: http://dx.doi.org, ou de cliquer sur le lien depuis la version PDF de l'ouvrage. 


\section{Résumé}

$\mathrm{D}$

ans l'imaginaire collectif, l'entrepreneur européen type est un homme, blanc et riche. En réalité, la plupart des entrepreneurs ne rentrent pas dans cette catégorie. Au contraire, ils sont issus de milieux très divers. Plusieurs groupes sociaux (p.ex. les femmes, les jeunes, les seniors, les chômeurs et les personnes handicapées) sont toutefois sous-représentés dans la sphère entrepreneuriale ou davantage pénalisés que la majorité des gens lorsqu'il s'agit de créer une entreprise. Au vu de l'apport considérable de l'entrepreneuriat en termes de croissance économique et de création d'emplois, l'UE ne peut pas se permettre de ne pas capitaliser sur le potentiel qu'offrent les personnes issues des groupes sous-représentés ou défavorisés.

Ce rapport analyse les données disponibles sur la création d'entreprise et le travail indépendant pour chacun des différents groupes sociaux au sein des États membres de l'UE, en mettant l'accent sur les personnes qui ne font pas partie de l'entrepreneuriat traditionnel. À titre d'exemple, en 2012, sur 30 millions de travailleurs indépendants dans l'Union européenne, seulement $30 \%$ étaient des femmes. De la même manière, seuls $3 \%$ des indépendants se situaient dans la tranche d'âge des 15-24 ans. On est loin de l'image d'une société inclusive où l'entrepreneuriat serait ouvert à tous. Le rapport montre également qu'un tiers des nouveaux entrepreneurs exercent leurs activités à domicile. La proportion est plus grande encore dans le cas des femmes et des seniors.

Si l'on veut développer davantage les activités entrepreneuriales au sein des groupes sous-représentés et défavorisés, il est important de comprendre les obstacles auxquels ils se heurtent. Le rapport révèle, par exemple, que les jeunes sont deux fois plus nombreux que les adultes à désigner le manque de compétences entrepreneuriales (18\% contre $8 \%$ ) comme un obstacle à la création d'entreprise. Toujours selon le rapport, les femmes sont généralement plus nombreuses que les hommes à estimer qu'il est difficile de concilier direction d'une entreprise et responsabilités familiales ( $8 \%$ contre $4 \%$ ). Il faut s'attaquer à ces obstacles pour garantir à chacun, quels que soient ses antécédents et ses caractéristiques personnelles, une chance égale de diriger une entreprise et d'exercer une activité indépendante.

Les politiques d'entrepreneuriat inclusif ont aussi pour but de combler les disparités qui affectent les groupes sociaux défavorisés, comme en témoignent par exemple les niveaux extrêmement bas des chiffres d'affaires et des revenus des indépendants et les taux de survie des entreprises détenues par des femmes, des jeunes ou des immigrés, comparés à ceux du reste de la population. Les créateurs d'entreprise issus de ces groupes doivent être orientés vers des activités qui offrent de bonnes perspectives de survie et de revenus. Il est par ailleurs important de les aider à mettre en place des modèles d'entreprise et de gestion d'entreprise de qualité.

Cet ouvrage fait partie d'une série de publications qui se penchent sur la manière de "pallier la pénurie d'entrepreneurs". Dans ce deuxième volume, les chapitres thématiques s'intéressent plus particulièrement à deux groupes défavorisés: les chômeurs 
et les entrepreneurs issus d'une minorité ethnique ou d'origine immigrée. Dans le cas des chômeurs, la création d'entreprise peut être une voie vers l'emploi intéressante et valorisante. Or, souvent, les personnes sans emploi n'ont pas les compétences et les ressources financières nécessaires pour créer une entreprise. Les mécanismes tels que les ponts sociaux instaurés en Allemagne, qui maintiennent le paiement des indemnités de chômage après la création de l'entreprise afin de soutenir la transition vers le travail indépendant, ont été une réussite. Plus de la moitié des participants au programme IchAG exerçaient toujours une activité indépendante à temps plein ou à temps partiel cinq ans après. De plus, les aides financières octroyées dans des pays tels que la France ont fait progresser le taux de survie des entreprises créées par des chômeurs. Il est désormais comparable au taux de survie global des entreprises (72\% après 3 ans contre $79 \%$ ). La mise en place de services de mentorat et de formation en adéquation avec les besoins des chômeurs constitue une autre facette de la solution. Parallèlement à cela, il faut reconnaître que seule une minorité de chômeurs voudra tenter l'expérience du travail indépendant. En moyenne, seulement $3 \%$ des personnes sans emploi en Europe témoignent un intérêt pour la création d'entreprise. Ce sont les chômeurs que la politique d'entrepreneuriat inclusif cible plus spécifiquement.

Les entrepreneurs issus des minorités ethniques ou d'origine immigrée forment un groupe très diversifié. Certains d'entre eux viennent de cultures très entreprenantes, d'autres non. Quoi qu'il en soit, dans les deux cas, les minorités ethniques et les immigrés ont plus de difficultés à créer une entreprise solide que les entrepreneurs autochtones. Par exemple, les nouveaux immigrants peuvent avoir du mal à comprendre les exigences légales, tandis qu'au niveau financier, il est plus probable que les entrepreneurs provenant de minorités ethniques seront obligés de se tourner vers le financement informel et non bancaire. Une réponse politique commune implique de proposer des programmes de formation spécialisée qui permettent aux immigrés et aux minorités ethniques d'élaborer des projets d'entreprise plus solides et d'être mieux informés des possibilités de financement mises à leur disposition. Au Danemark, les Getting Started Camps (camps de démarrage d'activité) proposent aux femmes réfugiées et immigrées une formation à l'entrepreneuriat de deux jours. Trois ans après leur participation, $16 \%$ de ces femmes exerçaient une activité indépendante, contre $3 \%$ au début de ces camps de formation. Le microfinancement ciblé fait également partie des efforts politiques. Par exemple, le programme entrepreneurial Szechenyi, destiné aux populations roms de Hongrie, inclut des subventions (par voie de concours) pouvant atteindre 15000 EUR, des services d'information et des événements de mise en réseau. Il a permis de créer plus de 400 emplois entre 2003 et 2007.

D'autres chapitres de l'ouvrage sont consacrés à la manière de mettre en place et de fournir des services d'aide au développement des entreprises aux groupes défavorisés et sous-représentés, et de redéfinir les systèmes de sécurité sociale de manière à éliminer les obstacles inutiles au travail indépendant et à la création d'entreprise. Les services d'aide au développement des entreprises incluent des services d'information, tels que des descriptions des procédures d'enregistrement des entreprises et des modèles entrepreneuriaux, un accompagnement personnalisé plus intensif et ciblé, du mentorat ou encore des conseils en entreprise. Il est souvent préférable que ce soutien soit apporté par l'intermédiaire d'organisations et de conseillers appartenant aux communautés (femmes, immigrés, par exemple) des entrepreneurs concernés. Il est également important de ne 
pas se focaliser uniquement sur la phase de démarrage d'une entreprise et de fournir un soutien a posteriori.

Les systèmes de sécurité sociale offrent bien souvent une couverture moins généreuse aux indépendants qu'aux salariés ou aux chômeurs. Ces disparités découragent la création d'entreprise ou le travail indépendant, en particulier chez les entrepreneurs issus de groupes sous-représentés ou défavorisés, qui sont davantage susceptibles de solliciter les systèmes de sécurité sociale pour bénéficier d'aides sociales sous de multiples formes, aides qui risquent d'être réduites s'ils deviennent travailleurs indépendants. Les systèmes de sécurité sociale des pays de l'UE sont profondément différents, mais des approches communes peuvent être envisagées pour soutenir l'entrepreneuriat inclusif. Le droit aux allocations de chômage et aux prestations de maternité, de santé ou autres pourrait notamment être étendu aux indépendants. En Finlande, par exemple, une réforme de 2005 a instauré une couverture sociale de base identique pour les salariés et les indépendants.

Enfin, pour chacun des État membre de l'UE, l'ouvrage fournit des données sur l'état des activités dans le domaine de l'entrepreneuriat inclusif ainsi qu'un exemple d'approche politique qui pourrait inspirer les autres.

\section{Principales recommandations politiques}

- Étendre les actions publiques visant à promouvoir l'entrepreneuriat des personnes issues de groupes sous-représentés ou défavorisés, dont les femmes, les jeunes, les seniors, les chômeurs, les immigrés et les minorités ethniques.

- Fournir une aide afin d'améliorer la qualité des entreprises créées par les groupes défavorisés ou sous-représentés, notamment en encourageant les projets d'entreprise sur des marchés où la demande est croissante ou excédentaire et en développant une expertise en gestion d'entreprise.

- Aider les chômeurs motivés et compétents à démarrer une activité en mettant à leur disposition un capital de départ et en leur permettant d'acquérir des compétences entrepreneuriales, en mettant les entrepreneurs sans emploi en relation avec les prestataires d'aide traditionnels tels que les chambres de commerce et les organismes de microcrédit.

- Octroyer les aides selon les préférences de fonctionnement et de communication des groupes de minorités ethniques et d'immigrés, par exemple, en diffusant les programmes de sensibilisation à l'entrepreneuriat par le biais de médias communautaires, en faisant appel à des organisations de prestation d'aides et à des conseillers en développement d'entreprise multiethniques et en soutenant la création ou le renforcement d'associations professionnelles regroupant des minorités ethniques.

- Proposer des programmes de financement et de formation aux entrepreneurs issus de minorités ethniques, y compris des formations linguistiques aux nouveaux immigrants, veiller à ce que les réglementations professionnelles puissent être aisément comprises par les entrepreneurs issus de minorités ethniques et améliorer le suivi de la mise en œuvre des programmes par les groupes de minorités ethniques et immigrés.

- Fournir des offres intégrées de services d'aide au développement des entreprises, combinant services de conseil, d'accompagnement individualisé et de mentorat et aides financières, couvriraient les étapes de prédémarrage, démarrage et post-démarrage de l'entreprise et amélioreraient la coordination et la cohésion des différents programmes. 
- Constituer des équipes de conseillers en entreprise, coaches et mentors accrédités, qualifiés et expérimentés, issus des catégories de population des bénéficiaires ciblés.

- Fournir des informations claires concernant les droits des indépendants en matière de sécurité sociale, y compris une description des interactions entre les différentes allocations et des répercussions inhérentes à leur changement de statut professionnel.

- Prévoir de la flexibilité dans le versement des prestations de sécurité sociale en autorisant les versements forfaitaires afin de soutenir la création d'entreprise et en versant des indemnités ou en maintenant le versement des allocations de chômage pendant une durée déterminée aux chômeurs personnes qui démarreraient une activité.

- Augmenter la couverture sociale des indépendants afin de leur offrir un filet de sécurité comparable à celui des salariés.

- Recourir davantage aux évaluations pour mesurer l'impact des mécanismes d'aide à la création d'entreprise sur l'entrepreneuriat et l'inclusion sociale. Celles-ci porteraient non seulement sur l'efficacité et la rentabilité, mais également sur les effets d'aubaine (personnes qui auraient démarré une entreprise sans aide) et de déplacement (personnes mises en faillite par les bénéficiaires d'aides publiques). 


\section{Guide de lecture}

Ce guide de lecture fournit des informations et des indications méthodologiques concernant les données utilisées dans cet ouvrage: (1) Programme d'indicateurs de l'entrepreneuriat OCDE-Eurostat, (2) Enquête Eurostat sur les forces de travail, (3) Global Entrepreneurship Monitor, (4) Eurobaromètre Flash, (5) Statistiques sur le revenu et les conditions de vie.

Cech chapitre fournit des informations sur chacune des sources de données utilisées dans les parties I et III de cet ouvrage. Il fournit également des indications méthodologiques et décrit les principaux concepts statistiques utilisés. Des renvois et des références sont proposés aux lecteurs qui souhaiteraient obtenir de plus amples informations.

Attention, étant donné que cet ouvrage s'appuie sur plusieurs sources de données, les concepts et définitions de ces sources ne sont pas toujours cohérents. Ces disparités sont plus manifestes lorsque les données sont présentées par âge. Par exemple, l'enquête sur les forces de travail d'Eurostat porte sur les personnes âgées de 15 ans et plus. Ainsi, pour Eurostat, les jeunes désignent tous les individus âgés de 15 à 24 ans. D'autres sources de données, parmi lesquelles le Global Entrepreneurship Monitor, sondent les personnes âgées de 18 à 65 ans et ont dès lors une autre définition de la jeunesse. Pour le Global Entrepreneurship Monitor, les jeunes sont âgés de 18 à 30 ans. Le même problème se pose pour les données relatives aux entrepreneurs plus âgés. Bien que des efforts soient faits pour harmoniser autant que possible les données rapportées, des différences subsistent. Les chiffres et textes indiquent clairement les définitions présentées et discutées.

\section{Programme d'indicateurs de l'entrepreneuriat OCDE-Eurostat}

Mené conjointement par la Direction des statistiques de l'OCDE et Eurostat, le Programme d'indicateurs de l'entrepreneuriat (PIE) OCDE-Eurostat vise à développer des indicateurs de l'entrepreneuriat pertinents sur le plan politique et comparables au niveau international en vue de soutenir les travaux analytiques et de politique relatifs à l'entrepreneuriat. À cette fin, le programme a élaboré un cadre d'analyse et de mesure de l'entrepreneuriat ainsi qu'une méthodologie pour la production de statistiques harmonisées sur l'entrepreneuriat. Ce cadre introduit une distinction conceptuelle entre la performance entrepreneuriale (c.-à-d. le type et la quantité d'entrepreneuriat), les déterminants de l'entrepreneuriat (c.-à-d. les facteurs influençant la performance entrepreneuriale) et les impacts sociaux et économiques de l'entrepreneuriat.

L'implication directe des instituts nationaux des statistiques (INS) de l'OCDE et des pays partenaires en vue de produire des statistiques harmonisées sur l'entrepreneuriat constitue un trait caractéristique de ce programme, qui distingue clairement le PIE d'autres initiatives internationales. Jusqu'à présent, les données produites ont porté sur un ensemble clé d'indicateurs de la performance entrepreneuriale, à savoir les statistiques sur la démographie des entreprises relatives à la naissance, au décès, à la survie et à la croissance des entreprises, ainsi que les statistiques sur l'impact des naissances et décès d'entreprises sur la création et la destruction d'emplois. Les statistiques officielles sont produites chaque année par les INS, conformément à la 
méthodologie figurant dans l'ouvrage Eurostat-OECD Manual on Business Demography Statistics (2007 - $h t t p: / / w w w . o e c d . o r g / s t d / 39974460 . p d f)$. Disponible sur OECD.Stat (http://stats.oecd.org/), cette base de données couvre quelque 25 pays et est mise à jour chaque année.

La méthodologie recommande d'employer des registres d'entreprises pour calculer les indicateurs de démographie des entreprises. Afin d'accroître la comparabilité internationale, et vu l'exclusion des firmes n'employant pas de personnel du registre des entreprises de certains pays, l'unité statistique adoptée pour les données de démographie des entreprises du PIE est l'entreprise comportant au moins un employé. Les sociétés avec personnel sont par ailleurs plus pertinentes, d'un point de vue économique, pour leur contribution à la création d'emplois et leurs plus grandes probabilités d'innovation.

S'agissant d'un programme à long terme, le PIE a été élaboré pour répondre aux nouveaux besoins exprimés par les responsables politiques et la communauté des chercheurs. Dans cette optique, le programme s'est récemment penché sur la question de la mesure de l'entrepreneuriat vert et a commencé à rassembler des indicateurs portant sur les femmes et l'entrepreneuriat. D'autre part, pour répondre à la demande de mises à jour trimestrielles, le programme a établi une nouvelle série d'«indicateurs récents d'entrepreneuriat», qui livre les dernières tendances en matière de créations et de faillites d'entreprises. Sur le plan des déterminants, le PIE a entamé des recherches en vue d'approfondir la compréhension de la comparabilité internationale de données capitales sur les entreprises.

La publication annuelle Panorama de l'entrepreneuriat (http://www.oecd-ilibrary. org/industry-and-services/entrepreneurship-at-a-glance_22266941) présente les principaux résultats ainsi que les développements du PIE.

\section{Encadré 1. Définition de l'entrepreneuriat par l'OCDE-Eurostat}

Introduit en 2006, le Programme d'indicateurs de l'entrepreneuriat OCDE-Eurostat a élaboré des définitions des termes «entrepreneur», «entrepreneuriat» et «activité entrepreneuriale» pour soutenir le développement des indicateurs associés. Le programme reconnaît le désaccord et les diverses perspectives opposant les chercheurs qui se penchent sur cette question et adopte délibérément une approche pragmatique reposant sur deux principes, la pertinence et la mesurabilité. Il importe de souligner que les définitions de l'OCDE et d'Eurostat mettent en exergue la nature dynamique de l'activité entrepreneuriale et sont axées non pas sur les intentions, mais sur les actions. Elles ont pour but de guider la collecte et l'analyse de données:

Les entrepreneurs sont des personnes (propriétaires de leur entreprise) qui cherchent à générer de la valeur via la création ou le développement d'une activité économique en identifiant et en exploitant de nouveaux produits, procédés ou marchés.

L'activité entrepreneuriale est l'action humaine consistant à entreprendre en vue de générer de la valeur via la création ou le développement d'une activité économique en identifiant et en exploitant de nouveaux produits, procédés ou marchés.

L'entrepreneuriat est le phénomène associé à l'activité entrepreneuriale.

Ces définitions distinguent l'activité entrepreneuriale de l'activité professionnelle «ordinaire», et en outre: (i) elles indiquent que des sociétés et autres entreprises peuvent se montrer entrepreneuriales, bien que seuls les individus aux commandes de ces organisations et les détenant peuvent être considérés comme des entrepreneurs, (ii) elles soulignent le fait que l'action entrepreneuriale est manifestée plutôt que planifiée ou voulue, (iii) elles n'assimilent pas l'activité entrepreneuriale à la formation de tout «véhicule» spécifique, qu'il soit formel comme une société constituée, ou informel, bien qu'elles autorisent les statistiques de véhicules spécifiques incarnant l'activité entrepreneuriale, et (iv) bien qu'elles soient définies dans le contexte des entreprises, elles incluent la création de valeur économique, sociale et culturelle.

Source: Ahmad et Seymour (2008). 


\section{Encadré 2. Le cadre d'analyse et de mesure de l'entrepreneuriat du Programme d'indicateurs de l'entrepreneuriat (PIE)}

Le PIE admet qu'aucun indicateur ne suffit à lui seul pour englober la complexité de l'entrepreneuriat. C'est pourquoi il a développé un ensemble de mesures destinées à saisir différents aspects ou différents types d'entrepreneuriat. Appelées «indicateurs de performance entrepreneuriale», ces mesures contribuent à analyser des questions clés telles que: Quel est le taux de création de nouvelles entreprises dans un pays? Combien d'emplois sont ainsi générés? Combien de jeunes entreprises survivent les premières années suivant leur création? Innoveront-elles ou exporteront-elles par la suite? Les entreprises sont-elles le plus souvent fondées par des hommes ou des femmes? Investissent-ils les mêmes secteurs?

En outre, le programme adopte une approche plus complète de la mesure de l'entrepreneuriat en examinant non seulement la manifestation du phénomène entrepreneurial, mais aussi les facteurs qui l'influencent, ceux-ci allant des conditions du marché au cadre réglementaire, en passant par la culture et les conditions d'accès au financement. Alors que certains de ces déterminants sont faciles à mesurer (p.ex. l'existence et le caractère restrictif de lois antitrust ou les coûts administratifs de la constitution d'une nouvelle entreprise dans tel pays), pour d'autres, la difficulté consiste à trouver une mesure appropriée (p.ex. capital-risque et capital venant d'investisseurs-tuteurs) et/ ou à saisir la nature exacte de leur rapport avec l'entrepreneuriat (p.ex. la culture). Le but du PIE est de progresser dans les recherches relatives à ces déterminants moins bien compris et moins facilement mesurables de l'entrepreneuriat.

\begin{tabular}{|c|c|c|c|c|c|c|c|}
\hline \multicolumn{6}{|c|}{ Déterminants } & \multirow{2}{*}{$\begin{array}{l}\text { Performance } \\
\text { entrepreneuriale } \\
\text { Entreprise }\end{array}$} & \multirow{2}{*}{$\begin{array}{l}\text { Impact } \\
\text { Création } \\
\text { d'emplois }\end{array}$} \\
\hline Cadre réglementaire & $\begin{array}{l}\text { Conditions du } \\
\text { marché }\end{array}$ & $\begin{array}{l}\text { Accès au } \\
\text { financement }\end{array}$ & $\begin{array}{l}\text { Création et diffusion } \\
\text { de connaissances }\end{array}$ & $\begin{array}{l}\text { Capacités } \\
\text { entrepreneuriales }\end{array}$ & Culture & & \\
\hline $\begin{array}{l}\text { Obstacles } \\
\text { administratifs à } \\
\text { l'entrée }\end{array}$ & $\begin{array}{l}\text { Législation } \\
\text { antitrust }\end{array}$ & $\begin{array}{l}\text { Accès à } \\
\text { l'emprunt }\end{array}$ & $\begin{array}{l}\text { Investissement en } \\
\text { R\&D }\end{array}$ & $\begin{array}{l}\text { Formation et expérience } \\
\text { des entrepreneurs }\end{array}$ & $\begin{array}{l}\text { Attitude du public face } \\
\text { aux risques }\end{array}$ & $\begin{array}{l}\text { Création } \\
\text { d'emplois }\end{array}$ & $\begin{array}{l}\text { Croissance } \\
\text { économique }\end{array}$ \\
\hline $\begin{array}{l}\text { Obstacles } \\
\text { administratifs à la } \\
\text { croissance }\end{array}$ & Concurrence & $\begin{array}{l}\text { Investisseurs- } \\
\text { tuteurs }\end{array}$ & $\begin{array}{l}\text { Interface université/ } \\
\text { industrie }\end{array}$ & $\begin{array}{l}\text { Formation à la } \\
\text { gestion d'entreprise } \\
\text { et à l'entrepreneuriat } \\
\text { (qualifications) }\end{array}$ & $\begin{array}{l}\text { Attitudes à l'égard des } \\
\text { entrepreneurs }\end{array}$ & $\begin{array}{l}\text { Création de } \\
\text { richesse }\end{array}$ & $\begin{array}{l}\text { Réduction de la } \\
\text { pauvreté }\end{array}$ \\
\hline $\begin{array}{l}\text { Réglementation des } \\
\text { faillites }\end{array}$ & $\begin{array}{l}\text { Accès au } \\
\text { marché intérieur }\end{array}$ & $\begin{array}{l}\text { Accès au } \\
\text { capital-risque }\end{array}$ & $\begin{array}{l}\text { Coopération } \\
\text { technologique entre } \\
\text { les entreprises }\end{array}$ & $\begin{array}{l}\text { Infrastructure } \\
\text { entrepreneuriale }\end{array}$ & $\begin{array}{l}\text { Désir de créer une } \\
\text { entreprise }\end{array}$ & & $\begin{array}{l}\text { Formalisation } \\
\text { du secteur } \\
\text { informel }\end{array}$ \\
\hline $\begin{array}{l}\text { Réglementation } \\
\text { en matière de } \\
\text { santé, sécurité et } \\
\text { environnement }\end{array}$ & $\begin{array}{l}\text { Accès aux } \\
\text { marchés } \\
\text { étrangers }\end{array}$ & $\begin{array}{l}\text { Accès à } \\
\text { d'autres types } \\
\text { de fonds } \\
\text { propres }\end{array}$ & $\begin{array}{l}\text { Diffusion de la } \\
\text { technologie }\end{array}$ & Immigration & $\begin{array}{l}\text { Formation à } \\
\text { l'entrepreneuriat (état } \\
\text { d'esprit) }\end{array}$ & & \\
\hline $\begin{array}{l}\text { Réglementation des } \\
\text { produits }\end{array}$ & $\begin{array}{l}\text { Niveau } \\
\text { d'intervention du } \\
\text { secteur public }\end{array}$ & $\begin{array}{l}\text { Marchés } \\
\text { boursiers }\end{array}$ & Accès au haut débit & & & & \\
\hline $\begin{array}{l}\text { Réglementation du } \\
\text { marché du travail }\end{array}$ & Marchés publics & & & Entreprises & Création d'emplois & Création c & richesse \\
\hline $\begin{array}{l}\text { Système judiciaire et } \\
\text { juridique }\end{array}$ & & & & $\begin{array}{l}\text { Taux de naissance des } \\
\text { entreprises employant } \\
\text { des salariés }\end{array}$ & $\begin{array}{l}\text { Taux d'entreprises à } \\
\text { forte croissance (emploi) }\end{array}$ & $\begin{array}{l}\text { Taux d'entreprise } \\
\text { croissance (chiffr }\end{array}$ & $\begin{array}{l}\text { à forte } \\
\text { d'affaires) }\end{array}$ \\
\hline $\begin{array}{l}\text { Sécurité sociale et } \\
\text { assurance-maladie }\end{array}$ & & & & $\begin{array}{l}\text { Taux de décès des } \\
\text { entreprises employant } \\
\text { des salariés }\end{array}$ & Taux de gazelles (emploi) & i) Taux de gazelles & chiffre d'affaires) \\
\hline $\begin{array}{l}\text { Impôts sur les } \\
\text { revenus; impôts sur le } \\
\text { patrimoine/legs }\end{array}$ & & & & $\begin{array}{l}\text { Taux de renouvellement } \\
\text { des entreprises }\end{array}$ & $\begin{array}{l}\text { t Taux de propriété de } \\
\text { start-up }\end{array}$ & $\begin{array}{l}\text { Valeur ajoutée pa } \\
\text { jeunes ou petites }\end{array}$ & les entreprises \\
\hline \multirow[t]{3}{*}{$\begin{array}{l}\text { Impôts sur les } \\
\text { sociétés et sur le } \\
\text { capital }\end{array}$} & $\begin{array}{l}\text { Système des } \\
\text { brevets; normes }\end{array}$ & & & $\begin{array}{l}\text { Croissance nette } \\
\text { de la population } \\
\text { entrepreneuriale }\end{array}$ & $\begin{array}{l}\text { Taux de propriété } \\
\text { de la population } \\
\text { entrepreneuriale }\end{array}$ & $\begin{array}{l}\text { Contribution à la } \\
\text { entreprises jeune }\end{array}$ & $\begin{array}{l}\text { roductivité des } \\
\text { ou petites }\end{array}$ \\
\hline & & & & $\begin{array}{l}\text { Taux de survie après } 3 \\
\text { et } 5 \text { ans }\end{array}$ & $\begin{array}{l}\text { Emploi dans les } \\
\text { entreprises de } 3 \text { et } 5 \text { ans }\end{array}$ & $\begin{array}{l}\text { Performance de I } \\
\text { les entreprises je }\end{array}$ & $\begin{array}{l}\text { innovation dans } \\
\text { unes ou petites }\end{array}$ \\
\hline & & & & $\begin{array}{l}\text { Proportion } \\
\text { d'entreprises de } 3 \text { et } \\
5 \text { ans }\end{array}$ & $\begin{array}{l}\text { Taille moyenne des } \\
\text { entreprises après } 3 \text { et } \\
5 \text { ans }\end{array}$ & $\begin{array}{l}\text { Résultat à l'expor } \\
\text { entreprises jeune }\end{array}$ & $\begin{array}{l}\text { tation des } \\
\text { ou petites }\end{array}$ \\
\hline
\end{tabular}

Source: OECD (2013), Entrepreneurship at a Glance 2013, OECD Publishing. 


\section{Enquête Eurostat sur les forces de travail}

L'Enquête Eurostat sur les forces de travail est une étude mensuelle menée auprès des ménages dans tous les États membres de l'UE et collectant des informations à propos du marché du travail. Le présent rapport se concentre sur les données de l'Enquête sur les forces de travail liées au travail indépendant. Eurostat définit un travailleur indépendant comme une personne œuvrant dans sa propre entreprise, son exploitation agricole ou son cabinet professionnel et tirant des avantages économiques de cette occupation, qu'il s'agisse d'un salaire, de bénéfices, d'avantages en nature ou de gains familiaux (dans le cas de personnes travaillant en famille). Les travailleurs bénévoles sont exclus de cette définition. L'objet de l'entreprise n'a aucune influence sur le statut d'indépendant d'un individu; en d'autres termes, l'entreprise peut avoir un but lucratif ou une vocation sociale non lucrative.

L'entreprise des travailleurs indépendants peut employer une personne ou davantage. Cela n'a aucun effet sur leur statut d'indépendant, tant qu'ils travaillent directement pour l'entreprise. Dans ce sens, la même entreprise peut occuper plus d'un indépendant. Par exemple, chaque membre d'un partenariat peut être considéré comme indépendant, aussi longtemps que l'entreprise demeure son activité professionnelle principale. Les dirigeants d'entreprise sont toutefois exclus du groupe des travailleurs indépendants s'ils ne sont pas impliqués dans la gestion journalière de l'entreprise.

Il existe différentes conceptions du travail indépendant:

- L'indépendant pour son propre compte est une personne n'employant aucun salarié pour son activité;

- L'employeur est un indépendant qui emploie du personnel;

- Le taux de travail indépendant est défini comme le nombre de travailleurs indépendants, comprenant les indépendants pour leur propre compte et les employeurs (c.-à-d. les indépendants employant des salariés) par rapport au nombre de travailleurs salariés.

Pour en savoir plus sur l'Enquête Eurostat sur les forces de travail, veuillez vous référer à: http://epp.eurostat.ec.europa.eu/portal/page/portal/labour_market/methodology.

\section{Global Entrepreneurship Monitor}

Le Global Entrepreneurship Monitor (GEM) est une initiative internationale qui mesure les activités et attitudes entrepreneuriales de par le monde par le biais d'enquêtes annuelles menées auprès de la population adulte (âgée de 18 ans et plus) des pays participants. Elle collecte les réponses données par les personnes interrogées sur leur attitude à l'égard de l'entrepreneuriat, leurs activités préalables au démarrage d'une entreprise, leur travail pendant la phase initiale de leur entreprise, leur implication lorsque celle-ci est établie et la fermeture de leur entreprise.

Contrairement à d'autres études portant sur les entreprises, le GEM interroge des ménages (des individus) de manière à pouvoir identifier les personnes engagées à divers stades de l'entrepreneuriat. L'unité d'analyse de cette étude étant l'individu, cela permet de collecter des informations sur les motivations et aspirations incitant à l'entrepreneuriat ainsi que sur d'autres caractéristiques individuelles.

En 2013, le GEM a couvert 70 pays. Depuis 1999, il a examiné plus de 90 pays. Les 28 États de l'UE ont été couverts en 2013, à l'exception de l'Autriche, de la Bulgarie, de Chypre, du Danemark et de Malte.

En 2013, la taille des échantillons s'est échelonnée de 2000 personnes dans la plupart des pays à 24600 en Espagne. L'échantillon total sur l'ensemble de l'UE regroupait 86237 personnes. Les réponses sont pondérées par âge et par sexe afin que les résultats reflètent la population nationale. Pour rendre les résultats plus fiables, les données présentées dans ce chapitre ont été rassemblées 
(c.-à-d. combinées) par pays pour les années 2008 à 2012, ce qui augmente considérablement la taille de l'échantillon et autorise l'élaboration de présentations plus détaillées.

Plusieurs indicateurs du GEM sont mentionnés dans ce rapport:

- Le taux d'entrepreneuriat naissant est la proportion des membres de la population activement impliqués dans la création d'une entreprise dont ils seront propriétaires en tout ou en partie. Cette activité n'a pas rapporté de traitement, de salaire ou toute autre rémunération aux propriétaires depuis plus de trois mois.

- Le taux de détention de nouvelles entreprises est la proportion des membres de la population qui sont actuellement dirigeants-propriétaires d'une nouvelle entreprise qui verse des traitements, des salaires ou toute autre rémunération à ses propriétaires depuis plus de trois mois mais moins de 42 mois.

- L'indicateur le plus connu publié par le GEM est l'indice d'activité entrepreneuriale totale au stade précoce (TEA), qui est la somme de la proportion de la population engagée dans l'entrepreneuriat naissant et de celle ayant démarré une nouvelle entreprise au cours des 42 derniers mois. Celui-ci mesure la phase préalable au lancement d'une nouvelle entreprise (entrepreneuriat naissant) ainsi que la phase venant directement après ce lancement (gestion-détention d'une nouvelle entreprise).

- Le taux de détention d'entreprises établies du GEM mesure la proportion des membres de la population qui sont actuellement dirigeants-propriétaires d'une entreprise établie qui verse des traitements, salaires ou toute autre rémunération à ses propriétaires depuis plus de 42 mois. Cet indicateur contribue à donner des informations sur le niveau d'activités entrepreneuriales au sein d'une économie.

\section{Encadré 3. Distinctions entre les données relatives au travail indépendant et celles portant sur la propriété d'entreprise}

- Les données relatives au travail indépendant présentées dans la première partie de cet ouvrage proviennent de l'enquête sur les forces de travail. Elles portent sur des propriétairesgérants d'entreprises s'octroyant un salaire ou des bénéfices sur le travail qu'ils effectuent pour leur propre compte dans leur entreprise et qui se déclarent indépendants. Les données relatives au travail indépendant se rapportent aux individus n'employant le plus souvent qu'eux-mêmes, ou très peu d'autres personnes, dans des sociétés non constituées. Les personnes qui gèrent des sociétés constituées de plus grande envergure ne sont généralement pas déclarées comme travailleurs indépendants. Cela tient au fait qu'elles apparaissent dans le registre du personnel de ces entreprises et qu'elles sont dès lors considérées comme des employés. Ces données excluent également les individus en passe de fonder une entreprise dont la création n'est pas encore aboutie, de même que les propriétaires d'entreprise non impliqués dans l'exploitation journalière de celle-ci.

- Bon nombre des données communiquées dans le présent ouvrage sont extraites du Global Entrepreneurship Monitor. Elles couvrent les individus déclarant tenter activement de démarrer leur affaire ou s'occupant déjà de leur entreprise ou de tout type de travail indépendant ou vendant des biens ou des services à des tiers. Cette définition est plus vaste que celle utilisée pour les données relatives au travail indépendant: elle inclut les travailleurs indépendants ainsi que toutes sortes de propriétaires d'entreprise. En particulier, les propriétaires-gérants de sociétés constituées sont englobés, alors qu'ils sont exclus des données sur le travail indépendant. Le Global Entrepreneurship Monitor inclut aussi les personnes qui gèrent une entreprise en tant qu'activité complémentaire, tandis que les données de l'enquête sur les forces de travail reprises dans ces chapitres portent sur l'activité professionnelle principale. Les chiffres sur le travail indépendant concerneront donc uniquement les personnes qui consacrent plus de temps à cette activité qu'à un autre emploi. 
Pour en savoir plus sur les méthodologies employées par le Global Entrepreneurship Monitor, veuillez consulter le «2013 GEM Global Report», disponible sur: www.gemconsortium. org/docs/cat/1/global-reports.

\section{Eurobaromètre Flash}

Le sondage Eurobaromètre Flash «L'entrepreneuriat dans l'UE et au-delà» ( $n^{\circ} 354$ ) est une enquête menée auprès des ménages parmi une population adulte âgée de 15 ans et plus. Ce sondage étudie la progression et les déterminants de l'entrepreneuriat et pose des questions sur les attitudes vis-à-vis de l'entrepreneuriat, l'éducation à l'entrepreneuriat, la prise de risques, la création d'entreprises et les incitants et freins au travail indépendant. Cette enquête a englobé 40 pays, dont les 28 États membres de l'UE.

L'édition 2012 de ce sondage a été réalisée en juin et août 2012. Un échantillon aléatoire d'environ 1000 personnes âgées de plus de 15 ans a été constitué dans chaque État membre de l'UE, soit un échantillon total de 42080 personnes pour l'ensemble des 40 pays. Les entretiens se sont, pour la plupart, déroulés via des lignes téléphoniques fixes, et les résultats ont subi une pondération par post-stratification pour garantir leur représentativité.

Pour en savoir plus, veuillez consulter: http://ec.europa.eu/public_opinion/flash/fl_354_ en.pdf.

\section{Statistiques sur le revenu et les conditions de vie}

Les statistiques de l'UE sur le revenu et les conditions de vie (EU-SILC) sont un cadre de référence pour la collecte régulière de données visant l'établissement de statistiques comparatives sur le revenu, la pauvreté, l'exclusion sociale et les conditions de vie. Ces données sont collectées dans les 28 États membres, ainsi qu'en Islande, Norvège, Suisse et Turquie.

Deux types de données sont collectées: des données transversales, obtenues auprès d'environ 130000 ménages et 270000 habitants de l'UE âgés de plus de 16 ans, et des données longitudinales rassemblées auprès de quelque 100000 ménages et 200000 habitants de l'UE âgés de plus de 16 ans. Les données relatives à l'exclusion sociale et aux conditions de logement proviennent de ménages et du travail, et les renseignements relatifs à la santé et à l'éducation proviennent d'individus.

Pour en savoir plus sur les statistiques sur le revenu et les conditions de vie, veuillez consulter: http://epp.eurostat.ec.europa.eu/portal/page/portal/microdata/eu_silc.

\section{Références}

Ahmad, N. and R. G. Seymour (2008), «Defining Entrepreneurial Activity: Definitions Supporting Frameworks for Data Collection", Document de travail Statistique OCDE 2008/01, Publication OCDE, Paris. DOI: http://dx.doi.org/10.1787/243164686763.

Commission européenne, 2012, «L'entrepreneuriat dans l'UE et au-delà», Eurobaromètre Flash 354, disponible sur: http://ec.europa.eu/public_opinion/flash/fl_354_en.pdf.

Global Entrepreneurship Monitor (2013), «Global Entrepreneurship Monitor 2013 Global Report», disponible sur: http://www.gemconsortium.org/docs/3106/gem-2013-global-report.

OCDE (2013), Panorama de l'entrepreneuriat, Publication OCDE, Paris. DOI: http://dx.doi.org/10.1787/ entrepreneur_aag-2013-en. 


\section{Chapitre 1}

\section{La politique d'entrepreneuriat inclusif de l'Union européenne $e^{1,2}$}

L'inclusion sociale est une priorité politique de longue date des États membres de l'UE. L'aggravation de la crise économique, du chômage et de l'exclusion du marché du travail n'a fait qu'accroître le besoin urgent de mesures. L'entrepreneuriat est un élément de réponse potentiel. Les politiques d'entrepreneuriat inclusif ont pour but de garantir à tous les membres de la société une chance égale de démarrer et de gérer une entreprise ou une activité indépendante, ou d'utiliser l'expérience d'une ébauche d'entreprise pour accroître leurs compétences et leur aptitude à l'emploi. Elles ont pour vocation d'aider les personnes qui ont des difficultés à créer des entreprises viables, comme les femmes, les jeunes, les seniors, les minorités ethniques et les personnes handicapées, mais qui recèlent d'autre part un potentiel entrepreneurial sous-estimé.

1. Note de la Turquie:

Les informations figurant dans ce document et faisant référence à "Chypre» concernent la partie méridionale de l'île. Il n'y a pas d'autorité unique représentant à la fois les Chypriotes turcs et grecs sur l'île. La Turquie reconnaît la République turque de Chypre du Nord (RTCN). Tant qu'une solution durable et équitable n'aura pas été trouvée dans le cadre des Nations unies, la Turquie maintiendra sa position sur la «question chypriote».

2. Note de tous les États de l'Union européenne membres de l'OCDE et de l'Union européenne:

La République de Chypre est reconnue par tous les membres des Nations unies sauf la Turquie. Les informations figurant dans ce document concernent la zone sous le contrôle effectif du gouvernement de la République de Chypre. 


\section{L'entrepreneuriat pour tous}

L'entrepreneuriat promeut la croissance économique à travers l'innovation et la création d'emplois (pour connaître la définition de l'entrepreneuriat par l'OCDE-Eurostat, reportez-vous au guide de lecture), mais son potentiel d'inclusion demeurera inexploité tant que les groupes sociaux défavorisés ne bénéficieront pas des mêmes opportunités que le reste de la population en termes de création et de gestion d'entreprises. De nombreux travaux de recherche suggèrent que la majorité des entrepreneurs de l'UE sont des hommes aisés, instruits, blancs et autochtones. On est loin de l'idéal en matière d'inclusion. Une série de chiffres illustre le manque d'entrepreneurs en dehors du système traditionnel. À titre d'exemple, en 2012, l'Union européenne comptait 21 millions d'hommes indépendants, pour seulement 9 millions de femmes. Dans les pays de l'UE, les taux d'enregistrement de nouvelles entreprises sont typiquement plus faibles chez les femmes que chez les hommes.

Parallèlement à cela, les groupes sociaux défavorisés subissent des disparités en matière d'entrepreneuriat. Les indicateurs de chiffres d'affaires, de revenus des indépendants et de taux de survie des entreprises des femmes, des jeunes et des immigrés sont tous largement inférieurs à ceux du reste de la population (Commission européenne, 2005). En outre, seulement $24 \%$ des femmes indépendantes et $11 \%$ des jeunes indépendants (âgés de 15 à 24 ans) de l'UE employaient du personnel en 2012, contre 34\% des hommes indépendants et $29 \%$ des adultes indépendants).

Les politiques d'entrepreneuriat inclusif ont pour but de garantir à toute personne, quels que soient ses antécédents et ses caractéristiques personnelles, une chance égale de démarrer et de gérer sa propre entreprise. Les responsables politiques aux niveaux national, régional et local peuvent soutenir cet objectif au moyen de programmes sensibilisant et motivant toutes les couches de population à poser l'entrepreneuriat comme choix de carrière et corrigeant les défauts de fonctionnement des marchés et institutions qui affectent certains groupes de population plus que d'autres.

Ces politiques visent à soutenir la création d'entreprise et le travail indépendant des personnes issues de groupes sociaux sous-représentés dans la sphère entrepreneuriale ou défavorisés sur le marché du travail. Par exemple, les femmes sont moins nombreuses que les hommes à posséder une entreprise ou à exercer une activité indépendante. Cela concerne également les catégories qui présentent un plus grand risque d'exclusion sociale et qui peuvent tirer profit d'une création d'entreprise, comme les minorités ethniques et les immigrés, les personnes handicapées, les jeunes sans emploi et les habitants de lieux où règne une grande détresse économique.

La création d'entreprises, ou plutôt la création d'entreprises durables, est un des objectifs des politiques d'entrepreneuriat inclusif, mais elle ne convient pas à tout le monde. Ces politiques contribuent également au développement des qualifications, de la confiance en soi, de la motivation et des réseaux et multiplient ainsi les chances de décrocher un emploi rémunéré. Elles peuvent aussi soutenir l'entrepreneuriat social et favoriser l'intégration des personnes issues de groupes défavorisés sur le marché du travail et au sein de la société. 


\section{Lutte contre l'exclusion sociale}

L'inclusion sociale est un objectif de longue date de l'Union européenne, mais la récente crise économique a intensifié l'urgence de s'attaquer à ce problème, la proportion de la population présentant un risque d'exclusion sociale ayant augmenté dans de nombreux États membres de l'UE (Graphique 1.1). En 2012, $25 \%$ de la population de l'UE était menacée de pauvreté ou d'exclusion sociale, soit 124,5 millions de personnes.

Les pays où le pourcentage de population à risque est le plus faible sont les Pays-Bas (15\%), la République tchèque $(15,4 \%)$ et la Finlande $(17,2 \%)$. Ces chiffres ont peu évolué depuis 2008. En revanche, ils ont augmenté dans quasiment tous les pays où le nombre de personnes à risque était déjà élevé en 2008. Par exemple, près de la moitié de la population bulgare était menacée de pauvreté ou d'exclusion sociale en 2012, soit une augmentation de $4,5 \%$ depuis 2008. Les autres pays qui connaissent une forte proportion de personnes exposées sont la Roumanie, la Lettonie et la Grèce, où plus de d'un tiers de la population présentait un risque de pauvreté ou d'exclusion sociale en 2012.

\section{Graphique 1.1. Proportion de la population menacée de pauvreté ou d'exclusion sociale, comparaison 2008-2012 \\ Pourcentage des 15-64 ans}

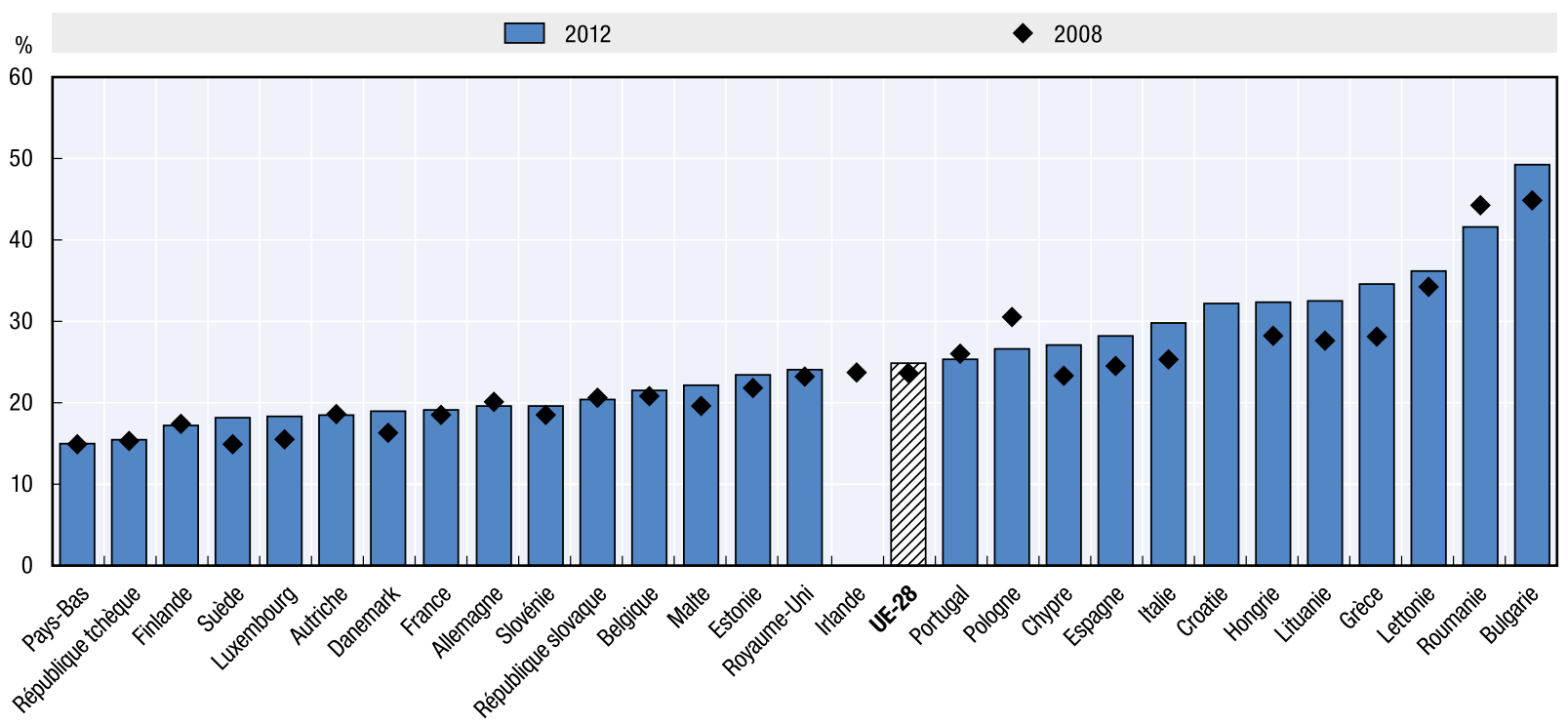

Notes: 1. Aucune donnée n'est disponible pour l'Irlande pour l'année 2012. 2. Le chiffre de l'UE-28 pour l'année 2008 n'inclut pas la Croatie.

Source: Eurostat, Statistiques sur le revenu, l'inclusion sociale et les conditions de vie, 2013.

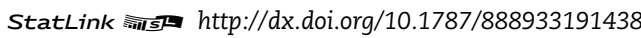

Les États membres de l'UE ont renouvelé leur engagement à relever ce défi grandissant dans le cadre de la stratégie Europe 2020 (http://ec.europa.eu/europe2020/index_fr.htm), qui a pour but de réduire de 20 millions le nombre de personnes menacées de pauvreté à l'horizon 2020. Cependant, des mesures d'entrepreneuriat inclusif existent pour lutter contre l'exclusion sociale.

Une politique active du marché du travail (PAMT) constitue l'une des manières les plus efficaces de lutter contre l'exclusion sociale, de même que les mesures de création d'emplois visant à soutenir l'insertion et la réinsertion sur le marché du travail. Parallèlement à la hausse du chômage et au recul de la participation au marché du travail, 
les dépenses engagées au titre de la PAMT au sein de l'UE ont augmenté de $22 \%$ entre 2007 et 2011. Ces mesures comprennent des mécanismes de soutien à l'entrepreneuriat tels que la formation et les incitants au lancement d'entreprises. Les dépenses de la PAMT consacrées au soutien et aux incitants à la création d'entreprises ont progressé de $12 \%$ entre 2007 et 2011, soit moins que l'augmentation globale des dépenses de la PAMT, ce qui s'est traduit par un recours moins fréquent aux incitants au démarrage d'entreprises au sein de l'UE (Graphique 1.2). L'utilisation des mesures d'aide au démarrage d'entreprises de la PAMT varie sensiblement selon les États membres. En 2011, les dépenses consacrées aux incitants à la création d'entreprises de la PAMT étaient pratiquement nulles dans bon nombre d'États membres, dont Chypre, la Bulgarie, le Luxembourg, la Belgique, Malte, le Portugal, la Roumanie, l'Autriche, la Lettonie et la République tchèque (Graphique 1.3). L'impact de ces aides sur l'ancrage dans le marché de l'emploi n'est pas bien connu, car nombre d'entre elles ne font pas l'objet d'une évaluation adéquate. Toutefois, certains programmes semblent produire leurs effets. Par exemple, de nombreux programmes de pont social ont aidé des chômeurs à lancer leur entreprise en leur fournissant une aide au revenu de base durant les premières étapes du démarrage. La question des ponts sociaux est abordée plus en détail au chapitre 6, qui traite de l'aide aux entrepreneurs sans emploi qui démarrent une entreprise, et au chapitre 9, qui analyse l'influence des systèmes de sécurité sociale sur la création d'entreprise et le travail indépendant.

\section{Graphique 1.2. Part du soutien aux start-up dans les dépenses de la PAMT au sein de l'UE-28, 2005-2011}

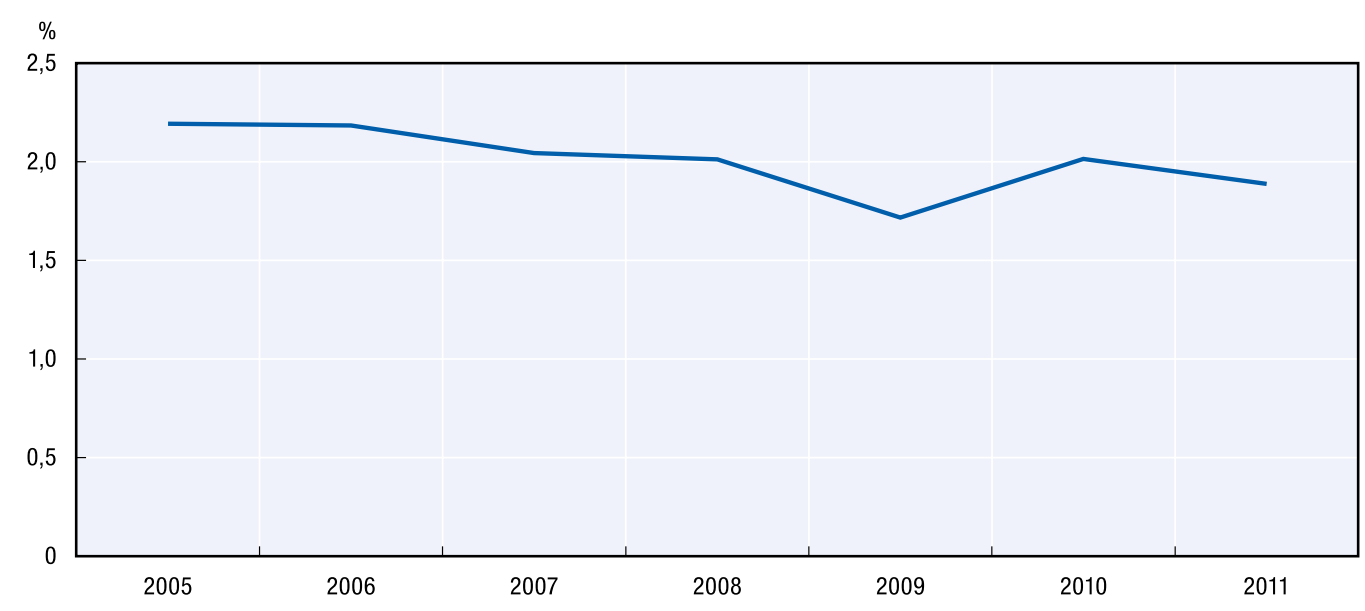

Source: Eurostat, Dépenses publiques pour les mesures des politiques du marché du travail, par type d'action, 2014.

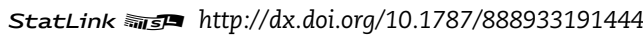

Une deuxième approche consiste à définir des mécanismes faisant appel aux Fonds structurels de l'UE. L'une des principales sources de financement disponibles en matière de recours à l'entrepreneuriat comme moyen de promotion de l'inclusion sociale est le Fonds social européen (FSE). Les programmes de cofinancement du FSE sont précisément conçus pour aider les personnes vulnérables pour lesquelles l'accès au marché du travail est difficile. Cela comprend des programmes de formation et d'éducation pour les groupes défavorisés, en particulier les chômeurs, ainsi que des programmes de lutte contre la discrimination et les obstacles au marché du travail. Chacun de ces domaines peut englober l'entrepreneuriat. Au cours de la période de programmation 2007-2013, la contribution du FSE s'élevait à près de 76 milliards EUR, dont environ un sixième a été alloué à des programmes de promotion de l'inclusion sociale. Jusqu'à présent, les États membres 
n'ont pas utilisé tout son potentiel réservé à la promotion de l'entrepreneuriat, mais cette option est davantage mise en valeur durant la période de programmation actuelle (2014-2020).

\section{Graphique 1.3. Part du soutien aux start-up dans les dépenses de la PAMT, 2011}

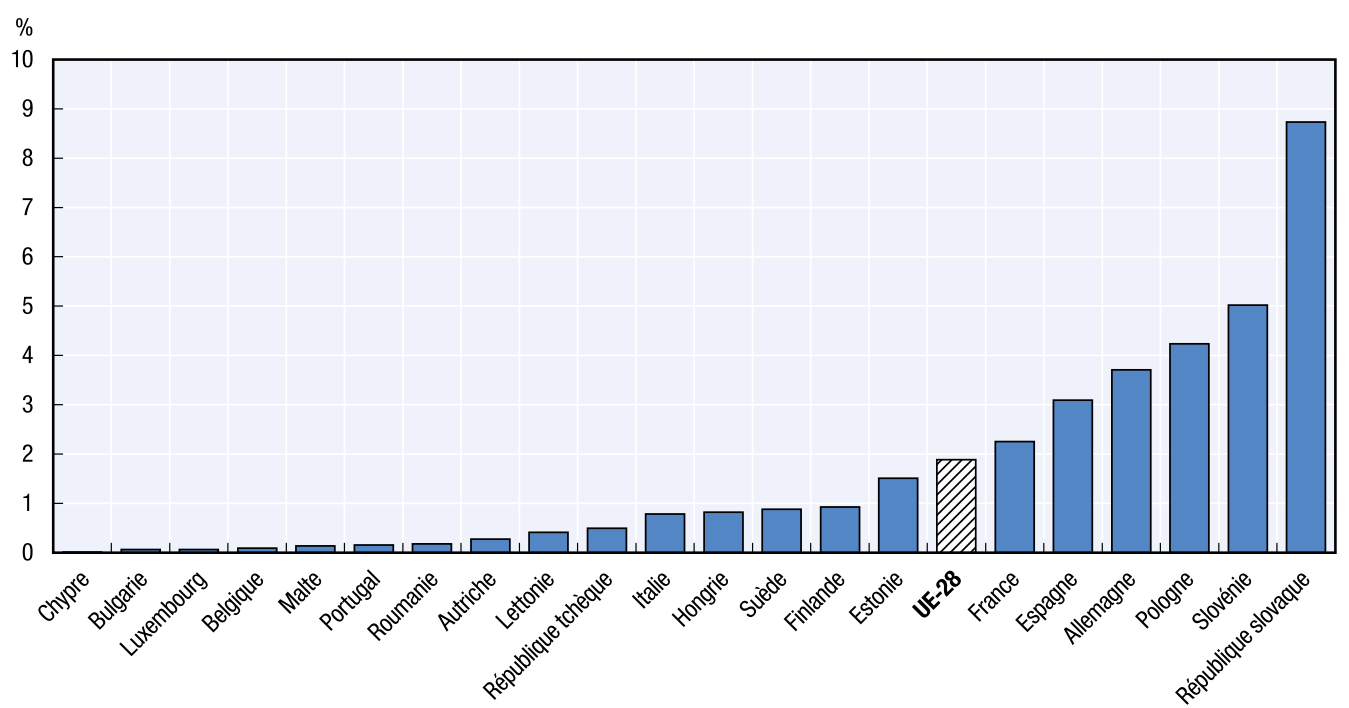

Note: 1. Aucune donnée n'est disponible pour la Croatie, le Danemark, l'Irlande, la Grèce, la Lituanie, les Pays-Bas et le Royaume-Uni.

Source: Eurostat, Dépenses publiques pour les mesures des politiques du marché du travail, par type d'action, 2014.

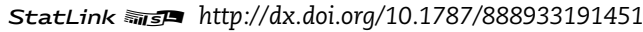

\section{Guide de lecture de la présente publication}

Cet ouvrage examine de quelle façon une politique peut soutenir l'entrepreneuriat inclusif. La première partie présente des données relatives au degré et à la qualité de l'entrepreneuriat dans le chef de groupes défavorisés ou sous-représentés, à savoir les femmes, les jeunes et les seniors, dans l'UE. Y sont également reprises des données liées à la localisation des activités entrepreneuriales. Les données sur les chômeurs et les minorités ethniques sont présentées dans la deuxième partie de l'ouvrage.

Le premier chapitre de cette partie, le chapitre 2, commente des données relatives aux activités entrepreneuriales et indépendantes des femmes dans l'UE, comprenant les proportions et nombres d'entre elles ayant un statut d'indépendant ainsi que les secteurs économiques où elles sont actives. Sont également présentées dans ce chapitre les données d'une étude domestique de la Global Entrepreneurship Research Association portant sur les activités entrepreneuriales à diverses époques de la vie. Ces données dressent un Tableau des intentions avant le lancement d'une entreprise et des activités pendant le démarrage et après celui-ci, dans le chef de personnes défavorisées ou sousreprésentées dans l'entrepreneuriat. D'autres données tirées de l'étude indiquent les obstacles rencontrés par les entrepreneurs au moment de démarrer leur entreprise et d'autres caractéristiques clés relatives à l'impact des activités d'indépendant. De même, les chapitres 3 et 4 présentent des données relatives aux activités d'entrepreneuriat et d'indépendant des jeunes et des seniors. Le chapitre 5 fournit des données sur la localisation des activités entrepreneuriales, notamment si les activités de création d'entreprise sont exercées à domicile ou dans des locaux séparés ou mobiles. 
Après avoir établi les taux d'activité entrepreneuriale par les principaux groupes cibles, la deuxième partie poursuit en examinant en détail deux groupes clés des politiques d'entrepreneuriat inclusif et leurs mesures. Les chapitres 6 et 7 se penchent sur le soutien des activités entrepreneuriales des chômeurs, minorités ethniques et immigrés. Les données présentées dans chaque chapitre illustrent l'ampleur et le potentiel de l'entrepreneuriat de chaque groupe. Chaque chapitre se concentre toutefois sur les différentes approches politiques visant à promouvoir et soutenir la création d'entreprise et le travail indépendant de ces groupes. Des exemples de pratiques actuelles ainsi que des recommandations politiques sont formulés.

La seconde moitié de la deuxième partie met l'accent sur une série d'instruments spécifiques réunis dans une boîte à outils que les représentants politiques peuvent utiliser afin de soutenir l'entrepreneuriat inclusif. Le chapitre 8 explore comment ces derniers peuvent appuyer les services d'aide au développement des entreprises en faveur des groupes sous-représentés et défavorisés. Y sont décrites différentes approches adoptées au sein de l'UE. Un certain nombre de recommandations sur la manière d'améliorer ces aides sont également formulées. Le chapitre 9 analyse la façon dont les systèmes de sécurité sociale peuvent influencer la création d'entreprise et le travail indépendant. Plus précisément, il évalue comment les différentes composantes des régimes de sécurité sociale peuvent jouer un rôle dans la décision de création d'entreprise, en particulier chez les groupes défavorisés qui peuvent faire appel à la sécurité sociale à plusieurs titres. Outre la présentation d'initiatives récentes prises dans plusieurs pays de l'UE en vue d'offrir une meilleure couverture sociale aux indépendants, des recommandations y sont formulées à l'attention des représentants politiques.

Enfin, la troisième partie de cet ouvrage se penche plus en détail sur chacun des 28 États membres. Le chapitre $\mathbf{1 0}$ présente pour chaque pays de l'UE une pratique politique instructive d'aide à l'entrepreneuriat inclusif et communique des données clés relatives au travail indépendant et à l'entrepreneuriat des groupes sous-représentés et défavorisés.

\section{Références}

Ahmad, N. and R. G. Seymour (2008), «Defining Entrepreneurial Activity: Definitions Supporting Frameworks for Data Collection", Document de travail Statistique OCDE 2008/01, Publication OCDE, Paris. DOI: http://dx.doi.org/10.1787/243164686763.

Commission européenne (2005), «Enquête sur les facteurs de réussite des entreprises», Eurostat.

Eurostat (2014), LMP expenditure by type of action, http://epp.eurostat.ec.europa.eu/portal/page/portal/ labour_market/labour_market_policy.

Eurostat (2013), Statistiques sur le revenu, l'inclusion sociale et les conditions de vie, http://epp.eurostat. ec.europa.eu/portal/page/portal/income_social_inclusion_living_conditions/introduction. 


\section{PARTIE I}

\section{Les activités d'entrepreneuriat inclusif en Europe}





\section{Chapitre 2}

\section{Le travail indépendant et l'entrepreneuriat chez les femmes ${ }^{1,2}$}

Ce chapitre traite de l'ampleur et de la qualité des activités d'indépendant effectuées par des femmes. Il comprend des données sur la proportion de ces activités dans les différents États membres de l'UE, les caractéristiques du travail indépendant et les freins au démarrage d'une entreprise.

1. Note de la Turquie:

Les informations figurant dans ce document et faisant référence à «Chypre» concernent la partie méridionale de l'île. Il n'y a pas d'autorité unique représentant à la fois les Chypriotes turcs et grecs sur l'île. La Turquie reconnaît la République turque de Chypre du Nord (RTCN). Tant qu'une solution durable et équitable n'aura pas été trouvée dans le cadre des Nations unies, la Turquie maintiendra sa position sur la «question chipriote».

2. Note de tous les États de l'Union européenne membres de l'OCDE et de l'Union européenne:

La République de Chypre est reconnue par tous les membres des Nations unies sauf la Turquie. Les informations figurant dans ce document concernent la zone sous le contrôle effectif du gouvernement de la République de Chypre. 


\section{Le travail indépendant chez les femmes}

- Bien que la proportion de femmes travaillant en tant qu'indépendantes ait légèrement augmenté ces dix dernières années, les femmes ont nettement moins tendance à endosser ce statut que les hommes. En 2012, on comptait plus de 9,6 millions de travailleuses indépendantes dans l'UE, pour 21,3 millions d'hommes.

- Sur les près de 30,9 millions d'indépendants en 2012, environ 8,9 millions employaient du personnel. Ce chiffre était en recul ces dix dernières années. Parmi les indépendants qui employaient des salariés, $26 \%$ étaient des femmes. Le nombre de femmes indépendantes ayant des employés à leur service s'est maintenu à environ 2,3 millions ces dix dernières années.

- Les femmes indépendantes sont moins susceptibles de travailler dans les secteurs de la construction et de la production que les hommes indépendants.

Le travail indépendant est une forme de travail selon lequel une personne œuvre dans sa propre entreprise, exploitation agricole ou cabinet professionnel et tire des avantages économiques de cette occupation, qu'il s'agisse d'un salaire, de bénéfices, d'avantages en nature ou de gains familiaux (dans le cas de personnes travaillant en famille). Le bénévolat est exclu de cette définition. Les travailleurs indépendants peuvent travailler seuls (travail pour son propre compte) ou avoir des employés. Pour examiner l'évolution de l'ampleur des forces de travail, mieux vaut souvent regarder la part du travail indépendant, qui mesure la proportion de travailleurs indépendants par rapport à l'ensemble des forces de travail. Pour en savoir plus sur ces notions et les sources de données, voir le Guide de lecture proposé au début de cet ouvrage.

\section{Graphique 2.1. Taux de travail indépendant des hommes et des femmes dans l'UE-28, 2002-2012}

Pourcentage des 15-64 ans

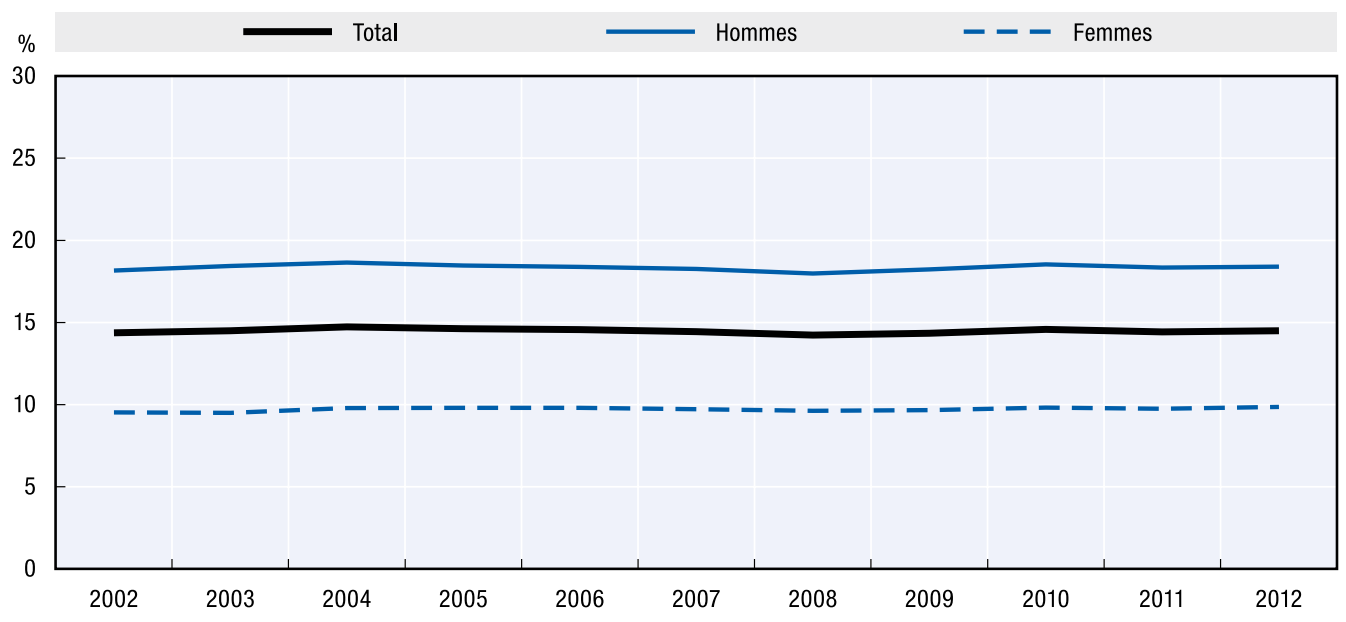

Source: Eurostat, Enquête sur les forces de travail 2002-2012. 
Le Graphique 2.1 montre les taux de travail indépendant dans l'UE (y compris en Croatie) entre 2002 et 2012, par sexe. Ceux-ci sont restés relativement constants pendant cette période. En 2012, la proportion d'activité indépendante chez les femmes s'élevait à $9,9 \%$, loin derrière le taux masculin de $18,4 \%$. Sur un total d'environ 30,9 millions de travailleurs indépendants, 9,6 millions étaient des femmes (31,1\%).

\section{Graphique 2.2. Taux de travail indépendant des hommes et des femmes, 2002-2012}

Pourcentage des 15-64 ans
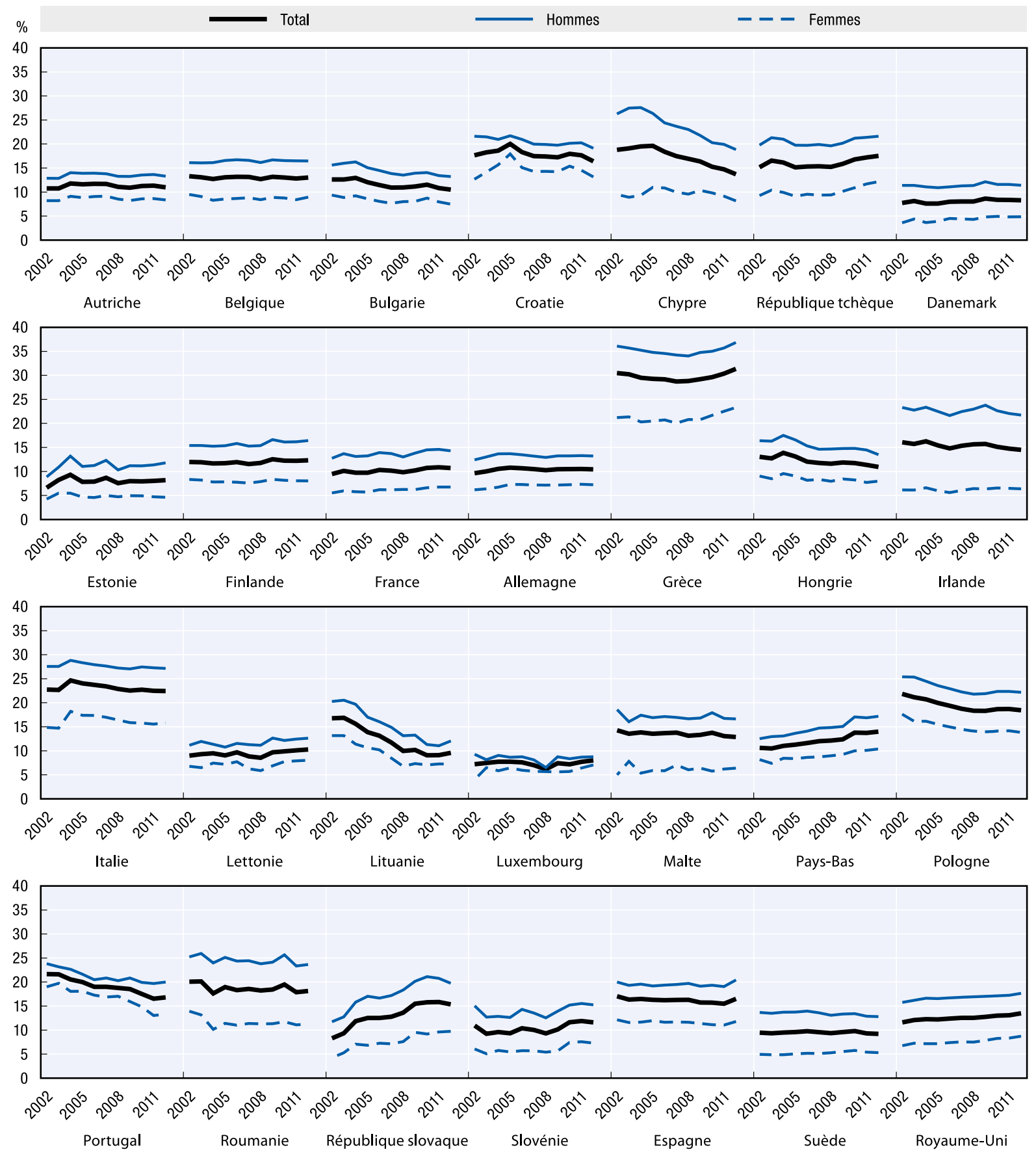

Source: Eurostat, Enquête sur les forces de travail 2002-2012. 
Le Graphique 2.2 illustre les différences de taux de travail indépendant entre les États membres. Un écart significatif apparaît clairement entre les pourcentages nationaux. Les niveaux de travail indépendant sont les plus élevés en Grèce $(23,3 \%)$, Italie $(15,8 \%)$ et Pologne (13,8\%), et les plus bas en Estonie (4,6\%), au Danemark (4,9\%) et en Suède (5,3\%). Ces différences peuvent s'expliquer par divers facteurs, notamment les attitudes sociales à l'égard du rôle des femmes dans la société, les conditions du marché du travail et les facteurs macroéconomiques.

La part des femmes exerçant une activité indépendante est bien moindre que celle des hommes dans tous les États membres, à l'exception de certains pays où elle est élevée. C'est le cas de la Grèce où elle atteignait 23,3\%, soit plus que le taux masculin de 25 États membres de l'UE.

Entre 2002 et 2012, 18 États membres de l'UE ont enregistré une hausse du pourcentage de femmes indépendantes. Ce sont la République slovaque (+ 130\%), le Luxembourg (+ $77 \%$ ) et le Danemark (+ $35 \%$ ) qui ont connu les augmentations les plus fortes. Les 10 autres pays de l'UE étaient en recul. Les diminutions les plus notables ont été enregistrées en Lituanie (- $45 \%)$, au Portugal (- $30 \%$ ) et en Pologne (- $22 \%)$.

De 2002 à 2012, le pourcentage de femmes indépendantes employant des salariés a diminué de $14,2 \%$, soit approximativement la baisse observée chez les indépendants masculins (15,8\%) (Graphique 2.3). En 2002, environ $28 \%$ des femmes indépendantes dans l'UE employaient des salariés. Cette proportion a été ramenée à $23,8 \%$ en 2012. Ainsi, sur les 9,6 millions de femmes indépendantes dans l'UE en 2012, seules 2,3 millions possédaient du personnel. Cela étant, la proportion des femmes indépendantes employant des employés a augmenté dans 11 pays: Belgique, Bulgarie, Chypre, Grèce, Hongrie, Lettonie, Lituanie, Pologne, Portugal, Espagne et Suède, entre 2002 et 2012 (Graphique 2.4).

Le Graphique 2.4 met également en évidence deux autres points. Premièrement, l'Irlande est le seul État membre à présenter une proportion de femmes indépendantes avec salariés supérieure à celle des hommes indépendants possédant du personnel. En 2012, 35,1\% des femmes indépendantes employaient des salariés, contre 30,1\% des hommes indépendants. Deuxièmement, on note de grandes variations des proportions de femmes indépendantes avec personnel selon les pays. Environ un tiers d'entre elles avaient au moins un employé en France, en Allemagne, en Hongrie, en Irlande, en Lettonie et en Suède, contre moins de $10 \%$ en Roumanie.

\section{Graphique 2.3. Proportion des indépendants (hommes et femmes) employant des salariés dans l'UE-28, 2002-2012}

Pourcentage des 15-64 ans

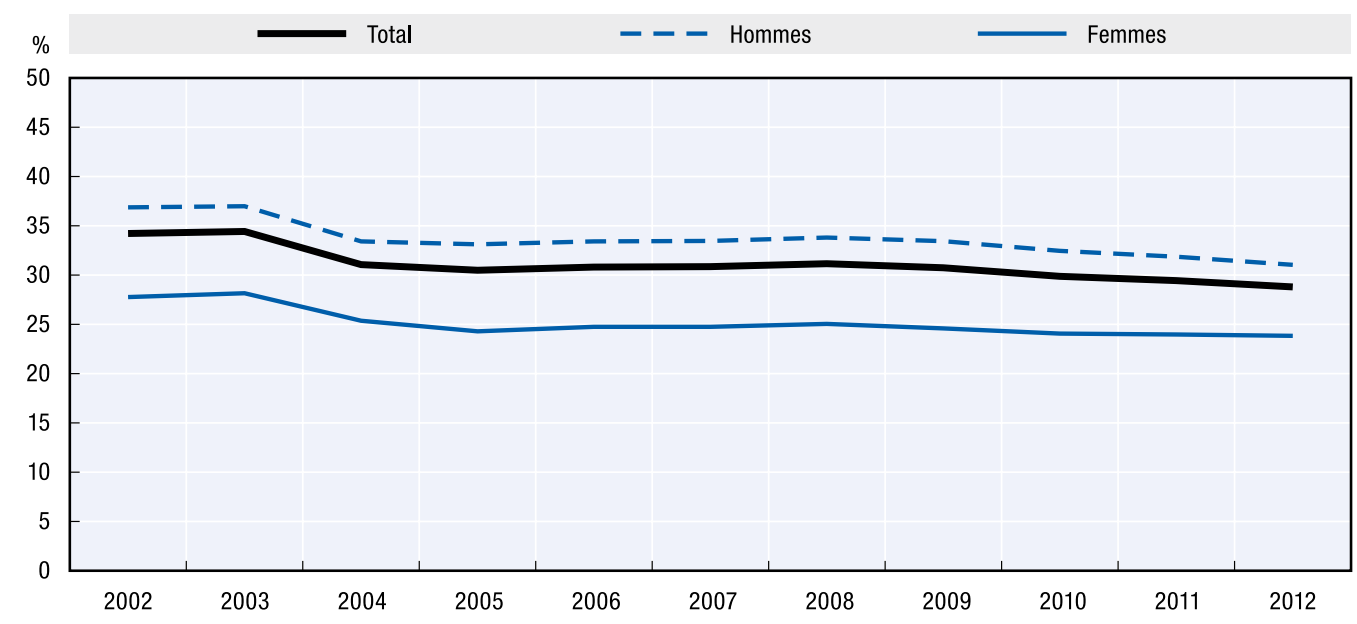

Source: Eurostat, Enquête sur les forces de travail 2002-2012. 


\section{Graphique 2.4. Proportion des indépendants (hommes et femmes) employant des salariés, 2002-2012}

Pourcentage des 15-64 ans
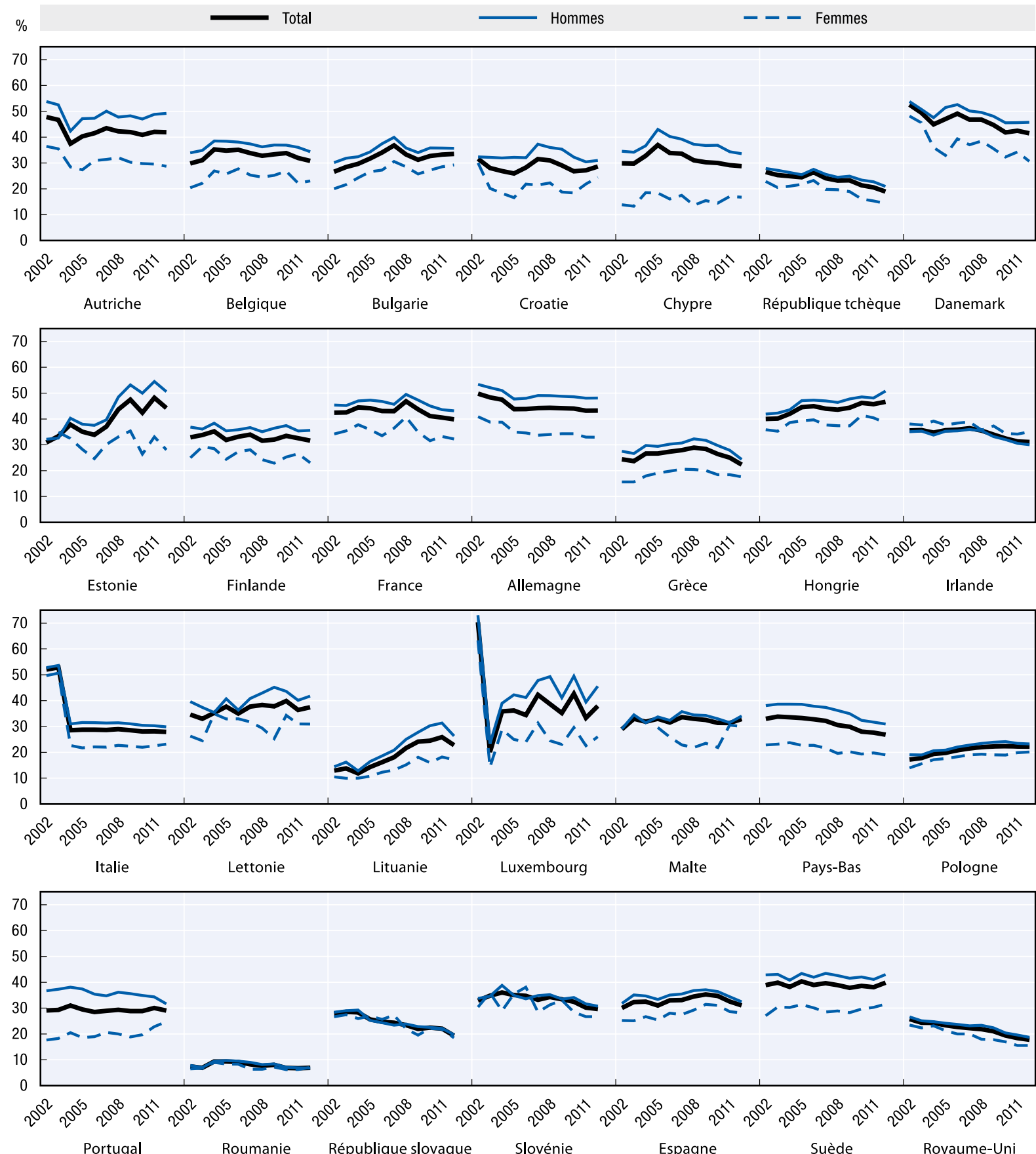

Source: Eurostat, Enquête sur les forces de travail 2002-2012.

StatLink त्नाज्ञ http://dx.doi.org/10.1787/888933191494

La Graphique 2.5 illustre la répartition des activités de travail indépendant par sexe et par secteur. En 2012, la plupart des femmes indépendantes travaillaient dans les secteurs de l'agriculture, la sylviculture et la pêche (15,5\%); le commerce de gros et de détail (17,6\%); le secteur professionnel, scientifique et technique $(12,6 \%)$; le secteur social et des soins de santé $(11,5 \%)$; et les autres services (y compris services de dépannage, services liés 


\section{Graphique 2.5. Répartition des hommes et femmes indépendants par secteur professionnel dans l'UE-28, 2012}

15-64 ans

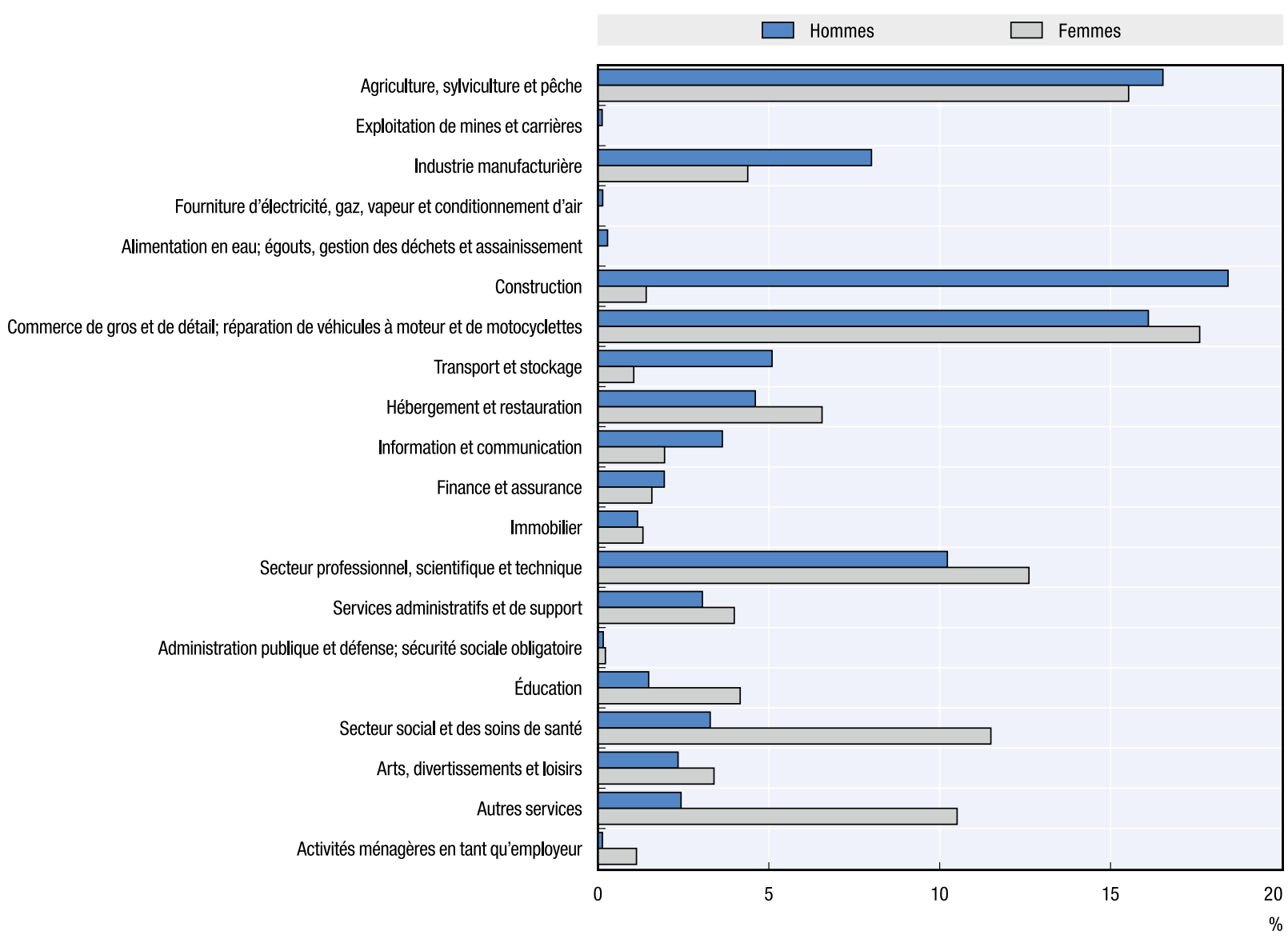

Source: Eurostat, Enquête sur les forces de travail 2012.

aux biens de consommations et aux personnes) (10,5\%). Ces cinq secteurs professionnels représentaient à eux seuls $67,7 \%$ des activités indépendantes féminines.

De manière générale, les femmes indépendantes étaient plus susceptibles que les hommes indépendants de travailler dans le commerce de gros et de détail; l'hébergement et la restauration; le secteur professionnel, scientifique et technique; les services administratifs et de support, l'éducation; la santé et les œuvres sociales; les arts, les divertissements et les loisirs; les autres services; et chez les particuliers qui emploient du personnel (c.-à-d. les foyers qui font appel à des cuisinière s, des blanchisseuses, etc.).

\section{Activités exercées par des femmes tout au long du cycle de vie entrepreneuriale}

Les femmes ont moins tendance que les hommes à s'engager dans la création d'une entreprise (c.-à-d. à être des entrepreneurs naissants). Dans l'ensemble de l'UE, 4,5\% des hommes étaient impliqués dans la création d'une entreprise entre 2008 et 2012, contre $2,4 \%$ des femmes seulement. 
- Pour la même période, les femmes étaient environ deux fois moins susceptibles que les hommes de gérer une nouvelle entreprise (1,8\% contre $3,5 \%)$.

- Elles avaient également moins tendance à posséder une entreprise établie. De 2008 à 2012, $3,6 \%$ des femmes de l'UE possédaient une entreprise établie, soit moitié moins que les hommes $(7,7 \%)$.

Le Graphique 2.6 présente les taux d'entrepreneuriat naissant par sexe dans les pays de l'UE, c'est-à-dire la proportion d'individus adultes déclarant être activement impliqués dans la création d'une entreprise dont ils sont propriétaires en tout ou partie. Cette activité ne doit pas avoir rapporté de traitements, de salaires ou toute autre rémunération à ses propriétaires depuis plus de trois mois. Pour en savoir plus sur cette notion et sur cette source de données, nous vous renvoyons au guide de lecture proposé au début de cet ouvrage.

Les femmes ont moins tendance que les hommes à être des entrepreneurs naissants, aussi bien à l'échelle de l'UE que dans chaque État membre. Autrement dit, elles sont moins susceptibles d'être engagées dans la création d'une entreprise. Elles sont tout de même fortement impliquées dans plusieurs États membres. Entre 2008 et 2012, la part des femmes engagées dans le lancement d'une entreprise en Estonie, en Autriche et en République slovaque était plus élevée que celle des hommes dans bon nombre d'États membres. L'écart entre les sexes le plus marqué en termes de taux d'entrepreneuriat naissant a été observé en République slovaque (6,6\%). À l'inverse, l'Allemagne présentait le plus petit écart (0,9\%).

\section{Graphique 2.6. Taux d'entrepreneuriat naissant chez les hommes et les femmes, 2008-2012 (combinés)}

Pourcentage des 18-64 ans

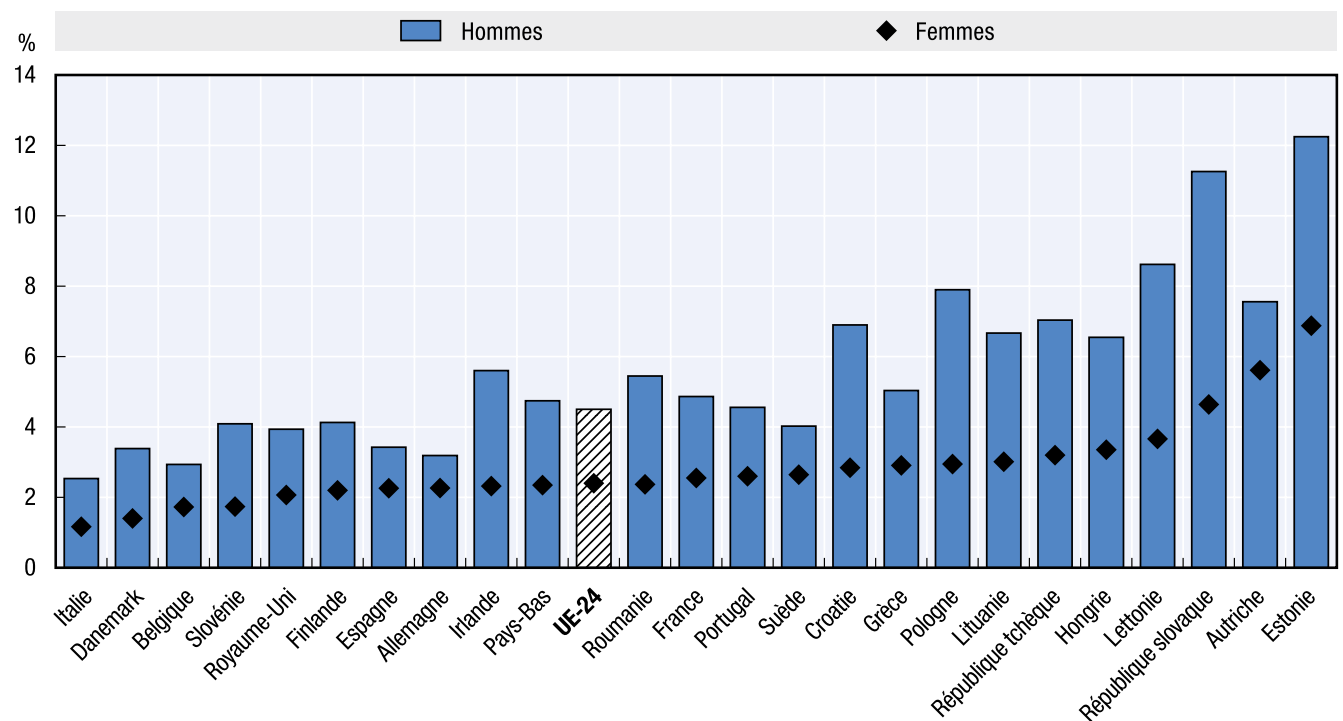

Notes: 1. Les pays de l'UE ayant participé à l'enquête Global Entrepreneurship Monitor pendant cette période sont: l'Allemagne, l'Autriche, la Belgique, la Croatie, le Danemark, l'Espagne, l'Estonie, la Finlande, la France, la Grèce, la Hongrie, l'Irlande, l'Italie, la Lettonie, la Lituanie, les Pays-Bas, la Pologne, le Portugal, la République slovaque, la République tchèque, la Roumanie, le Royaume-Uni, la Slovénie et la Suède. 2. Les données présentées dans ce Graphique ont été combinées: elles cumulent les résultats des enquêtes annuelles portant sur la période 2008-2012. Certains pays n'ont pas pris part aux enquêtes GEM réalisées chaque année, mais ont été inclus dans les graphiques: l'Autriche (2012), l'Estonie (2012), l'Irlande (2008, 2010, 2011, 2012), l'Italie (2008, 2009, 2010, 2012), la Lituanie (2011 et 2012), la Pologne (2011 et 2012), le Portugal (2010, 2011, 2012), la République slovaque (2011 et 2012), la République tchèque (2011) et la Suède (2010, 2011, 2012). 3. Le taux d'entrepreneuriat naissant est défini comme la proportion de la population adulte (âgée de 18 à 64 ans) activement engagée dans la création d'une entreprise qu'elle détiendra seule ou en copropriété; cette entreprise ne peut pas avoir octroyé de traitements, salaires ou toute autre rémunération à ses propriétaires depuis plus de trois mois.

Source: Présentations tabulaires spéciales des enquêtes 2008-2012 sur la population adulte, extraites du Global Entrepreneurship Monitor. 
Le Graphique 2.7 illustre les taux de détention de nouvelles entreprises par sexe, et indique la proportion de la population adulte déclarant être actuellement gérantepropriétaire d'une nouvelle entreprise qui verse des traitements, des salaires ou toute autre rémunération à ses propriétaires depuis plus de trois mois mais moins de 42 mois.

Globalement, les femmes étaient environ deux fois moins susceptibles que les hommes de posséder une nouvelle entreprise (1,8\% contre 3,5\%). Toutefois, à l'instar de l'entrepreneuriat naissant, les taux de propriété de nouvelles entreprises par des femmes divergent fortement selon les États membres. Sur l'ensemble des pays de l'UE-28, la République tchèque affichait le taux le plus bas $(1,1 \%)$, alors que la Lettonie arrivait en tête du classement $(3,2 \%)$. Ces chiffres montrent que l'écart constaté entre les hommes et les femmes au niveau de l'entrepreneuriat naissant s'applique également à la détention de nouvelles entreprises.

\section{Graphique 2.7. Taux de détention de nouvelles entreprises chez les hommes et les femmes, 2008-2012 (combinés)}

Pourcentage des 18-64 ans

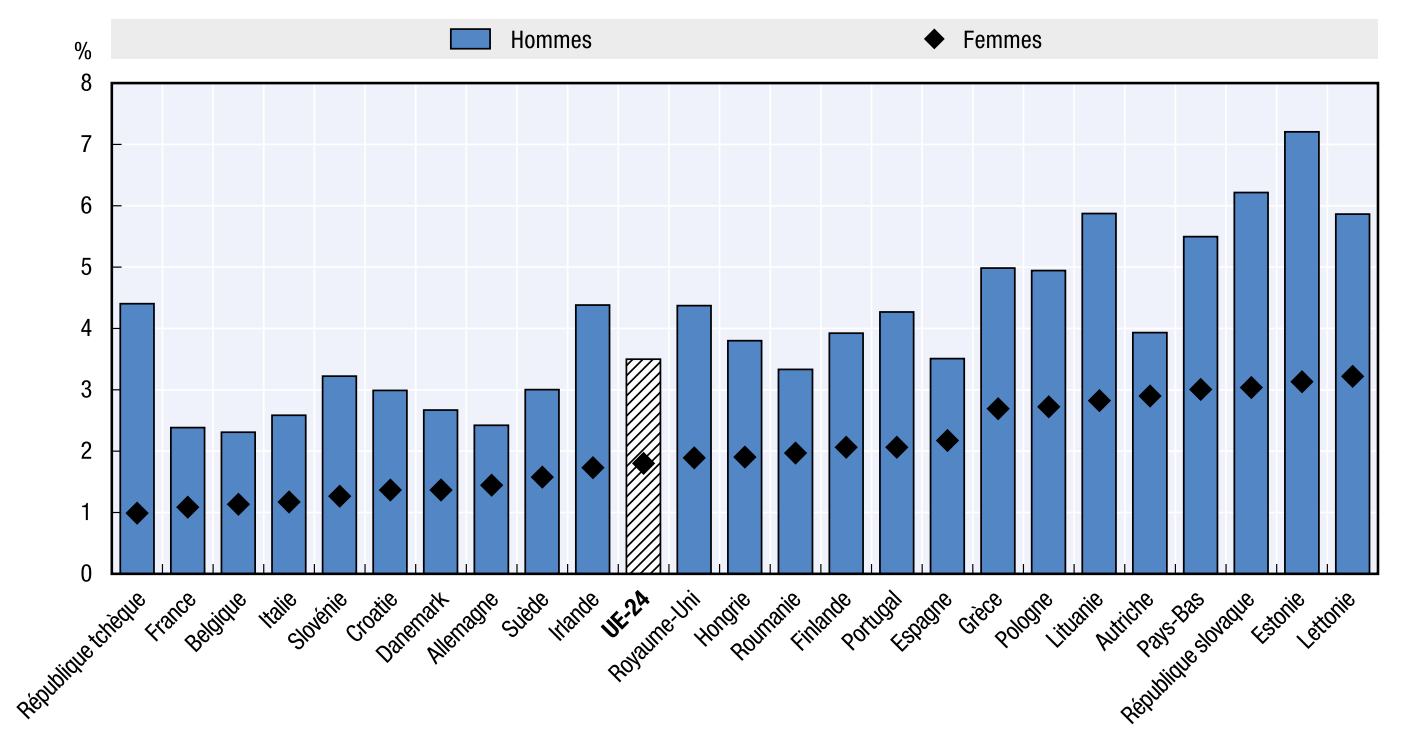

Notes: 1. Les pays de l'UE ayant participé à l'enquête Global Entrepreneurship Monitor pendant cette période sont: l'Allemagne, l'Autriche, la Belgique, la Croatie, le Danemark, l'Espagne, l'Estonie, la Finlande, la France, la Grèce, la Hongrie, l'Irlande, l'Italie, la Lettonie, la Lituanie, les Pays-Bas, la Pologne, le Portugal, la République slovaque, la République tchèque, la Roumanie, le Royaume-Uni, la Slovénie et la Suède. 2. Les données présentées dans ce Graphique ont été combinées: elles cumulent les résultats des enquêtes annuelles portant sur la période 2008-2012. Certains pays n'ont pas pris part aux enquêtes GEM réalisées chaque année, mais ont été inclus dans les graphiques: l'Autriche (2012), l'Estonie (2012), l'Irlande (2008, 2010, 2011, 2012), l'Italie (2008, 2009, 2010, 2012), la Lituanie (2011 et 2012), la Pologne (2011 et 2012), le Portugal (2010, 2011, 2012), la République slovaque (2011 et 2012), la République tchèque (2011) et la Suède $(2010,2011,2012)$. 3. Le taux de détention de nouvelles entreprises est la proportion de la population adulte gérant ou possédant actuellement une nouvelle entreprise qui verse des traitements, des salaires ou toute autre rémunération à ses propriétaires depuis plus de trois mois mais moins de 42 mois.

Source: Présentations tabulaires spéciales des enquêtes 2008-2012 sur la population adulte, extraites du Global Entrepreneurship Monitor.

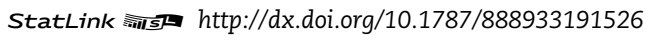

Le Graphique 2.8 présente les taux de détention de sociétés établies par sexe à travers l'UE entre 2008 et 2012. Le taux de détention d'entreprises établies mesure la proportion des membres de la population adulte qui sont actuellement dirigeants-propriétaires d'une entreprise établie qui verse des traitements, des salaires ou toute autre rémunération à ses propriétaires depuis plus de 42 mois.

À l'image des taux d'entrepreneuriat naissant et de propriété de nouvelles entreprises, les taux de détention de sociétés établies révèlent un écart important entre les sexes. À l'échelle de l'UE, les femmes étaient moins susceptibles de posséder une entreprise établie que les hommes (3,6\% contre 7,7\%). La Grèce enregistrait l'écart entre les sexes le plus marqué (12,6\%). Les écarts les plus faibles ont été relevés en France et en Roumanie (1,8\%). On constate une variation des taux 


\section{Graphique 2.8. Taux de détention d'entreprises établies chez les hommes et les femmes, 2008-2012 (combinés)}

Pourcentage des 18-64 ans

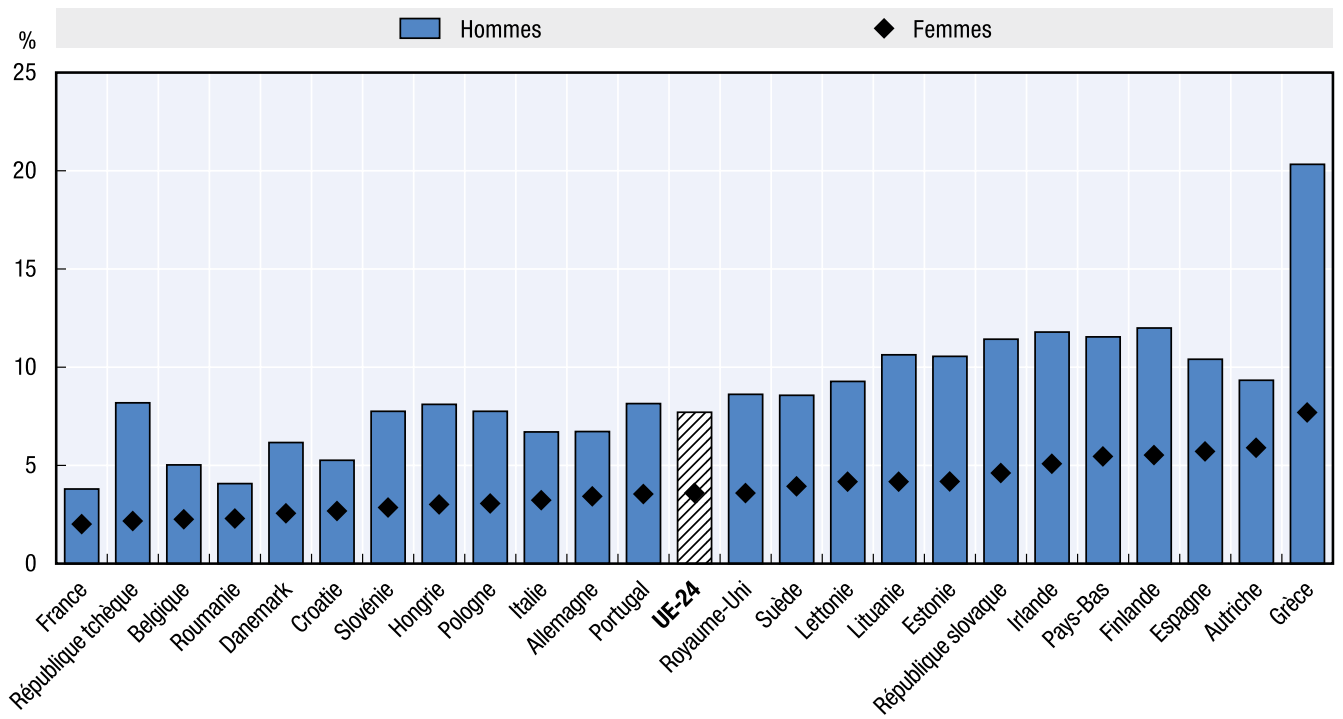

Notes: 1. Les pays de l'UE ayant participé à l'enquête Global Entrepreneurship Monitor pendant cette période sont: l'Allemagne, l'Autriche, la Belgique, la Croatie, le Danemark, l'Espagne, l'Estonie, la Finlande, la France, la Grèce, la Hongrie, l'Irlande, l'Italie, la Lettonie, la Lituanie, les Pays-Bas, la Pologne, le Portugal, la République slovaque, la République tchèque, la Roumanie, le Royaume-Uni, la Slovénie et la Suède. 2. Les données présentées dans ce Graphique ont été combinées: elles cumulent les résultats des enquêtes annuelles portant sur la période 2008-2012. Certains pays n'ont pas pris part aux enquêtes GEM réalisées chaque année, mais ont été inclus dans les graphiques: l'Autriche (2012), l'Estonie (2012), l'Irlande (2008, 2010, 2011, 2012), l'Italie (2008, 2009, 2010, 2012), la Lituanie (2011 et 2012), la Pologne (2011 et 2012), le Portugal (2010, 2011, 2012), la République slovaque (2011 et 2012), la République tchèque (2011) et la Suède $(2010,2011,2012)$. 3. Le taux de détention d'entreprises établies est la proportion des membres de la population adulte qui sont actuellement dirigeants-propriétaires d'une entreprise établie qui verse des traitements, des salaires ou toute autre rémunération à ses propriétaires depuis plus de 42 mois. Cet indicateur renseigne sur le niveau d'activités entrepreneuriales au sein d'une économie.

Source: Présentations tabulaires spéciales des enquêtes 2008-2012 sur la population adulte, extraites du Global Entrepreneurship Monitor.

StatLink न्ताड़ $h t t p: / / d x . d o i . o r g / 10.1787 / 888933191535$

de propriété de nouvelles entreprises dans les pays et États membres où il existe une corrélation entre les taux élevés ou faibles d'entrepreneuriat naissant ou de propriété de nouvelles entreprises, d'une part, et les taux élevés ou faibles de détention d'entreprises établies, d'autre part.

\section{Entraves à la création d'entreprise par des femmes}

- L'un des obstacles à la création d'entreprise et au travail indépendant des femmes réside dans leur propre perception de la faisabilité d'une telle démarche. Les femmes ont moins tendance que les hommes à envisager le travail indépendant comme un type d'emploi à privilégier $(33 \%$ contre $42 \%)$ et à estimer ce choix de carrière possible ( $26 \%$ contre $35 \%)$.

- Parmi les raisons invoquées, les femmes citent le plus souvent le manque de capital financier (22\% en 2012), un argument également fréquemment repris par les hommes (20\%).

- Les motifs invoqués sont souvent communs aux hommes et aux femmes, mais ces dernières mettent plus fréquemment en avant la difficulté de concilier le statut d'indépendant avec leurs obligations familiales ( $8 \%$ contre $4 \%$ ).

Le Graphique 2.9 illustre les différences de perception entre les hommes et les femmes en termes d'intérêt pour le travail indépendant et de faisabilité en 2012. Les hommes avaient beaucoup plus tendance que les femmes à préférer le travail indépendant au salariat (42\% contre $33 \%$ ) et à le considérer comme une carrière possible (35\% contre $26 \%$ ). De nombreux facteurs peuvent expliquer ces différences de perception vis-à-vis du travail indépendant, notamment l'impact des entraves à la création d'entreprise sur les hommes et les femmes. 


\section{Graphique 2.9. Attrait pour le travail indépendant et faisabilité chez les hommes et les femmes dans l'UE-28, 2012}

«Si vous pouviez choisir entre divers types de métiers, préféreriez-vous être indépendant?» "Que vous le souhaitiez ou non, serait-il faisable pour vous d'être indépendant au cours des 5 prochaines années?»

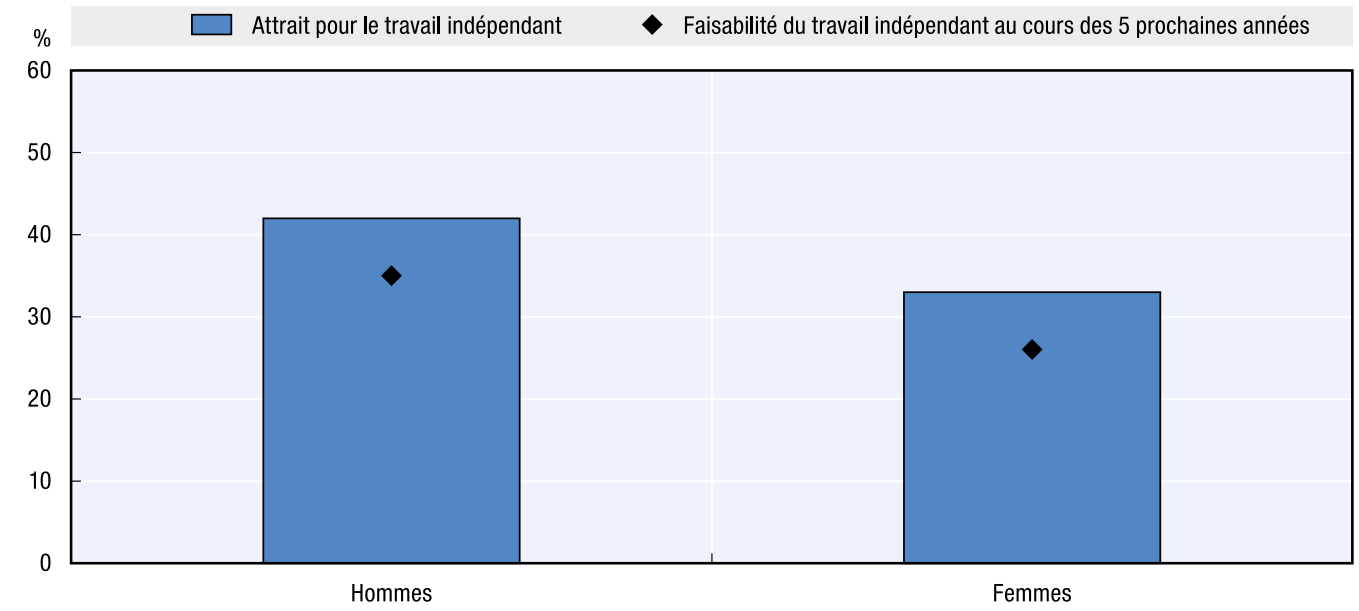

Source: Commission européenne, 2012, «L'entrepreneuriat dans l'UE et au-delà», Eurobaromètre Flash 354.

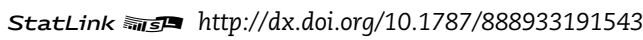

Les perceptions des entraves à la création d'entreprise sont présentées par sexe au Graphique 2.10. L'accès au capital nécessaire pour démarrer une entreprise constituait le frein principal tant pour les hommes que pour les femmes, ces dernières ayant même légèrement

\section{Graphique 2.10. Entraves au travail indépendant des hommes et des femmes dans l'UE-28, 2012}

«Pourquoi ne serait-il pas faisable pour vous de devenir indépendant au cours des 5 prochaines années?»

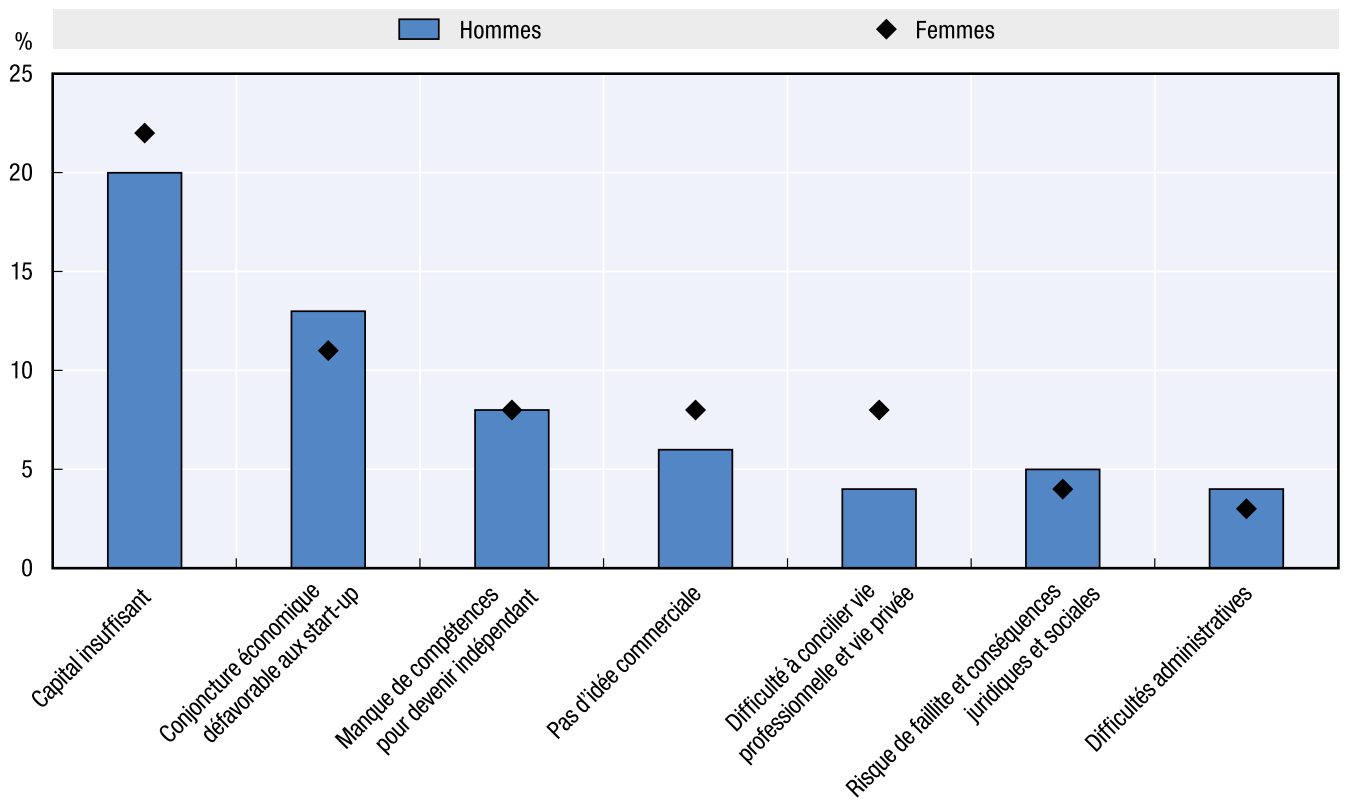

Source: Commission européenne, 2012, «L'entrepreneuriat dans l'UE et au-delà», Eurobaromètre Flash 354. 
plus tendance à le voir comme un obstacle (22\% contre $20 \%$ ). Hommes et femmes désignaient par ailleurs dans des proportions égales le manque de compétences, le risque élevé d'échec et les conséquences importantes qui en découlent ainsi que les difficultés administratives. La difficulté de concilier le statut d'indépendant et les obligations familiales ( $8 \%$ contre $4 \%$ ) et l'absence d'idée commerciale ( $8 \%$ contre $6 \%$ ) étaient plus fréquemment citées par les femmes. Elles étaient en revanche un peu moins nombreuses que les hommes à identifier le climat économique actuel comme une entrave au démarrage d'une entreprise (11\% contre $13 \%)$.

\section{Heures de travail des femmes indépendantes}

- En 2012, les femmes indépendantes dans l'UE travaillaient en moyenne 45,3 heures par semaine, soit 3,5 heures de moins que les hommes indépendants (48,8 heures par semaine).

- En 2012, les femmes indépendantes travaillaient en moyenne six heures hebdomadaires de plus que les salariées. C'est un peu moins que la différence entre hommes indépendants et salariés (7,7 heures par semaine).

- En 2012, le nombre d'heures hebdomadaires travaillées des femmes indépendantes variait fortement d'un État membre à l'autre, allant de 39,3 heures en Roumanie à 52,2 heures en Autriche.

Les travailleurs indépendants ont davantage tendance à faire plus d'heures que les salariés (Graphique 2.11). En 2012, les salariés travaillaient en moyenne 41,1 heures par semaine, contre 48,8 heures pour les indépendants. De la même manière, les salariées travaillaient 39,3 heures par semaine, contre 45,3 heures pour les indépendantes. Si, au cours de la dernière décennie, on a observé une légère tendance à la baisse du nombre d'heures de travail hebdomadaires chez les indépendants, le chiffre des salariés reste stable.

\section{Graphique 2.11. Nombre moyen d'heures de travail hebdomadaires chez les indépendants (hommes et femmes) dans l'UE-28, 2002-2012 \\ Heures hebdomadaires travaillées chez les 18-64 ans travaillant à temps plein}

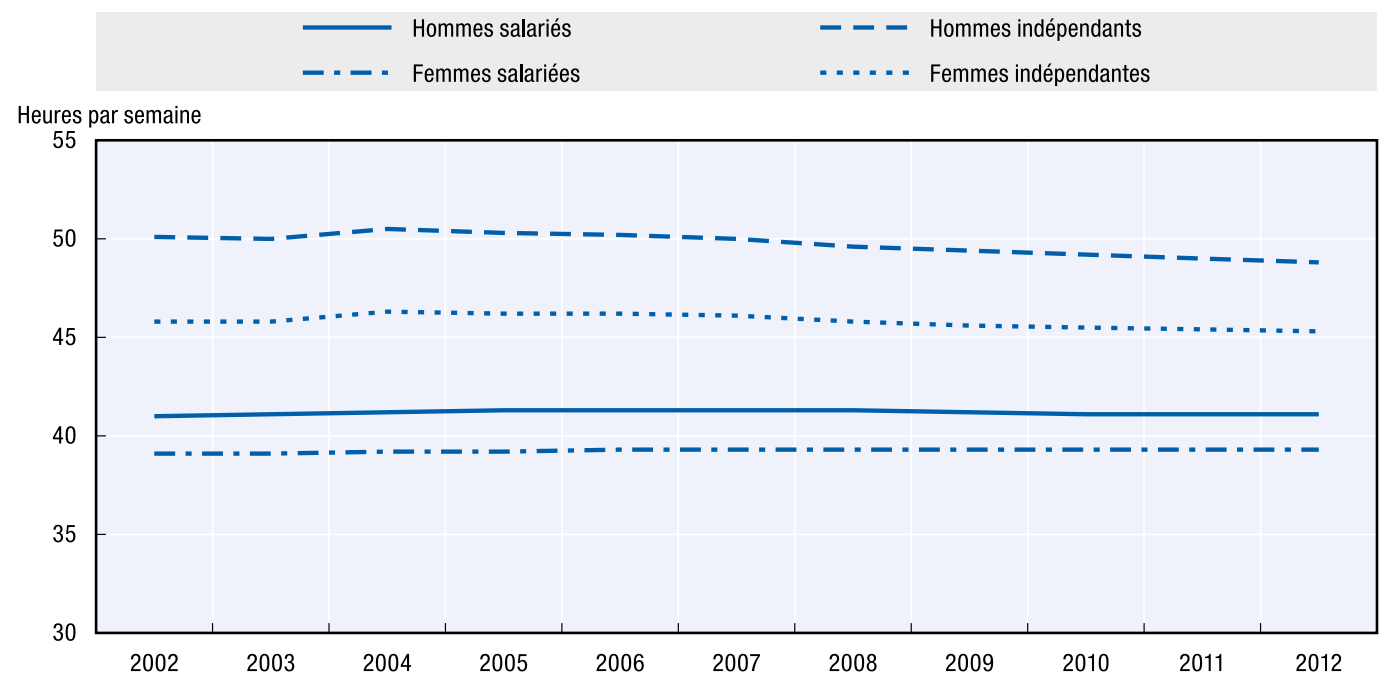

Source: Eurostat, Enquête sur les forces de travail 2002-2012. 
Le Graphique 2.12 présente les disparités en termes d'heures de travail par État membre sur la même période. Le nombre moyen d'heures de travail hebdomadaires varie sensiblement d'un État membre à l'autre. En Lettonie, Lituanie et Roumanie, il a peu varié selon le sexe ou le statut professionnel en 2012. En revanche, les résultats étaient beaucoup plus inégaux entre les sexes en Belgique, en France, en Irlande et aux Pays-Bas.

\section{Graphique 2.12. Nombre moyen d'heures hebdomadaires travaillées chez les hommes et les femmes indépendants, 2002-2012}

Heures hebdomadaires travaillées chez les 18-64 ans travaillant à temps plein
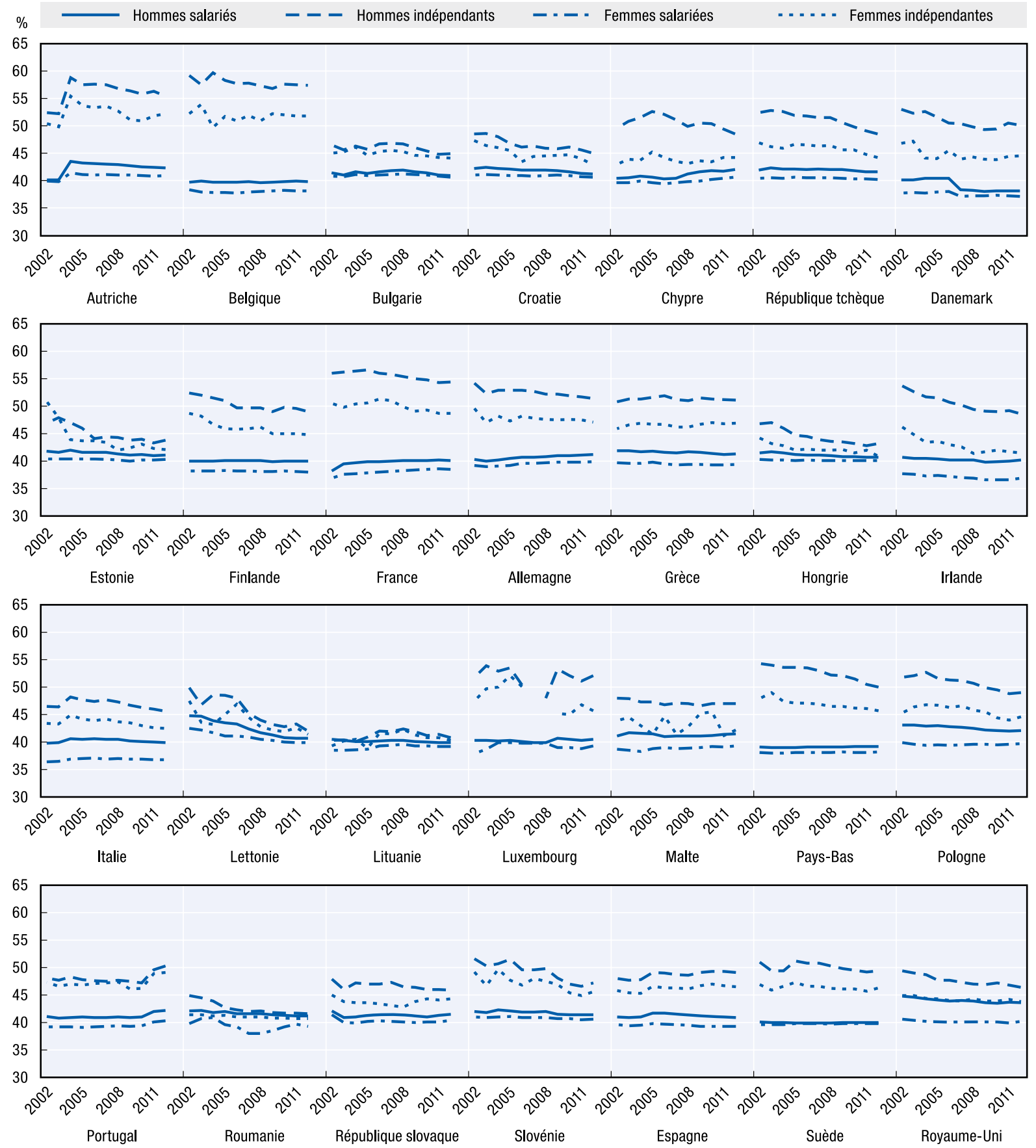

Source: Eurostat, Enquête sur les forces de travail 2002-2012. 


\section{Revenu des indépendantes}

- En 2012, les femmes propriétaires d'entreprise étaient moins susceptibles que les hommes de compter sur leur activité entrepreneuriale comme source de revenu principale (66\% contre $79 \%$ ). Parmi les femmes propriétaires d'entreprise, $12 \%$ avaient un emploi à temps plein et $14 \%$ un emploi à temps partiel, contre respectivement 11 et $7 \%$ chez les hommes.

- En 2012, les indépendantes gagnaient moins que les salariées. En revanche, à l'échelle de l'UE, elles touchaient autant que les hommes indépendants.

En 2012, les femmes dont l'activité professionnelle principale était salariée ont gagné en moyenne près de 18000 EUR, contre un peu moins de 14000 EUR pour les indépendantes (Graphique 2.13). Dans tous les États membres, sauf en France, au Luxembourg et en Suède, les salariées ont mieux gagné leur vie que les indépendantes. Leur revenu était quasiment identique en Bulgarie, en République tchèque, en Allemagne et en Hongrie.

\section{Graphique 2.13. Revenu annuel des femmes, 2012}

Revenu médian net des activités professionnelles à temps plein

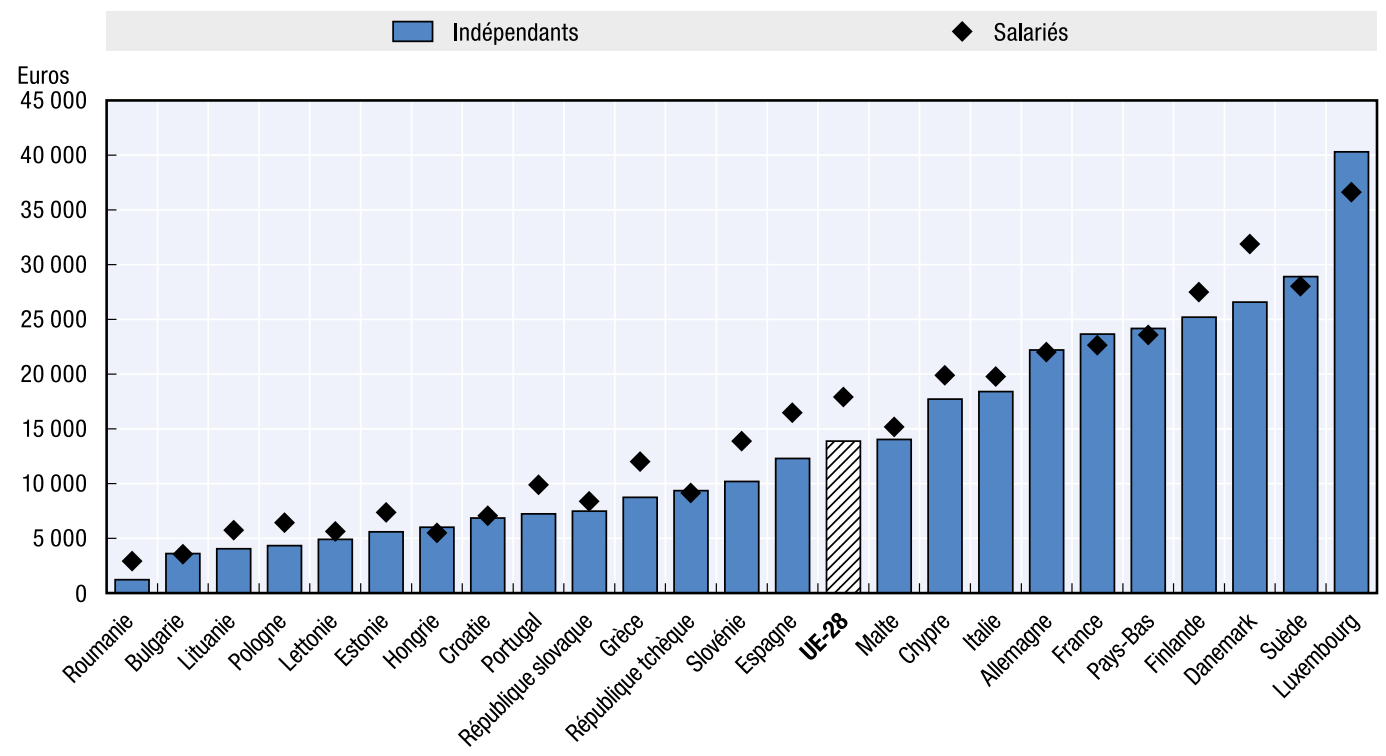

Source: Eurostat, Statistiques sur le revenu et les conditions de vie 2012.

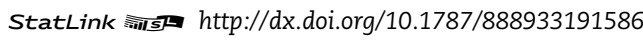

À l'échelle de l'UE, les indépendantes ont quasiment perçu le même revenu que les hommes indépendants en 2012 (Graphique 2.14). En 2012, les indépendants, hommes et femmes, ont gagné un peu moins de 14000 EUR, soit une légère baisse par rapport à 2011. Malgré quelques écarts de revenu entre les États membres, les indépendantes ont gagné autant que les indépendants dans quasiment tous les pays. Quelques pays font figure d'exceptions. Au Danemark et en Lituanie, les indépendants ont gagné légèrement plus que les indépendantes, tandis qu'en France, au Luxembourg, à Malte et en Espagne, ce sont les indépendantes qui ont perçu le plus. 
Graphique 2.14. Revenu du travail indépendant des hommes et des femmes, 2012 Revenu médian net des activités professionnelles à temps plein

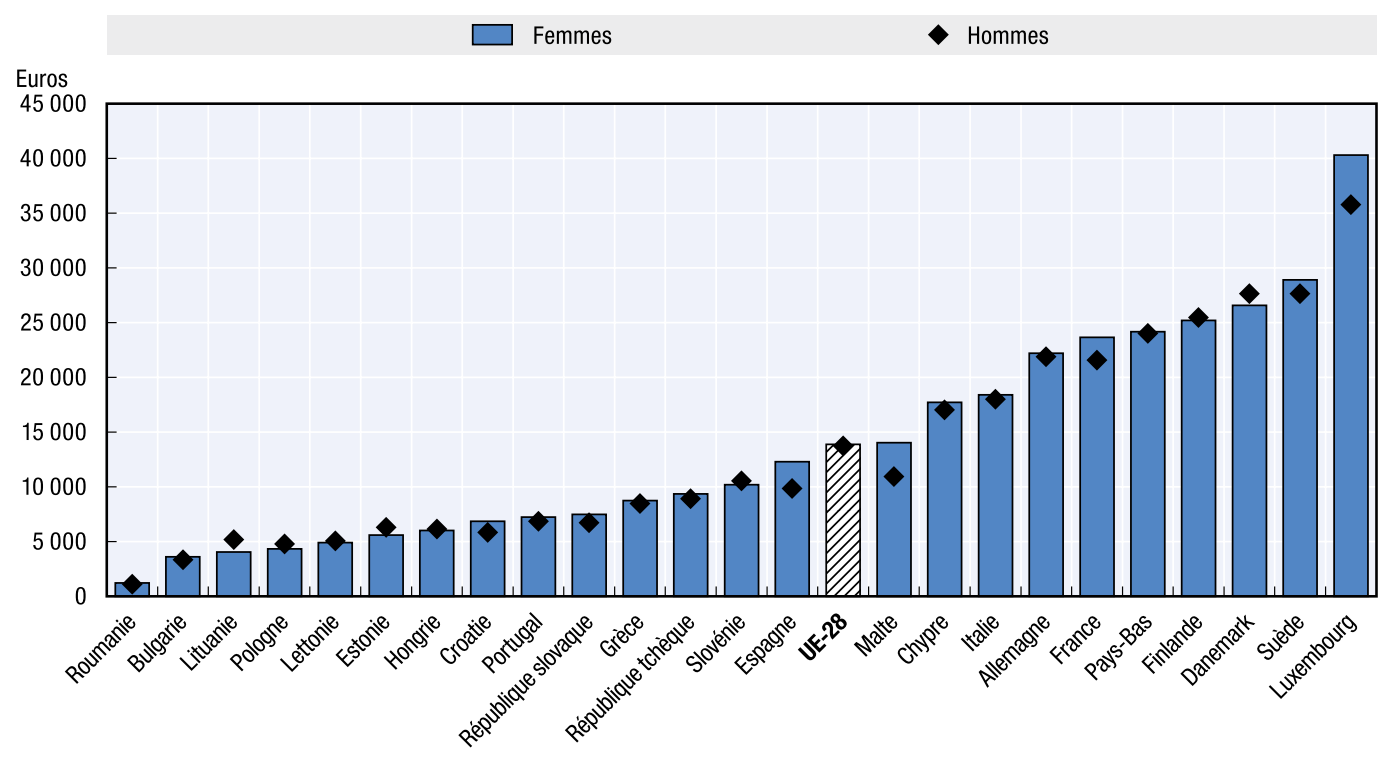

Source: Eurostat, Statistiques sur le revenu et les conditions de vie 2012.

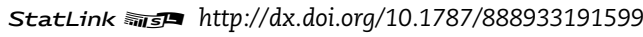

Le Graphique 2.15 fournit une vision plus précise du revenu des propriétaires d'entreprise. Les femmes propriétaires d'entreprise comptaient moins sur leur activité entrepreneuriale comme source de revenu principale. Seuls $66 \%$ du revenu des femmes indépendantes provenaient de leur entreprise, contre $79 \%$ pour les hommes. Les propriétaires d'entreprise, les hommes comme les femmes, comptaient sur un emploi à temps plein comme source de revenu principale, mais les femmes avaient davantage tendance à s'appuyer sur un emploi à temps partiel et les pensions.

\section{Graphique 2.15. Principales sources de revenu des indépendants (hommes et femmes) dans l'UE-28, 2012}

"Quelle est ou quelles sont actuellement votre ou vos principale(s) source(s) de revenu?» (pour les propriétaires d'une entreprise)

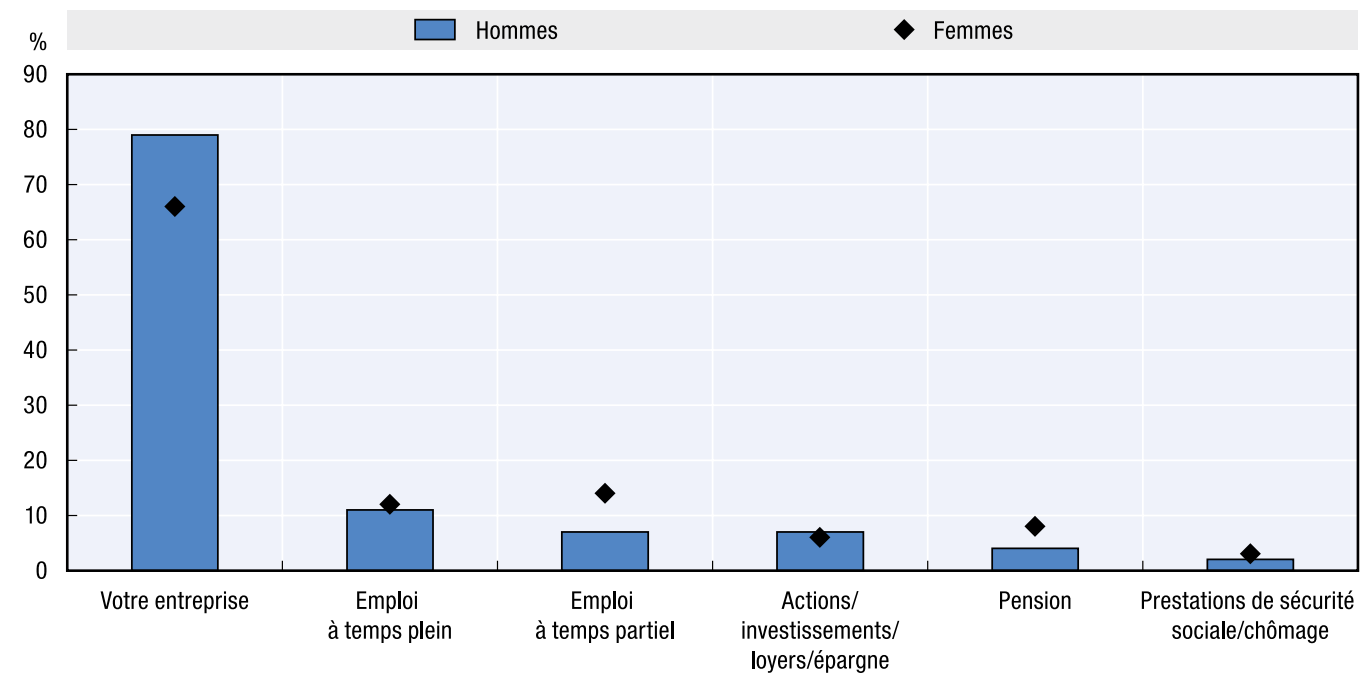

Source: Commission européenne, 2012, «L'entrepreneuriat dans l'UE et au-delà», Eurobaromètre Flash 354. 


\section{Prévisions de croissance chez les femmes entrepreneurs}

- Entre 2008 et 2012, moins de 1\% des femmes dans l'UE ont été impliquées dans une activité entrepreneuriale au stade précoce, avec la perspective de créer plus de six emplois au cours des cinq premières années d'exploitation. C'est moitié moins que les hommes $(2,3 \%)$.

Le Graphique 2.16 présente la proportion de femmes impliquées dans des activités entrepreneuriales au stade précoce entre 2008 et 2012, avec la perspective de créer plus de six emplois au cours des cinq années suivantes. Les hommes étaient deux fois plus nombreux que les femmes à être engagés dans une activité entrepreneuriale au stade précoce et à espérer générer six emplois ( $0,8 \%$ contre $2,3 \%$ ). Dans quelques États membres comme la Lettonie $(2,6 \%)$ et la Lituanie $(2,5 \%)$, elles étaient plus nombreuses à envisager la création d'au moins six emplois au cours des cinq prochaines années que les hommes de douze États membres. En revanche, ce pourcentage de femmes était inférieur à 1\% dans deux tiers des États membres.

\section{Graphique 2.16. Prévisions de croissance chez les entrepreneurs (hommes et femmes), 2008-2012 (combinés)}

Pourcentage des 15-64 ans engagés dans une activité entrepreneuriale totale au stade précoce qui prévoient de créer plus de six emplois dans les cinq prochaines années

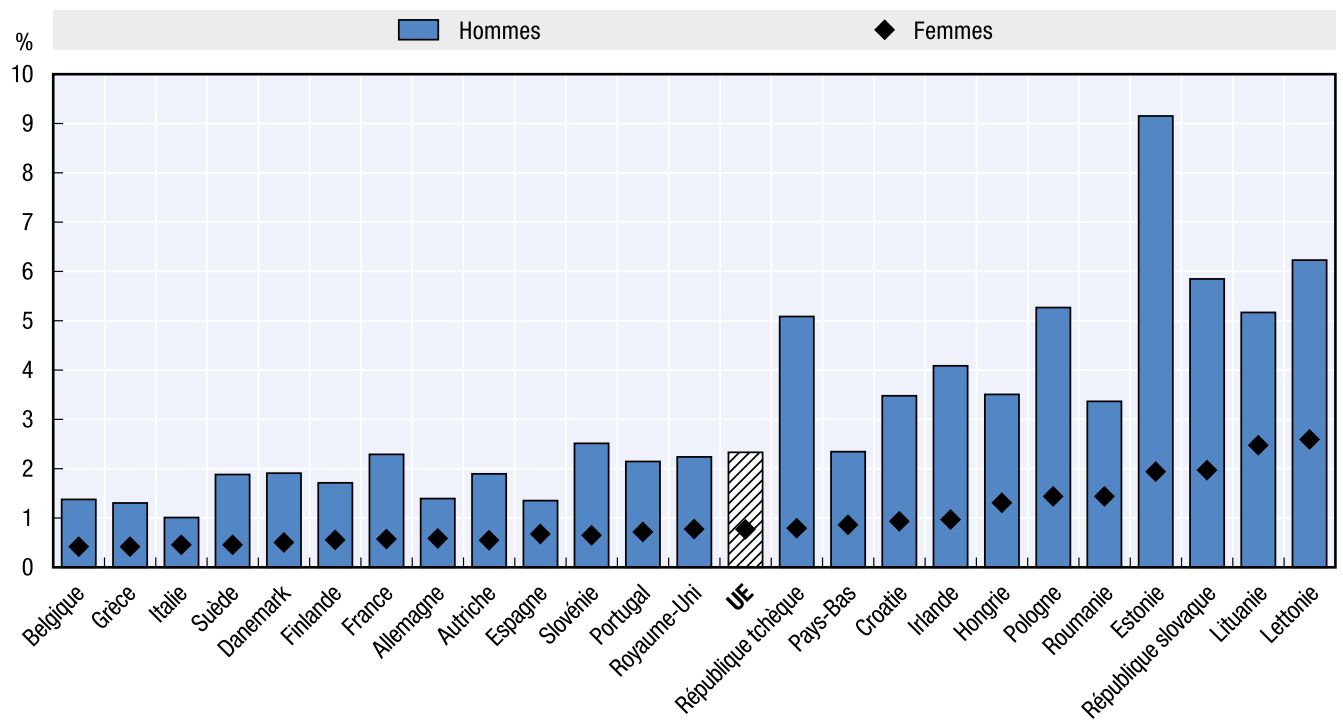

Note: L’activité entrepreneuriale totale au stade précoce désigne la proportion de la population activement impliquée dans la création d'une entreprise dont elle sera propriétaire ou copropriétaire et la proportion de la population ayant créé une entreprise au cours des 42 derniers mois.

Source: Présentations tabulaires spéciales des enquêtes 2008-2012 sur la population adulte, extraites du Global Entrepreneurship Monitor.

StatLink त्ञाज् http://dx.doi.org/10.1787/888933191618

\section{Références}

Commission européenne, 2012, «L'entrepreneuriat dans l'UE et au-delà», Eurobaromètre Flash 354, disponible sur: http://ec.europa.eu/public_opinion/flash/fl_354_en.pdf.

Eurostat (2013a), Enquête sur les forces de travail, disponible sur: http://epp.eurostat.ec.europa.eu/portal/ page/portal/employment_unemployment_lfs/data/database.

Eurostat (2013b), Statistiques sur le revenu et les conditions de vie, disponible sur: http://epp.eurostat. ec.europa.eu/portal/page/portal/income_social_inclusion_living_conditions/introduction.

Global Entrepreneurship Monitor (GEM) (2013), Présentations tabulaires spéciales des enquêtes 20082012 sur la population adulte du Global Entrepreneurship Monitor. 



\section{Chapitre 3}

\section{Le travail indépendant et l'entrepreneuriat chez les jeunes ${ }^{1,2}$}

Ce chapitre traite des activités d'indépendant et d'entrepreneuriat exercées par les jeunes. Il illustre la proportion de jeunes qui possèdent une entreprise et exercent une activité indépendante, renseigne sur les freins à la création d'entreprise et décrit quelques-unes des caractéristiques clés des travailleurs indépendants.

1. Note de la Turquie:

Les informations figurant dans ce document et faisant référence à «Chypre» concernent la partie méridionale de l'île. Il n'y a pas d'autorité unique représentant à la fois les Chypriotes turcs et grecs sur l'île. La Turquie reconnaît la République turque de Chypre du Nord (RTCN). Tant qu'une solution durable et équitable n'aura pas été trouvée dans le cadre des Nations unies, la Turquie maintiendra sa position sur la «question chipriote».

2. Note de tous les États de l'Union européenne membres de l'OCDE et de l'Union européenne:

La République de Chypre est reconnue par tous les membres des Nations unies sauf la Turquie. Les informations figurant dans ce document concernent la zone sous le contrôle effectif du gouvernement de la République de Chypre. 


\section{Le travail indépendant chez les jeunes}

- Le travail indépendant est peu répandu chez les jeunes de l'UE. À titre d'exemple, en 2012, sur les 30,8 millions de travailleurs indépendants, moins de 820000 étaient des jeunes âgés de 15 à 24 ans (2,6\%).

- Le pourcentage de jeunes indépendants en 2012 était compris entre 1,2\% au Danemark et $12,2 \%$ en Italie.

- Le plus souvent, les jeunes indépendants n'ont pas d'employés. Seuls $11,3 \%$ des jeunes indépendants employaient au moins une personne en 2012, contre 18,9\% en 2002.

- Les activités d'indépendant des jeunes concernaient principalement les secteurs suivants: l'agriculture, la sylviculture et la pêche (12,6\%); la construction (16,9\%); le commerce de gros et de détail $(13,7 \%)$.

Les jeunes (âgés de 15 à 24 ans) sont beaucoup moins susceptibles d'être indépendants que la population adulte (Graphique 3.1). En 2012, 4,3\% des jeunes actifs étaient des indépendants, soit moins d'un tiers du taux des adultes (14,5\%). Les taux de travail indépendant chez les jeunes et les adultes sont restés stables entre 2002 et 2012.

\section{Graphique 3.1. Taux de travail indépendant des jeunes dans l'UE-28, 2002-2012 Pourcentage des 15-64 ans}

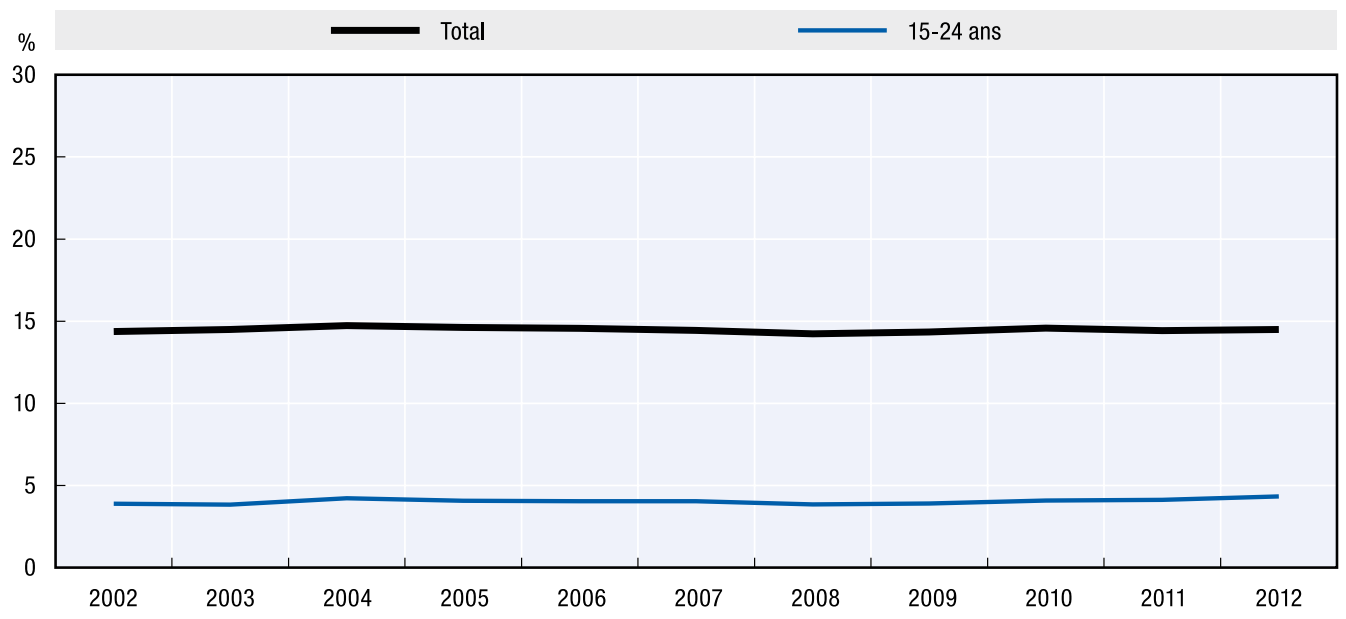

Source: Eurostat, Enquête sur les forces de travail 2002-2012.

Ceux du travail indépendant des jeunes sont présentés pour chaque État membre au Graphique 3.2. Entre 2002 et 2012, ils ont augmenté dans 19 États membres, parmi lesquels plus particulièrement la République slovaque (6,9\%), et baissés dans 7 d'entre eux, dont la Pologne (3\%) et la Bulgarie (2,9\%). Celui du Danemark reste inchangé sur la période 2002-2012. 


\section{Graphique 3.2. Taux de travail indépendant des jeunes, 2002-2012}

Pourcentage des 15-64 ans
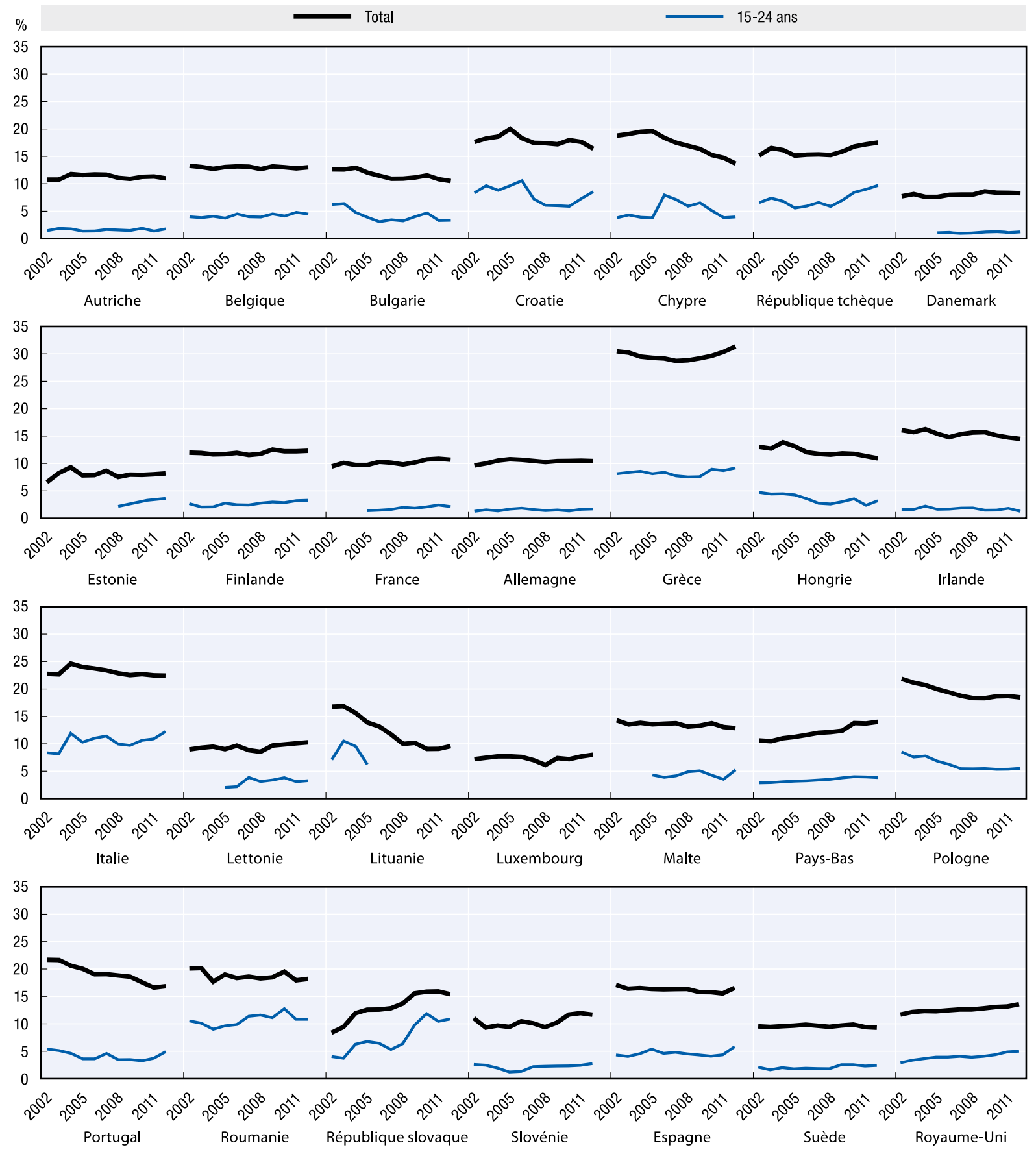

Source: Eurostat, Enquête sur les forces de travail 2002-2012.

Les responsables politiques doivent également tenir compte de la motivation à commencer une activité indépendante, en particulier chez les jeunes. Cet aspect peut en effet avoir une influence sur les chances de transformer une start-up en une entreprise durable. Certains jeunes démarreront une entreprise pour exploiter une opportunité qu'ils ont identifiée et d'autres le feront faute d'avoir trouvé un emploi. Ces motivations 
évoluent avec le temps. Quelqu'un qui se lance dans la création d'entreprise à défaut d'un emploi peut identifier et poursuivre une opportunité à fort potentiel de croissance. Cela étant, les décideurs politiques doivent également reconnaître qu'un certain nombre de personnes optent pour le statut d'indépendant parce qu'un employeur préfère recruter un indépendant plutôt qu'un salarié.

Entre 2002 et 2012, on observe une nette diminution du nombre de jeunes indépendants (âgés de 15 à 24 ans) qui emploient des salariés (Graphique 3.3). Environ 19\% des jeunes indépendants de l'UE employaient du personnel en 2002. Ils n'étaient plus que $11 \%$ en 2012. Sur les 819000 jeunes indépendants de l'UE, seuls 92400 avaient des employés à leur service en 2012. Cette diminution va dans le sens du recul général du nombre d'indépendants faisant appel à des employés. Cette tendance peut s'expliquer par plusieurs facteurs, tels que le contexte macroéconomique et les problèmes structurels du marché du travail. Par exemple, la proportion d'employeurs qui font appel à des indépendants au lieu d'engager des salariés est une source de préoccupation pour les responsables politiques. Les travailleurs se retrouvent de ce fait avec un régime de travail moins stable, tandis que les employeurs voient leurs cotisations aux systèmes de sécurité sociale se réduire. Bien qu'il soit impossible de tirer des conclusions à ce sujet simplement à partir des données du travail indépendant, cette tendance à la baisse du taux d'indépendants avec employés corrobore le fait que les employeurs privilégient désormais fortement les contrats de travail indépendant au détriment du recrutement de salariés.

\section{Graphique 3.3. Proportion des jeunes indépendants employant des salariés dans l'UE-28, 2002-2012}

Pourcentage des 15-64 ans

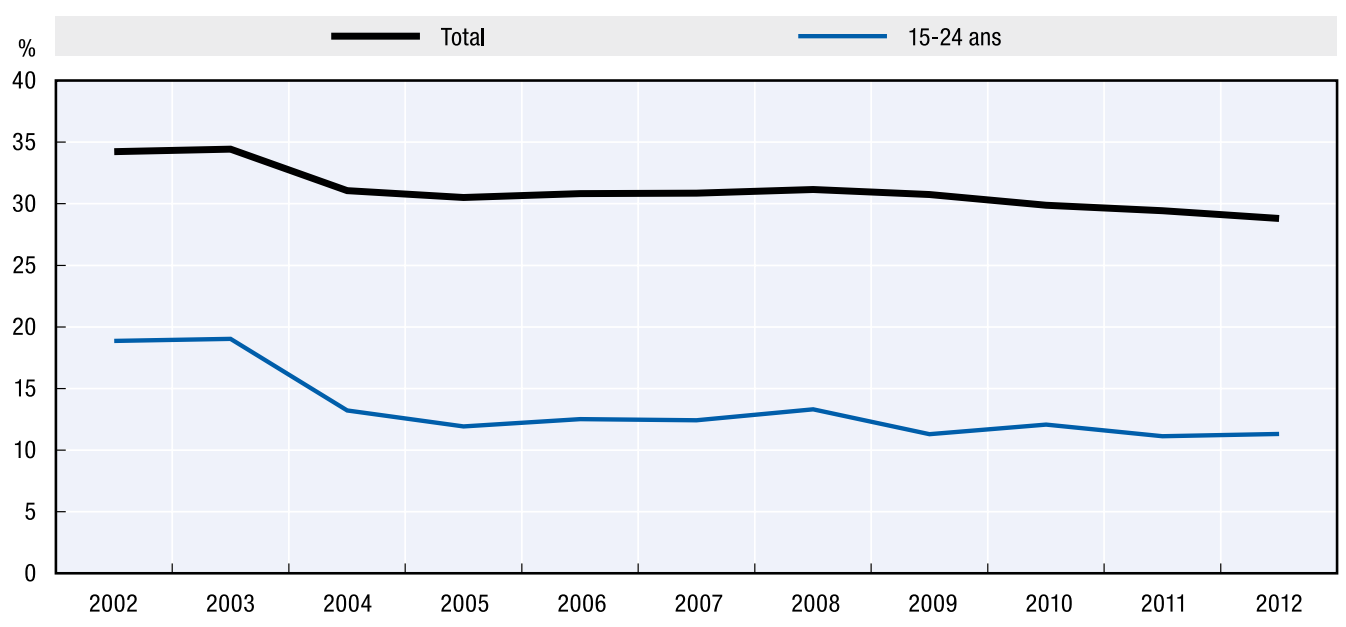

Source: Eurostat, Enquête sur les forces de travail 2002-2012.

La part des jeunes indépendants faisant appel à des employés dans chaque État membre est présentée au Graphique 3.4. Ces données permettent d'identifier deux problématiques majeures. Premièrement, les jeunes indépendants étaient moins susceptibles de faire appel à du personnel dans l'ensemble des pays pour lesquels des données sont disponibles. Deuxièmement, si la proportion de jeunes indépendants avec employés a connu une baisse dramatique à l'échelle de l'UE, elle a progressé dans certains États membres, notamment en Pologne et en Espagne. 


\section{Graphique 3.4. Proportion des jeunes indépendants employant des salariés, 2002-2012}

Pourcentage des 15-64 ans
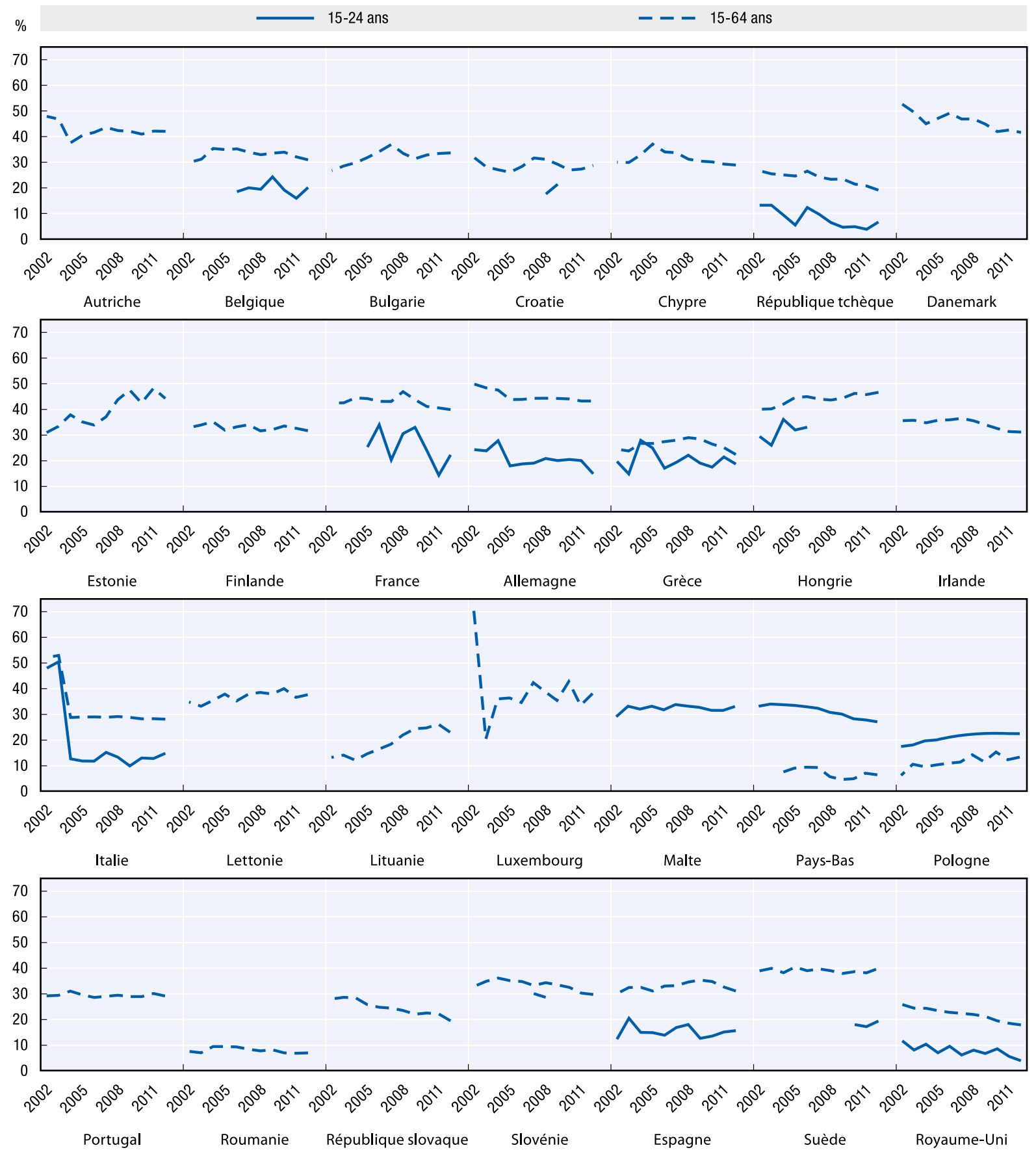

Source: Eurostat, Enquête sur les forces de travail 2002-2012.

StatLink त्नाज्ञ http://dx.doi.org/10.1787/888933191650

Le Graphique 3.5 montre la répartition des activités des jeunes indépendants (âgés de 15 à 24 ans) par secteur professionnel. Ces activités se concentraient en 2012 dans trois secteurs professionnels: l'agriculture, la sylviculture et la pêche (12,6\%); la construction $(16,9 \%)$; le commerce de gros et de détail $(13,7 \%)$. Au total, ces secteurs représentaient $43,2 \%$ des activités des jeunes indépendants. 


\section{Graphique 3.5. Répartition des jeunes indépendants par secteur professionnel dans l'UE-28, 2012}

Pourcentage des 15-64 ans

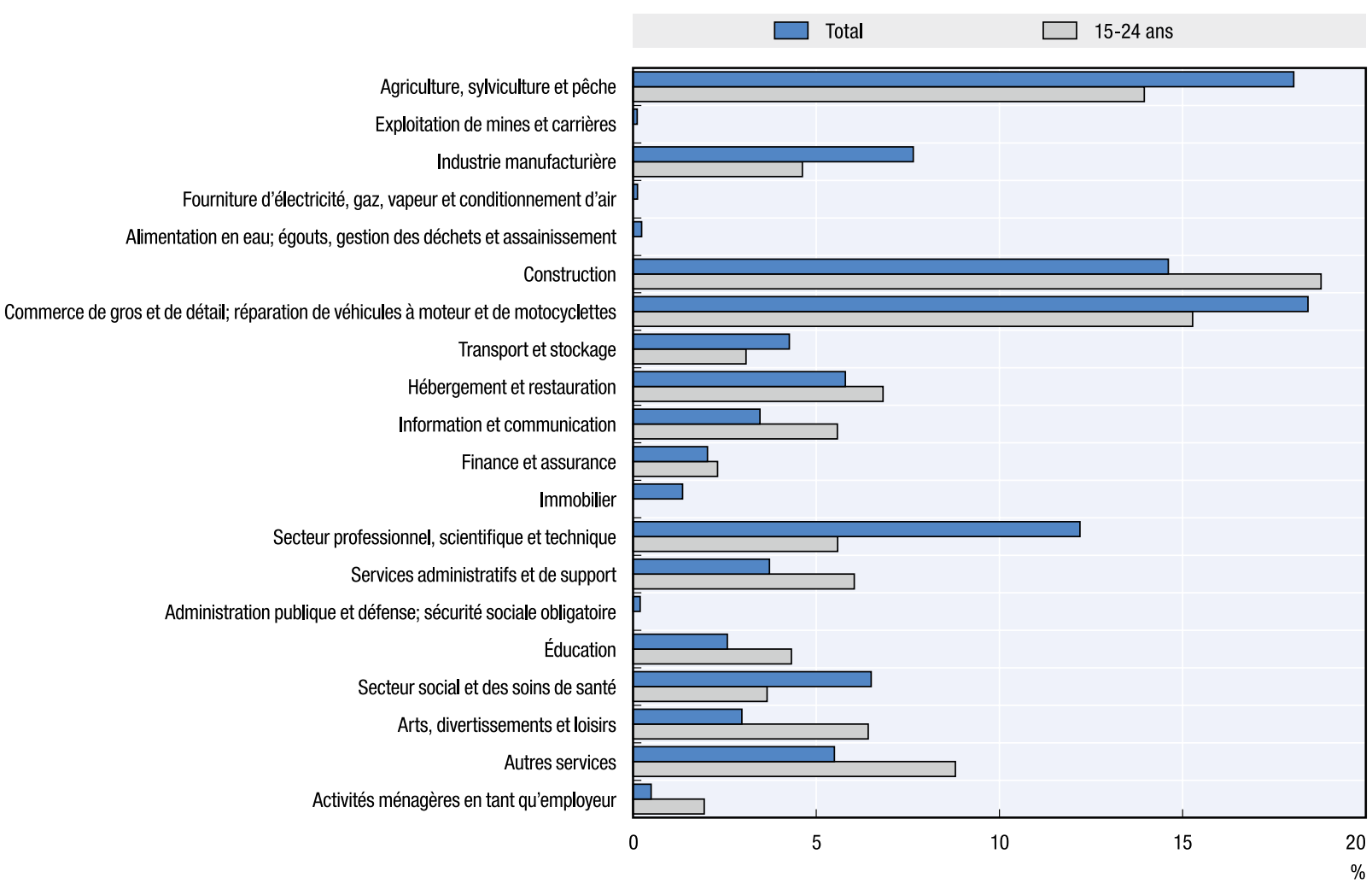

Source: Eurostat, Enquête sur les forces de travail 2012.

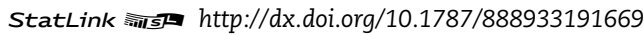

\section{Activités exercées par les jeunes tout au long du cycle de vie entrepreneuriale}

- Entre 2008 et 2012, les jeunes (âgés de 18 à 30 ans) de l'UE avaient légèrement plus tendance que les adultes à s'engager dans la création d'une entreprise (4,1\% contre $3,4 \%)$.

- Le pourcentage de jeunes créateurs d'entreprise variait fortement d'un État membre à l'autre, de 2,5\% au Danemark à 13,1\% en Estonie.

- Entre 2008 et 2012, l'UE comptait quasiment autant de jeunes que d'adultes susceptibles de devenir propriétaire d'une entreprise (2,6\% contre $2,9 \%)$.

- Au sein de l'UE, les jeunes étaient très peu nombreux à posséder une société établie: moins de $2 \%$ des personnes âgées de 18 à 30 ans étaient dans ce cas.

Le Graphique 3.6 présente les taux d'entrepreneuriat naissant chez les jeunes (âgés de 18 à 30 ans) et l'ensemble de la population adulte (âgée de 18 à 64 ans) dans les pays de l'UE. Le taux d'entrepreneuriat naissant mesure la proportion d'adultes déclarant être activement engagés dans la création d'une entreprise qu'ils détiennent seuls ou en copropriété. Cette activité ne doit pas avoir rapporté de traitements, de salaires ou toute autre rémunération à ses propriétaires depuis plus de trois mois. Pour en savoir plus sur cette notion et sur cette source de données, nous vous renvoyons au guide de lecture. 


\section{Graphique 3.6. Taux d'entrepreneuriat naissant chez les jeunes, 2008-2012 (combinés)}

Pourcentage des 18-64 ans

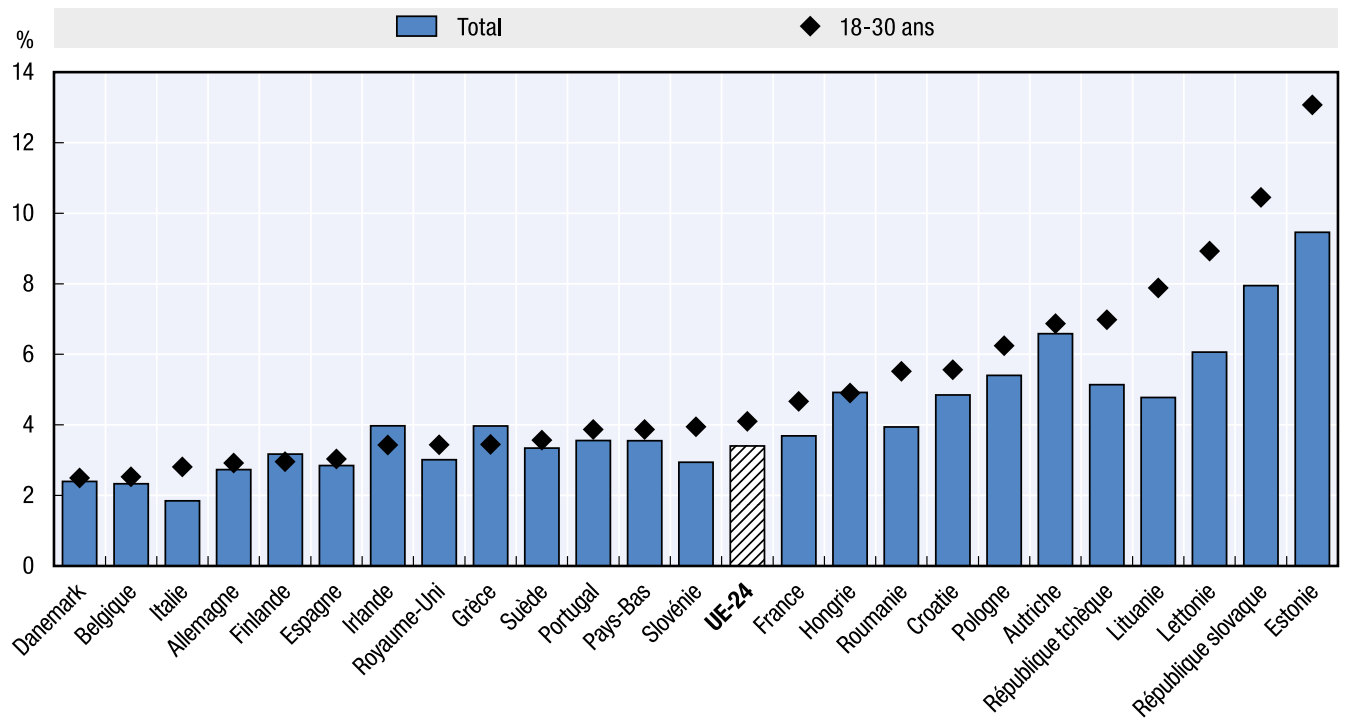

Notes: 1. Les pays de l'UE ayant participé à l'enquête Global Entrepreneurship Monitor pendant cette période sont: l'Allemagne, l'Autriche, la Belgique, la Croatie, le Danemark, l'Espagne, l'Estonie, la Finlande, la France, la Grèce, la Hongrie, l'Irlande, l'Italie, la Lettonie, la Lituanie, les Pays-Bas, la Pologne, le Portugal, la République slovaque, la République tchèque, la Roumanie, le Royaume-Uni, la Slovénie et la Suède. 2. Les données présentées dans ce Graphique ont été combinées: elles cumulent les résultats des enquêtes annuelles portant sur la période 2008-2012. Certains pays n'ont pas pris part aux enquêtes GEM réalisées chaque année, mais ont été inclus dans les graphiques: l'Autriche (2012), l'Estonie (2012), l'Irlande (2008, 2010, 2011, 2012), l'Italie (2008, 2009, 2010, 2012), la Lituanie (2011 et 2012), la Pologne (2011 et 2012), le Portugal (2010, 2011, 2012), la République slovaque (2011 et 2012), la République tchèque (2011) et la Suède (2010, 2011, 2012). 3. Le taux d'entrepreneuriat naissant est défini comme la proportion de la population adulte (âgée de 18 à 64 ans) activement engagée dans la création d'une entreprise qu'elle détiendra seule ou en copropriété; cette entreprise ne peut pas avoir octroyé de traitements, salaires ou toute autre rémunération à ses propriétaires depuis plus de trois mois.

Source: Présentations tabulaires spéciales des enquêtes 2008-2012 sur la population adulte, extraites du Global Entrepreneurship Monitor.

StatLink ails $h$ ttp://dx.doi.org/10.1787/888933191675

Les taux d'entrepreneuriat naissant étaient plus élevés chez les jeunes que chez les adultes dans la grande majorité des États membres de l'UE (Graphique 3.6). L'écart entre jeunes et adultes était le plus marqué en Estonie, à 3,6\%. Les taux étaient à égalité en Hongrie. Le Graphique 3.6 illustre également les écarts importants entre les États membres. Les taux d'entrepreneuriat naissant des jeunes étaient les plus élevés en Estonie (13,1\%), en République slovaque (10,4\%) et en Lettonie (8,9\%). Ils étaient les plus bas au Danemark $(2,5 \%)$, en Belgique $(2,5 \%)$ et en Italie $(2,8 \%)$.

On observe des tendances similaires concernant le taux de détention de nouvelle entreprise, qui mesure la proportion de la population adulte gérant ou possédant actuellement une nouvelle entreprise qui verse des traitements, des salaires ou toute autre rémunération à ses propriétaires depuis plus de trois mois mais moins de 42 mois. Ce taux était plus élevé chez les jeunes que chez les adultes dans 16 États membres (Graphique 3.7). Comme pour le taux d'entrepreneuriat naissant, l'Estonie $(7,1 \%)$, la Lettonie $(6,2 \%)$ et la République slovaque $(6,1 \%)$ détenaient les pourcentages de détention de nouvelles entreprises les plus élevés. Les taux les plus faibles ont été constatés au Danemark $(1,5 \%)$, en France $(1,8 \%)$ et en Suède $(1,8 \%)$. L'écart entre le taux de propriété de nouvelles entreprises des jeunes et celui des adultes était le plus grand en Estonie $(2 \%)$ et le plus petit au Portugal (0,3\%). 


\section{Graphique 3.7. Taux de détention de nouvelles entreprises chez les jeunes, 2008-2012 (combinés)}

Pourcentage des 18-64 ans

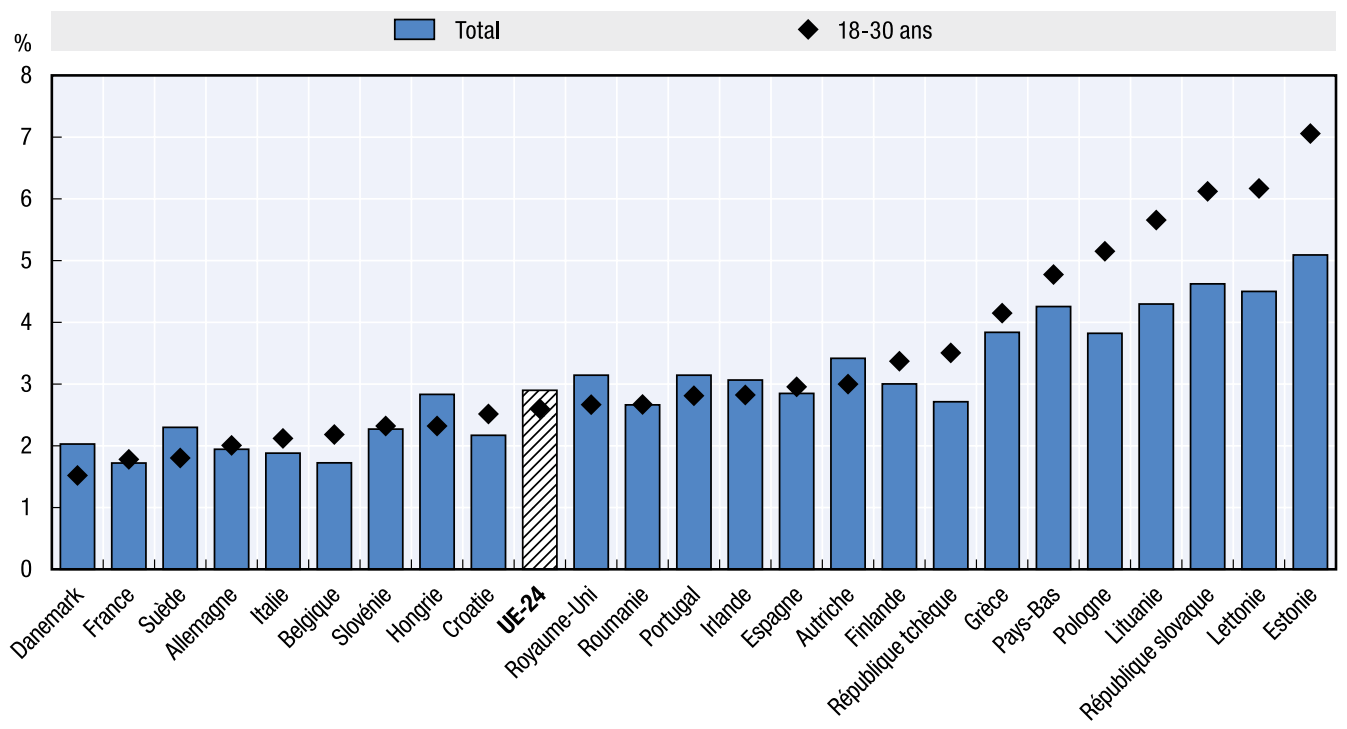

Notes: 1. Les pays de l'UE ayant participé à l'enquête Global Entrepreneurship Monitor pendant cette période sont: l'Allemagne, l'Autriche, la Belgique, la Croatie, le Danemark, l'Espagne, l'Estonie, la Finlande, la France, la Grèce, la Hongrie, l'Irlande, l'Italie, la Lettonie, la Lituanie, les Pays-Bas, la Pologne, le Portugal, la République slovaque, la République tchèque, la Roumanie, le Royaume-Uni, la Slovénie et la Suède. 2. Les données présentées dans ce Graphique ont été combinées: elles cumulent les résultats des enquêtes annuelles portant sur la période 2008-2012. Certains pays n'ont pas pris part aux enquêtes GEM réalisées chaque année, mais ont été inclus dans les graphiques: l'Autriche (2012), l'Estonie (2012), l'Irlande (2008, 2010, 2011, 2012), l'Italie (2008, 2009, 2010, 2012), la Lituanie (2011 et 2012), la Pologne (2011 et 2012), le Portugal (2010, 2011, 2012), la République slovaque (2011 et 2012), la République tchèque (2011) et la Suède $(2010,2011,2012)$. 3 . Le taux de détention de nouvelles entreprises est la proportion de la population adulte gérant ou possédant actuellement une nouvelle entreprise qui verse des traitements, des salaires ou toute autre rémunération à ses propriétaires depuis plus de trois mois mais moins de 42 mois.

Source: Présentations tabulaires spéciales des enquêtes 2008-2012 sur la population adulte, extraites du Global Entrepreneurship Monitor.

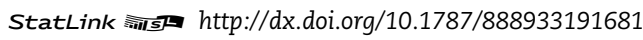

Contrairement aux taux d'entrepreneuriat naissant et de détention de nouvelles entreprises, le taux de détention d'entreprises établies était beaucoup plus bas chez les jeunes que chez les adultes dans l'ensemble des États membres de l'UE (Graphique 3.8). Le taux de détention d'entreprises établies mesure la proportion des membres de la population adulte qui sont actuellement dirigeants-propriétaires d'une entreprise établie qui verse des traitements, des salaires ou toute autre rémunération à ses propriétaires depuis plus de 42 mois. Sur l'ensemble de l'UE, les jeunes étaient trois fois moins susceptibles d'être propriétaires d'une société établie que les adultes. Le taux de détention d'entreprises établies par des jeunes connaît d'importantes variations, tout comme l'écart relatif entre jeunes et adultes. Le taux le plus élevé de détention d'entreprises établies par des jeunes revient à la Grèce, avec $7,4 \%$, soit légèrement plus de la moitié du taux des adultes (14\%). L'État membre avec l'écart le plus faible entre jeunes et adultes en termes de détention de sociétés établies était la Roumanie, où le taux des jeunes (1,9\%) représentait $60 \%$ de celui des adultes $(3,2 \%)$. 


\section{Graphique 3.8. Taux de détention d'entreprises établies chez les jeunes, 2008-2012 (combinés)}

Pourcentage des 18-64 ans

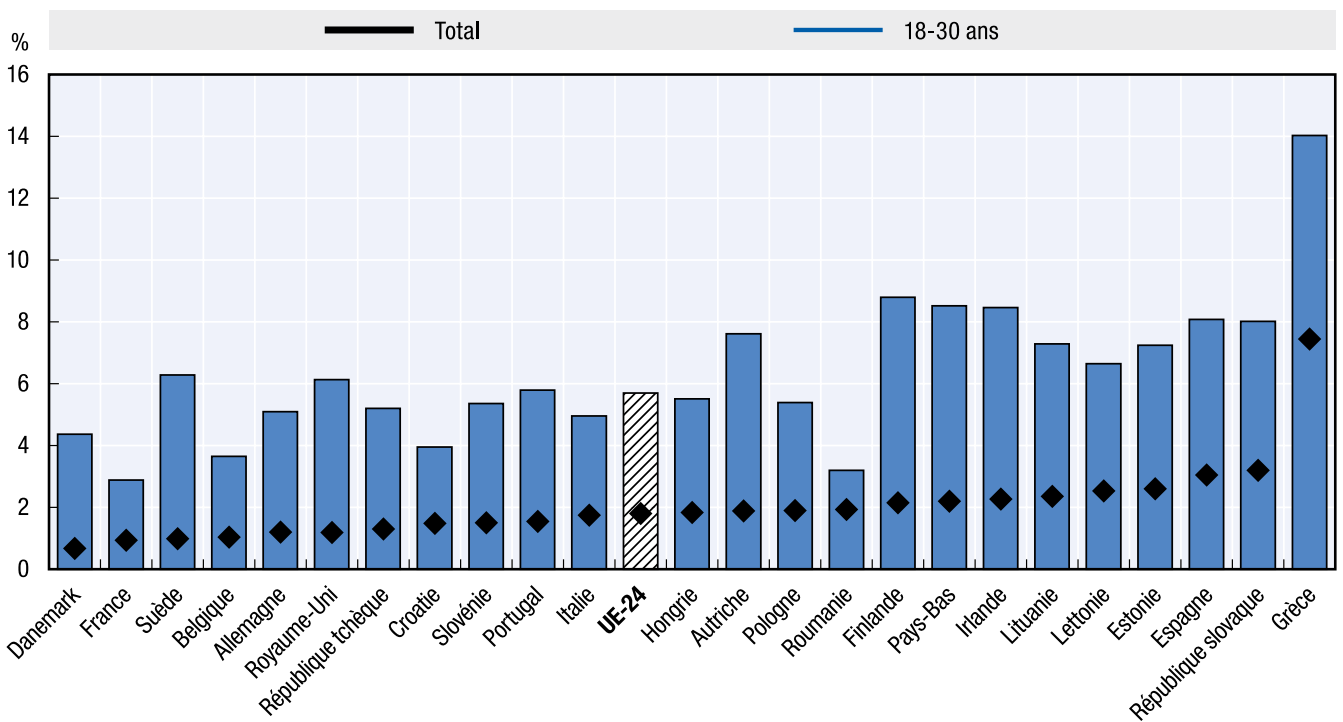

Notes: 1. Les pays de l'UE ayant participé à l'enquête Global Entrepreneurship Monitor pendant cette période sont: l'Allemagne, l'Autriche, la Belgique, la Croatie, le Danemark, l'Espagne, l'Estonie, la Finlande, la France, la Grèce, la Hongrie, l'Irlande, l'Italie, la Lettonie, la Lituanie, les Pays-Bas, la Pologne, le Portugal, la République slovaque, la République tchèque, la Roumanie, le Royaume-Uni, la Slovénie et la Suède. 2. Les données présentées dans ce Graphique ont été combinées: elles cumulent les résultats des enquêtes annuelles portant sur la période 2008-2012. Certains pays n'ont pas pris part aux enquêtes GEM réalisées chaque année, mais ont été inclus dans les graphiques: l'Autriche (2012), l'Estonie (2012), l'Irlande (2008, 2010, 2011, 2012), l'Italie (2008, 2009, 2010, 2012), la Lituanie (2011 et 2012), la Pologne (2011 et 2012), le Portugal (2010, 2011, 2012), la République slovaque (2011 et 2012), la République tchèque (2011) et la Suède (2010, 2011, 2012). 3. Le taux de détention d'entreprises établies est la proportion des membres de la population adulte qui sont actuellement dirigeants-propriétaires d'une entreprise établie qui verse des traitements, des salaires ou toute autre rémunération à ses propriétaires depuis plus de 42 mois. Cet indicateur renseigne sur le niveau d'activités entrepreneuriales au sein d'une économie.

Source: Présentations tabulaires spéciales des enquêtes 2008-2012 sur la population adulte, extraites du Global Entrepreneurship Monitor.

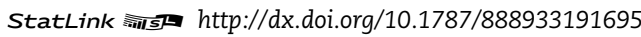

\section{Entraves à la création d'entreprise par des jeunes}

- Les jeunes entre 15 et 24 ans avaient plus tendance que la population adulte à considérer le travail indépendant comme préférable au travail salarié (45\% contre $37 \%)$. Ils l'estimaient également plus réalisable ( $41 \%$ contre $30 \%$ ).

- Les jeunes citaient plus fréquemment que les adultes l'accès au financement (26\% contre $21 \%$ ) et le manque de qualifications ( $18 \%$ contre $8 \%$ ) comme des obstacles au travail indépendant.

Les jeunes (âgés de 15 à 24 ans) avaient plus tendance que les adultes (âgés de 15 à 64 ans) à indiquer leur préférence pour le travail indépendant par rapport au travail salarié (Graphique 3.9). En 2012, $45 \%$ des jeunes de l'UE préféraient le travail indépendant, pour 37\% d'adultes.

Les jeunes avaient aussi beaucoup plus tendance à considérer le travail indépendant comme une carrière possible (Graphique 3.9). En 2012, pour 41\% des jeunes de l'UE, le travail indépendant constituait une activité envisageable dans un délai de cinq ans. Seuls $30 \%$ des adultes déclaraient la même chose.

Plusieurs facteurs peuvent expliquer cetécartentre jeunes et adultes dans la façon d'appréhender le travail indépendant en termes d'attrait et de faisabilité. Premièrement, les jeunes sont moins susceptibles d'avoir une expérience du marché de l'emploi et du travail indépendant que les adultes. De ce fait, ils peuvent méconnaître le travail indépendant ou sous-estimer le degré d'investissement et de travail que cela demande. Deuxièmement, les jeunes peuvent changer d'attitude vis-à-vis du marché de l'emploi au fur et à mesure que la nature des relations employeur-employé change. 


\section{Graphique 3.9. Attrait pour le travail indépendant et faisabilité chez les jeunes dans l'UE-28, 2012}

«Si vous pouviez choisir entre divers types de métiers, préféreriez-vous être indépendant?» "Que vous le souhaitiez ou non, serait-il faisable pour vous d'être indépendant au cours des 5 prochaines années?»

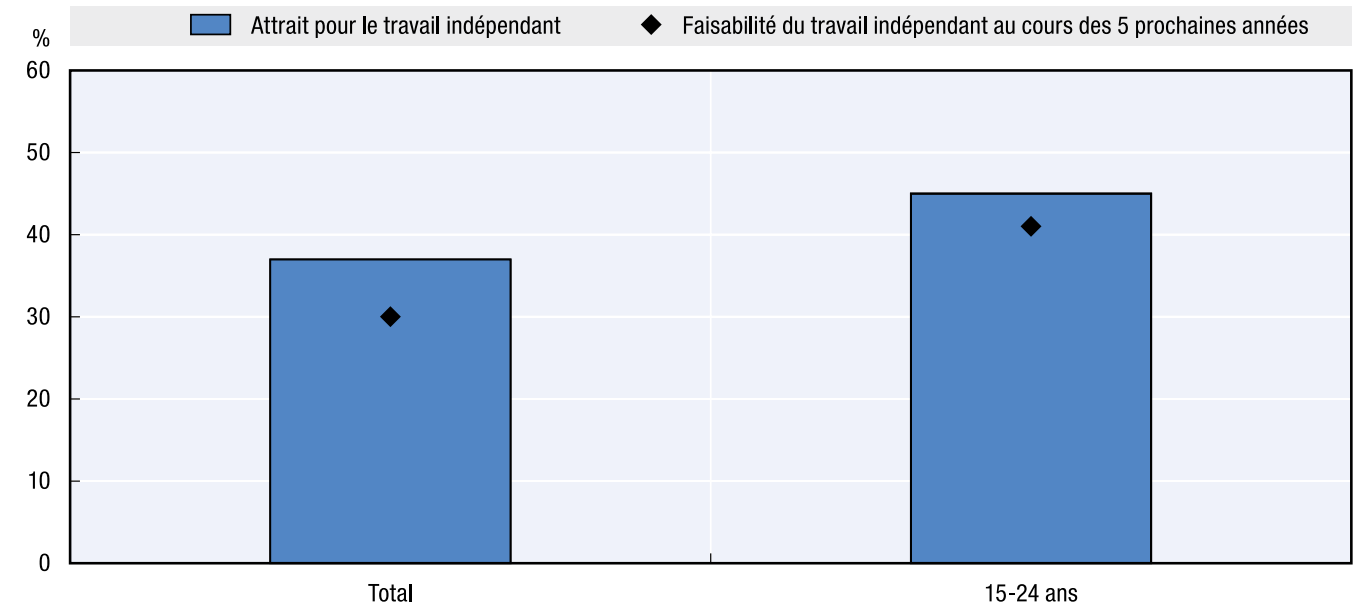

Source: Commission européenne, 2012, «L’entrepreneuriat dans l'UE et au-delà», Eurobaromètre Flash 354.

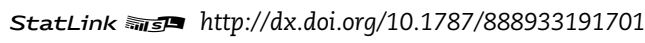

Le Graphique 3.10 présente les écarts entre jeunes et adultes concernant les raisons pour lesquelles le travail indépendant ne serait pas réalisable dans les 5 prochaines années. Les jeunes déclaraient plus fréquemment manquer de capital (26\% contre $21 \%)$ et de qualifications pour devenir entrepreneur (18\% contre $8 \%$ ). S'agissant des autres freins perçus, il existait peu de différences entre jeunes et adultes. Les difficultés administratives ne semblent pas constituer une entrave majeure aux yeux des jeunes, ce qui suggère que les efforts en faveur de la réduction des charges réglementaires auraient peu d'influence.

\section{Graphique 3.10. Entraves au travail indépendant des jeunes dans l'UE-28, 2012}

«Pourquoi ne serait-il pas faisable pour vous de devenir indépendant au cours des 5 prochaines années?»

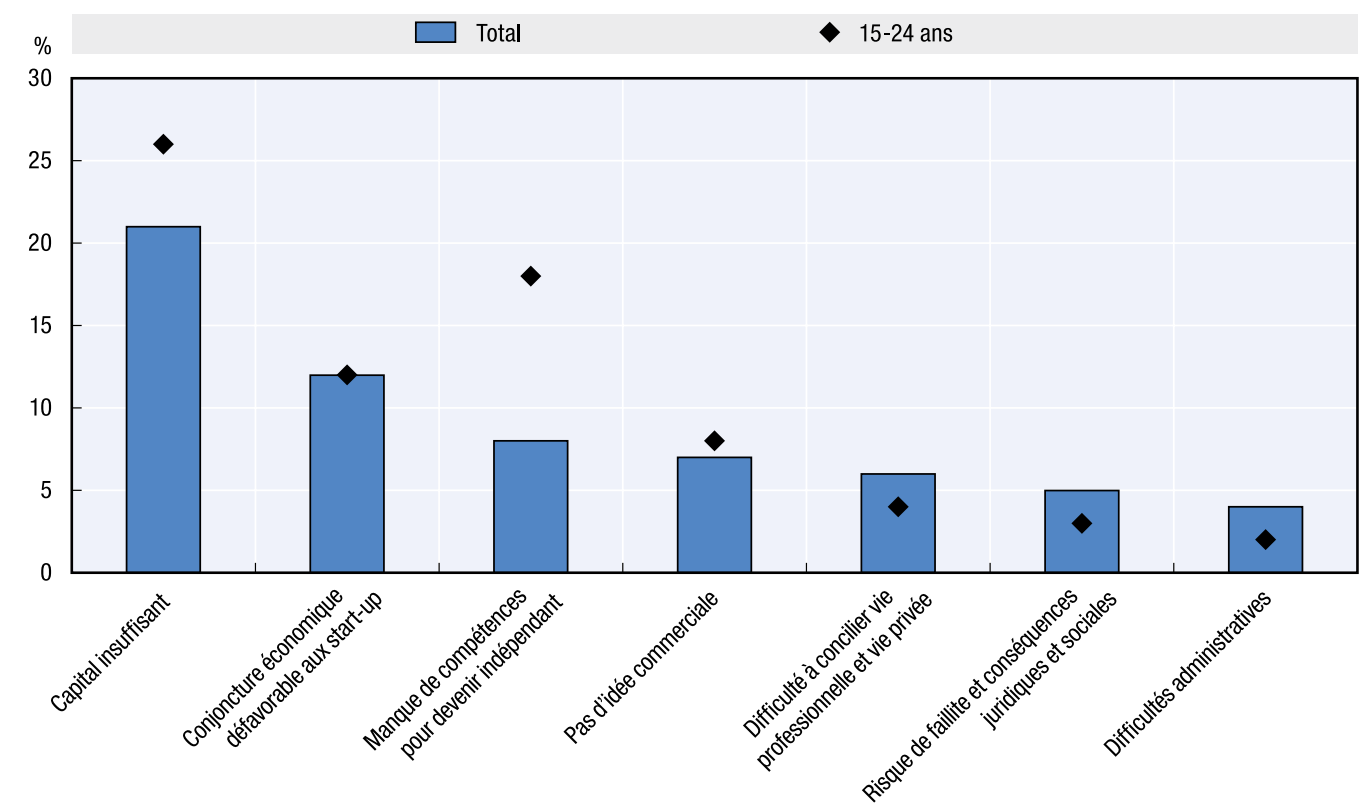

Source: Commission européenne, 2012, «L'entrepreneuriat dans l'UE et au-delà», Eurobaromètre Flash 354. 


\section{Revenu des jeunes indépendants}

- Les jeunes (âges de 15 à 24 ans) étaient moins susceptibles que les adultes de compter sur leur activité entrepreneuriale comme principale source de revenu en 2012 (65\% contre $79 \%$ ). Près de $20 \%$ d'entre eux ont donc fait état d'un emploi à temps partiel comme principale source de revenu.

Le Graphique 3.11 présente les sources de revenu des jeunes propriétaires d'entreprise (âgés de 15 à 24 ans). Les jeunes ont tiré moins de revenus de leur activité entrepreneuriale que les adultes (âgés de 25 à 64 ans). Cette dernière représentait $65 \%$ de leur rémunération globale, contre $79 \%$ pour les adultes. Ils étaient moins nombreux que les adultes à occuper un emploi à temps plein ( $7 \%$ contre $12 \%)$, mais plus nombreux à travailler à temps partiel $(17 \%$ contre $9 \%$ ). Très peu de jeunes propriétaires d'entreprise ont tiré leurs revenus d'investissements, d'une épargne, de pensions, de la sécurité sociale ou d'allocations de chômage.

\section{Graphique 3.11. Principales sources de revenu des jeunes dans l'UE-28, 2012 «Quelle est ou quelles sont actuellement votre ou vos principale(s) source(s) de revenu?» (pour les propriétaires d'une entreprise)}

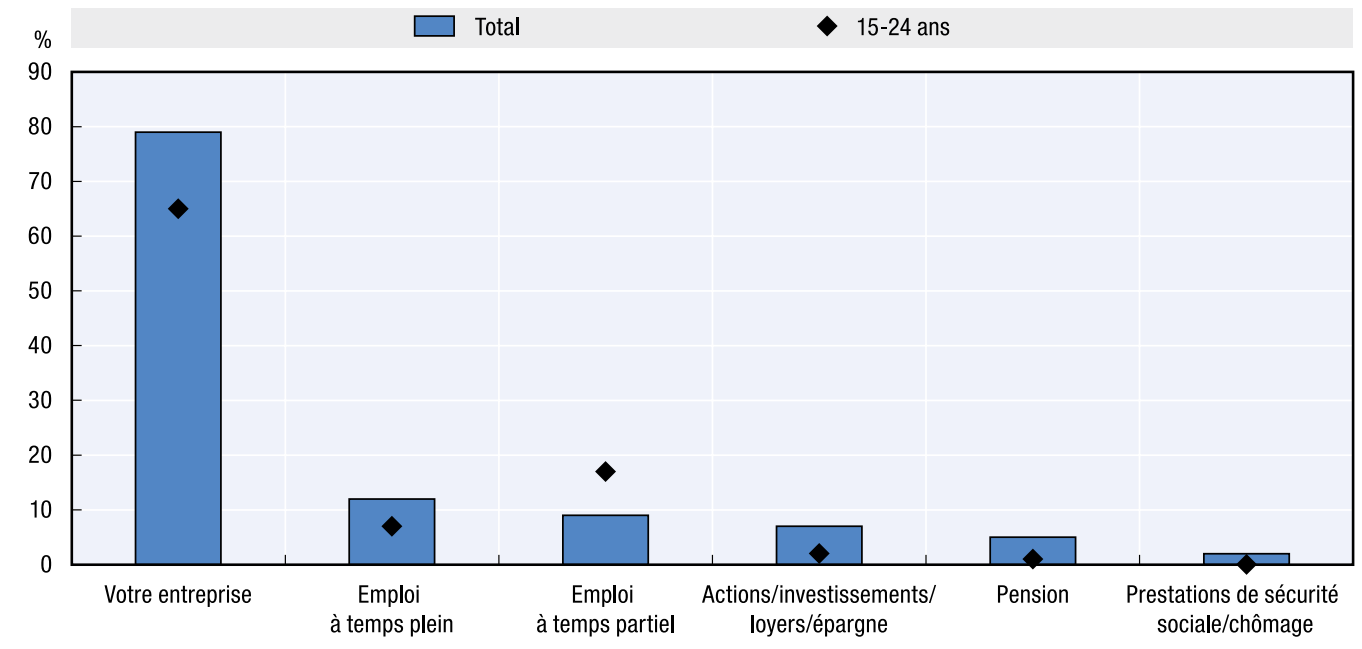

Source: Commission européenne, 2012, «L'entrepreneuriat dans l'UE et au-delà», Eurobaromètre Flash 354.

StatLink त्ञ⿰ता http://dx.doi.org/10.1787/888933191723

\section{Prévisions de croissance chez les jeunes entrepreneurs}

- Les jeunes (âgés de 18 à 30 ans) impliqués dans une activité entrepreneuriale au stade précoce avaient davantage tendance que les adultes à envisager la création de plus de six emplois au cours des cinq années suivantes.

- Dans cinq États membres (Estonie, Lituanie, Lettonie, République slovaque et République tchèque), le pourcentage de jeunes engagés dans une activité entrepreneuriale au stade précoce qui envisageaient de créer plus de six emplois au cours des cinq prochaines années était plus de trois fois supérieur à la moyenne des adultes dans l'UE. 


\section{Graphique 3.12. Prévisions de croissance chez les jeunes entrepreneurs, 2008-2012 (combinés)}

Pourcentage des 15-64 ans engagés dans une activité entrepreneuriale totale au stade précoce qui prévoient de créer plus de six emplois dans les cinq prochaines années

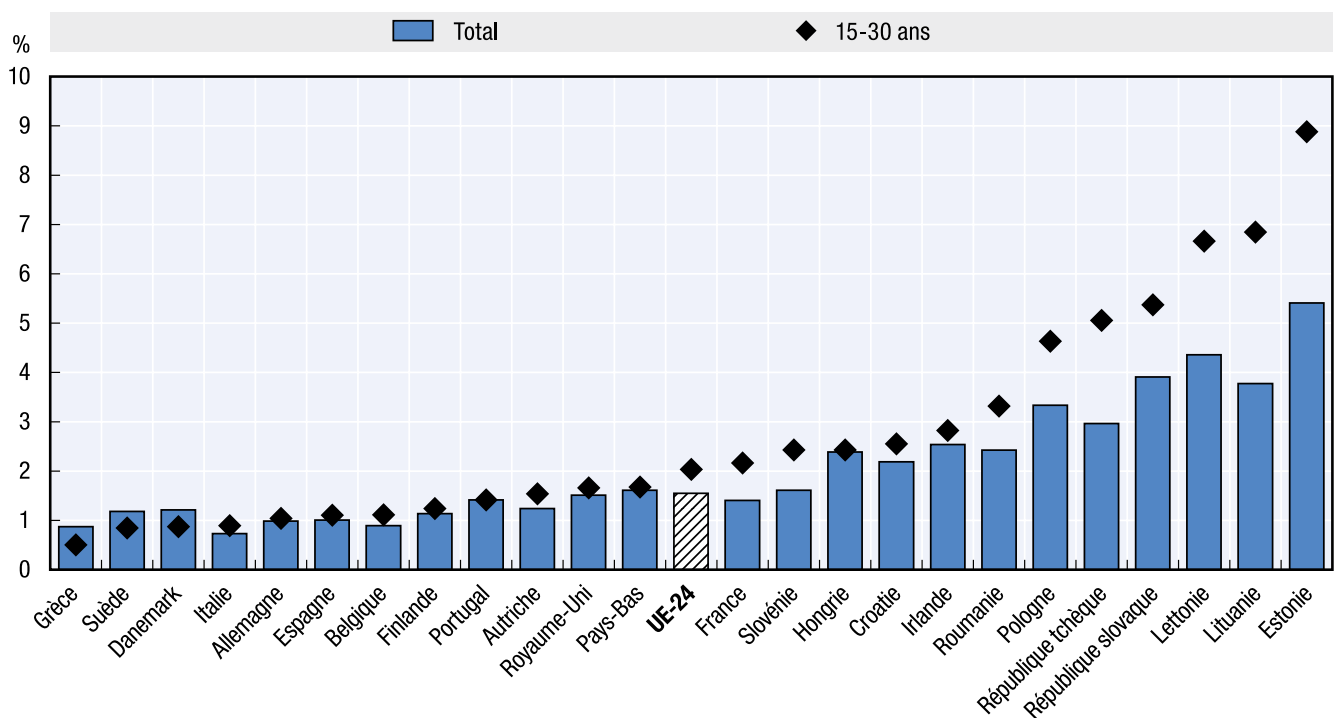

Note: L’activité entrepreneuriale totale au stade précoce désigne la proportion de la population activement impliquée dans la création d'une entreprise dont elle sera propriétaire ou copropriétaire et la proportion de la population ayant créé une entreprise au cours des 42 derniers mois.

Source: Présentations tabulaires spéciales des enquêtes 2008-2012 sur la population adulte, extraites du Global Entrepreneurship Monitor.

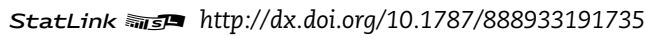

Les proportions de jeunes (âgés de 18 à 30 ans) dans l'UE impliqués dans une activité entrepreneuriale au stade précoce, avec la perspective de créer plus de six emplois au cours des cinq années suivantes, sont présentées au Graphique 3.12. Cela comprend ceux qui étaient activement impliqués dans la création d'une entreprise dont ils seront propriétaires ou copropriétaires et ceux ayant démarré une entreprise au cours des 42 derniers mois. Globalement, environ $2 \%$ des jeunes de l'UE impliqués dans une activité entrepreneuriale au stade précoce espéraient créer au moins six emplois au cours des cinq prochaines années. Ce chiffre supérieur à la moyenne générale des adultes. Cette observation vaut pour la grande majorité des États membres. Ce taux varie toutefois de 0,9\% en Grèce à 8,9\% en Estonie.

\section{Références}

Commission européenne, 2012, «L'entrepreneuriat dans l'UE et au-delà», Eurobaromètre Flash 354, disponible sur: http://ec.europa.eu/public_opinion/flash/fl_354_en.pdf.

Eurostat (2013), Enquête sur les forces de travail, disponible sur: http://epp.eurostat.ec.europa.eu/portal/ page/portal/employment_unemployment_lfs/data/database.

Global Entrepreneurship Monitor (GEM) (2013), Présentations tabulaires spéciales des enquêtes 20082012 sur la population adulte du Global Entrepreneurship Monitor. 


\section{Chapitre 4}

\section{Le travail indépendant et l'entrepreneuriat chez les seniors ${ }^{1,2}$}

Ce chapitre traite des activités d'indépendant et d'entrepreneuriat exercées par les seniors. Il fournit des informations sur le nombre et la proportion des seniors qui travaillent comme indépendants et sur les principales caractéristiques de ce type d'activité professionnelle. La question des entraves au travail indépendant y est également abordée.

1. Note de la Turquie:

Les informations figurant dans ce document et faisant référence à "Chypre» concernent la partie méridionale de l'île. Il n'y a pas d'autorité unique représentant à la fois les Chypriotes turcs et grecs sur l'île. La Turquie reconnaît la République turque de Chypre du Nord (RTCN). Tant qu'une solution durable et équitable n'aura pas été trouvée dans le cadre des Nations unies, la Turquie maintiendra sa position sur la «question chypriote».

2. Note de tous les États de l'Union européenne membres de l'OCDE et de l'Union européenne:

La République de Chypre est reconnue par tous les membres des Nations unies sauf la Turquie. Les informations figurant dans ce document concernent la zone sous le contrôle effectif du gouvernement de la République de Chypre. 


\section{Le travail indépendant chez les seniors}

- Les seniors (de 55 à 64 ans) sont plus susceptibles que les adultes d'exercer une activité indépendante. En 2012, on recensait 6,5 millions de seniors indépendants au sein de l'UE, soit $21 \%$ de l'activité professionnelle de cette catégorie d'âge. Cette proportion est néanmoins en recul par rapport à 2002 (25,2\%).

- Au sein des États membres de l'UE, le pourcentage de seniors exerçant une activité indépendante allait de 7,3\% en Estonie à 51,8\% en Grèce en 2012.

- Les seniors indépendants étaient aussi nombreux que le reste de la population adulte à faire appel à des employés. En 2012, près de 30\% des seniors indépendants avaient des employés.

- En 2012, les seniors indépendants étaient surreprésentés dans les secteurs de la production, de la construction et de la consommation par rapport à la population adulte.

Le Graphique 4.1 illustre les taux de travail indépendant des seniors (de 55 à 64 ans) et des adultes (âgée de 15 à 64 ans). En 2012, les seniors de l'UE étaient plus susceptibles de travailler comme indépendants que la population adulte ( $21 \%$ contre $14,5 \%$ ). Si le taux de travail indépendant des adultes s'est maintenu dans l'UE entre 2002 et 2012, celui des seniors a diminué de $16 \%$ (de $25,2 \%$ à $21 \%$ ).

\section{Graphique 4.1. Taux de travail indépendant des seniors dans l'UE-28, 2002-2012} Pourcentage des 15-64 ans

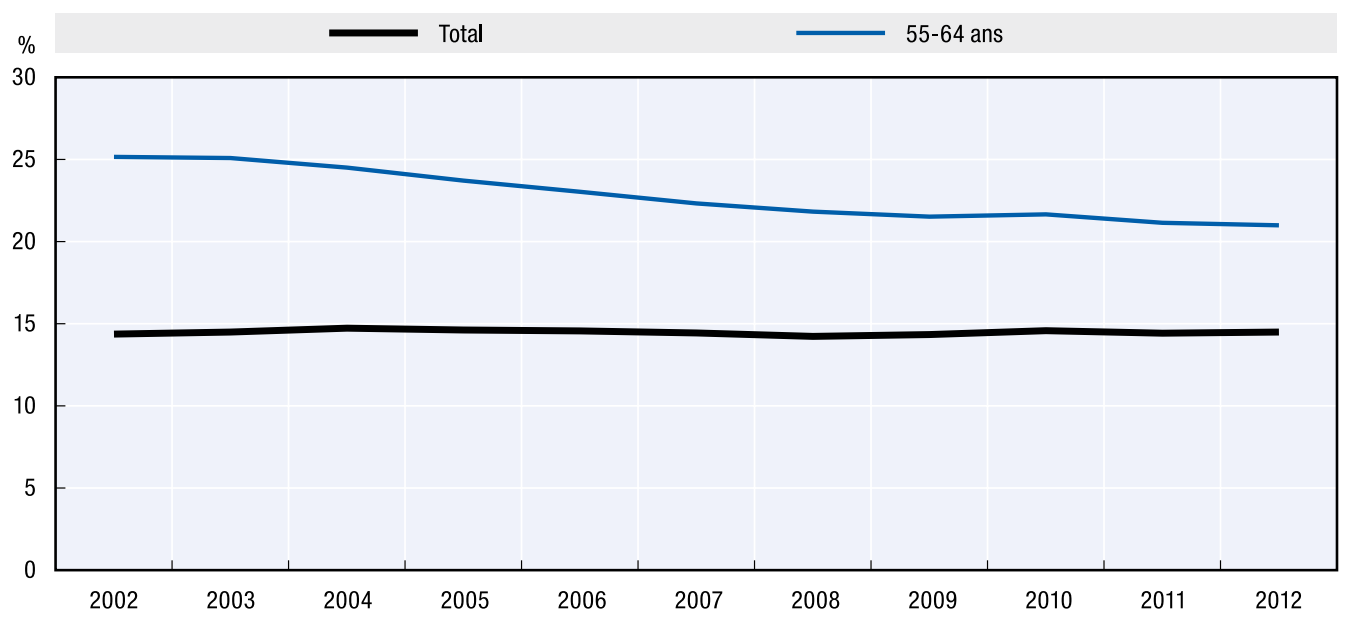

Source: Eurostat, Enquête sur les forces de travail 2002-2012.

StatLink त्ताइ http://dx.doi.org/10.1787/888933191743

Le Graphique 4.2 présente les taux de travail indépendant des seniors et de la population adulte pour chaque État membre de 2002 à 2012. Au cours de cette période, le taux de travail indépendant des seniors a augmenté dans seulement trois États membres: la République slovaque $(7,2 \%)$, la République tchèque $(5,2 \%)$ et le Royaume-Uni (1,6\%). Les baisses les plus significatives ont été observées en Roumanie (20,5\%), en Croatie (13,7\%), au Portugal (11,9\%) et en Lituanie (10,5\%). 


\section{Graphique 4.2. Taux de travail indépendant des seniors, 2002-2012}

Pourcentage des 15-64 ans
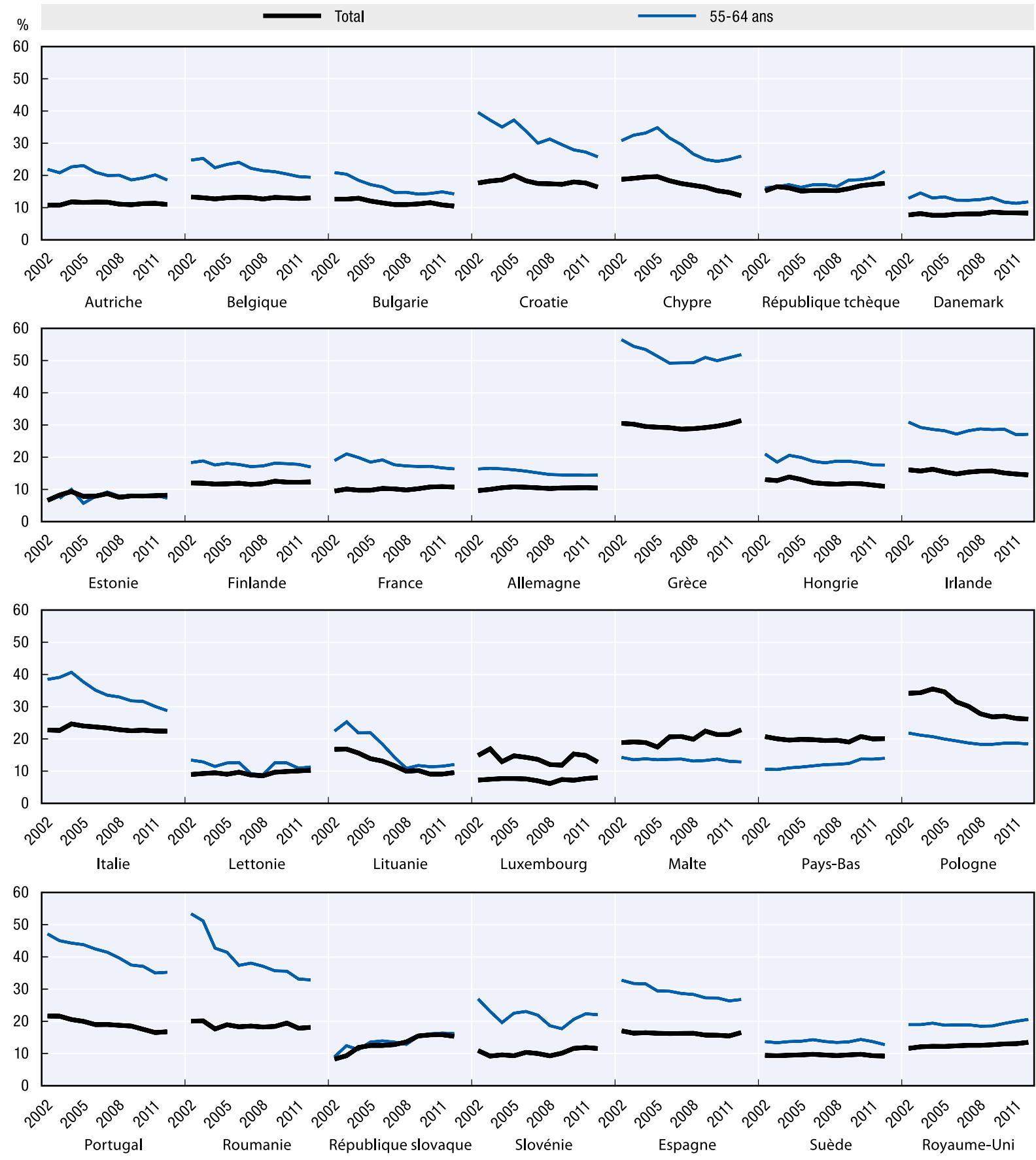

Source: Eurostat, Enquête sur les forces de travail 2002-2012. 


\section{Graphique 4.3. Proportion des seniors indépendants employant des salariés dans l'UE-28, 2002-2012}

Pourcentage des 15-64 ans

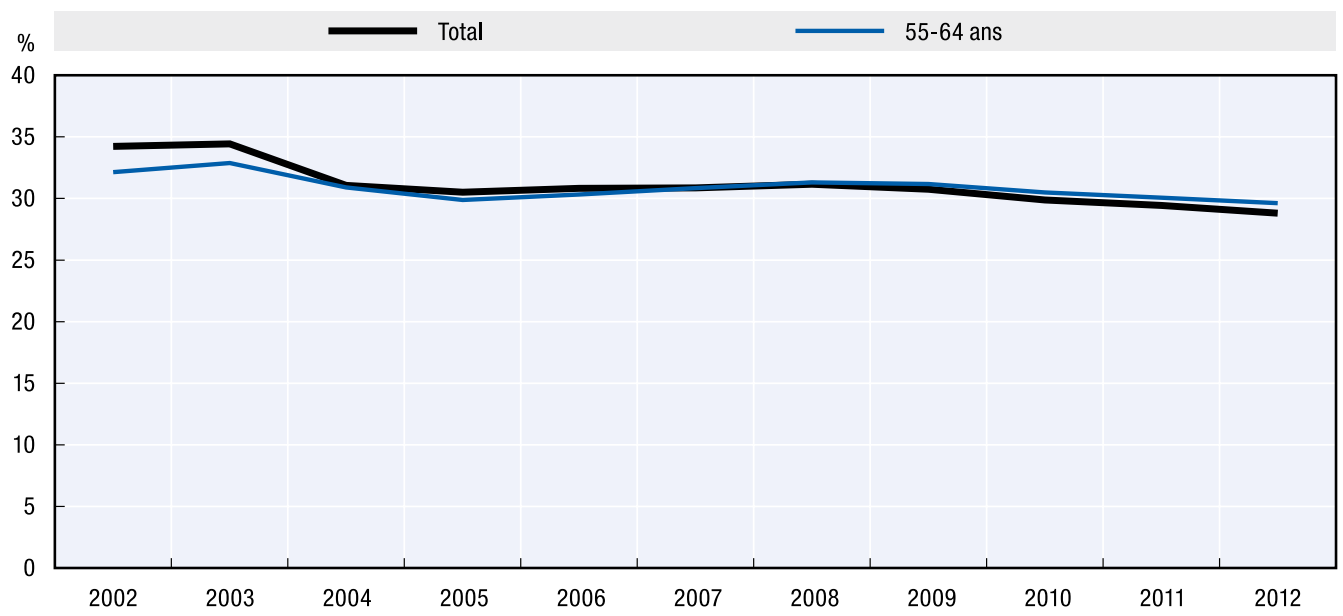

Source: Eurostat, Enquête sur les forces de travail 2002-2012.

En 2012, au sein de l'UE, près de 30\% des seniors indépendants (de 55 à 64 ans) employaient au moins une personne, soit à peu près la même proportion que pour la population adulte dans son ensemble (de 15 à 64 ans). Sur les 6,5 millions de seniors indépendants, 1,9 million avaient un ou plusieurs employés. Cependant, cette proportion a légèrement baissé au cours de la dernière décennie. En 2002, ils étaient 32,1\% à avoir un ou plusieurs employés à leur service. On observe un déclin similaire parmi la population totale des adultes indépendants avec employés au cours de cette même période.

Les pourcentages de seniors indépendants faisant appel à des employés dans chaque État membre sont présentés au Graphique 4.4. En 2012, les seniors indépendants avaient davantage tendance à employer du personnel que l'ensemble de la population dans dix États membres. C'était le cas au Luxembourg (46,7\%), en Allemagne $(46,6 \%)$ et en Hongrie $(44,5 \%)$. Ces chiffres contrastent avec la Roumanie (4,4\%), le Royaume-Uni $(18,8 \%)$ et la Grèce $(19,6 \%)$, où moins d'un cinquième d'entre eux avaient des employés.

La répartition des seniors indépendants (de 50 à 64 ans) par secteur professionnel est présentée au Graphique 4.5. Ceux-ci avaient plus tendance que l'ensemble de la 


\section{Graphique 4.4. Proportion des seniors indépendants employant des salariés,} 2002-2012

Pourcentage des 15-64 ans

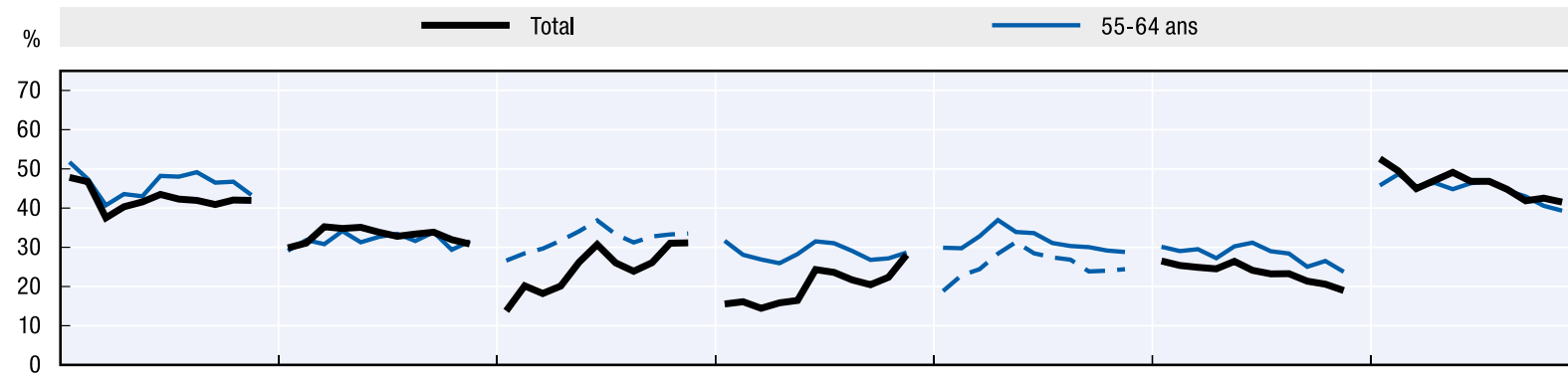

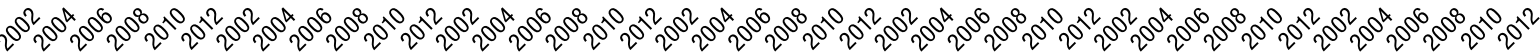
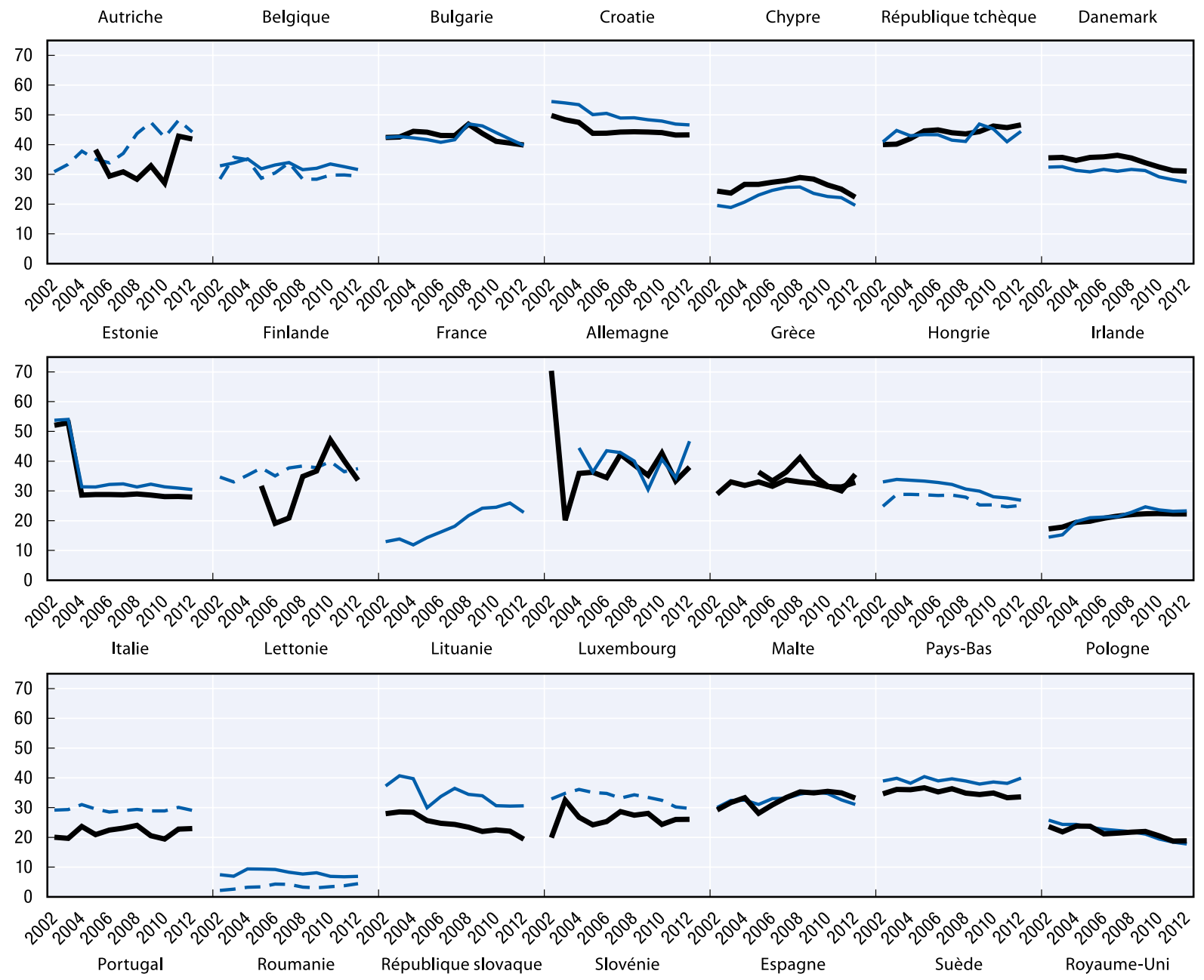

Source: Eurostat, Enquête sur les forces de travail 2002-2012. 
population adulte à travailler dans les secteurs de l'agriculture, la sylviculture et la pêche; du commerce de gros et de détail et de la réparation de véhicules à moteur; du transport et de la logistique; de l'immobilier; ainsi que des soins de santé et des œuvres sociales. En 2012, la majeure partie d'entre eux travaillaient dans l'agriculture, la sylviculture et la pêche (20,5\%); le commerce de gros et de détail et la réparation de véhicules à moteur (16,9\%); la construction $(11,0 \%)$; et le secteur professionnel, scientifique et technique $(10,3 \%)$. Ces quatre secteurs professionnels regroupaient près de $60 \%$ des seniors indépendants en 2012.

\section{Graphique 4.5. Répartition des seniors indépendants par secteur professionnel dans l'UE-28, 2012 \\ Pourcentage des 15-64 ans}

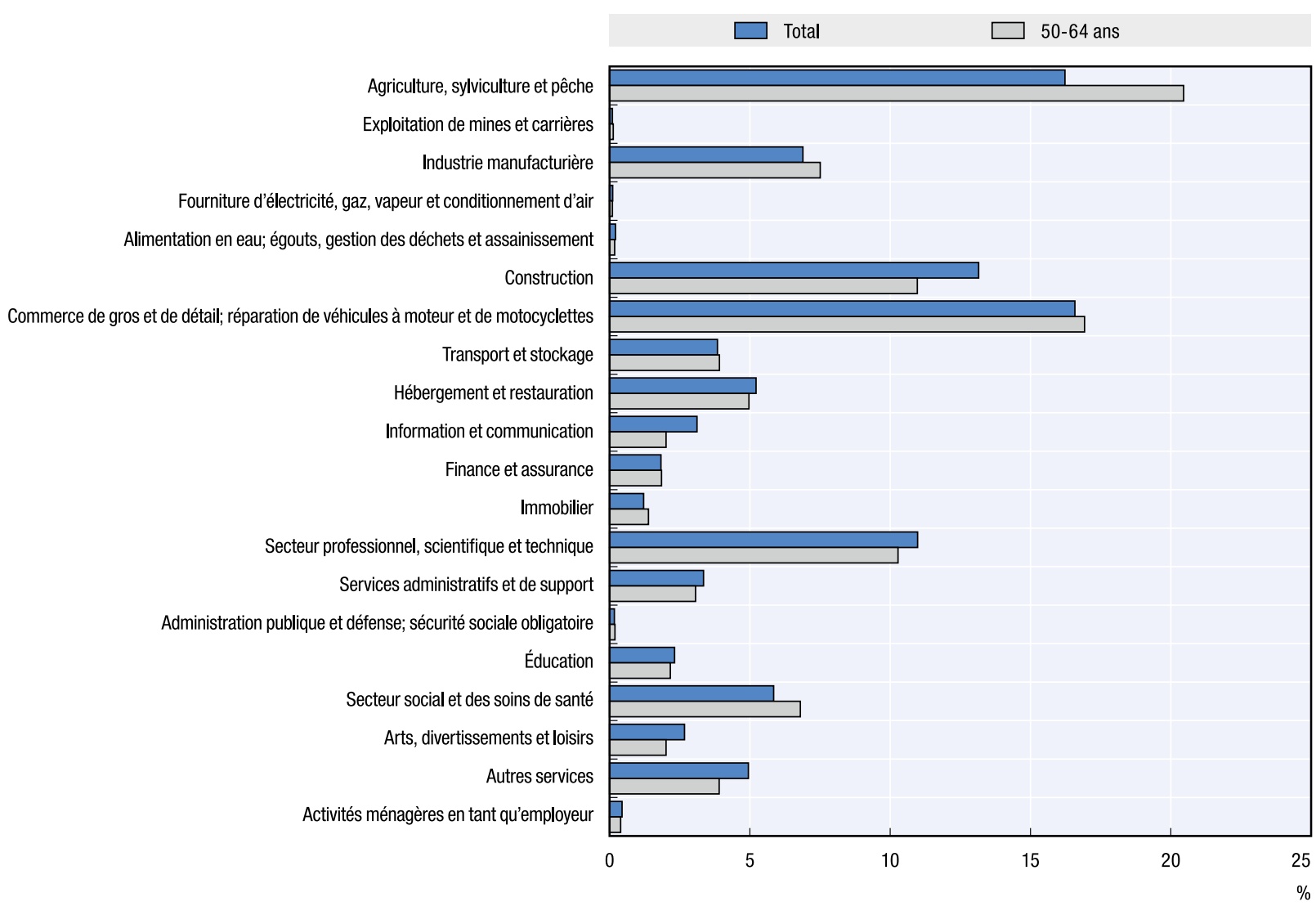

Source: Eurostat, Enquête sur les forces de travail 2012.

\section{Activités exercées par les seniors tout au long du cycle de vie entrepreneuriale}

- Peu de seniors (de 50 à 64 ans) de l'UE ont été impliqués dans la création d'une entreprise au cours de la période 2008-2012 (un peu plus de $2 \%$ ).

- Environ $2 \%$ et $7 \%$ des seniors de l'UE possédaient respectivement de nouvelles entreprises et des sociétés établies entre 2008 et 2012. Ces taux sont relativement comparables à ceux de la population adulte en général. 
Le Graphique 4.6 présente les taux d'entrepreneuriat naissant chez les personnes âgées (de 50 à 64 ans) dans les pays de l'UE. Ce taux mesure la proportion d'adultes déclarant être activement engagés dans la création d'une entreprise qu'ils détiennent seuls ou en copropriété. Cette activité ne doit pas avoir rapporté de traitements, de salaires ou toute autre rémunération à ses propriétaires depuis plus de trois mois. Les données sont présentées par sexe, âge, niveau d'instruction et niveau de revenu. Pour en savoir plus sur cette notion et sur cette source de données, nous vous renvoyons au guide de lecture proposé au début de cet ouvrage.

\section{Graphique 4.6. Taux d'entrepreneuriat naissant chez les seniors, 2008-2012 (combinés)}

Pourcentage des 18-64 ans

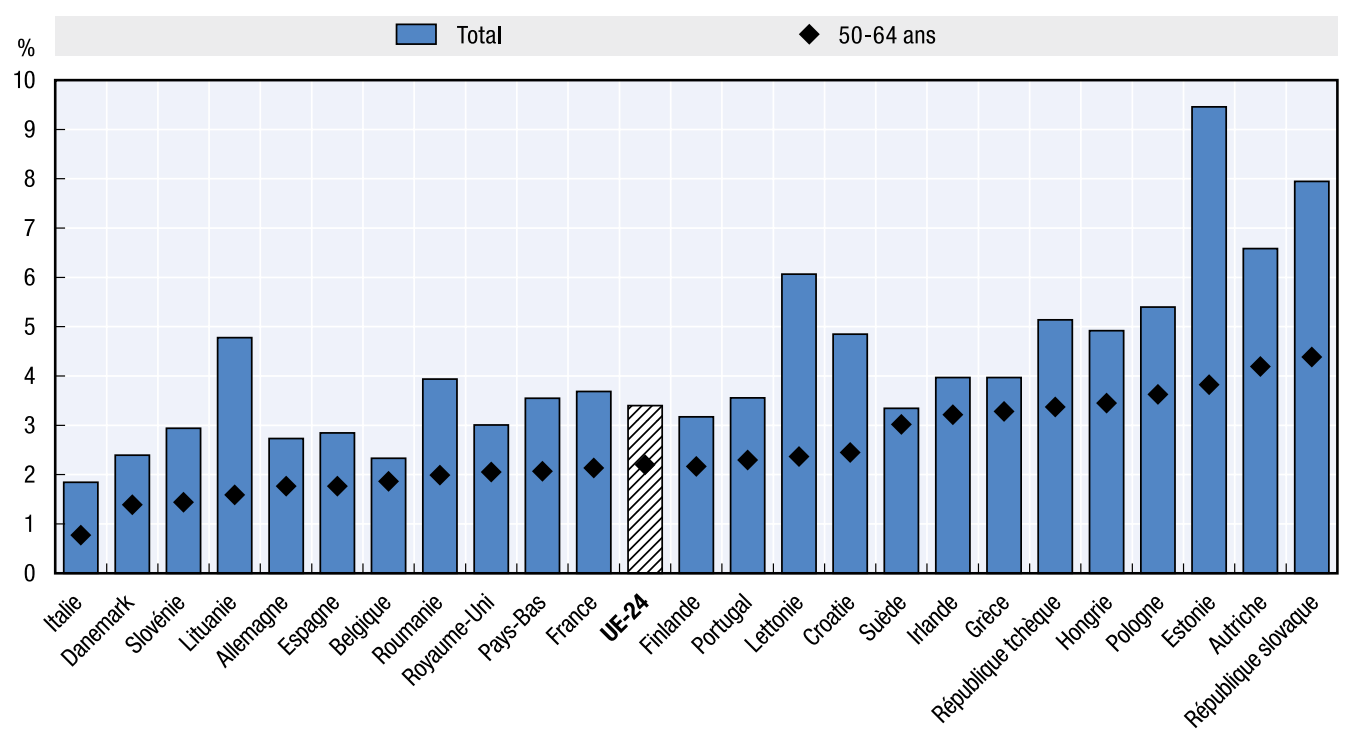

Notes: 1. Les pays de l'UE ayant participé à l'enquête Global Entrepreneurship Monitor pendant cette période sont: l'Allemagne, l'Autriche, la Belgique, la Croatie, le Danemark, l'Espagne, l'Estonie, la Finlande, la France, la Grèce, la Hongrie, l'Irlande, l'Italie, la Lettonie, la Lituanie, les Pays-Bas, la Pologne, le Portugal, la République slovaque, la République tchèque, la Roumanie, le Royaume-Uni, la Slovénie et la Suède. 2. Les données présentées dans ce Graphique ont été combinées: elles cumulent les résultats des enquêtes annuelles portant sur la période 2008-2012. Certains pays n'ont pas pris part aux enquêtes GEM réalisées chaque année, mais ont été inclus dans les graphiques: l'Autriche (2012), l'Estonie (2012), l'Irlande (2008, 2010, 2011, 2012), l'Italie (2008, 2009, 2010, 2012), la Lituanie (2011 et 2012), la Pologne (2011 et 2012), le Portugal (2010, 2011, 2012), la République slovaque (2011 et 2012), la République tchèque (2011) et la Suède $(2010,2011,2012)$. 3. Le taux d'entrepreneuriat naissant est défini comme la proportion de la population adulte (âgée de 18 à 64 ans) activement engagée dans la création d'une entreprise qu'elle détiendra seule ou en copropriété; cette entreprise ne peut pas avoir octroyé de traitements, salaires ou toute autre rémunération à ses propriétaires depuis plus de trois mois.

Source: Présentations tabulaires spéciales des enquêtes 2008-2012 sur la population adulte, extraites du Global Entrepreneurship Monitor.

StatLink 需吉 $h$ ttp://dx.doi.org/10.1787/888933191798

Les taux d'entrepreneuriat naissant des entrepreneurs seniors de l'UE étaient plus faibles que ceux de l'ensemble de la population adulte (de 18 à 64 ans) entre 2008 et 2012 (Graphique 4.6). Le taux d'entrepreneuriat naissant des seniors (de 50 à 64 ans) de l'UE était de $2,2 \%$, contre $3,4 \%$ pour les adultes. Il est compris entre $1,8 \%$ en Italie et $4,4 \%$ en République slovaque. C'est en Estonie (5,6 points de pourcentage), en Lettonie (3,7 points de pourcentage) et en République slovaque (3,6 points de pourcentage) que l'écart entre le taux d'entrepreneuriat naissant des adultes et celui des seniors était le plus grand. La Suède $(0,3 \%)$, la Belgique $(0,5 \%)$ et la Grèce $(0,7 \%)$ enregistraient les écarts les plus faibles.

De la même manière, partout dans l'UE, les taux de détention de nouvelles entreprises étaient plus bas chez les seniors que dans la population adulte (Graphique 4.7). Le taux de 


\section{Graphique 4.7. Taux de détention de nouvelles entreprises chez les seniors, 2008-2012 (combinés)}

Pourcentage des 18-64 ans

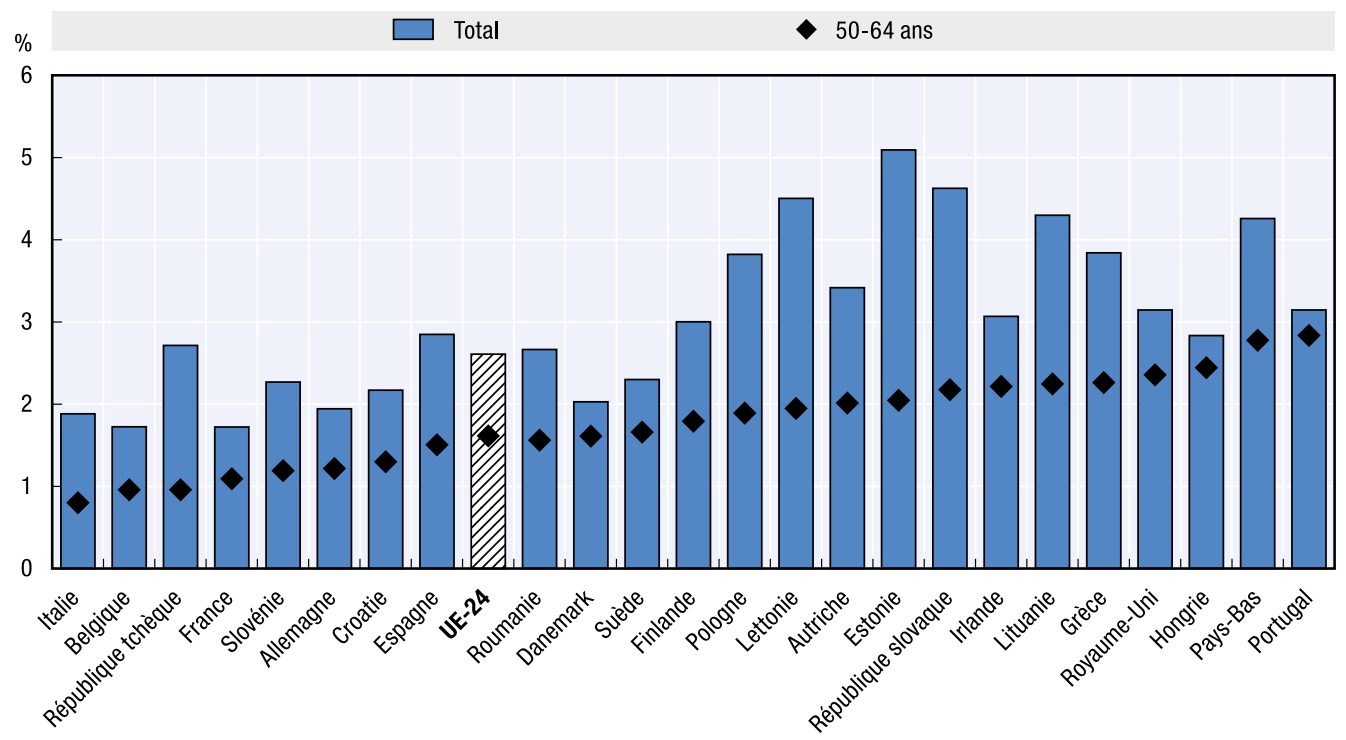

Notes: 1. Les pays de l'UE ayant participé à l'enquête Global Entrepreneurship Monitor pendant cette période sont: l'Allemagne, l'Autriche, la Belgique, la Croatie, le Danemark, l'Espagne, l'Estonie, la Finlande, la France, la Grèce, la Hongrie, l'Irlande, l'Italie, la Lettonie, la Lituanie, les Pays-Bas, la Pologne, le Portugal, la République slovaque, la République tchèque, la Roumanie, le Royaume-Uni, la Slovénie et la Suède. 2. Les données présentées dans ce Graphique ont été combinées: elles cumulent les résultats des enquêtes annuelles portant sur la période 2008-2012. Certains pays n'ont pas pris part aux enquêtes GEM réalisées chaque année, mais ont été inclus dans les graphiques: l'Autriche (2012), l'Estonie (2012), l'Irlande (2008, 2010, 2011, 2012), l'Italie (2008, 2009, 2010, 2012), la Lituanie (2011 et 2012), la Pologne (2011 et 2012), le Portugal (2010, 2011, 2012), la République slovaque (2011 et 2012), la République tchèque (2011) et la Suède (2010, 2011, 2012). 3. Le taux de détention de nouvelles entreprises est la proportion de la population adulte gérant ou possédant actuellement une nouvelle entreprise qui verse des traitements, des salaires ou toute autre rémunération à ses propriétaires depuis plus de trois mois mais moins de 42 mois.

Source: Présentations tabulaires spéciales des enquêtes 2008-2012 sur la population adulte, extraites du Global Entrepreneurship Monitor.

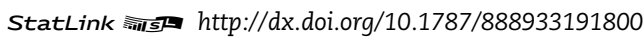

détention de nouvelle entreprise désigne la proportion de la population adulte gérant ou possédant actuellement une nouvelle entreprise qui verse des traitements, des salaires ou toute autre rémunération à ses propriétaires depuis plus de trois mois mais moins de 42 mois. Le taux moyen à l'échelle de l'UE s'élevait à 2,6\% pour l'ensemble de la population adulte en 2012 , contre $1,6 \%$ chez les seniors. C'est au Portugal que la part de seniors détenant une nouvelle entreprise est la plus élevée sur la période 2008-2012 (3,1\%). L'Italie comptait la part la plus faible (1,9\%). L'écart entre le taux de détention des adultes et celui des seniors variait peu d'un État membre à l'autre. Il était le plus grand en Estonie $(3,1 \%)$ et le plus petit au Portugal (0,3\%).

Les seniors étaient toutefois plus susceptibles de posséder une entreprise établie dans tous les États membres, à l'exception de l'Italie (Graphique 4.8). Le taux de détention d'entreprises établies est la proportion d'adultes qui sont actuellement dirigeantspropriétaires d'une entreprise établie qui verse des traitements, des salaires ou toute autre rémunération à ses propriétaires depuis plus de 42 mois. Entre 2008 et 2012, au sein de l'UE, $7,1 \%$ des seniors étaient propriétaires d'une entreprise établie, soit plus que la moyenne de $5,7 \%$ de la population adulte. 


\section{Graphique 4.8. Taux de détention d'entreprises établies chez les seniors, 2008- 2012 (combinés)}

Pourcentage des 18-64 ans

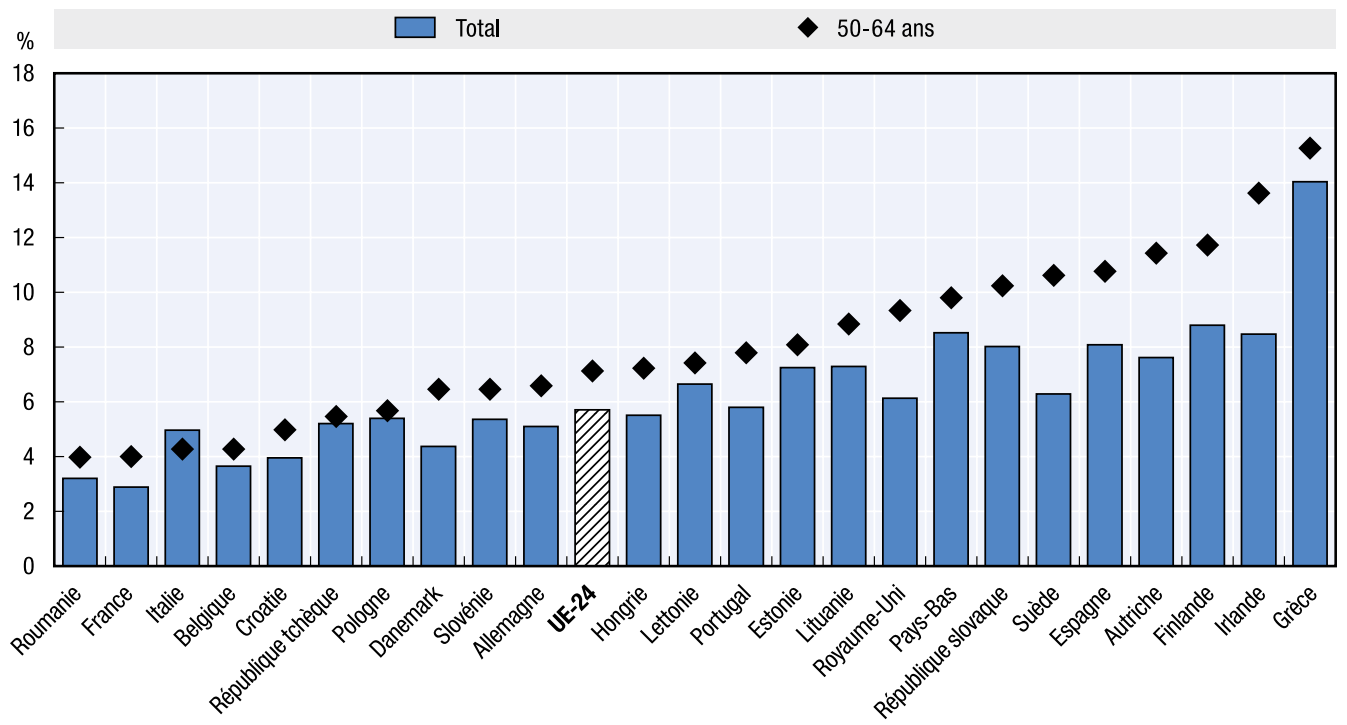

Notes: 1. Les pays de l'UE ayant participé à l'enquête Global Entrepreneurship Monitor pendant cette période sont: l'Allemagne, l'Autriche, la Belgique, la Croatie, le Danemark, l'Espagne, l'Estonie, la Finlande, la France, la Grèce, la Hongrie, l'Irlande, l'Italie, la Lettonie, la Lituanie, les Pays-Bas, la Pologne, le Portugal, la République slovaque, la République tchèque, la Roumanie, le Royaume-Uni, la Slovénie et la Suède. 2. Les données présentées dans ce Graphique ont été combinées: elles cumulent les résultats des enquêtes annuelles portant sur la période 2008-2012. Certains pays n'ont pas pris part aux enquêtes GEM réalisées chaque année, mais ont été inclus dans les graphiques: l'Autriche (2012), l'Estonie (2012), l'Irlande (2008, 2010, 2011, 2012), l'Italie (2008, 2009, 2010, 2012), la Lituanie (2011 et 2012), la Pologne (2011 et 2012), le Portugal (2010, 2011, 2012), la République slovaque (2011 et 2012), la République tchèque (2011) et la Suède (2010, 2011, 2012). 3. Le taux de détention d'entreprises établies est la proportion des membres de la population adulte qui sont actuellement dirigeantspropriétaires d'une entreprise établie qui verse des traitements, des salaires ou toute autre rémunération à ses propriétaires depuis plus de 42 mois. Cet indicateur renseigne sur le niveau d'activités entrepreneuriales au sein d'une économie.

Source: Présentations tabulaires spéciales des enquêtes 2008-2012 sur la population adulte, extraites du Global Entrepreneurship Monitor.

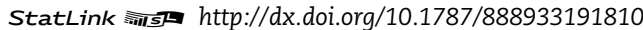

\section{Entraves à la création d'entreprise par des seniors}

- À l'instar de la population adulte, les seniors de l'UE manifestaient un attrait égal pour le travail indépendant et le travail salarié. En revanche, ils étaient deux fois moins susceptibles de considérer le travail indépendant comme une carrière possible (16\% contre $30 \%)$.

- Le manque de financement était la réponse la plus souvent donnée par les seniors, mais les adultes sont deux fois plus nombreux à mentionner ce frein (10\% contre $21 \%)$.

Le Graphique 4.9 présente le taux de seniors (plus de 55 ans) et d'adultes qui privilégient le travail indépendant par rapport au travail salarié, et leur perception de la faisabilité de devenir indépendants au cours des cinq prochaines années. En 2012, $35 \%$ des seniors préféraient le travail indépendant au travail salarié, soit une proportion équivalente à celle des adultes (37\%).

En revanche, ils étaient deux fois moins susceptibles que ces derniers de considérer le travail indépendant comme quelque chose de réalisable au cours des cinq prochaines années. En 2012, ils étaient $16 \%$ à percevoir le travail indépendant comme une carrière possible, pour $30 \%$ d'adultes. 


\section{Graphique 4.9. Attrait pour le travail indépendant et faisabilité chez les seniors dans l'UE-28, 2012}

«Si vous pouviez choisir entre divers types de métiers, préféreriez-vous être indépendant?» "Que vous le souhaitiez ou non, serait-il faisable pour vous d'être indépendant au cours des 5 prochaines années?»

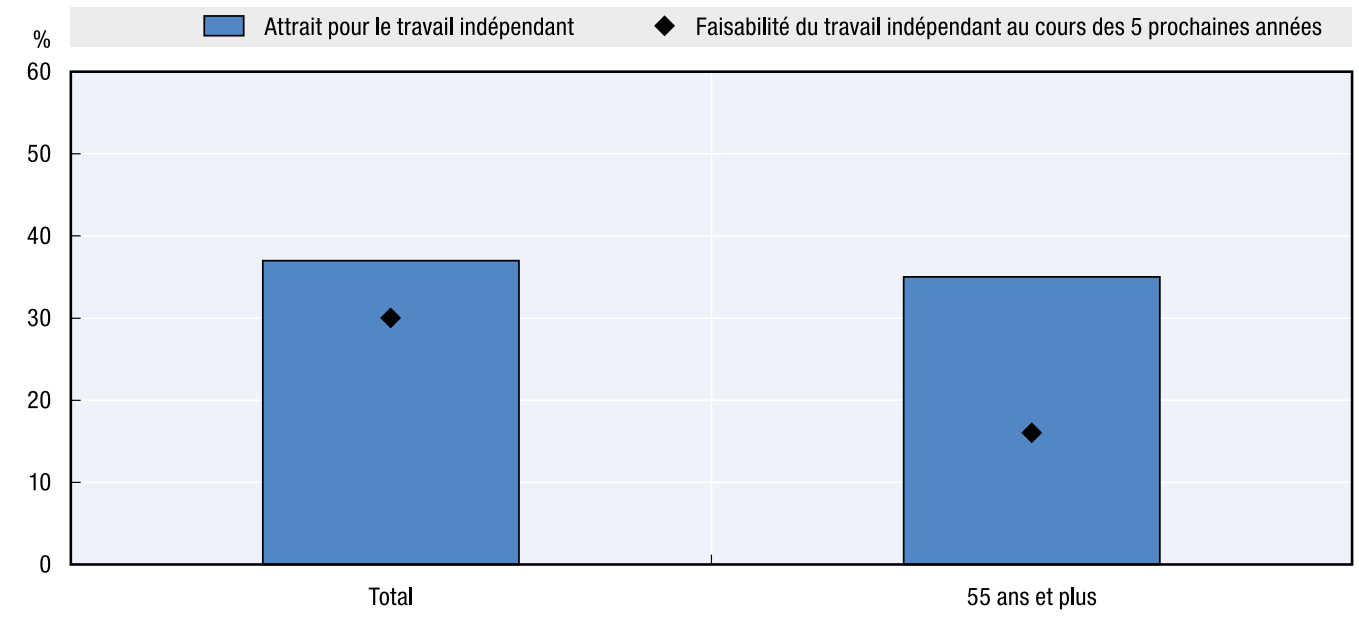

Source: Commission européenne, 2012, «L'entrepreneuriat dans l'UE et au-delà», Eurobaromètre Flash 354.

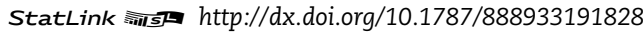

Graphique 4.10. Entraves au travail indépendant des seniors dans l'UE-28, 2012 «Pourquoi ne serait-il pas faisable pour vous de devenir indépendant au cours des 5 prochaines années?»

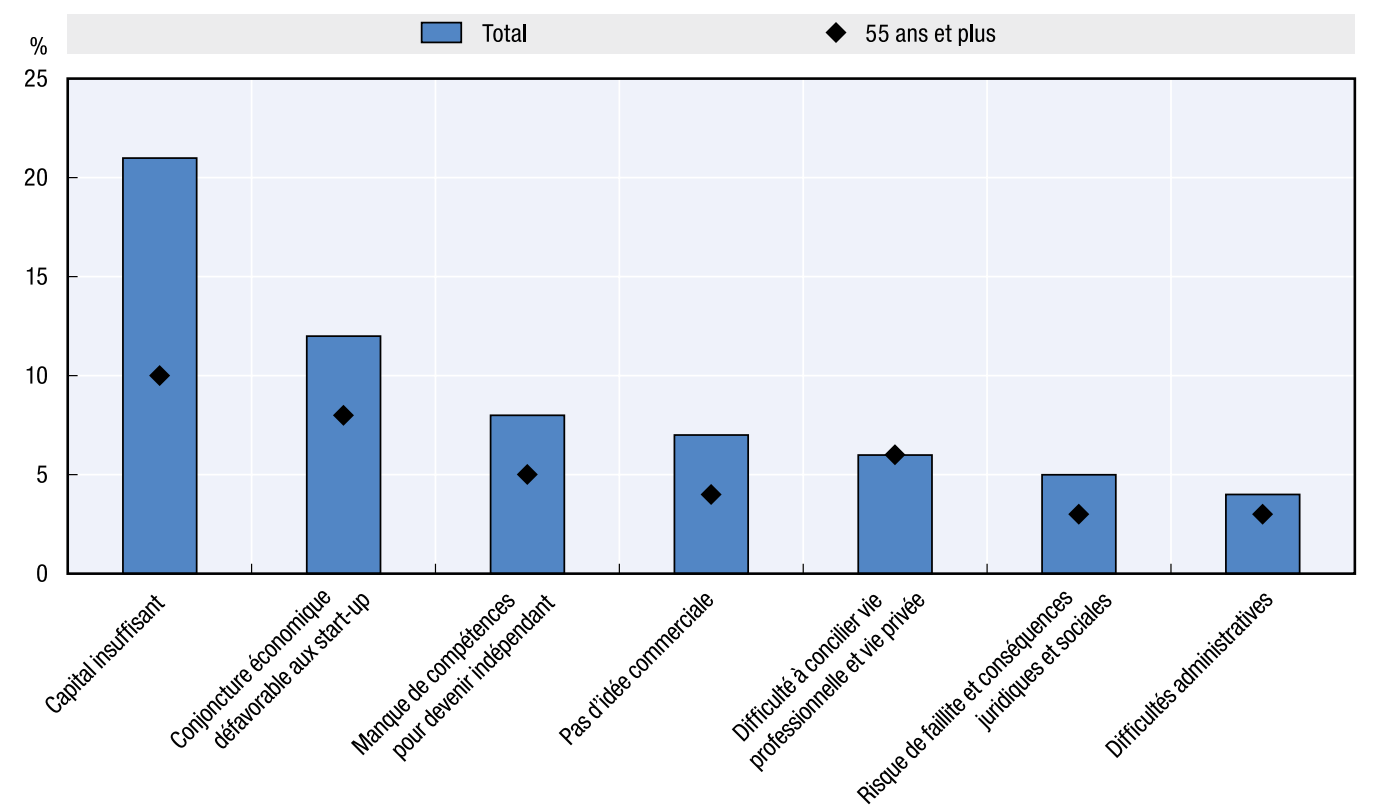

Source: Commission européenne, 2012, «L'entrepreneuriat dans l'UE et au-delà», Eurobaromètre Flash 354.

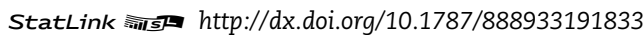

Malgré cela, ils avaient beaucoup moins tendance à identifier des freins au travail indépendant. Seuls $10 \%$ des seniors déclaraient que le manque de capital les empêcherait de démarrer une entreprise, contre $21 \%$ d'adultes. De la même façon, parmi les obstacles à la création d'entreprise, $5 \%$ des seniors désignaient le manque de qualifications et $4 \%$ l'absence d'idée commerciale, des motifs invoqués respectivement par 8 et $7 \%$ des adultes. 


\section{Revenu des seniors indépendants}

- Les propriétaires d'entreprise de plus de 55 ans étaient quasiment aussi nombreux que les adultes à déclarer leur entreprise comme principale source de revenu.

Le Graphique 4.11 présente les principales sources de revenu des seniors qui détiennent une entreprise. Près de $70 \%$ des propriétaires d'entreprise seniors déclaraient que leur entreprise constituait leur principale source de revenu. Ce chiffre inférieur à la moyenne des adultes (79\%) indique que les propriétaires d'entreprise seniors avaient davantage tendance à compter sur d'autres sources de revenu. Près de $20 \%$ des propriétaires d'entreprise seniors déclaraient que leur retraite constituait leur principale source de revenu et $10 \%$ dépendaient d'un revenu locatif, d'une épargne ou d'investissements. Près de $10 \%$ occupaient un emploi à temps partiel ou temps plein pour compléter le revenu généré par leur entreprise.

\section{Graphique 4.11. Principales sources de revenu des seniors dans l'UE-28, 2012 "Quelle est ou quelles sont actuellement votre ou vos principale(s) source(s) de revenu?» (pour les propriétaires d'une entreprise)}

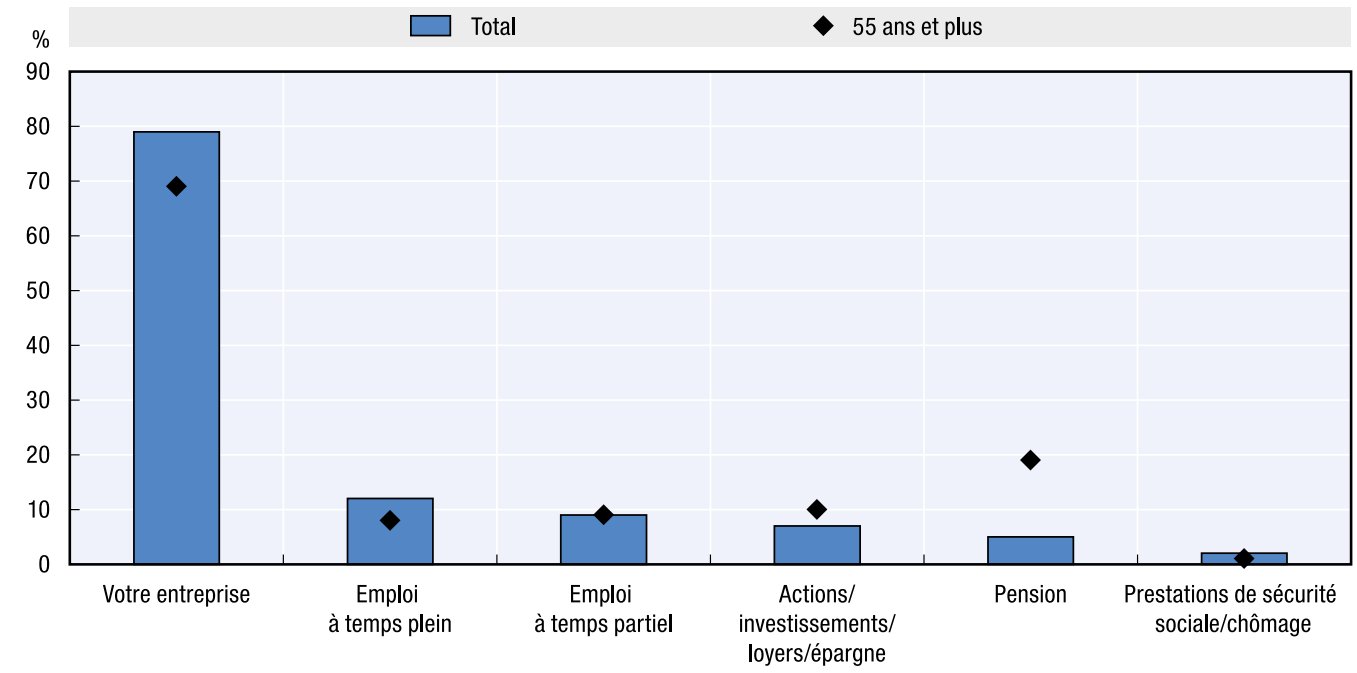

Source: Commission européenne, 2012, «L'entrepreneuriat dans l'UE et au-delà», Eurobaromètre Flash 354.

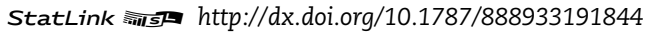

\section{Prévisions de croissance chez les entrepreneurs seniors}

- Moins de $1 \%$ des seniors (50-64 ans) impliqués dans une activité entrepreneuriale au stade précoce dans l'UE prévoient de créer plus de six emplois au cours des cinq prochaines années.

Le Graphique 4.12 présente la proportion de seniors (50-64 ans) de l'UE impliqués dans des activités entrepreneuriales au stade précoce entre 2008 et 2012, avec la perspective de créer plus de six emplois au cours des cinq années suivantes. Les personnes impliquées dans une activité entrepreneuriale au stade précoce sont celles qui étaient activement impliquées dans la création d'une entreprise dont elles seront propriétaires ou copropriétaires et celles ayant démarré une entreprise au cours des 42 derniers mois.

Dans l'ensemble de l'UE, moins de 1\% des seniors impliqués dans une activité entrepreneuriale au stade précoce comptaient créer au moins six emplois au cours des cinq prochaines années, soit un taux inférieur à la moyenne globale des adultes (1,6\%). Ce taux suggère que très peu de créateurs d'entreprise seniors aspirent à se développer. Si 


\section{Graphique 4.12. Prévisions de croissance chez les entrepreneurs seniors, 2008-2012 (combinés)}

Pourcentage des 15-64 ans engagés dans une activité entrepreneuriale totale au stade précoce qui prévoient de créer plus de six emplois dans les cinq prochaines années

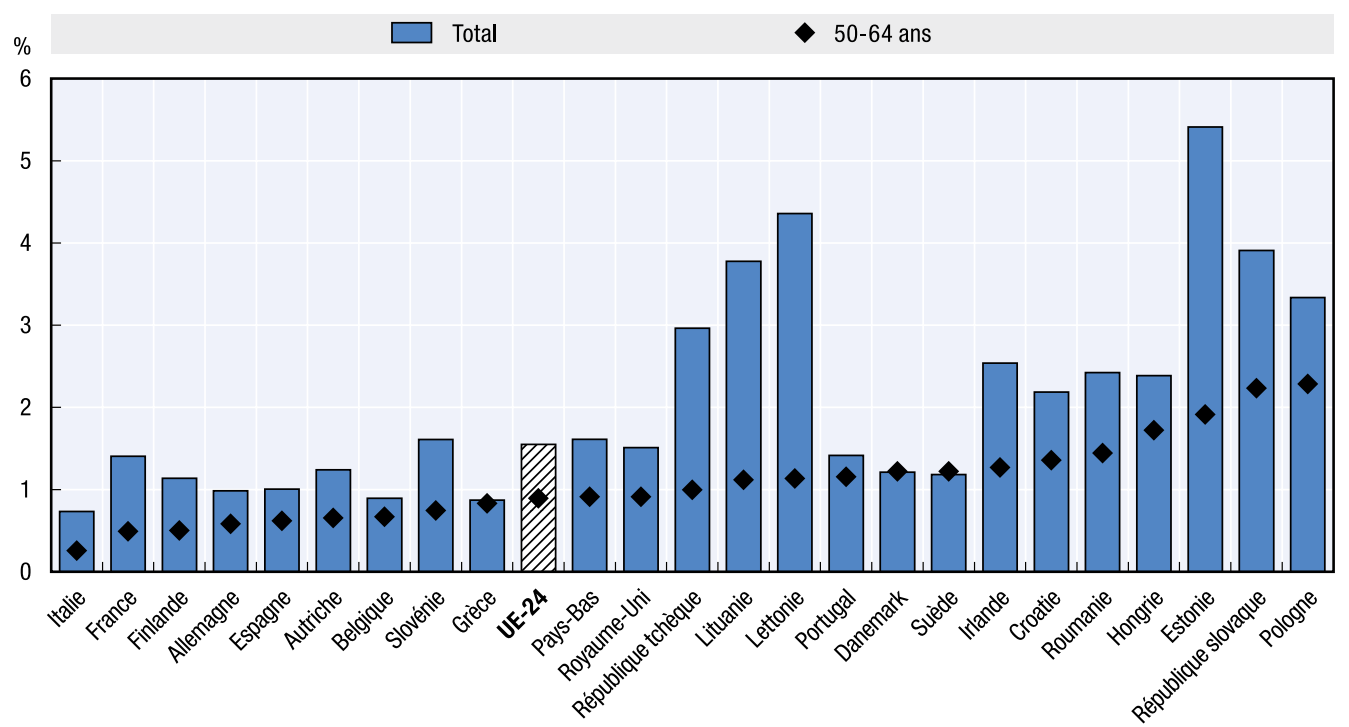

Note: L’activité entrepreneuriale totale au stade précoce désigne la proportion de la population activement impliquée dans la création d'une entreprise dont elle sera propriétaire ou copropriétaire et la proportion de la population ayant créé une entreprise au cours des 42 derniers mois.

Source: Présentations tabulaires spéciales des enquêtes 2008-2012 sur la population adulte, extraites du Global Entrepreneurship Monitor.

StatLink 司Is http://dx.doi.org/10.1787/888933191852

cette proportion variait peu d'un État membre à l'autre, c'est en Pologne qu'on trouvait les entrepreneurs seniors les plus ambitieux: 2,3\% des créateurs d'entreprise de cette tranche d'âge avaient pour objectif de créer au moins six emplois dans les cinq ans.

\section{Références}

Commission européenne, 2012, «L'entrepreneuriat dans l'UE et au-delà», Eurobaromètre Flash 354, disponible sur: http://ec.europa.eu/public_opinion/flash/fl_354_en.pdf.

Eurostat (2013), Enquête sur les forces de travail, disponible sur: http://epp.eurostat.ec.europa.eu/portal/ page/portal/employment_unemployment_lfs/data/database.

Global Entrepreneurship Monitor (GEM) (2013), Présentations tabulaires spéciales des enquêtes 20082012 sur la population adulte du Global Entrepreneurship Monitor. 


\section{Chapitre 5}

\section{Localisation des activités entrepreneuriales}

Ce chapitre traite de la proportion d'entrepreneurs qui exercent leur activité à domicile, dans des locaux distincts, de façon itinérante ou dans un autre lieu tout au long des différentes étapes de la création d'entreprise. Les données relatives à la localisation des entreprises sont présentées par sexe et par âge. 


\section{Localisation des activités entrepreneuriales}

- En 2012, près de la moitié des entreprises de l'UE étaient exploitées dans un établissement fixe qui n'était pas le domicile de leur propriétaire.

- Environ un tiers des sociétés établies étaient exploitées en dehors du domicile de leur propriétaire, et $17 \%$ d'entre elles étaient des entreprises mobiles.

- Les femmes et les personnes de plus de 40 ans avaient davantage tendance à travailler à domicile.

- Les start-up et les nouvelles entreprises étaient aussi nombreuses que les sociétés établies à être établies au domicile de leur propriétaire. En revanche, elles avaient moins tendance à être installées dans des locaux distincts.

- Près d'un quart des start-up et des nouvelles entreprises étaient mobiles, c'est-à-dire sans établissement fixe.

En 2012, environ 46\% des entreprises de l'UE étaient exploitées dans un établissement fixe, autre que le domicile de leur propriétaire (Graphique 5.1). Les entreprises établies désignent les sociétés versant des rémunérations, des salaires ou tout autre paiement à son propriétaire depuis plus de 42 mois. Environ un tiers des sociétés établies étaient exploitées en dehors du domicile de leur propriétaire, et $17 \%$ d'entre elles étaient des entreprises mobiles. Ces dernières incluent les entreprises dont l'activité se déroule en dehors d'un véhicule, comme un stand de restauration rapide, ou directement chez le client. Une faible proportion d'entreprises établies, environ $3 \%$, avaient une «autre» localisation. Il s'agit essentiellement d'entreprises présentes uniquement en ligne.

Toutefois, ce Tableau de la localisation des activités entrepreneuriales évolue lorsque l'on s'intéresse aux activités des start-up et nouvelles entreprises. Les entreprises naissantes (entreprises n'ayant pas versé de traitements, de salaires ou toute autre rémunération à ses propriétaires depuis plus de trois mois) étaient moins susceptibles d'être exercées dans des locaux distincts. Cela signifie que seules $38 \%$ de ces entreprises avaient un établissement fixe en dehors du domicile de leur propriétaire. Un tiers des entreprises naissantes étaient installées au domicile de leur propriétaire tandis qu'un quart d'entre elles n'avaient pas d'établissement fixe.

Les localisations des nouvelles entreprises (sociétés versant des salaires, des rémunérations ou tout autre paiement à ses propriétaires depuis plus de trois mois mais pas plus de 42 mois) et des entreprises naissantes étaient quasiment les mêmes. Les nouvelles entreprises n'étaient pas plus susceptibles que les entreprises naissantes d'avoir un établissement fixe. De même, les proportions étaient égales concernant les entreprises à domicile. 


\section{Graphique 5.1. Localisation des activités entrepreneuriales dans l'UE, 2012}

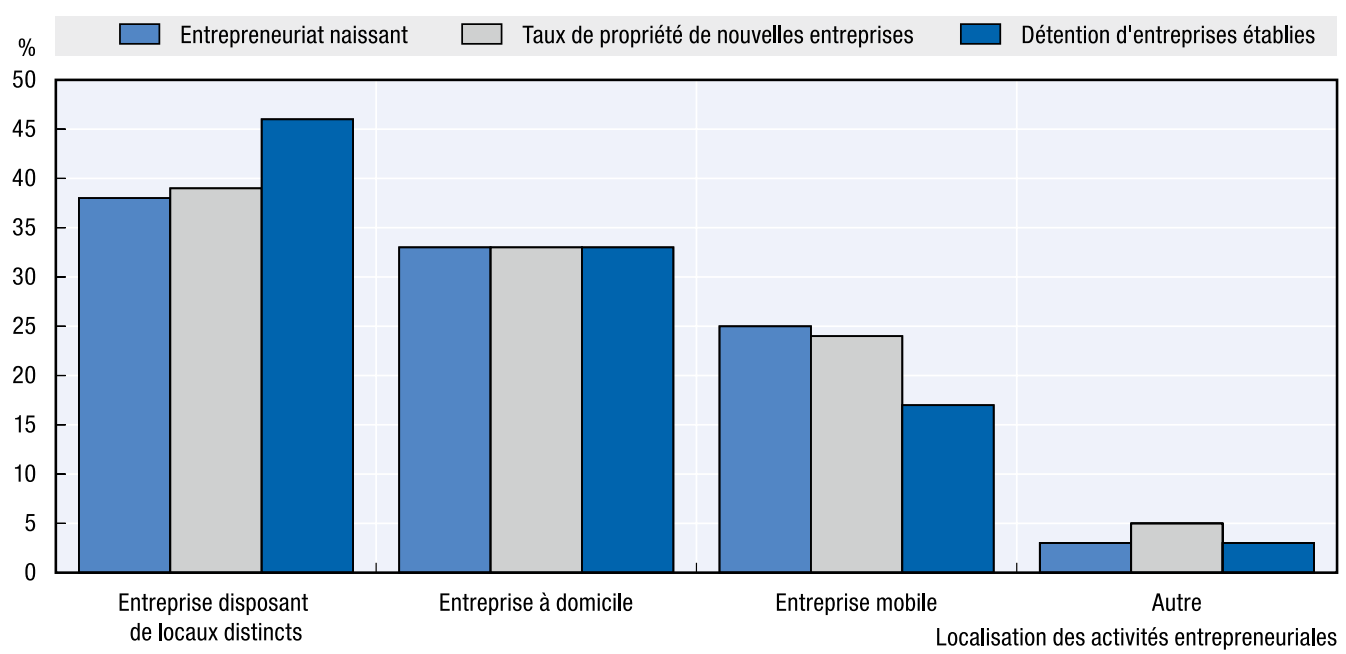

Note: Les pays inclus dans le total européen sont les suivants: l'Allemagne, l'Autriche, la Belgique, la Croatie, le Danemark, l'Espagne, l'Estonie, la Finlande, la Grèce, la Hongrie, l'Irlande, l'Italie, la Lettonie, les Pays-Bas, la Pologne, la République slovaque, la Roumanie, le Royaume-Uni, la Slovénie et la Suède.

Source: Présentations tabulaires spéciales de l'enquête 2012 sur la population adulte, extraites du Global Entrepreneurship Monitor.

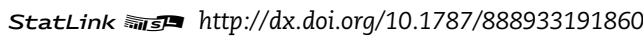

\section{Localisation des activités entrepreneuriales au stade précoce par sexe et par âge}

- En 2012, les femmes avaient davantage tendance que les hommes à établir leur activité entrepreneuriale au stade précoce dans des locaux distincts ou à leur domicile. Les hommes menaient davantage leur activité de façon itinérante.

- Les personnes de plus de 40 ans étaient plus nombreuses à exercer une activité entrepreneuriale au stade précoce à domicile que les moins de 40 ans, plus susceptibles quant à eux de le faire dans des locaux distincts ou de manière itinérante.

Le Graphique 5.2 présente la localisation des activités entrepreneuriales totales au stade précoce par sexe pour 2012. Ce taux représente la proportion de la population impliquée dans une activité entrepreneuriale naissante et celle ayant démarré une entreprise au cours des 42 derniers mois. Les femmes avaient légèrement plus tendance que les hommes à diriger leur start-up ou leur une nouvelle entreprise dans des locaux séparés fixes ( $41 \%$ contre $37 \%$ ) et à domicile (36\% contre $32 \%)$. En revanche, elles étaient moins nombreuses à travailler de manière itinérante $(20 \%$ contre $28 \%)$.

Le Graphique 5.3 présente la localisation des activités entrepreneuriales totales au stade précoce par âge en 2012. On constatait très peu de différences entre la situation géoGraphique des activités entrepreneuriales au stade précoce des personnes de moins de 30 ans et celle des 30-39 ans. Environ 40\% d'entre elles occupaient des locaux fixes distincts et $30 \%$ étaient installées au domicile du propriétaire. Près de $27 \%$ des activités au stade précoce menées par des personnes de moins 30 ans étaient mobiles, contre $29 \%$ chez les 30-39 ans. 


\section{Graphique 5.2. Localisation des activités entrepreneuriales au stade précoce (hommes et femmes) dans l'UE, 2012}

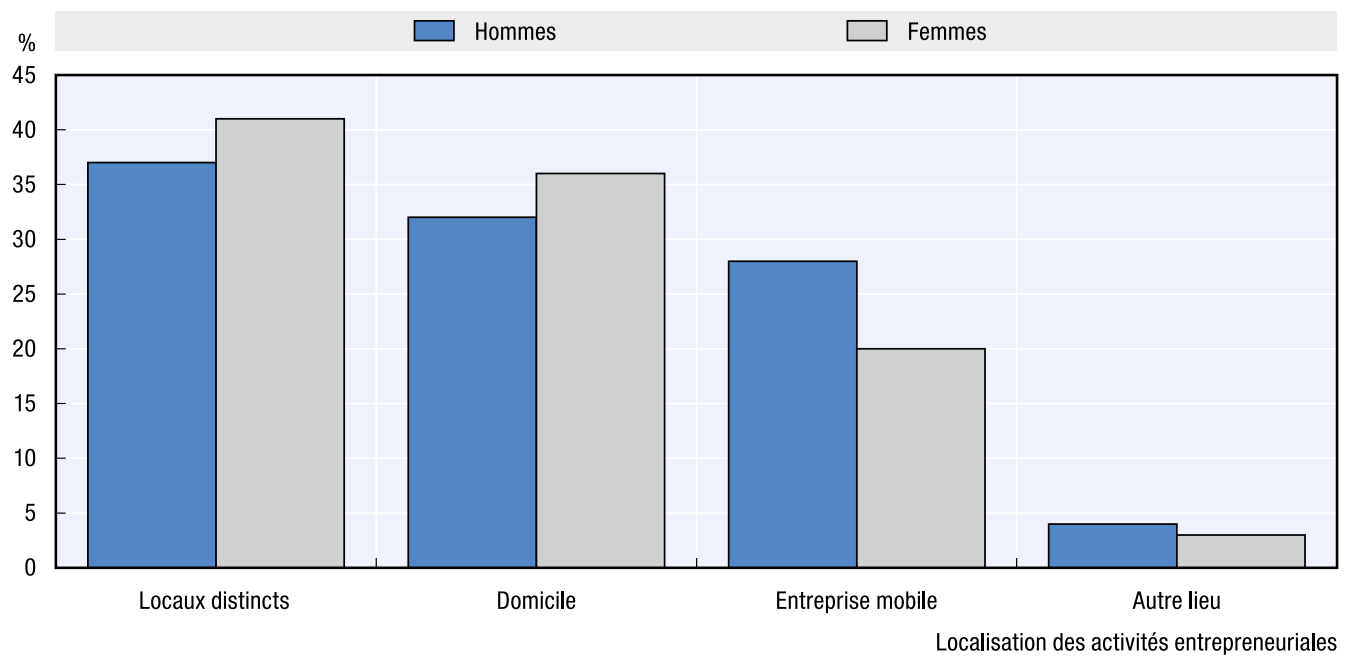

Note: 1. Les pays inclus dans le total européen sont les suivants: l'Allemagne, l'Autriche, la Belgique, la Croatie, le Danemark, l'Espagne, l'Estonie, la Finlande, la Grèce, la Hongrie, l'Irlande, l'Italie, la Lettonie, les Pays-Bas, la Pologne, la République slovaque, la Roumanie, le Royaume-Uni, la Slovénie et la Suède. 2. Ce Graphique présente l'activité entrepreneuriale totale au stade précoce, c'est-à-dire la proportion de la population activement impliquée dans la création d'une entreprise dont elle sera propriétaire ou copropriétaire et la proportion de la population ayant créé une entreprise au cours des 42 derniers mois.

Source: Présentations tabulaires spéciales de l'enquête 2012 sur la population adulte, extraites du Global Entrepreneurship Monitor.

\section{Graphique 5.3. Localisation des activités entrepreneuriales au stade précoce par âge dans l'UE, 2012}

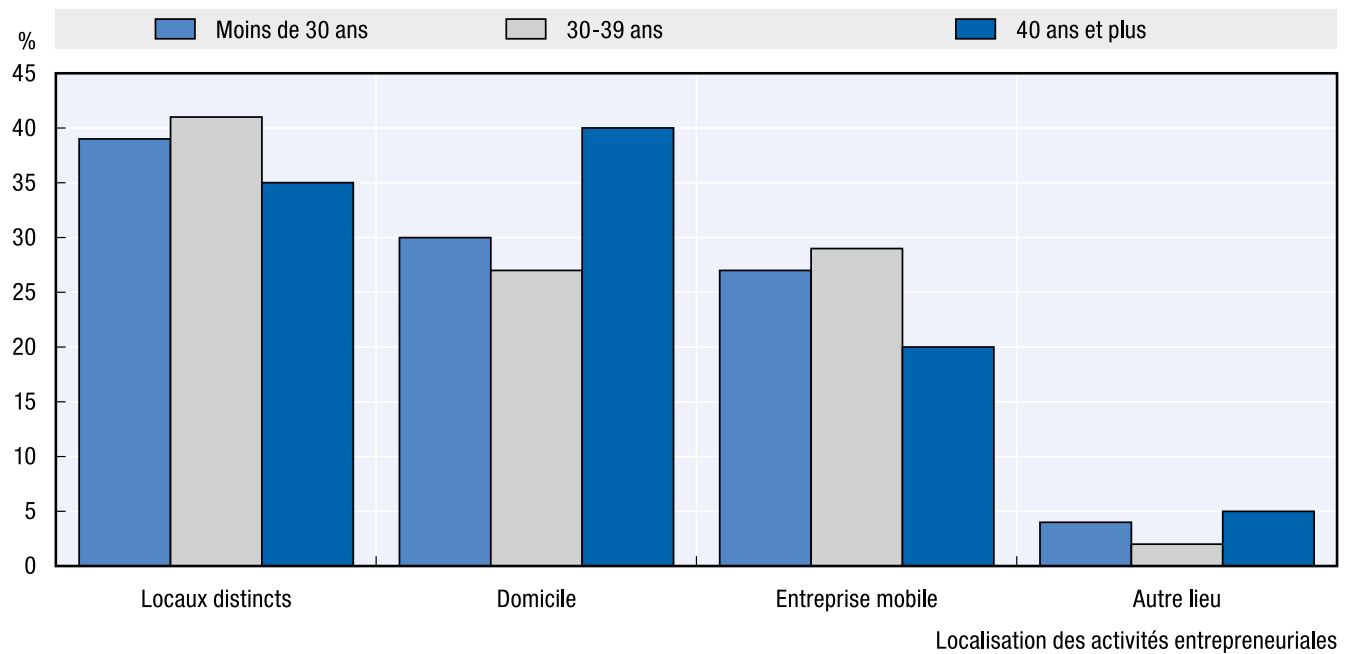

Notes: 1. Les pays inclus dans le total européen sont les suivants: l'Allemagne, l'Autriche, la Belgique, la Croatie, le Danemark, l'Espagne, l'Estonie, la Finlande, la Grèce, la Hongrie, l'Irlande, l'Italie, la Lettonie, les Pays-Bas, la Pologne, la République slovaque, la Roumanie, le Royaume-Uni, la Slovénie et la Suède. 2. Ce Graphique présente l'activité entrepreneuriale totale au stade précoce, c'est-à-dire la proportion de la population activement impliquée dans la création d'une entreprise dont elle sera propriétaire ou copropriétaire et la proportion de la population ayant créé une entreprise au cours des 42 derniers mois.

Source: Présentations tabulaires spéciales de l'enquête 2012 sur la population adulte, extraites du Global Entrepreneurship Monitor. 
Les plus de 40 ans avaient davantage tendance à établir leur activité entrepreneuriale au stade précoce à leur domicile. Près de $40 \%$ de ces activités étaient réalisées à domicile. En outre, cette tranche d'âge avait moins tendance que les jeunes à exercer une activité entrepreneuriale au stade précoce de façon itinérante $(20 \%$ contre $27 \%$ chez les moins de 30 ans et $29 \%$ chez les $30-39$ ans).

\section{Références}

Global Entrepreneurship Monitor (GEM) (2013), Présentations tabulaires spéciales de l'enquête 2012 sur la population adulte du Global Entrepreneurship Monitor. 

PARTIE II

\section{Les politiques d'entrepreneuriat inclusif}





\section{Chapitre 6}

\section{Politiques en faveur de l'entrepreneuriat des chômeurs ${ }^{1,2}$}

La création d'entreprise est l'une des voies qui permet d'accéder au marché du travail à partir d'une situation de chômage. Les chômeurs rencontrent toutefois un grand nombre d'obstacles au travail indépendant, notamment un accès limité aux financements d'aide à la création d'entreprise ainsi qu'un manque de qualifications et de réseaux. Ce chapitre décrit les politiques publiques communes appliquées au sein de l'UE afin d'aider les chômeurs à créer des entreprises, telles que l'information, le soutien financier avant et après la création, le recours à des modèles, la formation, l'accompagnement individualisé, le mentorat ainsi que le conseil en entreprise.

1. Note de la Turquie:

Les informations figurant dans ce document et faisant référence à «Chypre» concernent la partie méridionale de l'île. Il n'y a pas d'autorité unique représentant à la fois les Chypriotes turcs et grecs sur l'île. La Turquie reconnaît la République turque de Chypre du Nord (RTCN). Tant qu'une solution durable et équitable n'aura pas été trouvée dans le cadre des Nations unies, la Turquie maintiendra sa position sur la «question chypriote».

2. Note de tous les États de l'Union européenne membres de l'OCDE et de l'Union européenne:

La République de Chypre est reconnue par tous les membres des Nations unies sauf la Turquie. Les informations figurant dans ce document concernent la zone sous le contrôle effectif du gouvernement de la République de Chypre. 


\section{Potentiel de créateurs d'entreprise et de travailleurs indépendants chez les chômeurs}

- Le chômage demeure l'un des principaux défis sociaux et économiques auxquels doivent faire face les États membres de l'UE.

- Le taux de chômage des jeunes est deux fois plus important que celui des adultes, une tendance qui s'est maintenue tout au long de la crise économique.

- Seul un faible pourcentage de chômeurs manifeste un intérêt pour le travail indépendant.

- Certains éléments montrent que l'action politique peut accroître la viabilité des nouvelles entreprises créées par des chômeurs.

Le chômage, en particulier chez les jeunes, est l'un des principaux défis sociaux et économiques auxquels doivent faire face les États membres de l'UE et de nombreux autres pays à travers le monde. Ses répercussions sont visibles tant au niveau macroéconomique qu'au niveau individuel. Pour les économies, les populations sans emploi représentent une réserve inexploitée de ressources économiques, qui pourrait être utilisée pour accroître la production et, potentiellement, la croissance économique. Pour les individus, les effets peuvent être dévastateurs. Le temps passé sans emploi diminue à la fois leurs revenus du moment et les gains acquis tout au long de leur vie, et augmente les risques de pauvreté et d'exclusion sociale. Ces effets négatifs sont encore plus prononcés chez les jeunes. À titre d'exemple, une majoration de la période de chômage de trois mois avant l'âge de 23 ans conduit en moyenne à deux mois d'inactivité supplémentaires entre l'âge de 28 et de 33 ans (Gregg, 2001). On estime par ailleurs qu'une année de chômage durant la jeunesse peut entraîner une réduction du revenu annuel pouvant atteindre $21 \%$ à l'âge de 42 ans (Gregg et Tominey, 2005).

Le taux de chômage de l'UE dans son ensemble s'élevait à 10,7\% au quatrième trimestre 2013. Chez les jeunes (15-24 ans), il atteignait un peu plus du double, à $23 \%$. L'UE comptait ainsi 25,6 millions de chômeurs, dont 5,4 millions de jeunes. Les taux de chômage varient sensiblement d'un État membre à l'autre (Graphique 6.1). En 2012, la Grèce et l'Espagne enregistraient des taux de chômage deux fois supérieurs à la moyenne de l'UE et supérieurs à 50 \% chez les jeunes. À l'inverse, les taux de chômage de l'Autriche, du Luxembourg et des Pays-Bas représentaient moins de la moitié du taux moyen de l'UE.

Bien que dans tous les États membres, sauf en Croatie, au Danemark, en Irlande et en Slovénie, les taux de participation au marché du travail aient retrouvé leurs niveaux d'avant la crise, les dépassant même parfois, le chômage de l'UE demeure nettement plus élevé qu'avant la crise (Graphique 6.2). Les seuls pays où le taux de chômage a baissé depuis le début de la crise sont l'Allemagne et l'Autriche. En Allemagne, il a perdu 3,8\% entre 2007 et 2012, alors qu'en Autriche il est revenu à son niveau de 2007 en 2012.

Face à ce défi persistant, les décideurs politiques continuent de chercher des moyens de remédier à une croissance économique au point mort et à un chômage élevé. La création d'entreprise et le travail indépendant pourraient constituer un point d'entrée potentiel sur le marché du travail pour les personnes en situation de chômage. En 2011, 2,6\% des chômeurs 


\section{Graphique 6.1. Taux de chômage par État membre, 2012}

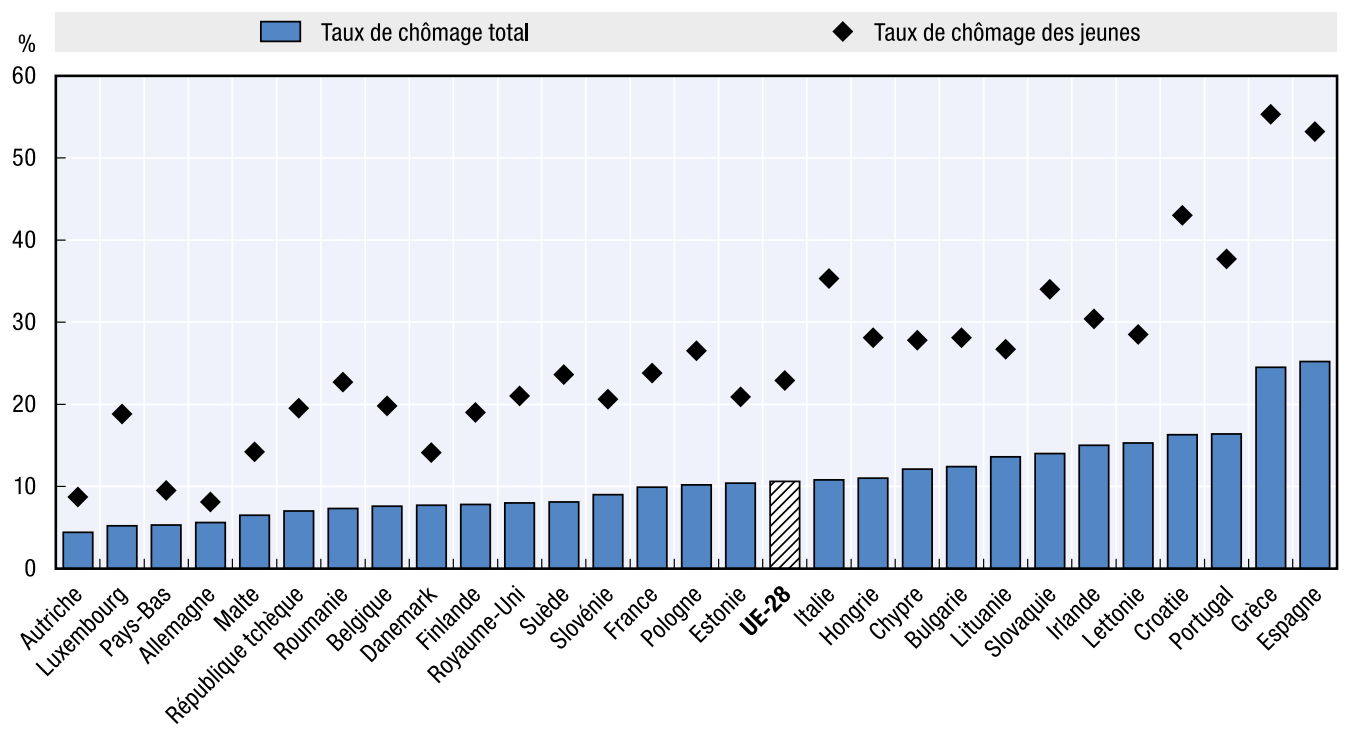

Source: Eurostat, Enquête sur les forces de travail 2012.

Graphique 6.2. Taux de chômage dans l'UE-28, 2002-2012

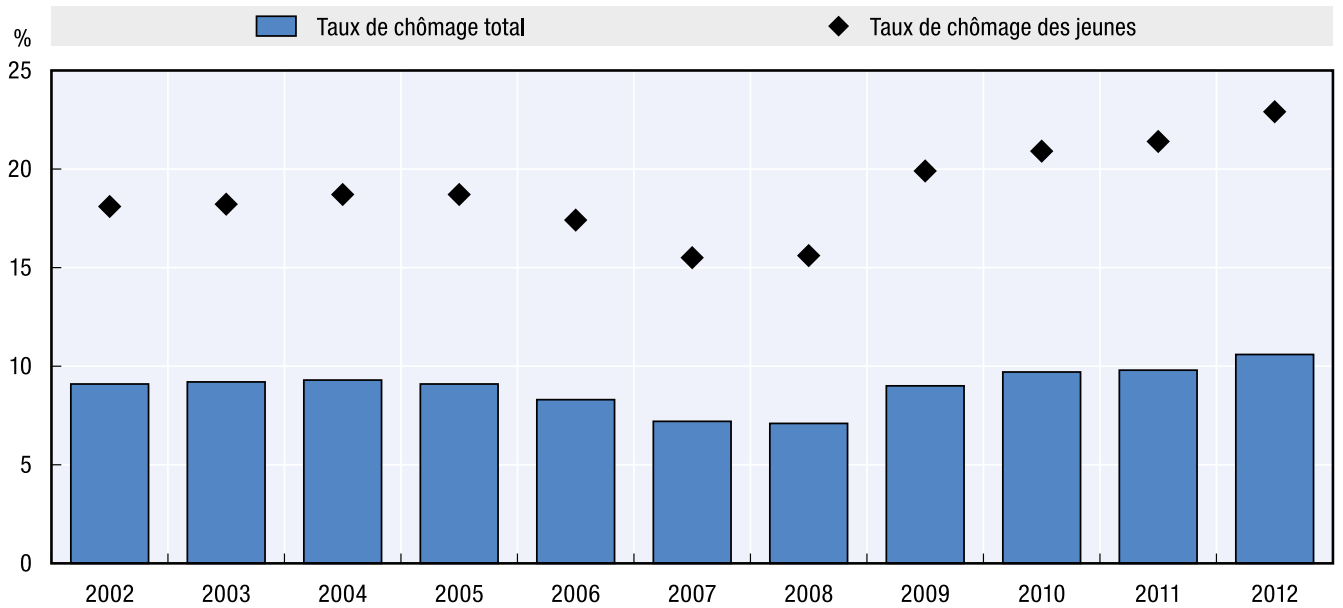

Source: Eurostat, Enquête sur les forces de travail 2002-2012.

de l'UE voyaient dans le travail indépendant leur principal moyen de réintégrer le marché de l'emploi (Graphique 6.3) et 3\% des chômeurs en 2011 sont devenus indépendants en 2012. Au total, près de 700000 personnes sont passées du chômage au travail indépendant entre 2011 et 2012. Si ces tendances s'appliquent à la plupart des États membres de l'UE, les taux de transition réels varient fortement d'un pays à l'autre. En Italie, seuls 1,9\% des chômeurs en 2011 avaient pour ambition de devenir indépendants. Pourtant, 9,3\% d'entre eux ont fait ce choix en 2012. Cela montre que, sous certaines conditions, un grand nombre de chômeurs optent pour le travail indépendant, même si peu d'entre eux le préfèrent au travail salarié. 


\section{Graphique 6.3. Potentiel de travailleurs indépendants chez les chômeurs, 2011}

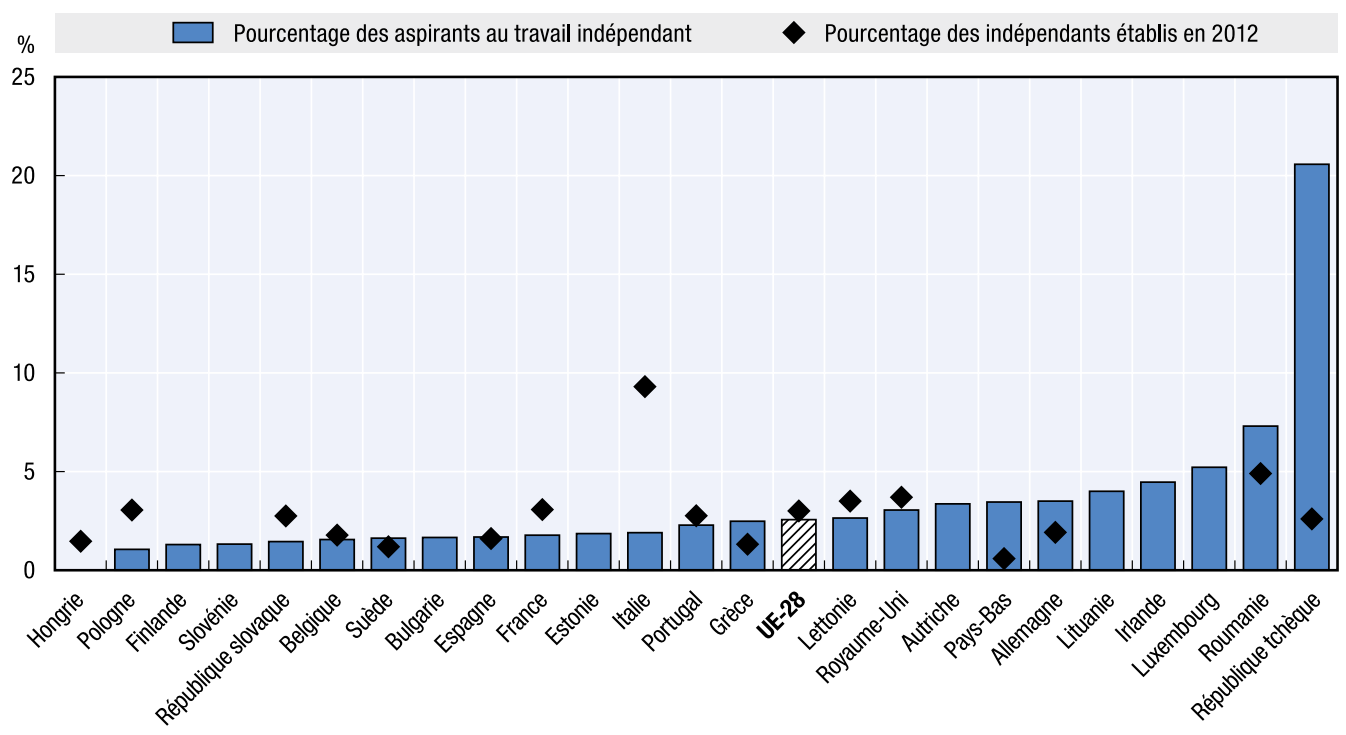

Source: Présentations tabulaires spéciales de l'enquête Eurostat sur les forces de travail, 2012.

$\mathrm{Au}$ cours des dix dernières années, la proportion de chômeurs européens ayant souhaité devenir indépendants a légèrement augmenté, mais se maintient sous la barre des $4 \%$ (Graphique 6.4). Elle a connu un pic au début de la crise pour ensuite redescendre à son niveau de 2007.

L’UE manque de données sur les types et la qualité des activités entreprises par les personnes qui quittent le chômage pour se mettre à leur compte. Des données françaises indiquent une légère différence entre les sexes en ce qui concerne la proportion d'individus au chômage qui se lancent dans une activité indépendante. Il apparaît également que les chômeurs ont plus tendance à créer leur entreprise dans le secteur des transports (p.ex. chauffeurs de taxi, camions de transport) que les personnes salariées. En revanche, ils sont moins susceptibles de créer une entreprise dans le domaine de l'éducation, de la santé et des œuvres sociales (INSEE, 2012). D'après d'autres données françaises, comparées aux entreprises créées par des salariés, les entreprises créées par des chômeurs avaient un taux de survie inférieur de $5 \%$ après 5 ans et de $4,7 \%$ après 8 ans (Désiage et al., 2011).

Malgré le faible nombre d'Européens qui créent une entreprise après une période de chômage, la politique peut potentiellement jouer un rôle. Des données allemandes suggèrent que le soutien politique peut éliminer les disparités qui existent au niveau des taux de survie (voir p.ex. May-Strobl, 2010) et déboucher sur la création d'emplois supplémentaires via le recrutement d'employés (Caliendo et al., 2009; Caliendo et al., 2010). De plus, les décideurs politiques doivent prendre en considération le coût de l'inaction, en particulier chez les jeunes en situation de chômage. Le fait de ne pas les maintenir sur le marché du travail peut avoir d'énormes répercussions financières sur l'économie, surtout si l'on considère les contributions potentielles que représente une carrière de 35 à 40 ans, sans compter les effets dévastateurs à titre individuel. 


\section{Graphique 6.4. Potentiel de travailleurs indépendants chez les chômeurs dans} l'UE-28, 2002-2011

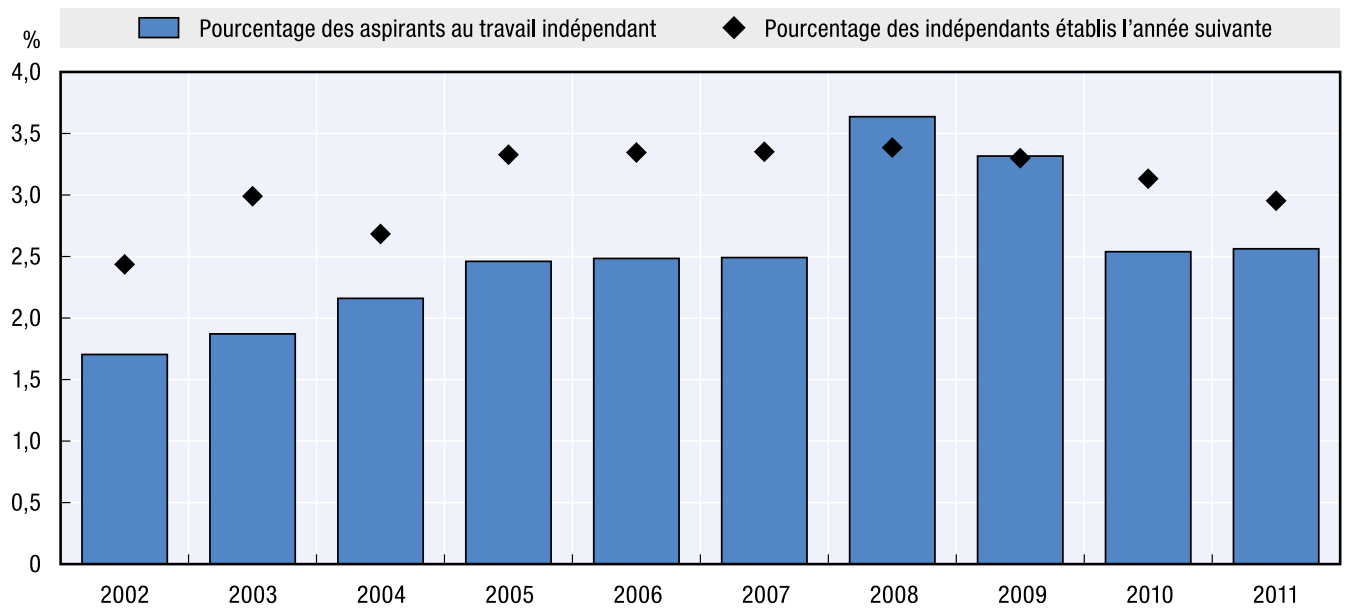

Source: Présentations tabulaires spéciales de l'enquête Eurostat sur les forces de travail, 2013.

StatLink त्ञाज http://dx.doi.org/10.1787/888933191923

\section{Entraves à la création d'entreprise par des chômeurs}

- Les chômeurs qui créent une entreprise sont confrontés aux mêmes obstacles que les autres entrepreneurs: manque de financement, manque de capital humain et manque de capital social. Cependant, l'ampleur de l'obstacle est souvent plus grande chez les chômeurs en raison de leurs niveaux d'épargne et de capital humain et social plus faibles, et de la confiance limitée des banques et autres établissements de prêt.

- Le coût d'opportunité de la création d'entreprise constitue un autre effet dissuasif important pour les chômeurs qui se lancent dans l'entrepreneuriat. En d'autres termes, le fait de créer une entreprise pourrait entraîner une baisse de leur revenu malgré leurs efforts accrus pour entrer et rester sur le marché du travail. Cela est particulièrement vrai pour ceux qui possèdent une grande expérience professionnelle et bénéficient d'allocations de chômage importantes.

- Les jeunes chômeurs (à savoir ceux qui ne sont pas scolarisés, n'exercent aucun emploi et ne suivent aucune formation, les NEET) rencontrent les mêmes entraves que les adultes, bien que d'après certaines données, l'absence de compétences entrepreneuriales et le manque de capital social semblent avoir plus d'impact que le manque de financement.

Comparés aux salariés qui créent une entreprise, les chômeurs qui se lancent dans une activité indépendante manquent généralement de capital pour démarrer et développer leur entreprise (Davidsson et Honig, 2003; Dunn et Holtz-Eakin, 2000; Taylor, 1996). Ces ressources sont de trois ordres: capital financier, capital humain et capital social. Et elles sont complémentaires par nature, c'est-à-dire qu'un chômeur bénéficiant d'un capital humain et social peut généralement compenser son déficit de capital financier (Baker et Nelson, 2005; Grichnik et al., 2014). En outre, ces formes de capital s'additionnent. Autrement dit, les individus qui disposent de deux de ces ressources, ou des trois, auront toutes les cartes en mains pour réussir leur passage à l'entrepreneuriat et bâtir une entreprise capable de générer suffisamment de revenus pour subvenir à leurs besoins voire prospérer et recruter (Honig, 1998; Jonsson et Lindbergh, 2011).

Dans le cas des entreprises créées par des chômeurs, ces trois ressources doivent être envisagées conjointement, étant donné qu'elles sont intimement liées à la position de l'individu 
sur le marché du travail. Les personnes sans emploi ont peu de moyens financiers pour créer une entreprise. C'est pourquoi les mécanismes d'aide publique visent essentiellement à octroyer des subventions ou des prêts à taux réduit aux chômeurs créateurs d'entreprise. Toutefois, le manque de capital humain (compétences générales et entrepreneuriales) et de capital social (réseaux professionnels pouvant servir à trouver des partenaires, des fournisseurs et des clients, de l'aide et des connaissances) constitue un obstacle aussi important que le manque de financement, car ces deux capitaux ont tous deux tendance à se détériorer au fur et à mesure du chômage. Plus la durée du chômage se prolonge, plus le capital humain perd de sa valeur, car, les compétences se détériorent faute de les utiliser (Ritsilä et Tervo, 2002). De la même façon, la durée du chômage affecte la qualité du capital social car les réseaux professionnels se construisent et s'entretiennent principalement sur le lieu de travail (Nanda et Sørensen, 2010).

\section{Manque de capital financier}

Les chômeurs sont confrontés à une autre difficulté. Ils ne disposent généralement pas du capital de départ requis pour créer leur entreprise et subvenir à leurs besoins jusqu'à ce qu'elle soit en mesure de générer des bénéfices. Le capital financier nécessaire peut prendre la forme d'un emprunt ou de fonds propres. Le capital d'emprunt provient souvent de sources informelles (prêts contractés auprès de membres de la famille ou d'amis) ou formelles (prêts octroyés par des banques ou d'autres établissements de prêt). Les fonds propres proviennent généralement de l'épargne des entrepreneurs eux-mêmes ou d'investisseurs extérieurs (Le, 1999; Nykvist, 2008; Taylor, 2001). Là encore, les fonds propres informels (coinvestissement de membres de la famille ou d'amis) sont bien plus utilisés que les capitaux d'investisseurs providentiels ou de sociétés de capital-risque.

La difficulté des chômeurs à accéder aux prêts à la création d'entreprise s'explique par plusieurs raisons. Premièrement du fait de leur période d'inactivité, leur épargne personnelle est généralement limitée. Ils peuvent donc difficilement financer eux-mêmes une entreprise et fournir des garanties pour l'obtention d'un prêt (Fairlie et Krashinsky, 2012; Rodgers, 1991). On peut y voir ici des entraves à l'accès au marché. De plus, des barrières culturelles peuvent apparaître, tant du côté de la demande que de l'offre. Du côté de l'offre, les chômeurs peuvent hésiter à contacter des établissements de prêt s'ils partent du principe qu'ils n'obtiendront pas de prêt. Du côté de la demande, les chômeurs peuvent ne pas correspondre au profil du client de banque idéal et rencontrer des difficultés en raison de discriminations (CE-OCDE, 2014). Les chômeurs ont aussi des difficultés à accéder aux financements, car ils ignorent comment déposer une demande de prêt ou rédiger les plans d'affaires demandés (CE-OCDE, 2014).

\section{Manque de compétences entrepreneuriales}

Pour lancer une entreprise et la diriger efficacement, les entrepreneurs doivent déployer une grande variété de compétences (Otani, 1996; Unger et al., 2011). Ils doivent posséder des compétences professionnelles générales requises dans n'importe quel environnement de travail, ainsi que des compétences propres à l'entrepreneuriat. Celles-ci incluent, par exemple, la planification des activités, l'automotivation, l'évaluation et la gestion des risques, la réflexion stratégique, la mise à profit des réseaux personnels et la motivation d'autrui. Vous trouverez une liste plus complète des compétences entrepreneuriales au Tableau 6.1.

Comparés aux actifs, les chômeurs manquent de compétences générales, d'une part, et de compétences spécifiques à l'entrepreneuriat, d'autre part (Iyigun et Owen, 1998). Ce déficit de compétences rend la création de leur entreprise faire difficile. Plus la période de chômage est longue, plus le chômeur verra son capital humain s'amenuiser rapidement faute de rester actif sur le marché du travail (Ljungqvist et Sargent, 1998). 
Tableau 6.1. Types de compétences requises de la part des entrepreneurs

\begin{tabular}{lll}
\hline Compétences techniques & Compétences en gestion des activités & $\begin{array}{l}\text { Compétences entrepreneuriales } \\
\text { personnelles }\end{array}$ \\
\hline Communication écrite et orale & Planification et fixation des objectifs & Maîtrise de soi/discipline \\
Surveillance de l'environnement & Prise de décisions & Gestion des risques \\
Résolution des problèmes & Gestion des ressources humaines & Innovation \\
Mise en œuvre et utilisation des technologies & Marketing & Persévérance \\
Interaction avec autrui & Finances & Aptitude à diriger \\
Capacité d'organisation & Comptabilité & Gestion du changement \\
& Relations avec la clientèle & Création de réseaux \\
& Contrôle de la qualité & Réflexion stratégique \\
& Négociations & \\
& Lancement d'activité & \\
& Gestion de la croissance & \\
Conformité aux règlements & \\
\hline
\end{tabular}

Source: OCDE/CE (2013).

\section{Manque de capital social}

Le capital social sous la forme de réseaux personnels et professionnels joue un rôle déterminant pour les entrepreneurs (Batjargal, 2003). Durant la phase de création d'une entreprise, les entrepreneurs utilisent leurs réseaux pour établir des contacts avec les parties prenantes (partenaires, fournisseurs, clients, etc.) qui pourront contribuer à sa mise en place (Hite, 2005), et pour trouver d'autres professionnels susceptibles de leur apporter de l'expérience et des connaissances (Davidsson et Honig, 2003; Hite, 2005). Sur le plan géographique, ces réseaux se limitent souvent à la communauté locale (Cooke et al., 2005; Dahl et Sorenso, 2012). Ils peuvent par ailleurs fournir une structure d'appui à travers différentes formes de soutien et d'encouragement (Kwon et al., 2013; Ram et al., 2008).

Les chômeurs entrepreneurs manquent souvent du capital social requis pour créer une entreprise durable. Pour les individus, le capital social est souvent défini comme «la somme des ressources actuelles ou virtuelles qui reviennent à un individu du fait qu'il possède un réseau durable de relations, de connaissances et de reconnaissances» (Bourdieu et Wacquant, 1992). Tandis que les capitaux humain et financier constituent des ressources uniquement sur le plan individuel, le capital social peut être davantage considéré comme une forme de bien public que comme une propriété privée puisqu'il découle de la structure sociale des relations entre individus. Durant la phase de création d'une entreprise, le capital social est important pour interagir avec les clients et fournisseurs et les convaincre. Une fois la société établie, il permet d'identifier et d'attirer plus facilement les bons collaborateurs, financiers, clients et fournisseurs (Kim et al., 2013; Stam et al., 2014).

\section{Coût d'opportunité}

Les chômeurs qui se lancent dans une activité indépendante peuvent également faire face à des coûts d'opportunité élevés durant cette période de transition. En d'autres termes, ils peuvent gagner moins d'argent en tant qu'indépendants qu'au chômage. Ainsi, le fait de devoir renoncer aux prestations de chômage peut avoir un effet dissuasif sur la création d'entreprise et sur toute autre activité professionnelle. Cet effet ne se traduit pas de la même manière chez toutes les catégories de population au chômage. Par exemple, les jeunes dont le parcours professionnel est relativement court perçoivent généralement peu de la part des régimes d'assurance-chômage. L'effet dissuasif est donc ici limité. À l'opposé, les personnes présentant une expérience professionnelle plus longue percevront davantage. 
Les personnes ayant des enfants sont souvent éligibles à des prestations et aides sociales supplémentaires. Ces dernières doivent également prendre en compte les éventuels frais de garde. Autant de facteurs qui contribuent à accroître le coût d'opportunité lié au démarrage d'une activité. En Allemagne, un certain nombre de données et de simulations indiquent que le coût d'opportunité est le plus bas chez les jeunes et le plus élevé chez les hommes sans emploi dont le salaire était élevé ainsi que chez les mères célibataires avec plusieurs enfants (Gawlitta et al., 2010).

\section{Encadré 6.1. Entraves à la création d'entreprise rencontrées par les jeunes qui ne sont pas scolarisés, n'exercent aucun emploi et ne suivent aucune formation (NEET)}

Les jeunes qui ne sont pas scolarisés, n'exercent aucun emploi et ne suivent aucune formation (ou NEET) rencontrent les obstacles décrits précédemment, mais ils sont aggravés par leur manque d'expérience professionnelle, de réseaux professionnels et d'épargne (Fairlie, 2005). De ce fait, ils sont potentiellement moins au courant des possibilités offertes par l'entrepreneuriat, et moins susceptibles d'avoir les compétences et l'expérience requises pour les exploiter.

Des preuves suggèrent que la mise en place de solutions pour répondre au manque de compétences entrepreneuriales et de capital humain chez les NEET passe avant l'octroi de financements en faveur de la création d'entreprise, la raison étant que l'accès à ces financements n'augmentera pas la probabilité qu'ils se tournent vers l'entrepreneuriat et développent une entreprise viable (Battistin et al., 2001). L'éducation à l'entrepreneuriat dans l'enseignement primaire et supérieur aura tendance à renforcer les compétences non cognitives chez les jeunes (Rosendahl Huber et al., 2012), leur fera découvrir le potentiel offert par l'entrepreneuriat et leur apportera les qualifications qui contribueront à leur réussite. Dans le cas des NEET ayant terminé leur scolarité, des programmes de formation à l'entrepreneuriat plus spécifiques ont démontré leur efficacité (Rotger et al., 2012).

Le coût d'opportunité des NEET est faible par rapport à celui des autres chômeurs. Ils perçoivent généralement très peu, voire pas, d'allocations de chômage et les possibilités offertes par le marché du travail ne leur garantissent pas forcément de revenus substantiels.

\section{Mesures politiques en faveur de l'entrepreneuriat des chômeurs}

- Diverses approches politiques sont mises en œuvre au sein de l'UE afin de soutenir le passage du chômage au travail indépendant. La sensibilisation, la formation, le soutien financier avant et après la création d'entreprise, les services d'aide au développement des entreprises ainsi que des modifications plus profondes de la réglementation font partie des approches courantes.

- Les trains de mesures intégrés se révèlent souvent plus efficaces parce qu'ils éliminent plusieurs obstacles et proposent des formes de soutien complémentaires.

- L'efficacité et l'impact de l'aide à la création d'entreprises par les chômeurs sont remis en cause. Toutefois, des éléments suggèrent que la mise en place de mesures locales ciblées et de services personnalisés pour les groupes cibles peuvent avoir des retombées positives sur la viabilité de ces nouvelles entreprises et sur leur potentiel de création d'emplois.

Les mesures politiques qui soutiennent le passage du chômage au travail indépendant prévoient (i) une meilleure connaissance des possibilités offertes par l'entrepreneuriat, (ii) une meilleure acquisition des compétences entrepreneuriales, (iii) des aides financières à la création d'entreprise, (iv) un soutien financier après la création d'entreprise, (v) des services d'aide au développement des entreprises, et (vi) des changements réglementaires 
profonds. Ces différentes approches peuvent être combinées dans le cadre d'une approche globale qui s'attaque à la nature aux entraves complémentaire évoquées dans le chapitre précédent. Le Graphique 6.5 illustre les différents types de mécanismes qui peuvent faire partie d'une stratégie politique générale et la façon dont ces composantes interagissent entre elles. Un Tableau récapitulatif des principales problématiques politiques est proposé à l'annexe 6 A1.

\section{Graphique 6.5. Une réponse politique globale en faveur de l'entrepreneuriat des
chômeurs}

Changements apportés au cadre réglementaire qui affectent l'entrepreneuriat et le chômage en général

Modifier les politiques institutionnelles afin d'encourager et de soutenir l'entrepreneuriat des chômeurs:

Gouvernements nationaux:

- Effets d'attraction (p.ex. coûts de création d'entreprise)

- Effets d'entraînement (p.ex. allocations de chômage)

Sensibiliser davantage aux possibilités offertes

par l'entrepreneuriat comme moyen de créer

son propre emploi

Gouvernements nationaux:

- Accroître la mobilité du marché du travail

Gouvernements régionaux:

- Éducation à l'entrepreneuriat

Autorités locales:

- Modèles: effets des pairs
Faciliter le passage du chômage à l'entrepreneuriat

Faciliter l'acquisition de compétences entrepreneuriales

Gouvernements nationaux:

- Accroître la mobilité du marché du travail

- Formation à l'entrepreneuriat

Donner ou faciliter l'accès des start-up aux financements

Gouvernements nationaux/régionaux:

- Subventions de démarrage

- Aide au revenu pendant une durée déterminée

- Contrôler la réglementation bancaire

Gouvernements régionaux:

- Microprêts

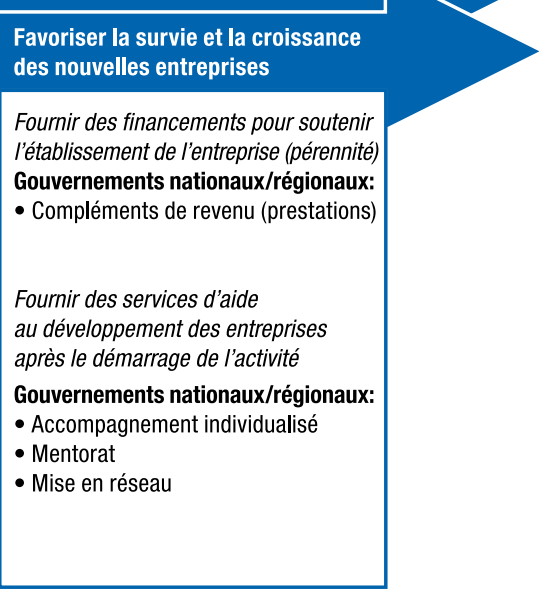

Source: Adapté de Wennberg, K. (2013), «Entrepreneurship from unemployment: A review of active labour market programmes and policy recommendations", préparé dans le cadre du programme LEED de l'OCDE.

\section{Sensibiliser davantage à l'entrepreneuriat}

La sensibilisation accrue aux possibilités de l'entrepreneuriat comme moyen de créer son propre emploi fait généralement partie des mesures de l'UE en faveur d'un marché du travail actif. Cela passe notamment par la fourniture d'informations sur le travail indépendant et ses avantages et l'organisation de formations de base à l'entrepreneuriat ou à la gestion des petites entreprises. Il s'agit de mettre l'accent sur les bienfaits potentiels de l'entrepreneuriat en tant qu'activité professionnelle et d'informer les chômeurs sur les entraves, perçues et réelles, à la création d'entreprise.

Plusieurs approches de l'UE peuvent être une source d'inspiration. C'est le cas, p.ex. du programme fédéral allemand Perspektive 50plus qui promeut la création d'entreprise par les seniors aux fins de les maintenir et les réinsérer sur le marché du travail. Il a été lancé suite à un changement de réglementation en 2008 qui allongeait la durée des allocations de chômage de 12 à 24 mois pour les personnes de plus de 50 ans. D'après les évaluations, les seniors sont moins effrayés à l'idée d'échouer que les jeunes, mais sont 22,5\% plus susceptibles d'abandonner que ces derniers (Werner et al., 2008). Ces données suggèrent que les mesures politiques ont un rôle important à jouer, celui de renforcer l'efficacité personnelle des chômeurs (c'est-à-dire renforcer la confiance des chômeurs entrepreneurs potentiels dans leurs propres capacités à créer avec succès leur entreprise). 


\section{Proposer des formations à l'entrepreneuriat}

Une formation à l'entrepreneuriat peut être dispensée aux chômeurs, soit de manière autonome, soit dans le cadre d'un programme intégré. Ce type de formation prend le plus souvent la forme d'ateliers et de cours structurés. La prudence doit être de mise avec les formations en ligne, car les chômeurs n'ont pas systématiquement accès à ce type de formation. En outre, le fait d'être en contact avec des entrepreneurs actifs contribue à acquérir l'efficacité nécessaire pour réussir le passage à l'entrepreneuriat (Krueger, 2003).

Les formations à l'entrepreneuriat destinées aux chômeurs ressemblent à celles suivies par la population en général. Elles permettent d'acquérir des compétences entrepreneuriales pratiques telles que la gestion d'entreprise (comptabilité, finance, législation de base), mais elles favorisent également le développement personnel et la confiance en soi (OCDE/CE, 2013). Dans l'ensemble, les programmes de formation à l'entrepreneuriat sont efficaces (Rotger et al., 2012), en particulier lorsque la formation a été correctement ciblée (Kluve and Schmidt, 2002). La formation donne souvent de meilleurs résultats lorsqu'elle est associée à d'autres formes de soutien. Par exemple, une évaluation de huit programmes suédois de politique active du marché du travail révèle que les plus programmes les plus performants sont ceux qui combinent formation et expérience pratique (Carling et Richardson, 2004). Les formations sont également efficaces parce qu'elles permettent aux nouveaux entrepreneurs d'examiner et d'évaluer leurs qualifications, leurs compétences et leurs besoins (Dupuy et Mègemont, 2007).

En plus de préparer à la création d'entreprise, la formation à l'entrepreneuriat peut également accroître l'employabilité. Un individu sera ainsi plus susceptible de retourner à l'emploi après un passage par l'entrepreneuriat ou une expérience liée à la création d'entreprise. Même si cela ne donne pas lieu à la création d'une entreprise durable, on peut y voir un succès en cas de retour réussi sur le marché du travail. Des données de Roumanie et d'Allemagne montrent que la formation et la reconversion des chômeurs ainsi que l'aide à la création de petites entreprises améliorent les résultats du marché du travail (Rodriguez-Planas et Benus, 2007; Baumgartner et Caliendo, 2008) et les revenu potentiels des chômeurs (Caliendo et Künn, 2011).

Les évaluations ne vont cependant pas toutes dans ce sens. Au Royaume-Uni, les données indiquent que les formations à l'entrepreneuriat et autres aides à la création d'entreprise destinées aux jeunes n'ont pas d'influence sur leur future situation professionnelle (Meager et al., 2003). Ces évaluations font apparaître une procédure de candidature trop axée sur la qualité des plans d'affaires et pas assez sur les profils des candidats. Les motivations individuelles doivent être prises en compte lors de la sélection des participants (sans emploi) aux programmes de formation à l'entrepreneuriat.

\section{Soutenir financièrement la création d'entreprise}

Une des aides à la création d'entreprise pour les chômeurs prévoit l'octroi d'un financement sous forme de subvention de démarrage ou le paiement des allocations de chômage sous forme de versement forfaitaire. Le principe est le même que pour les entrepreneurs traditionnels. Préalablement à l'attribution du financement, les idées d'entreprise sont examinées minutieusement, puis sélectionnées. Une fois le financement alloué, le nouvel entrepreneur dispose d'un certain nombre d'aides au développement d'entreprise.

Les chômeurs peuvent bénéficier de subventions de démarrage et de programmes de financement ciblés qui soutiennent spécifiquement les entreprises créées par des chômeurs. En Italie, la loi 608/1996 vise à soutenir la création d'entreprise par des personnes au chômage depuis plus de six mois. Après un processus de sélection qui évalue le plan d'affaires, une subvention pouvant couvrir jusqu'à $60 \%$ des coûts de création de 
l'entreprise et un prêt à taux réduit sur cinq ans peuvent être accordés. L'aide comprend également des formations et des services de conseil en entreprise.

Des mécanismes similaires existent en France. Par exemple, entre 1993 et 1997, l'ACCRE (Aide aux chômeurs créateurs ou repreneurs d'entreprises) octroyait des aides à la création d'entreprise de près de 5000 EUR (voir encadré 6.2). Les chiffres montrent que le taux de survie des sociétés créées par des chômeurs ayant bénéficié d'une aide était supérieur à celui des entreprises qui n'en avaient pas bénéficié et légèrement inférieur à celui des entreprises créées par des actifs (p.ex. le taux de survie à 3 ans était de $72 \%$ dans le cas des chômeurs de courte durée, soit légèrement inférieur à celui de la population active qui était de 79\%) (Crépon et Duguet, 2002). S'agissant des chômeurs de longue durée, le taux de survie à 3 ans était en revanche de 64\% (Crépon et Duguet, 2002).

Une autre aide à la création d'entreprise destinée aux chômeurs consiste à leur payer leurs allocations de chômage sous forme de versement forfaitaire pour qu'ils puissent démarrer leur activité. Cette approche existe au Portugal par exemple (encadré 6.3). Dans ce cas-ci, les chômeurs peuvent percevoir un montant pouvant atteindre la somme totale des allocations de chômage auxquelles ils ont droit (moins celles déjà perçues) sous forme de versement forfaitaire pouvant servir à la création d'une entreprise. Dans le cadre de ce mécanisme, les entrepreneurs potentiels soumettent leur plan d'affaires à leur agence pour l'emploi qui vérifie la faisabilité de l'idée d'entreprise. Une fois celle-ci validée, l'entrepreneur reçoit son versement forfaitaire. D'autres aides sont à la disposition des participants à ce mécanisme, notamment des formations et des conseils en entreprise. Deux programmes de financement public leur donnent également accès à des prêts bonifiés et des microcrédits.

Comme indiqué dans la précédente section, les aides financières et les formations sont souvent proposées conjointement. Un programme slovène de création d'entreprise destiné aux NEET illustre la manière dont ces deux formes d'aide se complètent (encadré 6.4).

\section{Soutenir financièrement la viabilité des entreprises}

La période qui suit la création d'une entreprise se caractérise presque toujours par des activités qui visent à l'établir (à savoir le développement de produits et de services). Il faut généralement un certain temps avant que son propriétaire ne puisse en retirer des gains (Parker et Belghitar, 2006). Par conséquent, l'aide au démarrage la plus fréquemment accordée aux demandeurs d'emploi est une subvention visant à leur assurer un revenu pendant une durée déterminée après la création de leur entreprise. Ces subventions sont généralement déterminées en fonction des indemnités de chômage des participants au programme, mais elles peuvent aussi être fixes. En outre, ces mécanismes s'accompagnent souvent d'autres services d'appui tels que des formations (sur une base volontaire ou comme prérequis à la participation) et/ou d'autres services d'aide au développement des entreprises (p.ex. conseils en entreprise).

Cette forme de soutien est généralement connue sous le nom de pont social. Les exemples sont nombreux au sein de l'UE. Les initiatives les plus connues sont la subvention d'amorçage et l'indemnité-relais en Allemagne. Ces programmes ont permis d'effectuer des versements réguliers à des chômeurs ayant démarré une entreprise (après approbation de leur plan d'affaires) afin de les aider à couvrir leurs frais de subsistance durant la période de lancement. Les évaluations montrent que les participants avaient moins tendance à retourner au chômage et à vivre des revenus de leur entreprise (Caliendo et Steiner, 2007; Baumgartner et Caliendo, 2008). Malgré leur succès, ces programmes ont fusionné en 2006 en une subvention unique baptisée Gründungszuschuss. Même si, selon les évaluations, ce mécanisme s'est révélé moins efficace pour toucher les jeunes et les femmes peu qualifiés, 


\section{Encadré 6.2. ACCRE - Aide financière aux chômeurs, France}

Description: l'ACCRE (Aide aux chômeurs créateurs ou repreneurs d'entreprises) est un programme national qui octroie des aides financières en matière de création d'entreprise destinées aux chômeurs et aux allocataires sociaux. Sont admissibles:

- les demandeurs d'emploi inscrits et indemnisés, ou en passe d'être inscrits;

- les demandeurs d'emploi inscrits, mais non indemnisés, à condition qu'ils aient été inscrits à Pôle Emploi (l'agence gouvernementale pour l'emploi) au moins six mois au cours des 18 derniers mois;

- tout salarié d'une entreprise en faillite ou en liquidation qui décide de créer sa propre entreprise;

- les bénéficiaires de certaines allocations sociales (p.ex. RSA, API);

- les jeunes de moins de 30 ans éligibles aux contrats «emplois jeunes».

- L'ACCRE accorde des exonérations de charges sociales aux entreprises en phase de démarrage. La nature de l'aide dépend du statut fiscal de l'entreprise à créer.

i) Le niveau d'aide le plus généreux s'applique aux personnes inscrites comme autoentrepreneurs, celles-ci bénéficiant de taux de cotisation minorés pendant les trois premières années d'activité.

ii) Les personnes qui ne sont pas autoentrepreneurs sont exonérées des principales cotisations de retraite et de santé, même si elles restent redevables des cotisations sociales CSG/CRDS au taux de $8 \%$. De plus, elles sont exonérées des prestations d'invaliditédécès et des cotisations au régime de retraite complémentaire. Ces exonérations ne sont toutefois valables qu'un an.

Problème abordé: la montée du chômage à la fin des années 1970 a amené le gouvernement français à réagir. Le Premier ministre a alors recommandé de soutenir les demandeurs d'emploi à créer leur propre emploi.

Approche: en 1979, les entrepreneurs qui étaient demandeurs d'emploi ont été exonérés pour la première fois d'une partie de leurs cotisations sociales (loi $n^{\circ}$ 79-10 du 3 janvier 1979). Cette exonération est venue s'ajouter à l'aide financière directe déjà existante. Depuis lors, le mécanisme a plusieurs fois été modifié pour être adapté au contexte changeant. Le principal changement est intervenu en 1997 lorsque l'attribution directe de l'aide financière a été remplacée par une exonération massive des cotisations sociales pendant les trois premières années suivant la création de l'entreprise. Selon un récent rapport de la Cour des comptes française, l'ACCRE représentait en 2011 une charge de 245 millions EUR (150 millions EUR en 2006) pour les finances publiques, soit $40 \%$ du coût total des exonérations des cotisations sociales pour les employeurs.

Impact: d'après la Cour des comptes française, 179301 demandeurs d'emploi ayant créé leur propre entreprise ont bénéficié de ce régime en 2011. Chacun des entrepreneurs soutenus a bénéficié une exonération de 1370 EUR en moyenne.

les taux de survie demeurent très élevés (Caliendo et al., 2011). Le programme Ich-AG («MoiS.A.» ou «autoentrepreneur») a été lancé en Allemagne en 2004 dans le but de soutenir les demandeurs d'emploi à créer leur entreprise. D'après les chiffres, les participants à Ich-AG ont connu des taux de survie relativement élevés durant les premières années d'activité, bien que légèrement inférieurs à ceux des bénéficiaires de l'indemnité-relais. Veuillez lire l'encadré 6.5 pour une description plus détaillée du programme Ich-AG. 


\section{Encadré 6.3. Apoios à Criação do Próprio Emprego por Beneficiários de Prestações de Desemprego, Portugal}

Description: cette mesure nationale a été prise en 2009 dans le cadre du Programme pour l'entrepreneuriat et le travail indépendant. Elle vise à soutenir les projets entrepreneuriaux des chômeurs indemnisés. Ces indemnités sont payées en tout ou partie sous forme de versement forfaitaire aux fins de la création d'entreprise. Cette aide peut être combinée avec le crédit garanti et les bonifications d'intérêt d'autres programmes de microfinancement nationaux (à savoir les programmes Microinvest et Invest+).

Problème abordé: les effets de la récession mondiale qui a débuté fin 2007 ont été moins dramatiques au Portugal que dans de nombreux autres pays de l'UE. Le taux de chômage est toutefois passé de 9,5\% en 2009 à 16,4\% au deuxième trimestre 2013. Il atteint actuellement $40 \%$ chez les jeunes, plus gravement touchés que le reste de la population.

Approche: le programme soutient les projets entrepreneuriaux des demandeurs d'emploi indemnisés en anticipant le paiement de ces allocations sous forme de versement forfaitaire, à condition qu'elles garantissent l'emploi à temps plein des demandeurs. Ces derniers doivent être âgés d'au moins 18 ans au moment de la demande. Les candidats ne peuvent pas combiner l'activité subventionnée et une autre activité à but lucratif. Les projets financés dans le cadre de la mesure Apoios peuvent bénéficier gratuitement d'un tutorat ou d'un mentorat au cours des deux premières années d'activité.

Les projets de création d'entreprise doivent être économiquement viables. À ce titre, les candidats doivent soumettre leur plan d'affaires à leur agence locale pour l'emploi. Si, toutefois, un prêt garanti ou une bonification d'intérêt est également sollicité, le projet doit être présenté à l'une des agences ci-dessus ainsi qu'à une des banques participantes aux programmes Microinvest et Invest+.

Impact: aucune évaluation rigoureuse de ce programme n'a été publiée. Entre septembre 2009 et août 2011, cette mesure a permis de créer 6234 emplois. Le microcrédit et les lignes de crédit Microinvest et Invest+ ont quant à elle contribué à créer 2113 emplois pour les primo-demandeurs d'emploi. Pour l'année 2012, on estime le nombre d'emplois créés à 2000 et le budget annuel à 7,8 millions EUR.

Facteurs de réussite: le programme portugais se montre plus généreux que son pendant espagnol. En effet, les versements forfaitaires peuvent atteindre le montant total de l'allocation de chômage à laquelle le bénéficiaire a droit (et non de 60 à $80 \%$ selon les catégories d'âge comme c'est le cas en Espagne).

Les activités de tutorat et de mentorat mises en place gratuitement par Apoios constituent un facteur supplémentaire de réussite potentielle. C'est un aspect essentiel, en particulier chez les jeunes. Selon l'organisation Prince's Youth Business International (2011), la formation et le mentorat compensent, dans une certaine mesure, le manque d'expérience et de garanties qui conduit souvent les banques à limiter leurs crédits à destination des jeunes.

Parmi les autres exemples de ponts sociaux, citons le programme français d'aide aux chômeurs créateurs, qui soutient les demandeurs d'emploi dans la création de leur entreprise en leur versant une somme forfaitaire en guise de capital de départ en lieu en place de leurs indemnités de chômage (Elias et Whitfield, 1987; Meager, 1996; Michaelides et Benus, 2012). La Belgique, le Danemark, la Hongrie, l'Italie, la Pologne et l'Espagne ont également instauré des programmes similaires (Meager, 1996; O’Leary et al., 1998; Cueto et Mato, 2006). 


\section{Encadré 6.4. Programme de transition des NEET vers le travail indépendant, Slovénie}

Description: le programme vise explicitement à réduire le chômage des jeunes. Durant la période de création, une aide au travail indépendant peut être octroyée sous forme de maintien des allocations de chômage à tout demandeur d'emploi inscrit depuis trois moins. Un autre volet du programme concerne les «placements de diplômés», une sorte de soutien ciblé destiné aux jeunes diplômés qui créent une entreprise. Cette mesure permet aux diplômés de moins de 25 ans d'avoir accès au programme d'aide même si leur période de chômage a été relativement courte. Mis en place avant la crise financière de 2008, le programme a vu les demandes et le nombre de candidats augmenter parallèlement à la hausse du chômage entre 2008 et 2010.

Problème abordé: le principal objectif du programme est de faire baisser le chômage en général et celui des jeunes en particulier. La priorité est mise également sur l'aide aux diplômés et aux jeunes chômeurs (NEET) afin qu'ils puissent intégrer le marché de l'emploi par l'intermédiaire du travail indépendant.

Approche: les procédures du programme varient selon les régions et les administrations. Les subventions sont plus importantes dans les régions où les taux de chômage sont plus élevés. Les candidats commencent par rédiger un plan d'affaires à leur agence locale pour l'emploi (une branche de l'Agence slovène pour l'emploi, ZRSZ). Ils doivent ensuite passer un entretien préliminaire au cours duquel leur idée d'entreprise est évaluée, et assister à un atelier de formation au travail indépendant. Ils perçoivent alors une subvention de travailleur indépendant pouvant aller jusqu'à 4500 EUR par personne. Selon la région, les participants peuvent bénéficier de formations complémentaires.

Le budget du programme est financé à 85 \% par le Fonds social européen (FSE). Les $15 \%$ restants proviennent du budget de l'État slovène. En août 2011, le ZRSZ a bénéficié d'une injection de capital de 9,5 millions EUR, qui a permis de financer 2110 nouveaux candidats.

Impact: l'Agence slovène pour l'emploi (ZRSZ) estime que le programme est un succès puisque $85 \%$ des participants ont exploité une entreprise pendant au moins deux ans. Leur nombre a d'ailleurs augmenté chaque année, passant de 417 en 2007 à 4330 en 2009 pour atteindre 5148 en 2010.

Facteurs de réussite: la différenciation du programme de formation selon les régions est probablement un avantage pour les pays confrontés à une situation semblable à celle de la Slovénie où le chômage et les conditions économiques connaissent d'importantes disparités régionales.

Les nombreux mécanismes de subventionnement qui existent dans l'UE offrent suffisamment d'éléments permettant de mettre en lumière leur degré d'efficacité. Le Tableau 6.2 fournit les principaux résultats de l'évaluation des taux de survie des entreprises créées par des chômeurs bénéficiant d'une subvention. Il ressort que les taux de survie et le nombre d'emplois créés pour 100 start-up varient fortement d'une étude à l'autre. Après deux ans, ces taux se situent entre 66 et $85 \%$, soit légèrement en dessous des taux globaux de survie des nouvelles entreprises (Wennberg, 2009; Yang et Aldrich, 2012).

Toutefois, l'analyse des taux de survie ne permet pas à elle seule de juger de l'efficacité de ces programmes. Les coûts de ces derniers doivent être pris en compte, ainsi que les coûts des effets d'aubaine et de déplacement (encadré 6.6). L'estimation des coûts des effets d'aubaine (généralement des mesures autodéclarées du type «'aurais créé une entreprise avec ou sans subvention") varie selon les pays et les caractéristiques du programme. Les effets de déplacement sont rarement analysés dans les évaluations et mériteraient d'être examinées par les responsables politiques. 


\section{Encadré 6.5. Programme Ich-AG, Allemagne}

Description: le programme allemand Ich-AG («Moi-S.A.») visait à soutenir les créations d'entreprise des demandeurs d'emploi indemnisés et des participants d'autres programmes de l'Agence fédérale pour l'emploi. Il fonctionne comme un complément à l'indemnitérelais, moins attractive pour les chômeurs qui perçoivent déjà des aides du gouvernement. En augmentant le niveau des subventions, il rend la création d'entreprise plus favorable.

Problème abordé: issue des propositions de réforme de la commission Hartz, cette initiative visait à lutter contre le chômage en subventionnant le travail indépendant.

Approche: le candidat déposait auprès de l'agence pour l'emploi (Arbeitsagentur) une demande de subvention et un plan d'affaires que des conseillers payés par l'État se chargeaient d'évaluer. Les participants dont la demande était validée recevaient pendant une durée maximale de trois ans une aide financière dégressive (600 EUR la première année, 360 EUR la deuxième et 240 EUR la troisième). Ils bénéficiaient également d'une couverture des régimes de retraite et d'autres régimes d'assurance. En outre, à la différence des autres travailleurs indépendants allemands, les participants avaient l'obligation de cotiser aux systèmes d'assurance et de retraite. Ils bénéficiaient également d'une réduction des cotisations d'assurance-maladie.

Lors de la mise en place du programme en 2003, les participants n'étaient pas tenus de soumettre un plan d'affaires. Cette exigence date de novembre 2004.

En 2004, le programme a reçu 670 millions EUR du budget de la politique active du marché du travail.

Impact: les évaluations montrent que cinq ans après la création de leur entreprise, 50 à $60 \%$ des anciens participants du programme Ich-AG étaient toujours indépendants, que ce soit à temps plein ou à temps partiel.

Facteurs de réussite: le programme prévoit des prestations destinées à promouvoir l'intégration des participants au système de sécurité social allemand.

Tableau 6.2. Évaluation du succès des aides aux start-up

\begin{tabular}{|c|c|c|c|}
\hline Pays & Survie de l'entreprise & Emplois créés pour 100 start-up & Référence \\
\hline Danemark & $76 \%$ après 2 ans & 36 après 2 ans & Meager (1996; 1994) \\
\hline Danemark & $40 \%$ après 1 an & $\mathrm{n} / \mathrm{d}$ & Wilson et Adams (1994) \\
\hline France & $75 \%$ après 2 ans & 97 après 5 ans & Meager (1996; 1994) \\
\hline France & $51 \%$ après 4,5 ans & 45 après 54 mois & Wilson et Adams (1994) \\
\hline Allemagne & $90 \%$ après 1 an & 16 après 1 an & Pfeiffer et Reize (2000) \\
\hline Allemagne & $70 \%$ après 3 ans & $\begin{array}{l}\text { Au moins un salarié pour } 45 \% \\
\text { d'entre elles }\end{array}$ & Wießner (1998) \\
\hline Hongrie & $85,4 \%$ après 1 an & $\begin{array}{l}\text { Au moins un salarié pour } 17,6 \% \\
\text { d'entre elles }\end{array}$ & O'Leary et al. (1998) \\
\hline Pays-Bas & $52 \%$ après 3 ans & $\mathrm{n} / \mathrm{d}$ & Wilson et Adams (1994) \\
\hline Pologne & $84,5 \%$ après 2 ans & $\begin{array}{l}\text { Au moins un salarié pour } 26,7 \% \\
\text { d'entre elles }\end{array}$ & O'Leary et al. (1998) \\
\hline Espagne & $\begin{array}{l}93,1 \% \text { après } 1 \text { an, } 76,2 \% \text { après } \\
4 \text { ans }\end{array}$ & $\mathrm{n} / \mathrm{d}$ & Cueto et Mato (2006) \\
\hline Suède & $65 \%$ après 4 ans & $n / d$ & Carling et Gustafsson (1999) \\
\hline Royaume-Uni & $72 \%$ après 2 ans & $\mathrm{n} / \mathrm{d}$ & Meager et al. (2003) \\
\hline Royaume-Uni & $66 \%$ après 2 ans & 35 après 5 ans & Meager (1996; 1994) \\
\hline Royaume-Uni & $71 \%$ après 7 mois & 27 après 18 mois & Wilson et Adams (1994) \\
\hline
\end{tabular}

Source: Wennberg (2013). 


\section{Encadré 6.6. Coûts liés aux effets d'aubaine et effets de déplacement}

Coûts des effets d'aubaine: mesure dans laquelle les participants auraient créé une nouvelle entreprise en l'absence de subvention. Le comportement de ces "participants d'aubaine» n'est pas influencé par le programme, mais leur participation ne contribue pas à la valeur économique et engendre une dépense publique. Le coût social de cette dépense correspond à la somme du coût de distorsion ou de la charge excédentaire de la taxe qui le finance et des dépenses destinées à couvrir les coûts de mise en œuvre.

Effets de déplacement: mesure dans laquelle les entreprises subventionnées s'emparent de l'activité et des emplois des entreprises établies non subventionnées.

Une autre approche en matière de soutien aux entrepreneurs adoptée dans le contexte d'une création d'entreprise consiste à accorder des exonérations de taxes salariales. Celle-ci s'accompagne souvent d'une aide au démarrage. Par exemple, en France, le programme ACCRE lancé au début des années 1990 prévoyait une aide au démarrage et une exonération de certaines retenues salariales. En 1998, la subvention a été supprimée et l'aide a consisté essentiellement en une exonération des charges sociales pendant un an. (L'ACCRE a depuis fait place à la NACRE (Nouvelle aide à la création d'entreprise), un prêt à taux zéro). Une récente évaluation a montré que les taux de survie à cinq ans des startup ayant bénéficié de ce programme dans sa version de 1998 étaient supérieurs de $17 \%$ à ceux des entreprises non subventionnées. Cette disparité s'explique essentiellement par la procédure rigoureuse de sélection des participants (Cabannes et Fougere, 2012). D'autres évaluations font néanmoins ressortir des résultats moins positifs. Une étude de 2011 a révélé que les chômeurs bénéficiaires présentaient un taux de survie à cinq ans $49,5 \%$, inférieur à celui des sociétés non subventionnées (53,2\%) (Vari-Lavoisier, 2011). Une des explications avancées par les analystes voudrait que les entreprises qui sollicitent des aides soient de moindre qualité que les autres.

\section{Proposer des services d'aide au développement des entreprises}

Des services d'aide au développement des entreprises sont généralement proposés aux nouveaux entrepreneurs dans le cadre des aides dont ils bénéficient. C'est également le cas des chômeurs qui créent leur entreprise. Ces services incluent des formations, un accompagnement individualisé, un mentorat et des conseils en entreprise. L'objectif est d'accroître le niveau de compétences entrepreneuriales des entrepreneurs et augmenter ainsi leurs chances de réussir. Pour une description plus complète des services d'aide au développement des entreprises, nous vous renvoyons au chapitre 8.

Les services d'aide au développement des entreprises font souvent partie des conditions imposées pour bénéficier d'une aide au démarrage ou de certaines allocations. Ce point est illustré dans les encadrés 6.4 et 6.5. Un troisième exemple est proposé à l'encadré 6.7. Celuici concerne le programme New Enterprise Allowance (Allocation de création d'entreprise) du Royaume-Uni. Il illustre la manière dont les aides au développement des entreprises peuvent être combinées à des aides financières. La réussite de cette approche réside dans le fait que les deux types d'aide se renforcent mutuellement: le soutien non financier aide l'entrepreneur à mieux utiliser l'aide financière, et l'aide financière l'aide à mettre en pratique les connaissances acquises en formation ou auprès d'un coach ou d'un mentor. D'autres exemples d'aides publiques incluant des services d'aide au développement des 
entreprises dans le cadre d'une offre intégrée sont présentés dans la partie III de cet ouvrage: «Programme d'aide à la création d'entreprise (UGP, Unternehmensgründungsprogramm)» (Autriche) et "Aide au travail indépendant» (Espagne).

Les services d'aide au développement des entreprises ne sont pas systématiquement intégrés à l'aide financière. En Allemagne, par exemple, la société Innovative Beschäftigungsförderung GmbH G.I.B. a mis en place un service de conseil et de formation en plusieurs étapes afin de préparer les chômeurs à la création d'entreprise, ainsi qu'un suivi post-démarrage (par exemple, sous forme de conseils). Ce programme mis en œuvre de 2004 à 2007 a permis à ses participants d'enregistrer un taux de survie de $85 \%$ après trois ans (May-Strobl, 2010).

\section{Encadré 6.7. New Enterprise Allowance, Royaume-Uni}

Description: le programme New Enterprise Allowance (NEA) s'adresse aux bénéficiaires de l'allocation de demandeur d'emploi (Jobseeker's Allowance, JSA) désireux de créer une entreprise. Les parents célibataires percevant une aide au revenu sont également éligibles. Ce programme s'inscrit dans le cadre des mesures «Get Britain Working" destinées à lutter contre le chômage. Opérationnel durant de nombreuses années, il a rencontré des succès divers selon les caractéristiques spécifiques et la situation économique globale de la période étudiée.

Problème abordé: le programme a été conçu afin d'aider les demandeurs d'emploi à créer des entreprises durables.

Approche: le programme collabore étroitement avec le personnel du Jobcenter Plus, qui supervise le projet et participe à l'identification des candidats potentiels. Les candidats perçoivent une allocation hebdomadaire de 1274 GBP (environ 1490 EUR) pendant 26 semaines: 65 GBP (environ 75 EUR) par semaine les 13 premières semaines et 33 GBP (environ 39 EUR) par semaine les 13 semaines suivantes. En outre, les candidats ont accès à des prêts non garantis leur permettant de couvrir les coûts liés au démarrage de leur activité. Le programme propose également aux participants des formations sous la forme d'ateliers. Il leur permet aussi de faire appel au mentorat d'entreprise durant les six premiers mois de leur activité d'indépendant.

Une fois leur demande d'allocation de demandeur d'emploi validée, les participants peuvent déposer une demande de NEA. Dès qu'ils intègrent le programme, les candidats peuvent se faire aider d'un mentor pour la rédaction de leur plan d'affaires. Si son plan est viable, le participant pourra percevoir l'aide financière sous forme de subventions et de prêt.

Des changements ont été apportés en octobre 2012, donnant la possibilité aux personnes de bénéficier de ces aides et du mentorat dès l'entrée en vigueur de leurs droits à l'allocation de demandeur d'emploi. Auparavant, il leur fallait attendre six mois. Le programme était initialement conçu pour venir en aide à 60000 personnes jusqu'en septembre 2013. Il a été étendu à 70000 demandeurs supplémentaires et prorogé jusqu'en décembre 2014.

Le coût de cette prolongation de ce programme, géré par le gouvernement britannique, se chiffrait à 34 millions GBP (environ 39,8 millions EUR).

Impact: dans l'ensemble, le programme prouve son efficacité dans l'orientation des demandeurs d'emploi vers le travail indépendant, même si les entreprises créées le sont à petite échelle et présentent un potentiel de croissance limité (Ecorys, 2013).

Facteurs de réussite: la principale force du programme réside dans l'association du mentorat et de l'aide financière. 
Rares sont les exemples de services d'aide au développement des entreprises qui ciblent spécifiquement les jeunes (les NEET). Cette catégorie peut profiter des aides destinées aux chômeurs, exception faite des initiatives qui visent les travailleurs plus âgés ou des groupes spécifiques de travailleurs licenciés. L'encadré 6.4 présente un exemple de programme intégré combinant aides financières et non financières (Programme de transition des NEET vers le travail indépendant en Slovénie). Le programme public Junge Leute machen sich selbständig, mis en place dans le Land de Brandebourg en Allemagne, est un autre exemple d'initiative destinée aux NEET. Il aidait les chômeurs de moins de 27 ans en organisant des ateliers et des formations de groupe ainsi que des services de conseil individualisé. L'un des principaux objectifs de l'initiative consistait à soutenir le développement professionnel et individuel. De 2005 à 2007, 685 jeunes ont participé au programme, parmi lesquels 396 ont démarré une entreprise et créé 300 emplois au cours des 24 premiers mois d'exploitation (Schreiber et al., 2009). Après deux ans, seules $26 \%$ des start-up avaient cessé leur activité, soit un taux de survie comparable à ceux observés dans l'ensemble des entreprises (Schreiber et al., 2009).

Malgré leur nombre, peu de services d'aide au développement des entreprises destinés aux chômeurs démarrant une activité ont été évalués de façon rigoureuse. Les initiatives locales telles que les services d'aide publique aux entreprises sont souvent remises en question du fait du manque d'informations permettant de déterminer dans quelle mesure elles faussent la concurrence et nuisent au bon fonctionnement des marchés (p.ex. Bessant, 1999; Huggins et Williams, 2009). Des études récentes suggèrent cependant que les aides publiques au développement des entreprises ont tendance à avoir un impact positif net. Des données britanniques issues du programme Business Link montrent que ce type de soutien a une influence positive sur la croissance de l'emploi dans les sociétés (mais pas sur la croissance des revenus). Une étude quasi-expérimentale a étudié l'efficacité d'un service de "préparation encadrée» des start-up au Danemark et a constaté les effets positifs de ce dernier sur la croissance future des entreprises (Rotger et al., 2012). Cette conclusion semble corroborer l'idée selon laquelle certaines interventions politiques dans les domaines de la formation aux fonctions de direction et du renforcement des compétences peuvent s'avérer bénéfiques pour les start-up (Littunen et Tohmo, 2003). De cela il faut essentiellement retenir que les responsables politiques doivent s'efforcer d'organiser la fourniture de ces services par des acteurs locaux, ceux-ci étant plus à même de faciliter les occasions de perfectionnement des compétences, de conseil et de création de réseaux avec les parties prenantes adéquates (Huggins et Williams, 2009).

\section{Modifier la réglementation en profondeur}

Les profonds changements réglementaires destinés à améliorer les conditions d'entrepreneuriat devraient accroître les taux de création d'entreprises, d'une part, et leurs taux de survie et de croissance, d'autre part. Les répercussions sur l'emploi et sur les recettes fiscales seront positives. Même en période de stagnation économique, les décideurs politiques doivent envisager des changements de la réglementation et des programmes plus personnalisés. Ces changements réglementaires profonds destinés à améliorer les conditions générales d'entrepreneuriat auront un impact plus durable que les programmes d'entrepreneuriat ciblés, avec des coûts de déplacement moindres (Henrekson et Johansson, 2008). S'agissant des chômeurs, les systèmes de sécurité sociale constituent l'instrument réglementaire global le plus pertinent à la disposition des responsables politiques. Ces questions sont abordées dans le détail au chapitre 9.

\section{Conclusions et recommandations politiques}

Le soutien de la transition du chômage vers le travail indépendant vise à offrir aux demandeurs d'emploi un autre choix que le salariat. Il contribue à la croissance économique et à la création d'emplois, mais son impact est encore plus grand pour les personnes qui trouvent là une possibilité de gagner leur vie, d'être actif et de participer à la société, et 
voient le risque de pauvreté s'éloigner. Cette perspective est particulièrement importante pour les jeunes dont la trajectoire professionnelle et le parcours de vie peuvent être abîmés par ces périodes de chômage. L'absence d'aide aux catégories telles que les NEET représente un coût d'opportunité extraordinairement élevé. En 2011, le coût économique direct des NEET pour l'économie de l'UE était estimé à 153 milliards EUR (Eurofound, 2013). L'expérience renforçant la productivité, on peut s'attendre à ce que ce coût augmente avec l'âge, sans compter les coûts sociaux.

En général, les chômeurs qui se lancent dans une activité indépendante connaissent une croissance et un taux de survie inférieurs à ceux des salariés qui se mettent à leur compte (Wennberg et Delmar, 2010). La création d'un emploi indépendant durable n'est cependant pas nécessairement le but à atteindre lorsque l'on donne la possibilité à des personnes de démarrer une entreprise. Certaines d'entre elles peuvent d'ailleurs retrouver un emploi salarié. Ce qui doit également être considéré comme une réussite. Peu de données attestent que de nombreuses personnes quittent leur activité indépendante pour devenir salariés. Des données de Finlande indiquent que 39\% des indépendants retournent à un emploi salarié (Johansson, 2000). Même constat au Royaume-Uni où, selon les chiffres, $48 \%$ des indépendants et $36 \%$ des indépendantes font de même (Taylor, 1999). Le travail indépendant pourrait ainsi jouer le rôle de passerelle vers le salariat, même si certaines données laissent penser que ce n'est pas nécessairement vrai chez les jeunes (Meager et al., 2003).

Dans l'ensemble, les données collectées indiquent que des programmes bien ciblés proposant à un large choix de formations peuvent améliorer les résultats des personnes ciblées sur le marché de travail. Elles suggèrent également que des incitations financières bien conçues peuvent aussi générer des emplois à moindre coût (Kluve et Schmidt, 2002). En outre, ces programmes ont tendance à être particulièrement efficaces dans un contexte de récession économique (Carling et Gustafson, 1999). À titre de comparaison, les aides à la création d'entreprise semblent plus rentables que les autres mesures de soutien en faveur des chômeurs (Baumgartner et Caliendo, 2008).

Les effets d'aubaine et de déplacement constituent un indicateur clé de l'efficacité des programmes politiques d'aide à la création d'entreprise en faveur des demandeurs d'emploi. Les évaluations des différents programmes ont fait ressortir des estimations des effets d'aubaine très variables selon les pays et les caractéristiques desdits programme. Par exemple, les coûts des effets d'aubaine sont souvent estimés entre $20 \%$ et $70 \%$ (Falkenhall et al., 2003; Meager et al., 2003). Si l'on en croit ces chiffres, les coûts pourraient être considérables. Les évaluations politiques ne peuvent dès lors pas simplement considérer le nombre de sociétés créées pour évaluer le succès d'un programme. Toutefois, les coûts des effets d'aubaine générés par le soutien à l'entrepreneuriat ne sont pas plus élevés que ceux des autres politiques actives du marché du travail. Ils sont même nettement inférieurs à ceux des mesures de création d'emplois directs, dans la fonction publique par exemple (Carling et Gustafson, 1999). Bien qu'ils soient rarement analysés lors des évaluations, les effets de déplacement doivent être pris en compte, en particulier s'agissant de programmes de grande ampleur et/ou de programmes maintenus en période de faible chômage (Meager et al., 2003).

Ces conclusions nous permettent de formuler les recommandations politiques suivantes:

\section{Principales recommandations politiques}

- Octroyer une indemnité ou maintenir le versement des allocations de chômage pendant une durée déterminée afin de soutenir les chômeurs durant les premières phases de développement de leur entreprise. 
- Adapter les aides aux besoins de catégories de chômeurs spécifiques (p.ex. les femmes, les jeunes, les seniors, les salariés récemment licenciés).

- Fournir des aides financières et non financières complémentaires dans le cadre d'offres intégrées afin d'exploiter au maximum la complémentarité entre soutien financier et développement des compétences entrepreneuriales.

- Impliquer les partenaires locaux dans les programmes d'aide à la création d'entreprise destinés aux chômeurs pour (i) mieux faire connaître ces aides avec l'aide des agences pour l'emploi, des chambres de commerce et des autres acteurs de la société civile (p.ex. communauté des entreprises, établissements de microcrédit), et (ii) exploiter leurs connaissances et leurs réseaux.

- Aligner les programmes d'aide à la création d'entreprise sur les régimes sociaux et fiscaux de façon à ce que les différentes approches politiques soient complémentaires et non concurrentes.

- Réaliser plus souvent des évaluations pour mesurer l'impact de ces programmes d'aide aux start-up sur le chômage, y compris sur les effets d'aubaine et de déplacement, pour développer une base de connaissances plus solide qui pourra faciliter l'élaboration des politiques à travers l'UE. 


\section{ANNEXE 6 A1}

\section{Actions politiques en faveur de l'entrepreneuriat des chômeurs}

\begin{tabular}{ll}
\hline \multicolumn{1}{c}{ Type d'action politique } & Objectifs et motivation \\
\hline $\begin{array}{l}\text { Sensibiliser davantage } \\
\text { aux possibilités offertes } \\
\text { par l'entrepreneuriat } \\
\text { comme moyen de créer } \\
\text { son propre emploi. }\end{array}$ & $\begin{array}{l}\text { Atténuer les } \\
\text { l'entraves perçues à }\end{array}$ \\
& $\begin{array}{l}\text { que choix de carrière } \\
\text { potentiel. }\end{array}$ \\
$\begin{array}{ll}\text { Faciliter l'acquisition } \\
\text { de compétences } \\
\text { entrepreneuriales }\end{array}$ & $\begin{array}{l}\text { Renforcer le capital } \\
\text { humain propre à } \\
\text { l'entrepreneuriat pour les } \\
\text { catégories de population } \\
\text { présentes sur le marché } \\
\text { du travail, en particulier } \\
\text { les jeunes. }\end{array}$ \\
\hline
\end{tabular}

Donner ou faciliter l'accès des start-up aux financements.

\begin{abstract}
Fournir des services d'aide au développement des entreprises après le démarrage de l'activité (p.ex. accompagnement individualisé et mentorat).

Renforcer le capital
social et humain propre
à l'entrepreneuriat des
entrepreneurs naissants,
en particulier ceux qui
débutent.
\end{abstract}

Résoudre la question du manque de liquidités des indépendants.
Résoudre le problème du faible revenu des ventes durant la phase de démarrage, qui oblige les entrepreneurs à vivre de leur épargne.

Actions éducatives,
programmes de
sensibilisation du
public, formation des
fonctionnaires.

Éducation et formation à l'entrepreneuriat.

Stages dans des start-up, par exemple sous la forme d'emplois subventionnés dans de jeunes/petites entreprises.

Aides au démarrage, garanties pour des prêts bancaires, prêts bancaires spécialisés (microprêts).

Aides au démarrage d'activité, allègements fiscaux pour les indépendants, possibilité de reporter le paiement des impôts à une date ultérieure ou une période plus rentable.

Conseils/ accompagnement individualisé par les services publics.

Enseignement par les pairs (pépinières d'entreprises, accélérateurs, groupements de start-up).
Augmentation du taux de Taux de réussite variables création d'entreprise chez (voir Tableau 6.2), mais les chômeurs et du taux avec effets d'aubaine. de survie des sociétés Coûts de déplacement (impact brut), recrutement rarement examinés. potentiel de salariés (impact net).

Augmentation du taux

D'après les évaluations, de survie des sociétés les programmes d'aide créées par des chômeurs qui garantissent un (impact brut), recrutement revenu pendant durée potentiel de salariés (impact net). déterminée sont plus efficaces que d'autres initiatives de formation professionnelle (Carling Gustafson, 1999).

Augmentation des taux de Une étude sur les création d'entreprise chez programmes danois les groupes ciblés. d'aide publique confirme Augmentation des taux de l'efficacité de la survie et de croissance "préparation encadrée» des entreprises des dans le démarrage groupes ciblés. et la croissance des indépendants (Rotger et al., 2012).
Facteurs à prendre compte dans l'élaboration et la mise en œuvre des actions politiques

Adopter une «attitude positive» ne signifie pas pour autant qu'on le devienne réellement indépendant. Par ailleurs, les comportements positifs n'ont aucune influence sur les compétences et/ou la capacité à créer une entreprise prospère. II existe plutôt un risque d'ingénierie sociale. Si le but est de renforcer l'esprit d'entreprise à court terme, l'accent doit être mis sur l'éducation à l'entrepreneuriat qui vise à améliorer les compétences cognitives. En revanche, si le but est d'améliorer les connaissances professionnelles à long terme, ce sont les compétences non cognitives doivent primer.

Les effets d'aubaine et de déplacement doivent être pris en compte pour déterminer l'efficacité des programmes politiques. Les programmes doivent tenir compte des aspects régionaux et de leurs complémentarités éventuelles avec les programmes de formation.

Il convient de s'interroger sur (i) les coûts de déplacement potentiels et/ou les effets négatifs du marché sur les start-up non subventionnées si l'aide au revenu est trop longue ou trop généreuse, et (ii) l'éviction potentielle d'autres activités de formation professionnelle.

Des programmes de bonnes pratiques doivent être validés et reproduits.

La pertinence de ces programmes dépend à la fois du groupe bénéficiaire (p.ex. compétences/motivation des participants) et du groupe prestataire (p.ex. compétences/motivation des coaches).

Les programmes doivent être élaborés avec des groupes de comparaison et des données collectées pour pouvoir être évalués. 


\begin{tabular}{|c|c|c|c|c|c|}
\hline Type d'action politique & Objectifs et motivation & Principales méthodes & Effets escomptés & Effets produits & $\begin{array}{l}\text { Facteurs à prendre compte dans } \\
\text { l'élaboration et la mise en œuvre des } \\
\text { actions politiques }\end{array}$ \\
\hline $\begin{array}{l}\text { Autres changements } \\
\text { réglementaires } \\
\text { importants qui } \\
\text { favorisent et soutiennent } \\
\text { l'entrepreneuriat des } \\
\text { chômeurs. }\end{array}$ & $\begin{array}{l}\text { Ces changements } \\
\text { profonds visent } \\
\text { à améliorer les } \\
\text { conditions générales de } \\
\text { l'entrepreneuriat. Des } \\
\text { changements de cette } \\
\text { ampleur auront un impact } \\
\text { plus durable et des coûts } \\
\text { de déplacement moindres } \\
\text { que les programmes } \\
\text { d'entrepreneuriat ciblés } \\
\text { en faveur des chômeurs. }\end{array}$ & $\begin{array}{l}\text { Changements } \\
\text { institutionnels majeurs } \\
\text { comme la réduction des } \\
\text { allocations de chômage } \\
\text { (effets d'entraînement) ou } \\
\text { la diminution des coûts } \\
\text { de création d'entreprise } \\
\text { (effets d'attraction). }\end{array}$ & $\begin{array}{l}\text { Les changements } \\
\text { réglementaires destinés } \\
\text { à améliorer les conditions } \\
\text { de l'entrepreneuriat } \\
\text { doivent permettre } \\
\text { d'augmenter les taux } \\
\text { de création, de survie } \\
\text { et de croissance des } \\
\text { entreprises. Cela doit } \\
\text { avoir des répercussions } \\
\text { positives sur l'emploi et } \\
\text { les recettes fiscales. }\end{array}$ & $\begin{array}{l}\text { Les effets positifs } \\
\text { engendrés par } \\
\text { l'amélioration des } \\
\text { conditions générales } \\
\text { de l'entrepreneuriat } \\
\text { sont bien connus, } \\
\text { surtout les facteurs } \\
\text { tels que la réduction } \\
\text { des taux d'imposition } \\
\text { des entrepreneurs, la } \\
\text { réduction des coûts } \\
\text { administratifs et la } \\
\text { réglementation. }\end{array}$ & $\begin{array}{l}\text { D'une manière générale, les effets } \\
\text { d'entraînement comme la réduction } \\
\text { des allocations de chômages ont } \\
\text { prouvé qu'ils n'engendraient pas } \\
\text { de travail indépendant durable. } \\
\text { C'est pourquoi il est recommandé } \\
\text { d'abaisser les coûts de création } \\
\text { d'entreprise et les autres charges } \\
\text { administratives. }\end{array}$ \\
\hline
\end{tabular}

Source: Adapté de Wennberg (2013).

\section{Références}

Baker, T. and R. Nelson (2005), "Creating something from nothing: Resource construction through entrepreneurial bricolage», Administrative Science Quarterly, vol. 50(3), p. 329-366.

Batjargal, B. (2003), «Social Capital and Entrepreneurial Performance in Russia: A Longitudinal Study», Organization Studies, vol. 24(4), p. 535-556.

Battistin, E., Gavosto, A. et Rettore, E. (2001), «Why do subsidised firms survive longer? An evaluation of a programme promoting youth entrepreneurship in Italy», ZEW Economic Studies, vol. 13, p. 153181.

Baumgartner, H. et M. Caliendo (2008), «Turning Unemployment into Self Employment Effectiveness of Two Start Up Programmes», Oxford Bulletin of Economics and Statistics, vol. 70(3), p. 347-373.

Bessant, J. (1999), «The rise and fall of 'supernet': a case study of technology transfer policy for smaller firms", Research Policy, vol. 28(6), p. 601-614.

Blanchflower, D. (2000), «Self-employment in OECD countries», Labour Economics, vol. 7(5), p. 471-505.

Bourdieu, P. et L. Wacquant (1992), An invitation to reflexive sociology, University of Chicago Press.

Cabannes, P.-Y. et Fougere, D. (2012), «Une évaluation de l'effet de l'ACCRE sur la durée de vie des entreprises», Rapport pour la chaire «Sécurisation des parcours professionnels», Paris.

Caliendo, M. et Künn, S. (2011), «Start-up subsidies for the unemployed: Long-term evidence and effect heterogeneity", Journal of Public Economics, vol. 95(3), p. 311-331.

Caliendo, M. et Steiner, V. (2007), The Monetary Efficiency of Start-Up Subsidies in Germany, Mimeo, Bonn/ Berlin.

Caliendo, M., Künn, S. et Wießner, F. (2010), «Die Nachhaltigkeit von geförderten Existenzgründungen aus Arbeitslosigkeit: Eine Bilanz nach fünf Jahren», Zeitschrift für Arbeitsmarktforschung, vol. 42, p. 269-291.

Caliendo, M., Künn, S. et Wießner, F. (2009), «Ich-AG und Überbrückungsgeld, Erfolgsgeschichte mit zu frühem Ende» dans IAB-Kurzbericht, 3/2009.

Caliendo, M., Hogenacker, J., Künn, S. et Wießner, F. (2011), «Alte Idee, neues Programm. Der Gründungszuschuss als Nachfolger von Überbrückungsgeld und Ich-AG», dans IAB (ed.), Discussion Paper, $n^{\circ} 24$, Nuremberg.

Carling, K. et Gustafson, L. (1999), "Self-employment grants vs. subsidized employment: Is there a difference in the re-unemployment risk?», IFAU: Swedish Institute for Market Policy Evaluation.

Carling, K. et Richardson, K. (2004), «The relative efficiency of labor market programmes: Swedish experience from the 1990s", Labour Economics, vol. 11(3), p. 335-354.

Cooke, P., Clifton, N. et Oleaga, M. (2005), «Social capital, firm embeddedness and regional development», Regional Studies, vol. 39(8), p. 1065-1077. 
Crépon, B. et E. Duguet (2002), «Prêt bancaire, aides publiques et survie des nouvelles entreprises: une analyse économétrique à partir des méthodes d'appariement sur données d'entrepreneurs", Cahiers de la MSE, université de Paris 1 Panthéon Sorbonne.

Cueto, B. et Mato, J. (2006), «An Analysis of Self-Employment Subsidies with Duration Models», Applied Economics, vol. 38(1) p. 23-32.

Dahl, M. et Sorenson, O. (2012), «Home Sweet Home: Entrepreneurs' Location Choices and the Performance of Their Ventures», Management Science, vol. 58(6), p. 1059-1071.

Davidsson, P. et B. Honig (2003), «The role of social and human capital among nascent entrepreneurs», Journal of Business Venturing, vol. 18(3), p. 301-331.

Désiage, L., R. Duhautois et D. Redor (2011), «Aider les chômeurs créateurs d'entreprise rend-il leur projet plus viable», Connaissance de l'emploi, 4 pages du CEE, mai, $\mathrm{n}^{\circ} 80$.

Dunn, T. et Holtz-Eakin, D. (2000), «Financial capital, human capital, and the transition to selfemployment: Evidence from intergenerational links", Journal of Labor Economics, vol. 18(2), p. 285-305.

Dupuy, R. et Mègemont, L.-L. (2007), «Accomplissement d'un projet de création d'entreprise en situation de formation. Conduites de personnalisation vs. individualisation», Psychologie du Travail et des Organisations, vol. 13(3). p. 21-45.

Ecorys (2013), « New Enterprise Allowance: Qualitative evaluation», Research Report n 836, réalisé sous l'égide du ministère du travail et des retraites, disponible sur: https:/www.gov.uk/government/ uploads/system/uploads/attachment_data/file/207518/rrep836.pdf.

Elias, P. et Whitfield, K. (1987), «The economic impact of the enterprise allowance scheme: Theory and measurement of displacement effects", rapport au minstère britannique de l'emploi, Coventry: Institute for Employment Research, University of Warwick (octobre).

Eurofound (2013), «NEETs Young people not in employment, education or training: Characteristics, costs and policy responses in Europe", disponible sur: http://www.eurofound.europa.eu/pubdocs/2012/54/ en/1/EF1254EN.pdf.

Commission européenne - OCDE (2014), «Accès au financement pour la création d'entreprise dans le cadre de l'entrepreneuriat inclusif», UE: Luxembourg.

Fairlie, R. (2005), «Entrepreneurship and Earnings among Young Adults from Disadvantaged Families», Small Business Economics, vol. 25(3), p. 223-236.

Fairlie, R. et Krashinsky, H. A. (2012), «Liquidity constraints, household wealth, and entrepreneurship revisited", Review of Income and Wealth, vol. 58(2), p. 279-306.

Falkenhall, B., Johansson, M. et Olofsson, J. (2003), «Utvärdering av de näringspolitiska effekterna av stöd till start av näringsverksamhet. (Evaluation of start-up subsidies as a strategy for enterprise promotion.)", Östersund: ITPS — Institutet för tillväxtpolitiska studier.

Gawlitta, L., Kay, R. et Boerger, S. (2010), «Die Opportunitätskosten der sozialen Absicherung beim Wechsel aus dem Arbeitslosengeld I in die Selbständigkeit», dans Institut für Mittelstandsforschung (ed.), IfM Materialien, $\mathrm{n}^{\circ} 197$.

Gregg, P. (2001), «The Impact of Youth Unemployment on Adult Unemployment in the NCDS», Economic Journal, vol. 111(475), pp. F623-F653.

Gregg, P. et Tominey, E. (2005) «The wage scar from male youth unemployment», Labour Economics, vol. 12, p. 487-509.

Grichnik, D., Brinckmann, J., Singh, L. et Manigart, S. (2014), «Beyond environmental scarcity: Human and social capital as driving forces of bootstrapping activities», Journal of Business Venturing, vol. 29(2), p. 310-326, http://dx.doi.org/10.1016/j.jbusvent.2013.02.006

Henrekson, M. (2005), «Entrepreneurship: a weak link in the welfare state?», Industrial and Corporate Change, vol. 14(3), p. 437-467.

Henrekson, M. et D. Johansson (2008), «Competencies and Institutions Fostering High-Growth Firms», Foundations and Trends ${ }^{\circ}$ in Entrepreneurship, vol. 5(1), p. 1-80.

Hite, J. (2005), «Evolutionary processes and paths of relationally embedded network ties in emerging entrepreneurial firms», Entrepreneurship Theory and Practice, vol. 29(1), p. 113-144.

Honig, B. (1998), «What determines success? Examining the human, financial, and social capital of Jamaican microentrepreneurs», Journal of Business Venturing, vol. 13(5), p. 371-394. 
Huggins, R. et N. Williams (2009), «Enterprise and public policy: a review of Labor government intervention in the United Kingdom», Environment and Planning C: Government and Policy, vol. 27(1), p. 19-41.

INSEE (2012), «Créations et créateurs d'entreprises - Première interrogation 2010, profil du créateur», INSEE Résultats, $n^{\circ} 58$, février.

Iyigun, M. et Owen, A. (1998), «Risk, entrepreneurship and human capital accumulation», American Economic Review, vol. 88, p. 454-457.

Johansson, E. (2000), «Self-employment and Liquidity Constraints: Evidence from Finland», Scandinavian Journal of Economics, vol. 102(1), p. 123-134.

Jonsson, S. et Lindbergh, J. (2011), «The Development of Social Capital and Financing of Entrepreneurial Firms: From Financial Bootstrapping to Bank Funding», Entrepreneurship Theory and Practice, vol. 37 (4), p. 661-686.

Kim, P., Longest, K. et Aldrich, H. (2013), «Can You Lend Me a Hand? Task-Role Alignment of Social Support for Aspiring Business Owners», Work and Occupations, vol. 40(3), p. 213-249.

Kluve, J. et Schmidt, C. (2002), "Can training and employment subsidies combat European unemployment?», Economic Policy, vol. 35, p. 409-448.

Krueger, N. (2003), «The cognitive psychology of entrepreneurship», dans Acs, Z. et Audretsch, D. (eds.), Handbook of entrepreneurship research: An interdisciplinary survey and introduction (p. 105-140). New York: Springer.

Kwon, S-W., Heflin, C. et Ruef, M. (2013), «Community Social Capital and Entrepreneurship», American Sociological Review (prochainement).

Le, A. (1999), «Empirical Studies of Self-Employment», Journal of Economic Surveys, vol. 13(4), p. 381-416.

Littunen, H. et Tohmo, T. (2003), «The high growth in new metal-based manufacturing and business service firms in Finland», Small Business Economics, vol. 21 (2), p. 187-200.

Ljungqvist, L. et Sargent, T. (1998), «The European unemployment dilemma», Journal of Political Economy, vol. 106(3), p. 514-550.

May-Strobl, E. (2010), «Nachhaltigkeit und Erfolg von Gründungen aus der Arbeitslosigkeit. Ergebnisse einer Nachbefragung bei aus den Gründungs- und Begleitzirkeln der G.I.B. hervorgegangenen Gründungen», dans Institut für Mittelstandsforschung (ed.), IfM Materialien, n 196, Bonn.

Meager, N. (1994), «Self-employment schemes for the unemployed in the European Community: the emergence of a new institution and its evaluation", dans Schnid G. (ed.) Labor Market Institutions in Europe, New York: M. E. Sharpe.

Meager, N. (1996), «From Unemployment to Self-employment: Labour Market Policies for Business Start-up", dans Schmidt, G., O’Reilly, J. et Schömann, K. (eds.), International Handbook of Labour Market Policy and Evaluation, (p. 489-519). Cheltenham: Edward Elgar.

Meager, N., Bates, P. et Cowling, M. (2003), «An evaluation of business start-up support for young people», National Institute Economic Review, vol. 186(1), p. 59-72.

Michaelides, M. et Benus, J. (2012), «Are self-employment training programmes effective? Evidence from Project GATE», Labour Economics, vol. 19(5), p. 695-705.

Moberg, K. (2013), "What effects do we want entrepreneurship education to have?», Working paper, Copenhagen Business School.

Nanda, R. et Sørensen, J. (2010), «Workplace Peers and Entrepreneurship», Management Science, vol. 56(7), p. 1116-1126.

Nykvist, J. (2008), «Entrepreneurship and Liquidity Constraints: Evidence from Sweden», The Scandinavian Journal of Economics, vol. 110(1), p. 23-43.

OCDE/Commission européenne (2013), «Pallier la pénurie d'entrepreneurs: Politiques d'entrepreneuriat inclusif en Europe», Publication OCDE, Paris http://dx.doi.org/10.1787/9789264188211-fr.

O'Leary, C., Kolodziejcyk, P. et Lazar, G. (1998), «The Net Impact of Active Labor Programmes in Hungary and Poland", International Labor Review, vol. 137(3), p. 321-346.

Otani, K. (1996), «A human capital approach to entrepreneurial capacity», Economica, vol. 63(250), p. 273-289. 
Parker, S. et Belghitar, Y. (2006), «What Happens to Nascent Entrepreneurs? An Econometric Analysis of the PSED», Small Business Economics, vol. 27, No. 1, p. 81-101. DOI: 10.1007/s11187-006-9003-4

Pfeiffer, F. et Reize, F. (2000), «Business start-ups by the unemployed - an econometric analysis based on firm data", Labour Economics, vol. 7, p. 629-663.

Prince's Youth Business International (2011), «Global Youth Entrepreneurship Survey 2011», disponible sur: http://www.youthbusiness.org/wp-content/uploads/2012/08/YouthEntrepreneurshipSurvey2011.pdf.

Ram, M., Theodorakopoulos, N. et Jones, T. (2008), «Forms of capital, mixed embeddedness and Somali enterprise», Work, Employment and Society, vol. 22(3), p. 427-446.

Ritsilä, J. et Tervo, H. (2002), «Effects of Unemployment on New Firm Formation: Micro-Level Panel Data Evidence from Finland», Small Business Economics, vol. 19(1), p. 31-40.

Rodgers, W. (1991), «How do loan officers make their decisions about credit risks? A study of parallel distributed processing», Journal of Economic Psychology, vol. 12(2), p. 243-265.

Rodriguez-Planas, N. et Benus, J. (2007), «Evaluating active labor market programmes in Romania», IZA Discussion Paper Series, IZA DP n² 2464, disponible sur: http://ftp.iza.org/dp2464.pdf.

Rosendahl Huber, L., Sloof, R. et van Praag, M. (2012), «The effect of early entrepreneurship education: Evidence from a randomized field experiment", disponible sur: http://papers.ssrn.com/sol3/papers. cfm?abstract_id=2044735.

Rotger, G., Gørtz, M. et Storey, D. (2012), «Assessing the effectiveness of guided preparation for new venture creation and performance: Theory and practice», Journal of Business Venturing, vol. 27(4), p. 506-521.

Schreiber, K., Lohr, B., Zwick, M. ET Bartel, T. (2009), Evaluation des Förderprogramms «Junge Leute machen sich selbstständig", Isoplan-Marktforschung und GiW Gesellschaft für Infrastrukturund Wirtschaftsentwicklung $\mathrm{mbH}$, Saarbrücken und Potsdam.

Stam, W., Arzlanian, S. et Elfring, T. (2014), «Social capital of entrepreneurs and small firm performance: A meta-analysis of contextual and methodological moderators», Journal of Business Venturing, vol. 29(1), p. 152-173.

Taylor, M. (1996), «Earnings, independence or unemployment: Why become self-employed?», Oxford Bulletin of Economics and Statistics, vol. 58, p. 253-265.

Taylor, M. (1999), «Survival of the fittest: An analysis of self-employment duration in Britain», The Economic Journal, vol. 109 - mars), p. 140-155.

Taylor, M. (2001), «Self-employment and windfall gains in Britain: Evidence from panel data», Economica, vol. 68, pp. 539-565.

Unger, J., Rauch, A., Frese, M. et Rosenbusch, N. (2011), «Human capital and entrepreneurial success: A meta-analytical review», Journal of Business Venturing, vol. 26(3), p. 341-358.

Vari-Lavoisier,I. (2011), «Heurs et malheurs des chômeurs créateurs d'entreprises: De la complémentarité entre ethnographie et économétrie», Terrains \& travaux, vol. 2(19), p. 121-139.

Wennberg, K. (2013), «Entrepreneurship from unemployment: A review of active labour market programmes and policy recommendations», préparé dans le cadre du programme LEED de l'OCDE.

Wennberg, K. (2009), Entrepreneurship Exit, Stockholm: Economic Research Institute.

Wennberg, K. et Delmar, F. (2010), Knowledge Intensive Entrepreneurship: The Birth, Growth, and Demise of Entrepreneurial Firms in the Knowledge Intensive Economy. Cheltenham: Edward Elgar.

Werner, A., Faulenbach, N. et Brockmeyer, A. (2008), «Das Gründungsverhalten Älterer: Eine empirische Analyse mit Daten des Gründerpanels des IfM Bonn», dans Institut für Mittelstandsforschung (ed.), IfM-Materialien, $\mathrm{n}^{\circ} 184$.

Wießner, F. (1998), «The Bridging Allowance as an Instrument of Labour Market Policy: A Provisional Appraisal», Institut für Arbeitsmarkt- und Berufsforschung der Bundesanstalt für Arbeit.

Wilson, S. et Adams, A. (1994), Self-employment for the unemployed: Experience in OECD and transitional Économies, Banque mondiale.

Yang, T. et Aldrich, H. (2012), "Out of sight but not out of mind: Why failure to account for left truncation biases research on failure rates», Journal of Business Venturing, vol. 27(4), p. 477-492. 



\section{Chapitre 7}

\section{Soutien politique en faveur de l'entrepreneuriat des minorités ethniques ${ }^{1,2}$}

Dans de nombreux pays de l'UE, les minorités ethniques sont très actives dans le domaine de l'entrepreneuriat. Ce chapitre s'intéresse au volume d'activités entrepreneuriales des minorités ethniques ainsi qu'à quelques-unes des principales caractéristiques de ces entreprises. Y sont également décrits les freins majeurs à la création d'entreprise par des entrepreneurs potentiels issus de ces minorités et les initiatives que les responsables politiques doivent prendre pour les aider à les surmonter. À cet égard, des pratiques instructives de toute l'UE sont présentées en guise d'illustration.

1. Note de la Turquie:

Les informations figurant dans ce document et faisant référence à "Chypre» concernent la partie méridionale de l'île. Il n'y a pas d'autorité unique représentant à la fois les Chypriotes turcs et grecs sur l'île. La Turquie reconnaît la République turque de Chypre du Nord (RTCN). Tant qu'une solution durable et équitable n'aura pas été trouvée dans le cadre des Nations unies, la Turquie maintiendra sa position sur la "question chypriote».

2. Note de tous les États de l'Union européenne membres de l'OCDE et de l'Union européenne:

La République de Chypre est reconnue par tous les membres des Nations unies sauf la Turquie. Les informations figurant dans ce document concernent la zone sous le contrôle effectif du gouvernement de la République de Chypre. 


\section{Potentiel de création d'entreprise et de travail indépendant chez les minorités ethniques}

- Les entrepreneurs issus des minorités ethniques ou d'origine immigrée forment un groupe diversifié, avec des différences très marquées selon l'origine ethnique, le sexe et la durée d'installation dans le pays d'accueil (immigrants récemment arrivés, de première génération, de deuxième génération, etc.).

- Le taux de travail indépendant des personnes d'origine étrangère est plus élevé que celui de la population autochtone dans neuf États membres de l'UE, soulignant ainsi le potentiel entrepreneurial de ce groupe.

- Il existe peu de données sur les taux de survie des entreprises gérées par des personnes nées à l'étranger. Certaines données de France indiquent cependant que leurs taux sont inférieurs à ceux des entreprises exploitées par des autochtones.

L'entrepreneuriat des minorités ethniques désigne les activités de création d'entreprise et de travail indépendant exercées par des personnes appartenant à une minorité ethnique et par celles qui sont nées dans un autre pays que celui dans lequel elles résident. De toute évidence, ce groupe n'est pas homogène en raison des différences d'origine ethnique, de sexe et d'arrivée sur le territoire (arrivée récente, immigrants de première ou deuxième génération) (Pécoud, 2012). Cette notion varie également selon le contexte, les villes, les régions et les pays (Rath et al., 2011).

\section{Taux de travail indépendant}

Pour diverses raisons, il est difficile de mesurer avec précision et de façon comparable l'ampleur et la portée des activités d'indépendant des minorités ethniques dans les différents États membres de l'UE. Premièrement, les enquêtes nationales sur les forces de travail ne contiennent aucune question sur l'origine ethnique. Deuxièmement, l'identification d'un individu par lui-même comme appartenant à une minorité ethnique dépend de sa propre perception et du contexte. Malgré leur appartenance à une minorité ethnique, certains individus peuvent considérer qu'ils n'en font pas partie et dès lors ne pas s'identifier comme tels. Troisièmement, une minorité ethnique d'une ville ou d'une région ne constitue pas nécessairement un groupe minoritaire dan le reste du pays.

Pour se rapprocher des taux de travail indépendant des minorités ethniques, il convient d'analyser un segment de population plus restreint, à savoir les personnes allochtones. À des fins statistiques, cette notion est plus facile à définir. Il convient néanmoins de souligner que, du point de vue conceptuel, population allochtone et minorité ethnique sont deux notions différentes. En effet, les personnes issues de minorités ethniques peuvent être nées dans le pays et, à l'inverse, celles n'appartenant pas à une minorité ethnique peuvent être nées à l'étranger. En outre, le profil des allochtones varie d'un État membre à l'autre. En 2012, à l'échelle de l'UE, 63,3\% des travailleurs indépendants étrangers étaient nés en dehors de l'UE (Graphique 7.1). En 2012, c'est le Luxembourg qui comptait le moins d'étrangers. C'est en Slovénie et en Croatie qu'ils étaient les plus nombreux (respectivement $87,2 \%$ et $88,9 \%$ ). Autre aspect important, la population née en dehors de 
l'UE varie sensiblement d'un pays d'un à l'autre. Elle est le reflet du passé historique, de la situation macroéconomique, des conditions du marché du travail, des lois en matière d'immigration et des politiques sociales du pays.

\section{Graphique 7.1. Proportion des travailleurs indépendants nés en dehors de l'UE, 2012}

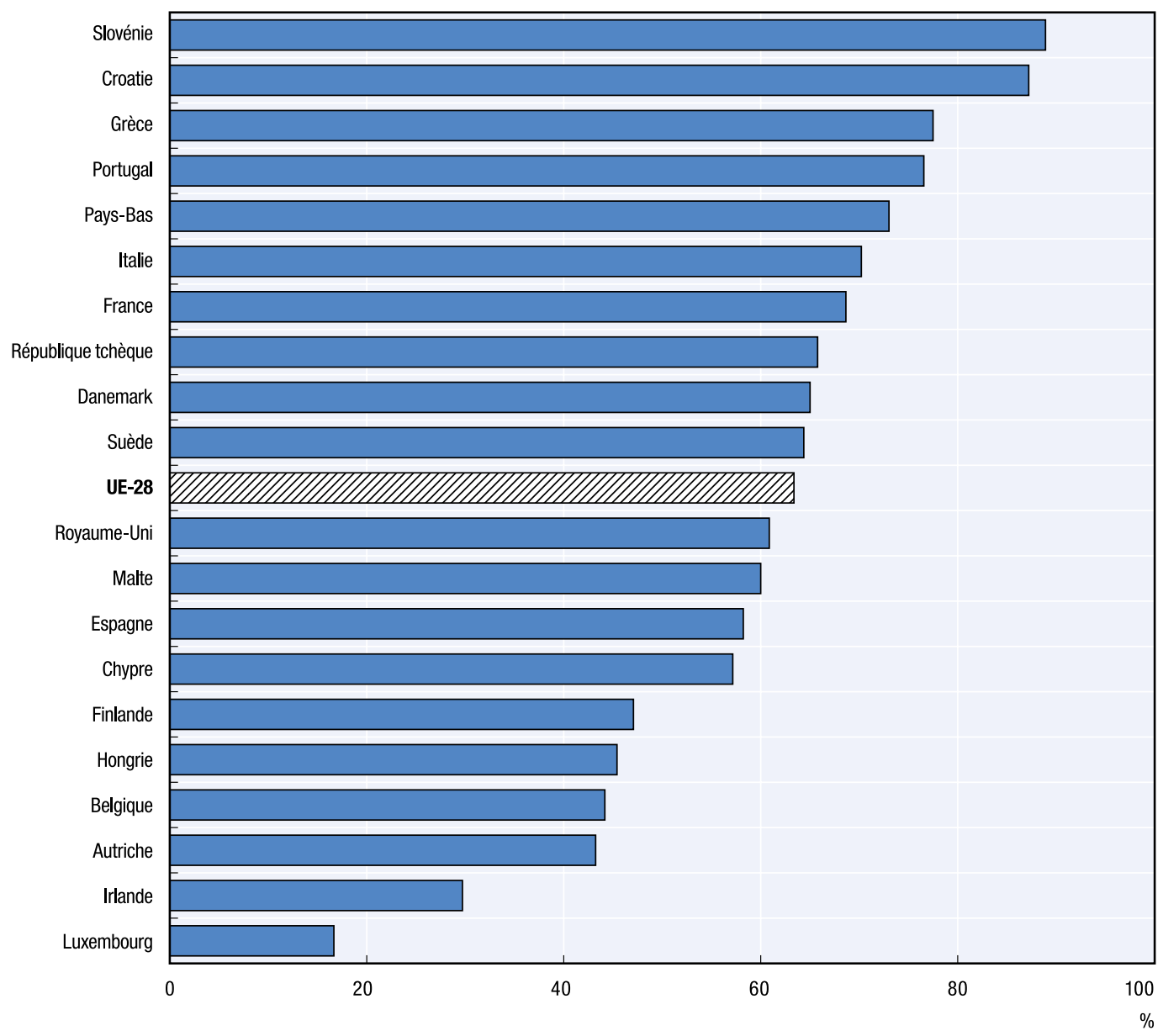

Source: Eurostat, Enquête sur les forces de travail 2012.

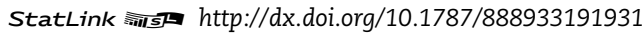

Dans de nombreux États membres de l'UE, les étrangers étaient plus susceptibles d'exercer une activité indépendante que la population autochtone (Graphique 7.2). En 2012, parmi ces pays, on retrouve la Belgique, la République tchèque, le Danemark, la France, l'Allemagne, la Hongrie et le Royaume-Uni. La tendance était toutefois inversée dans la moitié des pays de l'UE. D'après les chiffres, l'écart de taux le plus grand entre autochtones et allochtones se situait en Grèce, où ces derniers étaient trois fois moins nombreux à être indépendants. Cependant, les écarts sont souvent plus importants entre les minorités ethniques qu'entre populations autochtones et allochtones.

Le taux d'indépendants étrangers au sein de l'UE reste relativement stable depuis 2004 (Graphique 7.3). Seuls l'Estonie et le Danemark ont connu de grandes variations. En Estonie, la proportion a augmenté d'environ $7 \%$ tandis qu'elle a diminué de près de $5 \%$ au Danemark. Dans le même temps, des évolutions marginales ont été observées en France (légère hausse) et au Royaume-Uni (légère baisse). 


\section{Graphique 7.2. Taux de travail indépendant par lieu de naissance et par État membre, 2012}

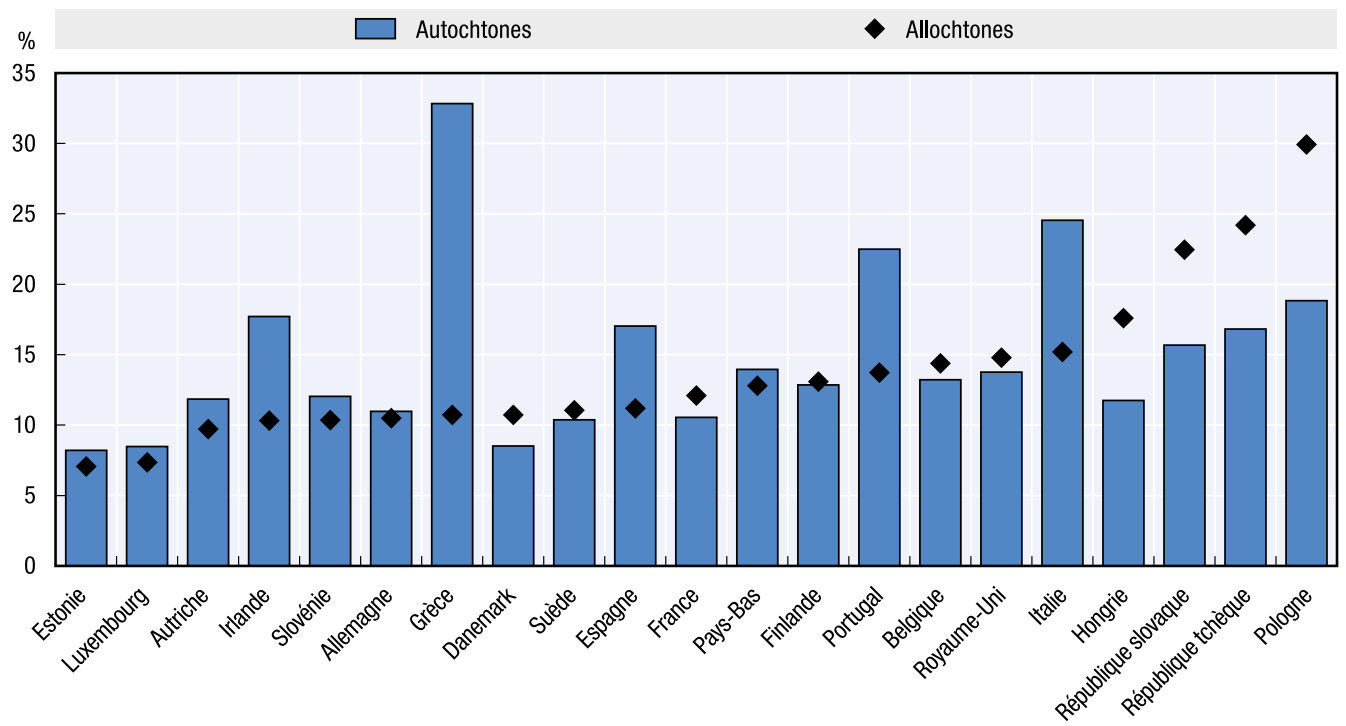

Source: Eurostat, Enquête sur les forces de travail 2012.

\section{Graphique 7.3. Proportion des indépendants nés à l'étranger, comparaison 2004-2006 et 2009-2011}

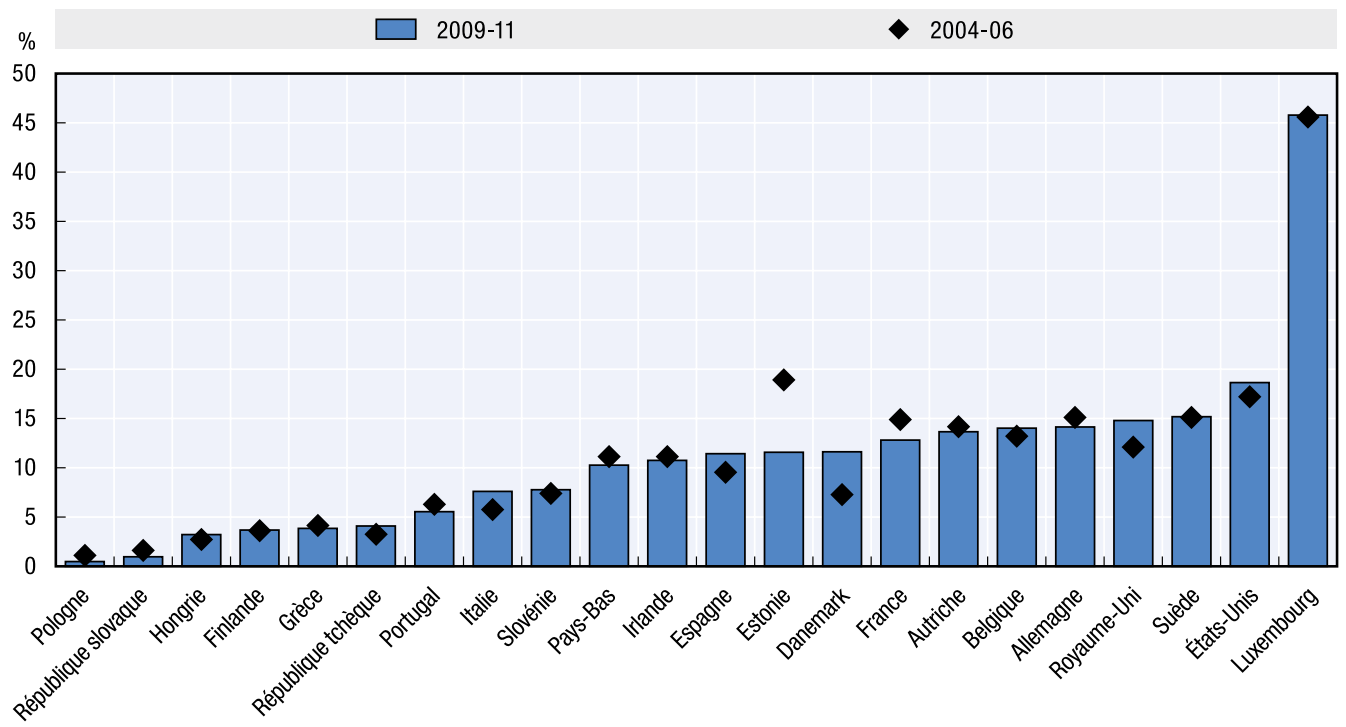

Note: Ces chiffres ne tiennent pas compte des indépendants du secteur agricole. Source: Adapté de l'OCDE (2013), Panorama de l'entrepreneuriat.

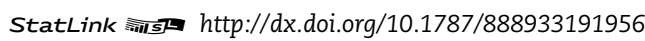

À l'échelle de l'UE, les indépendants étrangers et autochtones emploient du personnel dans des proportions similaires (Graphique 7.4). On observe malgré tout des variations d'un État membre à l'autre. Dans neuf États membres, les allochtones étaient moins susceptibles d'avoir des employés, les différences les plus marquées apparaissant en Italie (32\%), à Chypre (28\%) et au Luxembourg (24\%). Dans neuf autres États (pour lesquels des données 
sont disponibles), le nombre d'employeurs était plus important parmi les indépendants étrangers. C'était notamment le cas en Slovénie (73\%), en Lettonie (64\%) et au Portugal (36\%).

\section{Graphique 7.4. Proportion d'indépendants employant des salariés par lieu de naissance, 2012}

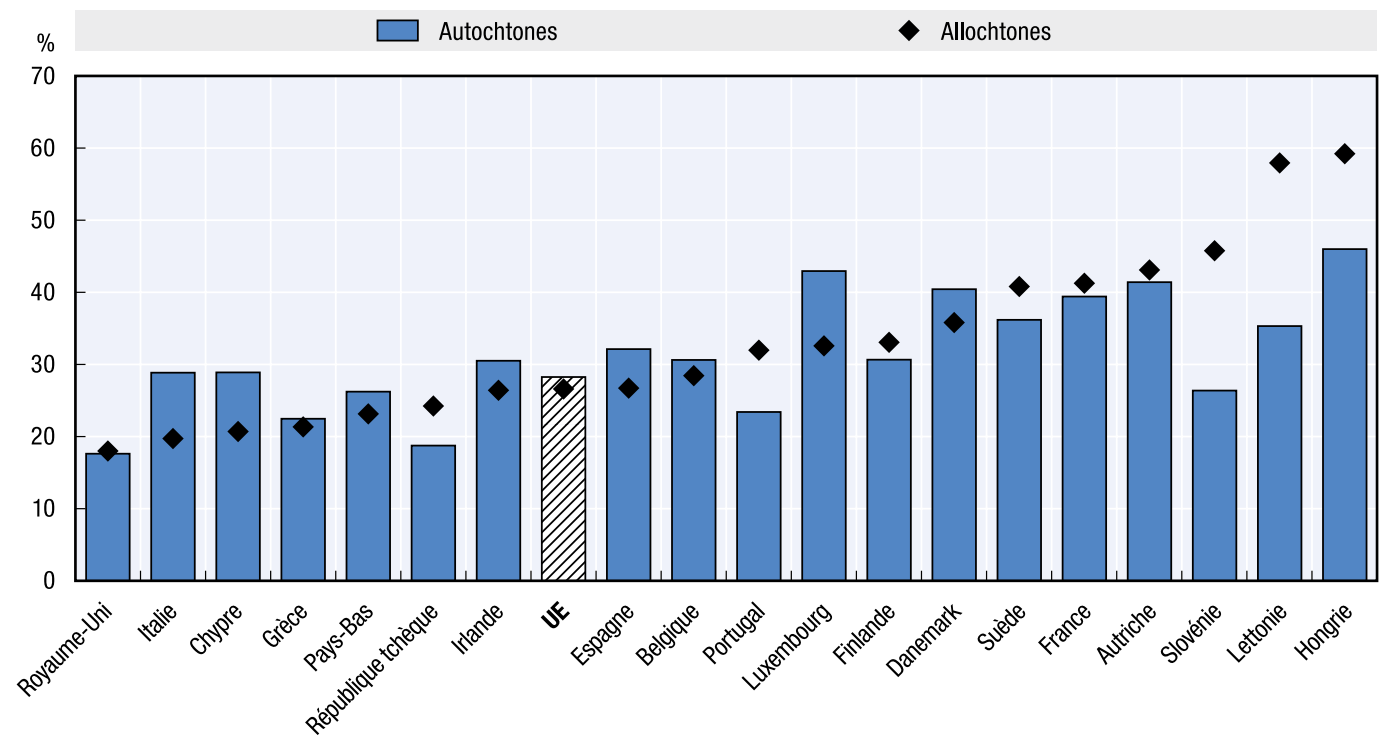

Source: Eurostat, Enquête sur les forces de travail 2012.

StatLink त्ताज्ञ http://dx.doi.org/10.1787/888933191964

\section{Taux de survie}

Les entrepreneurs immigrés ou issus de minorités ethniques opèrent fréquemment dans des secteurs professionnels hautement concurrentiels au sein desquels les barrières à l'entrée et les qualifications requises sont peu élevées (Kloosterman et Rath, 2003; APCE, 2013) les restaurants, les magasins de détail et l'industrie textile, par exemple. Ces entreprises se font souvent concurrence sur les prix (Rezaei et Goli, 2006; Kloosterman et Rath, 2003; Rath et al., 2011). Il s'agit essentiellement de sociétés à forte intensité de maind'œuvre qui ne génèrent pas suffisamment de revenus pour soutenir leur croissance et leur développement (McKay et al., 2009).

Il n'est donc pas étonnant que les taux de survie des entreprises exploitées par des indépendants étrangers soient inférieurs à ceux des sociétés des autochtones. Des données de France indiquent que les indépendants étrangers connaissent des taux de survie inférieurs à ceux des indépendants autochtones (Graphique 7.5). En outre, les taux des indépendants nés en dehors de l'UE sont plus bas que ceux des indépendants nés en Europe. Si l'écart n'est que de quelques points de pourcentage après un an d'activité, il grimpe à $20 \%$ après trois années. 


\section{Graphique 7.5. Taux de survie des entreprises gérées par des immigrés (France)}

Moyenne des cohortes 2006-2009

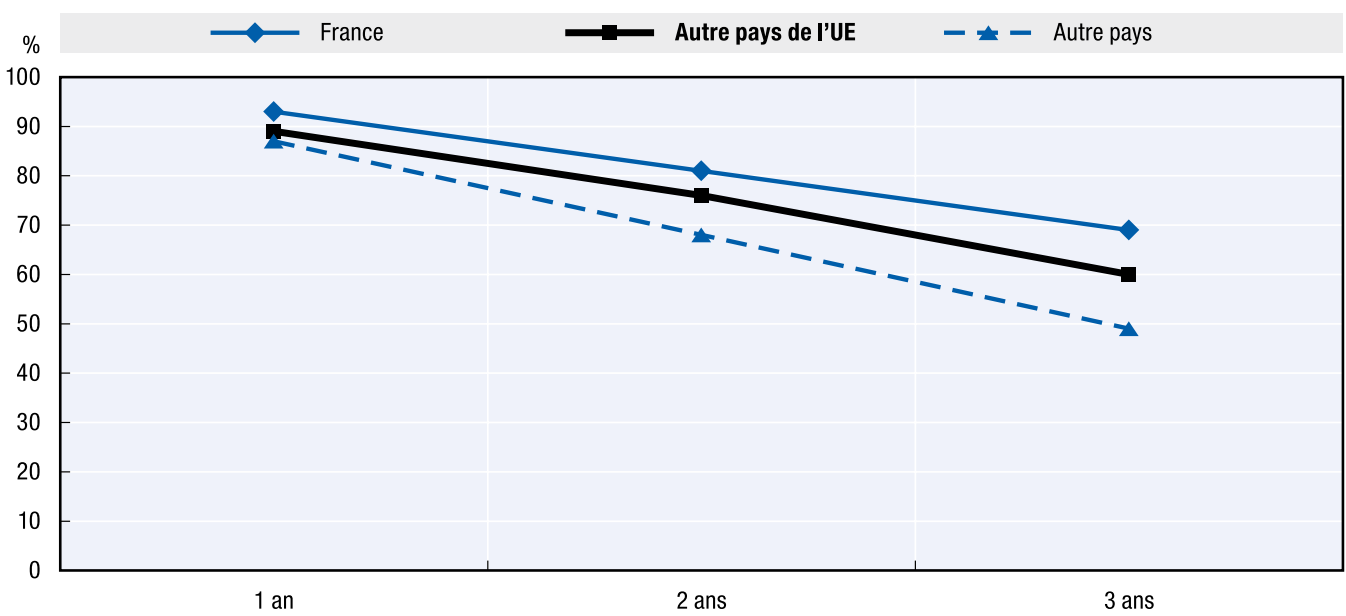

Note: Ces chiffres ne tiennent pas compte des indépendants du secteur agricole. Source: Adapté de l'OCDE (2013), Panorama de l'entrepreneuriat.

StatLink 尚IS http://dx.doi.org/10.1787/888933191978

\section{Niveaux de compétence}

Le Graphique 7.6 renseigne sur le niveau d'instruction des indépendants. Bien que niveau d'instruction et niveau de compétence constituent deux variables distinctes, les deux sont fréquemment corrélés. À l'échelle de l'UE, les indépendants étrangers sont plus susceptibles d'avoir suivi des études supérieures que les indépendants autochtones. Ce constat est valable dans une grande majorité d'États membres, à l'exception de l'Allemagne, de la France, de la Belgique et du Danemark, où ce sont les autochtones qui sont les plus

\section{Graphique 7.6. Proportion d'indépendants ayant suivi des études supérieures par lieu de naissance, 2012}

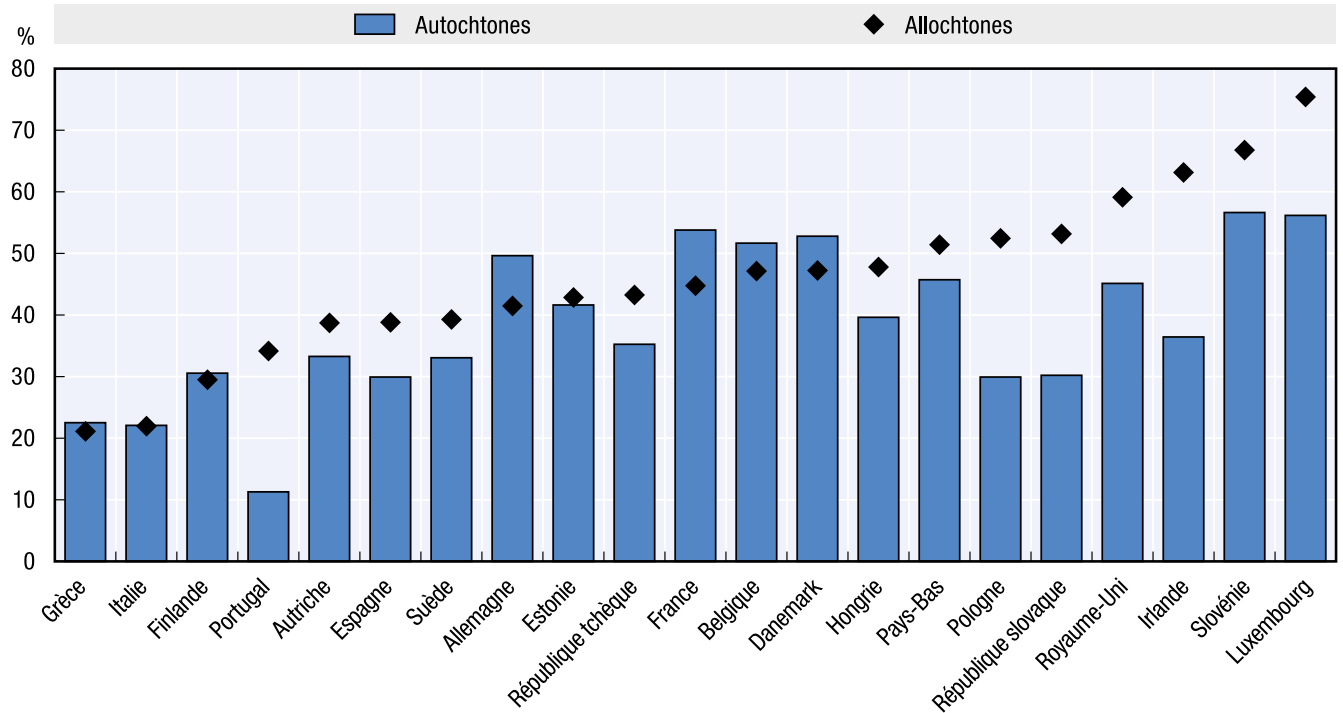

Notes: 1. Par enseignement supérieur, on entend le niveau 5 ou plus de la Classification internationale type de l'éducation (CITE). 2. Ces chiffres ne tiennent pas compte des indépendants du secteur agricole.

Source: Adapté de l'OCDE (2013), Panorama de l'entrepreneuriat. 
nombreux à avoir suivi des études. La part d'indépendants autochtones et allochtones à avoir atteint ce niveau d'éducation est à peu près égale en Grèce, Italie, Finlande et Estonie.

Ces données ne traitent pas de la question de la reconnaissance des qualifications acquises par les étrangers. Il n'est pas rare que les qualifications acquises dans un pays étranger ne soient pas reconnues dans le pays d'accueil (Rezaei et Goli, 2006). Cela constitue un obstacle supplémentaire pour les entrepreneurs issus des minorités ethniques, qui pourraient ne pas avoir accès aux licences et certifications requises pour démarrer leur entreprise.

\section{Entraves à la création d'entreprise par des minorités ethniques}

- Les entrepreneurs issus des minorités ethniques rencontrent les mêmes entraves à la création d'entreprise que les entrepreneurs autochtones, à la différence qu'elles représentent pour eux un frein plus important.

- Les institutions formelles et informelles peuvent avoir une influence négative sur les entreprises et les activités indépendantes des immigrés, car ces derniers méconnaissent le milieu d'affaires et le cadre réglementaire. Cela est particulièrement vrai lorsqu'ils souhaitent mettre en place des entreprises dans des secteurs très réglementés.

- L'accès au financement peut être un obstacle à la création d'entreprise, surtout dans le cas des immigrés arrivés récemment qui n'ont pas la possibilité de prouver leurs antécédents de crédit ou qui n'ont jamais appartenu au système bancaire formel.

- Comme pour tous les entrepreneurs, le manque de compétences entrepreneuriales peut freiner la création d'entreprise. Les difficultés spécifiques rencontrées par les entrepreneurs immigrés ou issus de minorités ethniques sont souvent liées aux qualifications en gestion d'entreprise et à la maîtrise de la langue utilisée dans l'environnement commercial.

- En revanche, ils bénéficient de certains avantages concurrentiels. Ils peuvent avoir accès à des clients et fournisseurs par l'intermédiaire de leur communauté ethnique et mettre à profit leurs relations avec leur pays d'origine à des fins de commerce international.

Les entrepreneurs immigrés ou issus d'une minorité ethnique sont confrontés aux mêmes obstacles à la création d'entreprise que le reste de la population. Ces entraves sont toutefois plus contraignantes pour nombre d'entrepreneurs issus de minorités. Des données indiquent qu'au sein des minorités ethniques, les femmes sont confrontées à de plus grandes difficultés que les hommes (Agentur fur Gleichstellung, 2010).

Les obstacles souvent évoqués au sujet des entrepreneurs issus de minorités ethniques sont davantage liés au secteur d'activité qu'à l'origine ethnique en elle-même. Cependant, ces difficultés peuvent être plus fréquemment observées dans les entreprises exploitées par des entrepreneurs issus de minorités ethniques, ces derniers ayant tendance à se concentrer davantage dans des secteurs particuliers (Ram et Smallbone, 2003). Par exemple, on retrouve bon nombre de ces entrepreneurs dans les secteurs très concurrentiels du textile et de la distribution, au sein desquels les grandes chaînes dominantes peuvent appliquer des marges plus faibles et vendre moins cher que leurs concurrents.

\section{Entraves institutionnelles}

Le terme «institutions» désigne les structures spécifiques telles que les organismes de réglementation et/ou les infrastructures d'aide aux entreprises. On distingue les institutions formelles des institutions informelles, mais toutes deux jouent un rôle dans les entraves institutionnelles auxquelles les entrepreneurs issus de minorités ethniques sont confrontés puisqu'elles forment les structures institutionnelles au sens large d'une 
société. Elles peuvent être une force stimulante et contraignante en matière de création d'entreprise. En tant que force stimulante, elles peuvent réduire les coûts de transaction et faciliter le fonctionnement des économies de marché. Mais les institutions peuvent également entraver les entrepreneurs, car elles définissent un champ d'action, qui n'affecte pas tous les entrepreneurs, ou groupes ethniques, de la même façon (OCDE/CE, 2013).

Institutions formelles

Les institutions formelles incluent les lois, réglementations et toute autre règle qui influencent directement les coûts de création, d'exploitation ou de fermeture d'une entreprise. Il s'agit des règlements régissant l'entrée sur le marché et la sortie du marché ainsi que les lois relatives aux transactions commerciales. En font également partie les institutions réglementaires et les politiques qui influencent l'image de l'entrepreneuriat et sa faisabilité (p.ex. les politiques relatives au marché du travail et au développement des entreprises) de même que celles qui affectent les coûts et les coûts d'opportunité liés à la création d'une entreprise (p.ex. le cadre légal).

La réglementation gouvernementale soit souvent citée parmi les entraves à l'entrepreneuriat, mais les lois et règlements peuvent aussi offrir des opportunités en la matière en instaurant un environnement favorable. D'une grande diversité, les processus réglementaires peuvent être contraignants (p.ex. législation relative à la santé et à la sécurité) comme stimulants (p.ex. incitants financiers). Qu'ils soient stimulants ou contraignants, ces processus ont des répercussions sur l'ensemble des entrepreneurs, même si ceux issus d'une minorité ethnique ont tendance à percevoir la réglementation gouvernementale comme une entrave majeure. Ces derniers peuvent avoir des difficultés à comprendre les lois, les exigences administratives et les règlements, en particulier pour les entrepreneurs immigrés qui ont connu un cadre réglementaire différent.

Peu de données indiquent que les institutions réglementaires pénalisent plus fortement les entrepreneurs issus de minorités ethniques que le reste de la population (Welter, 2012), mais elles sont susceptibles d'affecter encore davantage les immigrants récemment arrivés. Leurs attitudes peuvent être davantage dictées par l'environnement du pays qu'ils ont quitté que par celui de leur pays d'accueil. Contrairement aux entrepreneurs issus de minorités ethniques qui sont nés dans le pays et connaissent ses règles, sa culture et ses institutions, les immigrés n'ont pas l'expérience, les connaissances et les compétences suffisantes pour s'adapter à une institution ou un environnement méconnus, une situation qui peut être aggravée par un faible niveau d'instruction (Welter, 2012). La création d'entreprise a été très problématique pour les immigrés, surtout dans les secteurs et professions fortement réglementés (Kay et Schneck, 2012). Des données d'Italie confirment que les entrepreneurs immigrés comprennent difficilement les procédures et obligations légales liées à la création d'entreprise (De Luca, 2011). Ces difficultés peuvent inciter un certain nombre d'entrepreneurs issus de minorités ethniques à s'établir et à opérer dans le secteur informel. En Suède, des éléments indiquent que des immigrés asiatiques n'hésitent pas à contourner les règles d'immigration et à entrer sur le territoire avec un visa touristique pour ensuite créer des entreprises non enregistrées (Alund, 2003).

L'une des entraves institutionnelles majeures concerne l'accès aux services d'aide aux entreprises. Les entrepreneurs issus de minorités ethniques sont sous-représentés parmi les bénéficiaires des organismes d'aide aux entreprises (Ram et Smallbone, 2003). Des données du Royaume-Uni attestent que cette catégorie d'entrepreneurs a de plus en plus fréquemment recours à ces services, mais la situation varie considérablement d'un groupe ethnique à l'autre (Ram et Smallbone, 2003). On observe également des différences entre les immigrés récents et les minorités ethniques autochtones (Tisserant, 2003). 
D'aucuns prétendent que les aides publiques et privées se valent, laissant entendre qu'ils compensent l'absence d'accès aux aides publiques en faisant appel à leurs amis, à leur famille et à leur réseau professionnel. C'est pourtant faux. La plupart des entrepreneurs qui réussissent font appel à leurs amis, leur famille et leurs associés en plus des services et des aides du secteur public. Cette précision est importante, car des données du Royaume-Uni suggèrent que les entrepreneurs issus d'une minorité ethnique qui réussissaient le mieux étaient les Chinois, principalement les comptables et experts chinois, car ces derniers avaient plus tendance à tenir compte des conseils lors du démarrage de leur activité (Ram et al., 2002). Cette question doit être abordée avec prudence, car les données reflètent souvent plus les perceptions des entrepreneurs que leurs expériences et leurs actions (Law, 2007).

\section{Institutions normatives}

Les institutions normatives désignent les valeurs qui conditionnent les préférences d'une société ou les normes sociales de ce qui est considéré comme préférable ou souhaitable. Leur influence sur l'importance que la société accorde généralement à l'entrepreneuriat a été démontrée (Davidsson et Wiklund, 1997). La question essentielle est de savoir comment ces institutions affectent la nature et l'ampleur des activités entrepreneuriales des minorités ethniques et des immigrés par rapport au reste des entrepreneurs.

Les modèles et la culture entrepreneuriale font partie des entraves institutionnelles normatives. Pour ces deux cas, il a été démontré que les entrepreneurs africains et caribéens au Royaume-Uni accueillaient moins bien l'entrepreneuriat et lui accordaient moins d'importance que les communautés sud-asiatiques, par exemple (Ram et Smallbone, 2003). À l'inverse des entrepreneurs africains et caribéens, les entrepreneurs chinois ou indiens sont beaucoup plus susceptibles d'avoir été en contact avec des modèles entrepreneuriaux ayant réussi, ce qui est moins probable dans le cas de Pakistanais et des Bangladais (Ram et Smallbone, 2003).

Parallèlement aux attitudes et normes propres à leur communauté qui peuvent stimuler ou freiner l'entrepreneuriat, les entrepreneurs issus de minorités ethniques sont également confrontés aux comportements qui dominent dans leur pays de résidence. Ces comportements peuvent renforcer l'attitude positive à l'égard de l'entrepreneuriat qui prévaut dans leur culture, ou donner lieu à des stéréotypes négatifs et comportements discriminatoires. Un nombre limité de données atteste d'une discrimination de la société et de la communauté des entrepreneurs vis-à-vis des minorités ethniques. D'autres données en provenance du Danemark suggèrent que la discrimination est valable dans les deux sens, la population autochtone étant également discriminée par les minorités ethniques (Serden Özcan, 2013). Les nouvelles générations des communautés ethniques s'adaptent probablement mieux et sont moins affectées par l'impact négatif des institutions normatives (stéréotypes et préjugés) que les générations précédentes. Le niveau d'instruction peut également influencer cette perception (Welter, 2012).

Le capital social a un rôle important à jouer pour aider les entrepreneurs immigrés ou issus de minorités ethniques à faire face aux institutions normatives. Si l'attitude à l'égard de l'entrepreneuriat est positive au sein de leur communauté, le capital social peut aider les membres à gérer les attitudes négatives et la discrimination. À titre d'exemple, les entrepreneurs des communautés sud-asiatiques se portent garants lorsque de nouveaux entrepreneurs sollicitent des prêts bancaires (Ram et Smallbone, 2003). Le capital social est particulièrement important pour les immigrés de première génération, qui n'ont pas eu la possibilité de se familiariser avec les systèmes sociaux et réglementaires du pays d'accueil. Il repose essentiellement sur les relations sociales et familiales au sein des communautés ethniques. Il implique rarement les relations interethniques, y compris celles avec la population autochtone. Ce type de capital social renforce les liens existants (Granovetter, 1983; Coleman, 
1987). Basé sur la confiance et la loyauté, il rapproche plutôt qu'il ne clive (Putnam et al., 1993). Le capital social peut donc aider les entrepreneurs issus de minorité ethniques à créer leur entreprise, mais il n'aura probablement pas d'incidence majeure sur la croissance ou la survie de ces dernières (Hegedahl et Rosenmeier, 2007).

\section{Accès au financement}

L'accès au capital de départ est l'une des entraves à la création d'entreprise les plus fréquemment citées par tous les entrepreneurs. C'est souvent vrai pour ceux issus de minorités ethniques. Selon des données provenant de France, les entrepreneurs étrangers sont plus susceptibles que les entrepreneurs autochtones de démarrer une activité sans capital de départ (73\% contre 62\% en 2006) (APCE, 2012). Des données d'autres pays de l'UE tels que l'Allemagne corroborent ce fait (Kay et Schneck, 2012).

Certains entrepreneurs issus de minorités ethniques ont la possibilité d'obtenir des financements auprès de membres de leur famille ou de connaissances vivant à l'étranger via des mécanismes de financement informels ou communautaires comme les hawalas et les systèmes de capitaux tournants (Rezaei et Goli, 2006).Toutefois, ces mécanismes de financement se limitent souvent à des montants relativement faibles, car ils reposent essentiellement sur des espèces. La plupart des entrepreneurs ayant accès à ces systèmes informels lors de la création de leur entreprise sont souvent contraints de revoir leur plan d'affaires à la baisse.

Les difficultés d'accès au financement de départ des entrepreneurs issus de minorités ethniques peuvent être liées au marché, à la culture, aux compétences et aux institutions.

Obstacles liés au marché

L'asymétrie des informations entre prêteurs et emprunteurs constitue est une caractéristique clé des marchés de crédit. Par exemple, les prêteurs manquent souvent d'informations sur les emprunteurs et la viabilité de leurs projets. Ils peuvent dès lors difficilement évaluer les propositions de prêt et exigent souvent des actifs en garantie pouvant faire l'objet d'une saisie en cas de défaut de paiement (financement sur actifs).

Les entreprises gérées par des entrepreneurs issus d'une minorité ethnique ou d'origine immigrée sont généralement perçues par le marché comme des clients à haut risque. Ils sont moins susceptibles d'apporter des actifs en garantie que le reste de la population (p.ex. bien immobilier, véhicules) et de pouvoir fournir de bons antécédents de crédit ou, dans certains cas, un historique bancaire (Heelsum, 2012). De ce fait, leurs demandes de prêts risquent davantage d'être rejetées (Kay et Schneck, 2012).

Le fait que les prêteurs puissent appliquer des taux d'intérêt plus élevés pour compenser leur profil plus risqué de ceux qui ne disposent pas de garanties suffisantes risque d'attirer des emprunteurs à risque et d'entraîner une antisélection. De plus, les emprunteurs peuvent se retrouver engagés dans des projets plus risqués pour rembourser des échéances plus importantes, augmentant aussi le risque défaut de paiement (risque moral). Ces défaillances du marché empêchent l'égalité d'accès des entrepreneurs immigrés ou issus de minorités ethniques au financement.

\section{Obstacles culturels}

Les obstacles culturels découlent des stéréotypes et des préjugés. Ils peuvent apparaître aussi bien du côté de l'offre que de la demande des marchés de crédit. Du point de vue de l'offre, ces obstacles résultent généralement des agents de crédit et des procédures officielles de prêt. Ces agents sont formés pour traiter avec des indépendants qui exploitent une entreprise à temps plein. Ce n'est évidemment pas toujours le cas. En 
outre, les entrepreneurs immigrés qui gèrent plusieurs entreprises à la fois peuvent être soumis à un rationnement de crédit du fait qu'ils n'ont pas le profil du client standard. Les cas de discrimination sociale à l'égard des minorités ethniques sont également possibles, bien qu'aucune donnée solide ne l'atteste sur les marchés de crédit de l'UE (OCDE/CE, 2013).

Du point de vue de la demande des marchés de crédit, les entrepreneurs issus de minorités ethniques sont confrontés à des barrières linguistiques et sociales ne leur permettant pas d'instaurer une relation étroite et confiante avec les banques et autres prêteurs. Ils peuvent également se montrer réticents à l'idée de communiquer leurs revenus personnels et leur taux d'endettement avec les agents de prêt qu'ils considèrent comme des étrangers (Leicht et al., 2012). Ils peuvent dès lors moins facilement accéder à des financements extérieurs.

En outre, les entrepreneurs issus d'une minorité ethnique ou d'origine immigrée peuvent ne pas demander de prêt parce qu'ils pensent avoir moins de chances de l'obtenir que les entrepreneurs autochtones. Ce comportement peut être dû à un sentiment de discrimination ou à un manque de connaissances du fonctionnement des marchés financiers. Des données du Royaume-Uni indiquent que des entrepreneurs issus de minorités ethniques qui exploitaient des entreprises informelles à temps partiel ou à temps plein ne sollicitaient pas de prêts, parce qu'ils étaient persuadés que les prêteurs privés avaient l'obligation de communiquer les informations des emprunteurs à l'administration fiscale (Ram et al., 2002). En outre, certains entrepreneurs musulmans refusent de payer des intérêts sur des prêts et n'en demandent donc jamais (Rezaei et Goli, 2006).

\section{Obstacles liés aux compétences}

Sur les marchés de crédit, la plupart des demandes de prêt sont rejetées parce que les informations soumises sont incomplètes ou erronées. Cela arrive plus souvent aux entrepreneurs qui n'appartiennent pas au groupe traditionnel des hommes blancs. Les disparités de qualifications entre les minorités ethniques et les immigrés, d'un côté, et les entrepreneurs ordinaires, de l'autre, y contribuent. Les obstacles les plus courants en matière de compétences portent sur la planification des activités et la gestion d'entreprise, ainsi que sur les connaissances financières. Premièrement, bon nombre d'entrepreneurs issus d'une minorité ethnique ou d'origine immigrée ne savent pas rédiger un plan d'affaires formel et n'ont jamais géré d'entreprise auparavant. Ils présentent donc souvent des dossiers financiers de mauvaise qualité, ce qui complique l'obtention de leur prêt puisque les organismes de prêt formels les exigent systématiquement. Deuxièmement, ces entrepreneurs ne maîtrisent pas suffisamment certains concepts de financement des affaires, indispensables pour comprendre les risques et les opportunités liés à l'activité entrepreneuriale (p.ex. taux d'intérêt, valeur temporelle de l'argent). Troisièmement, ils ne savent souvent pas où s'adresser pour demander des financements (Rath et al., 2012).

\section{Obstacles institutionnels}

La structure des institutions financières et leurs mécanismes de fonctionnement peuvent également causer un certain nombre de problèmes aux entrepreneurs immigrés ou issus de minorités ethniques. Par exemple, certaines formes de microcrédit ne permettent pas aux emprunteurs d'établir leurs antécédents de crédit, qui pourraient les aider à obtenir des prêts à des taux d'intérêt plus bas auprès d'organismes de prêt formels. La production de ces antécédents peut également s'avérer important pour les personnes qui ne disposent pas d'historique bancaire formel. 
L'absence de législation et de réglementations relatives au financement islamique et aux secteurs financiers émergents, tels que les prêts entre particuliers et le financement participatif, constitue un autre exemple.

\section{Manque de compétences entrepreneuriales}

Les entrepreneurs doivent posséder un large spectre de compétences s'ils veulent accroître leurs chances de démarrer une activité entrepreneuriale prospère. Ces compétences incluent des compétences techniques (p.ex. communication orale et écrite, résolution de problèmes, suivi environnemental), des compétences en gestion d'entreprise (p.ex. fixation des objectifs, prise de décisions, finances, négociations, relations avec la clientèle) et des compétences entrepreneuriales personnelles (p.ex. gestion des risques, gestion du changement, réflexion stratégique, aptitude à diriger) (OCDE/CE, 2013). Beaucoup de ces compétences font défaut aux entrepreneurs immigrés ou issus de minorités ethniques, principalement celles qui ont trait à la gestion (Rath et al., 2011). Cela est particulièrement vrai pour les femmes appartenant à ces minorités.

Les aptitudes linguistiques peuvent réellement les mettre en difficulté, car elles créent une barrière lorsqu'ils doivent se familiariser avec les nouveaux régimes institutionnels et réglementaires pour lancer leur entreprise (Rath et al., 2011). En outre, elles peuvent compliquer les demandes de prêt et de capital de départ ainsi que la recherche de partenaires commerciaux. Le développement des relations avec la clientèle et les fournisseurs s'avère également plus compliqué. Les entrepreneurs immigrés ou issus de minorités ethniques peuvent contourner ce problème en développant des entreprises qui ciblent des clients appartenant au même group ethnique qu'eux et en faisant appel à des fournisseurs qui parlent la même langue (Rezaei et Goli, 2007; Nkakleu et Levy-Tadjine, 2005). Cette solution peut évidemment restreindre le potentiel de croissance de l'entreprise.

\section{Encadré 7.1. Avantages concurrentiels des entrepreneurs issus de minorités ethniques}

S'ils rencontrent un certain nombre de difficultés, les entrepreneurs issus de minorités ethniques bénéficient par ailleurs de plusieurs avantages concurrentiels. Certaines opportunités de marché sont fermées aux entreprises locales, en particulier lorsque la ville, la région ou le pays est suffisamment grand pour accueillir des sociétés spécialisées dans la fourniture de biens et services aux minorités ethniques. Des exemples de ce phénomène sont observés dans plusieurs zones de concentration d'immigrés dans les grands centres urbains (Andersen, 2008; Rezaei et Goli, 2007).

La concentration d'individus d'un même groupe ethnique dans certaines zones génère certains avantages en termes d'accès aux clients et employés de cette origine ethnique et de soutien communautaire. Les entrepreneurs issus de minorités ethniques comptent souvent assez fortement sur les ressources ethniques, en particulier des salariés de même origine ethnique, et sur les membres de leur famille. Cela peut constituer un avantage pour la gestion de l'entreprise, car la pratique d'une langue commune avec les clients et les employés peut limiter le recours aux structures de gestion formelles. Cela peut également donner lieu à une plus grande flexibilité dans la gestion du personnel et des fournisseurs et bien souvent à une réduction des coûts de transaction.

Les entrepreneurs immigrés ont aussi l'avantage de connaître plusieurs cultures, ce qui leur confère un avantage potentiel en cas de développement à l'international. Les entrepreneurs appartenant à la première génération d'une minorité ethnique se lancent souvent plus facilement, car ils ont une connaissance approfondie de la culture de leurs parents et celle de leur pays de naissance (Light, 2010). 


\section{Actions politiques en faveur des entrepreneurs issus de minorités ethniques}

- Les responsables politiques peuvent prendre des mesures afin d'éliminer ces obstacles institutionnels, soit en réduisant directement la charge institutionnelle, soit en aidant les entrepreneurs à mieux appréhender l'environnement commercial. De nombreuses initiatives locales, nationales et européennes ont pour but de réduire la charge réglementaire des entreprises et de rendre les services plus accessibles (p.ex. guichets uniques). En outre, les gouvernements peuvent mettre en place des formations et faciliter l'accès à des services d'aide au développement des entreprises pour les aider à mieux s'orienter dans l'environnement institutionnel.

- Les garanties de prêt et le microcrédit sont deux approches couramment utilisées pour favoriser l'accès des entrepreneurs issus de minorités ethniques au financement d'amorçage. L'un des éléments clé de ces approches est la mise à profit de l'expertise du secteur financier dans l'élaboration et la mise en œuvre des programmes publics.

- Les programmes de formation et d'aide au développement des entreprises augmentent les chances de réussite de ces entrepreneurs en renforçant leurs compétences entrepreneuriales et en les aidant à s'adapter à une nouvelle culture d'entreprise. Des cours de langue peuvent être proposés afin de faciliter leur intégration dans la société.

- Les services de proximité sont un des enjeux les plus importants dans l'aide aux entrepreneurs issus de minorités ethniques, car nombre d'entre eux ne font pas confiance aux organismes de service public. Il est donc primordial de collaborer avec les organismes communautaires pour atteindre ces groupes.

Les interventions des politiques publiques visant à promouvoir et à soutenir l'entrepreneuriat des minorités ethniques ont tendance à être justifiées par l'un des arguments suivants voire les deux. Premièrement, les entreprises exploitées par des entrepreneurs issus de ces minorités contribuent à l'économie et les politiques publiques ont un rôle à jouer pour encourager l'entrepreneuriat à tous les niveaux de la société, y compris auprès des minorités ethniques. Deuxièmement, l'entrepreneuriat des minorités ethniques permet de relever les défis liés à l'inclusion sociale. C'est parfois comme la principale justification de l'intervention des politiques publiques dans ce domaine (Jaegers, 2008).

Les politiques publiques de promotion et de soutien à l'entrepreneuriat des minorités ethniques peuvent intervenir aux niveaux national, régional et local. L'étendue des mesures politiques publiques prises dans ce domaine varie fortement d'un État membre de l'UE à l'autre, selon la taille relative des populations de minorités ethniques et l'attitude à l'égard des contributions potentielles de ces entrepreneurs à l'économie. La plupart des pays du nord-ouest de l'UE ont mis en place une politique nationale des minorités ou d'intégration des immigrés récemment arrivés ainsi que des politiques de soutien aux PME (Triodos Facet, 2008). La manière dont ces différents pays combinent les deux, autrement dit promeuvent l'entrepreneuriat des minorités ethniques et des immigrés, se révèle très variable. Dans un certain nombre de pays, dont la France, la Grèce et la Slovénie, les politiques nationales ne font pas de distinction entre immigrés et ressortissants nationaux.

\section{Éliminer les entraves institutionnelles}

Les interventions des politiques publiques liées aux institutions sont réparties en deux grandes catégories. La première catégorie concerne les mesures politiques relatives aux contraintes structurelles telles que les cadres réglementaires et l'environnement institutionnel. Ces interventions réglementaires et structurelles doivent être envisagées dans le contexte plus large des politiques d'immigration et d'intégration car, dans de nombreux cas, les problèmes ne sont pas spécifiques aux entreprises, bien qu'ils puissent avoir des répercussions majeures sur 
l'entrepreneuriat. Les problèmes ont davantage trait à la création d'entreprise, notamment à la compréhension et au respect des exigences institutionnelles (p.ex. obtention d'une licence d'exploitation et enregistrement auprès de l'administration fiscale). Certains entrepreneurs issus de minorités ethniques peuvent le vivre comme une nouvelle expérience, malgré une expertise d'exploitation d'entreprise de plusieurs années dans leur pays d'origine.

L'Union européenne a pris plusieurs mesures globales pour remédier à certaines des difficultés rencontrées dans l'espace institutionnel et réglementaire. C'est le cas notamment du «Small Business Act pour l'Europe» (SBA), destiné à faciliter la vie des petites entreprises au sein de l'UE. Les entrepreneurs immigrés ou issus de minorités ethniques profiteront de ces mesures en vertu du principe «Penser aux PME d'abord» dont l'objectif est de réduire leurs charges administratives et d'accroître leur compétitivité (CE, 2008). Certaine actions spécifiques du SBA les concernent directement, notamment un meilleur accès au financement via des mécanismes de garanties de prêt renforcés et un meilleur accès au capital-risque, ainsi que des solutions de type «médiation de crédit» destinées à faciliter le dialogue entre PME et organismes de crédit. Des guichets uniques ont également été mis en place afin de guider les PME dans leurs demandes de subventions locales, nationales et européennes. Le SBA vise également à améliorer la mise en réseau et les règles de concurrence afin de rendre les PME plus compétitives sur les marchés mondiaux, et d'optimiser les systèmes de paiement transfrontaliers. Il doit également renforcer la concurrence entre les PME au sein de l'UE en élargissant l'accès aux marchés publics (CE, 2013).

À cela s'ajoutent de nombreuses mesures politiques prises au niveau local pour lutter contre les entraves institutionnelles que subissent les minorités ethniques et les immigrés. La majorité des interventions de politiques publiques locales consistent à fournir des informations et des conseils aux entreprises et à augmenter l'offre de biens immobiliers commerciaux et industriels. Il existe des exemples de villes où les pouvoirs publics agissent en faveur d'une réduction des entraves institutionnelles. Les mesures entreprises vont généralement dans le sens d'un allègement de la réglementation et des restrictions en matière d'urbanisme. La mise en place d'associations professionnelles de minorités ethniques est également encouragée et facilitée. Ce dernier aspect peut largement contribuer à renforcer la capacité des entrepreneurs issus de minorités ethniques à réagir face à leurs lacunes institutionnelles.

Le deuxième ensemble de mesures vise à améliorer les aptitudes personnelles des entrepreneurs issus de minorités ethniques afin qu'ils comprennent mieux l'environnement institutionnel dans lequel ils évoluent. Ces actions politiques publiques sont plus courantes à l'échelle d'une ville, les autorités locales jouissant d'une plus grande liberté pour apporter son soutien et prendre une part active dans ce domaine. À Dortmund, en Allemagne, par exemple, la ville propose plusieurs dispositifs d'aide, dont la Förderung ethnischer Ökonomie, qui fournit des services de conseil et d'aide à l'exportation aux entrepreneurs issus de minorités ethniques (Fischer-Krapohl, 2010).

La sensibilisation à l'entrepreneuriat au sein des communautés ethniques fait partie des actions politiques prioritaires. Certaines minorités ethniques ont une longue tradition culturelle du commerce, mais d'autres non. Des campagnes de promotion ciblées peuvent avoir un impact positif. Un autre enjeu important pour les autorités en termes de sensibilisation concerne la promotion des entrepreneurs issus de minorités ethniques au sein de leur ville, de leur région ou de leur pays, le but étant de mettre en exergue la valeur qu'ils représentent pour l'économie et d'attirer davantage l'attention sur leurs contributions à la société. Les cérémonies de remise de prix sont un exemple d'approche à mettre en place. À titre d'exemple, à Nottingham, au RoyaumeUni, la First Enterprise Business Agency, une organisation à but non lucratif, récompense chaque année des entreprises exploitées par des minorités ethniques. Doté d'un budget annuel de 25000 GBP (environ 29300 EUR), l'évènement se déroule en partenariat avec les autorités locales et des sponsors du secteur privé. L'objectif de ces prix est de promouvoir les entreprises des minorités 
ethniques auprès de la communauté et de motiver d'autres entrepreneurs de ces minorités en mettant en avant des modèles.

La formation, les services d'information et les centres de conseil aux entreprises constituent d'autres initiatives politiques destinées à aider ces entrepreneurs à s'orienter dans l'environnement institutionnel. Par la formation, ils peuvent acquérir les compétences qui leur permettront de comprendre le contexte réglementaire et le milieu d'affaires dans lesquels ils évoluent, et d'augmenter ainsi leurs chances de réussite. Les gouvernements locaux peuvent leur proposer des formations ciblées. Celles-ci sont généralement organisées en partenariat avec des organisations actives au sein des différentes communautés ethniques. Ce point est détaillé plus loin dans ce chapitre, à la section consacrée aux politiques axées sur les compétences.

En outre, les services d'information et les centres de conseil aux entreprises permettent d'apporter un soutien plus spécifique et plus informel. Bien que la plupart de ces services soient génériques et, de ce fait, valables pour tous les entrepreneurs, les autorités peuvent faire des efforts pour qu'ils ciblent les minorités ethniques. Les services d'aide aux entreprises sont abordés en détail plus loin dans ce chapitre. Les responsables politiques peuvent également contribuer à promouvoir et à soutenir l'entrepreneuriat au sein des minorités ethniques en apportant leur concours aux associations professionnelles.

\section{Améliorer l'accès au financement}

\section{Garanties de prêt}

Les mécanismes de garanties de prêt, également connus sous le nom de systèmes de garantie de crédit, sont fréquemment utilisés pour aider les entrepreneurs issus de minorités ethniques à obtenir des financements. Ils occupent une place de plus en plus importante dans les politiques publiques, car ils exploitent l'expertise et les ressources du secteur privé par l'intermédiaire des banques. Ces prêts sont couverts par des garanties publiques, qui limitent le risque de crédit. Ces mécanismes reposent sur trois grandes approches (CE/OCDE, 2014):

- Les programmes publics, qu'ils soient gérés directement par le gouvernement ou mis en œuvre de façon plus décentralisée via le système bancaire. Cette première approche, plus fréquente en Europe de l'Est (p.ex. en Slovénie et en République slovaque), tend à impliquer davantage les agences publiques dans le processus de décision concernant l'octroi de garanties de prêt. La deuxième approche, adoptée par le Royaume-Uni et les Pays-Bas, est mise en œuvre par l'intermédiaire du secteur bancaire, avec très peu voire aucune indication quant à la gestion du mécanisme de garantie et aux prêts concernés.

- Les mécanismes publics-privés, qui mobilisent des acteurs du secteur public et du secteur privé. Le gouvernement peut prendre une part plus ou moins active, par exemple en facilitant la création du programme. Quel que soit le degré d'engagement du secteur public, la gestion du programme (p.ex. l'évaluation des risques et le suivi du prêt) est laissée aux organismes de prêt. Le gouvernement hongrois a fait montre d'une participation plus active. Celui-ci a en effet sollicité l'implication des organismes de prêt et des associations de PME lors du lancement de son fonds de garantie nationale.

- Les mécanismes privés, qui fonctionnent généralement par le biais d'associations de cautionnement mutuel ascendantes regroupant des entrepreneurs de la même communauté locale ou du même secteur professionnel. Ici, ce sont les associations de cautionnement mutuel qui effectuent une première évaluation du membre qui souhaite emprunter et interviennent pour le recouvrement des pertes en cas de défaut de paiement. Le choix final du prêt incombe néanmoins à la banque, qui effectue à son tour une évaluation 
complète du risque de crédit. Le rôle du gouvernement se limite à la mise en place du cadre légal et réglementaire ainsi qu'à la fourniture d'une aide financière, sous la forme de financements directs ou de contregaranties. L'Italie fournit un exemple de mécanisme de garantie de prêt privé. Le gouvernement apporte aux banques une importante contregarantie en dernier ressort sur les garanties de premier rang fournies par les associations locales de cautionnement mutuel (appelées confidi en Italie).

Pour ces trois approches, la décision finale de prêt incombe aux banques puisqu'elles assument toujours une partie du risque de défaut de paiement, habituellement entre 20 et $50 \%$ du montant du prêt. Les programmes de garantie de prêt s'adressent souvent aux entrepreneurs immigrés ou issus de minorités ethniques. Pourtant, ceux-ci risquent d'en être exclus si les prêteurs du secteur privé ne s'écartent pas de leur profil de client traditionnel.

L'UE peut soutenir les mécanismes de garanties de prêt en faveur des minorités ethniques et des immigrés par le biais des Fonds structurels. Les initiatives JEREMIE (ressources européennes conjointes pour les PME et les microentreprises) et JASMINE (action commune pour soutenir les institutions de microfinance en Europe) datant de la période de programmation précédente en sont deux exemples. JEREMIE est une initiative conjointe de la Commission européenne et du Fonds européen d'investissement, qui encourage le recours aux instruments d'ingénierie financière en vue d'améliorer l'accès des PME au financement grâce à des interventions des Fonds structurels. Dans le cadre de cette initiative plus vaste, JASMINE a été lancée conjointement par la Commission européenne, la Banque européenne d'investissement et le Fonds européen d'investissement. Elle vise à diffuser les bonnes pratiques dans le domaine du microcrédit, à soutenir le renforcement des capacités des prestataires de microcrédit et à les aider à devenir des opérateurs commerciaux viables et durables. À l'origine, JASMINE proposait des services financiers et non financiers aux organismes de microfinance. L'initiative se concentre désormais sur la fourniture d'une assistance technique aux prestataires de microcrédit, les financements provenant désormais de l'instrument européen de microfinancement Progress, qui fait partie du programme pour l'emploi et l'innovation sociale (EaSI). Le programme EaSI est un instrument financier européen qui promeut un niveau d'emploi et de protection sociale durable et de qualité, et vise à lutter contre l'exclusion sociale et la pauvreté et à améliorer les conditions de travail en soutenant la modernisation de l'emploi et des politiques sociales, la mobilité de l'emploi, l'accès au microfinancement et l'entrepreneuriat social.

Dans le cadre de l'élaboration de leurs mécanismes de garanties de prêt, les gouvernements nationaux et régionaux devraient mettre à profit l'expertise des organismes de prêt du secteur privé en matière d'évaluation du risque de crédit. De leur côté, les prêteurs doivent continuer à supporter une partie du risque de défaut de paiement (p.ex. 10-20\%) afin qu'ils aient un intérêt à faire preuve de diligence dans l'évaluation des demandes de prêt. Les taux maximaux de non-remboursement doivent être fixés au préalable afin de garantir la rentabilité financière de ces mécanismes pour les finances publiques.

\section{Microcrédit}

Une deuxième approche politique en faveur de l'accès des entrepreneurs immigrés ou issus de minorités ethniques au financement d'amorçage consiste à améliorer l'accès au microcrédit. Dans l'Union européenne, le terme de microcrédit fait généralement référence aux prêts de moins de 25000 EUR octroyés aux microentreprises (moins de 10 personnes), aux indépendants ou aux chômeurs et inactifs qui souhaitent se mettre à leur compte, mais n'ont pas accès aux services bancaires traditionnels (FEI, 2009).

La ville d'Aarhus au Danemark figure parmi les exemples de collectivités dont les programmes de microcrédit pour les entrepreneurs issus de minorités ethniques ont été couronnés de succès. La région propose des microcrédits allant jusqu'à 7000 EUR. Chaque 
municipalité a la possibilité de mettre en œuvre et de gérer le programme de microcrédit comme bon lui semble. Le programme se déroule en quatre étapes. Tout d'abord, les candidats sont tenus de soumettre un plan d'affaires. Les plus prometteurs sont alors retenus pour une réunion informelle de consultation, qui constitue la deuxième phase. Durant la réunion, un conseiller en entreprises et le bénéficiaire discutent de leur "partenariat» et des domaines dans lesquels ce dernier pourrait avoir besoin d'aide et de formation. La troisième phase est une formation durant laquelle le bénéficiaire suit des cours de finances et de gestion d'entreprise pendant deux à quatre mois. L'étape finale consiste en un séminaire au cours duquel bénéficiaires et conseillers en entreprises discutent des préparatifs du démarrage de l'activité. Les conseillers désignent alors les bénéficiaires qu'ils jugent les mieux préparés pour créer une entreprise et leur proposent un microcrédit afin de les aider à se lancer (Goli et Rezaei, 2013). Cet exemple démontre que de nombreux programmes de microfinancement incluent également des services d'aide au développement des entreprises. Les entrepreneurs sont d'ailleurs souvent tenus de solliciter ce soutien pour pouvoir bénéficier d'un financement.

Outre des financements, plus de $70 \%$ des opérateurs de microcrédit proposent des services d'aide aux entreprises et d'autres services financiers (p.ex. des crédits à la consommation, des assurances) (EMN, 2010). Le modèle commercial des organismes de microcrédit repose donc sur une combinaison de produits et la possibilité d'appliquer des taux d'intérêt supérieurs à ceux du marché. Des frais de dossier sont également facturés aux bénéficiaires qui n'ont pas accès au système bancaire classique. Néanmoins, le secteur dépend toujours fortement de l'aide publique pour couvrir les coûts opérationnels et le capital de prêt, comme le démontre le ratio moyen de remboursement de $63 \%$ des organismes de microfinance supervisés par le Réseau européen de la microfinance (EMN, 2010).

D'autres exemples de programmes de microcrédit destinés aux entrepreneurs immigrés ou issus de minorités ethniques sont présentés dans les encadrés 7.2 et 7.3 consacrés au programme entrepreneurial Szechenyi pour les populations roms de Hongrie et au partenariat de développement EXZEPT en Allemagne. L'exemple hongrois apporte la preuve de l'efficacité du suivi du programme dans l'ajustement des approches retenues pour identifier et cibler les bénéficiaires. L'exemple d'EXZEPT est un réseau de guichets uniques mis en œuvre avec succès dans trois villes.

Si le microcrédit peut sembler être la solution idéale pour les entrepreneurs immigrés ou issus de minorités ethniques, il ressort de l'étude la plus récente de l'EMN (EMN, 2010) que seuls $41 \%$ de ses membres ont parmi leurs clients des personnes immigrées ou issus de minorités ethniques. Les décideurs politiques peuvent ainsi se rendre compte des efforts qu'il reste à faire pour favoriser l'accès au microcrédit de cette catégorie d'entrepreneurs.

\section{Financement islamique}

L'UE compte actuellement 19 millions de musulmans, soit 3,8\% de sa population totale. Ce chiffre est en augmentation (Pew Forum, 2011). Cette population n'est pas répartie de façon homogène sur son territoire. L'Europe de l'Ouest et du Nord, plus particulièrement les Pays-Bas, la Belgique, la France et le Royaume-Uni, a tendance à attirer davantage d'immigrés musulmans, et notamment davantage de musulmans européens de deuxième génération.

Le financement islamique désigne les instruments financiers conformes à la charia (loi islamique), qui interdit de facturer des taux d'intérêt. La hausse récente du nombre d'organismes financiers islamiques à travers le monde ouvre de réelles perspectives de financement, qui permettront de promouvoir et de faciliter l'entrepreneuriat au sein de la communauté musulmane. 


\section{Encadré 7.2. Programme entrepreneurial Szechenyi (SEP), Hongrie}

Description: le programme entrepreneurial Szechenyi (SEP) vise à encourager l'intégration des populations roms dans la société hongroise. Plus spécifiquement, il soutient financièrement l'amélioration de la position des entreprises roms sur le marché et une plus grande inclusion sociale des populations roms.

Problème abordé: les populations roms souffrent d'exclusion en Hongrie et dans un certain nombre de pays de l'UE. Plus précisément, elles sont régulièrement confrontées à la discrimination et ne bénéficient pas du soutien des services d'aide traditionnels. Ce programme a été mis en place pour permettre au gouvernement hongrois d'apporter un soutien adapté aux besoins des populations roms et sous une forme qui leur soit accessible.

Approche: l'initiative fournit un soutien financier dans le cadre d'une procédure d'appel d'offres. L'objectif est de répondre aux besoins d'investissement des entreprises roms et de celles qui emploient des Roms. Mis en œuvre par le ministère hongrois de l'économie et des transports, le programme couvre l'ensemble du pays. Il fournit également un soutien non financier, notamment des services d'information et des événements de mise en réseau.

Impact: le ministère hongrois de l'économie et des transports fait état d'une augmentation du taux de travail indépendant au sein des populations roms et du taux d'emploi de Roms dans des entreprises non roms. Entre 2003 et 2007, 332 subventions (pour un montant total de 4,6 millions EUR) ont été allouées. Selon les estimations, 400 emplois ont été créés.

Facteurs de réussite: Le succès du programme s'explique en partie par la volonté de ses gestionnaires de faire preuve de flexibilité et de redéfinir les critères d'éligibilité après la mise en œuvre du programme. Les aides financières et non financières offrent un réel avantage du fait de leur complémentarité. Un suivi régulier a permis d'éviter un détournement des subventions, comme ce fut le cas avec d'autres programmes similaires.

Les principaux mécanismes de financement islamiques sont les suivants (Molenaar, 2013):

- Partage des profits (moudaraba): l'investisseur met les fonds à la disposition de l'entrepreneur et perçoit en contrepartie une rémunération, calculée sur la base d'une clé de répartition déterminée à l'avance. Ce principe peut s'appliquer aussi bien aux dépôts bancaires qu'au financement d'activités. Les pertes éventuelles sont supportées par le pourvoyeur du capital.

- Majoration du prix de revient (mourabaha): cette transaction implique la vente de biens à un prix incluant une marge bénéficiaire établie par les deux parties. Toutefois, dans le cas de la mourabaha, le vendeur doit informer l'acheteur du prix réel des actifs au moment de l'accord initial.

- Entreprise commune (mousharaka): il s'agit d'un partenariat dans le cadre duquel les bénéfices sont répartis entre l'emprunteur et le prêteur sur la base d'un ratio prédéfini, qui peut ne pas correspondre au ratio des investissements de départ. Les pertes éventuelles seront divisées sur la base du ratio de départ des différents partenaires.

- Intermédiation (wakala): il s'agit d'un contrat par lequel une personne (le mandant) demande à un tiers d'effectuer une tâche particulière en son nom. La personne qui effectue la tâche en question est un agent, qui sera rémunéré pour ce service.

- Financement à taux zéro (quard): le financement est octroyé pour une période déterminée sur la base d'une décision de complaisance. L'emprunteur n'est tenu de rembourser que la somme empruntée. Il est néanmoins libre de rémunérer le prêteur en signe de reconnaissance.

Parmi les pays de l'UE, le Royaume-Uni est celui où le financement islamique est le plus développé. L'Islamic Bank of Britain est la seule banque du pays totalement conforme à la charia. Face à l'augmentation du nombre de banques qui introduisent des produits conformes 


\section{Encadré 7.3. Partenariat de développement EXZEPT, Allemagne}

Description: établi dans le Land allemand de la Hesse, le partenariat de développement EXZEPT cible les entrepreneurs issus des minorités ethniques et issus d'autres groupes défavorisés. Ce programme favorise l'accès aux microcrédits et propose des conseils en entreprise.

Problème abordé: cette initiative reconnaît la sous-représentation des groupes défavorisés parmi la clientèle des organismes d'aide aux entreprises et l'influence de celle-ci sur leur capacité à obtenir des financements. Le programme EXZEPT a été mis en place pour y remédier. Dans un premier temps, des recherches ont été menées dans le cadre du partenariat afin d'identifier les lacunes rencontrées par les minorités ethniques en matière d'aide aux entreprises. Les difficultés rencontrées par les entrepreneurs immigrés ou issus de minorités ethniques portaient sur la difficulté à réunir de petites sommes d'argent (inférieurs à 25000 EUR) et sur les structures d'aide existantes, dont les chambres de commerce, qui privilégient les entrepreneurs disposant d'antécédents, des pièces souvent difficiles à fournir pour les immigrés.

Approche: l'approche mobilise deux stratégies parallèles, l'une en matière de financement, l'autre dans le domaine du soutien aux entreprises. Le partenariat a donné lieu à la mise en place d'un "guichet unique» qui coopère avec l'Institut allemand de la microfinance et le cercle de qualité allemand de l'aide aux entreprises. De plus, EXZEPT fait partie du partenariat transnational, qui permet d'effectuer des analyses comparatives avec les autres pays de l'UE. Le personnel des initiatives d'aide aux entreprises travaillant avec des groupes immigrés dans quatre grandes villes d'Allemagne a été interrogé afin d'identifier les facteurs clés de réussite des start-up créées par des membres des minorités ethniques. L'une des forces du partenariat EXZEPT réside dans cette approche empirique.

Impact: mis en œuvre avec succès dans trois villes, le modèle de guichet unique proposé par EXZEPT est venu en aide à 2500 personnes en 2003-2004. Bien qu'il ait acquis une bonne réputation en matière d'aide aux start-up, le programme EXZEPT a surtout produit ses effets dans le domaine du microfinancement. EXZEPT a également participé à des études comparatives portant sur des initiatives de microcrédit en Allemagne et dans d'autres pays. Les partenaires du projet ont élaboré et appliqué un système en quatre points pour l'évaluation des demandes de prêts: analyse de la personnalité, du concept, du marché et du risque. Si la demande est validée, un système de suivi bien défini, composé de services d'accompagnement individualisé et collectif et d'autoévaluation, entre en jeu.

Facteurs de réussite: le modèle EXZEPT utilise une approche intégrée associant financement et conseil aux entreprises, des services complémentaires qui augmentent les chances de réussite. Cette approche s'appuie sur des guichets uniques, bien intégrés dans les réseaux des acteurs régionaux, ce qui contribue à les faire accepter par les organismes d'aide traditionnels. En outre, l'approche systématique et documentée permet à d'autres de se nourrir de cette expérience.

à la charia, il incombe au gouvernement de réguler l'offre et la demande sur le marché. Les entrepreneurs musulmans peuvent ignorer l'existence de nouveaux produits de ce type sur le marché des crédits tandis que les organismes financiers qui les proposent doivent collaborer avec ces entrepreneurs.

Le développement du financement islamique et le fort potentiel qu'il offre aux entrepreneurs musulmans ne doivent pas faire oublier aux responsables politiques que les récents essais menés dans l'UE en vue d'introduire des produits financiers islamiques n'ont pas tous été couronnés de succès. Les autorités négligent souvent le fait que les produits financier islamiques doivent être induits par la demande lorsqu'elles envisagent d'introduire ou de soutenir ce type de produits. Aucune donnée n'atteste que l'introduction de ces produits stimule les activités entrepreneuriales (Stressman Foundation, 2012). 


\section{Améliorer les compétences entrepreneuriales}

\section{Formation}

Un grand nombre de villes et régions à travers l'UE proposent des cours et des ateliers en création et gestion d'entreprise aux entrepreneurs issus de minorités ethniques. Ces cours couvrent les questions habituelles des formations sur l'entrepreneuriat, comme la planification, la fiscalité et la gestion des ressources humaines. La formation destinée aux entrepreneurs issus de minorités ethniques se différencie par le fait qu'elle inclut généralement des modules sur la culture d'entreprise et les enjeux de société. Ces sessions de formation sont souvent proposées dans plusieurs langues afin de les rendre les plus intéressantes et utiles possible pour ces entrepreneurs. Au Danemark, les Getting Started Camps sont un exemple unique en matière de formation pour les minorités ethniques (encadré 7.4). Ils organisent des camps de deux jours pour dispenser des formations et favoriser la mise en place de réseaux.

En plus de ces formations, certaines villes proposent des cours de langues qui peuvent favoriser l'intégration des entrepreneurs issus de minorités ethniques dans leur communauté. Par exemple, la municipalité de Terrassa, en Espagne, organise un cours de catalan, auquel participe la communauté chinoise (Goli et Rezaei, 2013).

\section{Services d'aide au développement des entreprises}

Les services d'aide au développement des entreprises couvrent une grande variété de services de conseil destinés à répondre aux besoins de développement des entrepreneurs et de leur entreprise. (Pour une explication plus approfondie des services d'aide au développement des entreprises, nous vous renvoyons au chapitre 8). Les services de conseil en entreprise, l'accompagnement individualisé et le mentorat en sont quelques exemples. L'encadré 7.5 décrit Cre'Action, un programme français de mentorat pour les jeunes entrepreneurs immigrés d'Afrique du Nord. Financé par le FSE, il utilise l'entrepreneuriat comme mécanisme de soutien à leur intégration dans la société française. D'autres exemples sont décrits dans la troisième partie de cet ouvrage, dont Stebo en Belgique et Best Form Boosting Entrepreneurship Tools for Migrants (outils de promotion de l'entrepreneuriat des immigrés) au Portugal, qui proposent un accompagnement individualisé et des formations aux entrepreneurs immigrés.

Les décideurs politiques doivent également prendre conscience des problèmes plus spécifiquement liés à la fourniture de ces services d'appui aux entrepreneurs issus de minorités ethniques. Des données allemandes indiquent que le coût et leur manque de confiance envers les conseillers freinent leur accès aux services d'aide au développement des entreprises (Leicht et al., 2012). Le problème du coût peut être résolu en proposant des services gratuits ou à bas prix. Cette approche est répandue dans l'UE. Le second problème est plus complexe à résoudre, car il faut du temps pour établir une relation de confiance entre les prestataires de services et la communauté. Souvent, les conseillers en entreprise n'appartiennent pas à l'ethnie de leurs clients cibles et ne reflètent donc pas la composition ethnique des groupes auxquels ils s'adressent, ce qui contribue au désintérêt des entrepreneurs issus de minorités ethniques. Ces problématiques sont encore plus marquées chez les femmes entrepreneurs appartenant à ces minorités. Des données allemandes indiquent que les femmes issues de minorités ethniques privilégient les services de conseil spécialisé (Leicht et al., 2009), mais il convient d'être prudent sur ce point. Les responsables politiques risquent toujours d'accroître l'exclusion en fournissant des services d'aide ciblée. 


\section{Encadré 7.4. Getting Started Camps, Danemark}

Description: le but des Getting Started Camps pour les femmes entrepreneurs issues de minorités ethniques (de janvier 2009 à avril 2010) était d'informer les femmes réfugiées et immigrées sur la possibilité de devenir indépendantes. Le projet a été mené avec le soutien du ministère des réfugiés, de l'immigration et de l'intégration ainsi que de la municipalité de Copenhague. Deux groupes de femmes étaient ciblées: 1) les femmes les plus douées, par exemple, les immigrées de pays occidentaux à qui il manque encore quelques compétences entrepreneuriales, et 2) les femmes moins douées, notamment celles des régions défavorisées, qui manquent à la fois de confiance en elles et de compétences formelles.

Approche: le projet reposait sur une coopération entre les autorités municipales et gouvernementales. Des entreprises du secteur privé ont financé les prix de différents concours. La proximité a été le premier volet important du projet. Des efforts ont été faits pour informer sur les opportunités du travail indépendant et les aides disponibles à Copenhague. Des sessions d'information ont été organisées dans les zones d'habitation à forte concentration de minorités ethniques et d'immigrés. Des impressions ont été distribuées dans les clubs, associations et groupes communautaires concernés.

Les camps ont permis de dispenser une formation intensive de deux jours sur le thème du développement d'idées créatives, des solutions et des notions relatives à l'entrepreneuriat. Lors du premier camp, qui réunissait 45 participantes issues du premier groupe cible, des femmes instruites et motivées, l'accent a été mis sur le développement des concepts et des projets d'entreprise des participantes. Le deuxième camp, qui s'est déroulé sur deux jours et demi, ciblait le second groupe cible, à savoir des femmes assez loin d'être indépendantes sur le plan économique. Il a réuni cinq participantes. La formation qui leur a été dispensée était d'un niveau plus élémentaire.

À la suite des camps, les participantes qui avaient élaboré un plan d'affaires détaillé ont pu participer à un concours de projet d'entreprise doté d'un prix de 20000 DKK (environ 2680 EUR). Le jury était composé de conseillers en entreprise ainsi que de membres d'associations professionnelles et d'organismes financiers. Il a décerné le prix après avoir émis un avis détaillé sur le projet de chaque participante.

Impact: selon l'évaluation de ce projet, $16 \%$ des participantes sont devenues indépendantes. Elles n'étaient que $3 \%$ à l'être au début du projet. $34 \%$ des participantes ont abandonné l'idée de devenir indépendantes pendant le projet et $44 \%$ d'entre elles ont déclaré avoir toujours l'intention de se lancer.

Facteurs de réussite: en mettant fortement l'accent sur des activités collectives telles que les camps, le projet a permis aux participantes de développer leurs réseaux et a suscité en elles confiance et détermination. Les évaluations montrent que l'approche du camp en matière de formation et la compétition autour du financement sont efficaces et devraient être incorporés à d'autres projets (EVU, 2007; Rezaei et Goli, 2006).

\section{Atteindre les bénéficiaires au sein des minorités ethniques}

La principale difficulté qui se pose aux responsables politiques en matière d'aide aux entrepreneurs issus de minorités ethniques réside dans l'inutilisation des aides aux entreprises par ces derniers (Ram et Smallbone, 2003). Les prestataires d'aide aux entreprises ont souvent du mal à identifier les bénéficiaires potentiels issus de ces minorités pour plusieurs raisons. Premièrement, rares sont ceux qui consignent l'origine ethnique des propriétaires d'entreprise qui bénéficient d'un soutien. Les bases de données existantes ne permettent donc pas d'effectuer un suivi adapté, ni de tirer des enseignements des expériences passées. Deuxièmement, les approches orientées produit adoptées par la grande majorité des prestataires traditionnels ne sont pas adaptées aux problématiques 


\section{Encadré 7.5. Cre'Action, France}

Description: le programme français Cre’Action («De la migration à la création d'activité») visait à aider des immigrés nord-africains sans emploi âgés de 18 à 30 ans à créer leur entreprise en les mettant en relation avec des propriétaires d'entreprise chevronnés issus de leur communauté ethnique. Ce programme de mentorat a débuté en 2002 et a été modifié en 2005, avant de prendre fin en 2007.

Problème abordé: les jeunes immigrés ou issus de l'immigration sont sous-représentés dans les créations d'entreprise en France. Le programme Cre'Action avait pour but d'aider les jeunes immigrés à s'intégrer dans la société française et à créer leur propre emploi.

Approche: ce programme de mentorat a permis de développer un réseau d'entrepreneurs nord-africains. La mobilisation d'entrepreneurs issus du même groupe ethnique visait à rendre le projet attractif aux yeux des jeunes et à exploiter le capital social de la communauté. Le budget total du programme s'élevait à 775000 EUR sur trois ans (2002-2005). En 2005, Cre'Action a été remplacé par le programme «De la migration à la création", doté d'un budget de 368400 EUR sur la période 2005-2007. Les fonds de chaque programme provenaient pour moitié du Fonds social européen, via le programme EQUAL, et pour $40 \%$ des pouvoirs locaux, les $10 \%$ restants étant apportés par des investisseurs privés.

Impact: entre 2002 et 2006, 223 entrepreneurs potentiels se sont portés candidats au programme. Ceux-ci étaient globalement bien instruits, $76 \%$ d'entre eux étant au moins titulaire d'une licence. Sur les 225 candidats, 48 ont été retenus pour le programme et 25 ont poursuivi le démarrage de leur activité. Même si 23 d'entre eux n'ont pas créé d'entreprise, pour bon nombre, le résultat a été positif puisque le mentorat leur a permis de trouver un emploi salarié.

Facteurs de réussite: l'aide à la création d'entreprise apportée aux jeunes issus de l'immigration reposait sur une relation de confiance. Des services de grande qualité ont ainsi pu leur être proposés en face-à-face. L'organisme responsable travaillait avec cette communauté depuis plus de 30 ans et connaissait bien les difficultés auxquelles les jeunes qui en sont issus sont confrontés.

culturelles telles que la langue, la religion et, dans certains cas, le sexe. Troisièmement, leurs offres peuvent ne pas convenir aux entreprises exploitées par des entrepreneurs issus de minorités ethniques. Quatrièmement, de nombreuses données attestent d'un manque de confiance de ces chefs d'entreprise envers ceux qui fournissent l'aide (p.ex. Ram et Smallbone, 2003; Leicht et al., 2012).

La réponse politique à ce problème doit mettre l'accent sur l'élaboration de stratégies d'engagement, qui définissent le rôle de la proximité. Il ne s'agit pas de la proximité à proprement parler, mais plutôt de la manière dont les organismes traditionnels développent leurs activités de proximité. Il est important que les prestataires d'aide aux entreprises soient en relation directe avec d'autres intermédiaires qui ont affaire aux personnes immigrées ou issus d'une minorité ethnique, car bon nombre d'obstacles sont liés aux institutions et à la législation.

Une approche communautaire apparaît donc nécessaire dès lors que l'aide et les conseils sont fournis par l'intermédiaire des réseaux et mécanismes de la communauté. Le principal avantage de cette approche est qu'elle permet de mieux identifier les besoins de la communauté et d'impliquer directement les parties prenantes concernées. Une approche communautaire «horizontale» qui met l'accent sur l'engagement joue également un rôle important, car elle sert de base au renforcement des relations de confiance. Il est essentiel d'établir la confiance si l'on veut être accepté par la communauté. C'est une première étape 
nécessaire pour attirer les entrepreneurs. L'encadré 7.6 explique comment des partenariats locaux britanniques ont permis d'atteindre les minorités ethniques.

Toujours au Royaume-Uni, l'expérience du Phoenix Fund confirme le potentiel des approches communautaires. De nombreuses entreprises exploitées par des noirs, des personnes issues de minorités ethniques des réfugiés n'ont pas accès à l'aide traditionnelle. L'approche doit donc s'appuyer sur des intermédiaires qui ont su gagner la confiance de la communauté (Ramsden, 2005). Bien que couronnée de succès, cette approche n'est pas la plus efficace et la plus économique, car le soutien aux bénéficiaires difficilement accessibles doit être intensif, flexible et local. La flexibilité peut impliquer que ces services soient dispensés en dehors des heures ouvrées et par des conseillers spécialisés et formés pour travailler avec ce type de bénéficiaires. Idéalement, ces conseillers sont recrutés et formés au sein des communautés elles-mêmes.

\section{Encadré 7.6. Conseillers en entreprise communautaires, Royaume-Uni}

Description: SIED/REFLEX est un partenariat conduit par les autorités locales, qui réunit plusieurs prestataires d'aide aux entreprises. Le groupe cible de l'initiative regroupe à la fois les entrepreneurs potentiels et ceux qui sont difficiles à atteindre. Dans le cas de Londres, il s'agit des femmes musulmanes, des immigrés récemment arrivés et des demandeurs d'asile. Leur point commun est qu'ils sont tous difficiles à atteindre du point de vue des prestataires d'aide aux entreprises traditionnels.

Problème abordé: le partenariat SIED/REFLEX vise à remédier à ce problème de fourniture d'aide en ciblant les groupes difficiles à atteindre, en grande partie en marge du système d'aide traditionnel. Le problème central est la méfiance à l'égard des prestataires traditionnels et de l'aide aux entreprises traditionnelle. Outre la question de la confiance et de l'identité, dans certains cas, les besoins dépassent le cadre strict de l'aide telle qu'elle a été définie. Cela est particulièrement vrai pour les immigrés récemment arrivés et les demandeurs d'asile, qui peuvent avoir besoin d'une aide plus basique lors de leurs échanges avec les institutions de leur nouvel environnement (p.ex. ouverture d'un compte bancaire).

Approche: les conseillers du partenariat informent, conseillent et accompagnent les sociétés, établies ou potentielles, dans leurs demandes de financement. L'objectif est de jeter les bases d'une relation de confiance entre ces derniers et leurs clients. Cela est rendu possible par le fait que ces conseillers sont recrutés directement au sein des communautés. Un autre aspect clé de cette approche réside dans le fait qu'ils sont pleinement formés et accrédités sur la base de critères nationaux.

Les conseillers communautaires sont rattachés à des institutions communautaires qui, dans un nombre limité de cas, peuvent être liées au monde des affaires (p.ex. cercle d'affaires, association professionnelle). La plupart d'entre elles sont des centres communautaires ou apparentés auxquels les membres de la communauté s'adressent régulièrement. Ainsi, pour de nombreux bénéficiaires potentiels, se rendre dans un centre communautaire pour obtenir des conseils en entreprise ne constitue pas un obstacle psychologique, comme cela peut être le cas avec certains prestataires traditionnels tels que Business Link, qu'ils considèrent comme appartenant à l'ordre établi.

Des ressources sont allouées aux organisations communautaires qui sont une source de stabilité au sein du système, contrairement aux conseillers qui peuvent changer d'emploi. Il est donc important qu'elles disposent d'une base institutionnelle. Le partenariat SIED/ REFLEX a reçu deux tranches de financement du programme EQUAL, qui lui ont permis de se développer pendant huit ans. Grâce à la seconde tranche de financement, le projet a pu être étendu à d'autres quartiers de Londres. 
Impact: le programme n'a pas été évalué officiellement, même si des données de suivi ont dû être fournies dans le cadre du programme EQUAL. De plus, le Small Business Research Centre de l'université de Kingston, l'un des partenaires de SIED/REFLEX, a été chargé de mener une évaluation destinée à faire remonter les impressions sur le programme. L'Association of Community Based Business Advice (ACBBA), créée dans le cadre du financement de départ, ont également fait partie des organisations majeures qui ont contribué au fonctionnement de l'initiative. L'ACBBA a joué un rôle majeur en gérant le partenariat, puis en recherchant de nouveaux contrats et en développant le partenariat après la période de financement.

Cette organisation centrale de mise en réseau facilite le partage de bonnes pratiques et l'évolution professionnelle de conseillers en entreprise. Lors de l'évaluation de l'impact, il convient de garder à l'esprit que la zone couverte par le projet est l'une des plus défavorisées du pays. Ce programme a eu des répercussions évidentes sur les entreprises clientes (plus de 1000 durant la période de financement) mais il a également une influence sur la politique et les pratiques en place.

Facteurs de réussite: tous les réseaux de partenaires ont besoin d'un leadership fort. En l'occurrence, c'est le district d'Islington, à l'origine du projet, qui a assuré ce rôle. Il s'est également chargé de la préparation de la demande initiale et des rapports de suivi exigés. La deuxième clé du succès implique de garantir un financement de base régulier: les organisations comme l'ACBBA disposent de ressources propres très limitées, mais occupent un rôle central dans le projet, en particulier dans la diffusion des résultats.

\section{Conclusions et recommandations politiques}

Les membres des minorités ethniques et des groupes d'immigrés sont confrontés à un certain nombre de difficultés lorsqu'ils créent leur entreprise. Des éléments suggèrent que l'environnement institutionnel, tant sur le plan des lois et des réglementations que de la culture et des comportements sociaux, a une influence négative sur les activités entrepreneuriales. Cette situation s'explique par sa méconnaissance et par le fait que bon nombre d'immigrés arrivant dans l'UE viennent d'environnements moins réglementés. L'accès au financement d'amorçage et le manque de compétences entrepreneuriales leur posent également des problèmes. Il existe de nombreux exemples de mesures politiques locales, nationales et européennes qui visent à aider les entrepreneurs issus de minorités ethniques dans chacun de ces domaines.

Toutefois, les responsables politiques de l'UE doivent souvent relever un double défi: renforcer la participation des minorités ethniques et faciliter l'accès à l'aide existante. À l'évidence, il n'est pas rentable de proposer des services spécialisés en cas de faible densité ethnique. Il apparaît donc nécessaire d'envisager d'autres options, telles que le recrutement de conseillers issus de minorités ethniques chargés de fournir une aide spécialisée dans le cadre de l'offre des prestataires traditionnels. Des prestataires dédiés aux besoins de ces minorités ne sont pas la solution, sauf dans les zones urbaines où les minorités ethniques sont plus présentes.

Nombre des besoins des entrepreneurs immigrés ou issus de minorités ethniques en matière d'aide ne sont pas spécifiquement liés à l'activité entrepreneuriale. Il est donc essentiel d'établir des liens solides entre les aides à l'entrepreneuriat et les programmes qui dispensent aux immigrés récemment arrivés les connaissances et compétences grâce auxquelles ils pourront prétendre à la citoyenneté de leur pays d'accueil. De même, des liens doivent être instaurés avec les politiques d'intégration afin de favoriser l'inclusion des minorités ethniques dans la société. 


\section{Principales recommandations politiques}

- Informer les minorités ethniques et les immigrés sur les opportunités d'entrepreneuriat et les régimes d'aide aux entreprises. Il est important d'utiliser les médias communautaires locaux tels que les stations de radio, les lettres d'information et les journaux, et de ne pas se limiter aux médias traditionnels.

- Obtenir la même diversité ethnique chez les prestataires d'aide aux entreprises que du côté de la demande (les entrepreneurs). Ce point est important, car la confiance influence fortement l'intérêt des minorités ethniques et des groupes immigrés à l'égard de l'aide traditionnelle aux entreprises. La collaboration avec des organisations communautaires est une approche efficace.

- Concevoir des actions politiques publiques visant à développer et renforcer le capital social et les réseaux au lieu d'imposer de nouvelles infrastructures. Par exemple, soutenir la création d'associations professionnelles de minorités ethniques et d'immigrés, qui peuvent contribuer à instaurer un climat de confiance autour de l'aide aux entreprises. En d'autres termes, toute tentative de renforcement des institutions informelles sera bénéfique au renforcement des institutions formelles.

- Évaluer activement les nouveaux règlements susceptibles d'affecter le développement des entreprises afin de s'assurer qu'ils ne discriminent pas les minorités ethniques ou les immigrés. Contrôler plus particulièrement ceux qui peuvent créer des entraves linguistiques.

- Veiller à ce que les minorités ethniques et les immigrés aient accès aux garanties de prêt et aux programmes de microcrédit soit en intégrant des branches spéciales dans les régimes traditionnels, soit en instaurant de nouveaux régimes ciblés.

- Organiser des formations pour améliorer les compétences financières de base des entrepreneurs issus d'une minorité ethnique ou d'origine immigrée et accroître ainsi leurs chances d'obtenir des financements sur les marchés de crédit.

- Proposer des formations linguistiques dans le cadre de formations à l'entrepreneuriat afin de favoriser l'intégration des minorités ethniques et des immigrés dans la société et leur permettre de mieux s'orienter dans l'environnement institutionnel.

- Améliorer l'évaluation et le suivi systématiques et exhaustifs des interventions politiques. Il est important de suivre l'utilisation des aides selon le sexe, l'origine ethnique et le statut de migrant des bénéficiaires des différents prestataires publics d'aides aux entreprises aux niveaux local, régional et national.

\section{Références}

Agentur für Gleichstellung im ESF (2010), Gender-Aspekte in der Existenzgründung, Berlin.

Alund, A. (2003), «Ethnic Entrepreneurs and Other Migrants in the Wake of Globalization», International Review of Sociology, vol. 13 (1), p. 77-87.

Andersen, J. (2008), «Ressourcemobiliserende beskæftigelsespoltitik», Roskilde Universitets Forlag, Danemark.

APCE (2013), «Les entreprises créées par des migrants trois ans après la création», Note d'analyse, APCE Observatoire, avril.

APCE (2012), Création d'entreprise par les entrepreneurs issus de l'immigration. L'exemple des entrepreneurs d'origines maghrébines, Collection FOCUS, Paris.

Coleman, J. (1987), «Social capital in the creation of human capital», Am. J. Social, vol. 94, p. 95-121. 
Davidsson, P. et Wiklund, J. (1997), «Values, Beliefs and Regional Variations in New Firm Formation Rates", Journal of Economic Psychology, vol. 19 (2), p. 81-104.

De Luca, F. (2011), «Percorsi e strategie imprenditoriali di fronte alla crisi», dans CNEL Il profilo nazionale degli immigrati imprenditori, (p. 173-196), Rome.

Commission européenne (CE) (2008), «Think Small First: Priorité aux PME. Un Small Business Act pour l'Europe», communication de la Commission au Parlement européen, au Conseil, au Comité économique et social européen et au Comité des régions, disponible sur: http://eur-lex.europa.eu/ LexUriServ/LexUriServ.do?uri=COM:2008:0394:FIN:FR:PDF.

Commission européenne - OCDE (2014), «Accès au financement pour la création d'entreprise dans le cadre de l'entrepreneuriat inclusif», UE: Luxembourg.

Fonds européen d'investissement (FEI) (2009), «Microfinance in Europe: A Market Overview», Working Paper 2009/01, Luxembourg.

European Microfinance Network (REM) (2010), «Overview of the Microcredit Sector in the European Union", Working Paper $n^{\circ}$ 6, Fundación Nantik Lum.

EVU (2007), «Dokumentation og analyse af effekterne af ops øgende rådgivning til etniske virksomheder og iværksættere i Københavns Kommune».

Fischer-Krapohl, Y. (2010), «Migrantenökonomie in der Stadt - Räumliche Verteilung, Potenziale und Good-Practice zur kommunalen Förderung", dans Matern, A., von Löwis, S. et Bruns, A. (eds.), Integration - Aktuelle Anforderungen und Strategien in der Stadt-, Raum- und Umweltplanung, Arbeitsmaterial der ARL, $n^{\circ} 353$, p. 43-57.

Goli, M. et Rezaei, S. (2013), «Entrepreneurship by ethnic minorities: A background paper on skills and finance», préparé dans le cadre du programme LEED de l'OCDE.

Granovetter, M. (1983), «The Strength of Weak Ties: A Network Theory Revisited», Sociological Theory, vol. 1, p. 201-233.

Heelsum, A. (2012), «Ethnic entrepreneurship - Case study: Terrassa, Spain», European network of cities for local integration policies, http://www.eurofound.europa.eu/publications/htmlfiles/ef112110. htm.

Hegedahl, P. et Rosenmeier, S. (2007), Social kapital — som teori og praksis, Samfundslitteratur.

Jaegers, T. (2008), «Supporting Entrepreneurial Diversity in Europe - Ethnic Minority Entrepreneurship/ Migrant Entrepreneurship", Migrações Journal, vol. 3, p. 281-284.

Kay, R. et Schneck, S. (2012), «Hemmnisse und Probleme bei Gründungen durch Migranten», Institut für Mittelstandsforschung (ed.), IfM Materialien, $\mathrm{n}^{\circ} 214$.

Kloosterman, R. et Rath, J. (2003), Immigrant Entrepreneurs. Venturing Abroad in the Age of Globalization, Oxford/New York: Berg/University of New York Press.

Law, I. (2007), «Ethnic Minority Business: Policy and Practice Review», document de communication présenté devant ESRC/CREMI/ETI/EMDA/

Leicht, R., Di Bella, J., Langhauser, M., Leiß, M., Philipp, R., Volkert, M. et Werner, L. (2012), Bedeutung, Triebkräfte und Leistungen von Migrantenunternehmen in Baden-Württemberg (und Deutschland), Studie im Auftrag des Ministeriums für Finanzen und Wirtschaft Baden-Württemberg, Institut für Mittelstandsforschung, Universität Mannheim.

Leicht, R., Strohmeyer, R., Leiß, M. et Philipp, R. (2009), Selbständig integriert? Studie zum Gründungsverhalten von Frauen mit Zuwanderungsgeschichte in Nordrhein-Westfalen, Ministerium für Generationen, Familie, Frauen und Integration NRW (Hg.), Düsseldorf.

Light, I. (2010), «Foreword» dans Honig, B., Drori, I. et Carmichael, B., Transnational and Immigrant Entrepreneurship in a Globalized World, Toronto: University of Toronto, p. ix-xvi.

McKay, S., Markova, E., Paraskevopoulou, A. et Wright, T. (2009), «The relationship between migration status and employment outcomes", disponible sur: http://cordis.europa.eu/documents/ documentlibrary/126625571EN6.pdf

Molenaar, K. (2013), «Financing of Micro, Small and Medium Enterprises for Underrepresented and Socially Disadvantaged Groups», document d'information préparé dans le cadre du programme LEED de l'OCDE, mars 2013.

Nkakleu, R. et Levy-Tadjine, T. (2005), «La singularité de l'entrepreneuriat des migrants en France», Reuue congolaise de gestion, $n^{\circ}$ 9-10, septembre, p. 23-43. 
OCDE (2013), Panorama de l'entrepreneuriat 2013, Publication OCDE, Paris http://dx.doi.org/10.1787/ entrepreneur_aag-2013-fr.

OCDE/Commission européenne (2013), Pallier la pénurie d'entrepreneurs: Politiques d'entrepreneuriat inclusif en Europe, Publication OCDE, Paris http://dx.doi.org/10.1787/9789264188167-fr.

Pécoud, A. (2012), «Immigration, entreprenariat et ethnicité», Métropoles, $\mathrm{n}^{\circ} 11$, disponible sur: http://metropoles.revues.org/4560, 8 septembre 2013.

Pew Forum (2011), The Future of the Global Muslim Population, Washington DC.

Putnam, R., Leonardi, R. et Nanetti, R. (1993), Making Democracy Work: Civic Traditions in Modern Italy, Princeton: Princeton University Press.

Ram, M. et D. Smallbone (2003), «Policies to Support Ethnic Minority Enterprise: the English Experience», Entrepreneurship and Regional Development, vol. 15(2), p. 151-166.

Ram, M., Smallbone, D. et Deakins, D. (2002), «Ethnic Minority Businesses in the UK: Access to Finance and Business Support», British Banking Association, Londres.

Ramsden, P. (2005), «Evaluation - The Phoenix Development Fund», Department for Business, Enterprise and Regulatory Reform.

Rath, J., Swagerman, A., Krieger, H., Ludwinek, A. et Pickering, L. (2011), Promoting ethnic entrepreneurship in European cities, Office des publications de l'Union européenne, Luxembourg.

Rezaei, S. et Goli, M. (2007), «Indvandreres tætte netværk: Katalysator eller hæmsko for innovation og vækst? Et studie af formelle og uformelle netværksrelationers betydning for dynamikken I indvandrerejede virksomheder", Roskilde University Press.

Rezaei, S. et Goli, M. (2006), «Det duale arbejdsmarked i et velfærdsstatsligt perspektiv - et studie af dilemmaet mellem uformel økonomisk praksis og indvandreres socio-økonomiske integration", University of Roskilde, Delrapport 4, Hovedrapport.

Serden Özcan, L. (2013), «In Danes we don't trust», disponible sur: http://www.jyllands-posten.dk/ premium/erhverv/ECE5792638/in-danes-we-don-t-trust/.

Stressman Foundation (2012), «Intrinsic Barriers of Islamic Finance: Sharia Scholars and the Low Muslim Income», Löbdergraben, Allemagne.

Tisserant, P. (2003), «L'entrepreneuriat immigré: contribution à l'étude de l'aide à la création d'entreprise par les personnes d'origine étrangère», document de travail, Laboratoire ETIC, Université de Metz.

Triodos Facet (2008), «Entrepreneurial Diversity in a Unified Europe — Ethnic Minority Entrepreneurship/ Migrant Entrepreneurship», Commission européenne, Bruxelles.

Welter, F. (2012), «Determinants of Entrepreneurship: Institutional Factors», document d'information relatif à un projet de l'OCDE sur l'entrepreneuriat et l'inclusion sociale. 



\section{Chapitre 8}

\section{Services d'aide au développement des START-UP}

Ce chapitre s'intéresse au rôle des services d'aide au développement d'entreprise dans la promotion et le soutien de la création d'entreprises et du travail indépendant des entrepreneurs potentiels issus de groupes défavorisés ou sous-représentés. Il se penche sur les approches de politique publique et non lucratives de l'Union européenne et formule des recommandations quant à la manière de renforcer ce type de soutien. 


\section{Justification des services d'aide au développement des start-up}

- Les services d'aide au développement des entreprises sont tout à fait justifiés pour améliorer le capital social et humain des entrepreneurs issus de groupes défavorisés ou sous-représentés.

- Ces services se justifient du point de vue économique, car ils remédient aux entraves et aux défaillances du marché auxquelles les entrepreneurs sont confrontés, en particulier ceux qui sont issus de groupes défavorisés et sous-représentés, lorsqu'ils créent et développent leur entreprise.

- Ils trouvent leur justification sociale dans les avantages qu'ils apportent en termes d'inclusion sociale.

Les services d'aide au développement des start-up sont des services destinés à améliorer la performance d'une nouvelle entreprise en renforçant sa capacité à pénétrer et exercer une concurrence sur les marchés. Ces services visent à stimuler l'envie d'entreprendre, renforcer les qualifications et compétences entrepreneuriales personnelles, multiplier les créations d'entreprise et accroître la viabilité des start-up. Ils peuvent être un précieux soutien pour les personnes qui ont des compétences dans un secteur ou un métier spécifique, mais qui ne disposent pas des qualifications et des connaissances suffisantes pour créer et exploiter une entreprise. Il s'agit notamment de services d'orientation, de promotion de modèles, de formation, d'accompagnement individualisé, de mentorat et de conseil en entreprise.

\section{Justification économique}

L'action politique publique se justifie principalement pour corriger les défaillances du marché, telles que le manque d'informations. Les individus peuvent ne pas avoir conscience de leur propre inclination pour l'entrepreneuriat ou ne pas le considérer comme un choix de carrière viable. Ils peuvent également ne pas maîtriser le fonctionnement de certains marchés, règlements ou chaînes d'approvisionnement et ne pas se rendre compte des avantages à faire appel aux conseils et à l'assistance d'un spécialiste extérieur pour développer leurs connaissances entrepreneuriales et managériales (p.ex. formation, planification, conseil stratégique) ainsi que leurs réseaux (p.ex. salons professionnels, mentors).

Les services d'aide au développement des entreprises peuvent aussi développer les ressources dont disposent les entrepreneurs. Cette aide extérieure présente l'avantage majeur d'enrichir leur capital social et humain en améliorant leurs capacités à détecter et évaluer des opportunités, à élaborer et mettre en œuvre des stratégies efficaces d'exploitation et d'occupation des marchés (Chrisman et al., 2005). Outre ces compétences, les entrepreneurs apprennent où s'adresser pour obtenir d'autres aides si nécessaire.

Les services d'aide au développement des entreprises se justifient en outre par le fait qu'ils complètent les aides financières publiques (p.ex. subventions ou prêts). Par exemple, la rédaction d'un plan d'affaires formel peut agir comme un filtre d'accès aux prêts et subventions. De même, l'approfondissement et l'élargissement des compétences d'un entrepreneur peuvent également augmenter leurs chances d'obtenir un soutien financier. Une analyse des mécanismes de microfinancement de l'UE indique que des 
dispositifs de soutien financier et d'accompagnement étaient généralement proposés aux entrepreneurs du type immigrés, femmes et chômeurs afin d'augmenter leurs chances de réussite (Botti et Corsi, 2011). L'étude ne tire pas de conclusions sur l'efficacité des services d'aide au développement des entreprises proposés par les opérateurs européens de microfinancement. Elle souligne néanmoins que les mécanismes qui octroient des prêts à des bénéficiaires défavorisés ou à faible revenu sont moins viables, car les prêts portent sur de faibles montants et sont plus coûteux à gérer (Botti et Corsi).

Enfin, les services d'aide au développement des entreprises peuvent tirer profit des externalités positives telles que des externalités de démonstration (p.ex. modèles) (Audretsch, 2002). Les modèles, par exemple, jouent un rôle primordial dans le soutien des aspirations entrepreneuriales (Van Auken et al., 2006) et sont essentiels au développement et à la viabilité des start-up (Bosma et al., 2012). Les exemples de modèles ayant réussi à sortir d'une situation économique désavantageuse peuvent avoir de l'importance pour certaines communautés et catégories de personnes chez qui l'entrepreneuriat est sous-représenté. Par exemple, les personnes dont les niveaux d'instruction sont faibles s'identifient moins fréquemment à un modèle, ce qui peut faire obstacle à leurs tentatives de créer et développer leur entreprise (Bosma et al., 2012). Parmi les autres externalités positives, citons le renforcement et l'ancrage du capital social des entrepreneurs issus des groupes défavorisés ou sous-représentés. Ceux-ci sont souvent désavantagés parce qu'ils n'ont ni le savoir-faire ni le carnet d'adresses suffisants. D'où l'intérêt d'avoir accès à des bonnes pratiques. Leur répercussion sur certains secteurs et marchés contribue à améliorer la viabilité à long terme des nouvelles entreprises.

\section{Justification sociale}

L'aide aux entrepreneurs issus de groupes défavorisés ou sous-représentés est également motivée par des raisons d'inclusion et d'égalité sociales. Des zones de déséquilibres économiques persistants demeurent dans de nombreuses économies de l'UE. Le soutien à l'entrepreneuriat peut produire des externalités positives pour certaines communautés. Des entrepreneurs issus de communautés défavorisées peuvent apporter la preuve à d'autres membres de leur communauté qu'il est possible de sortir de la pauvreté par la création d'entreprise et le travail indépendant. Les femmes chefs d'entreprise qui réussissent peuvent elles aussi souligner le potentiel de l'entrepreneuriat et encourager le développement des connaissances et des réseaux en partageant leurs expériences et leur expertise avec d'autres qui aspirent à créer leur entreprise.

L'entrepreneuriat peut en outre favoriser l'égalité des chances. Par exemple, au sein de l'UE, les femmes ne représentent que $31 \%$ des indépendants et seulement $25 \%$ des indépendants qui emploient des salariés (voir chapitre 2). Si un plus grand nombre femmes étaient encouragées à se lancer dans l'entrepreneuriat et si leurs entreprises pouvaient se développer durablement, cela pourrait contribuer à réduire les inégalités subies par les femmes et les entrepreneurs issus de groupes défavorisés et sous-représentés sur le marché du travail.

\section{Approches de politique publique concernant la prestation des services d'aide au développement des entreprises}

- Au sein de l'UE, les services d'aide au développement des entreprises mis en place par les pouvoirs publics incluent des services d'orientation, destinés à un grand nombre de bénéficiaires, et des formes plus intensives et plus personnalisées de soutien (p.ex. accompagnement individualisé, mentorat, conseil en entreprise). 
- Les bénéficiaires des aides individualisées s'identifient généralement mieux aux prestataires appartenant au même groupe cible (femmes, jeunes, seniors, minorités ethniques).

- Bien que limitées, les données sur l'efficacité des services publics d'aide au développement des entreprises suggèrent que les aides donnent de meilleurs résultats lorsqu'elles sont conçues et fournies d'une manière intégrée qui soutient les entrepreneurs pendant et après la phase de démarrage de l'entreprise.

- Les États membres de l'UE adoptent des approches différentes en matière de prestation de services d'aide au développement des entreprises. Certains passent par des prestataires spécialisés tandis que d'autres font appel aux mécanismes de mise en œuvre traditionnels. Il n'est pas clairement établi qu'une méthode serait plus efficace que l'autre. Cela dépend souvent de la taille relative du groupe cible.

En réponse aux obstacles identifiés dans le chapitre précédent, plusieurs solutions s'offrent au secteur public pour soutenir les services d'aide au développement des entreprises, soit en direct, soit via le secteur à but non lucratif. Le Graphique 8.1 présente les trois principaux types de services d'aide proposés aux start-up: l'orientation, la formation et le soutien personnalisé (p.ex. accompagnement individualisé, mentorat et conseil en entreprise).

\section{Graphique 8.1. Services d'aide au développement des start-up}

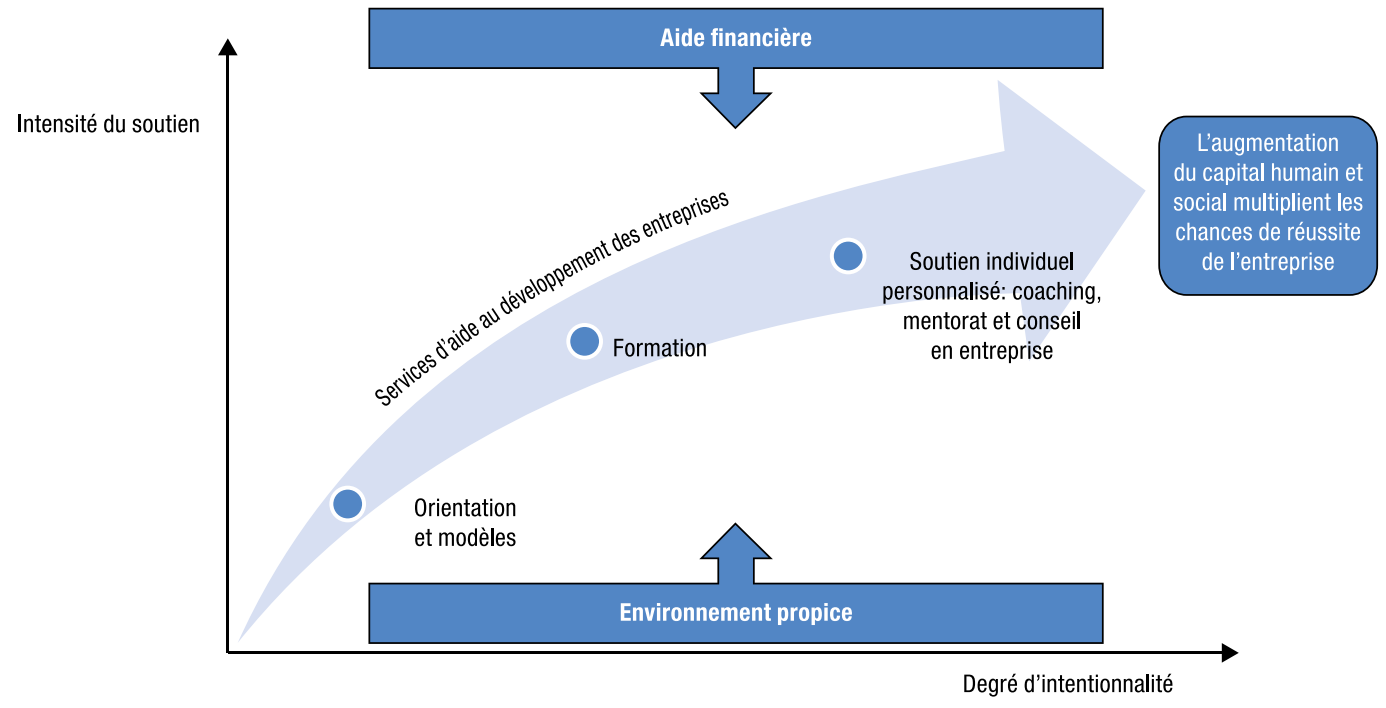

Source: Adapté de Greene, F. (2013), «Start-up Business Development Support Services for Inclusive Entrepreneurs», préparé dans le cadre du programme LEED de l'OCDE.

Bien qu'une entreprise puisse être créée sans aucun soutien officiel, le Graphique 8.1 présente les aides publiques dont les entrepreneurs naissants peuvent potentiellement bénéficier.Plusl'intention de créer uneentreprise est forte, plus les services d'aide aux entreprises ont tendance à s'intensifier. Les formes d'assistance opérationnelle ou transactionnelle (p.ex. orientation), qui s'adressent à la grande majorité des entrepreneurs, laissent alors place à des formes de soutien plus stratégiques ou transformationnelles (p.ex. accompagnement individualisé, mentorat, conseil en entreprise) qui tendent à être plus individualisées.

Bien qu'ils ne soient pas abordés dans ce chapitre, le soutien financier et la présence d'un environnement favorable jouent un rôle important dans le processus de création d'entreprise, en particulier dans le cas des entrepreneurs issus des groupes défavorisés et sous-représentés 
(OCDE/CE, 2013). Le soutien financier, même s'il s'adresse plus fréquemment aux entrepreneurs naissants résolus à créer une entreprise, peut également être disponible après la phase de démarrage pour contribuer au développement de la société. Comme l'indique le Graphique 8.1, la nature de l'environnement détermine la façon dont les entrepreneurs naissants développent et exploitent leur nouvelle entreprise. En général, plus l'environnement est porteur, plus les opportunités de création d'entreprise sont grandes.

\section{Orientation}

Les services d'orientation sont des ressources «opérationnelles» (Hjalmarsson et Johansson, 2003) qui peuvent jouer un rôle d'intermédiation, de sensibilisation et de diffusion important dans l'information des entrepreneurs potentiels sur leur propension à entreprendre, les aides disponibles et la manière dont ils peuvent identifier leurs besoins futurs. Selon l'Organisation internationale du travail (OIT) (2006), ce type de services peut informer les entrepreneurs issus de groupes défavorisés et sous-représentés sur les services de formation, de conseil et de mentorat. Les services d'information et d'orientation sont de plus en plus disponibles sur internet (CE, 2002). Diverses plateformes, mises en place par l'UE et par les États membres, proposent un guichet unique grâce auquel tous les entrepreneurs peuvent s'informer sur différentes questions opérationnelles liées à la création d'entreprise (p.ex. marketing, gestion, enregistrement d'une entreprise, fiscalité, sources de financement).

Il est difficile pour les entrepreneurs potentiels issus de groupes défavorisés ou sousreprésentés de déterminer quel type d'activité entrepreneuriale est à la fois souhaitable et réalisable. Deux tiers des femmes (63\%) n'ont jamais envisagé de créer une entreprise (CE, 2012), ce qui prouve que la connaissance constitue un obstacle majeur pour les groupes cibles de la politique d'entrepreneuriat inclusif. De plus, les personnes qui souhaitent démarrer une entreprise ne passent pas forcément à l'acte. À titre d'exemple, selon des données de l'UE, $45 \%$ des jeunes (15-24 ans) sont intéressés par l'entrepreneuriat, mais seuls $6 \%$ d'entre eux ont réellement entrepris des démarches en ce sens (CE, 2012).

D'aucuns pensent qu'il existe des entraves à l'information. Plus de la moitié des femmes, les chômeurs et les jeunes estiment qu'il est difficile d'obtenir des informations concernant la marche à suivre pour créer une entreprise (CE, 2012). Les résultats des entrepreneurs issus de groupes défavorisés ou sous-représentés peuvent également être limités et menacer leur viabilité à long terme. Les entrepreneurs seniors (plus de 55 ans) ont moins tendance à définir des orientations en termes de croissance que les jeunes (CE/OCDE, 2012) tandis que les femmes ont moins de chances de voir leur entreprise survivre et se développer (CE/OCDE, 2013).

Les initiatives des politiques publiques ont pour but d'orienter les entrepreneurs potentiels et en activité vers des sources d'information et d'assistance professionnelles. Bon nombre d'entrepreneurs naissants comptent sur leurs famille et amis. Ils ne sont qu'une minorité à suivre une formation professionnelle en lien avec leur activité. En France, par exemple, moins d'un quart des entrepreneurs interrogés en 2010 déclaraient avoir bénéficié d'une assistance professionnelle au cours de leur carrière (INSEE, 2012). Parmi les approches existantes, citons Empresarias en Espagne (www.e-empresarias.net). Il s'agit d'un portail d'information en ligne qui fournit des renseignements aux femmes qui réfléchissent à une idée d'entreprise et la développent activement. Cette plateforme de conseils en ligne promet de répondre aux demandes soumises dans un délai de 48 heures. Les sujets traités couvrent des domaines tels que les procédures d'enregistrement d'une entreprise, l'accès au financement, la fiscalité, l'emploi de salariés, l'internationalisation, l'étude de marché et les locaux. Des lettres d'information, des outils d'autodiagnostic, des forums de discussion et des présentations d'entreprises créées par des femmes sont également proposés. L'objectif est de fonder un réseau virtuel de femmes entrepreneurs au sein duquel elles peuvent 
partager leurs expériences, trouver des partenaires pour de nouveaux projets et apporter leur soutien à celles qui débutent dans l'entrepreneuriat. À ce jour, le portail a permis d'aider 96000 femmes chefs d'entreprise exploitant 16500 entreprises. Le «National Women's Enterprise Day» (journée nationale des femmes entrepreneurs) en Irlande constitue un autre exemple d'approche de sensibilisation à l'entrepreneuriat des femmes et d'information. Une description de cette initiative est disponible dans la troisième partie de cet ouvrage.

Des informations à la fois claires et accessibles sont nécessaires pour sensibiliser davantage à l'entrepreneuriat et mieux faire connaître les services d'aide disponibles, mais elles ont à elles seules peu d'impact sur les personnes qui démarrent une nouvelle entreprise. Peu de données s'intéressent directement à l'influence de l'orientation, mais l'évaluation d'un programme d'aide aux entreprises destiné aux jeunes révèle que les services d'information et d'orientation n'ont pas favorisé le passage au travail indépendant (Greene et Storey, 2004). (Pour un résumé des résultats des évaluations des programmes d'orientation et autres services d'aide au développement des entreprises, nous vous renvoyons à l'annexe $8 \mathrm{~A} 1$ ).

\section{Modèles}

Les modèles sont des entrepreneurs chevronnés qui promeuvent l'entrepreneuriat par le biais des mécanismes formels et informels. Ils peuvent avoir une influence dans les campagnes promotionnelles ou les médias (mécanismes formels), mais aussi dans leur communauté en encourageant d'autres personnes à faire comme eux (mécanismes informels).

Les modèles ont une fonction importante. Ils aident de nombreux entrepreneurs issus de groupes défavorisés et sous-représentés à dépasser les comportements sociaux négatifs et à créer leur entreprise. Les jeunes entrepreneurs et ceux qui poursuivent toujours leurs études sont plus particulièrement susceptibles d'éprouver le besoin de s'inspirer d'un modèle pour faire leurs premiers pas dans l'entrepreneuriat. Des données de l'UE confirment également que les femmes indépendantes sont plus nombreuses que les hommes à juger les modèles très importants (OCDE/ $C E$, 2013). Les membres des groupes défavorisés et sous-représentés s'identifient souvent mieux à des modèles appartenant à leur communauté qu'aux entrepreneurs traditionnels parce qu'ils ont le sentiment d'avoir les mêmes caractéristiques, motivations et objectifs qu'eux (Bosma et al., 2012).

De nombreuses approches de politique publique en matière de soutien et de promotion des modèles sont actuellement consacrées aux femmes. C'est le cas du Réseau européen d'ambassadrices de l'esprit d'entreprise. Financé par l'UE, ce projet vise à «inciter des femmes chefs d'entreprise fortes de leur réussite à faire campagne sur le terrain pour encourager des femmes [de tous âges] à créer leur propre entreprise et à devenir chef d'entreprise». Ces ambassadrices contribuent à leur donner la confiance nécessaire pour créer des entreprises prospères. Elles inspirent d'autres femmes à devenir chef d'entreprise en leur racontant leur histoire (Commission européenne, 2013). Le réseau rassemble 270 femmes chefs d'entreprise de toute l'UE. La première année, les ambassadrices ont organisé 141 réunions de lancement nationales et ont atteint 7600 femmes entrepreneurs naissants. Les données de cinq des pays participants indiquent que 52 entreprises et 68 emplois ont été créés avec l'aide des ambassadrices. Les ambassadrices suédoises de l'esprit d'entreprise sont présentées plus en détail au chapitre 10.

Parmi les autres exemples, on retrouve WomEqual, mis en place en Finlande entre 2007 et 2012 (encadré 8.1). Ce projet associe une communauté en ligne et des activités d'accompagnement individualisé et de formation. La communauté en ligne a pour but de présenter les histoires de réussite de femmes chefs d'entreprise dans le secteur des technologies afin de faire mieux connaître le potentiel qui s'offre aux jeunes diplômés et de renforcer la confiance en soi des jeunes femmes à devenir indépendantes. Dans la continuité de ces actions de sensibilisation, des services de formation, d'accompagnement individualisé et de mentorat sont proposés à celles qui décident 
de créer leur entreprise. WomEqual s'est transformé en une coopération internationale, avec des partenaires autrichiens et allemands, et met des modèles, des coaches et des mentors à la disposition des jeunes femmes.

\section{Formation}

La formation à l'entrepreneuriat a pour but d'améliorer les compétences entrepreneuriales et de gestion d'entreprise d'un entrepreneur. Elle contribue ainsi à augmenter les chances de réussite des nouvelles entreprises. Par exemple, la formation peut développer les capacités managériales des individus en leur apprenant à mieux gérer les ressources (p.ex. définition d'objectifs par la rédaction d'un plan d'affaires), les informations (p.ex. analyse et interprétation des données), les aspects relationnels (p.ex. compétences de négociation et interpersonnelles), le personnel (p.ex. aptitudes à communiquer et à déléguer) et leurs propres activités (p.ex. compétences en gestion du temps). Ils peuvent également auto-évaluer leurs capacités et compétences entrepreneuriales dans le cadre de formations (en ligne, supports pédagogiques, cours structurés en salle de classe) destinées à développer leur capacité à comprendre la nécessité de mettre en place une stratégie commerciale (p.ex. choix des produits, positionnement sur un marché (national, exportation ou niche)), une approche concurrentielle adaptative (p.ex. qualité, flexibilité, innovation, coûts, livraison), des pratiques commerciales (p.ex. relations avec les fournisseurs, innovation et pratiques technologiques) et une culture d'entreprise positive.

La formation peut également offrir des opportunités de mise en réseau et d'apprentissage entre pairs tandis que la formation accréditée signale les compétences et la crédibilité d'un entrepreneur à des parties prenantes extérieures (p.ex. investisseurs). Par ailleurs, elle permet d'étoffer le niveau d'information les entrepreneurs et de renforcer leur aptitude dynamique à apprendre (Chrisman et al., 2005). Il existe une corrélation entre la formation entrepreneuriale et l'émergence d'intentions positives vis-à-vis de l'entrepreneuriat (Peterman et Kennedy, 2003).

La formation peut se dérouler de manière formelle ou informelle. La formation formelle se définit comme tout «apprentissage dispensé dans un contexte organisé et structuré et explicitement désigné comme apprentissage» (OCDE, 2010). La formation informelle correspond à tout «apprentissage découlant des activités de la vie quotidienne liées au travail, à la famille ou aux loisirs» (OCDE, 2010). Les formations formelles sont souvent de courte durée, mais les ateliers portant sur des questions ou problématiques particulières sont également répandus. La formation en ligne est de plus en plus utilisée. Les données indiquent que cette méthode est aussi efficace que l'apprentissage à distance traditionnel (cours par correspondance, télévision éducative et vidéoconférence) et pourrait même donner de meilleurs résultats que l'apprentissage en classe lorsqu'elle s'accompagne d'une interaction en face-à-face (Means et al., 2010).

Les formes les plus courantes de formation à l'entrepreneuriat sont les cours en ligne, les ateliers thématiques et les cours structurés dispensés en personne. Elles peuvent enseigner diverses compétences en gestion d'entreprise comme la comptabilité et la finance, le droit et les questions juridiques et offrir un cadre propice au développement personnel. La plupart des formations de ce type sont dispensées via internet et nécessitent donc le développement de plateformes et de matériel pédagogique pour le web. L'enseignement en ligne présente l'avantage de permettre aux propriétaires d'entreprise établis ou potentiels de développer leurs compétences et d'être dispensé à un faible coût marginal une fois les frais fixes couverts.

L'UE compte plusieurs programmes de formation à l'entrepreneuriat renommés, dont Una Empresa en Mi Centro (EMC), un programme espagnol qui tente de renforcer les orientations et les compétences entrepreneuriales. Il s'agit d'un programme d'éducation à l'entrepreneuriat destiné à soutenir les adultes intellectuellement déficients dans la région des Asturies. Il vise plus spécifiquement à dispenser des compétences élémentaires (p.ex. notions de calcul, alphabétisation 


\section{Encadré 8.1. WomEqual, Finlande}

Description:WomEqual est l'un des programmes EQUAL de l'UE. Il a été dirigé par le département de génie électrique et communication de l'Institut universitaire de technologie d'Helsinki de 2005 à 2007.

Problème abordé: ce programme visait à répondre aux besoins des jeunes diplômées et femmes scientifiques désireuses de travailler dans le domaine des technologies, et des femmes chefs d'entreprise déjà actives dans ce secteur. L'objectif du projet WomEqual était d'élaborer des modèles opérationnels pour aider les femmes à faire évoluer leur carrière dans des entreprises technologiques et centres de recherche, et soutenir leur esprit d'innovation et d'entreprise.

Approche: deux outils ont été mis en place, une communauté internet weme.fi et un programme de formation et d'accompagnement individualisé baptisé "Introduction into business thinking", afin d'encourager la culture entrepreneuriale par l'intermédiaire de modèles et d'un savoir-faire pratique. Ces deux plateformes présentaient les histoires de réussite de femmes chefs d'entreprise dans le secteur des technologies dans le but de renforcer la confiance en soi des jeunes femmes.

En outre, un programme de mentorat a été élaboré afin de permettre à de nouvelles chefs d'entreprise de bénéficier de conseils pratiques de la part de mentors féminins expérimentés et diplômés de l'enseignement supérieur technique. Cette coopération était entérinée par un contrat de mentorat dans lequel les deux parties définissaient leurs besoins et leurs objectifs. L'université d'Oulu fait partie des partenaires du projet WomEqual à avoir mis en œuvre le programme de mentorat. WomEqual a ensuite été intégré dans une coopération transnationale baptisée Women Entrepreneurs East/West, qui incluait trois autres partenaires de développement d'EQUAL en Autriche (Selbstständigkeit als berufliche Alternative), en Lettonie (Reducing causes of professional segregation) et en Allemagne (AWoPE - Activating women's potential for entrepreneurship). Les participantes ont ainsi pu accéder à des plateformes internationales de mise en réseau, des ateliers et des conférences, et établir des normes respectueuses de la dimension de genre dans les formations professionnelles sur l'entrepreneuriat en Europe. Toutes les femmes du secteur technologique avaient le droit de participer gratuitement aux activités de WomEqual.

Le programme a été mis en œuvre dans plusieurs universités, chacune mettant l'accent sur une composante différente de celui-ci. L'Institut universitaire de technologie d'Helsinki (département de génie électrique et communication) était responsable de sa gestion, tandis que le département des télécommunications était en charge du développement et de la maintenance de la communauté weme.fi. La Graduate School in Electronics, Telecommunications, and Automation (GETA) a géré le programme de formation «Introduction into business thinking, technology applications and enterprise leadership" (introduction à l'esprit d'entreprise, aux applications technologiques et au leadership). Trois autres établissements universitaires ont pris part à la mise en œuvre du programme. Doté d'un budget de 1,3 million EUR pour une durée de deux ans (2005-2007), le projet a bénéficié du soutien du Fonds social européen (FSE), du ministère finlandais de l'éducation et de plusieurs municipalités finlandaises membres du programme EQUAL.

Impact: le succès du programme se reflète dans la rapide augmentation du nombre de membres de weme.fi. Dans les deux premiers mois qui ont suivi le lancement de la plateforme en mars 2007, le nombre d'utilisateurs est passé de 0 à 800.

Facteurs de réussite: le programme a pu compter sur l'appui continu des universités sélectionnées, qui ont mis l'accent sur la mise en réseau à travers le mentorat et la présentation de modèles. De plus, forte de l'expérience et du succès du programme, la GETA a placé l'éducation à l'entrepreneuriat au cœur de ses priorités.

et aptitudes communicationnelles) et des compétences entrepreneuriales (p.ex. travail d'équipe, résolution de problèmes), à faciliter le passage de l'école au monde du travail et à favoriser l'intégration des personnes ayant des besoins spécifiques en matière d'éducation au sein de la communauté. Les participants doivent travailler ensemble pour créer et gérer leur propre entreprise. 
En 2012, près de 2000 personnes ont participé au programme, qui a été transféré avec succès dans la région voisine de la Galice.

Un autre exemple de formation à l'entrepreneuriat à l'attention des femmes est décrit à l'encadré 8.2. D'autres exemples sont décrits dans la troisième partie de cet ouvrage, dont le Youth Entrepreneurship Support Scheme à Chypre, grâce auquel de jeunes entrepreneurs en herbe peuvent bénéficier de subventions et de formations, le Schüler-Institut für Technik und angewandte Informatik (SITI) en Allemagne, qui propose des formations pratiques aux jeunes, le programme MeXX en Hongrie, qui cible les femmes chefs d'entreprise, et le projet REGIONFEMME en République slovaque, dans le cadre duquel sont organisés des formations et des événements de mise en réseau destinés aux femmes entrepreneurs.

La formation a généralement une incidence positive sur les participants, mais certains programmes ont eu un effet de sélection. Autrement dit, la formation peut être une confrontation à la réalité, qui décourage les personnes de créer une entreprise si les conditions ne sont pas adaptées. Par exemple, l'évaluation de l'indemnité-relais allemande a révélé que l'accompagnement individualisé et la formation des demandeurs d'emploi désireux de créer une entreprise n'avaient pas eu d'influence sur la durée du travail indépendant, que la formation augmentait en réalité la probabilité d'un chômage ultérieur et que l'accompagnement avait tendance à favoriser la sortie de l'emploi (Oberschachtsiek et Scioch, 2011). De prime abord, ces résultats peuvent sembler négatifs, mais ils peuvent s'expliquer par le fait que la formation et l'accompagnement individualisé exacerbent les a priori sur les perspectives économiques futures de la start-up et engendrent ainsi des taux de sortie plus élevés, la préoccupation étant d'éviter l'endettement (Oberschachtsiek et Scioch, 2011).

\section{Coaching et mentorat}

Le coaching (ou accompagnement individualisé) consiste généralement en une relation de courte durée destinée à développer les compétences spécifiques d'un entrepreneur. Il s'agit d'un processus collaboratif, dans lequel les participants occupent des rôles clairement définis. Le coach est chargé de développer des objectifs à court terme et de guider son élève vers ces objectifs en formulant des commentaires constructifs. L'élève est chargé de produire des idées et de solutions, de prendre des mesures pour atteindre les objectifs et de faire part de ses progrès.

Le mentorat est une relation professionnelle dans laquelle une personne expérimentée (le mentor) aide une autre (l'élève) à développer des compétences et des connaissances qui renforceront son développement professionnel et personnel. Ces relations sont souvent de longue durée et informelle. Les fonctions du mentor peuvent être classées en trois thèmes: soutien psychologique (aider les entrepreneurs à identifier leurs forces et leurs faiblesses, apporter un soutien dans les périodes difficiles, encourager et motiver), soutien à la carrière (aider l'entrepreneur à développer ses réseaux, partager ses connaissances et ses informations, donner son avis sur de nouvelles idées, aider les élèves à résoudre leurs problèmes) et modèle (le mentor se sert de ses propres expériences et difficultés pour expliquer comment persévérer et surmonter les difficultés) (St-Jean, 2010).

L'accompagnement individualisé et le mentorat se déroulent traditionnellement en face-àface, mais ils peuvent se réaliser à distance avec des outils de messagerie instantanée en ligne tels que Skype. À la différence du mentorat, l'accompagnement individualisé repose généralement sur une relation de courte durée et se concentre sur une activité entrepreneuriale et un nombre limité d'objectifs, voire un seul.

La plupart des mécanismes en fonction ciblent la population générale, mais certains s'adressent en particulier aux groupes défavorisés et sous-représentés. Il est important de veiller d'une part à ce que les catégories socioéconomiques ciblées aient connaissance de ces programmes et puissent y accéder, et d'autre part à ce que les programmes soient conçus et mis en œuvre de 


\section{Encadré 8.2. Émancipation et participation à la vie active des femmes dans le comitat d'Osijek-Baranja, Croatie}

Description: le projet «Empowering and Activating Women in the Labour Market» était l'un des dixhuit projets financés au titre de l'Instrument d'aide de préadhésion IV de la Croatie dans le cadre de la mise en œuvre du Programme opérationnel en faveur du développement des ressources humaines «Les femmes sur le marché du travail», créé par le service croate de l'emploi.

Problème abordé: le but du programme de subvention était de renforcer l'aptitude à l'emploi des femmes défavorisées et d'accompagner leur entrée sur le marché du travail par l'intermédiaire du travail indépendant. Étaient concernées les chômeuses de longue durée, les femmes sans emploi de plus de 40 ans, les femmes inactives, les mères célibataires inactives ou sans emploi depuis plus de six mois, les femmes sans emploi des comitats les plus touchés par le chômage et les femmes sans emploi issues des minorités nationales, prioritairement la population rom.

Approche: le programme prévoit des subventions, des activités d'éducation, de formation et de travaux pratiques ainsi que des services de conseil individualisé et de mentorat. Le programme de subvention se consacre également au développement et à l'application de modèles organisationnels (p.ex. coopératives, associations) mieux adaptés à la fourniture d'un réseau d'aide aux personnes qui souhaitent réintégrer le marché de l'emploi via le travail indépendant.

Une enveloppe de 121120 EUR a été attribuée au programme de subvention en août 2009 à la suite d'un appel public à propositions. Le projet a démarré le 4 décembre 2010. Il a été mis en œuvre un an plus tard, sous la direction du bureau régional du service croate de l'emploi d'Osijek et de son partenaire, l'Association for Peace and Human Rights Baranja. Parmi les prestataires de services partenaires figuraient le Centre pour l'entrepreneuriat d'Osijek (formations aux compétences entrepreneuriales et à la planification d'entreprise), la Faculté d'agriculture de l'Université Josip Juraj Strossmayer d'Osijek (formations pratiques à la production légumière), le Centre de réinsertion professionnelle (formations pratiques à la fabrication artisanale à base de bois, de textile, de céramique, de verre et de laine) et Escape (formations pratiques au développement de boutiques en ligne).

Impact: au départ, 200 candidates ont postulé pour participer au programme et 79 femmes sans emploi ont été sélectionnées par des psychologues pour participer à des ateliers et formations de motivation à l'entrepreneuriat. Sur ce groupe, 31 participantes ont opté pour une formation plus pratique en agriculture, 29 pour une formation complémentaire dans l'artisanat et 19 ont choisi les deux. Grâce à leur formation et à leur subvention, 52 participantes ont réussi à créer leur propre entreprise (EuropeAid/128290/D/SER/HR: Evaluation of Active Labour Market Measures Targeting Disadvantaged Women in the Labour Market (2007-2010), Evaluation Report, septembre 2011, p. 130-136).

Facteurs de réussite: deux éléments majeurs expliquent le succès de ce projet: (a) la mise à la disposition des participants d'aides étroitement liées (ateliers de motivation, formations et subventions) et (b) la solide collaboration entre le bureau régional du service croate de l'emploi d'Osijek, l'Association for Peace and Human Rights Baranja et les organisations partenaires (Centre pour l'entrepreneuriat d'Osijek, Faculté d'agriculture de l'Université Josip Juraj Strossmayer d'Osijek, Centre de réinsertion professionnelle et Escape) pour offrir aux participants une aide adéquate à chaque étape de la création et du développement de leur entreprise.

manière à rendre leur participation effective, d'autre part (OCDE/CE, 2013). Nombre des programmes destinés aux personnes issues de groupes défavorisés ou sous-représentés proposent des services d'accompagnement individualisé avec un coach appartenant au même groupe cible que celui du bénéficiaire (p.ex. coaching de femmes par des femmes, ou de seniors par des seniors).

L'UE compte de nombreux exemples de programmes de coaching et de mentorat, dont Erasmus pour jeunes entrepreneurs. Il s'agit d'un programme de mentorat traditionnel, qui a pour vocation de donner aux jeunes entrepreneurs la possibilité de se rendre dans 
un autre pays européen et d'y être parrainés par un entrepreneur expérimenté. Ils sont supposés travailler avec leur mentor pendant un à six mois. L'objectif est qu'ils profitent de cet accompagnement en entreprise pour pénétrer de nouveaux marchés et développer une coopération et une collaboration à l'international. Les mentors en retirent aussi des avantages en acquérant de nouvelles compétences et expériences.

Parmi les autres exemples, figure le 12/8 Group, un programme de mentorat destiné aux entreprises afro-caribéennes dans les Midlands de l'Ouest en Angleterre. Depuis 2004, il vise à encourager le développement non seulement des entreprises déjà présentes dans le réseau de mentorat, mais aussi des personnes qui cherchent à créer leur propre entreprise et à développer leur communauté locale. Ce mécanisme a l'avantage d'être un outil rentable à l'aide duquel les entreprises peuvent encadrer et soutenir le développement d'entreprise. En outre, il illustre bien comment la responsabilité sociale des entreprises peut fonctionner de façon durable. Le 12/8 Group collabore avec une grande entreprise de la région dont il peut utiliser les ressources. Le groupe a pu ainsi renforcer ses capacités, son engagement et son soutien auprès des entrepreneurs potentiels et de la communauté locale.

Le caractère individuel du coaching et du mentorat est souvent perçu comme la force de ce type d'accompagnement. Des éléments indiquent que le mentorat est plus efficace lorsqu'il est proposé dans le cadre d'un programme d'aide intégré incluant un financement d'amorçage (Meager et al., 2003). Cette approche mixte, comparée au mentorat seul, augmente les chances de survie des jeunes entrepreneurs, en particulier durant la première année d'exploitation. Toutefois, les bénéficiaires du mentorat disposaient de faible revenus, ce qui laisse penser que ceux qui rencontraient des difficultés avec leur nouvelle entreprise étaient plus susceptibles de demander conseil à un mentor et de solliciter un niveau d'assistance plus élevé (Meager et al., 2003).

\section{Conseil en entreprise}

Les services de conseil en entreprise mettent l'accent sur le transfert des connaissances spécialisées du conseiller à l'entrepreneur afin que ce dernier développe des domaines précis de son activité. Ils prennent souvent la forme d'une aide stratégique ou transformationnelle individuelle. Ils ont fréquemment recours à une combinaison de techniques formelles (p.ex. modèles d'excellence et outils d'évaluation) et de connaissances informelles tacites acquises par la voie de l'expérience (p.ex. leçons tirées des expériences passées de l'entrepreneur). Ce type de services visent à renforcer le capital social et humain des entrepreneurs afin qu'ils puissent surmonter la ou les difficultés identifiées.

Le conseil en entreprise s'inscrit fréquemment dans le cadre d'un ensemble intégré de mesures d'aide, souvent en partenariat avec le secteur caritatif. Une approche courante consiste à donner la possibilité aux participants de recourir aux services d'un conseiller professionnel en entreprise dans le cadre d'un programme d'aide intégré. De nombreuses initiatives conditionnent l'aide financière au recours d'un conseiller en entreprise, les participants n'étant pas toujours intéressés par l'aide proposée. À titre d'exemple, seuls 38\% des participants au programme français ACCRE (Aide aux chômeurs créateurs ou repreneurs d'entreprises) font appel au service de conseil (Daniel, 2008).

Les participants peuvent bénéficier de ces services professionnels durant un nombre d'heures prédéfini. Il est important que les rendez-vous avec les conseillers en entreprise puissent être pris facilement et rapidement, que ces derniers disposent de grandes qualités d'écoute, qu'ils soient capables d'aider chaque entrepreneur à relever les défis qui lui sont propres (dans son contexte) et que ces services couvrent un grand choix de thèmes, dont la gestion d'entreprise, la comptabilité, la fiscalité et le respect des exigences administratives. Par exemple, le programme suédois Nutek propose un service d'accompagnement individualisé et de conseil en entreprise (encadré 8.3). En Lituanie, le projet «First business year baskets (vouchers) for youth» (voir la troisième partie de cet 
ouvrage) adopte une approche similaire en proposant des chèques aux participants, qui peuvent alors acheter les services de conseil en entreprise dont ils ont besoin.

Le conseil aux entreprises, qu'elles soient nouvelles ou établies, peut avoir des effets positifs. Au Danemark, une étude du North Jutland Entrepreneurial Network a eu recours à l'appariement des coefficients de propension pour évaluer la performance de trois types de services de conseil (conseil de base du centre d'affaires local, conseil avec conseillers du secteur privé et conseil approfondi par des conseillers du secteur privé). Les conclusions mettent en évidence l'impact globalement positif des services de conseil du secteur privé sur la survie des entreprises et le chiffre d'affaires, mais leur impact positif à court terme sur l'emploi (Rotger et al., 2012). Les données d'autres programmes d'aide intégrés corroborent ce point. C'est le cas, par exemple, du programme roumain Small Business Assistance qui combine soutien financier et aides ciblées pour les chômeurs qui créent leur entreprise. Les données attestent de son impact positif sur l'emploi (Rodriguez-Planas, 2010).

\section{Offrir des services d'aide au développement des entreprise}

Un débat a actuellement cours afin de déterminer qui des services ciblés ou traditionnels soutiennent le mieux l'entrepreneuriat inclusif. L'aide ciblée présente l'avantage de soutenir les entrepreneurs issus de groupes défavorisés ou sous-représentés qui rencontrent des difficultés particulières (p.ex. discrimination, stéréotypes, problèmes liés à la famille et au travail) et sont de fait moins susceptibles de s'adresser aux prestataires traditionnels. Par exemple, en Allemagne, les entrepreneurs issus de minorités ethniques évitent généralement de faire appel à l'aide traditionnelle, car celle-ci ne répond pas à leurs besoins spécifiques (Bella, 2013; Leicht et al., 2009; Leicht et al., 2012). Cependant, selon autre un point de vue, les services ciblés ont tendance à se révéler contre-productifs, car ils accentuent les différences entre les groupes sociaux, reproduisent les structures institutionnelles de la société (Ahl, 2006; Bella et Leicht, 2011) et négligent le fait que les entrepreneurs issus de groupes défavorisés et sous-représentés évoluent dans un environnement institutionnel, sociétal et culturel complexe (Rath et al., 2011).

Peu d'éléments permettent de savoir qui des services ciblés ou traditionnels sont mieux adaptés à l'entrepreneuriat inclusif. Cela explique en partie pourquoi des États membres de l'UE ont choisi une autre approche. Par exemple, l'aide aux femmes entrepreneurs prend des formes très variées dans les pays du nord de l'UE. Certains pays disposent de plans d'action nationaux, d'activités coordonnées aux niveaux national, régional et local et d'importants budgets tandis que d'autres n'ont pas défini de stratégie nationale distincte pour l'entrepreneuriat féminin et ont très peu d'aides ciblées (Pettersson, 2012). On peut donc en conclure que l'approche adéquate dépend souvent (i) de la taille relative du groupe bénéficiaire cible, (ii) du contexte économique local et régional et (iii) des priorités politiques.

Il est nécessaire de réaliser des évaluations d'impact de qualité. En plus d'élaborer et de mettre en œuvre des programmes de soutien aux entreprises, il est essentiel d'identifier ce qui fonctionne. Selon Tödtling-Schönhofer et al. (2011), les évaluations d'impact (évaluations de la rentabilité et de l'efficacité) ne sont pas légion parmi les évaluations réalisées dans le cadre du FSE. Le suivi améliore la gestion d'un programme en particulier, mais il ne remplace pas l'évaluation destinée à déterminer si les services d'aide au développement des entreprises améliorent le bien-être sociétal. Le recours accru aux évaluations, notamment aux essais contrôlés randomisés (encadré 8.4) permettra de dépasser le simple cadre des simples données chiffrées et effets perçus (p.ex. degrés de satisfaction, participation à des événements) pour déterminer si le programme a un impact majeur ou non. En outre, les décideurs politiques et les prestataires d'aide disposeront d'évaluations d'impact des services d'aide aux entrepreneurs issus de groupes défavorisés et sous-représentés de meilleure qualité. 


\section{Encadré 8.3. Nutek, Suède}

Description: Nutek est un programme public de coaching et de conseil destiné aux femmes chefs d'entreprise. Lancé en 1993, il est géré par l'Agence suédoise pour la croissance économique et régionale.

Problème abordé: au début des années 1990, la Suède a enregistré des taux de chômage élevés, en particulier dans les milieux ruraux et chez les femmes. Nutek peut donc être considéré comme la tentative du gouvernement suédois de redynamiser les zones rurales et les marchés en déclin avec la mise en place d'une agence de conseil destinée exclusivement aux femmes afin d'encourager l'entrepreneuriat féminin. Des études ont montré que les femmes sont moins enclines à faire appel à des services de conseil en entreprise «traditionnels» et qu'elles ne se sentent pas à l'aise pour aborder des questions fondamentales comme les finances avec des conseillers masculins. En outre, les banques étaient plutôt réticentes à l'idée d'octroyer des prêts à des femmes entrepreneurs. Ce comportement, que ces dernières considéraient comme un manque de respect et de confiance lors de la négociation de leurs prêts avec des conseillers bancaires, avait des répercussions négatives sur leur attitude à l'égard de l'entrepreneuriat. Un service de conseil de femme à femme a donc été créé afin d'offrir un contexte plus chaleureux et plus professionnel aux femmes entrepreneurs. Celles-ci peuvent ainsi discuter ouvertement de leurs problèmes et de leurs préoccupations sans craindre d'être humiliées et discriminées.

Approche: le programme cible principalement les femmes intéressées par l'entrepreneuriat et plus particulièrement les femmes des régions périphériques. Le but est de réduire leur propension à migrer vers les grandes villes et de promouvoir l'entrepreneuriat comme alternative au chômage du fait de l'absence d'opportunités d'emploi en milieu rural. L'approche consiste à intensifier les services de conseil des femmes entrepreneurs potentielles par des conseillères afin de répondre aux demandes de ce groupe cible.

Nutek demande également à des femmes chefs d'entreprise de partager leur expérience de l'entrepreneuriat avec les nouvelles venues. Ces chefs d'entreprise les conseillent et les assistent dans les domaines de la finance, du droit, de la comptabilité et du marketing et leur donnent accès à des réseaux par le biais de séminaires ou de conférences. Outre leur rôle de conseillères, elles servent de modèles de femmes entrepreneurs dans les zones rurales et luttent contre les comportements stéréotypés. À long terme, Nutek mise sur le développement d'outils de conseil à l'attention des femmes entrepreneurs, qui pourraient être utilisés dans tous les pays et régions. Le programme dispose d'un budget annuel compris entre 400000 et 600000 EUR. Les conseillères en entreprise sont subventionnées à $25 \%$ par l'autorité nationale, à 50\% par la région et à $25 \%$ par les municipalités. Les tâches sont réparties comme suit: l'autorité nationale (l'Agence suédoise pour la croissance économique et régionale) est chargée de la coordination, les régions participent au financement et les municipalités s'occupent de la mise en œuvre du programme.

Impact: entre 1993 et 2009, environ 1000 nouvelles entreprises ont été créées par des participantes au programme Nutek. Outre le fait d'aider des femmes entrepreneurs, le programme a permis de mieux faire connaître la création d'entreprise aux femmes sans emploi des zones rurales. Il a également contribué à l'élimination des obstacles susmentionnés. Il a ouvert la voie à l'entrepreneuriat et mis en exergue les atouts et la réussite d'entreprises gérées par des femmes.

Facteurs de réussite: l'utilisation de modèles s'est avérée efficace. Le recours à des femmes entrepreneurs favorise l'apprentissage entre pairs et attire des bénéficiaires potentielles. De plus, ces femmes qui travaillent pour le programme contribuent à en faire la promotion et à augmenter sa portée. 


\section{Encadré 8.4. Essais contrôlés randomisés}

Les essais contrôlés randomisés (ECR) sont fréquemment utilisés en développement international pour déterminer quelle politique est la plus performante. Les ECR consistent à affecter aléatoirement des individus ou entreprises à au moins deux groupes. Le groupe de traitement bénéficie de la politique tandis que le groupe de contrôle reçoit un placebo, voire rien. L'affectation aléatoire à différents groupes permet de comparer l'impact de l'intervention politique à l'absence d'intervention (le contrefactuel). De très nombreuses sources de biais sont ainsi éliminées. Par exemple, si une politique propose aux entrepreneurs naissants un service d'information leur permettant d'accéder à un soutien technique, on peut penser que ces derniers auraient pu le trouver par eux-mêmes. L'existence d'un groupe de contrôle permet d'éviter qu'un grand nombre de biais ne vienne influencer l'évaluation de l'efficacité du service en question.

Bien que les ECR s'imposent peu à peu comme la référence en matière de politique entrepreneuriale, une autre voie consiste à recourir à des approches statistiques non expérimentales (p.ex. modèles de sélection de type Heckman) pour constater les différences entre les bénéficiaire de la politique (groupe de traitement) et le groupe de contrôle (contrefactuel). S'il n'est pas possible de constituer un groupe de contrôle, l'évaluation devient de facto un exercice de suivi. Le suivi peut fournir des informations utiles sur le degré de satisfaction et d'assimilation du bénéficiaire, mais il ne remplace pas l'évaluation d'impact du programme ou de la politique.

Pour plus d'informations, veuillez vous reporter à la synthèse de la Commission européenne et de l'OCDE sur l'évaluation des politiques d'entrepreneuriat inclusif: $h t t p: / / w w w . o e c d . o r g /$ cfe/leed/Policy_brief_evaluation_inclusive_entrepreneurship_programmes.pdf.

La gratuité des services d'aide au développement des entreprises est une autre question fondamentale. La plupart des services destinés aux entrepreneurs défavorisés sont gratuits, car ils ont pour vocation d'être attractifs et accessibles. La plupart du temps, ces services font appel à des bénévoles ou à des professionnels qui proposent ces services à prix réduit. En principe, il est plus intéressant de les facturer (à prix réduit), même s'ils sont assurés par des bénévoles. Le paiement d'une redevance initiale ou annuelle engage l'entrepreneur, l'implication étant un gage de réussite de nombre de ces services. Rien ne permet de dire que les programmes de soutien payants sont de meilleure qualité que les programmes gratuits. Le fait que plusieurs des programmes les mieux établis prévoient une participation financière, même minime, permet néanmoins de supposer qu'ils ont plus de chances de durer.

Lors de l'élaboration des services d'aide au développement des entreprises, certains principes clés peuvent toutefois être appliqués afin de mieux impliquer et soutenir les entrepreneurs issus de groupes défavorisés et sous-représentés. Les caractéristiques du groupe cible peuvent avoir leur importance dans la définition et la mise en œuvre des services, mais l'aide en tant que telle doit davantage se concentrer sur les besoins des individus que sur les besoins généraux du groupe en question. Une aide ciblée peut en effet accentuer les stéréotypes et enfermer l'entrepreneuriat inclusif dans certaines formes d'activité. Les autres principes clés d'une aide efficace sont (OCDE/CE, 2013):

- garantir la diversité des gestionnaires et administrateurs des programmes et des agences d'aide aux entreprises, y compris de leur conseil d'administration et de leurs responsables;

- recruter des référents, des conseillers, des consultants et des formateurs au sein des groupes cibles;

- former les autres conseillers, consultants et formateurs au soutien des membres des groupes cibles; 
- utiliser les médias et les autres canaux d'information susceptibles d'être utilisés par les entrepreneurs effectifs et potentiels des groupes cibles;

- proposer des services multilingues;

- créer des liens avec les services d'aide traditionnels;

- suivre et mesurer l'impact des programmes sur la base d'objectifs d'aide préalablement fixés.

Dans la pratique, une offre de services d'aide au développement des entreprises efficace est une offre intégrée combinant aides financières et non financières, qui permet d'accroître les compétences entrepreneuriales et de gestion d'entreprise des entrepreneurs. Des évaluations révèlent que les approches intégrées sont efficaces, car les aides financière et non financière se complètent et augmentent les chances de réussite de l'entrepreneur (p.ex. Walsh et al., 2001; Meager et al., 2003). Un exemple d'approche globale intégrée est décrit à l'encadré 8.5. Il s'agit du programme autrichien RABE, qui prévoit un éventail d'aides aux personnes handicapées désireuses d'entrer ou de revenir sur le marché du travail, y compris par le biais de la création d'entreprise. Parmi les autres exemples d'offres intégrées, citons le projet «Build your own enterprise as a way to connect work with childcare» de la République tchèque, le projet «Promoting entrepreneurship in areas with an aging population» du Danemark et le programme IkStartSmart des Pays-Bas. Chacun d'eux est décrit dans la troisième partie de cet ouvrage.

Les guichets uniques sont une autre approche couramment adoptée par les régions et les localités. Ceux-ci présentent l'avantage de faciliter l'accès des entrepreneurs potentiels aux services d'information et d'orientation et des formes plus individualisées de soutien comme le conseil en entreprise. L'expérience de l'Italie indique que les guichets uniques peuvent avoir un léger impact positif sur les taux de création d'entreprise, car ils réduisent les charges administratives en la matière (Ferrara et Marini, 2004).

Souvent, ces guichets ne ciblent pas de groupes de bénéficiaires en particulier. On trouve un exemple de service local de guichet unique à Poznan en Pologne. La ville de Poznan s'est rendue compte que les entrepreneurs potentiels avaient des difficultés à s'orienter dan la multitude de services d'aide disponibles. Une étude menée pour le

\section{Encadré 8.5. RABE, Autriche}

Description: RABE est l'acronyme du programme public Regionales Arbeitsmarktpolitisches Behindertenprogramm, géré par le bureau fédéral (Landesstelle) du ministère fédéral des affaires sociales de Haute-Autriche. Il soutient les indépendants handicapés par de l'accompagnement individualisé et des subventions financières.

Problème abordé: la promotion de l'entrepreneuriat n'est qu'une des multiples facettes de cette approche globale destinée à aider les personnes handicapées à intégrer le marché du travail, à garder leur emploi ou à créer leur propre entreprise. Le programme régional repose à la fois sur la politique fédérale de l'emploi et sur le programme BABE (Bundesweites Arbeitsmarktpolitisches Behindertenprogramm), mais il a été adapté à la demande de la région et à la situation des personnes handicapées en Haute-Autriche.

Approche: le programme accorde une attention particulière à l'intégration des questions d'égalité entre les sexes en vue de renforcer l'égalité des chances des hommes et des femmes handicapés sur le marché de travail. Les difficultés des femmes handicapées sur le marché du travail sont considérées comme une problématique majeure et combattues par toute une série de mesures, parmi lesquelles une coopération étroite entre les acteurs qui coordonnent les politiques du marché du travail; la mise en place de mécanismes de transfert d'informations et de connaissances à des fin de transparence et d'efficacité accrues; des échanges d'expérience réguliers afin d'améliorer continuellement tous les niveaux de soutien 
et de promotion. Depuis 2012, l'accent est mis davantage sur un programme d'aide renforcée ayant pour but d'encourager l'entrée des jeunes handicapés autrichiens sur le marché du travail, notamment par la création de leur propre entreprise. Le sous-projet CLEARING, initié en tant que nouveau service à l'attention des jeunes élèves handicapés, a servi d'interface entre l'école et l'emploi. Une étroite coopération avec les écoles est la condition préalable à l'accompagnement de ces élèves à un stade précoce de leur orientation professionnelle. Des services de conseil individualisé, de mentorat et de diagnostic professionnel de leurs forces et opportunités leur sont proposés afin de leur présenter de nouvelles perspectives. En 2013, le programme a été rebaptisé Jugendcoaching, l'objectif étant de s'adresser non seulement aux élèves inscrits à l'école, mais également aux jeunes en formation professionnelle ou sans emploi. D'autres régimes d'aide ont été mis en œuvre afin de leur offrir un encadrement et un soutien individualisés leur permettant d'intégrer le marché du travail et/ou d'accéder au travail indépendant. Bien que le renforcement des compétences personnelles et entrepreneuriales constitue un aspect majeur de la promotion, le programme ne vise pas spécifiquement à ouvrir la voie à des activités d'entrepreneuriat.

Le bureau national de Haute-Autriche qui gère le programme RABE met l'accent sur les services en proposant notamment des activités de mentorat, d'accompagnementindividualisé, de bilan, de formation et de gestion de cas ainsi que d'autres approches destinées à aider les personnes handicapées à entrer ou rester sur le marché du travail. Les entrepreneurs potentiels reçoivent une subvention de $50 \%$ pour couvrir les frais et investissements liés au démarrage d'activité. Le montant maximal de l'investissement subventionné s'élève à 23800 EUR. Chaque année, environ 25 start-up créées par des personnes handicapées bénéficient d'un soutien. Les gestionnaires du programme soulignent le fait que la subvention et les régimes d'aides sont plutôt accueillis favorablement par les entrepreneurs handicapés plus âgés (plus de 40 ans). Leur création d'entreprise est surtout motivée par un fort désir de mener une carrière d'indépendant et d'avoir un emploi. En outre, le travail indépendant est reconnu comme une alternative au chômage. Particulièrement exposées au risque de chômage, les seniors souffrant d'un handicap reconnaissent que le programme est une aide très précieuse pour accéder au statut d'indépendant.

Impact: le programme est évalué tous les trois ans. $90 \%$ des entrepreneurs handicapés soutenus et subventionnés qui ont créé une entreprise avec l'aide du programme RABE sont toujours en activité après trois ans. Le financement total alloué au financement des entrepreneurs handicapés s'élève à 300000 EUR par an. Le programme est soutenu financièrement par l'Ausgleichstaxfonds (Fond de la taxe compensatoire), le gouvernement fédéral et le FSE (environ $5 \%$ des fonds du programme RABE).

Facteurs de réussite: l'attractivité du programme repose sur l'exhaustivité des approches visant à soutenir les personnes handicapées, notamment à travers l'entrepreneuriat. Les fonds en faveur de l'activité entrepreneuriale sont plutôt limités, mais ils ont des répercussions importantes sur les entrepreneurs seniors confrontés au chômage. Les jeunes bénéficient d'un accompagnement individualisé et d'un mentorat afin d'évaluer leurs forces et d'élaborer des stratégies d'entrée sur le marché du travail. Bien que l'entrepreneuriat ne soit pas vu comme une fin en soi, le programme prépare les jeunes à l'économie entrepreneuriale. Le succès du programme s'explique en grande partie par la coopération professionnelle des acteurs impliqués dans sa gestion aux niveaux fédéral et fédéré, mais aussi des services du bureau national de Haute-Autriche.

Pour plus d'informations, veuillez vous reporter aux sites suivants:

http://www.neba.at/jobcoaching/warum.html

http://www.bundessozialamt.gu.at/cms/basb/attachments/2/8/1/CH0011/CMS1199700026676/ rabe_oberoesterreich_2012_2013.pdf 
compte de la ville a conclu qu'il était nécessaire de mettre en place un guichet unique qui servirait d'intermédiaire entre les entrepreneurs et les prestataires d'aide, et assurerait la coordination et la diffusion des informations et du matériel promotionnel. La ville a ainsi créé un centre de formation et de conseil proposant des services d'information, d'orientation et de formation afin de sensibiliser les jeunes à l'entrepreneuriat et de soutenir les entrepreneurs. Entièrement financé par la ville de Poznan, le centre est mis en œuvre en partenariat avec 25 organisations publiques et privées, dont cinq chambres de commerce, trois parcs technologiques et industriels, des pépinières et des préincubateurs d'entreprises. En 2012, il a accueilli 5529 visiteurs dans le cadre d'événements de formation et de journées de sensibilisation à l'entrepreneuriat.

Toutefois, il existe des guichets uniques destinés à des groupes de bénéficiaires spécifiques. Par exemple, l'agence Bundesweite Gründerinnenagentur (BGA) en Allemagne propose un guichet unique complet, qui informe les femmes sur les opportunités du travail indépendant, favorise le développement de leurs réseaux et les met en relation avec les différents services d'aide aux entreprises. Les futures entrepreneuses et chefs d'entreprise établies y trouvent un éventail de services d'information, d'orientation, de conseil et d'assistance. Parmi ses principales activités figurent le développement de réseaux professionnels féminins, des actions de sensibilisation (p.ex. campagnes, expositions, journées d'action), la mise à disposition d'une assistance en ligne (p.ex. actualités, fiches d'information, base de données d'experts) et de plus de 400 services d'aide au développement des entreprises (p.ex. séminaires de formation et événements, formations en ligne, symposiums, salons, accompagnement individualise et mentorat). Pour ce faire, la BGA peut compter sur des partenaires nationaux, fédéraux et régionaux dans toute l'Allemagne. Dotée de représentants dans chacun des 16 Lands allemands, elle collabore avec plusieurs partenaires clés (p.ex. ministères, chambres de commerce, associations professionnelles) pour guider et soutenir l'entrepreneuriat féminin. Pour mener à bien ces activités, elle s'appuie sur 460 agences de conseil, 1080 experts et 320 centres d'affaires féminins.

\section{Conclusions et recommandations politiques}

Ce chapitre s'intéresse au rôle des services publics et caritatifs d'aide au développement des entreprises dans l'accompagnement des entreprises créées par des entrepreneurs issus de groupes défavorisés ou sous-représentés. Ce soutien se justifie par le fait qu'il crée des emplois, crée des richesses et encourage l'inclusion et l'intégration sociales.

Les entrepreneurs issus de groupes défavorisés et sous-représentés ont à leur disposition une large gamme de services destinés à mieux leur faire connaître l'entrepreneuriat, éveiller leurs aspirations entrepreneuriales et leur apporter les compétences et connaissances nécessaires pour créer une entreprise. Toutefois, ils ignorent souvent l'existence de ces services (Duke et al., 2013) et y font donc peu appel.

Les faits montrent que les services d'information et d'orientation ont un rôle à jouer, notamment en raison de la méconnaissance de l'entrepreneuriat comme choix de carrière. Parce qu'ils sont généraux, de grande portée et peu coûteux (par rapport à la formation et à l'aide personnalisée), ces services contribuent souvent au développement de la conscience entrepreneuriale. La formation et les services d'aide au développement des entreprises plus intensifs, tels que l'accompagnement individualisé, le mentorat et le conseil en entrepris, sont répandus dans l'UE et souvent proposés dans le cadre d'offres intégrées. Des données factuelles plus solides sont cependant nécessaires pour déterminer si le niveau et la combinaison des offres sont approprié et efficaces. De toute évidence, ces offres intégrées doivent répondre aux besoins locaux tout en étant suffisamment flexibles pour s'adapter à l'évolution de ces besoins. 


\section{Principales recommandations politiques}

- Fournir des informations sur les aides relatives au travail indépendant et à la création d'entreprise dans un grand choix de formats, y compris des formats accessibles aux personnes handicapées. Les bénéficiaires cibles ne disposant pas tous d'un accès à internet ou de la possibilité de travailler en ligne, les informations doivent être consultables sans connexion internet.

- Concevoir des services d'aide au développement des entreprises dans le cadre d'offres intégrées associant des services de conseil, d'accompagnement individualisé et de mentorat, et des aides financières. Ces offres doivent soutenir les entrepreneurs avant, pendant et après la création de leur entreprise.

- Constituer des équipes de coaches et de mentors accrédités, qualifiés et expérimentés issus des différentes communautés ciblées afin d'apporter une aide plus crédible et pertinente pour les groupes défavorisés et sous-représentés.

- Améliorer la coordination et la cohésion politiques pour garantir la complémentarité des services d'aide au développement des entreprises.

- Rendre les évaluations d'impact obligatoires lors des financements de programmes d'aide futurs. Réaliser des évaluations de plus en plus fiables des services d'aide $\mathrm{au}$ développement des entreprises dont profitent les bénéficiaires des politiques d'entrepreneuriat inclusif. Le FSE prévoit une assistance technique pour l'évaluation de ses activités. 


\section{Évaluations des aides au développement des entreprises en faveur des entrepreneurs issus de groupes défavorisés et sous-représentés}

\begin{tabular}{|c|c|c|c|c|c|}
\hline Source & Pays & Programme & Type d'assistance & Groupe(s) cible(s) & Résultats \\
\hline $\begin{array}{l}\text { Oberschachtsiek et } \\
\text { Scioch (2011) }\end{array}$ & Allemagne & Indemnité-relais & $\begin{array}{l}\text { Formation et coaching } \\
\text { en entreprise }\end{array}$ & Chômeurs & $\begin{array}{l}\text { Formation et accompagnement } \\
\text { individualisé: durée du travail indépendant } \\
\text { (n.s.); formation: sortie vers le chômage } \\
\text { (+), sortie vers l'emploi (n.s.); coaching: } \\
\text { sortie vers le chômage (n.s.) (+), sortie } \\
\text { vers l'emploi (-) }\end{array}$ \\
\hline $\begin{array}{l}\text { Rodriguez-Planas } \\
\text { (2010) }\end{array}$ & Roumanie & $\begin{array}{l}\text { Small Business } \\
\text { Assistance }\end{array}$ & $\begin{array}{l}\text { Conseil en entreprise, } \\
\text { formation, prêts }\end{array}$ & $\begin{array}{l}\text { 1) chômeurs; 2) } \\
\text { jeunes; 3) personnes } \\
\text { peu qualifiées }\end{array}$ & $\begin{array}{l}\text { 1) emploi (+), chômage (-), revenu (n.s.); 2) } \\
\text { emploi (n.s.), chômage (n.s.), revenu (n.s.); } \\
\text { 3) emploi (+), chômage (-), revenu (n.s.) }\end{array}$ \\
\hline $\begin{array}{l}\text { Almeida et Galasso } \\
\text { (2007) }\end{array}$ & Argentine & JEFES & $\begin{array}{l}\text { Formation technique, } \\
\text { subventions }\end{array}$ & Chômeurs & Heures travaillées (+), revenu (n.s.) \\
\hline Perry (2006) & Nouvelle-Zélande & Enterprise Allowance & $\begin{array}{l}\text { Formation en } \\
\text { entreprise et } \\
\text { subvention }\end{array}$ & Chômeurs & Chômage (-) \\
\hline $\begin{array}{l}\text { Greene et Storey } \\
(2004)\end{array}$ & Royaume-Uni & Shell Livewire & Conseil et orientation & Jeunes & Transition vers le travail indépendant (n.s.) \\
\hline Meager et al. (2003) & Royaume-Uni & Prince's Trust & $\begin{array}{l}\text { Mentorat dans le } \\
\text { cadre d'un dispositif } \\
\text { d'assistance } \\
\text { financière }\end{array}$ & Jeunes défavorisés & Survie de l'entreprise (+), gains (-) \\
\hline Walsh et al. (2001) & Bulgarie & $\begin{array}{l}\text { Motivating the } \\
\text { unemployed into self- } \\
\text { employment }\end{array}$ & $\begin{array}{l}\text { Versement d'un } \\
\text { montant forfaitaire } \\
\text { équivalent au droit } \\
\text { à la prestation, } \\
\text { aide à l'entreprise } \\
\text { (p.ex. formation, } \\
\text { développement de } \\
\text { compétences) }\end{array}$ & Chômeurs & $\begin{array}{l}\text { Impact net sur l'emploi: chômeurs (+), } \\
\text { femmes (+), niveaux d'instruction primaire } \\
(+) \text { et secondaire }(+) \text {; jeunes }(+) \text {, chômeurs } \\
\text { de longue durée }(+)\end{array}$ \\
\hline
\end{tabular}




\section{Références}

Hite, J. (2006), «Evolutionary processes and paths of relationally embedded network ties in emerging entrepreneurial firms», Entrepreneurship Theory and Practice, vol. 30(5), p. 595-621.

Almeida, R. et E. Galasso (2007), «Jump-Starting Self-Employment? Evidence AmongWelfare Participants in Argentina», Discussion Paper 2902, IZA.

Audretsch, D. (2002), «The dynamic role of small firms: Evidence from the US», Small Business Economics, vol. 18(1-3), p. 13-40.

Di Bella,J. (2013), Innovative Ansätze in der Beratung von Migrantinnen und Migranten mit Gründungsambitionen. Potenziale aus der akademischen Gründungslehre nutzen, WISO direkt, Friedrich-Ebert-Stiftung, Bonn.

Di Bella, J. et Leicht, R. (2011), «Zielgruppenorientierte Gründungsförderung: Migrantinnen und Migranten in der Gründungsberatung», dans Irsch, N. et Witt, P. (eds.), Gründungsförderung in Theorie und Praxis, herausgegeben von KfW Bankengruppe und Förderkreis Gründungs-Forschung e.V., Francfort-sur-le-Main, p. 223-240.

Bosma, N., Hessels, J., Schutjens, V., van Praag, M. et Verheul, I. (2012), «Entrepreneurship and Role Models", Journal of Economic Psychology, vol. 33(2), p. 410-424.

Botti, F. et Corsi, M. (2011), «Measuring the Social Performance of Microfinance in Europe», CEB Working Paper, 11/037.

Chrisman, J., McMullan, E. et Hall, J. (2005), «The influence of guided preparation on the long-term performance of new ventures", Journal of Business Venturing, vol. 20(6), p. 769-791.

Daniel, C. (2008), «Les bénéficiaires de l'ACCRE jugent l'accompagnement à la création d'entreprise: des motifs de satisfaction mais encore des attentes", DARES Premières, $n^{\circ}$ 09.2, février.

Duke, D., Lewis, M., Bernard, C. et Conlon, G. (2013), «A European Single Point of Contact», Parlement européen: Strasbourg.

Commission européenne (CE) (2012), «Eurobaromètre Flash n³54, L'entrepreneuriat dans l'UE et audelà», disponible sur: http://ec.europa.eu/public_opinion/flash/fl_354_en.pdf.

Commission européenne (CE) (2008), «Diversité de l'entrepreneuriat dans une Europe unifiée», disponible sur: http://ec.europa.eu/enterprise/policies/sme/files/support_measures/migrant/eme_study_ fr.pdf.

Commission européenne (CE) (2004), «Promoting entrepreneurship amongst women», Best Report $\mathrm{n}^{\circ} 2$ de la DG Entreprise et industrie, disponible sur: http://ec.europa.eu/enterprise/newsroom/cf/_ getdocument.cfm?doc_id=4094.

Commission européenne (CE) (2002), «Support Services for Micro, Small and Sole Proprietor's Businesses", CE: Vienne, disponible sur: http://ec.europa.eu/enterprise/policies/sme/files/craft/craftstudies/documents/supportservices-finalreport-en_en.pdf.

Commission européenne - OCDE (2013), «Synthèse sur l'évaluation des actions pour l'entrepreneuriat inclusif», UE: Luxembourg.

Commission européenne - OCDE (2012), «Synthèse sur l'entrepreneuriat des seniors», UE: Ferrara, F. et Marini, G. (2004), «L'impatto dello sportello unico per le attività produttive sulla natalità d'impresa: una valutazione quasi sperimentale», Politica Economica, vol. XX, nº 3 .

Greene, F. (2013), "Start-up Business Development Support Services for Inclusive Entrepreneurs», préparé dans le cadre du programme LEED de l'OCDE.

Greene, F. et Storey, D. (2004), «An assessment of a venture creation programme: the case of Shell LiveWIRE», Entrepreneurship and Regional Development, vol. 16(2), p. 145-159.

Hjalmarsson, D. et Johansson, A. (2003), «Public advisory services - theory and practice», Entrepreneurship and Regional Development, vol. 15(1), p. 83-98.

Organisation internationale du travail (OIT) (2006), «Stimulating Youth Entrepreneurship: Barriers and incentives to enterprise start-ups by young people», document de travail SEED n 76, OIT: Genève.

INSEE (2012), «Créations et créateurs d'entreprises - Première interrogation 2010, profil du créateur», INSEE Résultats, $\mathrm{n}^{\circ}$ 58, février IPREG (2011), «Entrepreneurship and SME Policies across Europe: The cases of Sweden, Flanders, Austria and Poland", rapport 2011:03, Swedish Agency for Growth Policy Analysis, Östersund, Suède. 
Leicht, R., Strohmeyer, R., Leiß, M. et Philipp, R. (2009), «Selbständig integriert? Studie zum Gründungsverhalten von Frauen mit Zuwanderungsgeschichte in Nordrhein-Westfalen", Ministerium für Generationen, Familie, Frauen und Integration NRW (Hg.), Düsseldorf.

Leicht, R., Di Bella, J., Langhauser, M., Leiß, M., Philipp, R., Volkert, M. et Werner, L. (2012), «Schöpferische Kraft der Vielfalt: Zugewanderte und ihre Unternehmen. Bedeutung, Triebkräfte und Leistungen von Migrantenunternehmen in Baden-Württemberg (und Deutschland)", Studie im Auftrag des Ministeriums für Finanzen und Wirtschaft Baden-Württemberg, Institut für Mittelstandsforschung, Universität Mannheim.

Meager, N., Bates, P. et Cowling, M. (2003), «An evaluation of business start-up support for young people», National Institute Economic Review, $\mathrm{n}^{\circ} 183$, octobre.

Means, B., Toyama, Y., Murphy, R., Bakia, M. et Jones, K. (2010), «Evaluation of Evidence-Based Practices in Online Learning: A Meta-Analysis and Review of Online Learning Studies», rédigé pour le département de l'éducation des États-Unis.

Michaelides, M. et Benus, J. (2012), «Are self-employment training programmes effective? Evidence from Project GATE», Labour Economics, vol. 19(5), p. 695-705.

Oberschachtsiek, D. et Scioch P. (2011), «The outcome of coaching and training for self-employment. A statistical evaluation of non-financial support schemes for unemployed business founders in Germany", IAB-Discussion Paper, $n^{\circ}$ 16, Nuremberg.

OCDE (2010), Reconnaître l'apprentissage non formel et informel: résultats, politiques et pratiques, Publication OCDE, Paris. http://dx.doi.org/10.1787/9789264063853-en.

OCDE/Commission européenne (2013), Pallier la pénurie d'entrepreneurs: Policies for Inclusive Entrepreneurship in Europe, Publication OCDE, Paris. http://dx.doi.org/10.1787/9789264188167-en.

Perry, G. (2006), «Are Business Start-up Subsidies Effective for the Unemployed: Evaluation of Enterprise Allowance», document de travail, Auckland University of Technology.

Peterman, N. et Kennedy, J. (2003), «Enterprise education: influencing students' perceptions of entrepreneurship». Entrepreneurship Theory and Practice, vol. 28(2), p. 129-144.

Pettersson, K. (2012), "Support for women's entrepreneurship: A Nordic spectrum», International Journal of Gender and Entrepreneurship, vol. 4(1), p. 4-19.

Rath, J., Swagerman, A., Krieger, H., Ludwinek, A. et Pickering, L. (2011), Promoting ethnic entrepreneurship in European cities, Office des publications de l'Union européenne, Luxembourg.

Rodriguez-Planas, N. (2010), «Channels through which Public Employment Services and Small Business Assistance Programmes Work», Oxford Bulletin of Economics and Statistics, vol. 72(4), p. 458-485.

Rotger, G., Gørtz, M. et Storey, D. (2012), «Assessing the effectiveness of guided preparation for new venture creation and performance: Theory and practice», Journal of Business Venturing, vol. 27(4), p. 506-521.

St-Jean, E. (2010), «Les fonctions du mentor de l'entrepreneur novice», Revue de l'entrepreneuriat, vol. 9(2), p. 34-55.

Tödtling-Schönhofer, H., Naylon, I., Génin, H., Basile, I. et Savioli, B. (2011), «Expert Evaluation Network: Final report to Contract No VC/2010/0153», Metis: Vienne.

Van Auken, H., Fry, F. et Stephens, P. (2006), «The influence of role models on entrepreneurial intentions», Journal of Developmental Entrepreneurship, vol. 11(2), p. 157-167.

Walsh, K., Kotzeva, M., Dölle, E. et Dorenbos, R. (2001), «Evaluation of the Net Impact of Active Labour Market Programme in Bulgaria», ministère bulgare du travail et de la politique sociale, Rotterdam. 



\section{Chapitre 9}

\section{Sécurité sociale et Entrepreneuriat inclusif 1,2}

Bien que la promotion de l'entrepreneuriat ne fasse pas partie de leurs objectifs généraux, les systèmes de sécurité sociale peuvent influencer les décisions de création d'entreprise. Les coûts et les avantages de la sécurité sociale ne sont pas les mêmes pour les salariés et les indépendants. Ces derniers bénéficient souvent de niveaux de couverture moindres. Ce chapitre s'intéresse à l'influence de la sécurité sociale pèse sur l'entrepreneuriat inclusif et aux approches politiques adoptées pour atténuer les effets néfastes des systèmes de sécurité sociale sur le travail indépendant et la création d'entreprise.

1. Note de la Turquie:

Les informations figurant dans ce document et faisant référence à "Chypre» concernent la partie méridionale de l'île. Il n'y a pas d'autorité unique représentant à la fois les Chypriotes turcs et grecs sur l'île. La Turquie reconnaît la République turque de Chypre du Nord (RTCN). Tant qu'une solution durable et équitable n'aura pas été trouvée dans le cadre des Nations unies, la Turquie maintiendra sa position sur la «question chypriote».

2. Note de tous les États de l'Union européenne membres de l'OCDE et de l'Union européenne:

La République de Chypre est reconnue par tous les membres des Nations unies sauf la Turquie. Les informations figurant dans ce document concernent la zone sous le contrôle effectif du gouvernement de la République de Chypre. 


\section{Systèmes de sécurité sociale}

- Les coûts, les avantages, les mécanismes de financement et les critères d'éligibilité des systèmes de sécurité sociale sont très différents d'un État membre à l'autre.

- Les systèmes de sécurité sociale peuvent avoir un impact sur les décisions d'entrepreneuriat et de travail indépendant, dans la mesure où ils exercent une influence sur les coûts d'opportunité ainsi que sur les coûts et avantages liés à la création d'entreprise.

Les systèmes de sécurité sociale sont des systèmes de protection sociale qui ont pour vocation d'aider les personnes confrontées à des circonstances imprévues ou difficiles. Les plus sophistiqués d'entre eux fournissent une grande variété de prestations. Dans ce chapitre, nous nous concentrerons sur celles qui ont la plus forte incidence sur l'entrepreneuriat (Panteia/EIM, 2007):

- l'assurance invalidité permanente;

- l'assurance maladie longue durée et invalidité temporaire;

- l'assurance vieillesse et la retraite;

- les prestations de survivants;

- l'assurance chômage (faillite ou cessation d'activité);

- l'aide au revenu (octroi de subventions aux faibles revenus pour éviter le chômage);

- l'assurance maternité (congé);

- l'assurance garde d'enfants (temporaire).

D'autres aspects de la législation ont des répercussions sur la sécurité. Par exemple, la législation sur la protection de l'emploi a un impact sur la flexibilité du travail, y compris sur le degré de facilité de la transition du salariat au travail indépendant.

Tous les pays de l'UE sont pourvus d'un système de sécurité sociale, mais leur composition varie fortement en termes de taux de cotisation, d'allocations de coûts et de niveaux de prestations (Tableau 9.1).

\section{Influence des systèmes de sécurité sociale sur l'entrepreneuriat}

Des données attestent qu'au niveau macroéconomique, les systèmes de sécurité sociale les plus évolués et les plus complets en termes de prestations ont tendance à avoir une incidence négative sur l'activité entrepreneuriale (Parker et Robson, 2004; Panteia/EIM, 2007; Hessels et al., 2007). De plus, il a été démontré que certains régimes (p.ex. ponts sociaux, voir ci-dessous) ont une incidence sur le travail indépendant, ce qui semble confirmer l'idée selon laquelle le système de sécurité sociale a des effets négatifs sur l'entrepreneuriat à certains égards. Toutefois, très peu d'études ont été réalisées sur les répercussions de certains volets du système de sécurité social sur les décisions en matière d'entrepreneuriat et de travail indépendant. 
Tableau 9.1. Taux de cotisation aux régimes de sécurité sociale, 2010 (en \% du salaire)

\begin{tabular}{|c|c|c|c|c|c|c|}
\hline \multirow[t]{2}{*}{ Pays } & \multicolumn{3}{|c|}{ Vieillesse, incapacité, survie } & \multicolumn{3}{|c|}{ Tous les régimes de sécurité sociale1 } \\
\hline & Assuré & Employeur & Total & Assuré & Employeur & Total \\
\hline Autriche $b$ & 10,25 & 12,55 & 22,8 & 17,2 & 25,15 & 42,35 \\
\hline Belgique $b$ & 7,5 & 8,86 & 16,36 & 13,07 & 24,77 & 37,84 \\
\hline Bulgarie $b$ & 7,1 & 8,9 & 16 & 12,1 & 16,8 & $28,9 d$ \\
\hline Croatie & $\mathrm{n} / \mathrm{d}$ & $\mathrm{n} / \mathrm{d}$ & $\mathrm{n} / \mathrm{d}$ & $\mathrm{n} / \mathrm{d}$ & $\mathrm{n} / \mathrm{d}$ & $\mathrm{n} / \mathrm{d}$ \\
\hline Chypre b & $6,8 \mathrm{c}$ & $6,8 \mathrm{c}$ & $13,6 c$ & 6,8 & 6,8 & $13,6 d$ \\
\hline République tchèque & 6,5 & 21,5 & 28 & 11 & $34 \mathrm{e}$ & $45 \mathrm{~d}, \mathrm{e}$ \\
\hline Danemark & $\mathrm{n} / \mathrm{d}$ & $\mathrm{n} / \mathrm{d}$ & $\mathrm{n} / \mathrm{d}$ & $\mathrm{n} / \mathrm{d}$ & $\mathrm{n} / \mathrm{d}$ & $\mathrm{n} / \mathrm{d}$ \\
\hline Estonie $\mathrm{d}$ & 2 & 20 & 22 & 2,6 & 33,3 & $35,9 \mathrm{~d}$ \\
\hline Finlande & 4,5 & 17,1 & 21,6 & 7,1 & 20,38 & $27,48 d$ \\
\hline France $b$ & $6,65 \mathrm{~g}$ & $9,9 \mathrm{~g}$ & $16,55 \mathrm{~g}$ & 9,8 & $32,68 \mathrm{e}$ & $42,48 \mathrm{e}$ \\
\hline Allemagne $b$ & 9,95 & 9,95 & 19,9 & 19,25 & 19,61 & $38,86 \mathrm{~d}$ \\
\hline Grèce $b$ & 6,67 & 13,33 & 20 & 11,55 & 22,1 & 33,65 \\
\hline Hongrie $b$ & $9,5 \mathrm{c}$ & $24 \mathrm{C}$ & $33,5 \mathrm{c}$ & 17 & 27 & $44 \mathrm{~d}, \mathrm{~h}$ \\
\hline Irlande & $4 \mathrm{C}$ & $8,5 \mathrm{c}$ & $12,5 \mathrm{c}$ & 4 & 8,5 & $12,5 \mathrm{I}$ \\
\hline Italie b & 9,19 & 23,81 & 33 & 9,19 & 30,17 & 39,36 \\
\hline Lettonie & $9 \mathrm{c}$ & $24,09 \mathrm{c}$ & $33,09 \mathrm{c}$ & 9 & 24.09 & $33,09 \mathrm{~d}$ \\
\hline Lituanie & 3 & 23.3 & 26.3 & 9 & 30,98 & 39,98 \\
\hline Luxembourg b & 8 & 8 & 16 & 12,35 & 11,4 & $23,75 d$ \\
\hline Malte $b$ & $10 \mathrm{c}$ & $10 c$ & $20 \mathrm{C}$ & 10 & 10 & 20 \\
\hline Pays-Bas b & 19 & 5,7 & 24,7 & $22,5 \mathrm{~h}$ & 17.5 & $40 \mathrm{~d}, \mathrm{~h}$ \\
\hline Pologne b & 11,26 & 14,46 & 25,52 & 22,71 & 17,61 & $40,32 d$ \\
\hline Portugal & $11 \mathrm{c}$ & $23,75 \mathrm{c}$ & $34,75 \mathrm{c}$ & 11 & 23,75 & 34,75 \\
\hline Roumanie & 10.5 & 20.8 & 31.3 & 16,2 & 27,8 & $44 \mathrm{~d}$ \\
\hline République slovaque & 4 & 14 & 18 & 10.4 & 27.2 & $37,6 \mathrm{~d}$ \\
\hline Slovénie & $15,5 \mathrm{c}$ & $8,85 \mathrm{c}$ & $24,35 \mathrm{c}$ & 22,1 & 16,1 & $38,2 \mathrm{~d}$ \\
\hline Espagne b & $4,7 \mathrm{c}$ & $23,6 \mathrm{c}$ & $28,3 \mathrm{c}$ & 6,25 & 31,08 & $37,33 \mathrm{~d}$ \\
\hline Suède & $7 \mathrm{~g}$ & 11,91 & 18,91 & 7 & 23,431 & $30,43 \mathrm{~d}, \mathrm{I}$ \\
\hline Royaume-Uni & $11 \mathrm{c}$ & $12,8 \mathrm{c}$ & $23,8 \mathrm{c}$ & 11 & 12,8 & $23,8 \mathrm{~d}$ \\
\hline
\end{tabular}

Note: 1 . Cela inclut les régimes vieillesse, incapacité, survie, maladie, maternité, accidents du travail, chômage ainsi que les allocations familiales. Dans certains pays, le taux ne couvre pas tous ces régimes. Dans certains cas, seules certaines catégories, comme les salariés, sont représentées. En cas de variation des taux de cotisation, c'est le taux médian ou le taux le plus bas qui est utilisé.

b. Les cotisations de certaines prestations sont plafonnées

c. Cela inclut également les taux de cotisation d'autres régimes.

d. Les allocations familiales sont intégralement prises en charge par l'État.

e. L'État prend en charge l'intégralité ou la majeure partie des prestations d'accident du travail.

f. Part du montant fixe des régimes vieillesse, incapacité et survie. Gouvernement central et local, et autres

types de cotisations à d'autres régimes.

g. Les cotisations financent uniquement le régime vieillesse. Des cotisations supplémentaires sont exigées pour

les prestations de survie et d'incapacité.

h. Plus cotisations forfaitaires pour les prestations maladie.

i. L'État prend en charge la majeure partie du coût des allocations familiales.

j. Les prestations de chômage sont intégralement prises en charge par l'État.

k. Les prestations incapacité relèvent d'un autre régime.

l. L'État assume l'intégralité de l'assurance-chômage de base. L'assurance-chômage volontaire est à la charge de l'employeur et du salarié.

Source: SSA (Social Security Administration), Office of Retirement and Disability Policy, Office of Research, Evaluation, and Statistics, (United States of America) (2010), Social Security Programs Throughout the World: Europe, 2010,

Washington, États-Unis d'Amérique. 
- Au niveau macroéconomique, il apparaît que la qualité des systèmes de sécurité sociale est inversement corrélée au taux de création d'entreprise et de travail indépendant.

- Les systèmes de sécurité sociale peuvent exercer une influence négative sur l'entrepreneuriat dans la mesure où les travailleurs indépendants peuvent payer plus que les salariés pour les mêmes prestations (p.ex. cotisations patronales et salariales); bénéficier de prestations moindres pour un coût identique (p.ex. retraite plus faible); ne pas avoir droit à certaines prestations (p.ex. assurance chômage); avoir des difficultés à travailler avec des systèmes complexes (normalement gérés par l'employeur); craindre de perdre des prestations acquises; subir des modifications de leurs prestations en cas de maternité ou de garde d'enfants; et cotiser plus longtemps avant d'être éligibles aux prestations.

- Les entrepreneurs défavorisés et sous-représentés sont d'ores et déjà davantage susceptibles de faire appel au système de sécurité sociale, sans doute sous plusieurs formes. Les dispositions détaillées des mesures peuvent alors être plus importantes pour l'entrepreneur handicapé que pour l'entrepreneur lambda.

Les systèmes de sécurité sociale affectent l'entrepreneuriat, dans la mesure où ils exercent une influence sur les coûts et avantages liés à la création d'entreprise. Le taux de cotisation de chaque individu peut varier en fonction de son statut professionnel, tout comme le niveau de ses droits et de ses prestations. La stimulation de l'entrepreneuriat ne faisant normalement pas partie de leurs objectifs généraux, nombre des systèmes de sécurité sociale ont des effets pervers dissuasifs sur l'entrepreneuriat, notamment en raison des différences de cotisations et d'avantages. En effet, les indépendants cotisent plus ou bénéficient d'une couverture moindre que le salarié moyen. Dès lors, ces considérations freinent la croissance des entreprises.

L'influence des systèmes de sécurité sociale sur la création d'entreprise et sur le travail indépendant est encore plus marquée chez les groupes socialement défavorisés du fait de leur plus grande vulnérabilité au sein de la société (Boylan et Burchardt, 2002). En particulier, les groupes défavorisés sont plus susceptibles d'avoir affaire au système de sécurité sociale et de demander des prestations. En outre, ils sont plus susceptibles d'interagir avec différentes composantes du système de sécurité sociale (p.ex. allocations multiples) et de ressentir cette incidence nette.

Parmi les principales influences des différentes composantes des systèmes de sécurité sociale figurent les facteurs financiers dissuasifs directs, les prestations moindres, la crainte de perdre certains droits, les frais administratifs, les dispositions en matière de maternité et de garde d'enfants, le rapport coût/avantage des retraites et la nécessité de cotiser avant de pouvoir prétendre à des prestations.

\section{Facteurs financiers dissuasifs directs}

Les systèmes de sécurité sociale de l'UE reposent sur un système de cotisation impliquant l'État, les employeurs et les salariés. Dans de nombreux pays, ceux qui deviennent des travailleurs indépendants doivent s'acquitter des cotisations patronales et salariales pour bénéficier du même niveau de couverture que les salariés (Panteia/EIM, 2007). Les coûts de création d'entreprise sont ainsi majorés dans de nombreux pays de l'UE. En Slovénie et en Hongrie, par exemple, le travailleur indépendant paie à la fois les cotisations patronales et salariales, soit un taux global de cotisation plus élevé. En Slovénie, $15,5 \%$ des cotisations sociales sont généralement payées par l'employeur, et 8,85\% par le salarié. Pour les indépendants, le taux est de $24,35 \%$. En Hongrie, les taux sont de $8,5 \%$ et $27 \%$ respectivement. Les indépendants doivent s'acquitter des deux (MISSOC, 2013). 


\section{Prestations moindres}

Dans la plupart des pays de l'UE, dont l'Estonie, la France, l'Irlande, Chypre et Malte, les indépendants ne bénéficient pas de l'assurance chômage (MISSOC, 2013). Ils sont cependant souvent tenus d'y cotiser. En d'autres termes, ils paient pour un mécanisme d'aide auquel ils n'ont pas droit. Cette réalité freine la décision de créer une entreprise, en particulier lorsqu'il s'agit d'anciens salariés confrontés à la perspective de ne pas être protégés en cas d'échec.

Les régimes d'assurance-maladie et de retraite couvrent moins bien les indépendants que les salariés, même si la situation varie grandement d'un pays de l'UE à l'autre (MISSOC, 2013). De plus, certains pays comme la République slovaque n'offrent aucune protection aux indépendants en cas de maladie professionnelle ou d'accident du travail (MISSOC, 2013).

\section{Crainte de perdre des droits acquis}

La crainte de perdre certaines prestations peut être aussi dissuasive que la connaissance des changements que suppose le passage au travail indépendant. Les personnes issues de groupes défavorisés peuvent bénéficier de prestations relativement importantes et sont donc plus réticentes à prendre des risques, à moins qu'elles ne soient clairement informées des changements qu'implique le fait de devenir indépendant.

La complexité des systèmes peut notamment être un obstacle. Par exemple, les prestations d'invalidité sont calculées en fonction du degré d'incapacité et du niveau d'aide requis. Cette complexité du calcul des prestations peut créer une certaine confusion auprès de ceux qui envisagent de se mettre à leur compte. Ils peuvent en effet ignorer si les prestations qu'ils perçoivent vont être affectées et renoncer alors à la création de leur entreprise.

\section{Frais administratifs}

Les frais à engager pour se conformer aux exigences administratives des systèmes de sécurité sociale augmentent les coûts du travail indépendant, le temps et les dépenses consacrés à la déclaration et au paiement des cotisations étant relativement fixes quelle que soit la taille de la société. En outre, l'impression de complexité peut constituer un frein à la création d'entreprise, les petites entreprises n'ayant pas les moyens de bien comprendre toutes les subtilités de leurs obligations administratives (Hessels et al., 2007). La difficulté est encore plus grande pour les entrepreneurs sans aucune expérience en matière de respect des règles administratives (Guyot et Lohest, 2008). Des données récentes d'Eurobaromètre indiquent que pour $72 \%$ des personnes interrogées, les charges administratives découragent le travail indépendant (Commission européenne, 2012).

\section{Dispositions en matière de maternité et de garde d'enfants}

Pour les entrepreneurs comme pour les salariés, la couverture en matière de congé de maternité et de garde d'enfants varie selon les pays de l'UE. Au niveau national, les données font état d'un lien négatif entre le soutien de l'État-providence en matière de maternité et de garde d'enfants et le niveau d'entrepreneuriat du pays (Elam et Terjesen, 2010).

À l'échelle des individus, les indépendantes rencontrent deux difficultés auxquelles ne sont pas confrontées les salariées. Premièrement, les indépendantes ne reçoivent généralement aucune rémunération (salaire ou traitement), ce qui dissuade les jeunes femmes qui envisagent de fonder une famille de se lancer dans une activité indépendante. 
Deuxièmement, dans les quelques pays qui octroient des allocations maternité aux indépendantes, c'est l'employeur qui doit assumer le cout de cette couverture.

Les services de garde d'enfants ont généralement une influence positive sur le travail indépendant. Une offre de services de garde abondante favorise le travail indépendant, car les femmes peuvent consacrer plus de temps à la création d'entreprise (Elam et Terjesen, 2010; OCDE, 2012).

\section{Rapport coût-avantages des retraites}

Les travailleurs plus âgés qui envisagent de travailler comme indépendants sont souvent découragés de créer ou de reprendre une entreprise pour des raisons financières, car passer du salariat au travail indépendant réduit la durée d'affiliation au régime de retraite des salariés et entraîne une diminution de la future pension de retraite (MISSOC, 2013; Zissimopoulos et al., 2003). Parallèlement à cela, certains pays de l'UE proposent des régimes de retraite pour les indépendants, mais ces derniers sont moins attractifs que ceux des salariés (Betzelt, 2004).

À l'inverse, la perspective de la retraite peut pousser les seniors à devenir entrepreneurs s'ils n'ont pas suffisamment cotisé pour partir à la retraite et conserver leur niveau de vie (Efrat, 2008). Le travail indépendant peut alors être un moyen efficace d'acquérir les annuités manquantes.

\section{Nécessité de cotiser avant de pouvoir prétendre à des prestations}

Le système de sécurité sociale impose aux indépendants et aux salariés une durée de cotisation minimale avant de pouvoir bénéficier de prestations. Cette obligation peut avoir des effets positifs sur la création d'entreprise, car certains groupes défavorisés peuvent ne pas avoir accès à certaines prestations sociales faute d'emploi. Le travail indépendant peut donc leur permettre de bénéficier du niveau minimal de couverture sociale. Cela est particulièrement vrai pour les nouveaux immigrés (OCDE, 2010).

\section{Approches politiques destinées à atténuer les effets dissuasifs sur l'entrepreneuriat}

S'ils veulent mettre les systèmes de sécurité sociale au service de l'entrepreneuriat, les décideurs politiques doivent d'abord miser sur une réduction des risques liés au travail indépendant (Commission européenne, 2012). Il existe plusieurs approches, notamment les ponts sociaux, la réduction des taux de cotisation et de l'imposition, l'extension de prestations aux familles des indépendants, l'offre d'une couverture supplémentaire facultative pour les indépendants et la garantie d'une égalité de traitement entre indépendants et salariés dans le cadre des systèmes de sécurité sociale.

\section{Ponts sociaux}

L'expression «pont social» désigne les politiques qui permettent à un individu de continuer à percevoir des prestations ou des versements (p.ex. petites subventions) durant la période de création de leur entreprise. Grâce à ces "ponts", les chômeurs bénéficient d'un revenu de base qui leur permet de subvenir à leurs besoins et les encouragent à créer leur activité indépendante.

Plusieurs pays de l'UE ont mis en place des ponts sociaux qui aident les chômeurs créateurs d'entreprise. Vous trouverez un aperçu des différentes mesures et dispositions au Tableau 9.2. Un des exemples fréquemment cités concerne l'aide allemande à la création d'entreprise (Gründungszuschuss), qui ressemble aux précédentes politiques de ponts sociaux qu'étaient la subvention de démarrage et l'indemnité-relais (Panteia/EIM, 2007). La 
- Les gouvernements de l'UE utilisent un certain nombre d'approches communes pour remédier à l'influence négative des systèmes de sécurité sociale, pourtant très hétéroclites, sur l'entrepreneuriat. Ces approches incluent:

1. Les ponts sociaux, qui permettent aux bénéficiaires de continuer à percevoir leurs indemnités pendant la création de leur entreprise. Ils facilitent la transition financière vers le travail indépendant et, dans certains cas, octroient un capital d'amorçage.

2. La réduction des cotisations des indépendants, afin qu'elles soient proportionnelles aux profits générés. Cette approche contribue ainsi à réduire la pression financière liée au démarrage d'une nouvelle activité.

3. L'extension des prestations à l'ensemble de la famille afin de diminuer le risque auquel s'exposent un entrepreneur et sa famille en cas d'échec.

4. La possibilité d'opter, sur la base du volontariat, pour des prestations complémentaires lorsque celles prévues des indépendants sont inférieures à celles des salariés. Le cas échéant, les entrepreneurs bénéficient d'une couverture plus flexible et ne sont pas contraints d'opter pour une assurance excessivement onéreuse ou inadaptée.

5. L'égalité de traitement entre indépendants et salariés dans le cadre des systèmes de sécurité sociale.

subvention de démarrage était octroyée aux chômeurs de moins de 65 ans durant les trois premières années de leur activité. L'indemnité-relais, également destinée aux chômeurs de moins de 65 ans, était une allocation mensuelle qui permettait de couvrir les dépenses quotidiennes durant la période d'installation du travailleur indépendant. Pour être éligibles à l'indemnité-relais, les bénéficiaires devaient être inscrits au chômage pendant au moins quatre semaines et disposer d'un plan d'affaires viable. Les bénéficiaires de ce programme percevaient leurs allocations de chômage pendant six mois, ainsi qu'une somme forfaitaire équivalant à $68,5 \%$ de leurs allocations pour couvrir leurs cotisations de sécurité sociale. Ces deux programmes ont été fusionnés pour créer la Gründungszuschuss.

Il existe un programme similaire baptisé Back to Work Enterprise Allowance en Irlande. Cette mesure, qui cible en particulier les bénéficiaires de régimes de protection sociale, comprend une aide financière sous la forme d'un maintien des prestations sociales. Elle est abordée plus en détail à l'encadré 9.1.

D'autres pays ont mis en place des mesures semblables. Au Royaume-Uni, par exemple, l'allocation de création d'entreprise (New Enterprise Allowance) soutient financièrement la création d'entreprise des chômeurs inscrits et des bénéficiaires d'une aide au revenu (Eurofound, 2011). Le programme verse un capital d'amorçage sous forme de prêt et une allocation hebdomadaire pouvant aller jusqu'à 1274 GBP (environ 1500 EUR) pendant 26 semaines. Des approches comparables existent au Danemark, en Suède et aux Pays-Bas.

Un pont social d'un genre quelque peu différent prévoit le paiement d'une somme forfaitaire en lieu et place du maintien du versement des prestations. C'est l'approche qui a été adoptée en Espagne et au Portugal. En Espagne, les chômeurs peuvent recevoir jusqu'à $60 \%$ de leurs allocations en une seule fois ( $80 \%$ pour les femmes de moins de 35 ans) (Bilan de l'Observatoire européen de l'emploi, 2010). Au Portugal, les allocataires peuvent toucher $100 \%$ de leurs indemnités sous forme de versement forfaitaire (Naumann, 2011).

Un troisième type de pont social permet d'allouer une subvention fixe aux chômeurs qui démarrent une activité d'entrepreneur, quelles que soient leurs prestations de chômage. En Estonie, par exemple, les chômeurs indemnisés peuvent bénéficier d'une subvention de démarrage pouvant atteindre 6400 EUR. Les entrepreneurs sont néanmoins tenus de 


\section{Tableau 9.2. Vue d'ensemble des principales politiques de pont social en Europe}

\begin{tabular}{|c|c|}
\hline \multicolumn{2}{|l|}{ Pont social classique } \\
\hline Danemark & Maintien des prestations de chômage pour les créateurs d'entreprise. \\
\hline Allemagne & Indemnité-relais pour les chômeurs indemnisés de moins de 65 ans. \\
\hline Irlande & Allocation de retour à l'emploi (Back to Work Allowance) pour les bénéficiaires de prestations sociales. \\
\hline Suède & Maintien des prestations de chômage pour les créateurs d'entreprise. \\
\hline Royaume-Uni & Aide à la création d'entreprise (New Enterprise Allowance) pour les bénéficiaires d'allocations chômage, d'aides au revenu ou de prestations d'invalidité. \\
\hline \multicolumn{2}{|c|}{ Paiement des prestations sous forme de versement forfaitaire } \\
\hline Portugal & Versement des allocations de chômage sous forme de versement forfaitaire unique afin de soutenir le démarrage de la nouvelle entreprise. \\
\hline Espagne & Versement d'un pourcentage des allocations de chômage sous forme de versement forfaitaire unique afin de soutenir le démarrage de la nouvelle entreprise. \\
\hline \multicolumn{2}{|c|}{ Subvention selon le statut d'affiliation à la sécurité sociale } \\
\hline Croatie & Politique nationale en matière d'emploi: octroi de prêts et de subventions aux chômeurs qui souhaitent devenir indépendants. \\
\hline République tchèque & $\begin{array}{l}\text { Subventions pour l'achat de machines, de locaux, etc. aux chômeurs qui présentent un plan d'affaires viable (Bilan de l'Observatoire européen de } \\
\text { l'emploi, 2010). }\end{array}$ \\
\hline Estonie & Subvention de démarrage aux chômeurs indemnisés. \\
\hline France & $\begin{array}{l}\text { «Contrat d'insertion à la vie sociale» (CIVIS): soutien intensif et personnalisé pendant un an et allocation pouvant atteindre } 450 \text { EUR par mois pour les } \\
\text { chômeurs et les jeunes peu qualifiés (Bilan de l'Observatoire européen de l'emploi, 2010). }\end{array}$ \\
\hline Hongrie & $\begin{array}{l}\text { Programme de subvention pour les chômeurs inscrits qui démarrent une activité d'indépendant: trois volets destinés respectivement aux handicapés, } \\
\text { aux nouveaux arrivants sur le marché du travail de plus de } 50 \text { ans, aux jeunes mères et aux chômeurs inscrits. Ces catégories bénéficient de } \\
\text { subventions de démarrage dans le cadre de la création de leur entreprise. }\end{array}$ \\
\hline Italie & Incitation à la création d'entreprise pour les jeunes et les chômeurs des zones urbaines sous-développées (Bilan de l'Observatoire européen de l'emploi, 2010). \\
\hline Pays-Bas & $\begin{array}{l}\text { Services d'aide à l'attention des chômeurs: prêts aux chômeurs et aux allocataires sociaux désireux de créer une entreprise; possibilité de } \\
\text { remboursement des frais engagés pour de l'accompagnement individualisé ou la réalisation d'études de marché. }\end{array}$ \\
\hline République slovaque & $\begin{array}{l}\text { Loi sur les services de l'emploi de 2004: subventions à l'attention des demandeurs d'emploi et subventions parallèles pour les personnes } \\
\text { handicapées souhaitant créer une entreprise. }\end{array}$ \\
\hline
\end{tabular}

\section{Encadré 9.1. Back to Work Enterprise Allowance, Irlande}

Description: cette initiative s'adresse aux bénéficiaires des aides sociales suivantes: allocation de demandeur d'emploi; indemnité de demandeur d'emploi; allocation de famille monoparentale; pension d'aveugle; allocation d'invalidité; allocation pour garde; aide agricole; pension d'invalidité; complément d'invalidité; allocation de préretraite; pension (non contributive) de veuf/veuve ou de conjoint survivant; indemnité ou allocation d'épouse abandonnée; allocation d'épouse de prisonnier; et indemnités maladie pendant trois ans ou plus. Cette mesure fournit des informations et des référents ainsi qu'une aide financière. Elle prévoit également la vérification de la viabilité du plan d'affaires (Panteia/EIM, 2007).

Problème abordé: cette initiative vise principalement à ramener les chômeurs menacés de pauvreté sur le marché du travail par le biais du travail indépendant.

Approche: le programme octroie pendant deux ans une allocation dégressive aux chômeurs de longue durée qui souhaitent créer une entreprise. Pour être éligible, il faut être sans emploi et percevoir des prestations sociales depuis 12 mois. La participation au programme impose de soumettre un plan d'affaires viable, qui a été approuvé par une société partenaire locale/société de développement local intégré ou par un membre du département de la protection sociale et de l'emploi. La durée de versement de l'allocation était initialement de quatre ans, mais cette disposition a été modifiée en mai 2009. Désormais, chaque personne perçoit l'intégralité de ses prestations durant la première année, puis $75 \%$ la deuxième année.

Impact: entre 1997 et 1999, 86,8\% des bénéficiaires n'ont pas fait de demande d'aide sociale. Seuls $5,9 \%$ ont fait une demande de courte durée et 7,3\% sont redevenus prestataires de l'aide sociale (ministère de l'entreprise, du commerce et de l'emploi, 2002). L'impact des récentes modifications n'a pas encore été mesuré.

Facteurs de réussite: le succès du programme s'explique par l'étendue du groupe cible. Son ouverture à diverses catégories sociales permet une couverture plus large. 
financer $20 \%$ des coûts de démarrage sur leurs propres économies ou via d'autres sources (Bilan de l'Observatoire européen de l'emploi, 2010).

Veuillez consulter le chapitre 6 pour en savoir plus sur les ponts sociaux.

\section{Réduction des taux de cotisation et de l'imposition}

Les indépendants paient proportionnellement plus que les salariés puisqu'ils s'acquittent à la fois des cotisations patronales et salariales (Panteia/EIM, 2007). Plusieurs gouvernements ont pris des mesures pour réduire les cotisations sociales des indépendants. Une approche consiste à baisser certaines de leurs cotisations de sécurité sociale afin de rendre le système plus équitable. En Finlande, par exemple, le régime de retraite lié au revenu (YEL) apporte une certaine flexibilité aux entrepreneurs finlandais qui peuvent choisir le montant de leurs cotisations aux régimes de retraite obligatoire, d'invalidité et de pension de survivants (Bilan de l'Observatoire européen de l'emploi, 2010). En outre, leurs cotisations sont déductibles des impôts (encadré 9.2). Cette approche existe également en Espagne, dont le plan d'action national sur l'inclusion sociale 2008-2010 prévoit une série de mesures fiscales destinées à aider les entrepreneurs, notamment une allégement de $20 \%$ de l'impôt sur le revenu et une réduction de $50 \%$ des cotisations pour chaque nouvel employé recruté pendant une durée pouvant atteindre 24 mois (Bilan de l'Observatoire européen de l'emploi, 2010).

Une seconde approche, moins courante, consiste à exonérer les indépendants de cotisations. En Lituanie, par exemple, les amendements de 2010 de la loi sur l'aide à l'emploi stipulent que les demandeurs d'emploi qui souhaitent créer une entreprise peuvent bénéficier d'une exonération de cotisations sociales et se faire rembourser les frais de formation liés au lancement de leur activité (Panteia/EIM, 2007). Les indépendants et les salariés lituaniens étant obligatoirement assurés en vertu de la loi sur les pensions d'assurance sociale de l'État, cette réduction des cotisations constituent une mesure d'incitation positive pour les entrepreneurs.

Le système de cotisation tchèque est également fondé sur le revenu. Le système de sécurité sociale s'applique uniformément à toutes les catégories de la population active et couvre les prestations de maladie, d'invalidité et de maternité. Les indépendants peuvent opter pour une estimation inférieure à leurs revenus réels (mais supérieure à $50 \%$ de la différence entre leurs revenus et leurs dépenses), mais ils bénéficieront le cas échéant de prestations inférieures. Les allocations familiales sont prises en charge par l'État tchèque (MISSOC, 2013). Ces réductions des cotisations fondées sur le revenu sont relativement universelles dans leur objectif, mais leur avantage pour les groupes socialement défavorisés est clair. Ces derniers occupent une position plus vulnérable sur le marché du travail et au sein de la société et ces mesures leur donnent davantage de flexibilité vis-à-vis des régimes de sécurité sociale obligatoires. La prise en charge des allocations familiales par l'État tchèque est particulièrement utile pour les chômeurs de longue durée et les femmes, notamment celles ayant des enfants à charge.

La Bulgarie utilise un système de cotisations fondées sur le revenu similaire pour les pensions complémentaires de maladie et de maternité. La pension de base concerne uniquement les assurances d'invalidité, de maladie, de vieillesse et de survie. 


\section{Encadré 9.2. Réforme de la loi sur les pensions des indépendants de 2005 (YEL), Finlande}

Description: en Finlande, les indépendants bénéficient des mêmes prestations de sécurité sociale de base que les salariés, à savoir les prestations de maladie, de maternité et familiales, les allocations de chômage de base et les pensions nationales. Avant 2005, les indépendants étaient obligatoirement assurés en vertu de la loi sur les pensions des indépendants (YEL). La réforme de 2005 a introduit les cotisations sociales liées au revenu, qui offre aux indépendants une plus grande liberté financière. Il s'agit là d'un moyen indirect d'améliorer leur trésorerie.

Problème abordé: avant la réforme, les indépendants étaient assujettis à des cotisations de sécurité sociale fixes. Cela entraînait une charge financière pour de nombreux indépendants, qui souvent ne bénéficiaient pas des prestations.

Approche: la loi sur les pensions des indépendants a été adoptée en 1970, mais c'est la réforme de 2005 qui a instauré les cotisations sociales liées au revenu. L'entrepreneur dispose ainsi d'une plus grande flexibilité et peut payer les cotisations de son choix, sous réserve de certains paramètres. Il peut également décider de souscrire à une couverture complémentaire en versant un pourcentage compris entre 10 à $100 \%$ du montant de ses cotisations obligatoires. La Caisse finlandaise des retraites gère les cotisations et fixe avec les entrepreneurs les taux de cotisation à payer sur la base de leur revenu. En 2006, par exemple, celle-ci s'élevait à 20,8\% du revenu annuel, payée intégralement par les entrepreneurs. Si les cotisations s'avèrent insuffisantes, l'État comble le déficit. Les cotisations de retraite des entrepreneurs sont également déductibles des impôts. En définissant librement le taux de leurs cotisations à l'assurance retraite obligatoire et à l'assurance complémentaire, les entrepreneurs peuvent épargner et réduire les contraintes financières associées au démarrage de leur activité (Eurofound, 2013b).

Impact: en 2011, la Caisse finlandaise des retraites a commandé deux évaluations distinctes du système des retraites. Les deux rapports ont jugé le système complet et viable (Eurofound, 2013b), mais ont mis en évidence des problèmes liés à une incitation excessive à la retraite anticipée et à la gestion inefficacité des retraites (Barr, 2013; Ambachtsheer, 2013). Une autre étude suggère que le système est loin d'être idéal pour les personnes à faible revenu (dont la couverture diminue en même temps que le revenu) et à revenu élevé (qui ne bénéficient plus de la couverture nationale lorsque leurs revenus dépassent un certain montant) (Panteia/EIM, 2007).

Facteurs de réussite: cette réforme des retraites requiert d'importantes capacités administratives pour calculer chaque année les cotisations sur la base des revenus. Le prochain grand problème à régler concerne toutefois le manque de couverture des personnes aux revenus trop faibles.

\section{Couverture de la famille ou du conjoint}

Les mesures qui relèvent de la catégorie «Couverture de la famille ou du conjoint» visent à étendre la couverture du système de sécurité sociale en autorisant la prise en charge d'un(e) conjoint(e) ou d'un membre de la famille dans le cadre de l'entreprise. Cette approche a pour but de limiter les risques inhérents au travail indépendant en permettant à un plus grand nombre de membres du foyer de bénéficier des prestations sociales en cas de défaillance de l'entreprise.

À titre d'exemple, au Danemark, tous les résidents sont assurés en vertu de la loi sur les pensions sociales de 2005, quel que soit leur statut professionnel. Ainsi, les conjoints et la famille élargie bénéficient automatiquement de la même couverture que l'indépendant lui-même (MISSOC, 2013). L'entrepreneur peut souscrire à une assurance retraite complémentaire pour toute sa famille. Les conditions de résidence rendent toutefois ce soutien inaccessible aux entrepreneurs immigrés. 
Le Luxembourg adopte une approche plus volontariste dans la couverture des indépendants. En vertu du règlement sur les conjoints collaborateurs, les conjoints sont assurés au même titre que les entrepreneurs pour toutes les branches de la sécurité sociale, dont la vieillesse, la maladie et le chômage. En revanche, les entrepreneurs s'acquittent des cotisations patronales et salariales, et paient donc plus qu'un salarié pour étendre leurs prestations à leur conjoint(e) ou à leur personnes à charge (Panteia/EIM, 2007).

Un autre exemple concerne l'Italie, où les entrepreneurs peuvent assurer les membres de leur famille qui contribuent à l'entreprise au titre du "partenariat familial». Ils peuvent ainsi distribuer $49 \%$ du revenu de l'entreprise aux membres de leur famille, dans le cadre de contrats enregistrés, et partager ainsi les taxes avec eux.

\section{Couverture complémentaire facultative}

La plupart des pays de l'UE prévoient une couverture sociale de base pour les indépendants, mais elle est généralement inférieure à celle des salariés. C'est pourquoi certains pays leur proposent une assurance complémentaire. Par exemple, l'assurance de base (Duchodové pojištenî) des pensions de vieillesse, de survie et d'invalidité est obligatoire pour toute la population active tchèque. L'assurance maladie n'est pas obligatoire pour les indépendants, mais ils peuvent y souscrire sur la base du volontariat (MISSOC, 2013). La Belgique propose une pension complémentaire libre et une pension complémentaire libre «sociale» (Panteia/EIM, 2007). Dans le cadre de ce programme, les entrepreneurs paient moins de cotisations d'assurance vieillesse obligatoire et peuvent déduire leurs cotisations de vieillesse complémentaire de leurs impôts. De plus, leur conjoint est également pleinement assuré au régime vieillesse.

La Bulgarie prévoit également une assurance obligatoire en matière d'invalidité, de maladie, de vieillesse et de survie. Les entrepreneurs peuvent également s'assurer au régime général d'assurance maladie et maternité (MISSOC, 2013). En Lituanie, les amendements de 2002 de la loi sur les pensions d'assurance sociale de l'État prévoient une couverture complémentaire pour toutes les catégories de la population, y compris pour les indépendants (Panteia/EIM, 2007).

Cette approche permet également de se protéger en cas de défaillance de l'entreprise. En Allemagne, les anciens chômeurs peuvent souscrire à une assurance chômage facultative. Les évaluations suggèrent que le système est performant, même s'il convient de mieux le cibler et de le rendre obligatoire pour certaines catégories d'entrepreneurs (Evers et al., 2013).

\section{Uniformiser les règles du jeu}

Il est assez fréquent que les systèmes de sécurité sociale ne couvrent pas le chômage des indépendants et, dans une moindre mesure, les maladies ou les accidents professionnels. L'absence de prestations de chômage peut, à juste titre, constituer un frein aux yeux des entrepreneurs potentiels. Faute de protection sur laquelle s'appuyer en cas d'échec de l'entreprise, l'entrepreneuriat est plus risqué que le salariat. Pour rendre le travail indépendant plus attractif, les décideurs politiques tentent d'harmoniser la prise en charge sociale des salariés et des indépendants. Pour ce faire, ils ont recours à diverses approches, décrites ci-dessous. 


\section{Changements législatifs profonds}

Ces dernières années, plusieurs pays de l'UE ont commencé à modifier la législation en profondeur afin d'améliorer le soutien aux indépendants. C'est le cas de la Lituanie et de la Pologne notamment.

L'amendement lituanien à la loi de 2002 sur la loi sur les pensions d'assurance sociale de l'État institue un mécanisme visant à harmoniser la protection sociale des salariés et des indépendants (Panteia/EIM, 2007). En vertu de cet amendement, les indépendants bénéficient de garanties d'assurance sociale renforcées, en particulier en matière de vieillesse et d'invalidité, et perçoivent ainsi les mêmes pensions complémentaires liées au revenu que les salariés, en plus des pensions de base de l'État qui s'appliquent à tous. Parallèlement à leurs cotisations obligatoires, les indépendants peuvent souscrire une assurance complémentaire en fonction de leur revenu. Si le revenu de leur entreprise égale ou excède douze fois le salaire minimum, les indépendants ont droit à une pension complémentaire pleine et bénéficient d'une couverture totale. S'ils ne peuvent pas s'acquitter de ces cotisations, ils conservent malgré tout leur droit à la pension de base et, de ce fait, à une protection sociale de base.

En Pologne, un amendement similaire a été voté pour la loi sur le système d'assurance sociale de 1998. Entré en vigueur en 2005, cet amendement étend la couverture sociale aux indépendants (MISSOC, 2013). Ces derniers sont désormais couverts pour la vieillesse, la survie, l'invalidité et les accidents du travail. Bien qu'obligatoire, cette couverture ne leur donne pas droit aux mêmes prestations que les salariés. Leurs cotisations sont par conséquent moins élevées. Pendant les vingt-quatre premiers mois, les taux de cotisation des indépendants sont fixés au minimum à $30 \%$ des revenus et augmentent à partir de la troisième année (Panteia/EIM, 2007).

Changements de politique ciblés

Une autre approche adoptée dans l'UE pour harmoniser la prise en charge sociale des indépendants et des salariés consiste à adopter des mesures ciblées. Par exemple, aux PaysBas, les indépendants bénéficient d'un seuil d'exonération plus bas pour certains impôts (Bilan de l'Observatoire européen de l'emploi, 2010). Des modifications ont également été apportées afin d'encourager le congé de maternité et la garde d'enfants. Les Pays-Bas ont réintroduit en 2008 une loi accordant le droit au congé de maternité et de paternité aux indépendants, ainsi qu'un accès aux services d'accueil de la petite enfance identique à celui prévu pour les salariés (Bilan de l'Observatoire européen de l'emploi, 2010).

Le Danemark et l'Espagne ont adopté une approche similaire. Au Danemark, les entrepreneurs et leur conjoint(e) bénéficient des mêmes droits aux prestations de chômage et de maternité ou de paternité que les salariés. De même, l'Espagne a introduit le statut de travailleur indépendant. Entré en vigueur en 2007, il stipule les conditions de travail des indépendants, hommes et femmes, et met l'accent sur l'équilibre entre vie professionnelle et vie privée. Ainsi, leur droit au congé de maternité et de paternité est désormais comparable à celui dont jouissent l'ensemble des salariés en vertu du régime général d'assurance. Ce cas est décrit plus en détail dans l'encadré 9.3. 


\section{Encadré 9.3. Le statut de travailleur indépendant, 2007, Espagne}

Description: le statut de travailleur indépendant (Estatuto del Trabajador Autónomo) est entré en vigueur en 2007 en Espagne. Cette mesure avait pour but de définir le statut juridique des indépendants, de les protéger par le droit du travail et de promouvoir l'égalité des conditions de travail entre les hommes et les femmes indépendants. La loi prévoit également des dispositions destinées à aligner le système de sécurité sociale général et le régime spécial des indépendants. C'est le cas de la disposition relative au congé de maternité et de paternité.

Problème abordé: les indépendants ne bénéficiaient pas d'une réglementation adaptée et étaient, de ce fait, moins bien protégés que les salariés sur le plan social. La priorité était également de mettre les hommes et les femmes sur un pied d'égalité et, pour ce faire, d'instituer des prestations de maternité et de paternité. Ce faisant, une réponse est également apportée au problème de l'entrée des femmes sur le marché du travail.

Approche: le statut prévoit des catégories d'emploi distinctes pour les indépendants avec et sans employés. En définissant juridiquement ces catégories et en fournissant des cadres légaux couvrant les aspects importants du travail indépendant, le droit du travail régit une part substantielle du marché du travail. Plusieurs dispositions de sécurité sociale ont été adoptées. Elles permettent notamment aux indépendants de bénéficier de prestations en cas de cessation d'activité et de congé maladie temporaire et de partir en retraite anticipée. Comme indiqué précédemment, ces dispositions incluent également des prestations de maternité et de paternité. Outre le fait d'offrir aux indépendants un traitement plus équitable, notamment en améliorant leur statut social, la loi cible spécifiquement les femmes en introduisant le régime de garde d'enfants. Des études espagnoles indiquent que, pour 32\% des femmes, la maternité a peut-être été un frein à leur carrière professionnelle (Eurofound, 2009). La garde d'enfants, qu'encourage ce statut, contribue à ce que les femmes puissent se ménager du temps et donc des possibilités.

Impact: l'impact de cette mesure est difficile à déterminer, en partie parce que les lois relatives au travail indépendant ont subi de nouvelles modifications. Le droit aux prestations de chômage pour les indépendants a été ajouté en 2010, par exemple (Bilan de l'Observatoire européen de l'emploi, 2010). Si l'on tient également compte des effets de la crise économique qui a frappé l'Espagne particulièrement durement, l'impact d'une mesure telle que le statut de travailleur indépendant est difficile à mesurer en termes d'entrepreneuriat. De même, il n'a pas été facile d'obtenir une évaluation des retombées de ce statut sur le plan politique. Il convient toutefois de garder à l'esprit que l'attribution d'un statut juridique aux chômeurs est susceptible d'avoir également des effets indirects et difficilement quantifiables.

Facteurs de réussite: s'il est difficile de déterminer concrètement si une réforme politique globale telle que celle-ci est une réussite ou un échec, la question de la participation plus active des femmes au marché du travail est depuis longtemps au cœur des priorités politiques de l'Espagne, comme en témoigne la loi de 2006 sur les services de garde d'enfants mise en œuvre en vue d'encourager, entre autres, l'emploi féminin (loi organique sur l'éducation, 2006). La garde d'enfants y contribue et fait l'objet de nombreux débats politiques. Eu égard à ces considérations et compte tenu du fait qu'un tiers de la population active espagnole était indépendante en 2009, le statut de travailleur indépendant peur constituer un appui majeur (Pereiro, 2008). Les partenaires sociaux et leurs discussions sur ce thème semblent en effet avoir joué un rôle important. 


\section{Conclusions et recommandations politiques}

Les systèmes de sécurité sociale sont définis sur la base d'objectifs généraux qui bien souvent ne prennent pas en compte le soutien à l'entrepreneuriat. Ils peuvent toutefois influencer les décisions en matière de création d'entreprise et de travail indépendant en modifiant les coûts d'opportunité ainsi que les coûts et avantages directs. Cela vaut en particulier pour les entrepreneurs issus de groupes défavorisés, qui sont plus susceptibles d'interagir avec eux, souvent à plusieurs titres.

Les différents systèmes de sécurité sociale de l'UE varient considérablement en termes de couverture, de mode de financement et d'accès des indépendants aux services proposés. Un certain nombre de conclusions peuvent néanmoins être tirées en ce qui concerne les effets de politiques de sécurité sociale sur le soutien à l'entrepreneuriat inclusif. Une refonte à grande échelle du système de sécurité sociale pour permettre une plus grande égalité de traitement entre indépendants et salariés n'est pas envisageable dans la plupart des pays (Ascoli et Pavolini, 2012). Sans un soutien public et politique adapté, une entreprise de cette nature ne serait pas réaliste.

Des changements politiques de moindre importance peuvent avoir des retombées positives plus immédiates. Les efforts entrepris par certains pays, comme l'Espagne et la République tchèque, pour harmoniser la situation de ces deux catégories de travailleurs pourraient ouvrir la voie à une amélioration de la situation de l'entrepreneuriat (inclusif) sur le plan de la sécurité sociale. Des changements politiques plus limités exigent un engagement moindre au niveau politique et public: des adaptations à la marge du système de sécurité sociale semblent plus efficaces et plus envisageables. Si le statut de travailleur indépendant en Espagne ne peut en aucun cas être considéré comme un simple aménagement, il n'a pas été important ou controversé au point de susciter un tollé auprès de l'opinion publique ou de la classe politique. Il a répondu à un besoin social particulier répandu en Espagne depuis longtemps, à savoir la participation des femmes au marché du travail et le renforcement de la protection des indépendants, nombreux dans le pays.

Des ajustements tels que la réduction des charges fiscales qui pèsent sur les entrepreneurs (p.ex. Pays-Bas) ou la mise en place d'une couverture sociale basée sur le revenu (p.ex. Pologne, Bulgarie, Finlande et Irlande) peuvent aussi s'avérer utiles pour favoriser l'entrepreneuriat inclusif. Ces mesures améliorent la flexibilité des entrepreneurs en termes de finances et de couverture sociale. Si cette liberté supplémentaire attire les entrepreneurs, les moyens ou les systèmes de couverture liés au revenu sont parfois synonymes de protection réduite lorsque les cotisations sont moins élevées. Comme souligné précédemment, le compromis entre flexibilité et sécurité doit être expressément pris en considération.

Les politiques qui ciblent les principaux problèmes auxquels les entrepreneurs sont confrontés semblent donner de meilleurs résultats. En l'absence d'évaluation systématique, cet avis repose sur le maintien à long terme de ces mesures et sur les statistiques disponibles sur leur application. La Back to Work Enterprise Allowance irlandaise constitue une bonne pratique de ce point de vue puisqu'elle a été maintenue malgré le contexte économique difficile et a aidé $86 \%$ de ses bénéficiaires (selon le dernier décompte en 2002) à ne plus dépendre de l'aide sociale. Le succès de l'aide à la création d'entreprise allemande tient visiblement au fait qu'elle résulte de la fusion de deux autres programmes de longue date (en partie pour réduire la complexité administrative). Pour en revenir une nouvelle fois à l'effet dissuasif des charges administratives sur les entrepreneurs mis en évidence par l'enquête Eurobaromètre, une organisation claire de cet instrument permettrait d'en améliorer l'efficacité. Les programmes et instruments qui proposent des financements ou des ponts sociaux aux bénéficiaires de prestations, et ce de façon claire, semblent donc les plus efficaces: ils ciblent un problème central de façon directe et transparente. 
Les groupes socialement défavorisés sont confrontés aux mêmes obstacles à l'entrepreneuriat que les entrepreneurs en général. Les politiques d'aide aux indépendants ont globalement tendance à avoir des retombées positives sur les personnes exclues socialement. Dans les cas d'exclusion sociale les plus extrêmes, cela peut ne pas suffire. Une approche plus personnalisée s'impose parfois lorsqu'il s'agit de cibler les problèmes propres à une catégorie sociale en particulier. Les mesures relatives aux retraites pourraient être présentées et communiquées aux seniors puisque cet aspect est considéré comme fortement dissuasif par rapport à l'entrepreneuriat. Pour ce qui est des femmes, la garde d'enfants et le congé de maternité/paternité ont démontré leur efficacité. Quant aux personnes handicapées, elles bénéficient, en plus de leurs prestations, de subventions permettant de financer leurs équipements et l'aménagement de leur environnement de travail. La discrimination et la vulnérabilité sur le marché du travail ayant des origines diverses, les instruments de sécurité sociale destinés à favoriser l'entrepreneuriat inclusif pourraient également bénéficier d'une approche sur mesure. Cependant, la mise en œuvre de règles spécifiques pourrait se faire au prix d'une plus grande complexité et de systèmes nationaux de sécurité sociale moins transparents, créant ainsi une autre forme de barrière à l'entrepreneuriat inclusif.

\section{Principales recommandations politiques}

- Augmenter la couverture sociale des indépendants afin de leur offrir un filet de sécurité comparable à celui des salariés.

- Fournir aux bénéficiaires plus d'informations claires et visibles sur la couverture sociale et les options offertes aux entrepreneurs. Ce besoin prévaut surtout chez les entrepreneurs défavorisés qui font généralement appel à plusieurs volets de la sécurité sociale. Il est important qu'ils comprennent comment leurs prestations interagissent entre elles et de quelle manière la création d'entreprise ou un changement de statut social peut les affecter.

- Rendre le paiement des prestations de sécurité sociale plus flexible en permettant les versements forfaitaires afin d'encourager la création d'entreprise.

- Simplifier les systèmes de sécurité sociale en réduisant les exigences administratives des indépendants. Si cela n'est pas possible, fournir des formations et des informations afin de démystifier la complexité du système.

- Réaliser des analyses d'impact régulières lorsque des modifications sont apportées aux systèmes de sécurité sociale, et analyser leur impact sur l'entrepreneuriat en général et sur l'entrepreneuriat inclusif en particulier. Cela contribuerait à éviter les mesures incitatives perverses, notamment financières, qui empêchent le travail indépendant.

\section{Références}

Ambachtsheer, K. (2013), "The pension system in Finland: Institutional structure and governance. Evaluation of the Finnish Pension System, Part 2", Finnish Centre for Pensions, Helsinki.

Ascoli, U. et Pavolini, E. (2012), «Ombre rosse. Il sistema di welfare italiano dopo venti anni di riforme», Stato e mercato, $\mathrm{n}^{\circ}$ 3, p. 429-464, DOI: 10.1425/38645.

Barr, N. (2013), «The pension system in Finland: Adequacy, sustainability and system design. Evaluation of the Finnish Pension System, Part 1», Finnish Centre for Pensions, Helsinki.

Betzelt, S. (2004), «Konzeptvorschlag zur sozialen Alterssicherung Selbstständiger», Gutachten im Auftrag des Projektes mediafon der Vereinten Dienstleistungsgewerkschaft (ver. di), Brême. 
Boylan, A. et Burchardt, T. (2002), «Barriers to self-employment for disabled people», Small Business Service, octobre 2002.

Caliendo, M., Hogenacker, J., Künn, S. et Wießner, F. (2011), «Alte Idee, neues Programm. Der Gründungszuschuss als Nachfolger von Überbrückungsgeld und Ich-AG», IAB Discussion Paper, $n^{\circ} 24$, Nuremberg.

Department of Enterprise, Trade and Employment for the PPF Standing Committee on the Labour Market (Ireland) (2002), Review of the Active Labour Market Programmes, Indecon International Economic Consultants, Dublin, Irlande.

Efrat, R. (2008), «Senior Entrepreneurs in Bankruptcy», Creighton Law Review, vol. 42, p. 83-121.

Elam, A. et Terjesen, S. (2010), «Gendered Institutions and Cross-National Patterns of Business Creation for Men and Women", European Journal of Development Research, vol. 22, p. 331-348.

EMN (European Microfinance Network) (2012a), “Youth Entrepreneurship», disponible sur: http://www.european-microfinance.org/docs/emn_publications/emn_research_papers/EMN\%20Study\%20 for\%20Youth\%20entrep\%20FINAL.pdf.

EMN (European Microfinance Network) (2012b), «Microfinance as a support to senior entrepreneurship and to the transfer of competences", Bruxelles, Belgique.

EMN (European Microfinance Network) (2006), «Nurturing Immigrant Entrepreneurship», Bruxelles, Belgique. Eurofound (2013a), «NEETs Young people not in employment, education or training: Characteristics, costs and policy responses in Europe», disponible sur: http://www.eurofound. europa.eu/pubdocs/2012/54/en/1/EF1254EN.pdf.

Eurofound (European Foundation for Living and Working Conditions) (2013b), «Finland: Social partners' involvement in pension reform in the EU», disponible sur: http://www.eurofound.europa.eu/eiro/ studies/tn1304032s/fi1304031q.htm.

Eurofound (European Foundation for Living and Working Conditions) (2011), «Public measures to support self-employment and job creation in one-person and micro enterprises», Dublin, Irlande.

Eurofound (European Foundation for Living and Working Conditions) (2009), "Spain: Self-employed workers", disponible sur: http://www.eurofound.europa.eu/comparative/tn0801018s/es0801019q.htm.

Commission européenne (CE) (2012), «Eurobaromètre Flash n³54, L'entrepreneuriat dans l'UE et audelà», disponible sur: http://ec.europa.eu/public_opinion/flash/fl_354_en.pdf.

Bilan de l'Observatoire européen de l'emploi (2010), Le travail indépendant en Europe, Bruxelles, Belgique.

Evers, K., Schleinkofer, M. et Wießner, F. (2013), «Freiwillige Arbeitslosenversicherung für Existenzgründer. Etwas mehr Sicherheit», IAB-Kurzbericht, $\mathrm{n}^{\circ} 12$.

Guyot, J.-L. et Lohest, O. (2008), «L'aversion au risque: une barrière à l'entrepreneuriat en Wallonie?», rapport de l'Institut wallon de l'évaluation, de la prospective et de la statistique, septembre.

Henrekson, M. (2005), «Entrepreneurship: a weak link in the welfare state?», Industrial and Corporate Change, vol. 14(3), p. 437-467.

Hessels, J., Van Stel, A., Brouwer, P. et Wennekers, S. (2007), Social security arrangements and early-stage entrepreneurial activity. Zoetermeer, Pays-Bas.

MISSOC (Mutual Information System on Social Protection) (2013), «Social protection in the member states of the European Union, of the European Economic Area and in Switzerland Social protection of the self-employed - situation on January 1, 2013", Bruxelles, Belgique.

Naumann, R. (2011), "Supporting young people into self-employment in Spain and Portugal: Similar paths and unequal outcomes", Peer Review on "Pathways to support young people into selfemployment», GHK Consulting Ltd et CERGE-EI.

OCDE (2012), Inégalités hommes-femmes: il est temps d'agir, Publication OCDE, Paris. http://dx.doi. org/10.1787/9789264179370-en.

OCDE (2010), Entrepreneurship and Migrants, Report by the OECD Working Party on SMEs and Entrepreneurship, OCDE, disponible sur: http://www.oecd.org/industry/smes/45068866.pdf. Loi organique sur l'éducation (Espagne) (2006), Titre VI Évaluation du système éducatif.

Parker, S. et Robson, M. (2004), «Explaining International Variations in Entrepreneurship: Evidence from a Panel of OECD Countries", Southern Economic Journal, vol. 71(2), p. 287-301.

Panteia/EIM (2007), «Good Practices on Social Protection of New Entrepreneurs and Assisting Partners and the Impact on Business Creation", Zoetermeer, Pays-Bas. 
Pereiro, P. (2008), «Notes, debates and communications - The status of self-employed workers in Spain", International Labour Review, vol. 147(1), p. 91-99.

SSA (Social Security Administration), Office of Retirement and Disability Policy, Office of Research, Evaluation, and Statistics, (United States of America) (2010), Social Security Programs Throughout the World: Europe, 2010, Washington, États-Unis d'Amérique.

Zissimopoulos, J. et Karoly, L. (2003), «Transitions to Self-Employment at Older Ages The Role of Wealth, Health, Health Insurance, and Other Factors", disponible sur: http://130.154.3.14/content/dam/rand/ pubs/working_papers/2004/RAND_WR135.pdf. 

PARTIE III

\section{Profils des pays}





\section{Chapitre 10}

\section{Données et pratiques instructives en matière de politique d'entrepreneuriat inclusif ${ }^{1,2}$}

Ce chapitre présente des pratiques politiques instructives issues des 28 États membres de l'UE ainsi qu'un ensemble de graphiques qui mesurent des indicateurs clés en matière d'entrepreneuriat et de travail indépendant dans les groupes sous-représentes et défavorises à l'aune des moyennes de l'Union européenne.

1. Note de la Turquie:

Les informations figurant dans ce document et faisant référence à «Chypre» concernent la partie méridionale de l'île. Il n'y a pas d'autorité unique représentant à la fois les Chypriotes turcs et grecs sur l'île. La Turquie reconnaît la République turque de Chypre du Nord (RTCN). Tant qu'une solution durable et équitable n'aura pas été trouvée dans le cadre des Nations unies, la Turquie maintiendra sa position sur la «question chypriote».

2. Note de tous les États de l'Union européenne membres de l'OCDE et de l'Union européenne:

La République de Chypre est reconnue par tous les membres des Nations unies sauf la Turquie. Les informations figurant dans ce document concernent la zone sous le contrôle effectif du gouvernement de la République de Chypre. 
Ce chapitre décrit brièvement des politiques instructives qui encouragent l'entrepreneuriat inclusif, dans chaque État membre de l'UE. Le Tableau 10.1 les répertorie toutes. Les descriptions fournies visent à aider les décideurs nationaux, régionaux et locaux à réfléchir aux méthodes qui s'offrent à eux pour relever les difficultés communes rencontrées pour soutenir l'entrepreneuriat inclusif dans l'Union européenne. Chaque description donne un bref aperçu des activités principales de la mesure politique, ainsi que des informations sur ses incidences et des points à prendre en considération pour la bonne mise en œuvre de ce type d'intervention.

Toutes les descriptions des exemples inspirants sont assorties d'un même ensemble de données propres à chaque pays, qui mesurent des indicateurs clés à l'aune de la moyenne de l'Union européenne, afin de replacer la perspective dans le contexte de chaque pays. Les notes des pays comportent trois diagrammes présentant des indicateurs majeurs en termes d'économie et d'entrepreneuriat, pour replacer la mesure politique décrite dans son contexte.

- Le diagramme A présente le taux de chômage du pays et montre comment il varie entre les différents groupes sociaux. Ces taux sont donnés pour la période 2000-2012 afin d'illustrer l'évolution à moyen terme et l'impact de la crise économique mondiale.

- Le diagramme B présente le taux de travail indépendant en 2012 pour différents groupes de population, par rapport à la moyenne de l'Union européenne. Le taux de travail indépendant équivaut au ratio du nombre de personnes exerçant un travail indépendant par rapport au nombre total de personnes salariées dans chaque groupe cible.

- Le diagramme $C$ illustre l'évolution du taux de travail indépendant pour différents groupes de population entre 2000 et 2012. Il indique au lecteur comment le niveau relatif de l'activité indépendante a évolué pour chaque groupe cible à la suite de la crise économique.

Deux autres tableaux sont fournis pour les États membres de l'UE qui ont participé aux enquêtes sur la population adulte menées par le Global Entrepreneurship Monitor (GEM) pendant au moins un an entre 2008 et 2012: l'Allemagne, l'Autriche, la Belgique, la Croatie, le Danemark, l'Espagne, l'Estonie, la Finlande, la France, la Grèce, la Hongrie, l'Irlande, l'Italie, la Lettonie, la Lituanie, les Pays-Bas, la Pologne, le Portugal, la République slovaque, la République tchèque, la Roumanie, le Royaume-Uni, la Slovénie et la Suède (UE-24).

- Le diagramme D montre le taux d'activité entrepreneuriale totale au stade précoce (TEA) par sexe, pour la population adulte (18-64 ans) dans chaque pays, pour la dernière année disponible. Ces données sont mises en balance avec la moyenne des pays de l'Union européenne qui participent à l'enquête du GEM. Pour de plus amples informations sur les données du GEM et sur le taux de TEA, nous vous renvoyons au guide de lecture proposé au début de cet ouvrage. Il est également à noter que les pays qui participent à l'enquête du GEM varient d'une année à l'autre. Partant, les moyennes de l'Union européenne ont été évaluées en utilisant uniquement les pays ayant participé cette année-là.

- Le diagramme E présente le taux de TEA par âge pour chaque pays, ainsi que la moyenne de l'Union européenne. Afin d'accroître la taille de l'échantillon, les données sont rassemblées (c.-à-d. combinées) pour la période 2008-2012. 
Tableau 10.1. Inventaire des mesures politiques décrites

\begin{tabular}{|c|c|c|c|c|}
\hline Pays & Nom du programme & Approche & $\begin{array}{l}\text { Groupe cible couvert par le } \\
\text { programme }\end{array}$ & $\begin{array}{l}\text { Financement } \\
\text { de l'UE }\end{array}$ \\
\hline Autriche & $\begin{array}{l}\text { Programme d'aide à la création d'entreprise UGP } \\
\text { (Unternehmensgründungsprogramm) }\end{array}$ & Approche intégrée & Chômeurs & \\
\hline Belgique & Stebo & $\begin{array}{l}\text { Information et } \\
\text { accompagnement individualisé }\end{array}$ & Immigrés & \\
\hline Bulgarie & $\begin{array}{l}\text { Social Entrepreneurship — Popularisation and Support for Social } \\
\text { Enterprises (phase pilote) }\end{array}$ & Entreprise sociale & Divers & FSE \\
\hline Croatie & «Together towards social inclusion» et «lt's time for women» & Approche intégrée & $\begin{array}{l}\text { Chômeurs de longue durée } \\
\text { Femmes }\end{array}$ & IAP \\
\hline Chypre & Youth Entrepreneurship Support Scheme & Subventions et formation & Jeunes & FEDER \\
\hline République tchèque & Build your own enterprise as a way to connect work with childcare & Approche intégrée & $\begin{array}{l}\text { Parents d'enfants en bas âge, en } \\
\text { particulier les femmes }\end{array}$ & FSE \\
\hline Danemark & $\begin{array}{l}\text { Promoting entrepreneurship in areas with an aging population } \\
\text { (Jutland-du-Nord et Bornholm) }\end{array}$ & Approche intégrée & $\begin{array}{l}\text { Divers, zones retirées et } \\
\text { population vieillissante }\end{array}$ & $\begin{array}{l}\text { FSE } \\
\text { FEDER }\end{array}$ \\
\hline Estonie & $\begin{array}{l}\text { Programme de microcrédit de l'ETNA pour les femmes } \\
\text { entrepreneurs des zones rurales }\end{array}$ & Financement & Femmes en milieu rural & \\
\hline Finlande & Women's Enterprise Agency & Approche intégrée & Femmes & FSE \\
\hline France & $\begin{array}{l}\text { Fonds de garantie pour la création, le rachat ou le développement } \\
\text { d'entreprises initiées par des femmes }\end{array}$ & Fonds de garantie & Femmes & FSE \\
\hline Allemagne & $\begin{array}{l}\text { Schüler-Institut für Technik und angewandte Informatik (SITI) à } \\
\text { Havelberg }\end{array}$ & Apprentissage pratique & Jeunes & FSE \\
\hline Grèce & $\begin{array}{l}\text { Coopératives sociales pour les personnes souffrant de problèmes } \\
\text { de santé mentale }\end{array}$ & Entreprise sociale & $\begin{array}{l}\text { Personnes souffrant de } \\
\text { problèmes de santé mentale }\end{array}$ & \\
\hline Hongrie & Programme MeXX & Formation & Femmes & \\
\hline Irlande & National Women's Enterprise Day & Événement promotionnel & Femmes & FSE \\
\hline Italie & Starting a Business, dans le cadre du projet Giovanisi en Toscane & Financement & Jeunes & \\
\hline Lettonie & Business incubators in the Latvian regions & Pépinières d'entreprises & Régions défavorisées & FEDER \\
\hline Lituanie & First business year baskets (vouchers) for youth & Chèques conseil & Jeunes & FSE \\
\hline Luxembourg & Jonk Entrepreneuren Luxembourg & $\begin{array}{l}\text { Entreprises dans le domaine } \\
\text { de l'éducation }\end{array}$ & Jeunes & \\
\hline Malte & Hands-on Project & $\begin{array}{l}\text { Amélioration des compétences } \\
\text { du corps éducatif }\end{array}$ & Étudiants handicapés & \\
\hline Pays-Bas & «lkStartSmart», Gueldre & Approche intégrée & Divers & \\
\hline Pologne & $\begin{array}{l}\text { PONAD: Solidarity between Generations Governmental Programme } \\
\text { for People } 50+\end{array}$ & Approche intégrée & Personnes de plus de 50 ans & FSE FEADER \\
\hline Portugal & Best Form — Boosting Entrepreneurship Tools for Migrants & Conseillers en formation & Immigrés & EFTLV \\
\hline Roumanie & A chance for those in rural areas, Roumanie & Approche intégrée & Zones rurales & FSE \\
\hline République slovaque & REGIONFEMME & Formation et mise en réseau & Femmes & FEDER \\
\hline Slovénie & Entrepreneurially into the world of business 2013 & Stage & Jeunes & FSE \\
\hline Espagne & Support for Self-Employment: Navarre, Espagne & $\begin{array}{l}\text { Subventions pour service } \\
\text { de conseil et de formation; } \\
\text { financement }\end{array}$ & Chômeurs & FSE \\
\hline Suède & Ambassadors for Women's Entrepreneurship & Événement promotionnel & Femmes & \\
\hline Royaume-Uni & Local Enterprise Growth Initiative (LEGI), Angleterre & Approche intégrée & Zones défavorisées & \\
\hline
\end{tabular}

Note: FEADER: Fonds européen agricole pour le développement rural; FEDER: Fonds européen pour le développement rural; FSE: Fonds social européen; IAP: Instrument d'aide de préadhésion; EFTLV: éducation et formation tout au long de la vie. 


\section{Autriche: programme d'aide à la création d'entreprise UGP (Unternehmensgründungsprogramm)}

Description: le programme d'aide à la création d'entreprise UGP (Unternehmensgründungsprogramm) du service autrichien de l'emploi (AMS - Arbeitsmarktservice) est une offre de soutien intégrée incluant des services de conseil en entreprise par des conseillers en gestion externes, des formations sur mesure ainsi qu'une allocation (couvrant les frais de subsistance) durant la période de lancement de l'entreprise. Il cible les demandeurs d'emploi ayant un projet d'entreprise et les qualifications professionnelles requises.

Problème abordé: les premiers projets pilotes régionaux destinés à soutenir les chômeurs motivés et compétents désireux de créer leur entreprise ont débuté en 1995. Ils ont été lancés alors que l'AMS cherchait de nouvelles solutions de réinsertion des demandeurs d'emploi expérimentés sur le marché du travail.

Approche: ce programme est mis en œuvre dans le cadre d'un partenariat entre l'AMS et des conseillers externes chargés de fournir des services de formation et de conseil en entreprise. Pour être éligibles, les participants doivent être inscrits comme chômeurs auprès de l'AMS ou en recherche d'emploi, manifester l'intention de créer une entreprise, avoir une idée d'activité précise et disposer des compétences et qualifications professionnelles requises. Les participants potentiels passent des entretiens de sélection dans les bureaux régionaux de l'AMS, durant lesquels leur éligibilité, la faisabilité de leur idée et leurs qualifications sont évaluées. Le soutien du programme UGP s'articule en quatre phases. La première étape est celle de la "clarification", lors de laquelle les participants travaillent sur la faisabilité de leur idée d'entreprise et élaborent des plans avec l'aide des conseillers. Vient ensuite la deuxième étape dite de "préparation» durant laquelle les conseillers les guident dans la personnalisation de leur concept et dans la planification financière. La troisième étape est celle de la "réalisation" qui leur donne droit à une aide à la création d'entreprise et à une allocation. La quatrième étape, celle du «suivi», donne lieu à des rencontres entre les conseillers en entreprise et les participants pendant les deux années qui suivent le lancement de leur entreprise. En 2012, le budget du programme UGP s'élevait à 4,8 millions EUR (pour 8069 participants). Une enveloppe de 11,1 millions EUR a été distribuée sous la forme d'allocations aux 4802 bénéficiaires ayant démarré leur activité en 2012.

Impact: prévu pour être temporaire lors de son lancement, le programme est devenu permanent, global et performant. Selon une évaluation réalisée en 2006 sur les créateurs et les non-créateurs d'entreprise, le programme UGP a contribué de façon déterminante à la création d'emplois (Dornmayer et al., 2006). Au total, depuis sa mise en place en 1995, plus de 20000 créateurs d'entreprise ont bénéficié du soutien du programme. La cohorte de participants ayant démarré leur entreprise en 2000 a créé, en moyenne, 0,34 emploi à temps plein dans l'année qui a suivi le démarrage de l'activité, 0,9 emploi à temps plein après trois ans et 1,26 emploi à temps plein après cinq ans. Le taux de survie des sociétés ainsi créées atteignait $94 \%$ après un an et $73 \%$ après cinq ans, ce qui correspond globalement aux taux de survie de la population entrepreneuriale dans son ensemble.

Facteurs de réussite: le programme UGP est devenu un élément majeur des politiques autrichiennes en matière d'économie et d'emploi. Il s'est construit à partir de projets régionaux couronnés de succès. L'éventail de ses activités et les incitants ont été ajustés au fil du temps afin de capitaliser sur les aspects qui ont eu un impact et refléter les expériences des autres pays en matière de programmes de transition du chômage vers le travail indépendant. 


\section{Données clés relatives à l'entrepreneuriat inclusif}

\section{Graphique 11.1. Données relatives à l'entrepreneuriat et au travail indépendant en Autriche}

Diagramme A. Taux de chômage, 2000-2012

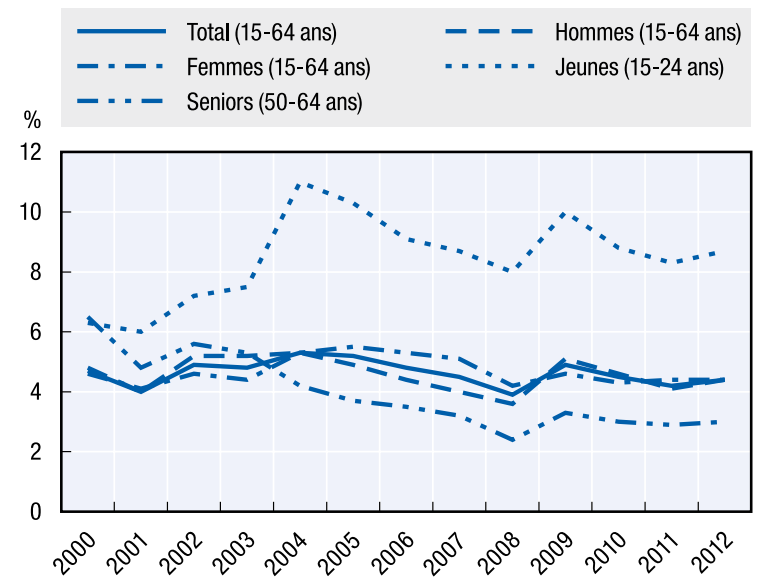

Diagramme C. Taux de travail indépendant, 2000-2012

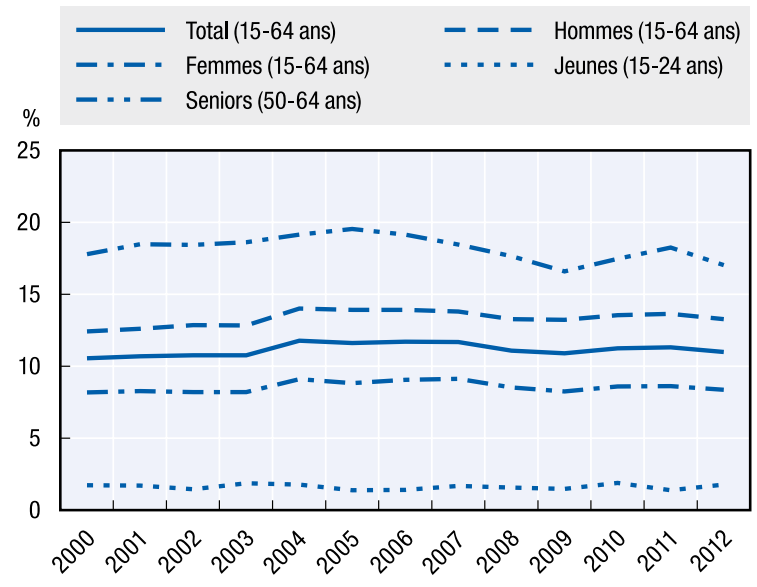

Diagramme E. Indice de l'activité entrepreneuriale totale au stade précoce, 2008-2012 (combinés)

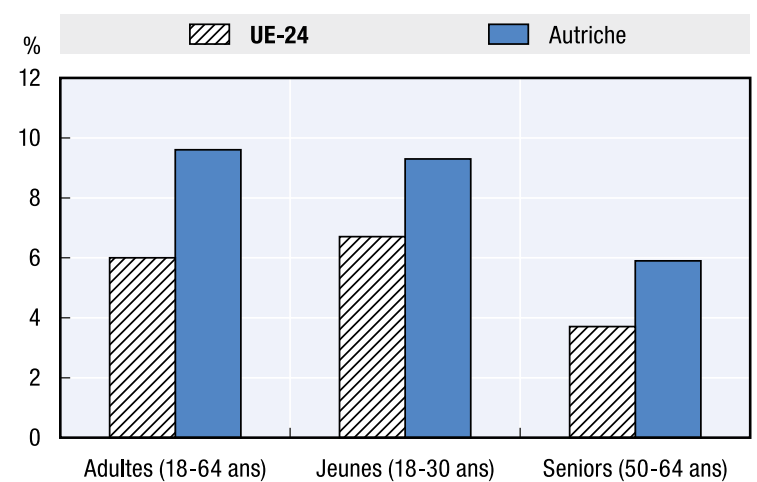

Diagramme B. Taux de travail indépendant, 2012

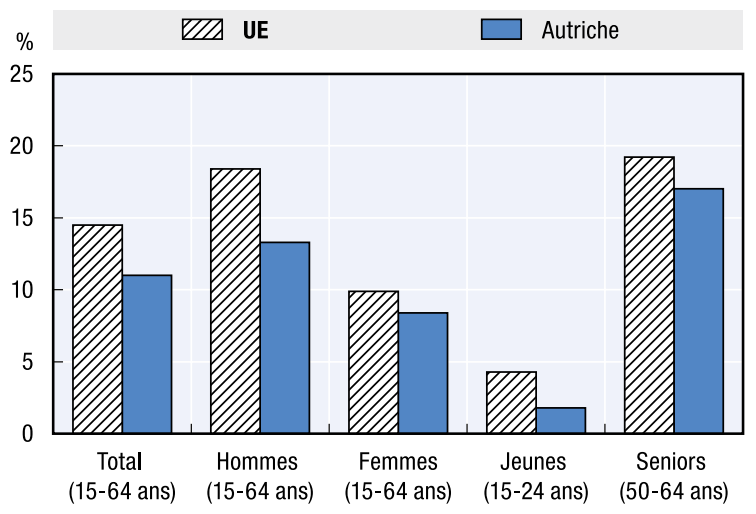

Diagramme D. Indice de l'activité entrepreneuriale totale au stade précoce, 2012

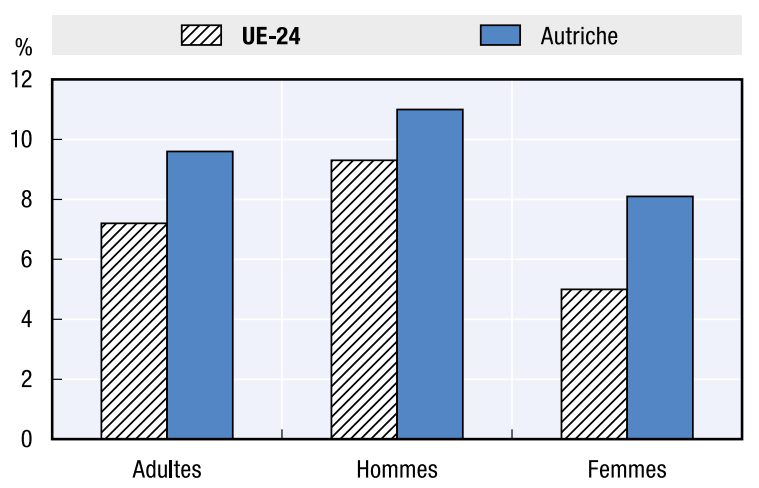

Sources: Diagramme A. Eurostat, Enquête sur les forces de travail, 2000-2012; Diagramme B. Eurostat, Enquête sur les forces de travail 2012; Diagramme C. Eurostat, Enquête sur les forces de travail, 2000-2012; Diagramme D. Présentation tabulaire spéciale de l'enquête sur la population adulte du Global Entrepreneurship Monitor, 2012; Diagramme E. Présentation tabulaire spéciale de l'enquête sur la population adulte du Global Entrepreneurship Monitor, 2008-2012. 


\section{Belgique: Stebo}

Description: Stebo (http://www.stebo.be/) est une organisation à but non lucratif qui développe et met en œuvre des projets, de services et des initiatives de lutte contre l'exclusion économique et sociale, notamment dans les domaines de l'accès au marché du travail, au logement et à l'éducation. Cela passe par un soutien aux entrepreneurs issus de groupes défavorisés, comme les immigrés récents, à travers des services d'information, de formation, d'accompagnement individualisé ainsi qu'une aide à la mise en réseau et au développement de projet.

Problème abordé: ces dix dernières années, l'immigration belge en provenance de l'Europe de l'Est a connu une augmentation. Une étude récente menée auprès d'entrepreneurs bulgares, polonais et roumains dans les Flandres révèle que ces derniers sont confrontés à deux types de problèmes (Mampaey, 2013). Premièrement, ils manquent de capital humain (p.ex. compétences linguistiques et connaissance des obligations juridiques des entrepreneurs), de capital social (p.ex. réseaux d'affaires) et de capital financier pour investir dans leur entreprise. Deuxièmement, ils rencontrent de grandes difficultés dans leur environnement d'affaires, notamment une forte concurrence.

Approche: Stebo aide les entrepreneurs immigrés en leur proposant un programme destiné à accroître et à soutenir les créations d'entreprise tout en les aidant à resserrer leurs liens avec la communauté locale. L'organisation a reçu la somme de 250000 EUR pour la période 2007-2009 de la part du gouvernement flamand. Ces fonds sont complétés par d'autres subventions publiques. L'aide proposée à titre gratuit aux participants repose sur la diffusion d'informations et la mise en place d'un accompagnement individualisé. Après inscription, une organisation partenaire (VDAB) évalue la motivation entrepreneuriale et les compétences des immigrés. Seuls les candidats ayant un niveau suffisant pour ces deux critères sont admis dans le programme. L'accompagnement individualisé se concentre sur le développement des compétences entrepreneuriales et sur l'élaboration de leur projet d'entreprise et de leur plan d'affaires. Pour aider les communautés immigrées à développer leur capital social, l'organisation adapte l'aide aux besoins de la communauté à laquelle elle s'adresse.

Impact: $28 \%$ des immigrés qui ont participé au programme en 2007, 2008 et 2009 ont créé leur entreprise.

Facteurs de réussite: ce programme montre l'importance d'offrir un soutien local aux entrepreneurs, en particulier immigrés. Les principaux facteurs de réussite de ce programme sont la mise en réseau qui permet de développer le capital social des individus et la diffusion d'informations juridiques auxquelles les immigrés ne parviennent pas à accéder. 


\section{Données clés relatives à l'entrepreneuriat inclusif}

\section{Graphique 12.1. Données relatives à l'entrepreneuriat et au travail indépendant en Belgique}

Diagramme A. Taux de chômage, 2000-2012

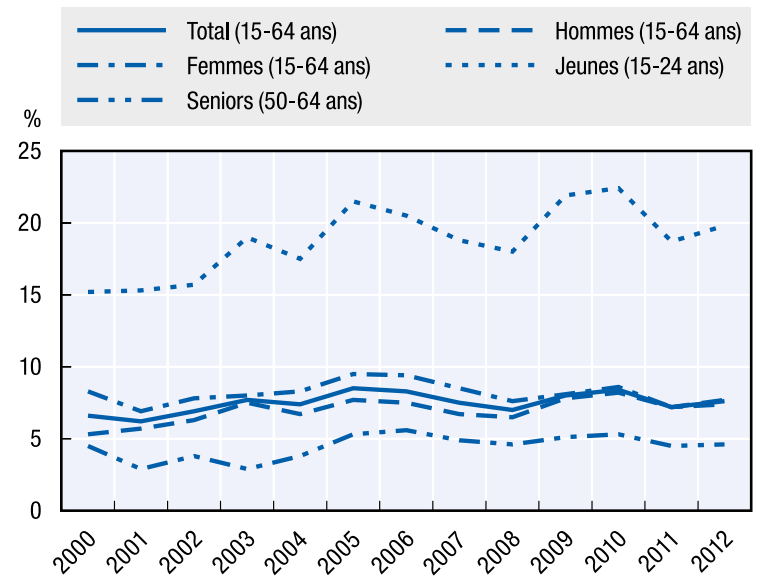

Diagramme C. Taux de travail indépendant, 2000-2012
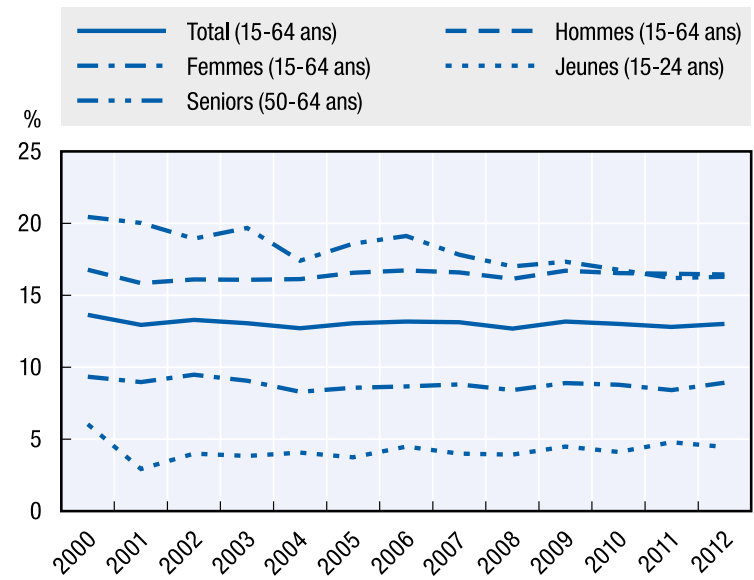

Diagramme E. Indice de l'activité entrepreneuriale totale au stade précoce, 2008-2012 (combinés)

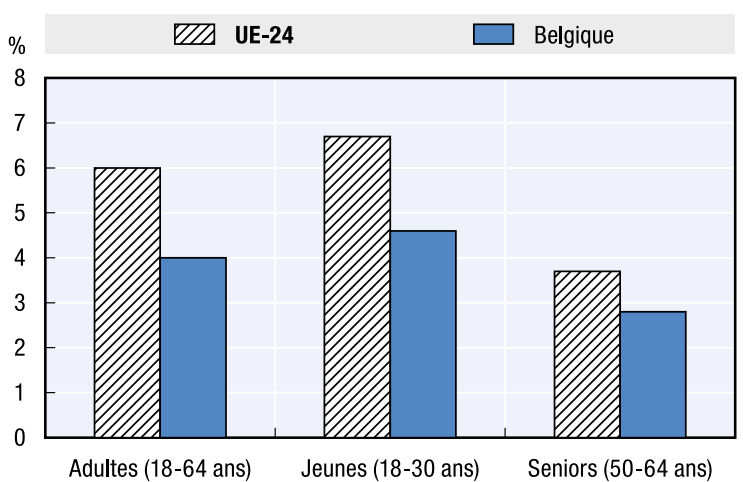

Diagramme B. Taux de travail indépendant, 2012

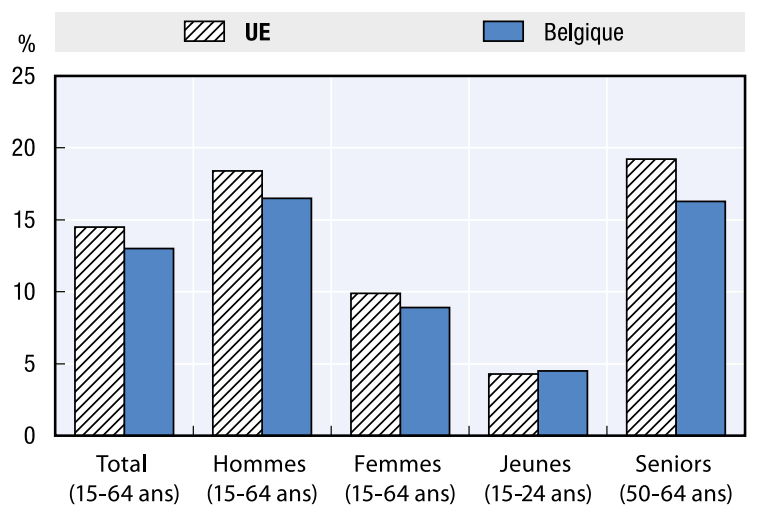

Diagramme D. Indice de l'activité entrepreneuriale totale au stade précoce, 2012

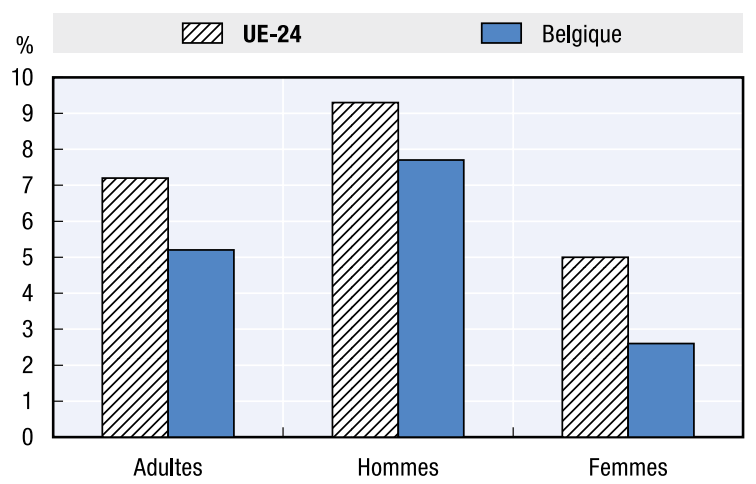

Sources: Diagramme A. Eurostat, Enquête sur les forces de travail, 2000-2012; Diagramme B. Eurostat, Enquête sur les forces de travail 2012; Diagramme C. Eurostat, Enquête sur les forces de travail, 2000-2012; Diagramme D. Présentation tabulaire spéciale de l'enquête sur la population adulte du Global Entrepreneurship Monitor, 2012; Diagramme E. Présentation tabulaire spéciale de l'enquête sur la population adulte du Global Entrepreneurship Monitor, 2008-2012. 


\section{Bulgarie: Social Entrepreneurship - Popularisation and Support for Social Enterprises}

Description: ce programme vise à soutenir l'acquisition de capital social à travers la création et le développement d'entreprises à caractère social qui réalisent des projets destinés à renforcer les compétences managériales et entrepreneuriales dans le cadre de formations motivationnelles et de services de conseil individualisé. Ce soutien s'adresse aux personnes handicapées, aux personnes ayant purgé une peine de prison, aux parents isolés, aux membres de minorités ethniques, aux personnes vivant en institution et souffrant d'addiction et aux chômeurs de longue durée.

Problème abordé: le programme soutient les groupes les plus vulnérables de la société. Les services fournis par le secteur tertiaire peuvent compléter l'aide publique dans les domaines pour lesquels celle-ci est inefficace ou inadaptée. La difficulté en Bulgarie réside dans le faible niveau de sensibilisation aux possibilités et aux avantages de l'entrepreneuriat social. Le financement est l'un des principaux défis des entreprises sociales bulgares.

Approche: le programme soutient à la fois la création d'entreprises sociales et le développement de celles déjà en place à travers l'octroi de subventions allant de 50000 BGN à 350000 BGN (environ entre 25000 et 175000 EUR). Celles-ci sont allouées dans le cadre d'une procédure de candidature destinée à soutenir financièrement le développement des entreprises sociales établies par l'élargissement de l'étendue et l'éventail de leurs activités, ainsi que la création d'entreprises sociales. Le budget total du programme s'élevait à 15680000 BGN (environ 8 millions EUR), dont 13328000 BGN (environ 6,7 millions EUR) financés par le FSE. Il a été mis en œuvre dans tout le pays sur la période 2010-2011.

Impact: en 2010 et 2011, au total 46 projets ont été financés. Ils ont débouché sur la création de 35 entreprises sociales et contribué au développement de 11 sociétés déjà existantes. Pendant ces deux années, environ 2694 personnes issues de divers groupes défavorisés ont bénéficié de cette aide. Sur les 1869 bénéficiaires en 2010, 43\% étaient des personnes handicapées et $34 \%$ déclaraient appartenir à une minorité ethnique (rom dans $90 \%$ des cas). En 2011, 45\% des 825 bénéficiaires souffraient d'un handicap et $23 \%$ se déclaraient membres d'une minorité ethnique (rom à $82 \%$ ).

Facteurs de réussite: l'un des principaux facteurs de réussite de cette aide à la création et au développement d'entreprises sociales viables réside dans la capacité à garantir un financement pérenne. L'exemple présenté était un projet pilote qui a permis de tester le modèle à petite échelle avant d'être étendu. Il peut être adapté aux besoins locaux dans le cadre d'une procédure de candidature au cours de laquelle les actions et les domaines prioritaires peuvent être identifiés. 


\section{Données clés relatives à l'entrepreneuriat inclusif}

\section{Graphique 13.1. Données relatives à l'entrepreneuriat et au travail indépendant en Bulgarie}

Diagramme A. Taux de chômage, 2000-2012

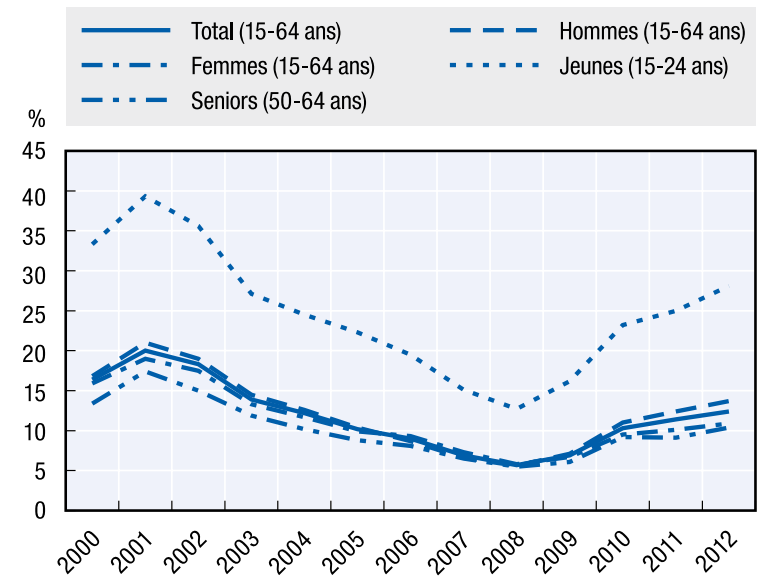

Diagramme C. Taux de travail indépendant, 2000-2012

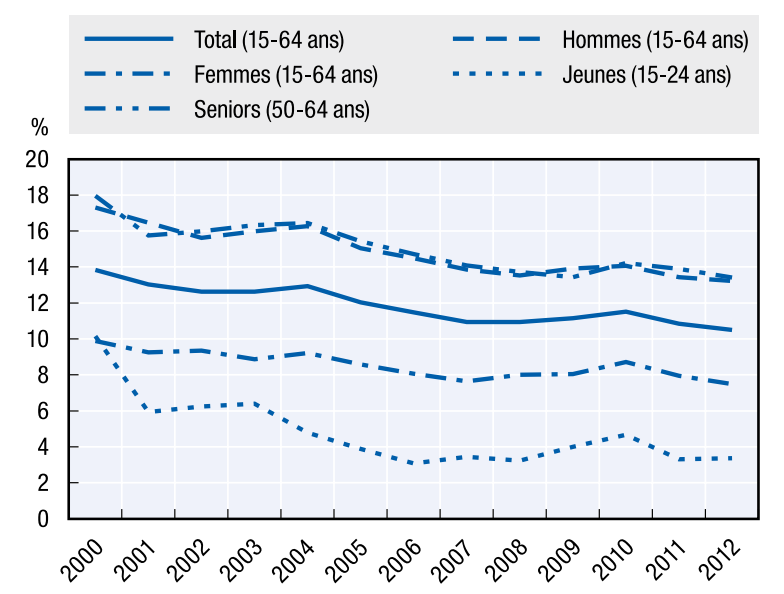

Diagramme B. Taux de travail indépendant, 2012

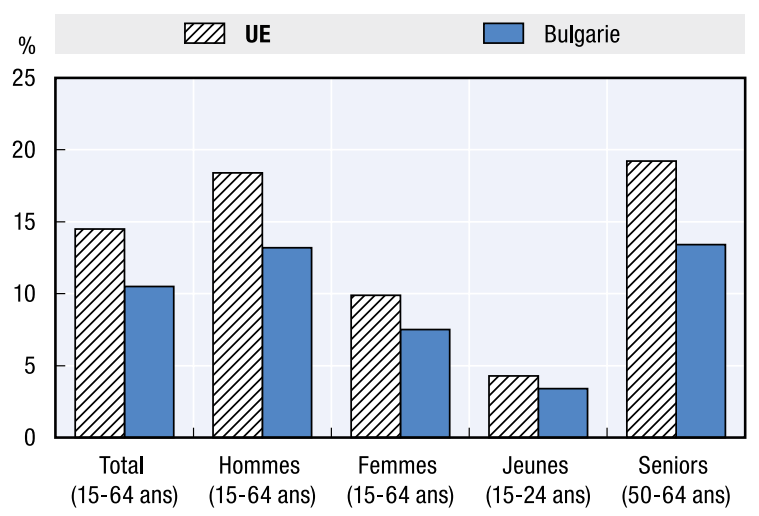

Sources: Diagramme A. Eurostat, Enquête sur les forces de travail, 2000-2012; Diagramme B. Eurostat, Enquête sur les forces de travail, 2012; Diagramme C. Eurostat, Enquête sur les forces de travail, 2000-2012. 


\section{Croatie: «It's time for women»}

Description: le projet «It's time for women» aide les femmes sans emploi à revenir sur le marché du travail par le biais de formations au travail indépendant. Il a été déployé dans les comitats touchés par la guerre, dont les taux de chômage des femmes demeurent supérieurs à la moyenne croate.

Problème abordé: "It's time for women" est une solution potentielle au problème de la participation des femmes au marché du travail des comitats touchés par la guerre, y compris aux taux de chômage élevés au chômage longue durée.

Approche: lancé en 2009, le projet propose sur une période de 12 mois des formations et une aide à la création d'entreprise aux demandeuses d'emploi. Il a été élaboré et mis en œuvre par l'Association for Peace and Human Rights (Baranja) du comitat d'OsijekBaranja, en partenariat notamment avec l'agence croate pour l'emploi (bureau régional de Beli Manastir) et les pouvoirs municipaux de Popovac, Draz et Petlovac. Les activités mises en place portaient sur le développement des compétences, capacités et connaissances individuelles dans le cadre de formations à la gestion d'entreprise et en informatique (p.ex. formation de base à Word et Excel), ainsi que sur le renforcement de la confiance en soi. À l'issue de ces formations, les participants pouvaient demander une petite subvention pour lancer leur projet. Les partenaires du projet ont contribué à lui donner de la visibilité en organisant des conférences de presse et en diffusant des spots sur Osjecka TV, Slavonia Television et à la radio. Des appels à participation ont été diffusés à la radio deux fois par jour pendant deux mois. Son budget s'élevait à 144285 EUR, financé en majeure partie par l'IAP IV ( $85 \%$ ). Le reste provenait de la contribution du bénéficiaire du contrat de subvention et de ses partenaires.

Impact: le projet «It's time for women» proposait trois programmes de formation distincts, suivis avec succès par 25 infirmières, 19 producteurs de légumes et 20 producteurs de poudre de paprika fort/doux. Tous les participants ont reçu une formation complémentaire sur la confiance en soi, les compétences entrepreneuriales et la maîtrise élémentaire de l'informatique. Sur les 64 participants, 14 ont élaboré un plan d'affaires en vue de produire du paprika et 10 d'entre eux ont bénéficié de subventions.

Facteurs de réussite: ces différents projets témoignent de l'importance d'une approche sur mesure et intégrée pour les chômeurs de longue durée. Leur financement dans le cadre d'appels d'offres a permis de mettre en place une grande variété d'approches adaptées aux besoins locaux. Les évaluations ont toutefois montré qu'il s'était écoulé trop de temps entre le moment de la soumission des propositions de projet et le début des activités proprement dites. 


\section{Données clés relatives à l'entrepreneuriat inclusif}

\section{Graphique 14.1. Données relatives à l'entrepreneuriat et au travail indépendant en Croatie}

Diagramme A. Taux de chômage, 2002-2012

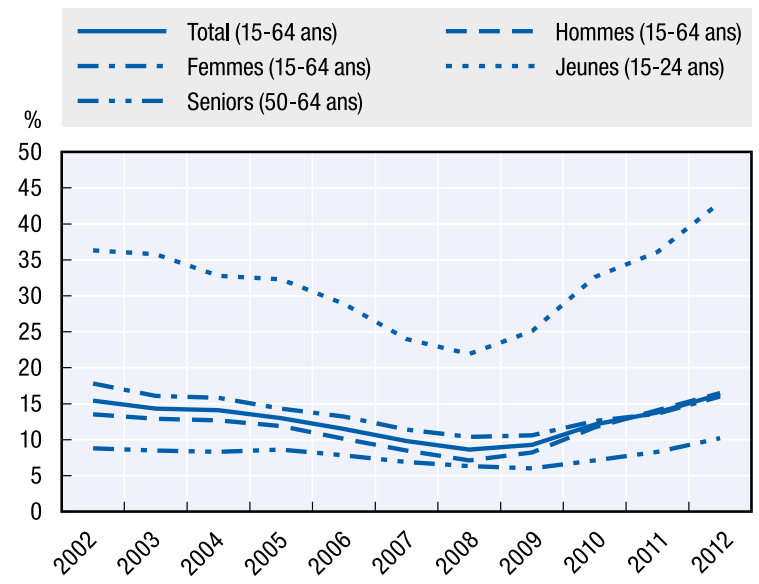

Diagramme C. Taux de travail indépendant, 2002-2012

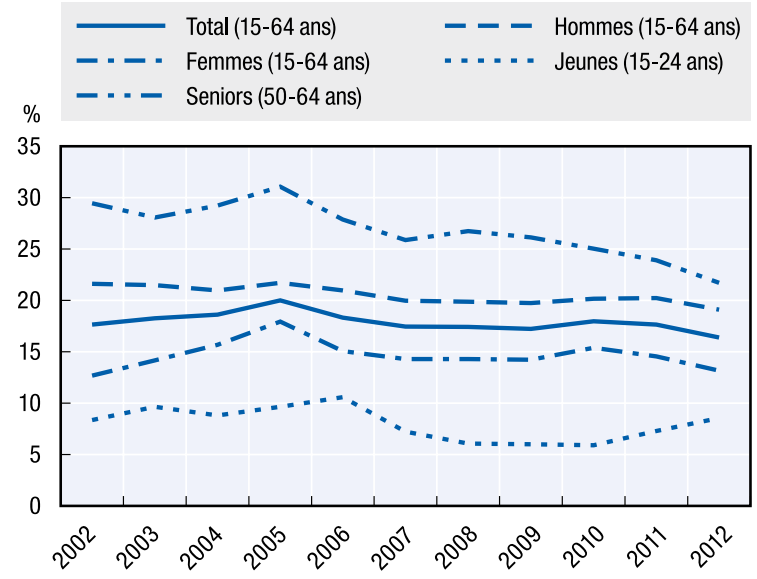

Diagramme E. Indice de l'activité entrepreneuriale totale au stade précoce, 2008-2012 (combinés)

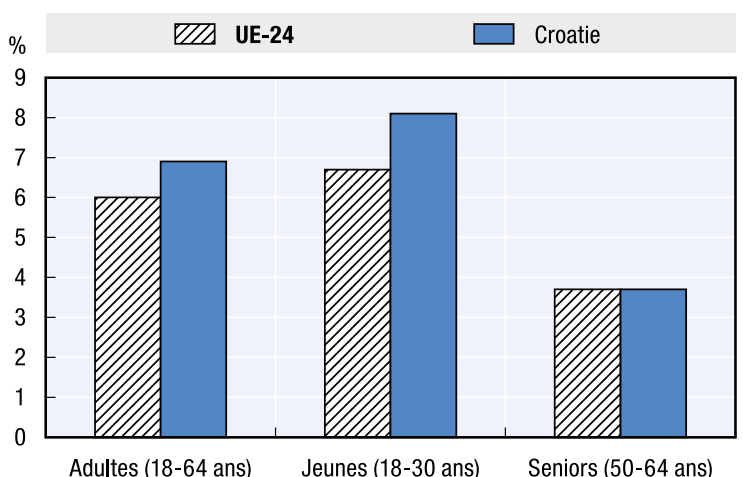

Diagramme B. Taux de travail indépendant, 2012

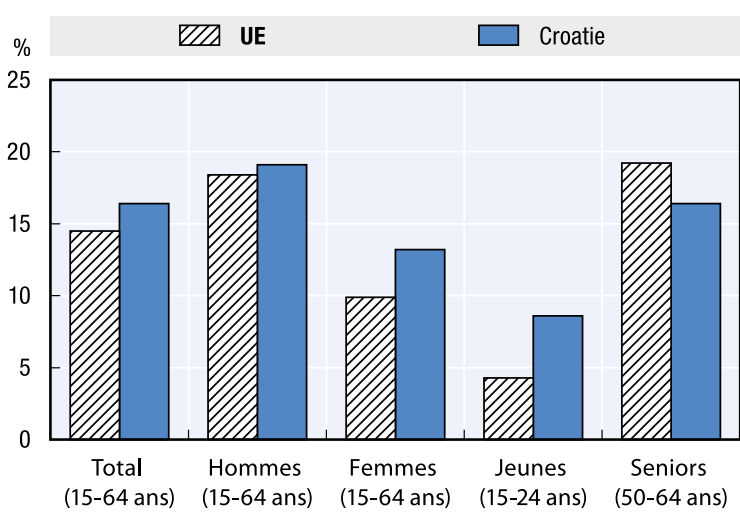

Diagramme D. Indice de l'activité entrepreneuriale totale au stade précoce, 2012

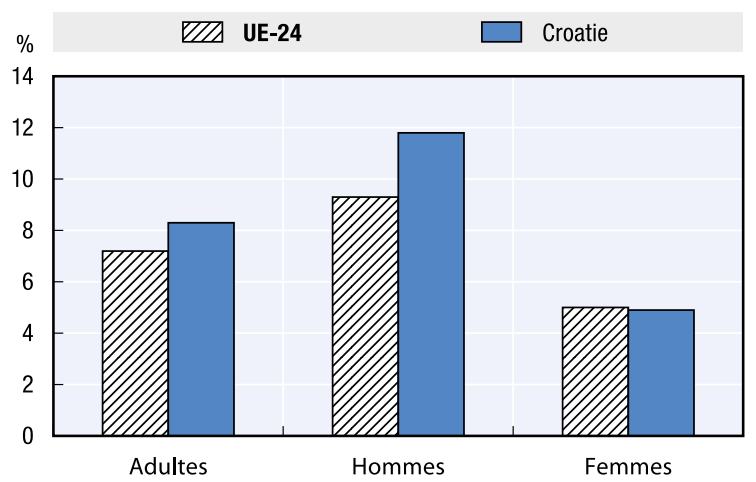

Sources: Diagramme A. Eurostat, Enquête sur les forces de travail, 2002-2012; Diagramme B. Eurostat, Enquête sur les forces de travail 2012; Diagramme C. Eurostat, Enquête sur les forces de travail, 2002-2012; Diagramme D. Présentation tabulaire spéciale de l'enquête sur la population adulte du Global Entrepreneurship Monitor, 2012; Diagramme E. Présentation tabulaire spéciale de l'enquête sur la population adulte du Global Entrepreneurship Monitor, 2008-2012. 


\section{Chypre: Grant Scheme for the Enhancement of Youth Entrepreneurship}

Description: le Grant Scheme for the Enhancement of Youth Entrepreneurship propose une aide financière sous la forme de subventions et des formations à la gestion de petite entreprise aux jeunes âgés de 20 à 39 ans qui souhaitent créer et développer leur propre entreprise. Il vise avant tout à faire reculer le chômage des diplômés et à réintégrer les femmes sur le marché de l'emploi (avec une limite d'âge établie à 55 ans).

Problème abordé: le programme de subvention vise à soutenir la création d'entreprise comme alternative au chômage élevé des jeunes (près de 30\% en 2012) et à leur mentalité qui les pousse généralement vers la fonction publique et le secteur bancaire fortement syndicalisé. Ces subventions constituent un capital de démarrage destiné à aider les jeunes à concrétiser leur projet d'entreprise, créer des emplois et ouvrir de nouvelles perspectives de croissance.

Approche: le programme soutient les créations d'entreprise dans les secteurs de la production, du commerce en ligne et des services. Il peut financer jusqu'à $50 \%$ des coûts de démarrage (jusqu'à 70000 EUR pour la production manufacturière et 50000 EUR pour les services). Les jeunes entrepreneurs peuvent bénéficier d'un financement à titre individuel ou en équipe. Les dépenses éligibles incluent les machines et les équipements, la formation, la promotion et le fonds de roulement. Les demandes doivent inclure un plan d'affaires décrivant les besoins de capitaux et l'utilisation qui sera faite de la subvention. Les subventions sont conditionnées à la participation à une formation à l'entrepreneuriat, coordonnée et soutenue par l'Agence chypriote pour l +e développement des ressources humaines. Le programme est cofinancé par la République de Chypre et le Fonds européen de développement régional (FEDER) au titre du programme opérationnel «Développement durable et compétitivité». Entre 2007 et 2013, environ 16 millions EUR lui ont été alloués par l'intermédiaire du FEDER.

Impact: le régime a contribué à la création de 395 entreprises et de près de 1000 emplois. La majorité de entreprises créées sont spécialisées dans les secteurs de la production (p.ex. boulangeries, petite usines de production alimentaire, usines métallurgiques, sociétés de commerce en ligne), des services (cabinets juridiques, comptables et médicaux, crèches), de la mécanique et du tourisme (tavernes, restaurants, bars, cafés et petits hôtels traditionnels).

Facteurs de réussite: le financement est conditionné à une formation obligatoire, qui contribue à améliorer les niveaux de compétences des participants et à augmenter leurs chances de réussir le lancement de leur projet grâce à la subvention.

Note de la Turquie:

Les informations figurant dans ce document et faisant référence à «Chypre» concernent la partie méridionale de l'île. Il n'y a pas d'autorité unique représentant à la fois les Chypriotes turcs et grecs sur l'île. La Turquie reconnaît la République turque de Chypre du Nord (RTCN). Tant qu'une solution durable et équitable n'aura pas été trouvée dans le cadre des Nations unies, la Turquie maintiendra sa position sur la «question chypriote».

Note de tous les États de l'Union européenne membres de l'OCDE et de l'Union européenne:

La République de Chypre est reconnue par tous les membres des Nations unies sauf la Turquie. Les informations figurant dans ce document concernent la zone sous le contrôle effectif du gouvernement de la République de Chypre. 


\section{Données clés relatives à l'entrepreneuriat inclusif}

\section{Graphique 15.1. Données relatives à l'entrepreneuriat et au travail indépendant à Chypre}

Diagramme A. Taux de chômage, 2000-2012

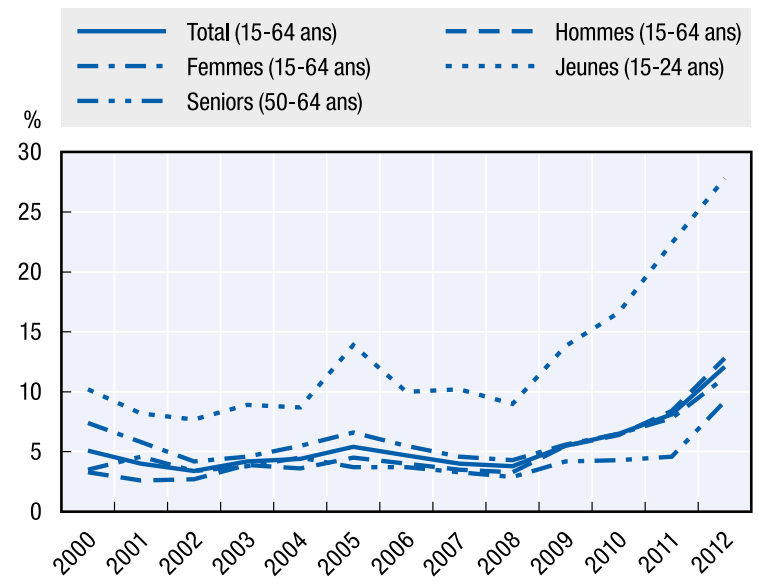

Diagramme C. Taux de travail indépendant, 2000-2012

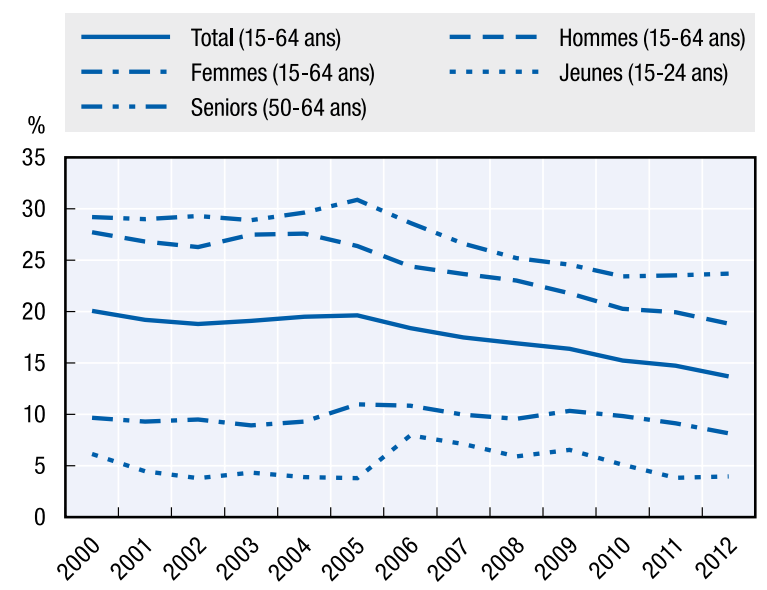

Diagramme B. Taux de travail indépendant, 2012

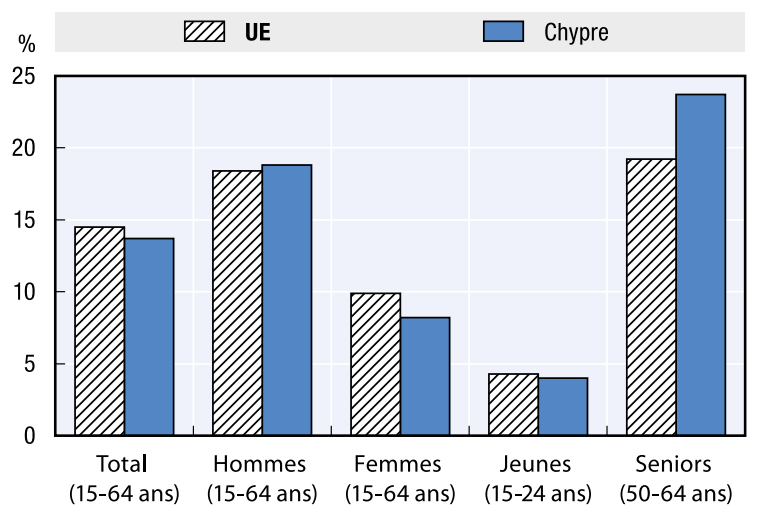

Sources: Diagramme A. Eurostat, Enquête sur les forces de travail, 2000-2012; Diagramme B. Eurostat, Enquête sur les forces de travail, 2012; Diagramme C. Eurostat, Enquête sur les forces de travail, 2000-2012. 


\section{République tchèque: Build your own enterprise as a way to connect work with childcare}

Description: le projet «Build your own enterprise as a way to connect work with childcare» soutient l'entrepreneuriat des parents en congé parental ou en fin de congé parental. Il visait à informer les parents sur le travail indépendant et la création d'entreprise afin de les guider dans le démarrage de leur activité. Le projet a été mis en œuvre à Prague, entre le $1^{\text {er }}$ juin 2011 et le 31 mai 2013.

Problème abordé: le projet a répondu au faible taux d'emploi des mères de jeunes enfants à charge en s'attaquant à un certain nombre d'obstacles au travail indépendant, parmi lesquels la peur de l'inconnu et le manque de confiance. Les familles avec de jeunes enfants rencontrent de nombreuses difficultés pratiques pour concilier vie de famille et vie professionnelle, comme la garde d'enfants et la gestion du temps. Ces difficultés peuvent être encore plus grandes pour les entrepreneurs parents de jeunes enfants en raison du caractère imprévisible de leurs revenus et des implications financières liées au démarrage d'une entreprise.

Approche: ce projet fournit un ensemble intégré de mesures d'aide comprenant de la formation et des services de conseil. Les bénéficiaires ciblés étaient les parents en congé parental (majoritairement des mères) qui vivent à Prague, capitale de la République tchèque. La plupart d'entre eux se trouvaient dans leur dernière année de congé parental (qui peut aller jusqu'à trois ans) ou venaient de le terminer. Tous étaient éligibles au projet, quels que soient leur situation d'emploi et leur niveau d'instruction. Le soutien s'est articulé en cinq phases. Premièrement, des entretiens ont été réalisés par des conseillers en entreprise en vue d'établir un diagnostic personnalisé et d'aider les bénéficiaires à identifier des idées d'entreprise potentielles. Deuxièmement, les participants ont suivi deux mois de formation aux questions juridiques et aux compétences générales, dont le marketing. Troisièmement, des cours spécialisés ont été organisés en fonction de leurs besoins et de leurs projets. Quatrièmement, les participants ont suivi un stage dans une petite entreprise afin qu'ils découvrent le fonctionnement d'une société dans la pratique. Enfin, ils ont bénéficié de services de conseil durant la phase de démarrage de leur entreprise. En outre, un système de formation en ligne ainsi qu'un site web comprenant du matériel pédagogique (p.ex. cas pratiques, devoirs et manuels) et des archives de documents de conseil en entreprise ont été développés dans le cadre du projet. Par ailleurs, un service de garde d'enfants a été mis en place pour les bénéficiaires participant à des séminaires et des séances de formation. Le budget du projet s'élevait à 244562 EUR, financés à $85 \%$ par le FSE.

Impact: le nombre de bénéficiaires ayant créé leur entreprise constitue un indicateur clé de la réussite du projet. Au total, 160 personnes y ont participé. Le programme a été suivi jusqu'à son terme par 152 personnes (95\%) et 103 des participants diplômés (64\%) ont créé leur entreprise.

Facteurs de réussite: les clés de la réussite du projet résident dans l'identification des besoins spécifiques du groupe de bénéficiaires cibles et la mise à profit de l'expérience tirée d'autres projets d'aide aux parent. De l'avis des participants, ce sont les stages en PME, organisés via l'Association des PME et de l'artisanat, qui ont été les plus bénéfiques en termes d'acquisition de savoir-faire, d'expérience et de découverte d'activités professionnelles dans leur domaine de travail. 


\section{Données clés relatives à l'entrepreneuriat inclusif}

\section{Graphique 16.1. Données relatives à l'entrepreneuriat et au travail indépendant en République tchèque}

Diagramme A. Taux de chômage, 2000-2012

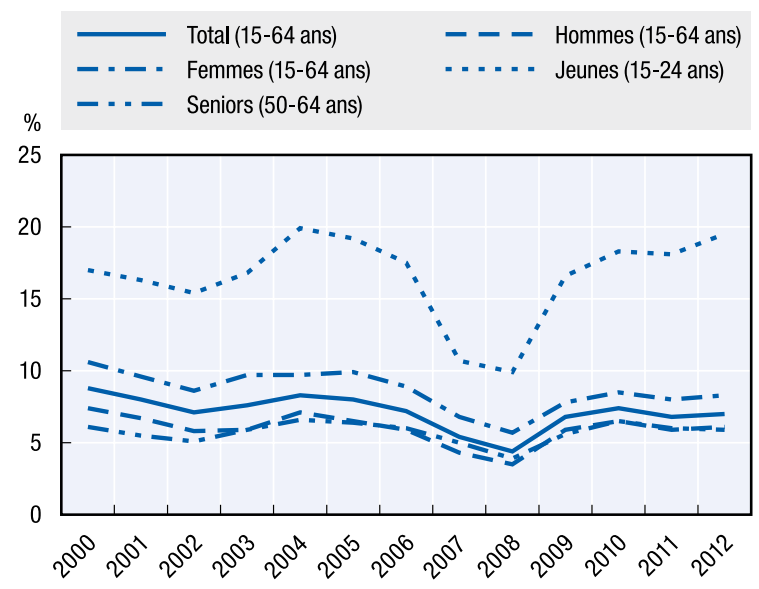

Diagramme C. Taux de travail indépendant, 2000-2012

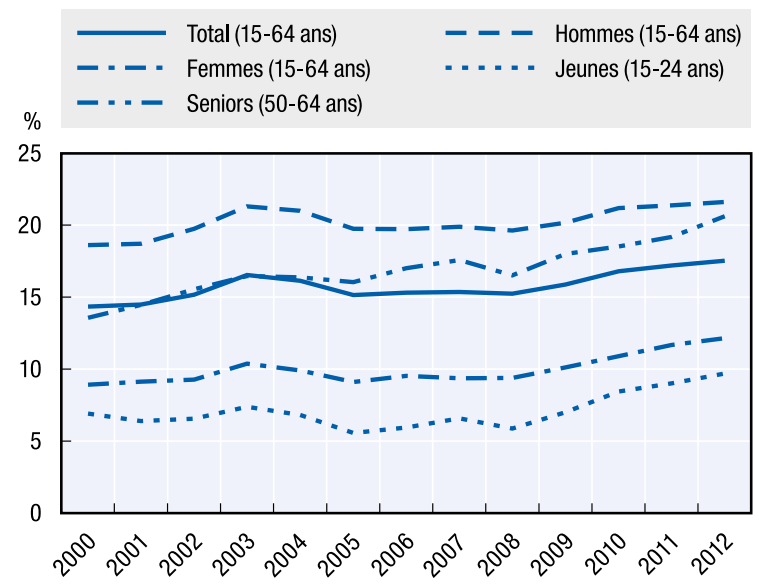

Diagramme E. Indice de l'activité entrepreneuriale totale au stade précoce, 2008-2012 (combinés)

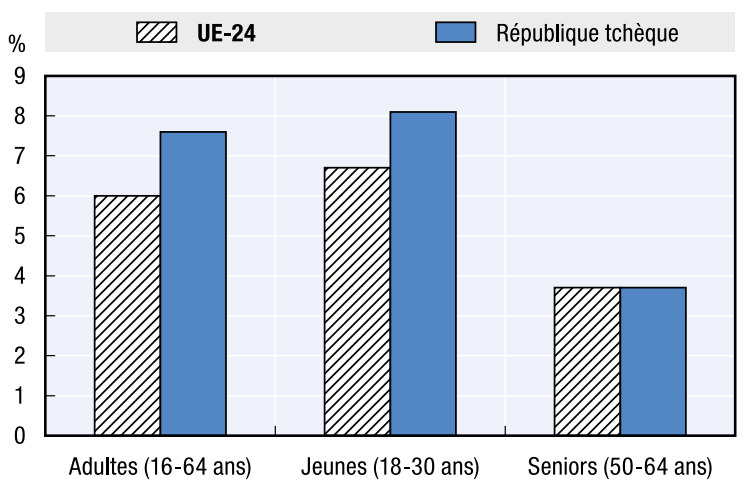

Diagramme B. Taux de travail indépendant, 2012

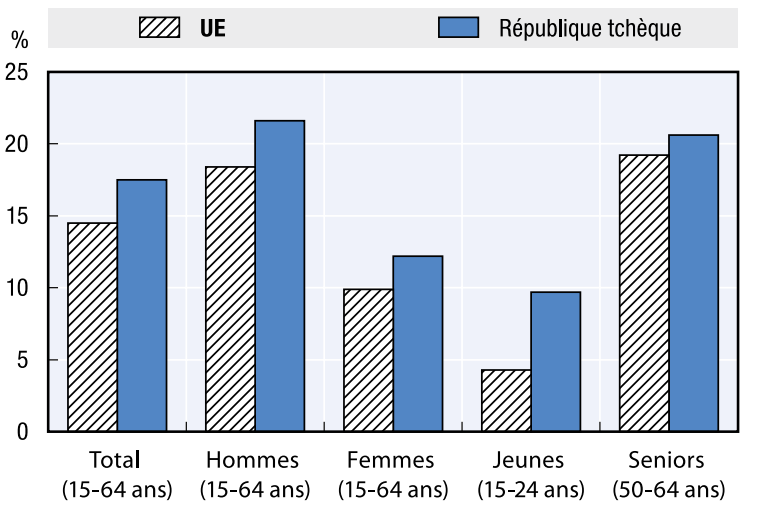

Diagramme D. Indice de l'activité entrepreneuriale totale au stade précoce, 2011

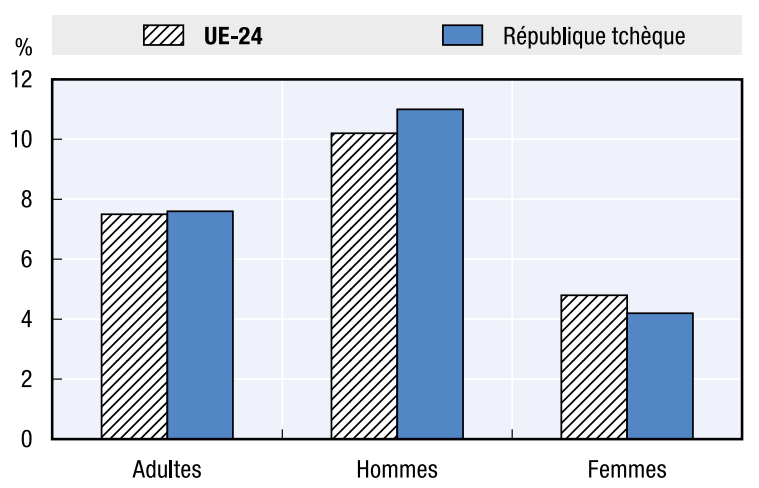

Sources: Diagramme A. Eurostat, Enquête sur les forces de travail, 2000-2012; Diagramme B. Eurostat, Enquête sur les forces de travail 2012; Diagramme C. Eurostat, Enquête sur les forces de travail, 2000-2012; Diagramme D. Présentation tabulaire spéciale de l'enquête sur la population adulte du Global Entrepreneurship Monitor, 2011; Diagramme E. Présentation tabulaire spéciale de l'enquête sur la population adulte du Global Entrepreneurship Monitor, 2008-2012. 


\section{Danemark: promotion de l'entrepreneuriat à Bornholm}

Description: ce projet mené à Bornholm vise à stimuler l'entrepreneuriat pour rajeunir l'économie régionale, et ainsi éviter l'exode des jeunes qui cherchent à se former et à se créer des opportunités d'emploi. Le centre d'affaires de Bornholm (BCB) propose un service de formation et de conseil aux personnes désireuses de créer leur entreprise.

Problème abordé: Bornholm est une île de la mer Baltique, qui s'étend sur $30 \mathrm{~km}$ de large et $40 \mathrm{~km}$ de long. Sa population est d'environ 41800 habitants, mais elle est en déclin depuis quelques années. Elle est en outre vieillissante. Bornholm a été davantage touché par la crise économique récente que le reste du Danemark. Son taux de chômage est supérieur de $3 \%$ à celui de la moyenne nationale. Par conséquent, de nombreux jeunes ont quitté l'île pour poursuivre leurs études et trouver un emploi.

Approche: le principal mécanisme d'aide est assuré par le $B C B$, partie prenante au programme national d'aide aux entreprises et aux entrepreneurs potentiels, qui les conseille et les oriente dans l'approche à adopter pour démarrer une entreprise locale. L'assistance sur le terrain couvre à la fois les aspects pratiques et stratégiques. Elle inclut des réunions individuelles avec des conseillers, des formations en analyse de marché, marketing, gestion de contrats, planification budgétaire et comptabilité, ainsi que des événements de mise en réseau par l'intermédiaire du réseau d'entrepreneurs Ziværk. Le BCB met également une boîte à outils en ligne à la disposition des entrepreneurs. Les candidats entrepreneurs peuvent demander à voir des conseillers locaux, financés à parts égales par le BCB et l'entrepreneur. Le centre dirige également les entrepreneurs vers d'autres services d'aide (p.ex. pépinières Growth Factory et Entrepreneur Factory) présents sur l'île et vers des sources de microfinancement (p.ex. Erhversfond et les Fonden for Beskoeftigelsesfremmende Initiativer). Le système de services d'aide aux entreprises de Bornholm est doté d'un budget annuel de 61,5 millions DKK (environ 8,2 millions EUR), financés à hauteur de 12 millions DKK (1,6 million EUR) par le Fonds national de développement régional, de 10,5 millions DKK (1,4 million EUR) par le FEDER, de 13 millions DKK (1,7 million EUR) par le FSE, de 13,2 millions DKK (1,8 million EUR) par des entreprises du secteur privé et de 12,8 millions DKK (1,7 million EUR) par d'autres sources.

Impact: d'après une analyse du programme de promotion de l'entreprise sur le cas de Bornholm, seules $10 \%$ des entreprises ayant collaboré avec le BCB ont jugé l'aide utile et instructive. Les évaluations suggèrent par ailleurs que cette dernière se serait concentrée sur un nombre trop limité d'entreprises. Le BCB planifie actuellement une évaluation d'impact ciblée des différents volets du programme. Les résultats serviront à l'élaboration d'une nouvelle stratégie de promotion de l'entreprise.

Facteurs de réussite: le projet montre l'importance pour les entrepreneurs d'accéder à des programmes de conseil réguliers aussi bien pour créer des entreprises que pour lutter contre le phénomène d'exode. L'analyse de Bornholm souligne l'importance d'impliquer les entreprises locales dans les programmes de promotion. 


\section{Données clés relatives à l'entrepreneuriat inclusif}

\section{Graphique 17.1. Données relatives à l'entrepreneuriat et au travail indépendant au Danemark}

Diagramme A. Taux de chômage, 2000-2012

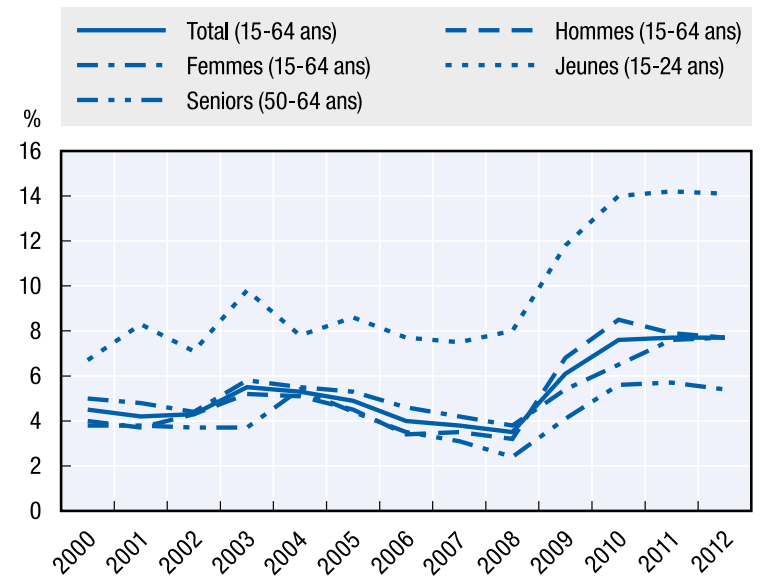

Diagramme C. Taux de travail indépendant, 2000-2012

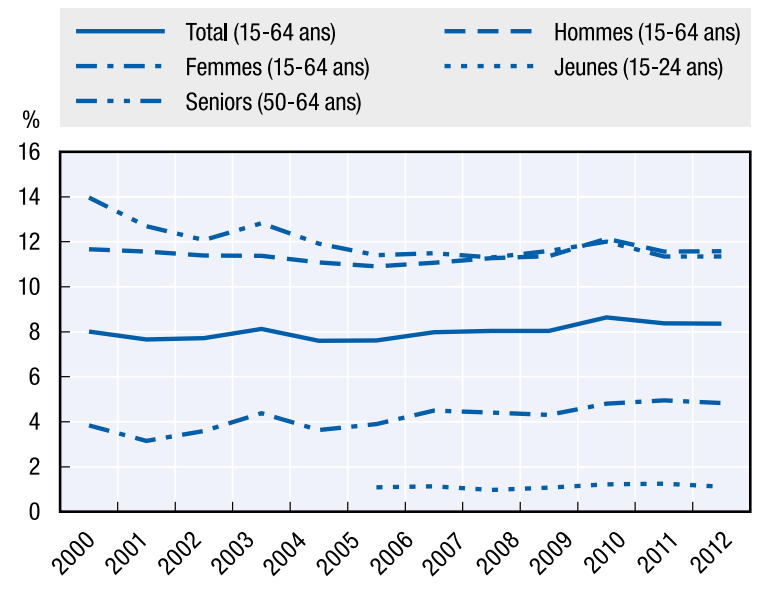

Diagramme E. Indice de l'activité entrepreneuriale totale au stade précoce, 2008-2012 (combinés)

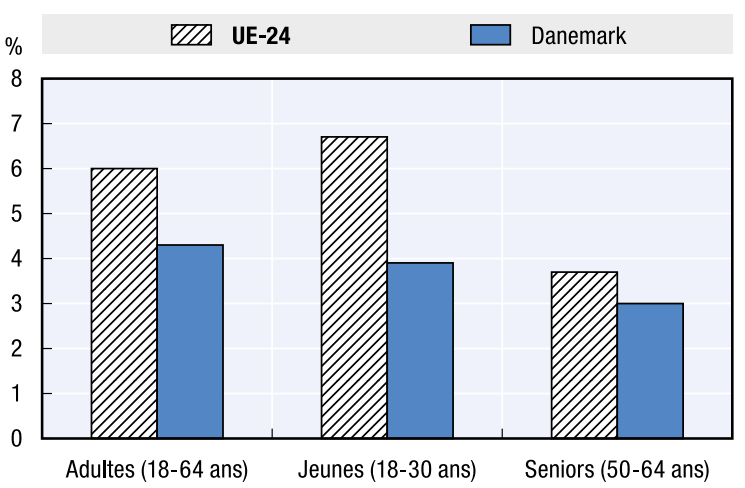

Diagramme B. Taux de travail indépendant, 2012

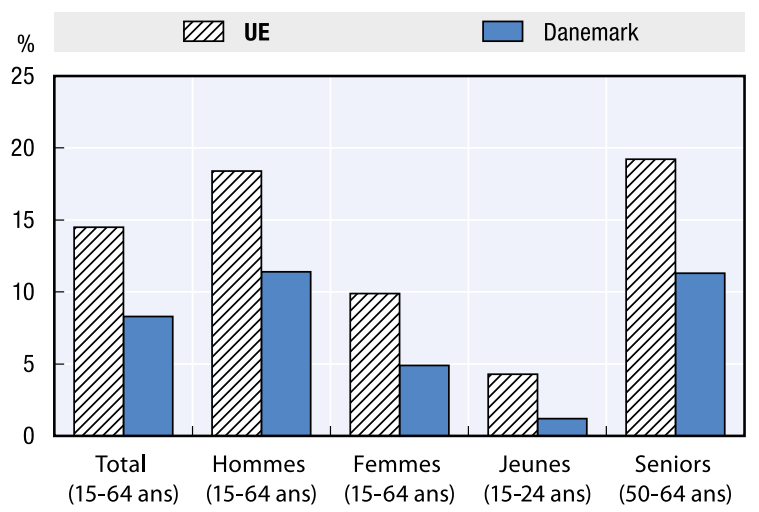

Diagramme D. Indice de l'activité entrepreneuriale totale au stade précoce, 2012

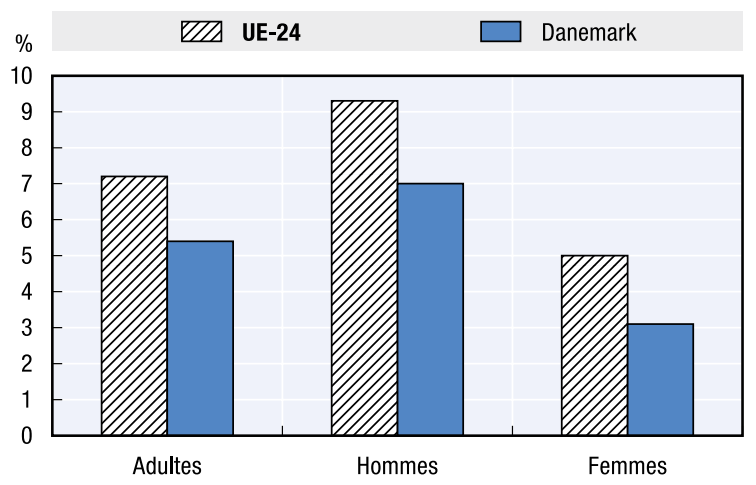

Sources: Diagramme A. Eurostat, Enquête sur les forces de travail, 2000-2012; Diagramme B. Eurostat, Enquête sur les forces de travail 2012; Diagramme C. Eurostat, Enquête sur les forces de travail, 2000-2012; Diagramme D. Présentation tabulaire spéciale de l'enquête sur la population adulte du Global Entrepreneurship Monitor, 2012; Diagramme E. Présentation tabulaire spéciale de l'enquête sur la population adulte du Global Entrepreneurship Monitor, 2008-2012. 


\section{Estonie: programme de microcrédit de l'ETNA pour les femmes entrepreneurs des zones rurales}

Description: ce programme de microcrédit s'adresse aux femmes indépendantes et propriétaires de microentreprises dans les zones rurales du pays. Il vise à établir des groupes de prêt dans 10 régions rurales pour les femmes qui créent et développent des entreprises, et propose un service de mentorat et de formation. Il a été mis en place par l'ETNA, une association estonienne de femmes entrepreneurs rurales à but non lucratif.

Problème abordé: ce programme de microcrédit est une initiative citoyenne de femmes entrepreneurs en milieu rural, qui soutient leurs entreprises et stimule l'activité économique dans les zones rurales. Le déclin continu de l'emploi dans le secteur agricole pousse un nombre croissant de personnes à quitter la campagne pour chercher un emploi en ville. En Estonie, les entreprises créées par des femmes sont généralement de petite taille, mais elles donnent un emploi à leurs dirigeantes et aux membres de leur famille, contribuant ainsi à soutenir les communautés rurales. Aider et encourager les femmes à démarrer des entreprises ou à se lancer dans une activité indépendante est particulièrement important en milieu rural, où les autres opportunités d'emploi sont rares.

Approche: ce programme de microfinancement fonctionne sur la base de groupes de prêt pouvant atteindre 10 membres. Ces derniers octroient des prêts aux membres du groupe dont l'entreprise est en cours de création ou d'expansion. Ces groupes sont composés de personnes qui sont issues de la même zone rurale, ont des réseaux sociaux communs et peuvent s'entraider. Pour devenir membres d'un groupe de prêt, les candidats potentiels doivent participer à des formations sur les fondamentaux de l'entrepreneuriat, la gestion de documents, la comptabilité et la rédaction du plan d'affaires. Chaque membre peut bénéficier d'un prêt de 2000 EUR maximum sur trois ans pour faire l'acquisition de services ou d'équipements, pour couvrir la part d'autofinancement exigée par d'autres programmes d'aide aux entreprises ou pour payer un service en particulier (conseils financiers, conseils en matière de plan d'affaires). Aucune garantie ou hypothèque n'est requise. La responsabilité du prêt incombe à son bénéficiaire. L'octroi du prêt se déroule en trois étapes: (i) préparation du plan d'affaires par le demandeur et approbation par le groupe prêteur; (ii) évaluation de la conformité de la demande de prêt au regard des objectifs du programme; (iii) signature et émission du prêt. Le programme s'appuie sur un budget annuel de 268794 EUR. Il est géré par 3 employés salariés, dont un coordinateur de réseau et un gestionnaire de prêts. Ce financement de départ a été versé par l'Open Estonia Foundation.

Impact: au cours des seize premiers mois du projet, 10 groupes de mentorat ont vu le jour et réuni 65 membres. Fin 2013, ils sont devenus 11 groupes de prêt comptant 72 membres. Ce projet était un projet de mentorat de groupe au départ. Il n'a commencé ses activités de prêt qu'en juillet 2013. Il est donc prématuré de tirer des conclusions quant à l'impact des prêts octroyés.

Facteurs de réussite: créé à partir de fonds privés, le programme aura besoin de financements extérieurs, car il est peu probable que le fonds de roulement ne génère un revenu suffisant pour être financièrement autonome. Des facteurs sociaux influencent aussi l'impact et la pérennité de ces fonds, parmi lesquels l'existence d'une structure par âge équilibrée au sein des groupes de prêt et des mesures de renforcement de la confiance en soi et de la motivation. 


\section{Données clés relatives à l'entrepreneuriat inclusif}

\section{Graphique 18.1. Données relatives à l'entrepreneuriat et au travail indépendant en Estonie}

\section{Diagramme A. Taux de chômage, 2000-2012}

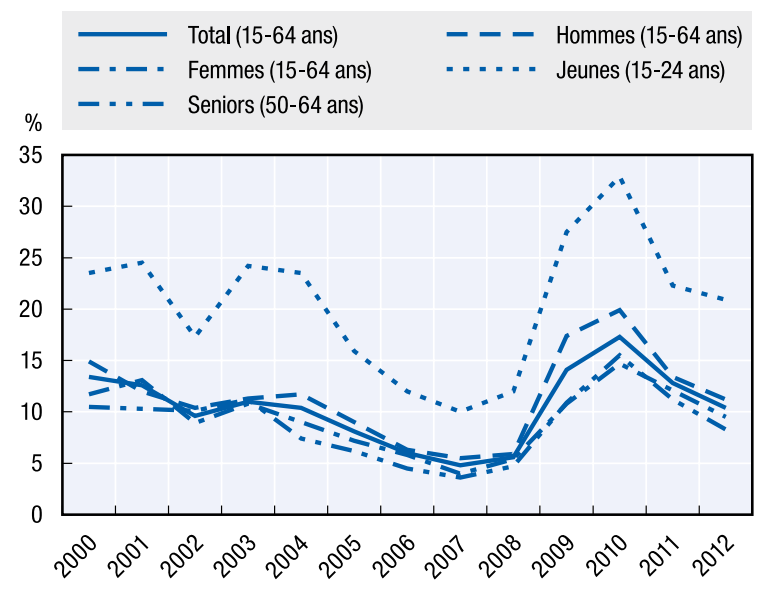

Diagramme C. Taux de travail indépendant, 2000-2012

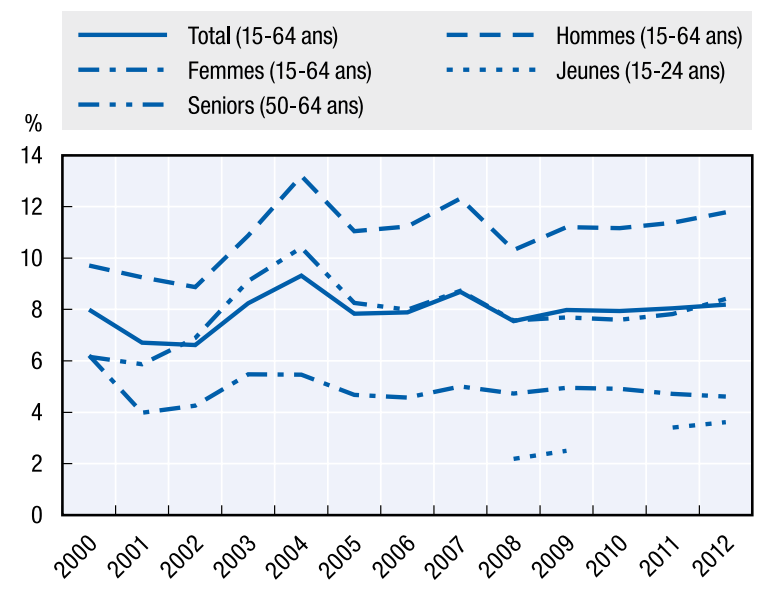

Diagramme E. Indice de l'activité entrepreneuriale totale au stade précoce, 2008-2012 (combinés)

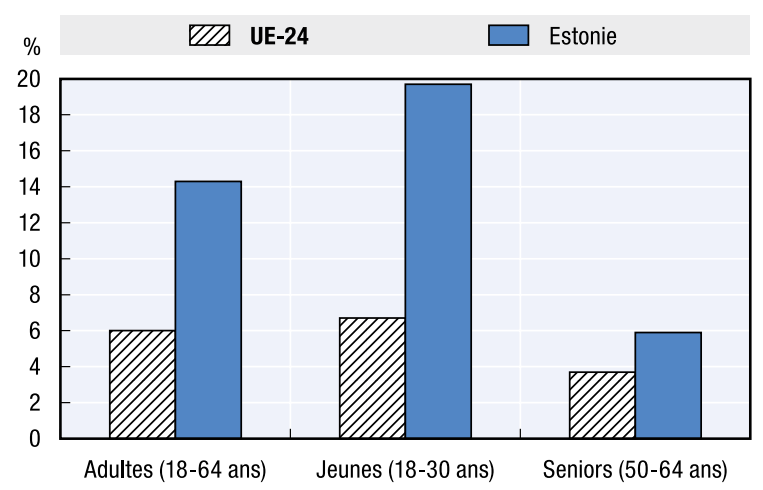

Diagramme B. Taux de travail indépendant, 2012

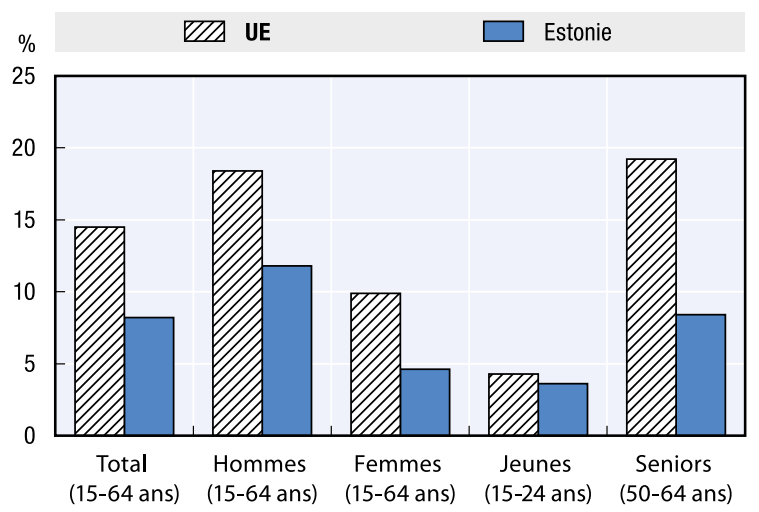

Diagramme D. Indice de l'activité entrepreneuriale totale au stade précoce, 2012

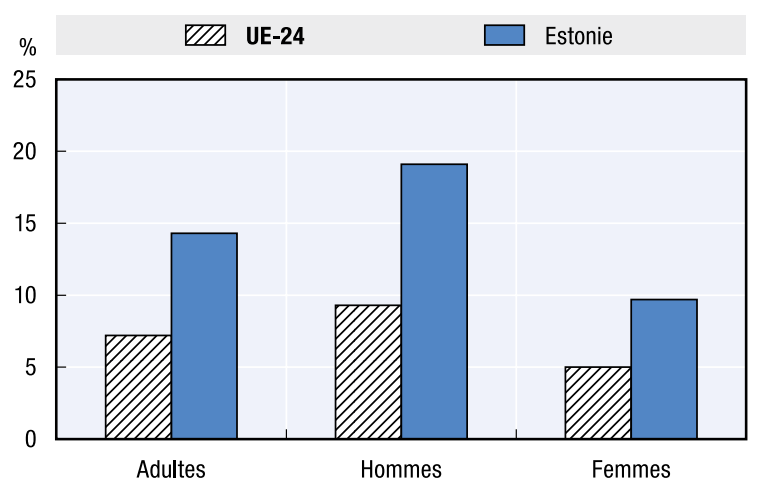

Sources: Diagramme A. Eurostat, Enquête sur les forces de travail, 2000-2012; Diagramme B. Eurostat, Enquête sur les forces de travail 2012; Diagramme C. Eurostat, Enquête sur les forces de travail, 2000-2012; Diagramme D. Présentation tabulaire spéciale de l'enquête sur la population adulte du Global Entrepreneurship Monitor, 2012; Diagramme E. Présentation tabulaire spéciale de l'enquête sur la population adulte du Global Entrepreneurship Monitor, 2008-2012. 


\section{Finlande: Women's Enterprise Agency}

Description: la Women's Enterprise Agency a pour mission de promouvoir l'entrepreneuriat féminin et de soutenir les femmes chefs d'entreprise dans le développement de leur entreprise et la création de réseaux. Cette agence propose divers services aux start-up dirigées par des femmes: diffusion d'informations, orientation vers des spécialistes, formation, mentorat, conseil... Établie en 1996, elle emploie exclusivement des femmes. Elles sont au nombre de 5, réparties entre deux bureaux (Helsinki et Tampere). Elle est l'une des 32 agences du réseau Finnish Enterprise Agencies (les autres ont une approche plus régionale que démographique).

Problème abordé: les femmes sont sous-représentées au sein de la population des entrepreneurs finlandais. Selon les chiffres de la Fédération des entreprises finlandaises, elles représentent $50 \%$ de la main-d'œuvre finlandaise, mais seulement $26 \%$ de la population entrepreneuriale. La finalité de cette initiative est d'exploiter le potentiel entrepreneurial latent de la population féminine. Les problèmes traités incluent le manque de courage pour solliciter des investisseurs, la difficulté à trouver l'équilibre entre vie professionnelle et vie privée, la capacité à valoriser et à rétribuer le travail ainsi que la compréhension des droits des employés en matière de congé de maternité et de maladie pour celles qui emploient des salariés.

Approche: le principe directeur est la mise du savoir-faire des entrepreneurs expérimentés au service des activités de l'agence. La gamme de services offerts inclut des conseils pratiques en entreprise, des formations et cours d'introduction à l'entrepreneuriat (dont un programme d'études organisé en une série de modules de formation consacrés aux compétences de base en gestion d'entreprise), des événements de mise en réseau et un service de mentorat. Le concept d'InnoLadyCamp a été créé en 2011 à l'attention des femmes diplômées de l'université qui occupent des postes d'expertise ou d'encadrement et envisagent de créer leur propre entreprise. Il propose un apprentissage pratique et un mentorat par les pairs lors de quatre «camps» organisés le week-end dans la campagne finlandaise. L'InnoLady Cloud est une plateforme web qui permet aux participantes de mettre au point leur idée d'entreprise en collaboration avec d'autres utilisatrices, parmi lesquelles des paires, des mentors et des investisseurs providentiels. L'agence aide également ces femmes entrepreneurs à solliciter des fonds de démarrage et des microprêts auprès de Finnvera, un organisme qui finance la création, la croissance et l'internationalisation des entreprises en fournissant des déclarations de soutien. Elle dispose d'un budget annuel d'environ 400000 EUR, pris en charge pour moitié par le FSE.

Impact: En 2012, les différentes activités de l'agence comptaient plus de 1000 participants. Cela représente moins de 400 EUR par participant. L'impact de cette initiative n'a pas fait l'objet d'une évaluation formelle, mais un suivi a été assuré par le biais d'enquêtes de satisfaction. Sur les 40 participantes à l'InnoLadyCamp, nombreuses sont celles à avoir fondé une entreprise. Quatre des 20 participantes à l'édition 2012 de l'InnoLadyCamp ont créé leur société durant le programme et 11 autres avaient l'intention de le faire après la fin de celui-ci.

Facteurs de réussite: cet exemple montre à quel point une agence appartenant à un réseau national et réservée aux femmes peut être efficace. Ce programme doit principalement sa réussite aux personnes actives et talentueuses qui sont chargées de gérer l'opération et de servir de mentors et de conseillers. La difficulté est de trouver les fonds pour organiser et promouvoir les activités, particulièrement au début lorsqu'aucune preuve de son impact ne peut venir étayer les demandes de financement. L'agence est gérée comme une association au sein de laquelle chacun des membres a voix au chapitre des décisions importantes. Si ce modèle peut s'avérer utile, par exemple pour des solutions innovantes, il peut aussi parfois ralentir les processus de décision. 


\section{Données clés relatives à l'entrepreneuriat inclusif}

\section{Graphique 19.1 Données relatives à l'entrepreneuriat et au travail indépendant en Finlande}

Diagramme A. Taux de chômage, 2000-2012

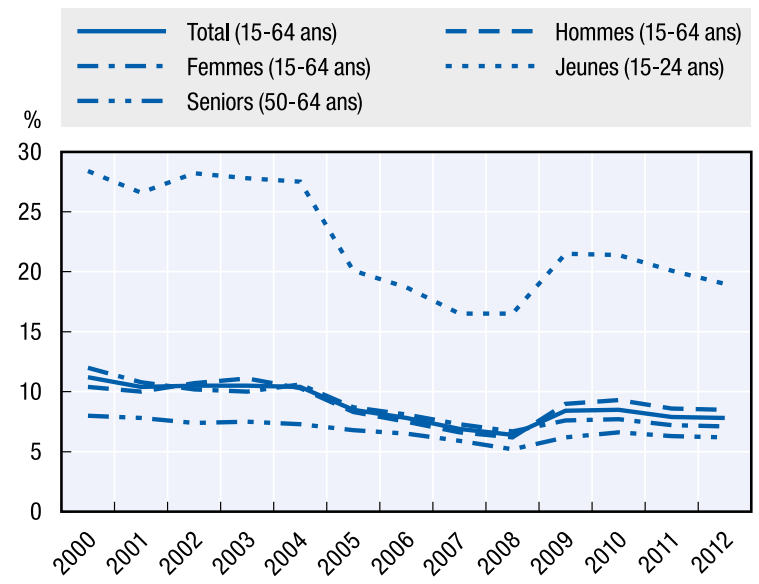

Diagramme C. Taux de travail indépendant, 2000-2012

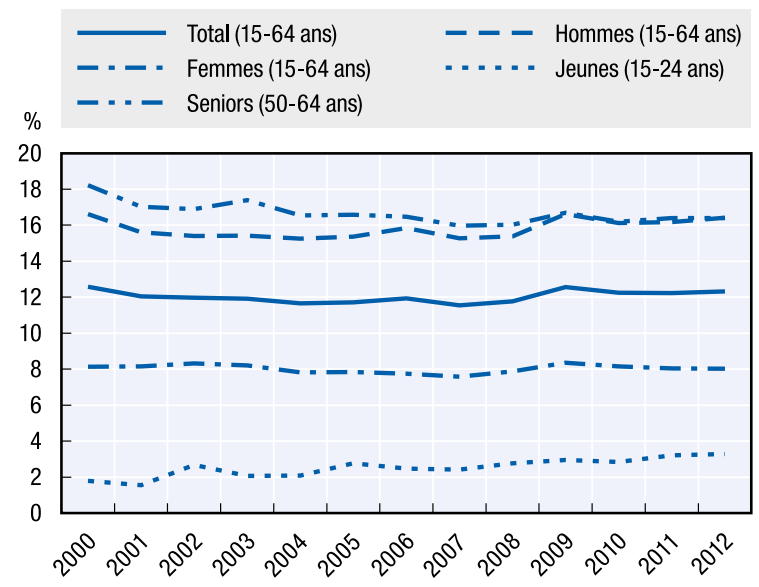

Diagramme E. Indice de l'activité entrepreneuriale totale au stade précoce, 2008-2012 (combinés)

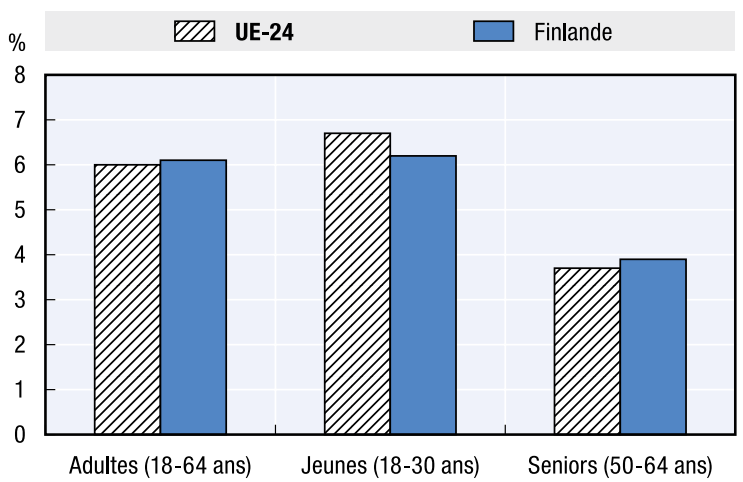

Diagramme B. Taux de travail indépendant, 2012

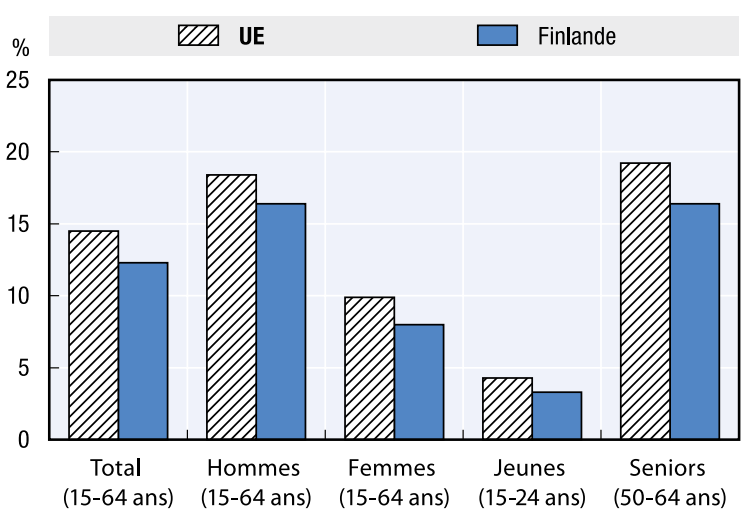

Diagramme D. Indice de l'activité entrepreneuriale totale au stade précoce, 2012

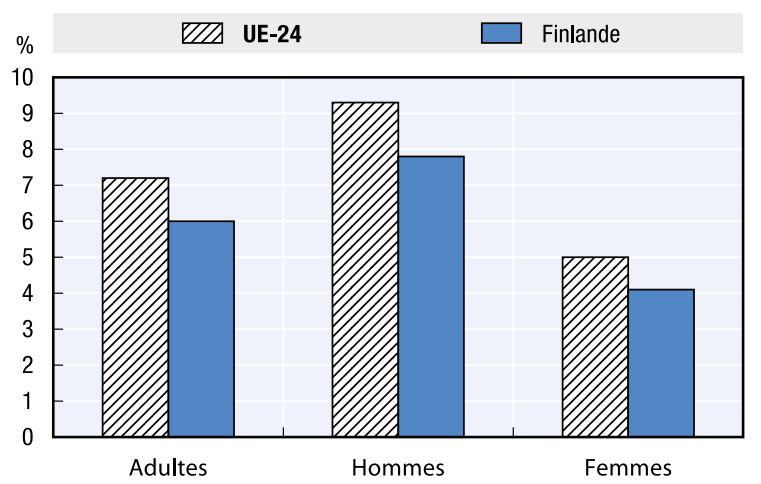

Sources: Diagramme A. Eurostat, Enquête sur les forces de travail, 2000-2012; Diagramme B. Eurostat, Enquête sur les forces de travail 2012; Diagramme C. Eurostat, Enquête sur les forces de travail, 2000-2012; Diagramme D. Présentation tabulaire spéciale de l'enquête sur la population adulte du Global Entrepreneurship Monitor, 2012; Diagramme E. Présentation tabulaire spéciale de l'enquête sur la population adulte du Global Entrepreneurship Monitor, 2008-2012. 


\section{France: Fonds de garantie pour la création, le rachat ou le développement d'entreprises initiées par des femmes}

Description: le Fonds de garantie à l'initiative des femmes (FGIF), qui fait partie du régime de Fonds de garantie national, encourage la création, la reprise et le développement d'entreprises par des femmes. L'État accorde une garantie de prêt, via la Garantie France Active, afin de faciliter l'octroi de prêts bancaires aux femmes désireuses de créer et de développer leur entreprise.

Problème abordé: seul un tiers des nouvelles entreprises créées en France le sont par des femmes. En outre, elles sont moins susceptibles de prospérer que celles établies par des hommes. Les taux de survie à cinq ans sont de $46,5 \%$ pour les femmes et de $52,5 \%$ pour les hommes (Fabre et Kerjosse, 2006). Selon une étude européenne, l'accès au crédit bancaire est la principale différence entre les hommes et les femmes chefs d'entreprise en France (Commission européenne, 2013b). En outre, la part des entreprises n'ayant pas sollicité de prêts bancaires au cours des six derniers mois par crainte d'un refus est bien plus grande chez les femmes que chez les hommes (9\% contre $5 \%$ ). Les fonds de garantie pour la création, la reprise ou le développement d'entreprise par des femmes s'adressent à celles qui disposent d'un plan d'affaires économiquement viable, mais dont les antécédents de crédit ou les fonds propres sont trop limités pour solliciter des prêts auprès de banques ou d'organismes de microcrédit.

Approche: le régime de garantie de prêt du FGIF s'adresse à toutes les femmes, quel que soit leur statut professionnel, qui veulent créer ou reprendre une société, indépendamment de sa forme juridique et du secteur d'activité concerné. Il est géré au niveau local, mais ses critères de sélection sont définis au niveau national. Toutes les propositions sont évaluées par des conseillers en entreprise et des professionnels (p.ex. juristes, comptables), qui déterminent les projets à couvrir. Les garanties de prêt portent sur des prêts d'au moins 5000 EUR par société et sur une période de deux à sept ans. Le taux de garantie est de $70 \%$ pour les prêts inférieurs à 38000 EUR et la garantie est plafonnée à 27000 EUR pour les prêts supérieurs ou égaux à 38000 EUR. Les garanties sont mises en place dès que la Garantie France Active reçoit de l'établissement bancaire les chèques de commission et de cotisation ainsi que les copies du contrat de prêt et du Tableau d'amortissement. Les garanties sont financées par le ministère du travail avec le soutien du FSE.

Impact: le service des droits des femmes et de l'égalité entre les femmes et les hommes du ministère du travail fait état d'une augmentation régulière du nombre de femmes bénéficiaires. Le nombre de garanties consenties était de 195 en 2004 et 745 en 2007.

Facteurs de réussite: ce projet montre que les garanties peuvent soutenir les femmes entrepreneurs tout en faisant la promotion de l'entrepreneuriat féminin. Ce programme repose sur un processus de sélection solide et personnalisé incluant une évaluation ex ante du demandeur et de son plan d'affaires ainsi que des réunions périodiques pour accompagner l'initiateur du projet. 


\section{Données clés relatives à l'entrepreneuriat inclusif}

\section{Graphique 20.1. Données relatives à l'entrepreneuriat et au travail indépendant en France}

Diagramme A. Taux de chômage, 2000-2012

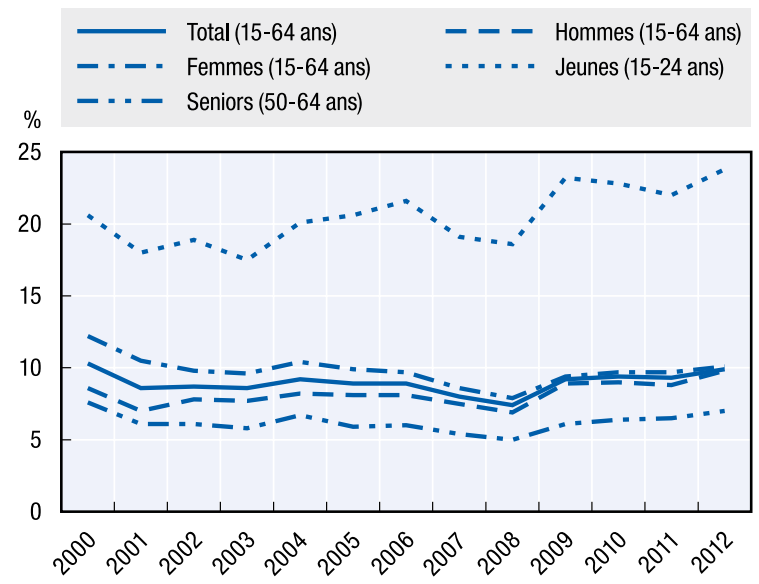

Diagramme C. Taux de travail indépendant, 2000-2012

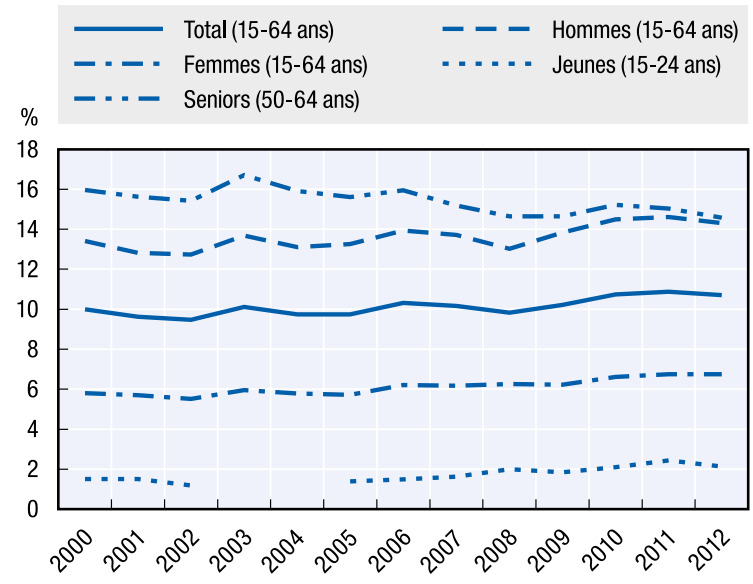

Diagramme E. Indice de l'activité entrepreneuriale totale au stade précoce, 2008-2012 (combinés)

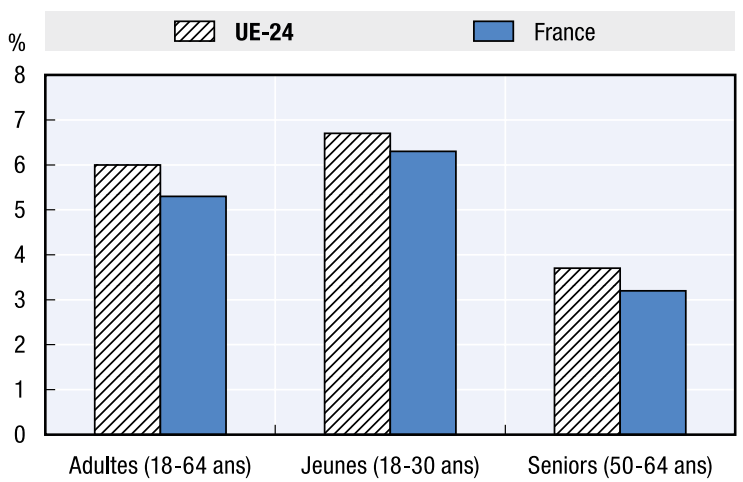

Diagramme B. Taux de travail indépendant, 2012

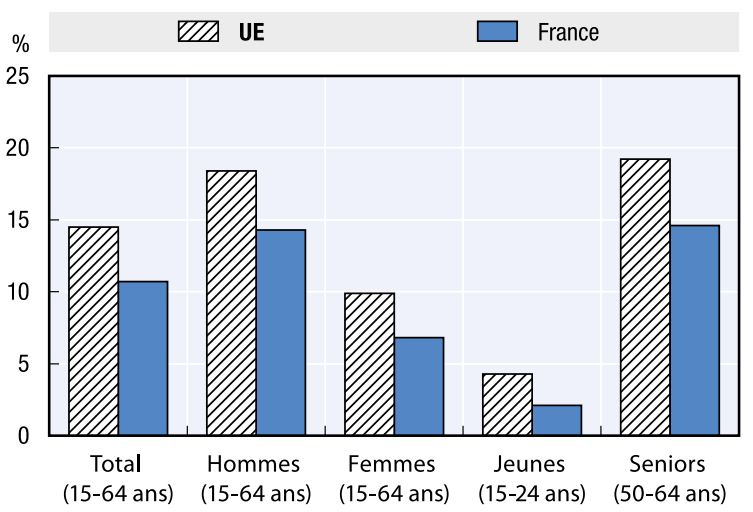

Diagramme D. Indice de l'activité entrepreneuriale totale au stade précoce, 2012

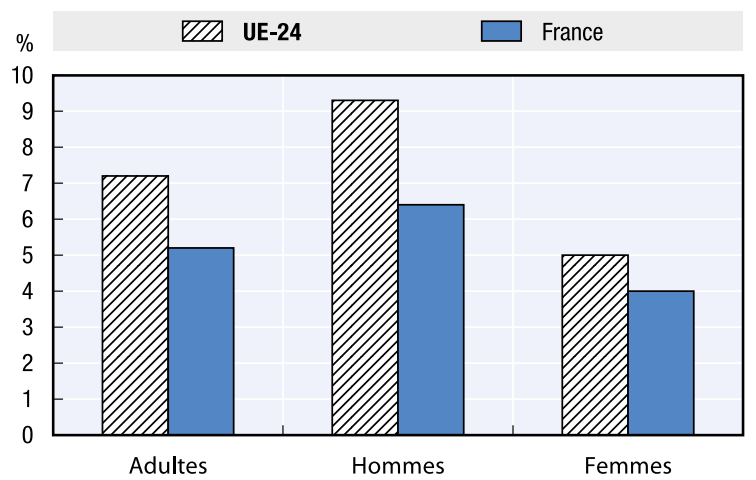

Sources: Diagramme A. Eurostat, Enquête sur les forces de travail, 2000-2012; Diagramme B. Eurostat, Enquête sur les forces de travail 2012; Diagramme C. Eurostat, Enquête sur les forces de travail, 2000-2012; Diagramme D. Présentation tabulaire spéciale de l'enquête sur la population adulte du Global Entrepreneurship Monitor, 2012; Diagramme E. Présentation tabulaire spéciale de l'enquête sur la population adulte du Global Entrepreneurship Monitor, 2008-2012. 


\section{Allemagne: Schüler-Institut für Technik und angewandte Informatik (SITI)}

Description: le Schüler-Institut für Technik und angewandte Informatik (SITI), fondé en 1999, est un pionner dans le domaine de l'éducation à l'entrepreneuriat et de la promotion des compétences technologiques et d'innovation auprès des jeunes, principalement dans les écoles secondaires (10-18 ans). Le SITI soutient le développement personnel et les compétences des jeunes dans des disciplines technologiques afin qu'ils développent des opportunités de carrière, en particulier comme indépendants, dans les secteurs de pointe de l'économie.

Problème abordé: l'Allemagne encourage les talents à s'exprimer dans les arts, la musique et le sport à travers un grand nombre d'écoles spécialisées et d'établissements de formation. En revanche, elle est à la traîne dans la promotion systématique des talents dans les domaines de l'entrepreneuriat, de l'innovation et des technologies (de l'information). En raison des programmes scolaires chargés, les cours classiques ne permettent généralement pas aux étudiants d'identifier et de développer leur intérêt et leurs capacités en matière de technologies et d'entrepreneuriat. N'ayant pas conscience de leurs talents, de nombreux étudiants font donc des choix de carrière plus conventionnels, dans le secteur bancaire, dans la vente ou encore dans l'administration.

Approche: le SITI propose une large gamme de projets d'apprentissage extrascolaire pratique à la fois novateurs et exigeants dans les domaines des technologies de production, des TIC appliquées, des sciences naturelles et de l'entrepreneuriat, selon une approche systématique et à long terme. À l'occasion de ce que l'on appelle une "conférence d'idées», étudiants et coaches décident ensemble des projets sur lesquels travailler au cours de l'année à venir. Le SITI ouvre ses portes tous les mardis, jeudis et vendredis. Il est fréquenté par environ 50 jeunes étudiants. Des sessions de formation de base régulières en TIC, multimédia, robotique, CAO/FAO/PIO, physique et astronomie posent les fondations du travail global sur le projet propre à chaque thématique. Chaque année, les étudiants du SITI travaillent sur trois à quatre projets de recherche et développement (R\&D) pour le compte d'entreprises technologiques et d'universités, et sur six projets "Jeunes chercheurs» dans le cadre d'un concours national de R\&D. Les étudiants participent également à plusieurs autres concours publics dans les domaines de la R\&D et de l'entrepreneuriat. Le SITI entretient des relations étroites et régulières avec plus de 30 institutions, parmi lesquelles des écoles, des universités, des entreprises innovantes, des centres technologiques, des pépinières d'entreprises, des associations professionnelles et des ministères. Le président du SITI, professeur d'informatique et d'économie, est l'initiateur et le moteur principal du projet. Il se consacre bénévolement au SITI. Il est assisté par un électricien local ainsi qu'un ingénieur et un enseignant, tous deux à la retraite. Depuis 2011, un assistant à temps partiel, dont le poste est financé par des fonds publics, s'occupe des tâches administratives pour le compte de l'équipe. L'institut occupe neuf salles du campus local, qui sont toutes équipées gracieusement en équipements technologiques et TIC de grande qualité. Le budget total annuel du SITI est d'environ 15000 EUR. Il est financé par différentes sources, dont le ministère de l'économie et le FSE.

Impact: une enquête officielle menée auprès des anciens élèves du SITI en 2013 révèle que près de $75 \%$ d'entre eux se sont tournés vers une carrière dans les domaines des technologies, des TIC et de l'entrepreneuriat. Pratiquement tous soulignent le fait que le SITI a vivement contribué à déceler, forger et encourager leur talent et leur choix de carrière.

Facteurs de réussite: ce projet montre que l'entrepreneuriat peut être introduit dans les écoles lorsque les élèves sont motivés et impliqués et peuvent compter sur des enseignants créatifs, capables d'accompagner et de former des enfants et des jeunes talentueux et enthousiastes de façon stimulante et avec des objectifs précis. La coopération à long terme avec des entreprises et d'autres partenaires qui partagent la même vision constitue un facteur de réussite important. 


\section{Données clés relatives à l'entrepreneuriat inclusif}

\section{Graphique 21.1. Données relatives à l'entrepreneuriat et au travail indépendant en Allemagne}

Diagramme A. Taux de chômage, 2000-2012

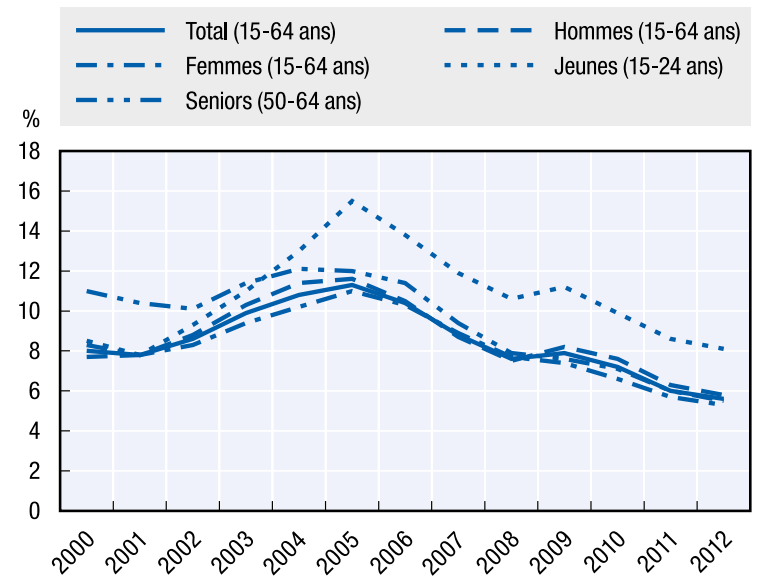

Diagramme C. Taux de travail indépendant, 2000-2012

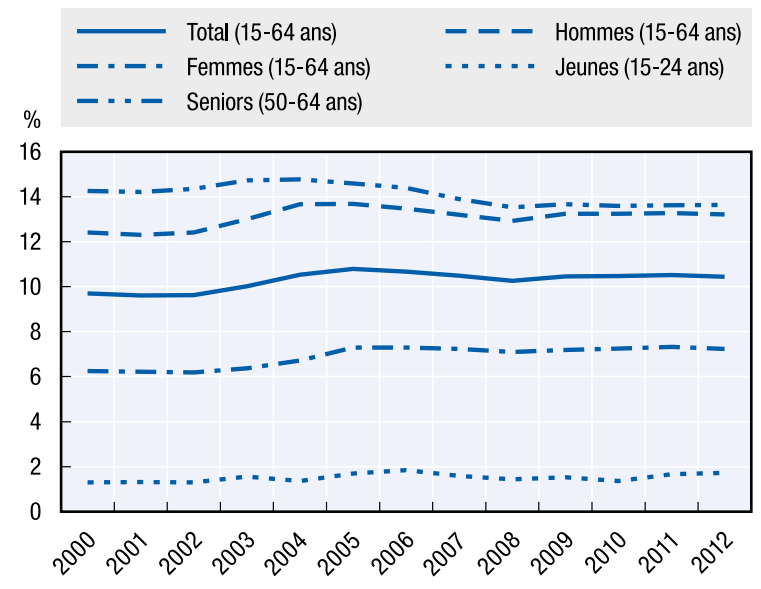

Diagramme E. Indice de l'activité entrepreneuriale totale au stade précoce, 2008-2012 (combinés)

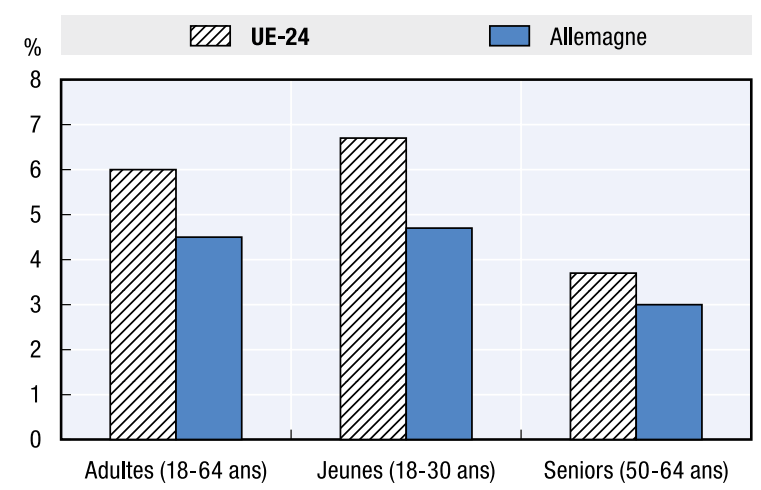

Diagramme B. Taux de travail indépendant, 2012

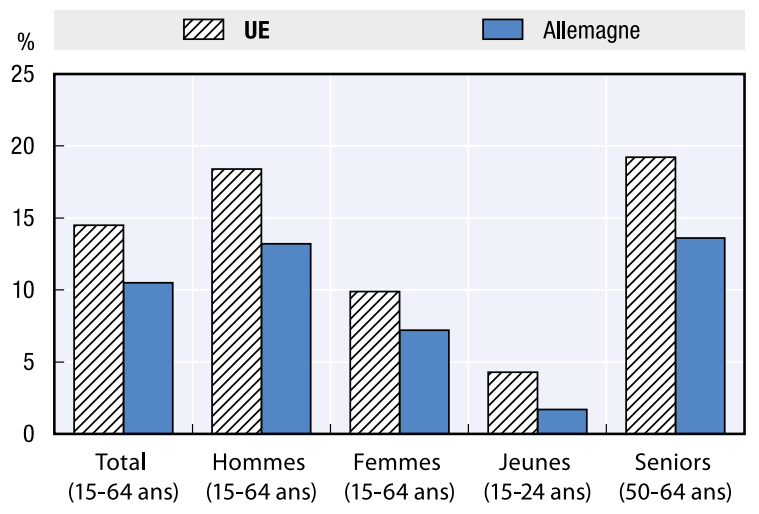

Diagramme D. Indice de l'activité entrepreneuriale totale au stade précoce, 2012

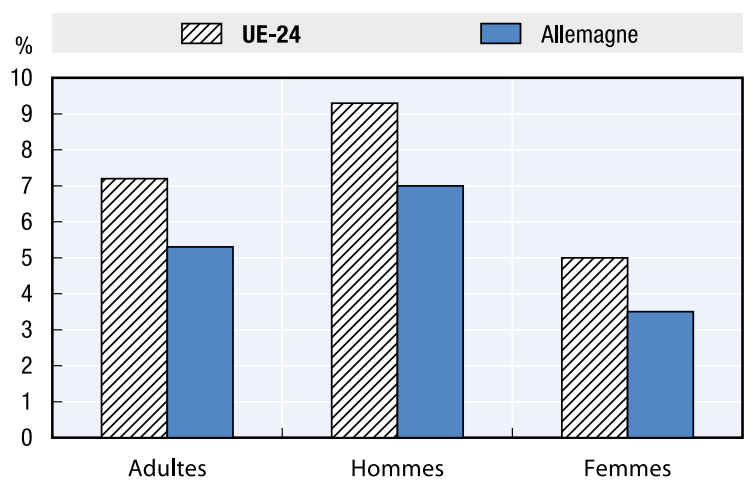

Sources: Diagramme A. Eurostat, Enquête sur les forces de travail, 2000-2012; Diagramme B. Eurostat, Enquête sur les forces de travail 2012; Diagramme C. Eurostat, Enquête sur les forces de travail, 2000-2012; Diagramme D. Présentation tabulaire spéciale de l'enquête sur la population adulte du Global Entrepreneurship Monitor, 2012; Diagramme E. Présentation tabulaire spéciale de l'enquête sur la population adulte du Global Entrepreneurship Monitor, 2008-2012. 


\section{Grèce: coopératives sociales à responsabilité limitée pour les personnes souffrant de problèmes de santé mentale}

Description: avec la mise en place en 1999 des coopératives sociales à responsabilité limitée (KoiSPE) en vertu de l'article 12 est née une forme particulière d'organisation coopérative (entreprise sociale), qui poursuit à la fois des buts économiques et sociaux. Elle vise à améliorer la réintégration socioéconomique et la réinsertion professionnelle des personnes souffrant de problèmes de santé mentale aux fins de leur réhabilitation et de leur autonomie économique.

Problème abordé: durant les années 1990, la Grèce a entamé un processus de désinstitutionalisation des grands hôpitaux psychiatriques, créant ainsi un besoin de services alternatifs pour les personnes souffrant de problèmes de santé mentale. Cette désinstitutionalisation a rendu la réintégration des patients sur le marché du travail particulièrement difficile.

Approche: les dispositions de l'article 12 de la loi grecque n² 2716/1999 ont été adoptées afin de favoriser la création d'activités alternatives offrant la possibilité aux personnes souffrant de problèmes de santé mentale d'avoir une activité professionnelle et de se réinsérer. Telle qu'elle est strictement définie par les dispositions juridiques applicables, une KoiSPE est un partenariat entre trois parties: (i) des personnes souffrant de problèmes de santé mentale (au moins $35 \%$ des membres de la coopérative); (ii) des professionnels de la santé mentale (au maximum $45 \%$ des membres); et, (iii) d'autres personnes et agences issues de la communauté locale (au maximum $20 \%$ des membres). Cette structure de partenariat évite de créer un environnement de travail «protégé» pour les bénéficiaires. À son adhésion, chaque membre reçoit une part de la coopérative, avec possibilité d'en obtenir davantage. Ces coopératives sociales permettent aux personnes souffrant de problèmes de santé mentale de retrouver des compétences et d'en acquérir de nouvelles grâce à des formations sur le terrain et à leur expérience professionnelle. Ils peuvent également apprendre à travailler en équipe et contribuer à la gestion des activités de la coopérative. Le fonctionnement des KoiSPE, y compris les salaires, est principalement financé par les ventes de produits et de services, mais également par les dons, les subventions publiques et les fonds de l'UE.

Impact: il existe actuellement 17 coopératives sociales à responsabilité limitée actives en Grèce. Elles ont développé un large éventail d'activités, dont la culture et le commerce de produits agricoles; des services de nettoyage; la transformation, le conditionnement et la commercialisation du miel; des services de remise en état et de protection de l'environnement; des services de restauration et de traiteur. Sur les 450 personnes actuellement engagées à temps plein dans ces activités, 330 souffrent de problèmes de santé mentale. En outre, environ 100 personnes également atteintes de troubles mentaux travaillent au sein des coopératives à temps partiel. Malgré les emplois créés pour ces travailleurs, une évaluation révèle que les membres de ces coopératives n'ont pas suffisamment de compétences en gestion et d'expérience. Les difficultés de fonctionnement qui en résultent affectent la viabilité financière des coopératives (Ziomas et Vezyrianni, 2010).

Facteurs de réussite: la création d'entreprises sociales a besoin d'un cadre législatif clair. La participation active des acteurs sociopolitiques locaux, notamment des organisations professionnelles et des entreprises locales, semble avoir favorisé la résistance des coopératives durant la récente crise économique, bien qu'elles continuent de rencontrer des problèmes majeurs qui nécessiteront probablement de nouvelles interventions politiques publiques. Le succès à long terme de ces coopératives dépend des ressources financières disponibles (p.ex. mise en place d'outils financiers de substitution et adoption de dispositions particulières en matière de marchés publics). 


\section{Données clés relatives à l'entrepreneuriat inclusif}

\section{Graphique 22.1. Données relatives à l'entrepreneuriat et au travail indépendant en Grèce}

Diagramme A. Taux de chômage, 2000-2012

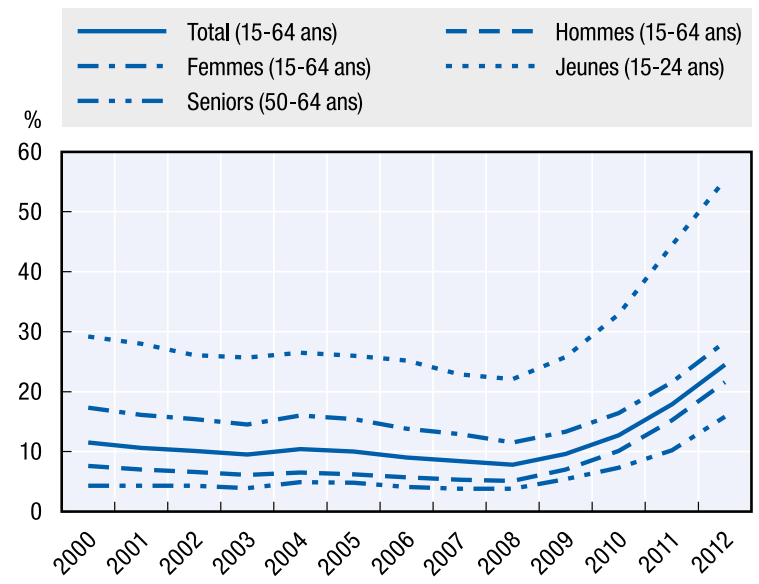

Diagramme C. Taux de travail indépendant, 2000-2012

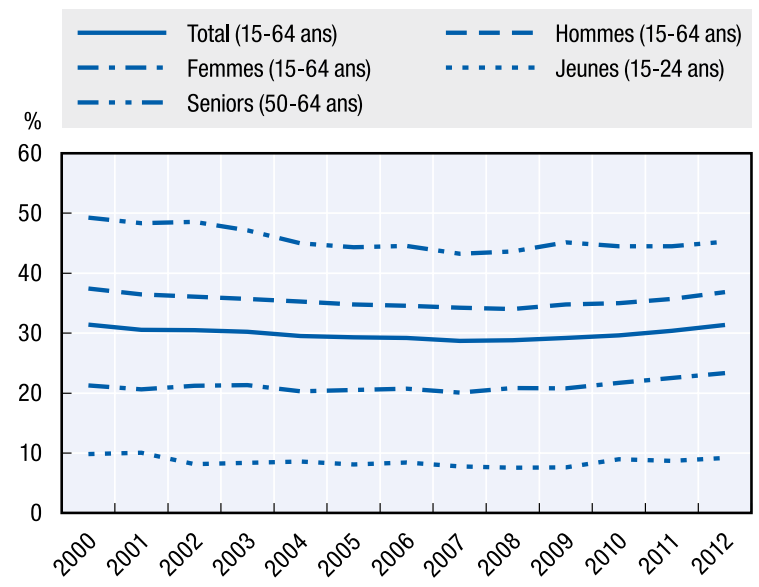

Diagramme $\mathrm{E}$. Indice de l'activité entrepreneuriale totale au stade précoce, 2008-2012 (combinés)

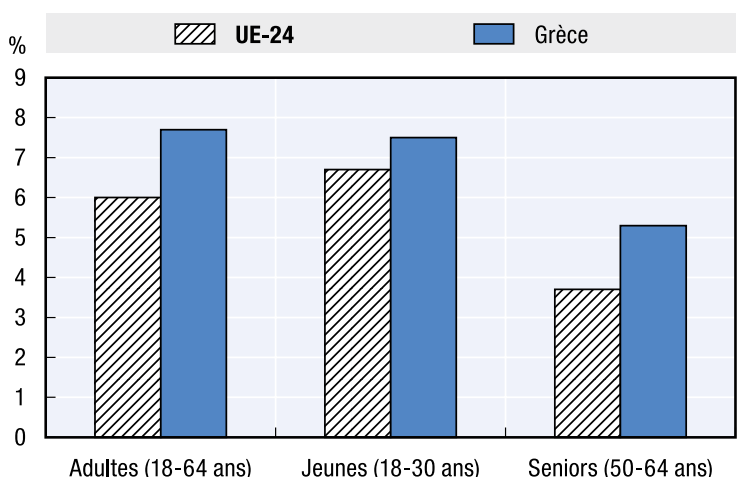

Diagramme B. Taux de travail indépendant, 2012

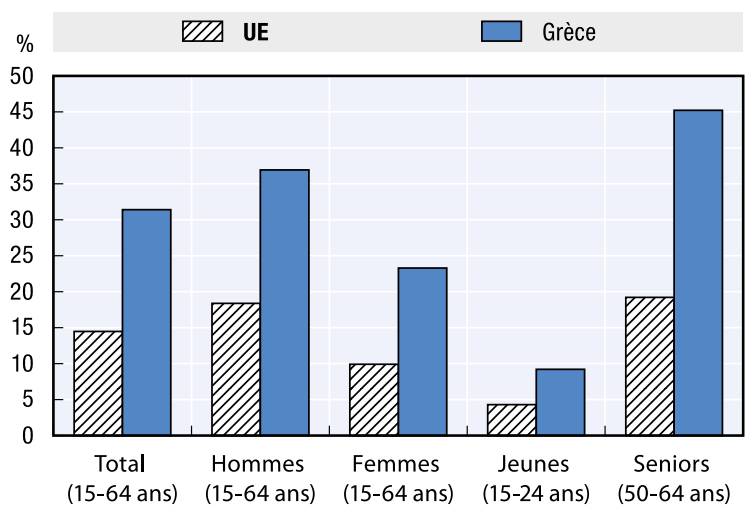

Diagramme D. Indice de l'activité entrepreneuriale totale au stade précoce, 2012

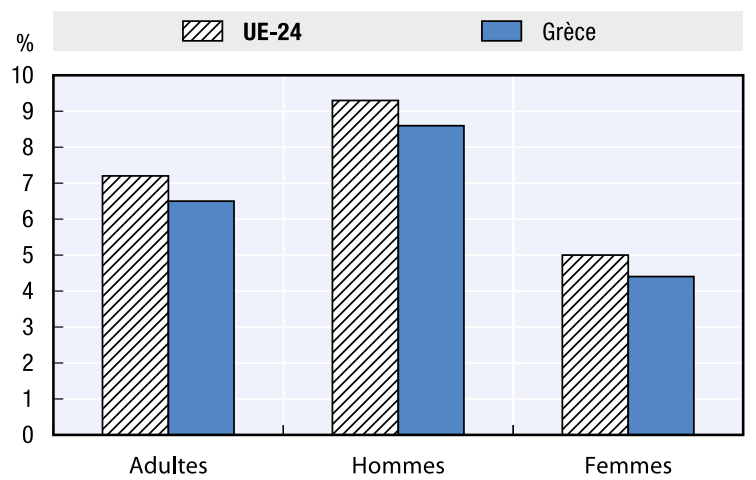

Sources: Diagramme A. Eurostat, Enquête sur les forces de travail, 2000-2012; Diagramme B. Eurostat, Enquête sur les forces de travail 2012; Diagramme C. Eurostat, Enquête sur les forces de travail, 2000-2012; Diagramme D. Présentation tabulaire spéciale de l'enquête sur la population adulte du Global Entrepreneurship Monitor, 2012; Diagramme E. Présentation tabulaire spéciale de l'enquête sur la population adulte du Global Entrepreneurship Monitor, 2008-2012. 


\section{Hongrie: programme MeXX, 2004-2009}

Description: le principal objectif du programme MeXX était d'aider les femmes sans emploi à entrer sur le marché du travail par le biais du travail indépendant et de soutenir les femmes chefs d'entreprise déjà établies. Le programme ciblait plus particulièrement les mères d'enfants en bas âge à charge ou en congé de maternité, les femmes enceintes et les femmes de plus de 40 ans. Le programme prévoyait un ensemble complet de mesures d'aide comprenant des services de formation, de mentorat par les pairs ou de conseil. Ces différentes composantes étaient destinées à stimuler la confiance en soi de ces femmes et à soutenir le développement de leurs compétences en communication et en entreprise.

Problème abordé: le taux d'emploi des femmes hongroises est parmi les plus bas de l'UE ( $56 \%$ en 2012). Des études indiquent que le faible taux de participation des femmes s'explique notamment par le manque d'emplois à temps partiel, l'écart salarial important entre les hommes et les femmes, l'accès limité aux services de garde d'enfants, des prestations de maternité relativement généreuses et la discrimination (Institut de Budapest, 2008; Lovász, 2012; Köllö, 2012). Les comportements sociaux à l'égard des rôles de genre ont tendance à avoir des répercussions négatives sur la poursuite de la carrière, en particulier dans le cas des femmes avec enfants (Nagy, 2006; Commission européenne, 2013a; SEED, 2007).

Approche: le programme débutait par un cours de formation de 12 jours à Budapest, organisé sous la forme de modules thématiques de deux jours étalés sur six semaines. Le premier module, consacré à la motivation, mettait l'accent sur la réflexion proactive, la prise de décision autonome et la gestion du risque. Les modules suivants abordaient les compétences en gestion d'entreprise et faisaient appel à des méthodes d'enseignement interactives incluant des présentations, du travail individuel et en équipe, des discussions de groupe et des jeux de rôle. L'apprentissage par les pairs occupait une place centrale dans cette approche. Les participantes ont pu également bénéficier gracieusement de conseils personnalisés afin de soutenir la création et le développement de leur entreprise pendant ou après les sessions de formation. Enfin, les gestionnaires du programme les informaient sur le développement d'entreprise par le biais de lettres d'information, d'un forum en ligne et d'un blog.

Impact: environ 250 femmes ont pris part au projet entre 2003 et 2009. Les activités de suivi ont, quant à elles, concerné 172 bénéficiaires. D'après les données de suivi, $37 \%$ des participantes étaient âgées de plus de 45 ans, 21\% avaient des enfants en bas âge à leur charge et $13 \%$ avaient une famille nombreuse au moment de s'engager dans le programme.

Facteurs de réussite: il ressort de l'expérience du programme qu'une longue phase pilote est nécessaire pour offrir un soutien adapté aux bénéficiaires. Le suivi est important pour fournir un soutien individualisé. 


\section{Données clés relatives à l'entrepreneuriat inclusif}

\section{Graphique 23.1. Données relatives à l'entrepreneuriat et au travail indépendant en Hongrie}

Diagramme A. Taux de chômage, 2000-2012

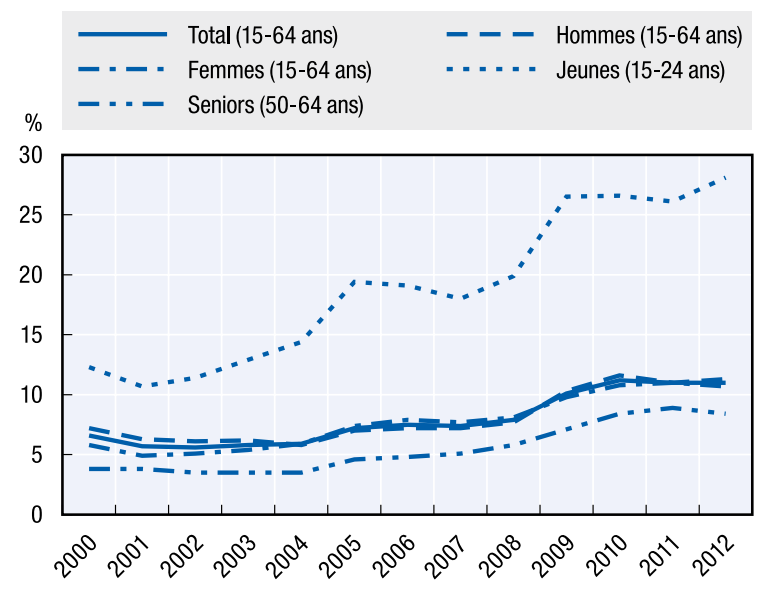

Diagramme C. Taux de travail indépendant, 2000-2012

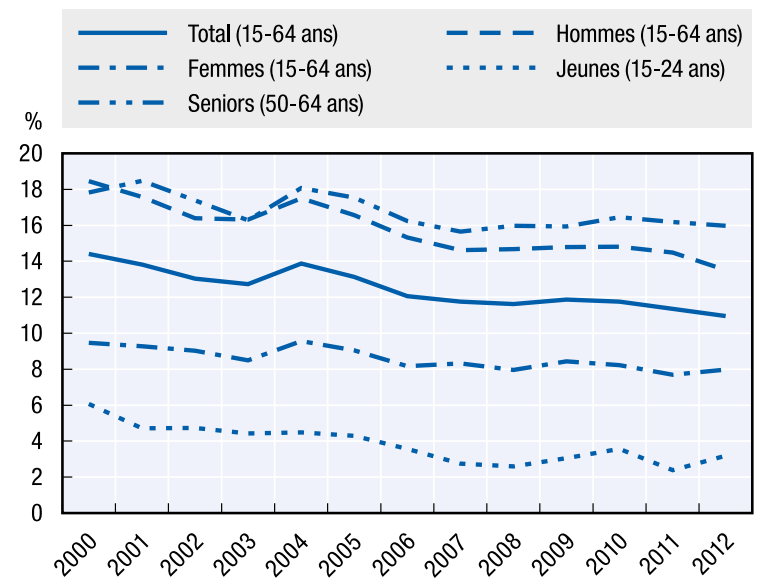

Diagramme E. Indice de l'activité entrepreneuriale totale au stade précoce, 2008-2012 (combinés)

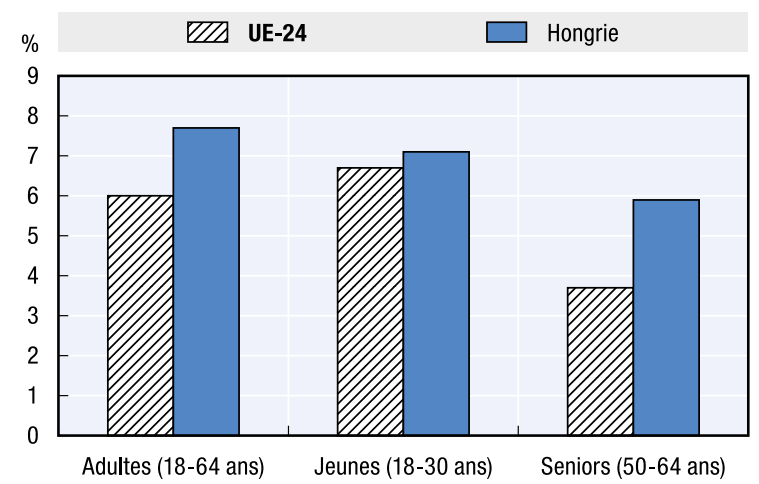

Diagramme B. Taux de travail indépendant, 2012

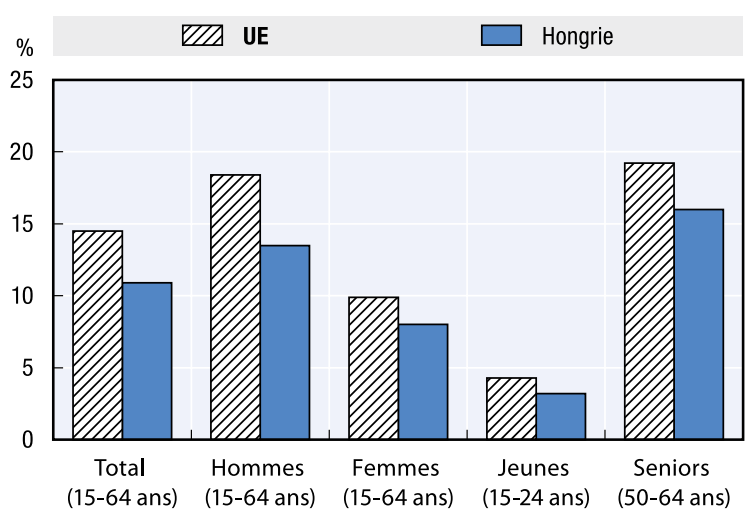

Diagramme D. Indice de l'activité entrepreneuriale totale au stade précoce, 2012

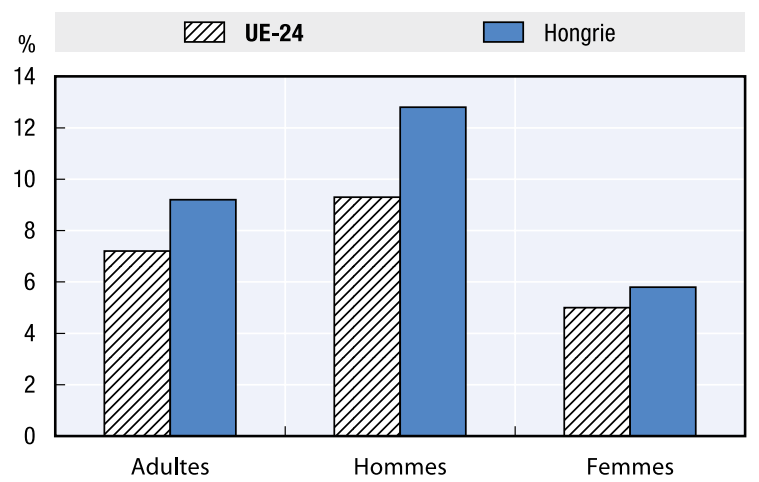

Sources: Diagramme A. Eurostat, Enquête sur les forces de travail, 2000-2012; Diagramme B. Eurostat, Enquête sur les forces de travail 2012; Diagramme C. Eurostat, Enquête sur les forces de travail, 2000-2012; Diagramme D. Présentation tabulaire spéciale de l'enquête sur la population adulte du Global Entrepreneurship Monitor, 2012; Diagramme E. Présentation tabulaire spéciale de l'enquête sur la population adulte du Global Entrepreneurship Monitor, 2008-2012. 


\section{Irlande: National Women's Enterprise Day}

Description: le National Women's Enterprise Day est un événement annuel. Il est organisé depuis 2008 par les 35 CEB (City and Country Enterprise Board, conseil d'entreprise des villes et comtés) et cofinancé par le Fonds social européen (FSE), avec le soutien du ministère de la justice et de l'égalité. Le but est d'encourager les femmes chefs d'entreprise et de les aider à développer leurs réseaux et à améliorer leurs compétences.

Problème abordé: les données collectées suggèrent que les hommes sont près de trois fois plus susceptibles que les femmes de se lancer dans la création d'une entreprise en Irlande. Le gouvernement a donc chargé ses agences de développement de différencier l'aide à la création d'entreprise en fonction du sexe. Les recommandations faites au gouvernement en 2006 (Small Business Forum, 2006) soutiennent l'idée que les femmes entrepreneurs devraient occuper une place centrale dans la politique nationale d'aide aux PME. Un appel à manifestations d'intérêt a été lancé en 2007 en vue d'organiser un événement national à l'attention des femmes du monde des affaires destiné à les accompagner dans la création et le développement de leur entreprise et à encourager les bonnes pratiques de mise en réseau.

Approche: le National Women's Enterprise Day est un événement national de deux jours, organisé par les CEB. Il s'articule autour d'une conférence qui présente des modèles, les aides publiques pour les entreprises, les opportunités de mise en réseau et des activités de mentorat en face-à-face. Les visiteurs peuvent ainsi s'informer sur la création et l'expansion des entreprises. Le but est de les stimuler, de les informer et de les motiver à exploiter pleinement leur potentiel en tant qu'entrepreneurs. Pour accroître son impact, l'événement s'appuie sur une grande campagne médiatique qui met en exergue les réalisations de femmes chefs d'entreprise et le potentiel entrepreneurial des femmes.

Impact: l'édition 2012 a réuni plus de 250 femmes entrepreneurs, qui ont pu s'informer et développer leur réseau plus qu'elles ne l'auraient fait dans leur localité. Les campagnes médiatiques de promotion de l'entrepreneuriat féminin ont une portée beaucoup plus large lorsqu'elles sont relayées par les journaux et la chaîne de télévision nationale RTÉ One. Selon les estimations, elles ont pu atteindre près de 2 millions de personnes entre juillet et octobre 2013.

Facteurs de réussite: le succès de l'événement repose en grande partie sur son appellation. Son nom indique clairement la finalité poursuivie et ce message simple a été essentiel dans la couverture médiatique. Les médias font non seulement la promotion de la manifestation, mais ils diffusent également son message auprès d'un public bien plus large afin d'influer positivement sur les comportements sociaux à l'égard de l'entrepreneuriat des femmes. Le contenu de l'événement joue également un rôle important dans l'information et le soutien des femmes entrepreneurs. 


\section{Données clés relatives à l'entrepreneuriat inclusif}

\section{Graphique 24.1. Données relatives à l'entrepreneuriat et au travail indépendant en Irlande}

\section{Diagramme A. Taux de chômage, 2000-2012}

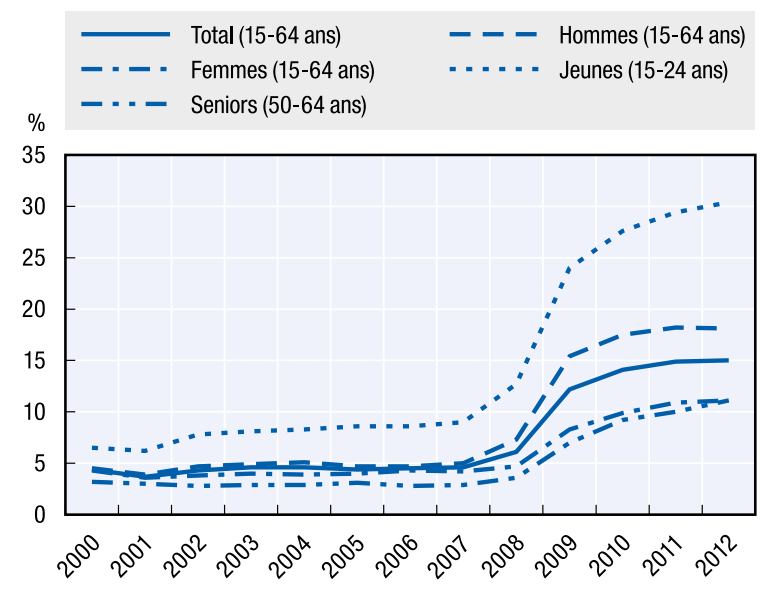

Diagramme C. Taux de travail indépendant, 2000-2012

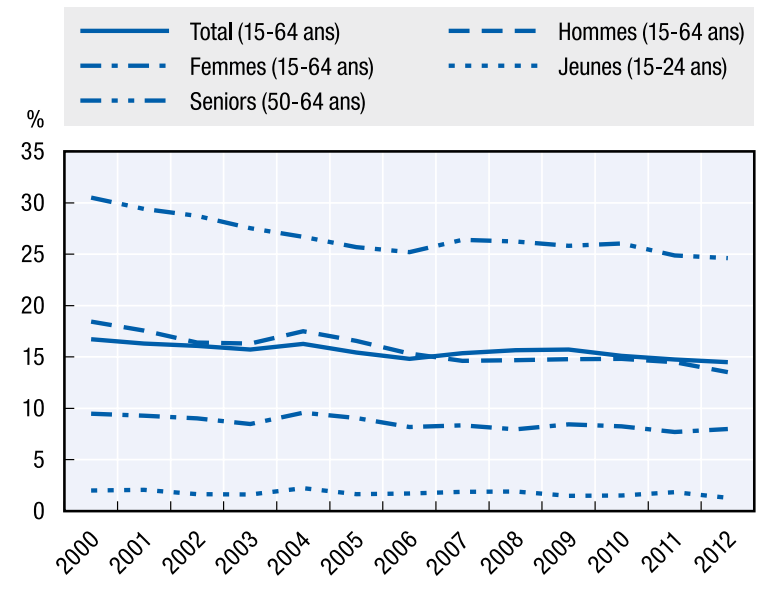

Diagramme E. Indice de l'activité entrepreneuriale totale au stade précoce, 2008-2012 (combinés)

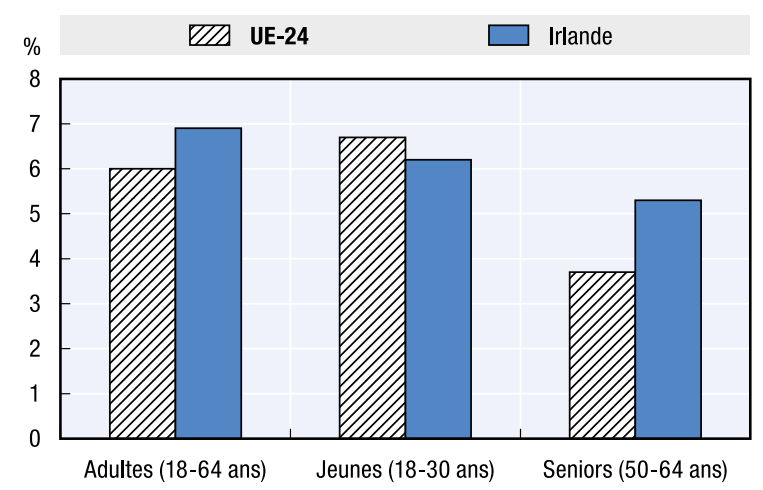

Diagramme B. Taux de travail indépendant, 2012

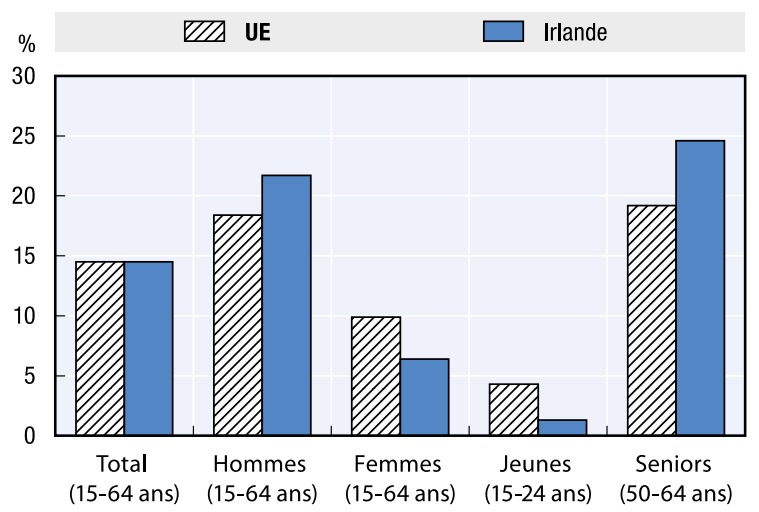

Diagramme D. Indice de l'activité entrepreneuriale totale au stade précoce, 2012

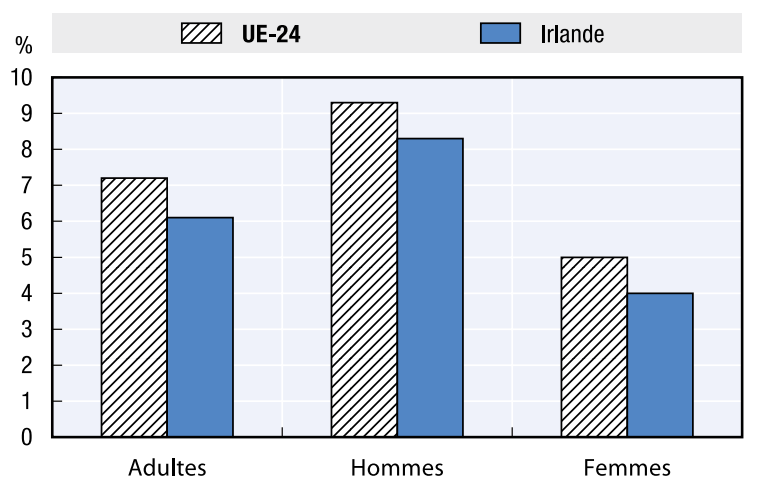

Sources: Diagramme A. Eurostat, Enquête sur les forces de travail, 2000-2012; Diagramme B. Eurostat, Enquête sur les forces de travail 2012; Diagramme C. Eurostat, Enquête sur les forces de travail, 2000-2012; Diagramme D. Présentation tabulaire spéciale de l'enquête sur la population adulte du Global Entrepreneurship Monitor, 2012; Diagramme E. Présentation tabulaire spéciale de l'enquête sur la population adulte du Global Entrepreneurship Monitor, 2008-2012. 


\section{Italie: Programme Starting a Business (dans le cadre de la stratégie Giovanisì en Toscane)}

Description: en 2011, le gouvernement régional de Toscane a mis en place une stratégie intégrée visant à améliorerl'entrée de jeunes sur le marché du travail.Cette stratégie, baptisée Giovanisì, vise à répondre aux défis à court terme posés par la récente crise économique et aux enjeux à plus long terme sur le plan démoGraphique et du développement. Ses quatre cibles prioritaires sont les étudiants; les diplômés de l'enseignement supérieur et les chercheurs; les jeunes qui ne sont pas scolarisés, n'exercent aucun emploi et ne suivent aucune formation (les NEET); et les entrepreneurs potentiels. Les mesures de promotion de l'entrepreneuriat mises en œuvre dans le cadre de la stratégie Giovanisì font l'objet d'un programme intitulé Starting a Business.

Problème abordé: le taux de chômage des jeunes a rapidement augmenté ces cinq dernières années en Toscane (passant de $13,7 \%$ à $28,9 \%$ en 2012). La crise qui a frappé les bassins industriels, historiquement très importants dans la région, a aggravé la récession. Les jeunes sont particulièrement frappés. Ils ne parviennent pas à accumuler un capital de départ suffisant et que leur accès au crédit est très limité (GfK, 2012).

Approche: le programme Starting a Business soutient les activités qui ne le sont pas par les banques. L'aide s'adresse à toutes les entreprises toscanes, quelle que soit leur forme juridique ou leur taille. Les candidats doivent être âgés de 18 à 40 ans, à l'exception des femmes et des salariés licenciés. Le programme s'appuie sur une récente loi régionale sur l'entrepreneuriat des jeunes et des femmes (legge regionale $\left.n^{\circ} 28,11.7 .2011\right)$. En vertu de cette loi, une société à responsabilité limitée (Fidi Toscana) évalue les demandes de financement, puis le programme Starting a Business alloue l'aide de trois façons. Premièrement, le soutien prend la forme d'une garantie de prêt, de subventions ou de fonds d'amorçage. Les garanties couvrent jusqu'à $80 \%$ du capital de départ total et les subventions jusqu'à $50 \%$ des coûts d'intérêt pour un montant maximal de 50000 EUR. Le programme alloue également jusqu'à 10000 EUR pour l'acquisition temporaire d'actions minoritaires dans de nouvelles entreprises innovantes. Celles-ci peuvent être détenues pendant une période maximale de sept ans. Deuxièmement, 21 bureaux d'information territoriaux ont ouvert leurs portes dans toute la Toscane afin d'informer, d'accompagner et d'impliquer les jeunes dans les différentes activités du programme. Un portail en ligne a par ailleurs été mis en place afin de leur fournir des informations et une assistance générale en matière d'entreprise. Troisièmement, le programme interagit avec le guichet unique pour les jeunes de Fidi Toscana (Fidi Toscana Giovani). Les jeunes candidats bénéficient d'un accompagnement et de conseils, notamment à travers un portail en ligne et 8 succursales dans la région. Au total, 12,5 millions EUR ont été investis dans le programme Starting a Business.

Impact: en septembre 2013, 1300 projets avaient été évalués dans le cadre de la loi 28-2011 et 884 d'entre eux avaient été financés. Toutefois, le nombre de subventions (et non les instruments financiers tels que les garanties ou les participations au capital qui peuvent être remboursées) est actuellement revu à la baisse afin d'accroître la viabilité financière du projet.

Facteurs de réussite: la principale innovation de Giovanisì a été de définir une stratégie intégrée pour répondre aux difficultés rencontrées par les jeunes. Le guichet unique renforce la responsabilité des acteurs non institutionnels (jeunes) dans le cadre du projet, ainsi que leur capacité à influer sur les politiques. En outre, il rend la communication plus efficace et simplifie l'accès des bénéficiaires potentiels, deux facteurs essentiels pour un ensemble de mesures qui s'adresse aussi à des sujets marginalisés tels que les NEET. 


\section{Données clés relatives à l'entrepreneuriat inclusif}

\section{Graphique 25.1. Données relatives à l'entrepreneuriat et au travail indépendant en Italie}

Diagramme A. Taux de chômage, 2000-2012

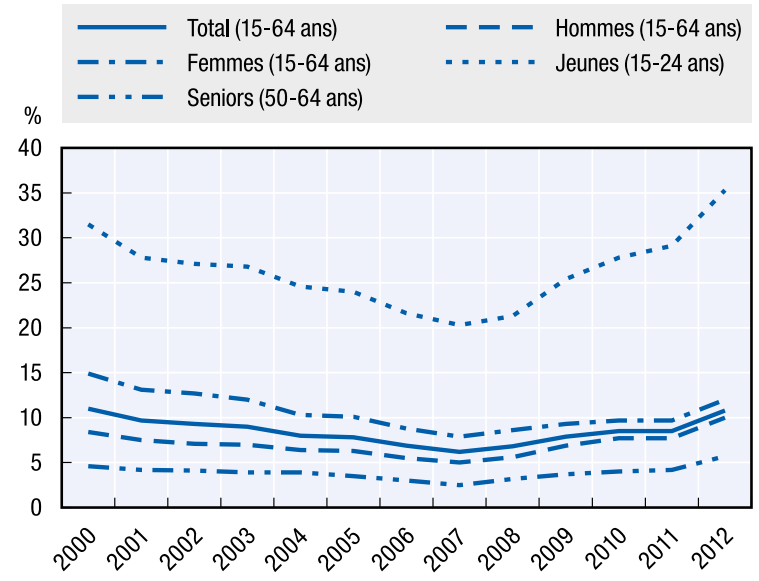

Diagramme C. Taux de travail indépendant, 2000-2012

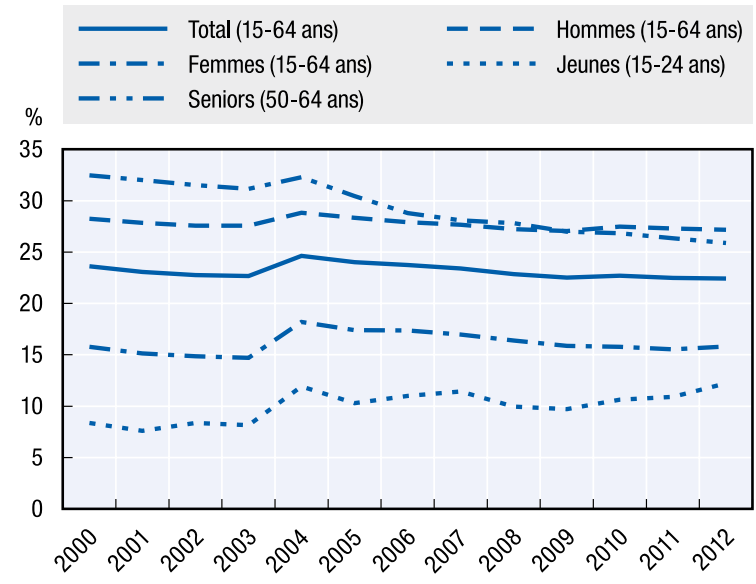

Diagramme E. Indice de l'activité entrepreneuriale totale au stade précoce, 2008-2012 (combinés)

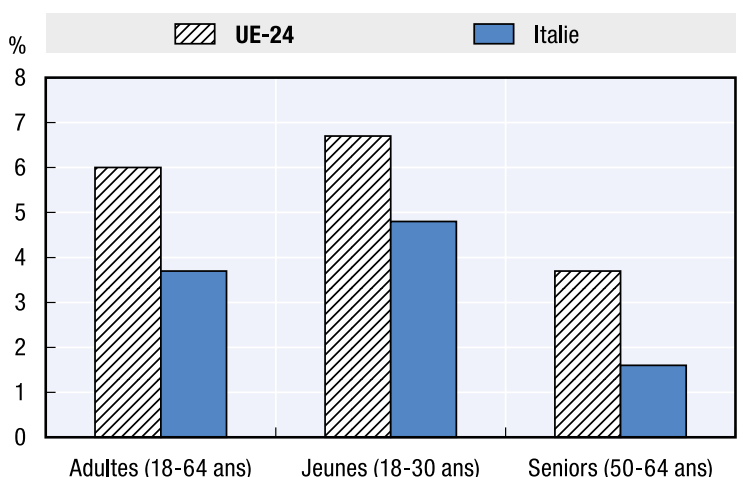

Diagramme B. Taux de travail indépendant, 2012

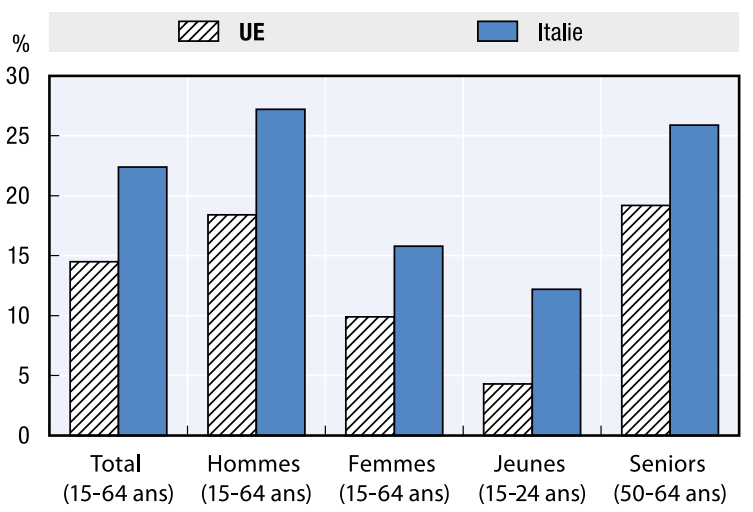

Diagramme D. Indice de l'activité entrepreneuriale totale au stade précoce, 2012

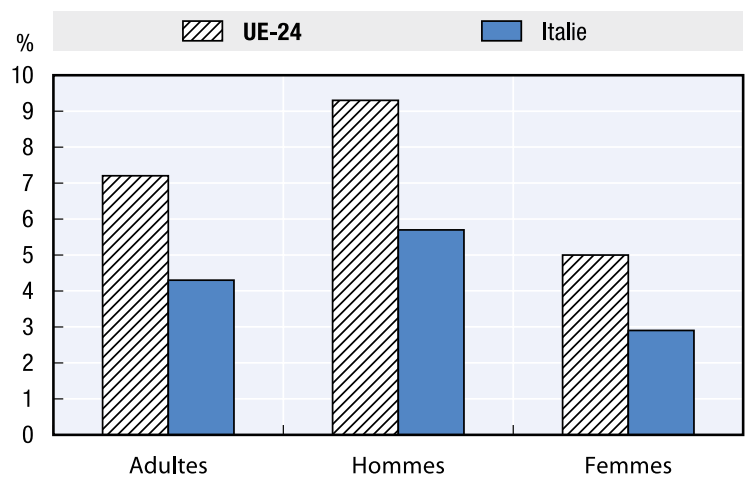

Sources: Diagramme A. Eurostat, Enquête sur les forces de travail, 2000-2012; Diagramme B. Eurostat, Enquête sur les forces de travail 2012; Diagramme C. Eurostat, Enquête sur les forces de travail, 2000-2012; Diagramme D. Présentation tabulaire spéciale de l'enquête sur la population adulte du Global Entrepreneurship Monitor, 2012; Diagramme E. Présentation tabulaire spéciale de l'enquête sur la population adulte du Global Entrepreneurship Monitor, 2008-2012. 


\section{Lettonie: Business incubators in the Latvian regions}

Description: le programme «Business incubators in the Latvian regions» soutient la création de pépinières d'entreprises dans les régions rurales et défavorisées dans le but d'aider les entrepreneurs à créer et développer leur entreprise. Cette mesure vise à stimuler le développement économique des régions lettones en dehors de Riga. Ces pépinières proposent aux sociétés des services d'aide au développement des entreprises et des installations/équipements à tarifs réduits au stade précoce de leur évolution.

Problème abordé: les régions lettones situées en dehors de Riga sont à la traîne en termes d'attraction des investissements et de création d'emplois (cabinet des ministres, 2012). Les nouvelles entreprises y sont aussi moins nombreuses et leurs taux de survie sont inférieurs. Parmi les obstacles des entreprises figurent les faibles compétences en gestion et la difficulté à attirer des ressources financières, dont les effets sont beaucoup plus marqués dans les régions rurales et sous-développées.

Approche: le projet est géré conjointement par le ministère letton de l'économie et l'Agence lettone d'investissement et de développement. Les nouvelles entreprises déposent une demande d'aide, puis sont sélectionnées en fonction de la faisabilité de leur projet. Elles peuvent bénéficier d'un soutien pendant une durée maximale de quatre ans. Tous les secteurs bénéficient d'un soutien, à l'exception de l'agriculture, de l'intermédiation financière, des transports et de l'industrie du tabac et de l'alcool. Les services des pépinières comprennent la location de locaux à bas prix, des services de communication (p.ex. internet, téléphone), un service de conseil en entreprise à prix réduit (p.ex. élaboration du plan d'affaires, comptabilité, recherche de financements, ventes et marketing, services juridiques), des services de mise en réseau aux niveaux local et international et une aide pour le recrutement du personnel. Durant la première année au sein de la pépinière, 80 $85 \%$ du coût des services sont pris en charge par le programme. Cette couverture passe à $55-60 \%$ la deuxième année, puis 35-40\% la troisième année et 10\% la quatrième année. Certaines pépinières aident aussi les entreprises extérieures. Le budget total de ce projet s'élève à un peu plus de 20 millions LVL (environ 28 millions EUR). Le Fonds européen de développement régional (FEDER) le finance à hauteur de $85 \%$. Les $15 \%$ restants proviennent du budget de l'État. Les cinq régions lettones sont financées à parts égales. Le programme s'est achevé fin 2014.

Impact: au premier trimestre 2013, 9 pépinières d'entreprises étaient en activité dans 22 villes. Celles-ci ont soutenu 513 entreprises et créé 1077 emplois dans les différentes régions.

Facteurs de réussite: le programme met en évidence le rôle des pépinières dans la promotion de l'entrepreneuriat régional. La suppression progressive de l'aide financière permettra d'assurer la viabilité à long terme des entreprises soutenues. 


\section{Données clés relatives à l'entrepreneuriat inclusif}

\section{Graphique 26.1. Données relatives à l'entrepreneuriat et au travail indépendant en Lettonie}

Diagramme A. Taux de chômage, 2000-2012

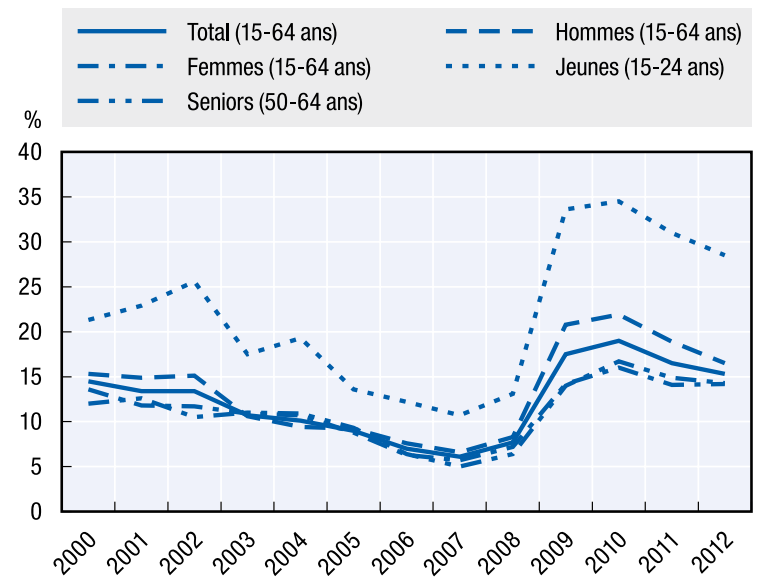

Diagramme C. Taux de travail indépendant, 2000-2012

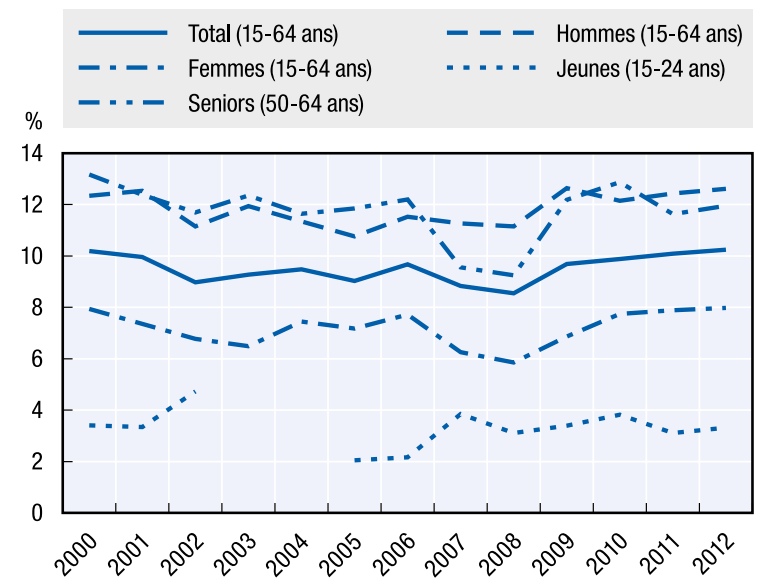

Diagramme E. Indice de l'activité entrepreneuriale totale au stade précoce, 2008-2012 (combinés)

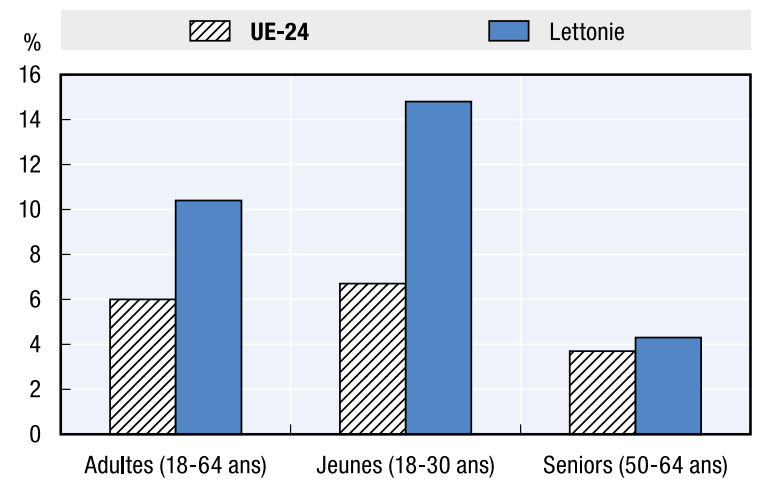

Diagramme B. Taux de travail indépendant, 2012

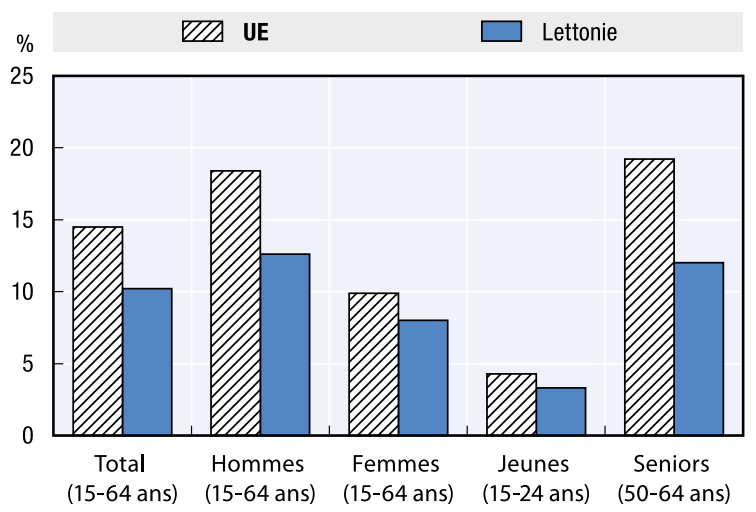

Diagramme D. Indice de l'activité entrepreneuriale totale au stade précoce, 2012

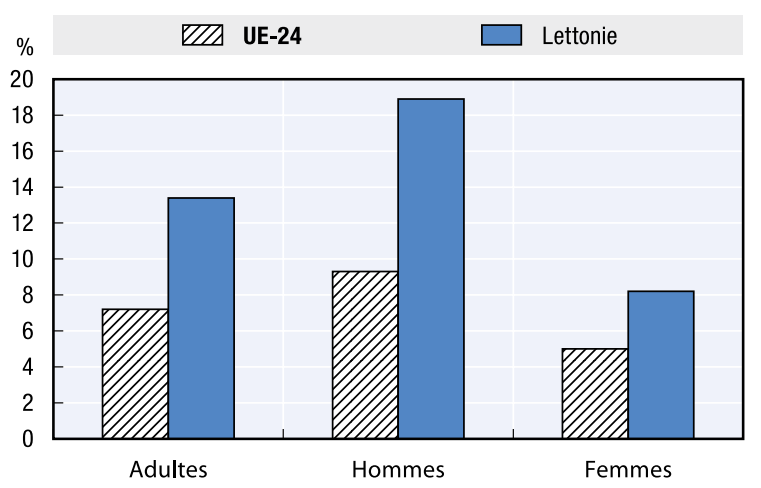

Sources: Diagramme A. Eurostat, Enquête sur les forces de travail, 2000-2012; Diagramme B. Eurostat, Enquête sur les forces de travail 2012; Diagramme C. Eurostat, Enquête sur les forces de travail, 2000-2012; Diagramme D. Présentation tabulaire spéciale de l'enquête sur la population adulte du Global Entrepreneurship Monitor, 2012; Diagramme E. Présentation tabulaire spéciale de l'enquête sur la population adulte du Global Entrepreneurship Monitor, 2008-2012. 


\section{Lituanie: First business year baskets for youth}

Description: le projet «First business year baskets» a été mené en Lituanie de mai 2011 à juillet 2013 afin d'aider les personnes de moins de 29 ans à créer des entreprises. Les participants pouvaient «acheter» ses différents services d'aide au développement des entreprises à l'aide des chèques reçus.

Problème abordé: ces dernières années, le taux de chômage des jeunes Lituaniens a été l'un des plus élevés de l'Union européenne, passant de 25 à 30\% entre 2009 et 2012. De nombreuses mesures ont été mises en œuvre pour lutter contre le chômage des jeunes, y compris la promotion de l'entrepreneuriat. Des données collectées témoignent de l'intérêt croissant des jeunes pour l'entrepreneuriat (GEM, 2012). Un projet qui proposait des chèques création d'entreprise aux jeunes a donc été renouvelé afin de renforcer leur confiance en eux et leurs compétences entrepreneuriales.

Approche: le projet est exécuté par Versli Lietuva (Lituanie Entreprise), une agence à but non lucratif sous la responsabilité du ministère de l'économie. Les chèques sont distribués aux personnes de moins de 29 ans présentes lors des événements de promotion de l'entrepreneuriat organisés par Versli Lietuva. Chaque personne reçoit un seul chèque qu'elle peut utiliser pour «acheter» des services publics d'aide au développement des entreprises auprès des prestataires désignés pour un montant maximal de 6000 LTL (environ 1740 EUR). Pour utiliser son chèque, le jeune entrepreneur doit créer et enregistrer une entreprise à but lucratif dans un délai de six mois à compter de la réception de celui-ci. Les services peuvent être "achetés» au cours des 12 premiers mois suivant l'immatriculation de la société. Le chèque donne droit à des consultations avant (4 heures) et après ( 50 heures) le démarrage de l'activité ainsi qu'à une formation post-création (24 heures). Les consultations préalables à la création incluent des conseils sur la forme juridique de l'entreprise et une assistance en matière d'immatriculation. Les services de consultation portent sur la tenue des livres et la comptabilité, le droit du travail, la sécurité au travail, la tenue des documents comptables, les passations de marchés, les licences et permis, le financement des entreprises, le statut du personnel, la publicité et les offres commerciales. La formation couvre le financement des entreprises, le marketing, la planification des activités, la négociation, la gestion stratégique, le droit du travail, la sécurité au travail ainsi que les questions contractuelles. Le budget de ce projet s'élevait à 1,5 million LTL (environ 435000 EUR) sur deux ans (20052007), avec le soutien du Fonds social européen (FSE).

Impact: de mai 2011 à juillet 2013, plus de 5000 chèques ont été distribués. Environ un tiers d'entre eux ont été utilisés pour créer une entreprise. Selon Versli Lietuva, 98,9\% des entreprises créées à l'aide de ces chèques ont survécu pendant au moins un an et un jour. À titre de comparaison, en 2012, le taux de survie n'était que de $63,3 \%$ en moyenne pour l'ensemble de la Lituanie.

Facteurs de réussite: le programme met en avant le rôle des chèques en tant que soutien flexible et orienté vers la demande. L'approche, qui consiste à identifier les besoins spécifiques et à fournir un soutien sur mesure, est bien établie et pourrait être appliquée à d'autres groupes défavorisés. 


\section{Données clés relatives à l'entrepreneuriat inclusif}

\section{Graphique 27.1. Données relatives à l'entrepreneuriat et au travail indépendant en Lituanie}

Diagramme A. Taux de chômage, 2000-2012

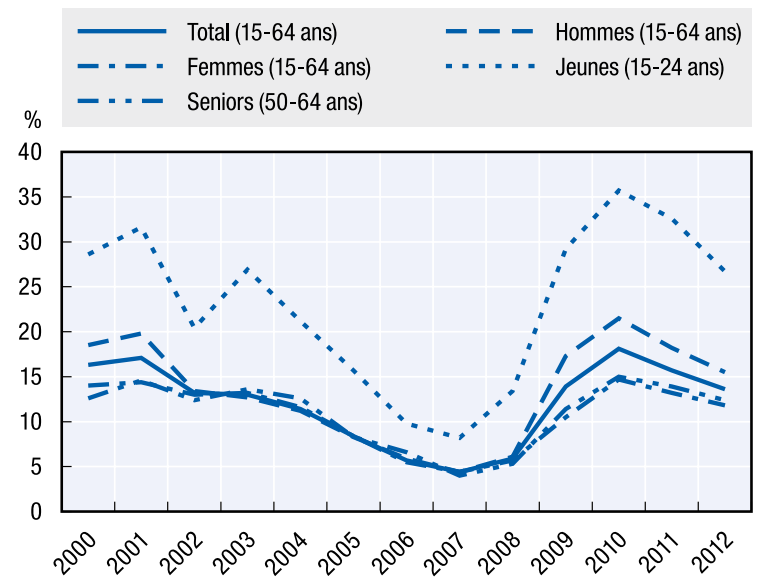

Diagramme C. Taux de travail indépendant, 2000-2012

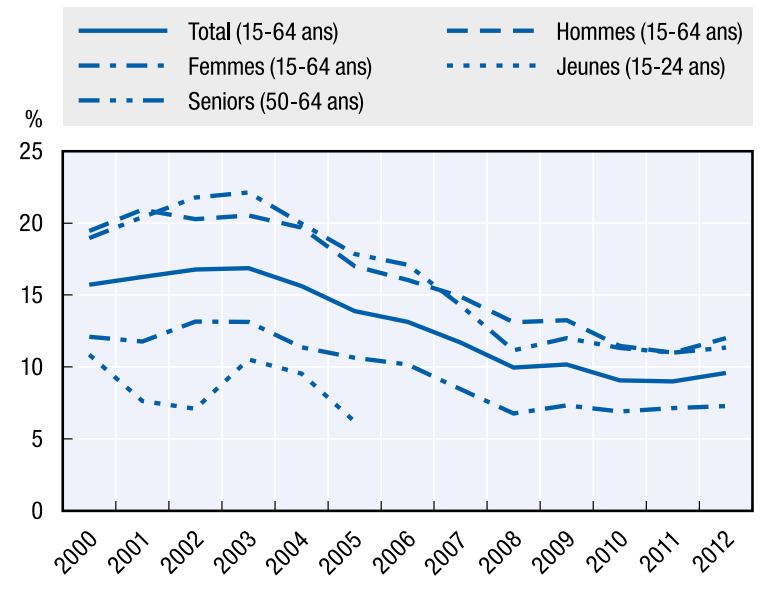

Diagramme E. Indice de l'activité entrepreneuriale totale au stade précoce, 2008-2012 (combinés)

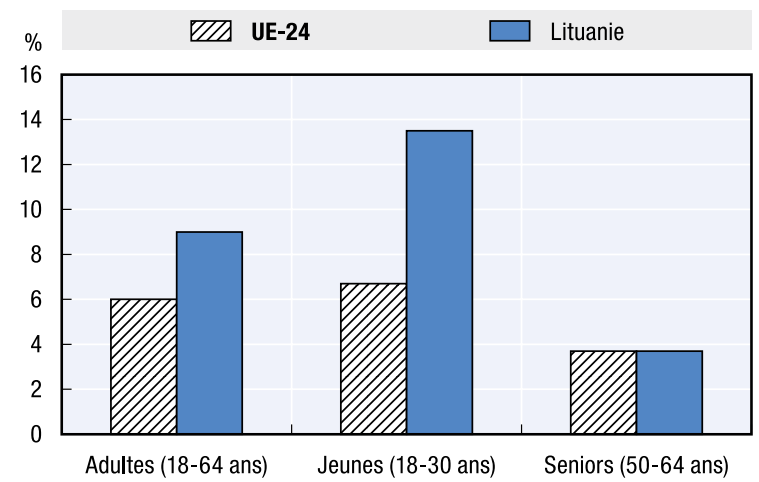

Diagramme B. Taux de travail indépendant, 2012

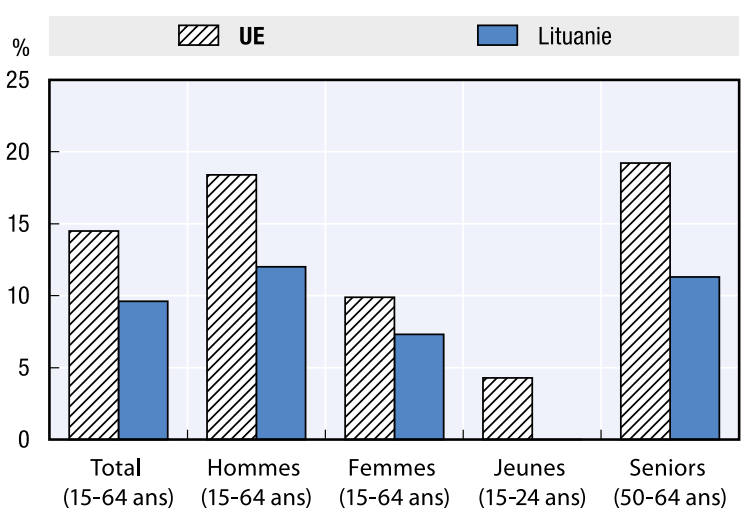

Diagramme D. Indice de l'activité entrepreneuriale totale au stade précoce, 2012

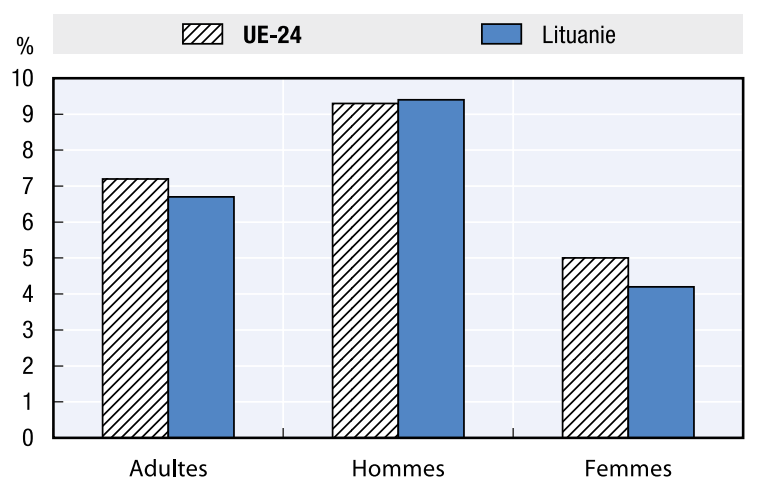

Sources: Diagramme A. Eurostat, Enquête sur les forces de travail, 2000-2012; Diagramme B. Eurostat, Enquête sur les forces de travail 2012; Diagramme C. Eurostat, Enquête sur les forces de travail, 2000-2012; Diagramme D. Présentation tabulaire spéciale de l'enquête sur la population adulte du Global Entrepreneurship Monitor, 2012; Diagramme E. Présentation tabulaire spéciale de l'enquête sur la population adulte du Global Entrepreneurship Monitor, 2008-2012. 


\section{Luxembourg: Jonk Entrepreneuren Luxembourg}

Description: l'initiative publique-privée Jonk Entrepreneuren Luxembourg (jeunes entrepreneurs du Luxembourg) vise à éveiller l'intérêt des étudiants pour l'entrepreneuriat. Son objectif est de promouvoir l'entrepreneuriat et le travail indépendant comme alternatives au salariat et d'encourager l'innovation chez les jeunes à travers un large éventail d'activités, dont des projets de groupe et des «mini-entreprises».

Problème abordé: les jeunes luxembourgeois préfèrent la stabilité et les revenus fixes du salariat au travail indépendant (Eurobaromètre, 2012). Compte tenu de la diminution du nombre d'offres d'emploi salarié depuis le début de la crise économique, le projet vise à renforcer les compétences entrepreneuriales des jeunes afin de leur ouvrir la voie de l'emploi via le travail indépendant.

Approche: l'organisation à but non lucratif propose aux étudiants des programmes de formation pratique sur mesure, avec le soutien du secteur privé et des principales chambres professionnelles luxembourgeoises, qui apportent leurs conseils et leur expertise. L'approche générale de l'initiative se veut à la fois flexible et interactive. Elle fait appel à de acteurs du secteur privé qui, sur la base du volontariat, transmettent leur expertise dans le cadre d'ateliers. À titre d'exemple, dans l'enseignement primaire, l'initiative «Boule et Bill créent une entreprise» enseigne la création et la gestion d'entreprise aux élèves à travers la réalisation d'un dessin animé sur le thème de l'entreprise. Dans l'enseignement secondaire, sept programmes ont été organisés, notamment des campagnes d'information telles que des journées de jumelage professionnelles et des prix qui récompensent des projets de promotion de la créativité. Lors des Innovation Camps d'une journée, les jeunes sont confrontés à un défi d'affaires qu'ils doivent tenter de résoudre sous la direction d'un expert. Bien que ces programmes aient été développés pour tous les niveaux d'éducation, la priorité est donnée à l'enseignement secondaire technique.

Impact: aucune évaluation d'impact n'a été réalisée, mais le projet atteint les élèves ciblés dans leur cadre scolaire formel et lors de salons annuels et d'événements sur l'entrepreneuriat. Par exemple, l'édition 2013 du salon annuel a attiré 400 élèves issus de 13 écoles. Le projet est également parvenu à valoriser et à mieux faire connaître l'entrepreneuriat aux jeunes grâce à une vaste couverture médiatique.

Facteurs de réussite: ce programme montre comment l'entrepreneuriat peut trouver sa place dans l'enseignement public en s'appuyant sur l'expertise des entreprises du secteur privé et des associations professionnelles. Le succès est réel si les écoles intègrent les programmes dans leur système et communiquent sur les opportunités offertes à la communauté étudiante. 


\section{Données clés relatives à l'entrepreneuriat inclusif}

\section{Graphique 28.1. Données relatives à l'entrepreneuriat et au travail indépendant en Luxembourg}

\section{Diagramme A. Taux de chômage, 2000-2012}

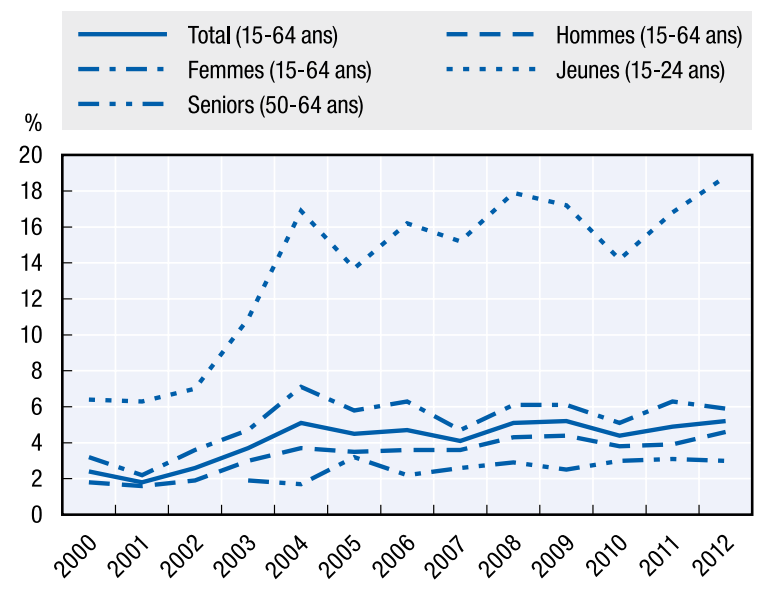

Diagramme B. Taux de travail indépendant, 2012

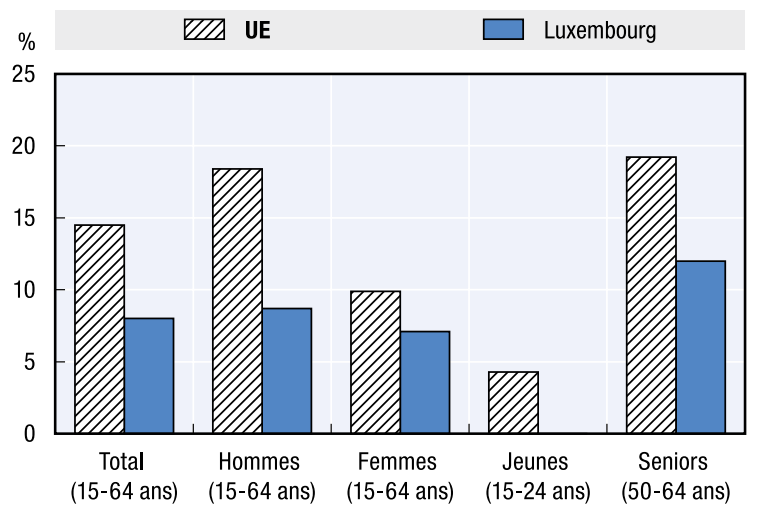

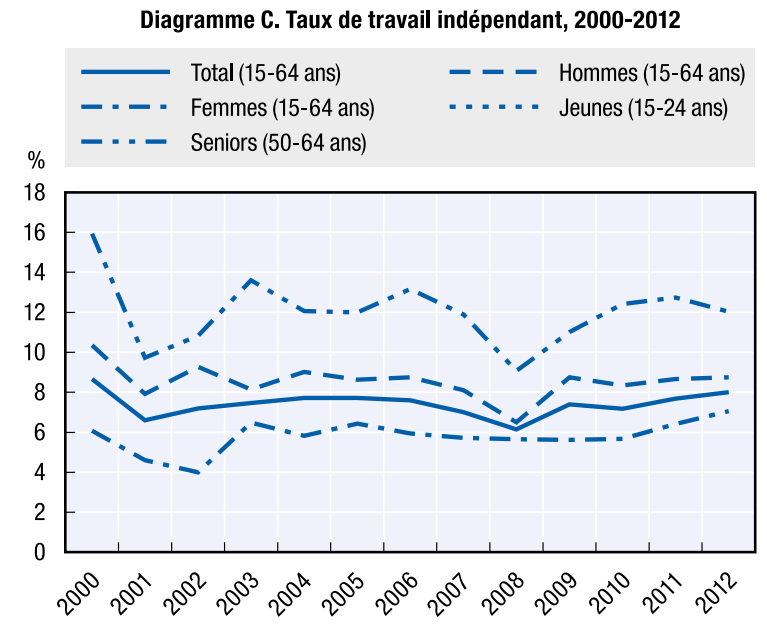

Sources: Diagramme A. Eurostat, Enquête sur les forces de travail, 2000-2012; Diagramme B. Eurostat, Enquête sur les forces de travail, 2012; Diagramme C. Eurostat, Enquête sur les forces de travail, 2000-2012. 


\section{Malte: projet Hands-on}

Description: le projet Hands-on a été conçu pour développer les compétences entrepreneuriales des étudiants qui présentent des besoins particuliers et fréquentent le Guardian Angel Secondary Education Resource Centre et le Dun Manwel Attard Young Adult Education Resource Centre à Malte. Le projet propose des formations aux éducateurs de ces deux établissements et les accompagne dans la transmission du programme de formation aux élèves.

Problème abordé: les étudiants ayant des besoins particuliers ont souvent des difficultés à entrer sur le marché du travail, que ce soit comme salariés ou comme travailleurs indépendants, en raison de leur handicap, de leurs niveaux de compétences plus faibles et de la discrimination dont ils font l'objet (Kummissjoni Nazzjonali Persuni b’Dizabilita, 2009). Le projet permet de mieux faire comprendre aux éducateurs ce qu'est l'entrepreneuriat afin qu'ils puissent à leur tour expliquer aux étudiants handicapés les opportunités que le travail indépendant peut leur offrir.

Approche: la première étape consistait à adapter le projet aux besoins des étudiants. Une évaluation a été réalisée par les Resource Centres (centres de ressources) afin d'évaluer les compétences entrepreneuriales des étudiants et des éducateurs ainsi que le climat de créativité et d'entrepreneuriat. Elle a mis en évidence le potentiel entrepreneurial d'un certain nombre d'étudiants, malgré des niveaux de qualification très variables. L'étape suivante consistait à former et soutenir les enseignants. Encouragés à exploiter au mieux les forces de leurs élèves, ces derniers ont acquis des méthodes pédagogiques visant à instaurer une réflexion de base sur l'entrepreneuriat et à aider les élèves à identifier leurs forces et faiblesses. Les participants ont pu s'approprier un certain nombre d'outils et de principes de réflexion tels que la production d'idées, tout en explorant les opportunités de commercialisation et de vente de produits. Le projet insistait sur le développement des compétences et attitudes entrepreneuriales telles que la créativité, la persévérance, la prise de risque et l'estime de soi. Les étudiants ont eu l'opportunité de participer à une série d'activités entrepreneuriales, dont la conception, la production et la vente d'une sélection de produits artisanaux, à savoir des sacs en toile peints à la main dans le cas du Guardian Angel Resource Centre et des invitations et des souvenirs de mariage faits main pour le Dun Manwel Attard Resource Centre.

Impact: des entretiens de suivi semi-structurés réunissant le directeur et les participants ont servi à mesurer l'impact du projet. Il en ressort que les étudiants se sont impliqués dans chacune des phases du projet, et que la création et la vente de leurs propres produits leur a donné confiance en eux.

Facteurs de réussite: le projet illustre l'importance de l'expérience pratique dans l'éducation à l'entrepreneuriat, en particulier pour les personnes handicapées. Afin de maximiser les retombées et les avantages d'un projet d'entrepreneuriat inclusif tel que celui-ci, les étudiants doivent participer activement à la planification de chaque phase du projet, des réunions préliminaires à la conception, la production, la promotion et la vente des produits en passant par la formation. 


\section{Données clés relatives à l'entrepreneuriat inclusif}

\section{Graphique 29.1. Données relatives à l'entrepreneuriat et au travail indépendant à Malte}

Diagramme A. Taux de chômage, 2000-2012
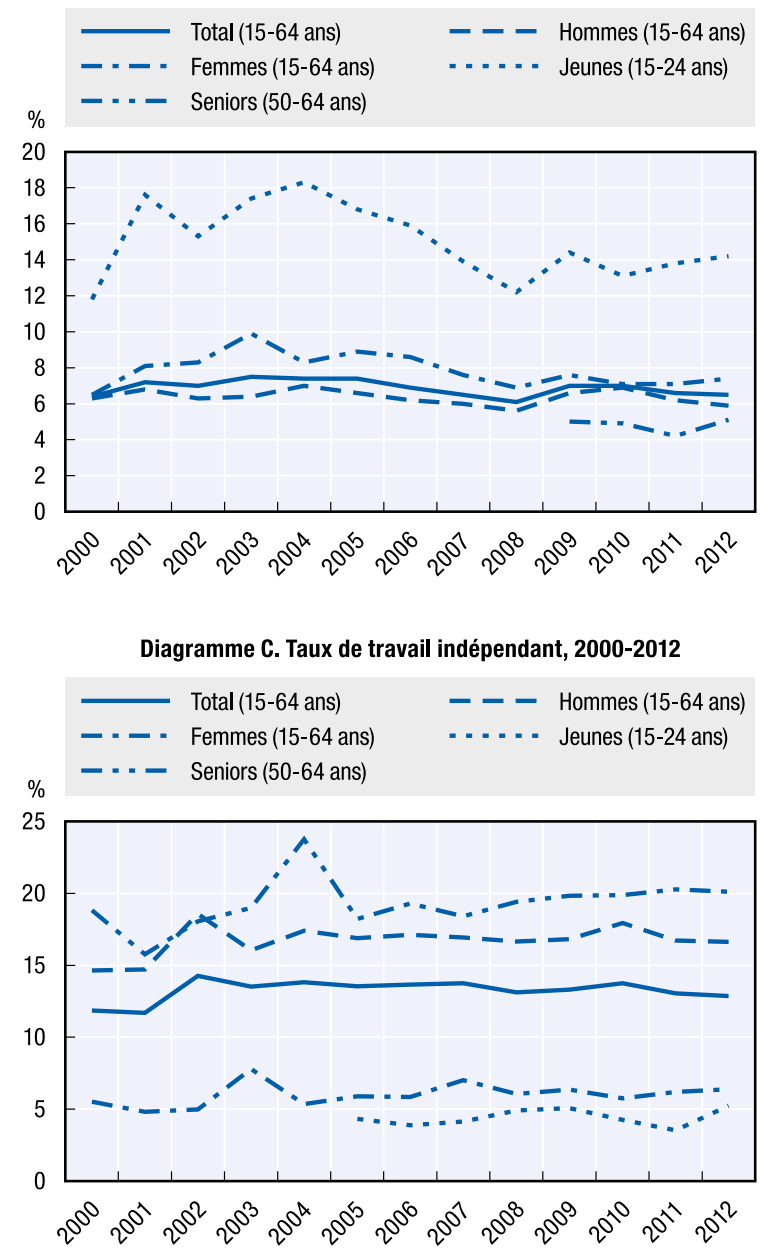

Diagramme B. Taux de travail indépendant, 2012

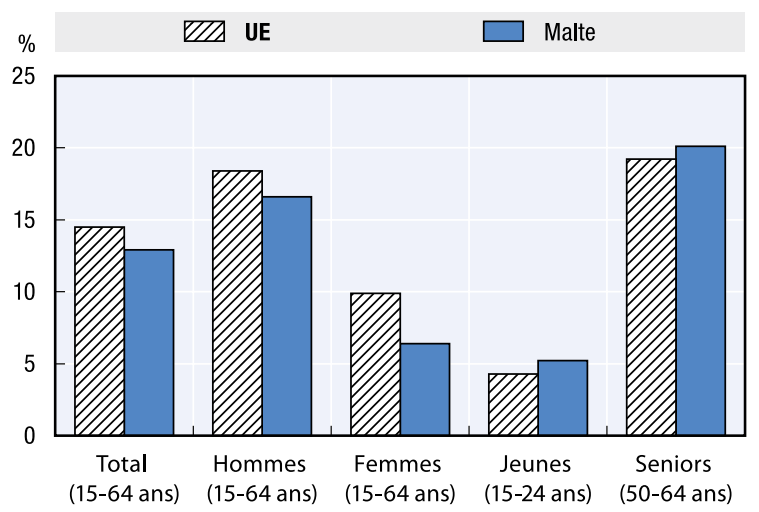

Sources: Diagramme A. Eurostat, Enquête sur les forces de travail, 2000-2012; Diagramme B. Eurostat, Enquête sur les forces de travail, 2012; Diagramme C. Eurostat, Enquête sur les forces de travail, 2000-2012. 


\section{Pays-Bas: «IkStartSmart», Gueldre}

Description: le programme IkStartSmart ("Je pars du bon pied») est un programme de soutien intégré destiné aux habitants de la province de Gueldre qui souhaitent créer une entreprise ou développer une société établie depuis moins de cinq ans.

Problème abordé: ce programme vise à multiplier les créations d'entreprise dans la province de Gueldre et à accompagner les jeunes entreprises dans leur développement. Les entreprises de cette province présentent des taux de survie inférieurs à la moyenne et il existe peu d'instruments politiques de soutien aux start-up.

Approche: l'initiative IkStartSmart (ISS) fait appel à un mécanisme en huit étapes pour former et aider les propriétaires de nouvelles entreprises. Tout d'abord, les participants potentiels participent à des réunions d'information durant lesquelles leur intérêt et leur aptitude sont évalués. Ils sont ensuite soumis à un test (ondernemerstest) d'évaluation de leurs forces et de leurs faiblesses, puis discutent des résultats de celui-ci avec un conseiller en d'entreprise de la chambre de commerce (dianosegesprek). Lors de cette entrevue, le conseiller élabore un programme de formation personnalisé. Des coaches dont le rôle est déterminé en collaboration avec le participant sont alors désignés. Leur but est de soutenir le développement personnel de l'entrepreneur. L'étape de conseil en entreprise donne aux participants l'occasion de rencontrer des experts professionnels qui leur apportent un soutien plus technique que les coaches. En complément, des formations personnalisées et des ateliers de mise en réseau sont organisés. L'étape finale leur donne accès aux microcrédits (Microkrediet ou Qcredit) proposés par les organismes partenaires. Les participants paient une contribution modique de 250 EUR pour bénéficier de ce soutien.

Impact: une évaluation officielle atteste que le programme ISS a atteint tous les objectifs fixés (Panteia/EIM, 2011). Malgré des critères d'éligibilité relativement larges (tous les propriétaires d'une entreprise de moins de cinq ans, indépendamment de leur sexe, de leur âge et de leur parcours professionnel), le programme a principalement attiré des chefs d'entreprise femmes et immigrés. Le taux de participation des femmes est quasiment deux fois supérieur au taux national d'entrepreneuriat féminin et montre ainsi à quel point le programme a réussi à toucher ce groupe en particulier.

Facteurs de réussite: il est préférable d'adopter une approche inclusive lorsque l'on développe des programmes de soutien intégrés, puisque les principaux besoins des différents groupes sont identiques. En outre, les contacts entre ces derniers sont utiles pour créer une entreprise prospère. En les tenant à distance les uns des autres, on risque de créer des stéréotypes (p.ex. concernant les femmes et les immigrés) et de retarder l'intégration de ces groupes dans la société et au sein des réseaux professionnels. 


\section{Données clés relatives à l'entrepreneuriat inclusif}

\section{Graphique 30.1. Données relatives à l'entrepreneuriat et au travail indépendant aux Pays-Bas}

Diagramme A. Taux de chômage, 2000-2012

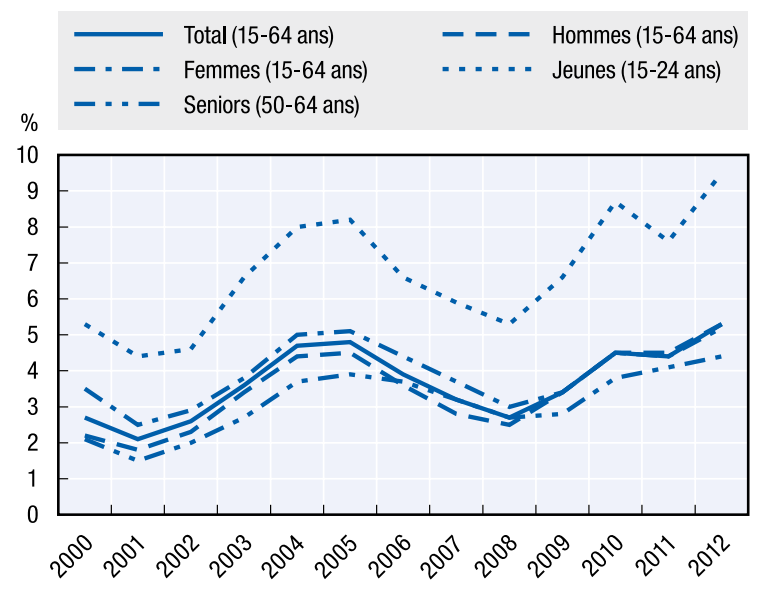

Diagramme C. Taux de travail indépendant, 2000-2012

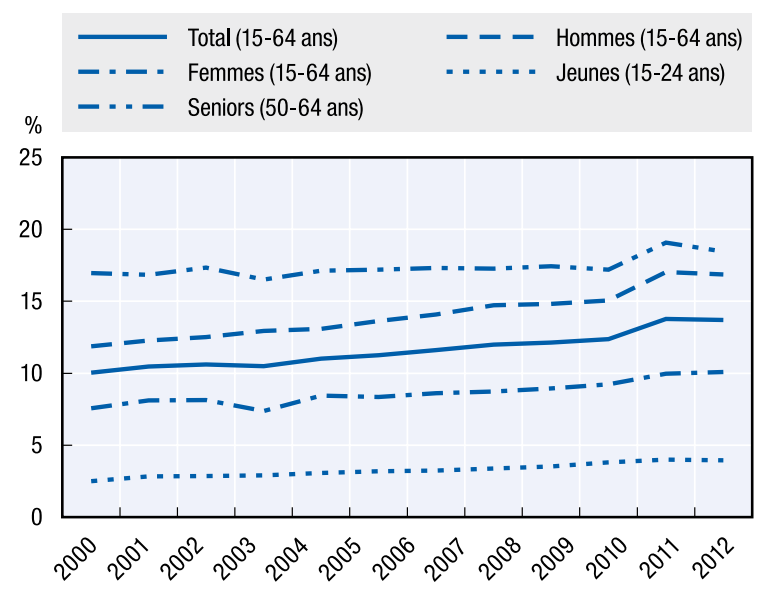

Diagramme E. Indice de l'activité entrepreneuriale totale au stade précoce, 2008-2012 (combinés)

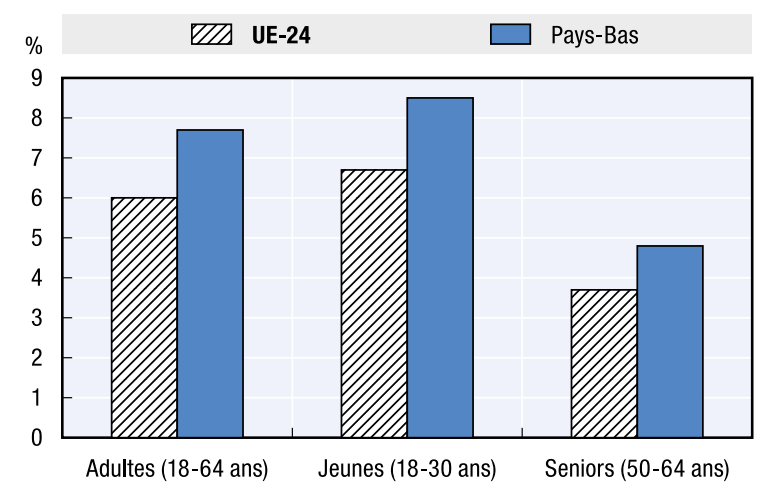

Diagramme B. Taux de travail indépendant, 2012

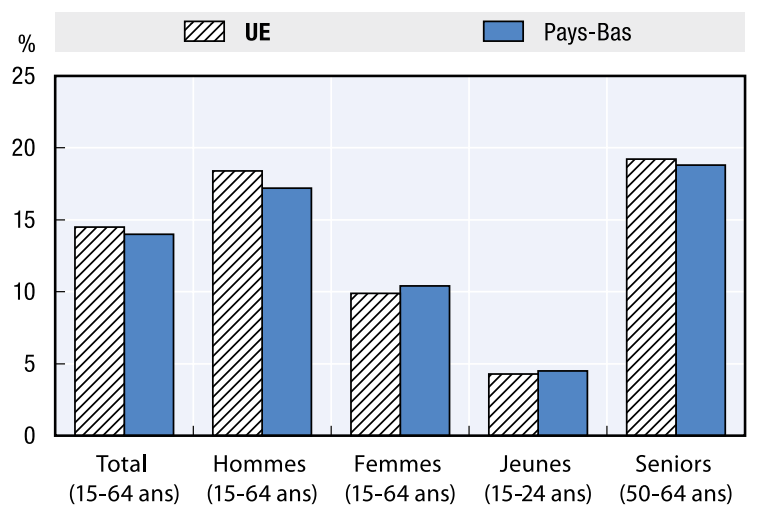

Diagramme D. Indice de l'activité entrepreneuriale totale au stade précoce, 2012

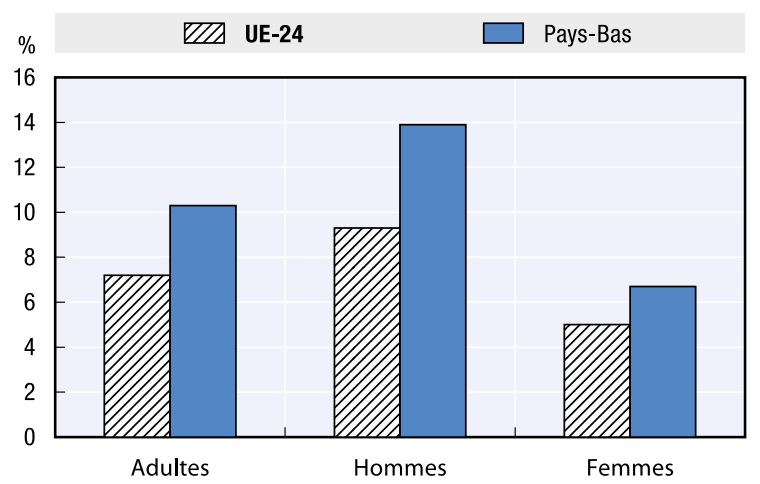

Sources: Diagramme A. Eurostat, Enquête sur les forces de travail, 2000-2012; Diagramme B. Eurostat, Enquête sur les forces de travail 2012; Diagramme C. Eurostat, Enquête sur les forces de travail, 2000-2012; Diagramme D. Présentation tabulaire spéciale de l'enquête sur la population adulte du Global Entrepreneurship Monitor, 2012; Diagramme E. Présentation tabulaire spéciale de l'enquête sur la population adulte du Global Entrepreneurship Monitor, 2008-2012. 


\section{Pologne: Solidarity between Generations}

Description: le gouvernement polonais dispose d'un programme intitulé «Solidarity between Generations: Measures to Increase Labour Force Participation of People Aged 50+». Ce programme, qui couvre la période 2009-2020, propose diverses activités organisées par d'institutions publiques ou financées par l'État et destinées à améliorer la qualité de vie des personnes d'âge mûr, notamment par le soutien à l'entrepreneuriat.

Problème abordé: le programme tente d'apporter une réponse au faible taux d'emploi des 55-64 ans, l'objectif étant d'atteindre la barre des 50\% à l'horizon 2020. Le travail indépendant fait partie des méthodes envisagées pour accroître le taux d'emploi de cette catégorie d'âge.

Approche: le programme «Solidarity between Generations» promeut et soutient l'emploi, le travail indépendant et l'entrepreneuriat social, en particulier chez les plus de 55 ans qui rencontrent des difficultés sur le marché du travail. Il propose 44 actions différentes, parmi lesquelles la promotion et le développement de l'entrepreneuriat social et du travail indépendant chez les plus de 50 ans. Les actions de soutien au travail indépendant et à l'entrepreneuriat social incluent des mesures de sensibilisation et des mesures d'aide spécifiques, comme de la formation et du conseil en entreprise, pour ceux qui souhaitent créer une société. La formation inclut des ateliers consacrés à l'élaboration du plan d'affaires et à la création d'entreprise. Le programme prévoit également des subventions financières comprises entre 20000 PLN et 40000 PLN (de 5000 à 10000 EUR environ) ainsi qu'une allocation mensuelle pour couvrir les frais de l'entreprise (p.ex. cotisations sociales). Le programme est financé par sept sources différentes, dont deux fonds européens (FSE et FEADER) et cinq fonds polonais. L'allocation totale s'élève à 17 millions PLN (4 millions EUR) au cours des trois premières années.

Impact: entre 2010 et 2011, 3695 personnes ont bénéficié des volets du programme relatifs au travail indépendant et 605 d'entre eux ont perçu une aide financière. Cependant, en raison de la crise économique, la mise en œuvre du programme a été plus lente que prévue et le suivi de son efficacité a été temporairement suspendu.

Facteurs de réussite: ce programme national consacré aux seniors comprend une grande variété d'activités. Il montre comment l'entrepreneuriat inclusif peut s'inscrire dans un ensemble plus large de mesures destiné à améliorer le taux d'emploi et la qualité de vie des seniors. La promotion de l'emploi et du travail indépendant des plus de 50 ans implique un changement de perception de la société polonaise à l'égard des personnes d'âge mûr et inversement. Les liens créés entre les mesures de soutien à l'entrepreneuriat, d'une part, et les mesures plus générales, d'autre part, montreraient alors une certaine synergie dans leurs effets à long terme. 


\section{Données clés relatives à l'entrepreneuriat inclusif}

\section{Graphique 31.1. Données relatives à l'entrepreneuriat et au travail indépendant en Pologne}

Diagramme A. Taux de chômage, 2000-2012

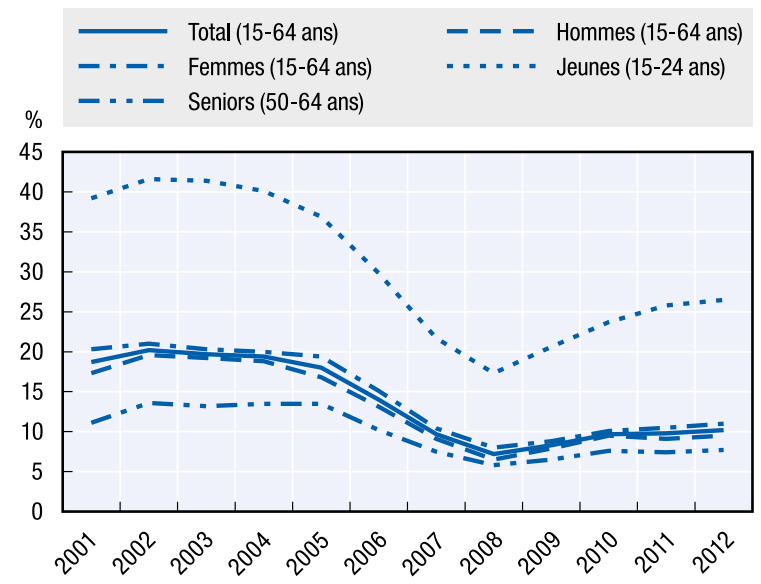

Diagramme C. Taux de travail indépendant, 2000-2012

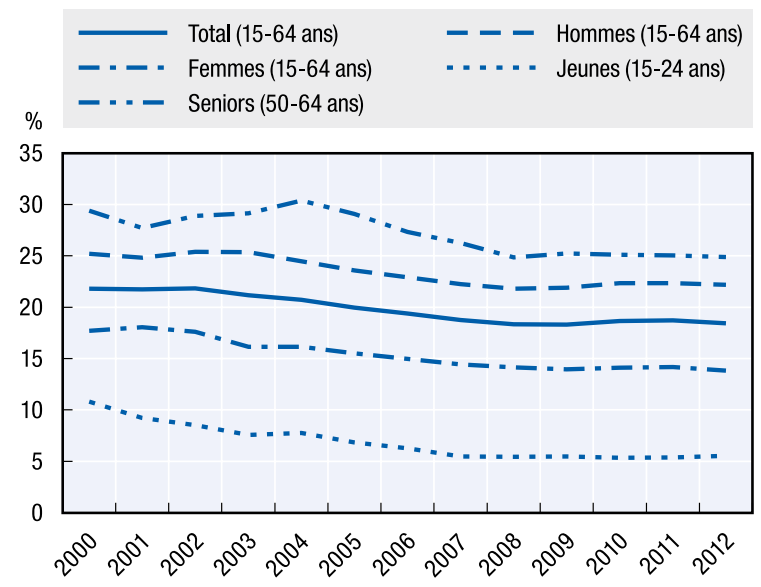

Diagramme E. Indice de l'activité entrepreneuriale totale au stade précoce, 2008-2012 (combinés)

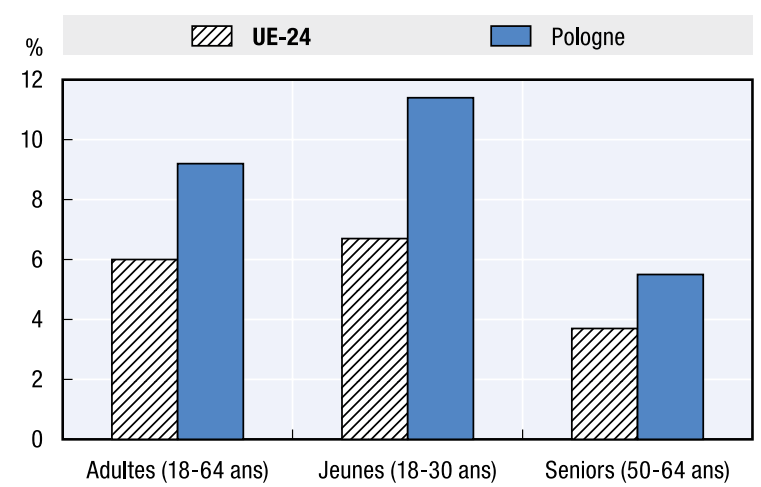

Diagramme B. Taux de travail indépendant, 2012

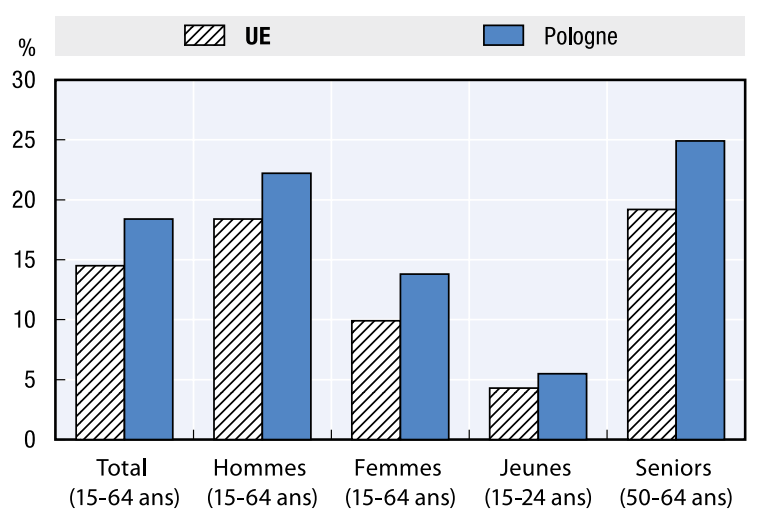

Diagramme D. Indice de l'activité entrepreneuriale totale au stade précoce, 2012

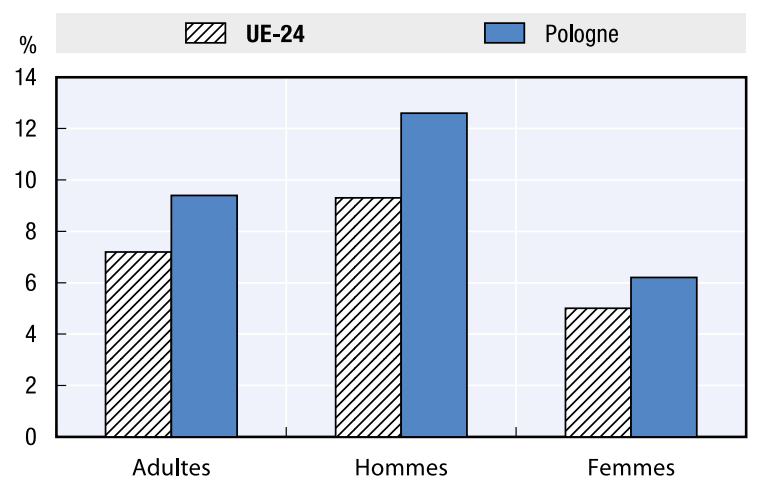

Sources: Diagramme A. Eurostat, Enquête sur les forces de travail, 2000-2012; Diagramme B. Eurostat, Enquête sur les forces de travail 2012; Diagramme C. Eurostat, Enquête sur les forces de travail, 2000-2012; Diagramme D. Présentation tabulaire spéciale de l'enquête sur la population adulte du Global Entrepreneurship Monitor, 2012; Diagramme E. Présentation tabulaire spéciale de l'enquête sur la population adulte du Global Entrepreneurship Monitor, 2008-2012. 


\section{Portugal: Best Form - Boosting Entrepreneurship Tools for Migrants}

Description: ce projet a reproduit, appliqué et diffusé un modèle d'aide aux entreprises communautaires développé au Royaume-Uni. Mis en place et coordonné par la Sociedade Portuguesa de Inovação (SPI), il a duré de 2010 à 2012. Sa priorité était de soutenir les activités entrepreneuriales des communautés immigrées en améliorant les aptitudes des conseillers en entreprise afin qu'ils puissent apporter des solutions à leurs difficultés particulières et en formant de nouveaux conseillers issus de ces communautés.

Problème abordé: la population croissante des immigrés au Portugal connaît un taux de chômage élevé depuis 2008. Une évaluation des besoins met en évidence des niveaux de compétences plus faibles chez les communautés immigrées qu'au sein de la population autochtone, ainsi qu'une tendance chez les entrepreneurs immigrés à ne pas faire appel à l'aide formelle aux entreprises. Le projet tente donc de les inciter à recourir aux services d'aide publics.

Approche: le projet Best Form a été créé par un consortium de 8 institutions de 7 États membres de l'UE. Il a permis de former des conseillers en entreprise issus de communautés immigrées travaillant déjà comme coaches et conseillers en entreprise, ainsi que des conseillers traditionnels désireux d'améliorer leurs compétences culturelles et/ou interpersonnelles pour s'occuper d'entrepreneurs immigrés. Un ensemble d'outils de formation a été mis au point. Il comprend un manuel d'appui (guide d'autoapprentissage), un manuel d'orientation (aide à l'organisation des séances de formation pour les formateurs) et un outil d'apprentissage interactif. Ces outils incluent du matériel d'appui pour la mise en place d'ateliers. Tous sont disponibles en ligne, traduits en portugais, anglais, allemand, italien, polonais, roumain et espagnol. Le projet a été financé par le Programme de l'Union européenne pour l'éducation et la formation tout au long de la vie, pour un budget total de 280000 EUR sur deux ans.

Impact: l'évaluation réalisée dans le cadre du projet souligne que la valeur ajoutée du cours pilote réside dans le fait qu'il a favorisé les opportunités de rencontre entre professionnels et organisations aux compétences diverses. Les commentaires recueillis auprès des participants aux ateliers (six mois après leur participation) confirment par ailleurs qu'ils mettent en pratique la formation et ce qu'ils ont appris lors des ateliers dans leur travail quotidien.

Facteurs de réussite: ce programme est une approche efficace pour la formation de conseillers issus de communautés immigrées. Il est clair qu'une évaluation préalable des besoins spécifiques doit être réalisée pour adapter l'approche en fonction du contexte. 


\section{Données clés relatives à l'entrepreneuriat inclusif}

\section{Graphique 32.1. Données relatives à l'entrepreneuriat et au travail indépendant au Portugal}

Diagramme A. Taux de chômage, 2000-2012

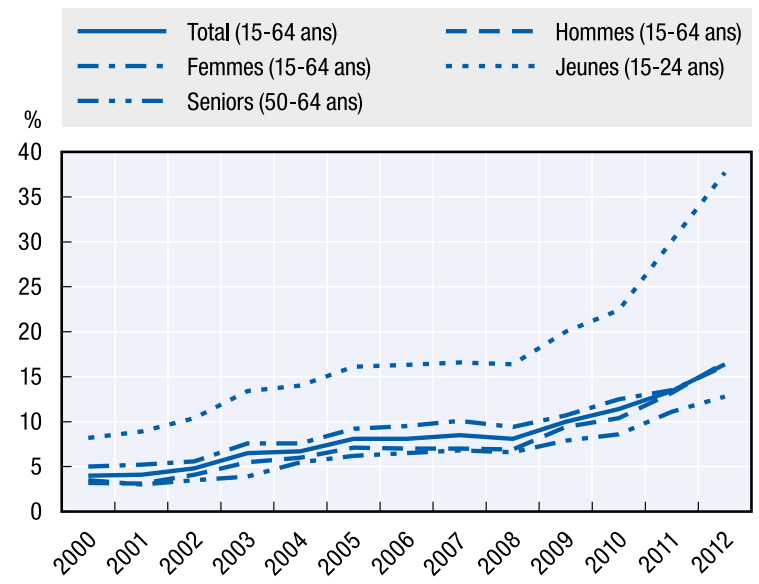

Diagramme C. Taux de travail indépendant, 2000-2012

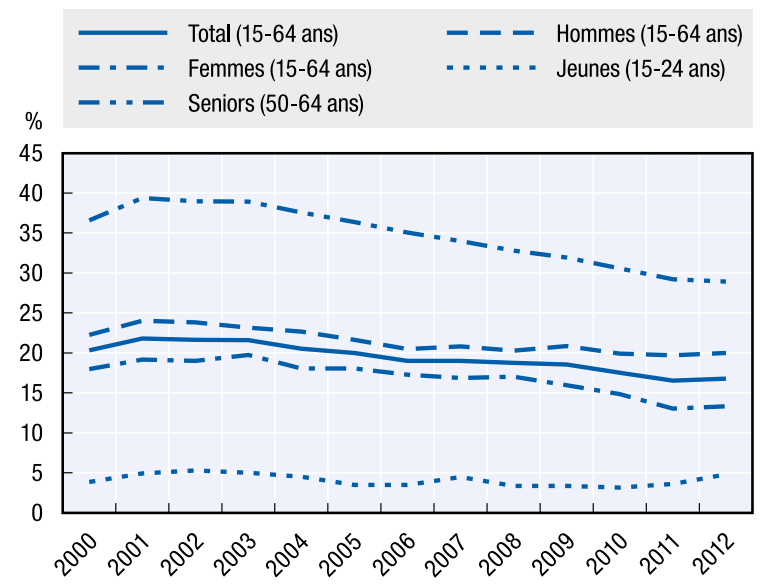

Diagramme E. Indice de l'activité entrepreneuriale totale au stade précoce, 2008-2012 (combinés)

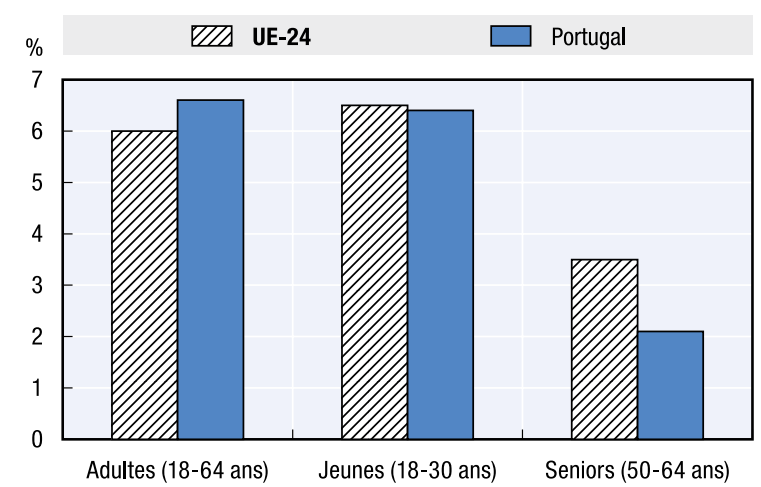

Diagramme B. Taux de travail indépendant, 2012

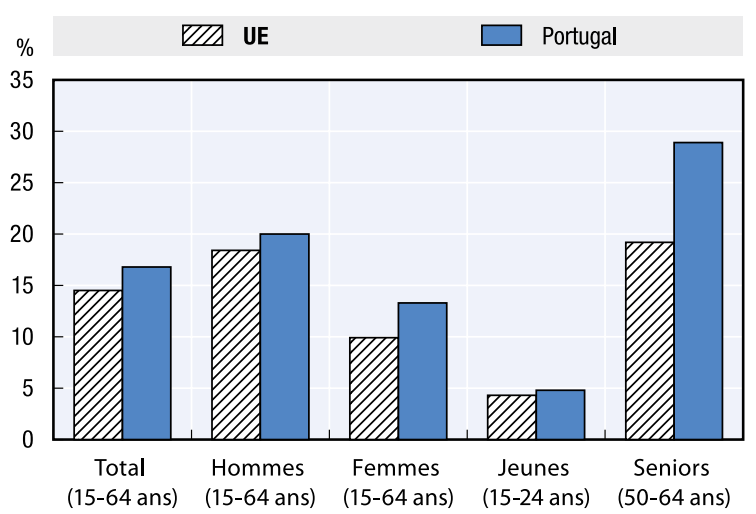

Diagramme D. Indice de l'activité entrepreneuriale totale au stade précoce, 2012

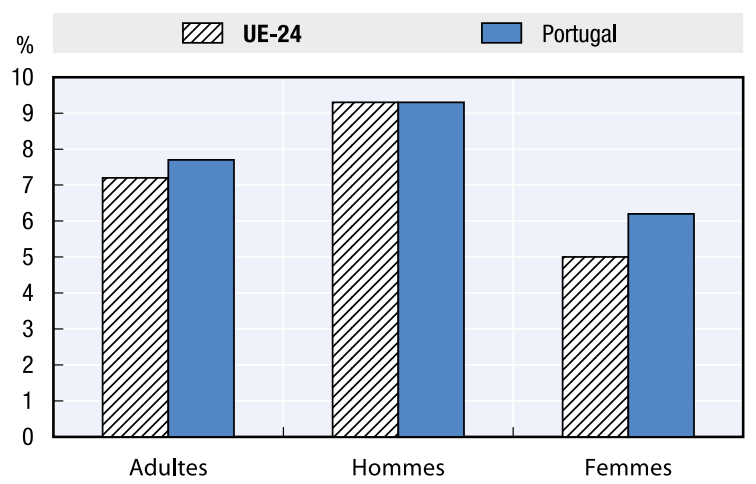

Sources: Diagramme A. Eurostat, Enquête sur les forces de travail, 2000-2012; Diagramme B. Eurostat, Enquête sur les forces de travail 2012; Diagramme C. Eurostat, Enquête sur les forces de travail, 2000-2012; Diagramme D. Présentation tabulaire spéciale de l'enquête sur la population adulte du Global Entrepreneurship Monitor, 2012; Diagramme E. Présentation tabulaire spéciale de l'enquête sur la population adulte du Global Entrepreneurship Monitor, 2008-2012. 


\section{Roumanie: A chance for those in rural areas}

Description: lancé en août 2010, ce projet d'une durée de trois ans visait à promouvoir la culture entrepreneuriale en milieu rural en créant des conditions favorables au développement d'entreprises non agricoles rentables. Mis en œuvre par deux ONG partenaires, le Maramures Center for Development of SMEs et le Harghita Center for Innovation and Business Incubation, il couvre les zones rurales du nord-ouest et du centre de la Roumanie. Le projet s'adresse aux personnes sans emploi ayant travaillé dans l'agriculture de subsistance.

Problème abordé: largement moins développées que les zones urbaines, les zones rurales roumaines dépendent traditionnellement de l'agriculture de subsistance. Le projet vise à stimuler la création d'entreprises en milieu rural afin d'encourager la pérennité de ces communautés.

Approche: ce projet utilise une approche intégrée comprenant des services d'information, de formation à la gestion et à l'entrepreneuriat, de conseil et d'autres, tels que la promotion des entreprises rurales et la mise en place d'un portail d'information en ligne sur le marché du travail. Le projet a débuté par une recherche sur l'emploi dans l'agriculture de subsistance en milieu rural et sur les opportunités professionnelles dans les activités non agricoles. Une campagne d'information et de sensibilisation sur les débouchés professionnels dans les secteurs non agricoles a ensuite été menée auprès des étudiants en dernière année de lycée, des personnes employées dans l'agriculture de subsistance et des femmes. À la suite de cela, des participants se sont inscrits aux différents projets de formation. Chacun d'eux signe un contrat stipulant son engagement à suivre le programme de formation jusqu'à son terme, à assister à toutes les sessions et à rédiger un plan d'affaires qui sera soumis à évaluation. Une fois la formation à l'entrepreneuriat terminée, les participants et d'autres membres de la communauté rurale peuvent bénéficier gracieusement de conseils en entreprise et d'une assistance pour commencer une activité indépendante ou créer une entreprise. Le budget total du projet s'élevait à 5,5 millions RON (environ 1,3 million EUR), quasiment entièrement financé par le Fonds social européen (FSE) et le gouvernement roumain.

Impact: 32 séminaires promotionnels, 8 sessions de formation à l'entrepreneuriat et 4 sessions de formation en gestion ont été organisés dans le cadre du projet. Au total, 232 personnes ont suivi les sessions de formation. Grâce au projet, 288 projets de start-up ont pu profiter de conseils en entreprise et 40 entreprises ont été créées.

Facteurs de réussite: ce programme est un exemple d'aide intégrée en milieu rural. Son succès dépend essentiellement des mesures gouvernementales en faveur de l'entrepreneuriat rural; d'un solide partenariat avec l'administration publique locale pour établir le contact avec les communautés rurales (qui sont en général relativement fermées); et, surtout, de la programmation des cours en automne et en hiver, périodes durant lesquelles les habitants des zones rurales ne se consacrent pas aux tâches agricoles. Le portail internet a contribué à partager des informations sur les entreprises et les opportunités d'emploi, mais cela implique évidemment d'améliorer la couverture internet dans les zones rurales. 


\section{Données clés relatives à l'entrepreneuriat inclusif}

\section{Graphique 33.1. Données relatives à l'entrepreneuriat et au travail indépendant en Roumanie}

Diagramme A. Taux de chômage, 2000-2012

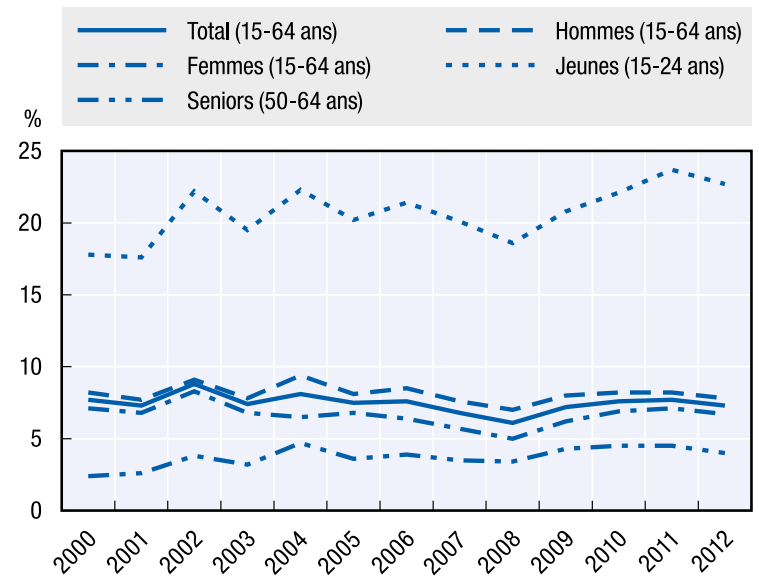

Diagramme C. Taux de travail indépendant, 2000-2012

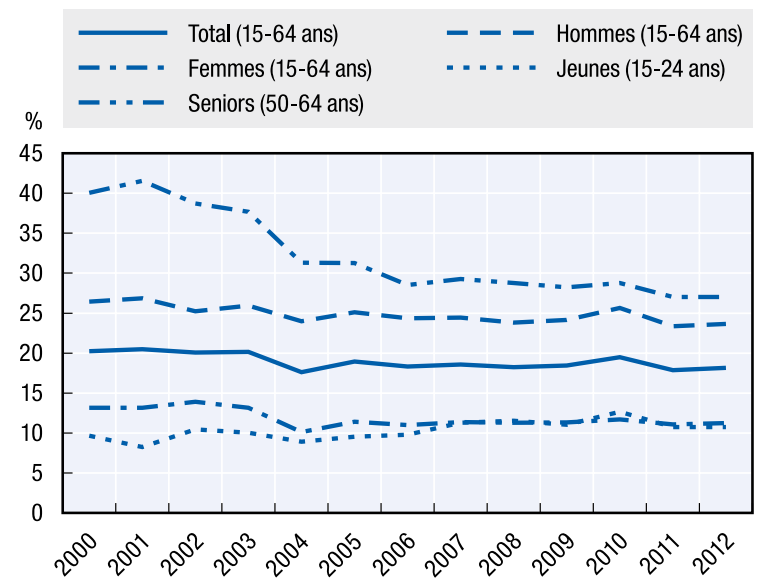

Diagramme E. Indice de l'activité entrepreneuriale totale au stade précoce, 2008-2012 (combinés)

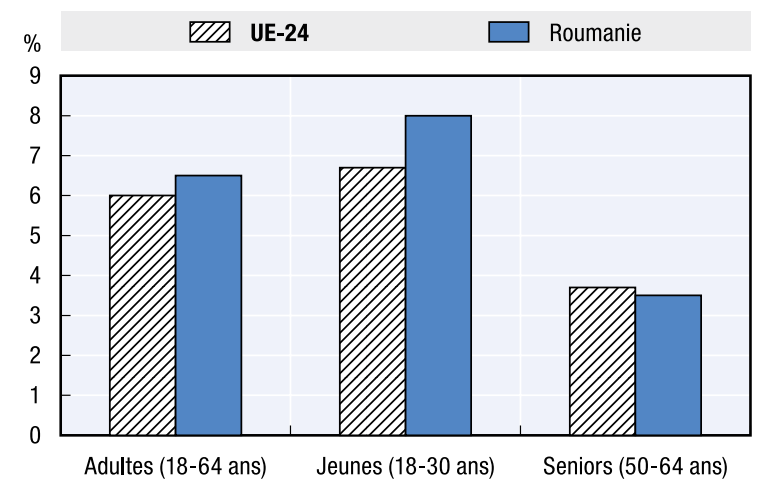

Diagramme B. Taux de travail indépendant, 2012

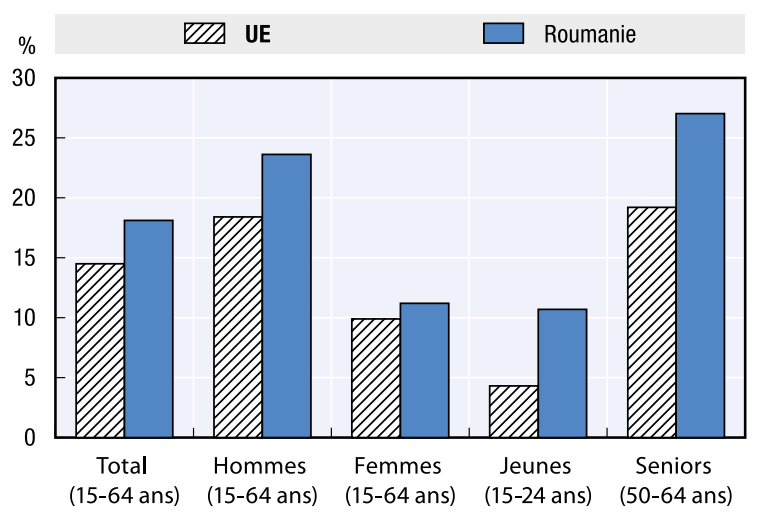

Diagramme D. Indice de l'activité entrepreneuriale totale au stade précoce, 2012

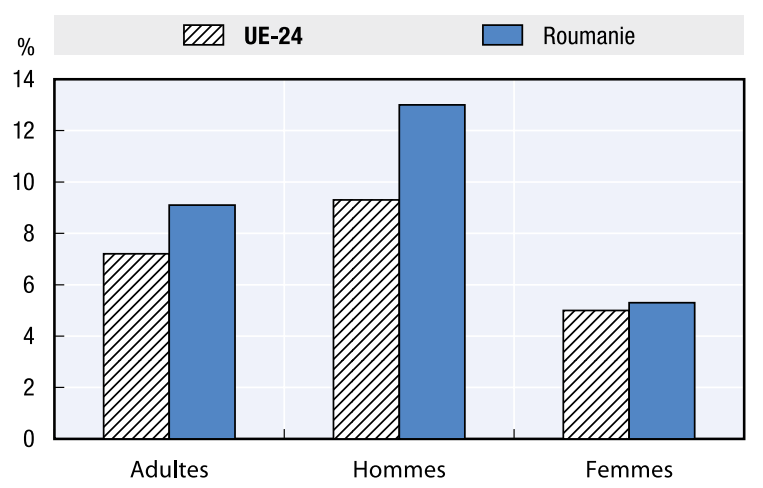

Sources: Diagramme A. Eurostat, Enquête sur les forces de travail, 2000-2012; Diagramme B. Eurostat, Enquête sur les forces de travail 2012; Diagramme C. Eurostat, Enquête sur les forces de travail, 2000-2012; Diagramme D. Présentation tabulaire spéciale de l'enquête sur la population adulte du Global Entrepreneurship Monitor, 2012; Diagramme E. Présentation tabulaire spéciale de l'enquête sur la population adulte du Global Entrepreneurship Monitor, 2008-2012. 


\section{République slovaque: REGIONFEMME}

Description: REGIONFEMME est un projet destiné à soutenir et à former les femmes chefs d'entreprise dans l'ouest de la République slovaque, à proximité de la frontière autrichienne. Mis en œuvre entre 2009 et 2013, le projet propose des services d'éducation, de formation et de conseil en entreprise. Il a été mis en œuvre en collaboration avec la Chambre de commerce et d'industrie slovaque - Chambre de commerce régionale de Bratislava et l'Association des femmes entrepreneurs. Le projet a également coopéré avec la Wirtschaftskammer Wien en Autriche.

Problème abordé: le pourcentage de femmes entrepreneurs en République slovaque est l'un des plus bas de l'UE. Environ $28 \%$ des entrepreneurs sont des femmes, contre près de $42 \%$ en Autriche (GEM, 2012). En outre, seuls $30 \%$ des PME confient des postes de direction de haut niveau à des femmes. Les femmes slovaques ont également moins tendance que les hommes à identifier les opportunités de créer une entreprise. Leur peur de l'échec est par ailleurs beaucoup plus marquée (GEM, 2012). En outre, les femmes sont beaucoup moins nombreuses que les hommes à considérer qu'elles possèdent les connaissances, les compétences et l'expérience suffisantes pour démarrer une entreprise. Le projet visait donc à stimuler les activités entrepreneuriales des femmes.

Approche: le projet s'est concentré sur la prise de conscience des opportunités entrepreneuriales et le développement des compétences managériales. Des séminaires ont été organisés sur les thèmes de l'environnement réglementaire, de la gestion d'entreprise et du commerce transfrontalier. Plus de 900 femmes ont assisté à 17 séminaires. Celles qui étaient prêtes à concrétiser leur projet d'entreprise ont pu bénéficier de différentes formes de soutien, dont des consultations de start-up proposées par les chambres de commerce de part et d'autre de la frontière austro-slovaque. Au total, 140 femmes ont eu recours à ce service. Les autres types de soutien destinés aux start-up incluaient des événements de mise en réseau ainsi que des académies pour start-up et pour femmes entrepreneurs qui mettaient l'accent sur la création d'entreprise, l'accès à l'information et la survie de l'activité au-delà de la période de démarrage. Les participantes ont pu profiter de l'ensemble de ces services gratuitement, la plupart du temps en slovaque ou en allemand. Des cours d'allemand leur ont également été proposés.

Impact: aucune évaluation d'impact formelle n'a été réalisée, mais les retours des participantes aux activités du projet ont été en grande partie positifs. Au total, 2200 femmes ont pris part au projet. Sur les 900 participantes aux séminaires, plus de $30 \%$ ont exprimé le désir de créer une entreprise. Et 33 des 50 participantes aux académies pour start-up de Bratislava ont créé leur entreprise, contre 23 participantes sur 57 en Autriche.

Facteurs de réussite: REGIONFEMME se penche sur ce qui est considéré comme une nécessité nationale et régionale. La région de Bratislava, où les femmes entrepreneurs peuvent saisir des opportunités des deux côtés de la frontière, mise beaucoup sur la coopération internationale et les échanges de savoir-faire et d'expériences. La coopération avec les chambres de commerce régionales a joué un rôle important dans ce projet. Cellesci disposent non seulement des informations dont les femmes ont besoin pour créer leur entreprise, mais elles peuvent également fournir des experts là où le besoin se fait sentir, ainsi que des réseaux de contacts de femmes chefs d'entreprise établies qui sont prêtes à partager leur expérience pratique et sont de formidables exemples aux yeux de celles qui se lancent comme entrepreneurs. 


\section{Données clés relatives à l'entrepreneuriat inclusif}

\section{Graphique 34.1. Données relatives à l'entrepreneuriat et au travail indépendant en République slovaque}

Diagramme A. Taux de chômage, 2000-2012

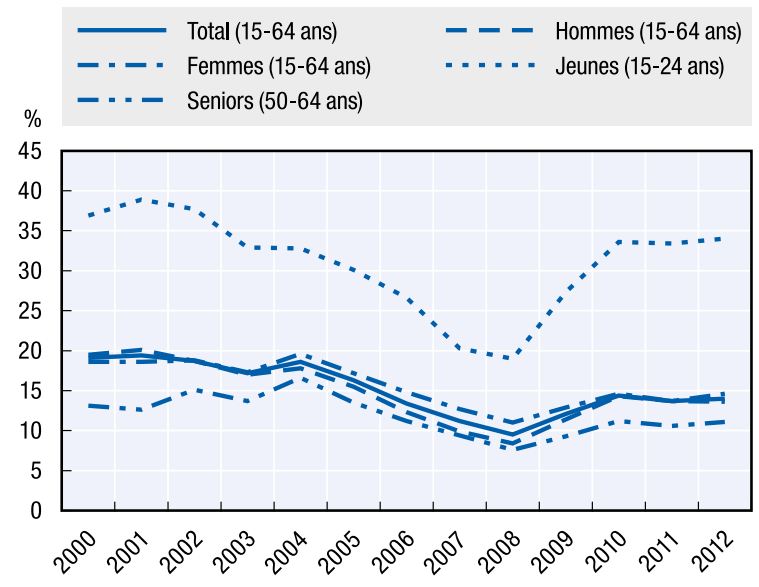

Diagramme C. Taux de travail indépendant, 2000-2012

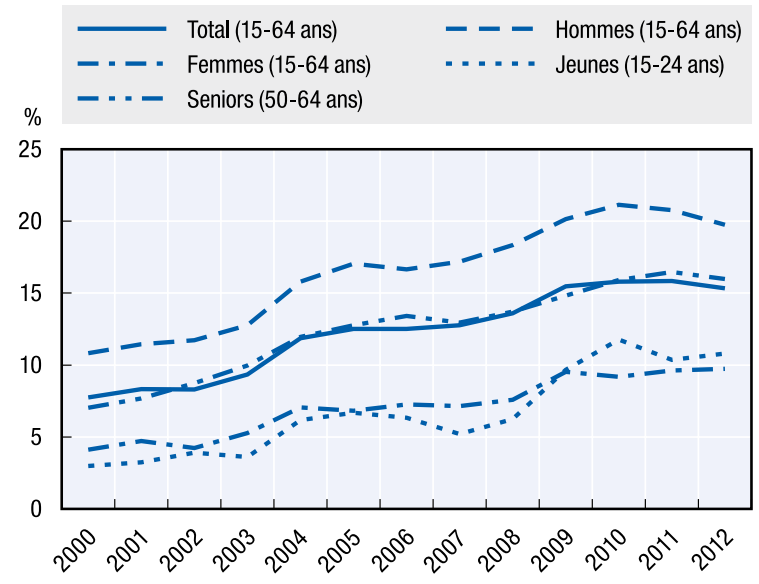

Diagramme E. Indice de l'activité entrepreneuriale totale au stade précoce, 2008-2012 (combinés)

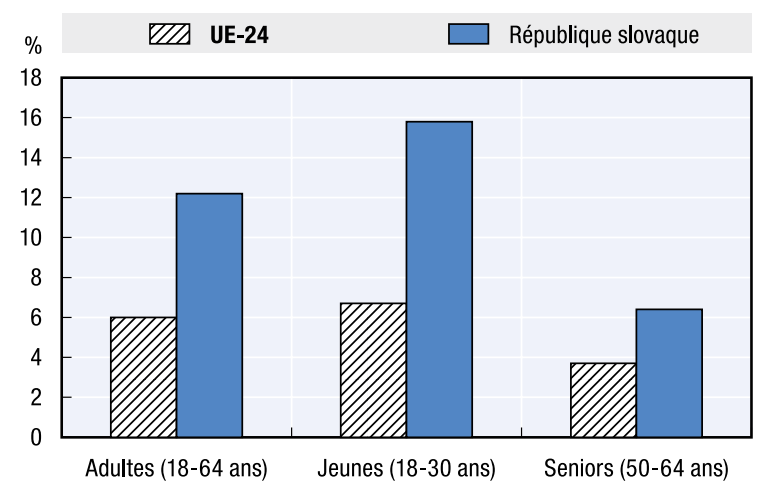

Diagramme B. Taux de travail indépendant, 2012

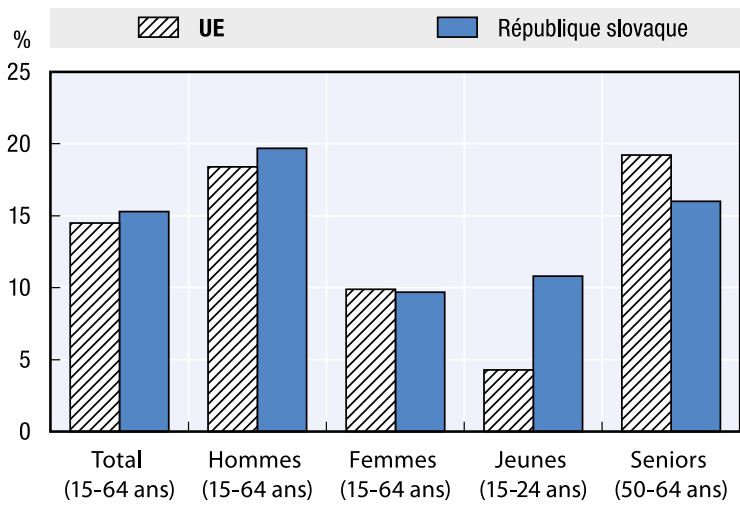

Diagramme D. Indice de l'activité entrepreneuriale totale au stade précoce, 2012

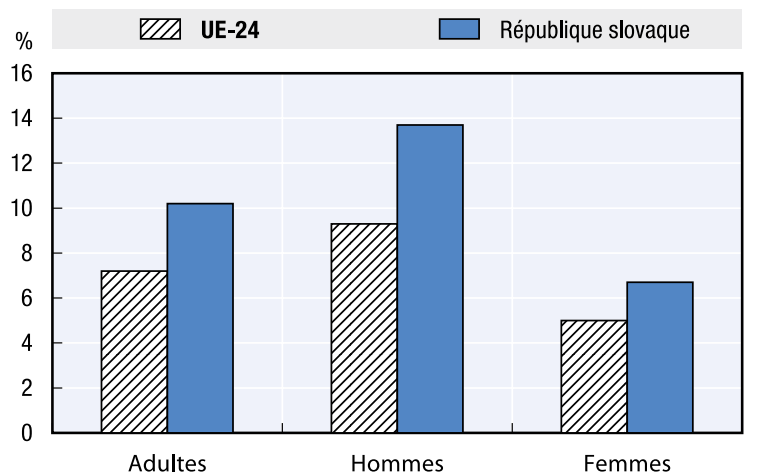

Sources: Diagramme A. Eurostat, Enquête sur les forces de travail, 2000-2012; Diagramme B. Eurostat, Enquête sur les forces de travail 2012; Diagramme C. Eurostat, Enquête sur les forces de travail, 2000-2012; Diagramme D. Présentation tabulaire spéciale de l'enquête sur la population adulte du Global Entrepreneurship Monitor, 2012; Diagramme E. Présentation tabulaire spéciale de l'enquête sur la population adulte du Global Entrepreneurship Monitor, 2008-2012. 


\section{Slovénie: Entrepreneurially into the world of business 2013}

Description: le projet «Entrepreneurially into the world of business 2013» a été mis en œuvre dans le cadre du Programme opérationnel en faveur du développement des ressources humaines pour la période 2007-2013. Il associe mentorat et formation afin d'aider les participants à acquérir les compétences fondamentales dont ils ont besoin pour lancer et de développer leur idée d'entreprise. Il vise essentiellement les chômeurs slovène instruits, âgés de moins de 35 ans et titulaires d'un diplôme de l'enseignement supérieur, d'une maîtrise ou d'un doctorat, indépendamment de l'établissement ou du programme d'études.

Problème abordé: le taux de chômage des jeunes atteignait 23,6\% au premier trimestre 2013, aggravé par une difficulté grandissante à entrer sur le marché du travail. Alors que l'entrepreneuriat constitue une voie d'entrée sur ce marché pour les jeunes, le nombre de jeunes entrepreneurs est en baisse en Slovénie, en particulier chez les plus instruits (Rebernik et al., 2013).

Approche: le projet est né d'un projet régional mené avec succès de 2009 à 2012 dans la région de Zasavje. Ce projet a été étendu à l'échelon national en 2013 et doté d'un budget de 3,89 millions EUR, financé à $85 \%$ par le Fonds social européen. Dans le cadre du projet national, chacune des 12 régions sélectionne 2 groupes de 10 participants ayant déjà développé un concept d'entreprise pendant le processus d'entretiens. Les participants retenus font alors un stage rémunéré de cinq moins dans la fonction publique. Les stagiaires ne travaillent pas comme employés. Ils reçoivent plutôt une formation à l'entrepreneuriat et une aide pour la rédaction de leur plan d'affaires. Des mentors les accompagnent également dans la réalisation de leur projet d'entreprise. Les participants perçoivent malgré tout une petite rémunération pour leur stage. Au total, 754 jeunes chômeurs se sont inscrits à l'édition 2013 du programme lors du premier appel à participation (janvier 2013) et 130 d'entre eux ont été sélectionnés, soit 10 par région. À la suite de un second appel à participation plus tard dans l'année, leur nombre est passé à 250 environ. Plus de 720 jeunes sont attendus pour l'édition 2014.

Impact: sur les 13 premiers groupes de 10 personnes, 36,2\% ont créé leur entreprise à l'issue de leur stage. Plus de la moitié de la dernière cohorte de participants a réussi son entrée dans le travail indépendant.

Facteurs de réussite: ce projet montre comment des stages ou des emplois peuvent fournir un revenu stable et aider les jeunes à développer leur idée d'entreprise. La puissance du réseau des agences de développement régional constitue ici un facteur essentiel de réussite. 


\section{Données clés relatives à l'entrepreneuriat inclusif}

\section{Graphique 35.1. Données relatives à l'entrepreneuriat et au travail indépendant en Slovénie}

Diagramme A. Taux de chômage, 2000-2012

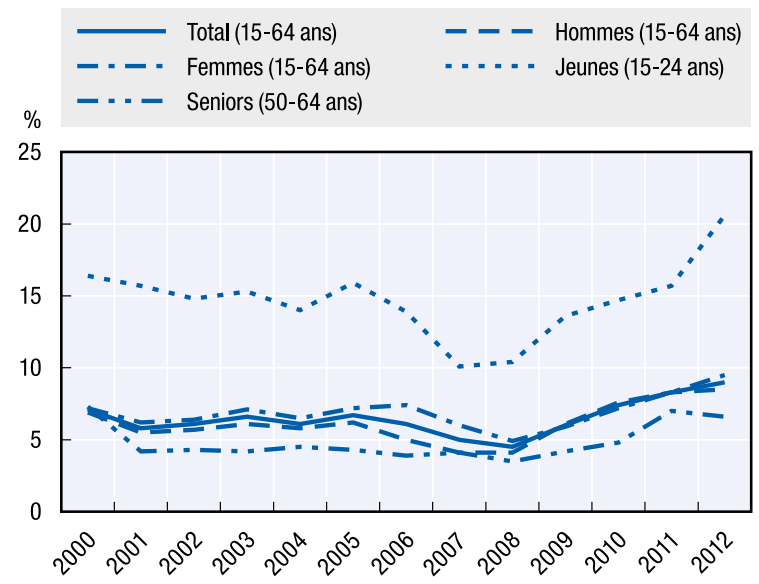

Diagramme C. Taux de travail indépendant, 2000-2012

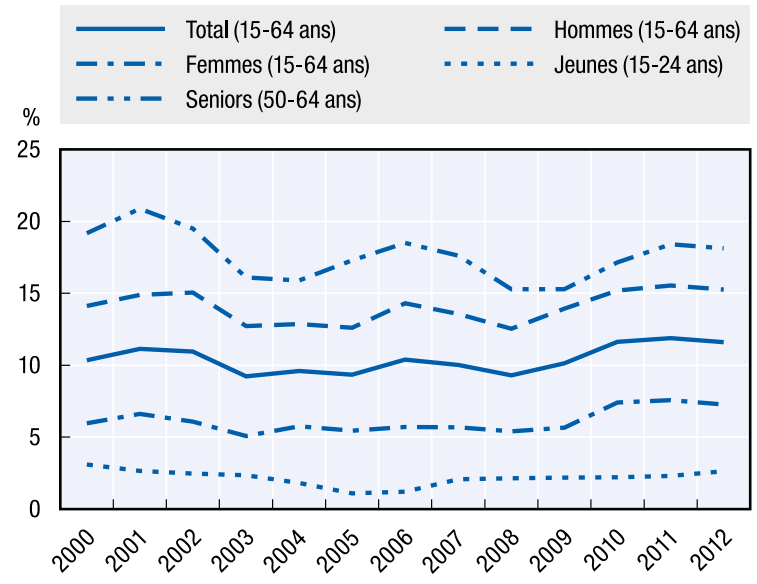

Diagramme $E$. Indice de l'activité entrepreneuriale totale au stade précoce, 2008-2012 (combinés)

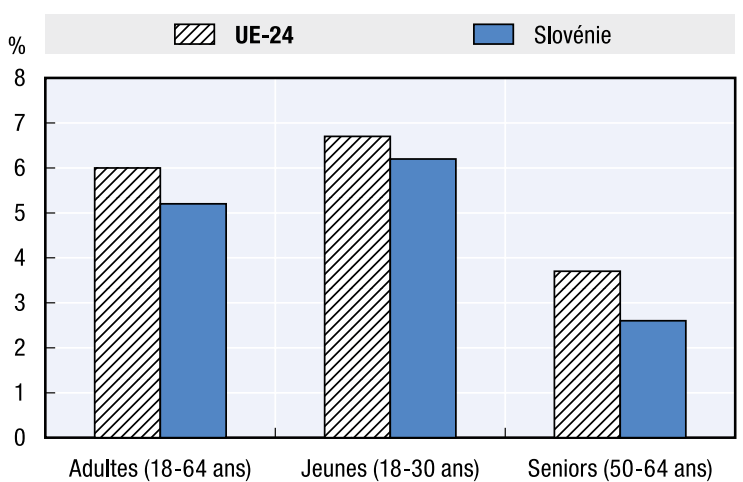

Diagramme B. Taux de travail indépendant, 2012

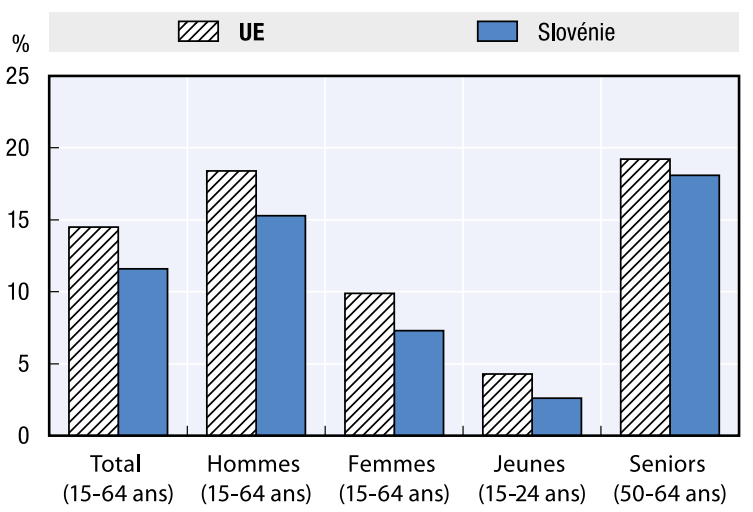

Diagramme D. Indice de l'activité entrepreneuriale totale au stade précoce, 2012

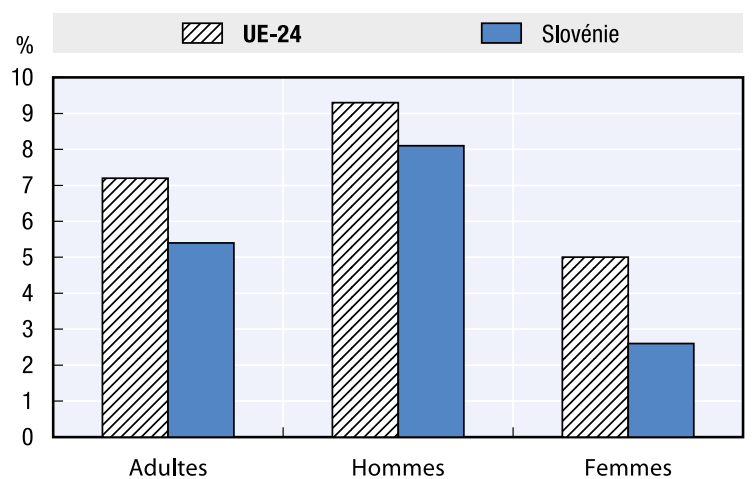

Sources: Diagramme A. Eurostat, Enquête sur les forces de travail, 2000-2012; Diagramme B. Eurostat, Enquête sur les forces de travail 2012; Diagramme C. Eurostat, Enquête sur les forces de travail, 2000-2012; Diagramme D. Présentation tabulaire spéciale de l'enquête sur la population adulte du Global Entrepreneurship Monitor, 2012; Diagramme E. Présentation tabulaire spéciale de l'enquête sur la population adulte du Global Entrepreneurship Monitor, 2008-2012. 


\section{Espagne: Programa operativo de la Comunidad Foral de Navarra 2007-2013 (soutenir le travail indépendant en Navarre 2007-2013)}

Description: l'objectif de ce programme est d'amener des demandeurs d'emploi à s'orienter vers le travail indépendant. Il permet aux chômeurs ayant investi au moins 12000 EUR dans des actifs à long terme au cours des six derniers mois de bénéficier de formations, de conseils techniques et d'une aide financière à la création d'entreprise (pouvant atteindre 10000 EUR).

Problème abordé: la Navarre, région de près de 600000 habitants, a vu son PIB par habitant passer de 29917 à 29071 EUR entre 2007 et 2012. Bien qu'inférieur au taux global espagnol (25\%), son taux de chômage (16\%) restait élevé en 2012 au regard des autres pays de l'UE. Les chômeurs des groupes défavorisés (jeunes, seniors, handicapés, femmes et minorités ethniques) font trop rarement appel aux programmes d'incitation au travail indépendant. Le programme vise à encourager l'activité économique et la création d'emplois à travers la mise en place de formations et d'aides financières pour les personnes intéressées par le travail indépendant.

Approche: les participants potentiels doivent déposer une demande auprès du Service public de l'emploi (PES) de Navarre et être inscrits comme demandeurs d'emploi depuis $\mathrm{au}$ moins trois mois. Une fois leur participation validée, ils doivent s'engager dans la création d'une entreprise pendant au moins 3 ans. Ils doivent également être affiliés au système de sécurité sociale et conserver les actifs investis pendant les trois ans. Une aide financière directe peut être accordée selon les circonstances. Les chômeurs et les personnes handicapées peuvent recevoir jusqu'à 5000 EUR et 10000 EUR respectivement. Cette aide n'est pas cumulable avec les allocations accordées par d'autres programmes. L'aide non financière inclut une formation au travail indépendant, dont les frais sont pris en charge jusqu'à $75 \%$ dans la limite d'un montant maximal de 3000 EUR. Les participants peuvent également bénéficier de conseils techniques en la matière, financés également à hauteur de $75 \%$ dans la limite d'un montant maximal de 2000 EUR. Le budget total du programme s'élève à 5,2 millions EUR, alloués à 50\% par le Fonds social européen (FSE).

Impact: près de 500 chômeurs ont bénéficié du programme au cours des trois dernières années. Ce groupe représente environ $0,5 \%$ des personnes nouvellement établies à leur compte sur la période 2010-2012. Plus de la moitié des bénéficiaires étaient des femmes et plus de $10 \%$ d'entre eux étaient des chômeurs.

Facteurs de réussite: le programme n'a pas encore été évalué officiellement, mais il apporte la preuve d'une demande de soutien financier de la part des chômeurs, même s'ils doivent prendre une partie des frais à leur charge. Il sera important de suivre le programme audelà des trois ans afin de déterminer dans quelle mesure les participants auront respecté l'engagement de rester indépendants. 


\section{Données clés relatives à l'entrepreneuriat inclusif}

\section{Graphique 36.1. Données relatives à l'entrepreneuriat et au travail indépendant en Espagne}

Diagramme A. Taux de chômage, 2000-2012

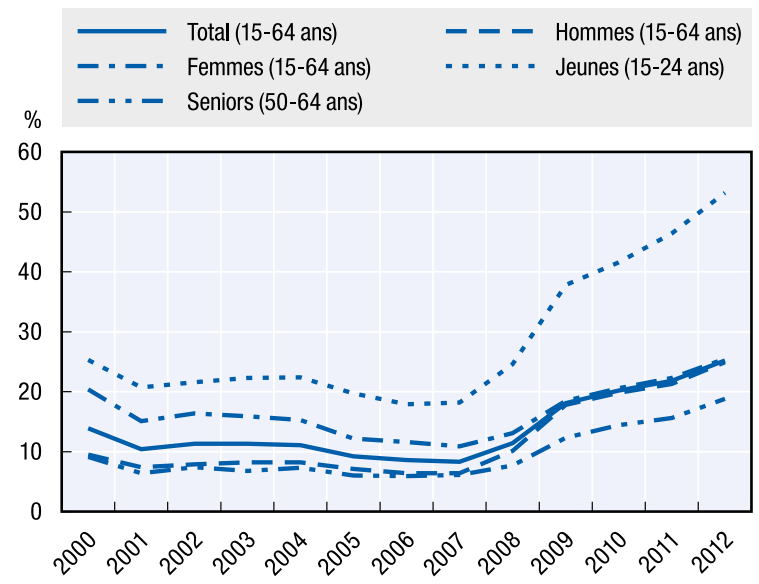

Diagramme C. Taux de travail indépendant, 2000-2012

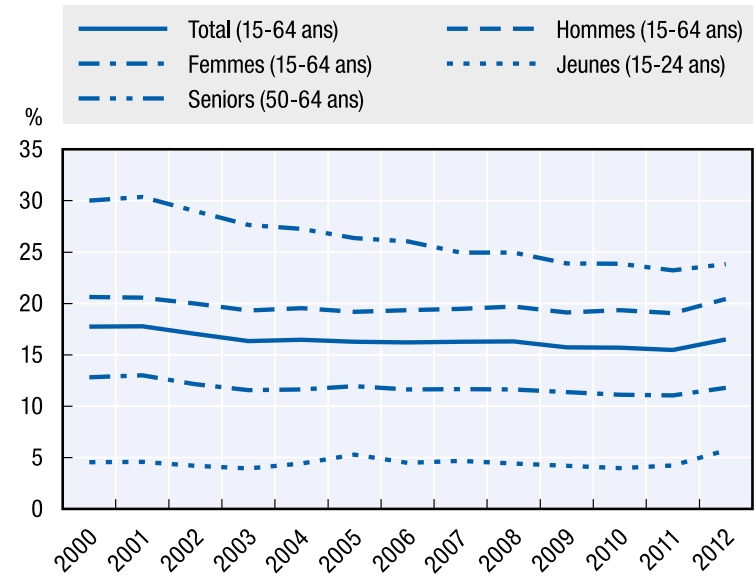

Diagramme E. Indice de l'activité entrepreneuriale totale au stade précoce, 2008-2012 (combinés)

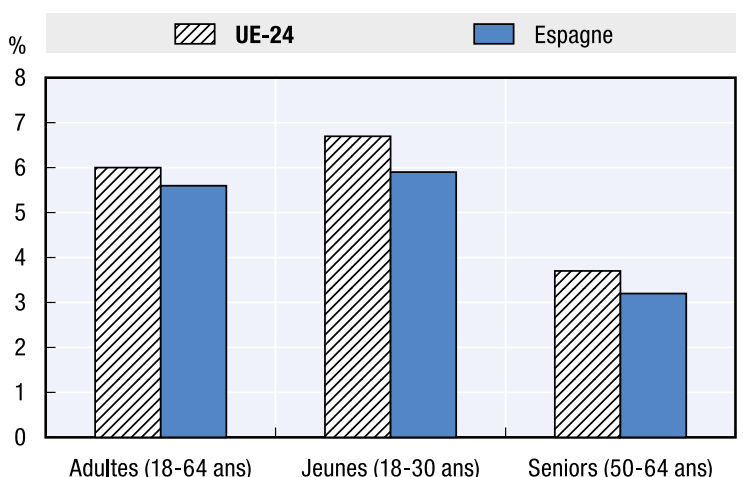

Diagramme B. Taux de travail indépendant, 2012

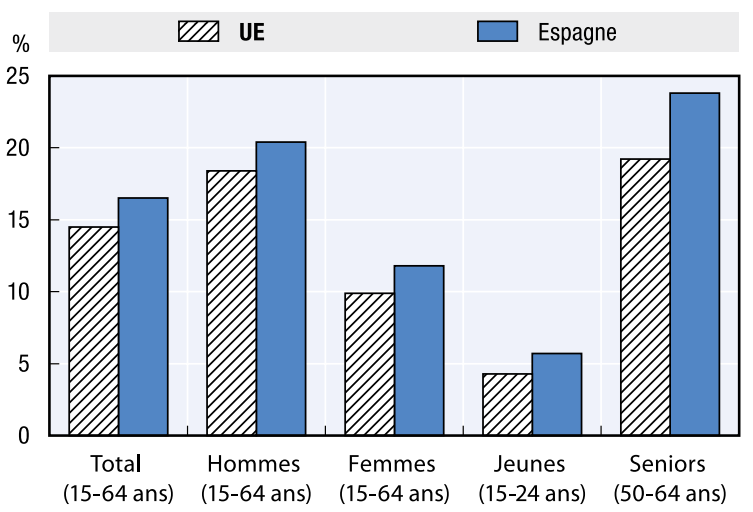

Diagramme D. Indice de l'activité entrepreneuriale totale au stade précoce, 2012

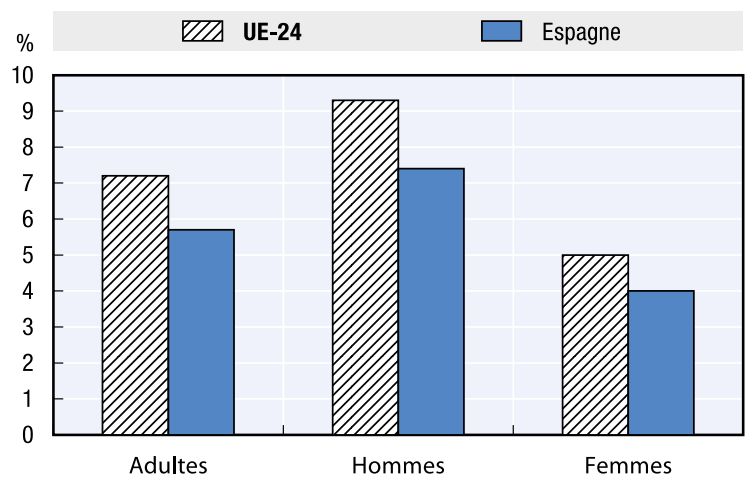

Sources: Diagramme A. Eurostat, Enquête sur les forces de travail, 2000-2012; Diagramme B. Eurostat, Enquête sur les forces de travail 2012; Diagramme C. Eurostat, Enquête sur les forces de travail, 2000-2012; Diagramme D. Présentation tabulaire spéciale de l'enquête sur la population adulte du Global Entrepreneurship Monitor, 2012; Diagramme E. Présentation tabulaire spéciale de l'enquête sur la population adulte du Global Entrepreneurship Monitor, 2008-2012. 


\section{Suède: Ambassadors for Women's Entrepreneurship}

Description: ce projet s'inscrit dans une politique plus globale visant à accroître l'intérêt et la participation des femmes dans l'entrepreneuriat. Son objectif est de mieux faire connaître l'entrepreneuriat féminin au sein de la société afin que davantage de femmes créent des entreprises. Il s'adresse aux femmes chefs d'entreprise confirmées (ambassadrices) et potentielles, ainsi qu'au grand public. Le projet inclut diverses actions mettant l'accent sur un groupe de femmes entrepreneurs modèles.

Problème abordé: en Suède comme ailleurs, les femmes sont minoritaires au sein de la communauté des entrepreneurs (environ $35 \%$ ). Cela n'a pas uniquement des conséquences sur l'afflux d'entrepreneurs. Non seulement les femmes sont sous-représentées, mais les secteurs dans lesquelles elles sont les plus susceptibles de démarrer une activité (les services et le commerce) le sont également parmi les nouvelles entreprises. Compte tenu de l'image traditionnellement masculine de l'entrepreneuriat et des entrepreneurs, ce programme occupe un rôle important dans la visibilité accrue des femmes en tant que chefs d'entreprise. Les ambassadrices jouent un rôle de modèle, en particulier auprès des jeunes femmes qui aspirent à se lancer dans l'entrepreneuriat.

Approche: dans le cadre de ce projet national, des ambassadrices issues de différents secteurs d'activité sont sélectionnées dans les 21 comtés. En tant que modèle, chaque ambassadrice accepte d'effectuer chaque année environ 4 missions volontaires, qui consistent à prendre la parole dans les écoles, les universités et autres organisations accueillant des visites d'étude ou à rencontrer des femmes qui envisagent de créer une entreprise. Depuis 2008, plus de 800 femmes entrepreneurs ont été sélectionnées pour devenir ambassadrices du programme «Ambassadors for Women's Entrepreneurship». Leurs frais de voyage ne sont pas remboursés et elles ne perçoivent pas de rémunération pour leurs interventions. L'Agence suédoise pour la croissance économique et régionale met en œuvre et coordonne les activités du programme, y compris la sélection et la formation des ambassadrices. Le projet «Ambassadors for Women's Entrepreneurship» s'inscrit dans le cadre d'un programme plus vaste destiné à développer l'entrepreneuriat féminin. Le budget de ce programme global s'élève à 100 millions SEK par an (11,3 millions EUR), dont seulement 6 millions SEK (680000 EUR) sont alloués au projet «Ambassadors for Women's Entrepreneurship".

Impact: depuis 2008, 127000 personnes ont présenté leur parcours et leur entreprise dans le cadre du programme "Ambassadors for Women's Entrepreneurship». Au terme de la période initiale du projet (2008-2011), un rapport sur ses effets à court terme a été rédigé. L'intérêt des médias et du public pour le projet atteste de la visibilité accrue donnée à l'entrepreneuriat féminin. À titre d'exemple, plus de 400 articles de journaux et de magazines ont été consacrés au projet en 2010.

Facteurs de réussite: ce projet est un exemple d'approche réussie faisant appel à des bénévoles pour promouvoir et encourager l'entrepreneuriat auprès des groupes défavorisés et sous-représentés. Son succès est en grande partie dû au faible degré d'implication demandé à ces bénévoles ainsi qu'à la dimension nationale du projet, qui lui assure de toucher un public élargi. Les ambassadrices investissent du temps et couvrent leurs propres dépenses, ce qui leur permet en échange de rendre ce qu'elles ont reçu à la communauté et d'étoffer leurs réseaux. Elles peuvent aussi tirer profit de l'exposition médiatique du projet. Cette situation gagnant-gagnant occupe une place centrale dans le programme. Celui-ci a été reproduit dans d'autre pays l'UE et offre de réelles possibilités d'adaptation à d'autres contextes. 


\section{Données clés relatives à l'entrepreneuriat inclusif}

\section{Graphique 37.1. Données relatives à l'entrepreneuriat et au travail indépendant en Suède}

Diagramme A. Taux de chômage, 2000-2012

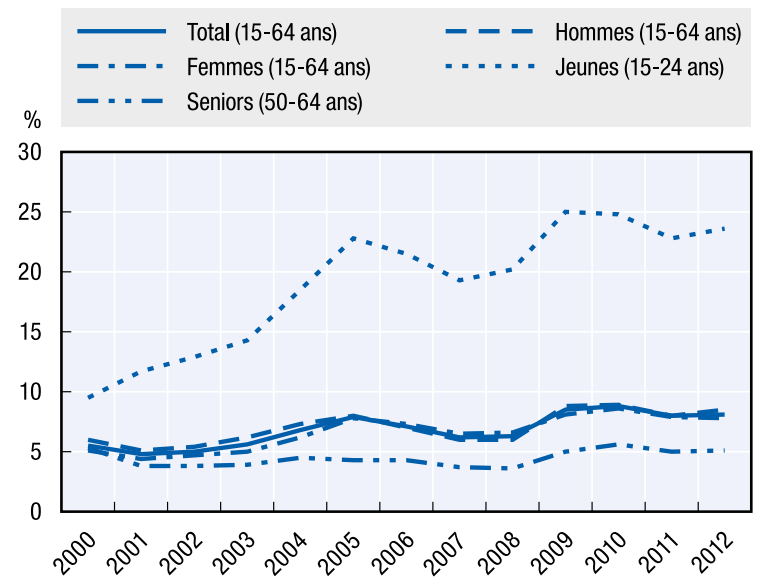

Diagramme C. Taux de travail indépendant, 2000-2012

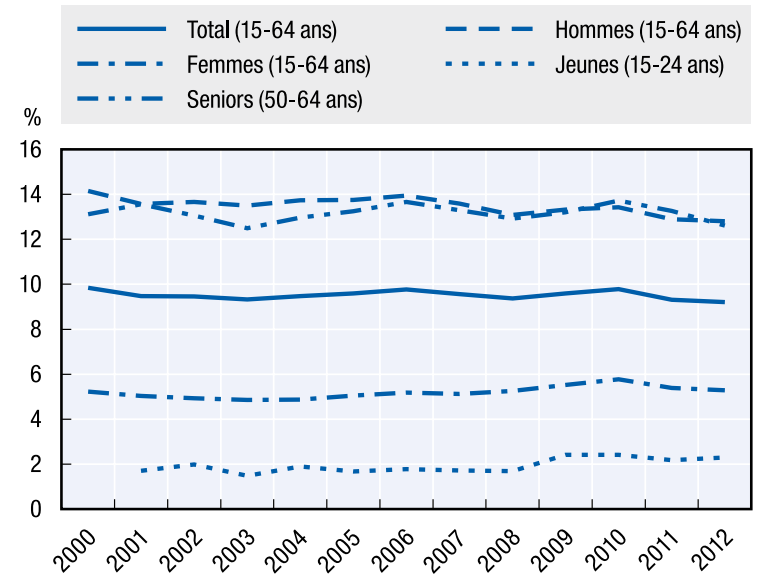

Diagramme E. Indice de l'activité entrepreneuriale totale au stade précoce, 2008-2012 (combinés)

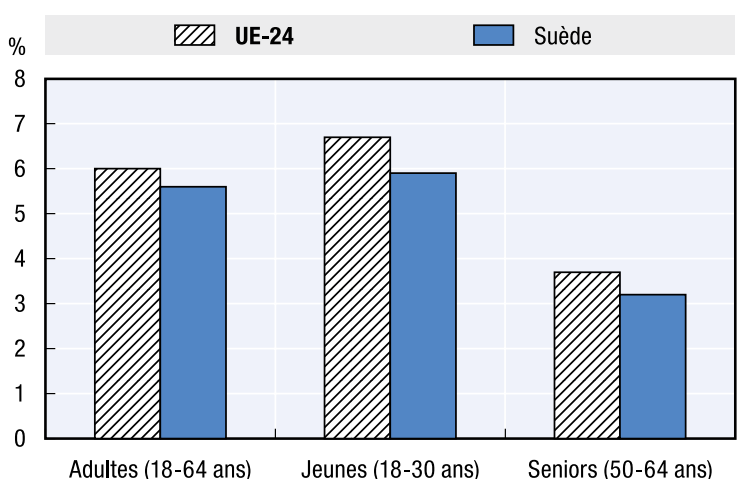

Diagramme B. Taux de travail indépendant, 2012

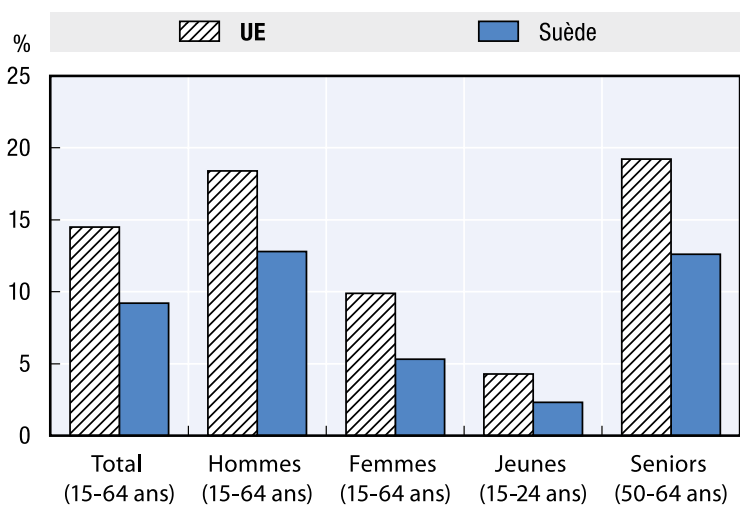

Diagramme D. Indice de l'activité entrepreneuriale totale au stade précoce, 2012

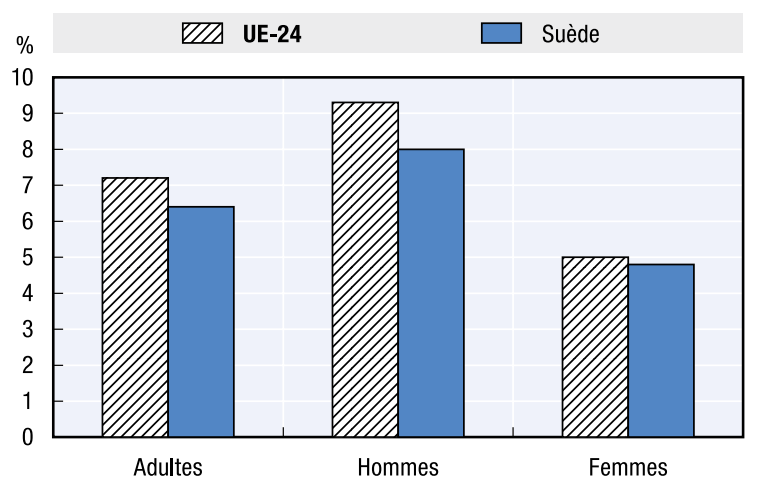

Sources: Diagramme A. Eurostat, Enquête sur les forces de travail, 2000-2012; Diagramme B. Eurostat, Enquête sur les forces de travail 2012; Diagramme C. Eurostat, Enquête sur les forces de travail, 2000-2012; Diagramme D. Présentation tabulaire spéciale de l'enquête sur la population adulte du Global Entrepreneurship Monitor, 2012; Diagramme E. Présentation tabulaire spéciale de l'enquête sur la population adulte du Global Entrepreneurship Monitor, 2008-2012. 


\section{Royaume-Uni: programme Local Enterprise Growth Initiative (LEGI)}

Description: le programme Local Enterprise Growth Initiative (LEGI) s'est déroulé de 2006 à mars 2011. Il visait à libérer le potentiel économique et productif des zones locales les plus démunies d'Angleterre par l'entrepreneuriat et l'investissement, et à stimuler ainsi les revenus et les opportunités d'emploi au niveau local pour bâtir des communautés pérennes. Le programme reposait sur des financements nationaux alloués à 20 zones défavorisées au terme d'une procédure d'appels d'offres. Pour prétendre à un financement du LEGI, une autorité locale devait être classée parmi les 50 collectivités locales les plus défavorisées selon l'indice de privations multiples (Index of Multiple Deprivation) de 2000 ou de 2004. Tous les soumissionnaires étaient tenus de proposer un ensemble de mesures d'aide intégré. Bien que très diverses, les offre incluaient souvent des aides aux entreprises et à l'emploi (p.ex. éducation à l'entreprise, soutien au franchisage, développement des secteurs et regroupements d'entreprises, accès accru aux marchés publics et attraction d'investisseurs).

Problème abordé: le programme LEGI s'intéressait principalement aux coûts d'amorçage élevés et aux autres freins liés aux marchés dans les zones défavorisées, comme le manque d'accès au financement en matière de création d'entreprise (Lee et Cowling, 2012). Parmi les autres entraves à la création d'entreprise dans ces zones figurent également les faibles niveaux de compétences de la main-d'œuvre, une culture entrepreneuriale limitée, l'accès difficile des petites et moyennes entreprises aux marchés publics et le manque d'engagement des entreprises vis-à-vis des populations locales.

Approche: le programme soutenait la création d'entreprises et d'emplois en donnant la possibilité aux autorités locales d'expérimenter un certain nombre d'approches innovantes. Il reconnaissait la nécessité d'élaborer et d'appliquer des stratégies flexibles en partenariat avec les autorités locales et les organisations du secteur associatif compte tenu des contextes très différents que connaissent les zones défavorisées. Ces partenariats locaux, placés sous l'égide des autorités locales, devaient soumettre une offre pour une enveloppe de financement limitée. Les offres ont été sélectionnées sur la base de la cohérence globale, et non sur des objectifs spécifiques. Entre 2006 et décembre 2009, les dépenses du programme étaient réparties comme suit: $31 \%$ à la croissance des entreprises, $29 \%$ à la création d'entreprise, $19 \%$ au développement des compétences et 10\% à l'amélioration et à la promotion des zones.

Impact: une évaluation finale publiée en décembre 2010 (Amion Consulting, 2010) fait état d'une diminution de l'écart entre les taux de création d'entreprise dans les zones couvertes par le programme LEGI et les taux nationaux entre 2006 et 2009, puisque 15 des 20 zones du programme ont obtenu des chiffres supérieurs à la moyenne anglaise en termes de création d'entreprise. Une analyse économétrique des écarts indique une augmentation statistiquement significative des taux de création d'entreprise dans les zones du programme. Selon une analyse de rentabilité, les gains du programme (mesurés en valeur ajoutée nette) étaient supérieurs aux coûts du secteur public. Une analyse indépendante indique toutefois des effets de déplacement importants dans les zones voisines (Einiö et Overman, 2012).

Facteurs de réussite: parmi les facteurs de réussite mis en évidence dans l'évaluation finale figurent la flexibilité laissée aux consortiums locaux d'organisations publiques, caritatives et issues du secteur lucratif dans l'élaboration d'une stratégie adaptée à leur contexte propre et dans leur collaboration à long terme au service de leur communauté, de sorte que les programmes LEGI restent complémentaires des dispositions existantes et ne les concurrencent pas; l'absence d'objectifs de performance à l'échelle nationale, au profit de l'innovation et de l'expérimentation d'approches nouvelles; et un soutien aux bénéficiaires à la fois inclusif et «intensif» permettant aux groupes défavorisés de s'impliquer. 


\section{Données clés relatives à l'entrepreneuriat inclusif}

\section{Graphique 38.1. Données relatives à l'entrepreneuriat et au travail indépendant au Royaume-Uni}

Diagramme A. Taux de chômage, 2000-2012
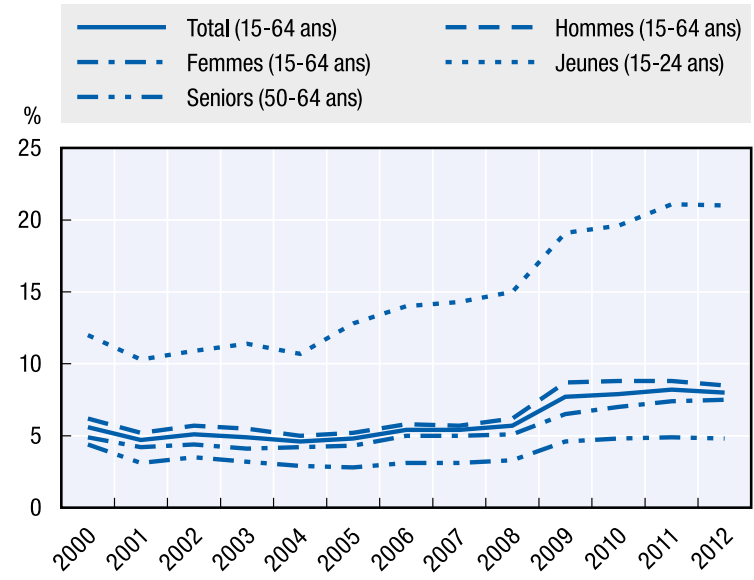

Diagramme C. Taux de travail indépendant, 2000-2012

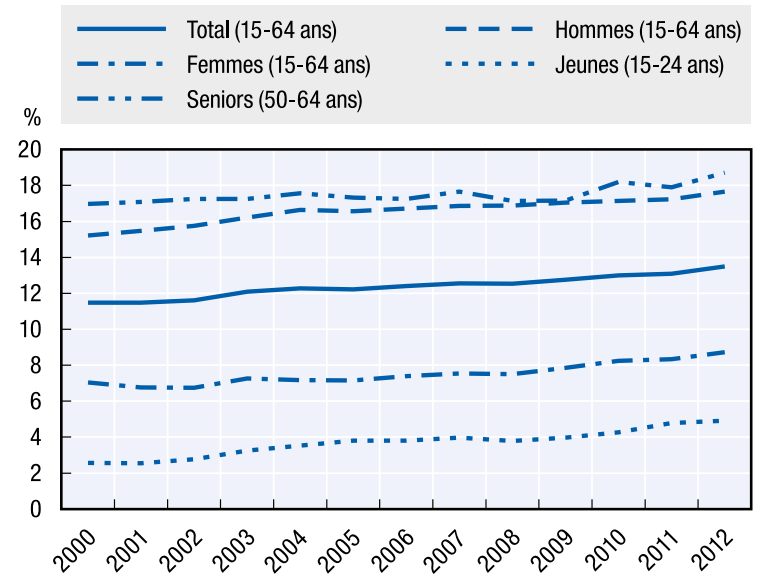

Diagramme E. Indice de l'activité entrepreneuriale totale au stade précoce, 2008-2012 (combinés)

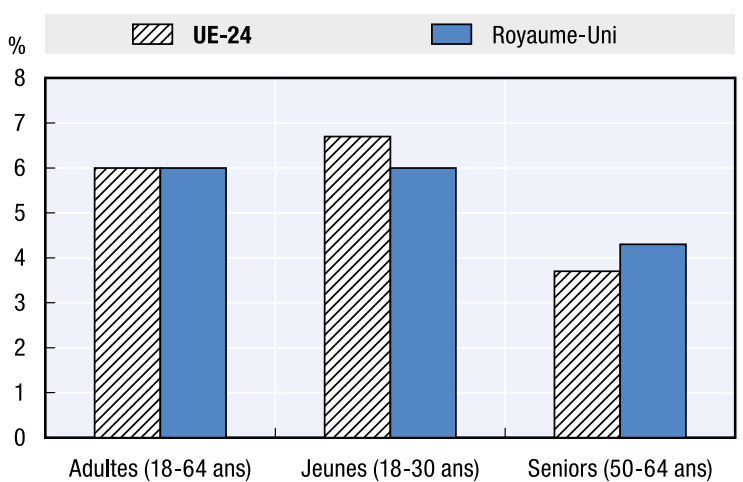

Diagramme B. Taux de travail indépendant, 2012

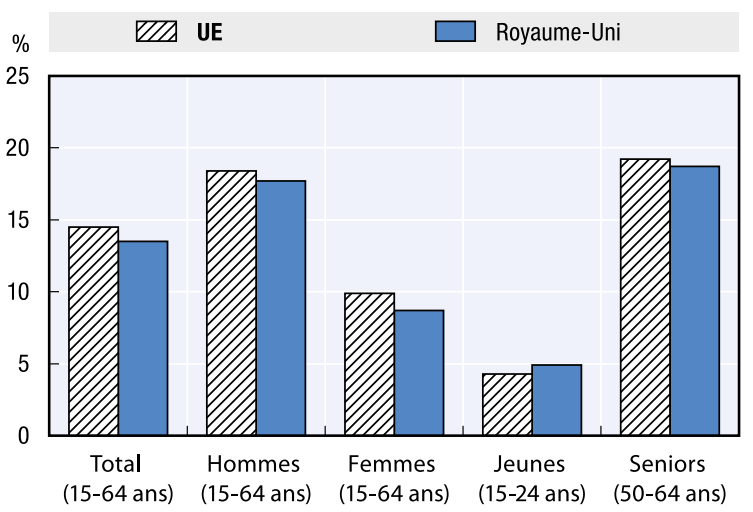

Diagramme D. Indice de l'activité entrepreneuriale totale au stade précoce, 2012

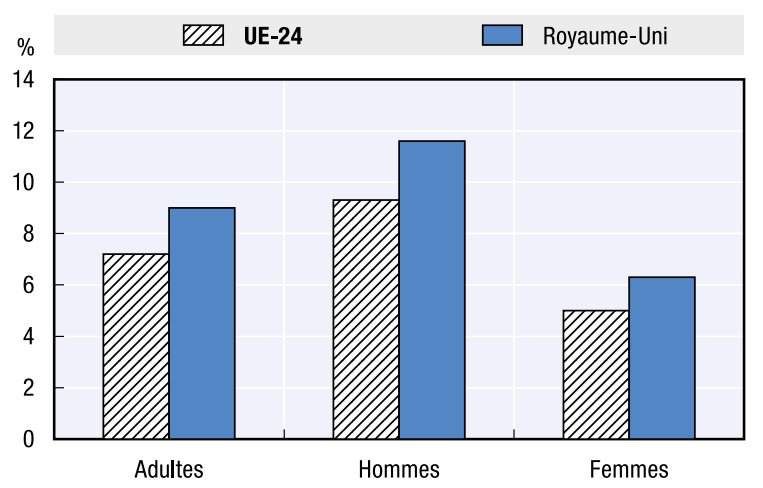

Sources: Diagramme A. Eurostat, Enquête sur les forces de travail, 2000-2012; Diagramme B. Eurostat, Enquête sur les forces de travail 2012; Diagramme C. Eurostat, Enquête sur les forces de travail, 2000-2012; Diagramme D. Présentation tabulaire spéciale de l'enquête sur la population adulte du Global Entrepreneurship Monitor, 2012; Diagramme E. Présentation tabulaire spéciale de l'enquête sur la population adulte du Global Entrepreneurship Monitor, 2008-2012. 


\section{Références}

Amion Consulting (2010), «National Evaluation of the Local Enterprise Growth Initiative Programme», Londres: Department for Communities and Local Government.

Budapest Institute (2008), «Impact analysis of increasing day care capacity for children aged 1-3». Budapest.

Cabinet of Ministers (2012), «Action plan for the development of Latgale region 2012-2013», http://ikumi.lv/doc. php?id=249821.

Dornmayr, H. et Lenger, B. (2006), «Evaluation of the business start-up programme (UGP) of the AMS (Austrian Labour Market Service)", Ibw research brief 22/2006.

Einiö, E. et Overman, H. (2012), «The effects of spatially targeted enterprise initiatives: Evidence from UK LEGI», document de travail de la London School of Economics, 6 février.

Eurobaromètre (2012), Eurobaromètre Flash 354: L'entrepreneuriat dans l'UE et au-delà.

Commission européenne (2013a), «The Policy on Gender Equality in Hungary», direction générale des politiques internes de l'Union - Mise à jour 2013.

Commission européenne (2013b), «2013 SMEs’ Access to Finance survey: Analytical Report».

Fabre, Virginie et Kerjosse, Roselyne (2006), Nouvelles entreprises, cinq ans après: l'expérience du créateur prime sur le diplôme.

GEM (2012), Global Entrepreneurship Monitor 2012 Global Report.

GfK (2012), The Amway European Entrepreneurship Report 2012.

IkStartSmart (2013), «IkStartSmart Gelderland 2008-2012: Endreport», https://ikstartsmart.nl/uploads/ Eindrapportage_IkStartSmart_2008-2012_def.pdf. (consulté le 11/09/2013)

Köllö, János (2012), «Reconciliation of work and family life - the impact of child allowances» dans Fazekas and Scharle (eds) From pensions to public works. Hungarian employment policy from 1990 to 2010, Budapest Institute and IE-HAS, 2012.

Kummissjoni Nazzjonali Persuni b’Dizabilita' — National Commission Persons with Disability (2009), «Proposed Employment Policy for Disabled People (Consultation Document)", Malte: KNPD, http://www.knpd.org/.

Lee, N. et Cowling, M. (2012), «Place, sorting effects and barriers to enterprise in deprived areas: Different problems or different firms?», International Small Business Journal, en ligne le 29 juin, DOI: $10.1177 / 0266242612445402$.

Lovász, A. (2012), «Labour market discrimination», dans Fazekas and Scharle (eds) From pensions to public works. Hungarian employment policy from 1990 to 2010, Budapest Institute and IE-HAS, 2012.

Mampaey, J. (2013), «Ondernemerschap van Bulgaarse, Poolse en Roemeense immigranten in België», Anvers: Steunpunt Inburgering \& Integratie.

Nagy, B. (2006), «Gender Equality and Gender Opportunities: Facts from Hungary».

OCDE (2007), «Étude économique de la Hongrie: l'assainissement budgétaire, principal enjeu de la politique économique», OCDE, Paris http://dx.doi.org/10.1787/eco_surveys-hun-2007-fr.

OCDE (2005), «Réformes économiques: objectif croissance 2006», note de la Hongrie, disponible sur: http://www.oecd.org/eco/labour/36012485.pdf.

OCDE (2001), Encourager les jeunes à entreprendre: les défis politiques, programme LEED, Territorial Development Division, OCDE, Paris.

Panteia/EIM (2011), «Evaluation of the entrepreneur initiatives IkStartSmart Gelderland», Zoetermeer, Pays-Bas.

Rebernik, M., Tominc, P., Crnogaj, K., Širec, K., Bradač-Hojnik, B. (2013), «Nezaznane priložnosti: GEM Slovenija 2012 (Unperceived opportunities: GEM Slovenia 2012)", Observatoire de l'entrepreneuriat slovène, Maribor: Faculté des sciences économiques et commerciales, Université de Maribor.

SEED Foundation (2007), «Proposal for the Entrepreneurial training for women in Budapest and surrounding area», SEED, Budapest. Mimeo.

Small Business Forum (2006), «Small business is big business», Report of the Small Business Forum.

Ziomas, D., Vezyrianni, K. (2010), «New approaches in the social and economic integration of the mentally ill: The case of Social Co-operatives», Greece's Social Portrait 2010, Centre national de recherche sociale (EKKE), Athènes. 


\section{Glossaire}

Mesures actives du marché du travail: mesures visant à aider les chômeurs et d'autres personnes à participer au marché du travail. Elles incluent habituellement le courtage (mise en correspondance des vacances d'emploi et des demandeurs d'emploi), la formation (pour améliorer et adapter les compétences des demandeurs d'emploi) et la création d'emplois directs (soit par l'emploi dans le secteur public, soit par la subvention du travail dans le secteur privé).

Conseil en entreprise: service d'aide au développement des entreprises proposant des conseils professionnels. Une approche courante consiste à proposer des services de conseil en entreprise dans le cadre de programmes d'aide intégrés et de conditionner l'octroi de l'aide financière à la demande de ce type de service.

Services d'aide au développement des entreprises: services destinés à améliorer les performances de l'entreprise en améliorant sa capacité à faire face à la concurrence et à accéder aux marchés. Les services d'appui incluent la formation, le mentorat, l'accompagnement individualisé, la consultance, l'assistance marketing, l'information, l'assistance pour le développement et le transfert de technologies et le réseautage. Tant les aspects stratégiques (questions à moyen et à long terme qui améliorent la performance) qu'opérationnels (gestion journalière) sont inclus.

Indicateurs de la création d'entreprise: ensemble de mesures quantitatives indiquant le nombre de personnes envisageant de créer une entreprise qui créent effectivement une entreprise inscrite au registre de commerce. En d'autres termes, ces indicateurs ont trait à la création d'entreprise, à savoir le moment où l'idée entrepreneuriale devient réalité et où l'entreprise apporte une contribution économique. Les décideurs politiques peuvent utiliser ces indicateurs pour mesurer en partie la culture entrepreneuriale.

Indicateurs de l'exploitation d'entreprise: ensemble de mesures quantitatives indiquant le nombre de personnes qui ont établi des entreprises commerciales en activité. Il peut s'agir du nombre d'entreprises, du chiffre d'affaires, des niveaux d'exportation, des travailleurs, etc. Les décideurs politiques peuvent utiliser ces indicateurs pour mesurer le nombre d'entrepreneurs et d'entreprises dans une économie donnée.

Coaching ou accompagnement individualisé: relation habituellement de courte durée destinée à développer les compétences d'un entrepreneur. Il s'agit d'un processus collaboratif, dans lequel les participants occupent des rôles clairement définis. Le coach est chargé de développer des objectifs à court terme et de guider son élève vers ces objectifs en formulant des commentaires constructifs. L'élève est chargé de produire des idées et des solutions, de prendre des mesures pour atteindre les objectifs et de faire part de ses progrès.

Actifs en garantie: actifs demandés par le prêteur à l'emprunteur pour l'émission d'un prêt. Il s'agit généralement de biens (bien immobilier, véhicule, etc.) qui peuvent être saisis par le prêteur en cas de défaut de paiement. 
Coûts des effets d'aubaine: mesure dans laquelle les participants auraient créé une nouvelle entreprise en l'absence de subvention ou de soutien. Le comportement de ces "participants d'aubaine» n'est pas influencé par le programme, mais leur participation ne contribue pas à la valeur économique et engendre une dépense publique. Le coût social de cette dépense correspond à la somme du coût de distorsion ou de la charge excédentaire de la taxe qui le finance et des dépenses destinées à couvrir les coûts de mise en œuvre.

Effets de déplacement: mesure dans laquelle les entreprises subventionnées s'emparent de l'activité et des emplois des entreprises établies non subventionnées.

Entrepreneurs handicapés: entrepreneurs atteints d'une invalidité. La grande majorité d'entre eux souffrent de handicaps «cachés», y compris de troubles de la santé mentale, de douleurs chroniques et de troubles musculosquelettiques. Une proportion très restreinte $a$ des handicaps visibles, par exemple les personnes se déplaçant en fauteuil roulant ou les déficients visuels. De nombreux pays ont maintenant recensé des barrières systémiques à l'encontre des personnes handicapées, comme des attitudes négatives et l'exclusion de la société (consciemment ou non).

Groupes défavorisés: groupes rencontrant des obstacles supplémentaires pour participer pleinement au marché du travail et à la société. Leur position défavorable est souvent due à des caractéristiques individuelles telles qu'une expérience limitée du monde du travail, un faible niveau d'instruction ou un capital social limité, mais peut également être liée à des caractéristiques partagées au sein d'un groupe. Par conséquent, les groupes défavorisés rencontrent des discriminations intentionnelles ou non.

Participation économique: mesure de la partie active de la force de travail d'une économie. Le taux de participation économique désigne la proportion de personnes qui sont soit employées, soit en recherche active de travail. Les personnes qui ne cherchent plus activement un travail ne sont pas reprises dans le taux de participation. La situation d'une personne influencera la probabilité qu'elle travaille ou qu'elle cherche du travail. Ainsi, les étudiants et les retraités ne recherchent habituellement pas de travail et sont donc exclus des taux d'activité. Durant une récession économique, le taux de participation diminue habituellement: le manque de possibilités d'emplois salariés décourage de nombreux travailleurs potentiels, qui arrêtent alors de chercher du travail.

Entrepreneur: personne (propriétaire d'entreprise) qui cherche à générer de la valeur, par la création ou l'expansion d'une activité économique, en identifiant et en exploitant de nouveaux produits, processus ou marchés (voir le programme d'indicateurs de l'entrepreneuriat de l'OCDE). Il est possible de se comporter de manière entrepreneuriale dans le secteur public, dans une entreprise sociale ou en qualité de salarié d'une entreprise.

Compétences entrepreneuriales: combinaison de compétences techniques, de compétences en gestion des affaires et de compétences personnelles requises pour se lancer dans l'entrepreneuriat et le travail indépendant et pour poursuivre sur cette voie. Elles incluent notamment le travail d'équipe, la négociation, le développement stratégique, la planification financière et le marketing.

Taux de détention d'entreprises établies: mesure de la proportion des membres de la population adulte qui sont actuellement dirigeants-propriétaires d'une entreprise établie qui verse des traitements, des salaires ou toute autre rémunération aux propriétaires depuis plus de 42 mois. Cette mesure a été développée par le Global Entrepreneurship Monitor et contribue à donner des informations sur le niveau d'activités entrepreneuriales au sein d'une économie. 
Entrepreneurs issus d'une minorité ethnique ou d'origine immigrée: les entrepreneurs issus d'une minorité ethnique sont nés dans leur pays de résidence, appartiennent à une minorité ethnique et conservent des liens forts avec leur culture ethnique. Les entrepreneurs immigrés ont migré dans un autre pays. S'ils peuvent appartenir au même groupe ethnique que la population majoritaire du pays, ils ne seront probablement pas aussi coutumiers de ses règles, de sa culture et de ses institutions.

Évaluation: l'évaluation a pour objectif de mesurer la pertinence, l'impact, l'efficacité et la rentabilité d'un programme ou d'une mesure. Les évaluations peuvent être qualitatives et/ou quantitatives. Les évaluations efficaces sont planifiées dès la conception de la mesure, et des indicateurs sont collectés tout au long de sa mise en œuvre pour alimenter l'évaluation. L'évaluation doit être conçue et mise en œuvre de manière à fournir des informations utiles aux décideurs, selon les circonstances politiques, les contraintes du programme et les ressources disponibles. Ses résultats doivent être utilisés pour améliorer la conception des mesures.

Exclusion financière: situation d'accès inexistant ou limité aux services financiers. Par exemple, les personnes n'ayant pas de compte en banque paient davantage pour leurs factures de services d'utilité publique, et un prêt revient beaucoup plus cher aux personnes ne disposant pas de garanties réelles. L'exclusion financière accroît les risques de pauvreté.

Entrepreneuriat inclusif: entrepreneuriat qui contribue à l'inclusion sociale et qui donne à tout le monde les mêmes chances de démarrer et de diriger une entreprise. Les groupes cibles sont les groupes défavorisés et sous-représentés dans l'entrepreneuriat et le travail indépendant, dont les jeunes, les femmes, les seniors, les minorités ethniques et les immigrés, les personnes handicapées et de nombreux autres groupes.

Couveuses: les couveuses d'entreprises sont des structures destinées à soutenir la création et la croissance des sociétés entrepreneuriales, par un large éventail de ressources et de services d'appui aux entreprises, offerts à la fois au sein de la couveuse directement et par son réseau de contacts. Les couveuses varient au niveau du mode de mise en œuvre de leurs services, de leur structure organisationnelle et du type de bénéficiaires. S'il existe des couveuses virtuelles/en ligne, la plupart des programmes accueillent dans leurs locaux des entreprises qui vont être lancées ou qui viennent de l'être, pour une période de temps limitée. Le fait qu'une jeune entreprise suive avec succès un programme de couveuse d'entreprise accroît ses chances de survie et de croissance.

Financement islamique: activités de financement conformes à la charia (loi islamique), qui interdit aux prêteurs d'appliquer des taux d'intérêt aux emprunteurs. Le prêt n'est pas exclu, mais les prêteurs doivent être traités comme des parties prenantes. Jusqu'ici, ce type de financement a plus souvent été utilisé par de grands fonds d'investissement qu'en soutien aux entrepreneurs.

Garantie de prêt: engagement d'un tiers à couvrir une partie des pertes liées à un défaut de paiement. Elle peut être apportée par un gouvernement et/ou par une association professionnelle privée. Elle est assortie d'un fonds servant de garantie.

Mentorat: le mentorat est une relation professionnelle dans laquelle une personne expérimentée (le mentor) aide une autre (l'élève) à développer des compétences et des connaissances qui renforceront son développement professionnel et personnel. Ces relations sont habituellement de plus longue durée que le coaching. 
Microcrédit: prêts de faible montant à des emprunteurs qui ont des difficultés à obtenir des crédits auprès d'établissements bancaires traditionnels. Les taux d'intérêt, supérieurs à ceux des banques traditionnelles, reflètent le profil à risque de l'emprunteur. Dans l'UE, le plafond du microcrédit est fixé à 25000 EUR.

Taux d'entrepreneuriat naissant: proportion des membres de la population qui sont activement impliqués dans la création d'une entreprise dont ils seront propriétaires en tout ou en partie. Cette activité n'a pas rapporté de traitement, de salaire ou toute autre rémunération aux propriétaires depuis plus de trois mois. C'est l'une des mesures développées par le Global Entrepreneurship Monitor pour quantifier les activités entrepreneuriales au sein d'une économie.

Taux de détention de nouvelles entreprises: proportion des membres de la population qui sont actuellement dirigeants-propriétaires d'une nouvelle entreprise qui verse des traitements, des salaires ou toute autre rémunération aux propriétaires depuis plus de trois mois mais moins de 42 mois. C'est l'une des mesures développées par le Global Entrepreneurship Monitor pour quantifier les activités entrepreneuriales au sein d'une économie.

Services de proximité: tentative systématique de fournir des services au-delà des limites traditionnelles pour atteindre des groupes particuliers d'une communauté. Les services de proximité peuvent servir à informer les gens de l'existence de services (plus traditionnels), ainsi qu'à toucher et mobiliser des groupes spécifiques et ceux qui n'ont pas l'habitude de recourir aux services traditionnels. Une approche possible consiste à fournir les services dans des lieux que les personnes fréquentent déjà (centres communautaires, maisons de jeunes, lieux de culte, centres commerciaux, etc.) plutôt qu'à installer un bureau et essayer d'y attirer les gens.

Entrepreneuriat parallèle: situation dans laquelle un entrepreneur dirige plus d'une entreprise. Ces entreprises peuvent offrir des biens et des services complémentaires à la même clientèle, créant ainsi des synergies entre elles. Il peut également s'agir d'entreprises sans rapport entre elles, destinées à fournir un revenu plus stable à l'entrepreneur.

Entrepreneuriat à temps partiel: entrepreneuriat mené à temps partiel. Il s'agit le plus souvent d'un travail indépendant à temps partiel: la personne consacre moins de 35 heures par semaine à une activité indépendante. Cette forme d'entrepreneuriat sert souvent à compléter d'autres activités telles qu'un emploi salarié, le travail ménager non rémunéré ou des activités d'apprentissage.

Indicateurs de précréation d'entreprise: ces mesures cernent l'attitude de la société vis-à-vis de l'entrepreneuriat et le niveau d'intérêt affiché par les gens pour créer une entreprise. Elles représentent un outil politique important pour déterminer la disposition culturelle à l'égard de l'entrepreneuriat.

Modèle: entrepreneur expérimenté qui peut donner à d'autres l'envie de se lancer dans la création d'entreprise ou le travail indépendant.

Travail indépendant: statut professionnel dans le cadre duquel les personnes travaillent à leur propre compte dans leur propre entreprise et perçoivent un retour économique en échange de leur travail, sous la forme de traitements, de bénéfices, d'avantages en nature ou de gain familial (pour les travailleurs familiaux). Les travailleurs indépendants peuvent travailler seuls ou employer d'autres personnes. Ils dirigent souvent leur entreprise en qualité d'entreprise à propriétaire unique, de contractant indépendant, de membre d'un partenariat ou d'entreprise non constituée en société. 
Entrepreneurs seniors: ce terme désigne habituellement les entrepreneurs de plus de 50 ans, également connus sous le nom d'«entrepreneurs grisonnants», d'«entrepreneurs âgés», d'«entrepreneurs du troisième âge» et de "seniorpreneurs». On estime qu'ils joueront un rôle de plus en plus important dans l'activité économique, compte tenu du vieillissement de la population et du déclin de la population traditionnellement en âge de travailler.

Entrepreneuriat en série: processus consistant à créer des entreprises et à les revendre lorsqu'elles sont encore jeunes plutôt que de les diriger pendant toute leur durée de vie.

Orientation: informations mises à la disposition d'entrepreneurs potentiels et en activité afin de les orienter vers des sources d'information et d'assistance professionnelles.

Capital social: valeur des réseaux sociaux, qu'il s'agisse de la famille, des amis ou des collègues, et des contacts professionnels et personnels qui permettent d'ouvrir de nouvelles portes. Le capital social donne accès aux connaissances, aux réseaux de clients, aux fournisseurs et au soutien professionnel, et peut ainsi augmenter les chances de réussite d'une entreprise donnée.

Entrepreneuriat social: entrepreneuriat dans lequel l'objectif principal est d'avoir un impact social plutôt que de rapporter des bénéfices aux propriétaires ou actionnaires. Les entreprises sociales délivrent des biens et des services au marché de manière entrepreneuriale et innovante et utilisent leurs bénéfices pour atteindre des objectifs sociaux avant tout. Elles sont gérées de manière ouverte et responsable et, plus particulièrement, impliquent les travailleurs, les consommateurs et les parties prenantes concernées par leurs activités commerciales.

Inclusion sociale: action positive prise pour inclure tous les secteurs de la société dans une activité économique et sociale, notamment en veillant à ce que les groupes marginalisés ou en situation de pauvreté participent davantage aux décisions les concernant, leur permettant ainsi d'améliorer leur niveau de vie et leur bien-être global.

Activité entrepreneuriale totale au stade précoce (TEA): mesure utilisée par le Global Entrepreneurship Monitor, équivalant à la somme de la proportion de la population impliquée dans une activité entrepreneuriale naissante et de la proportion de la population qui a créé une entreprise au cours des 42 derniers mois.

Groupes sous-représentés: groupes de la société moins représentés dans l'économie d'entreprise que leur proportion dans la population globale, par exemple les femmes et les personnes handicapées.

Équilibre vie professionnelle-vie privée: concept impliquant d'établir les bonnes priorités entre le «travail» (carrière et ambition) et le mode de vie (santé, plaisir, loisirs, famille et développement spirituel).

Jeunes entrepreneurs: entrepreneurs en fin d'adolescence ou dans la vingtaine. La fourchette d'âge exacte dépend du contexte. Le Global Entrepreneurship Monitor définit par exemple les jeunes entrepreneurs comme les 18-30 ans, tandis que pour l'Eurobaromètre Flash, il s'agit des 15-24 ans. 


\section{ORGANISATION DE COOPÉRATION ET DE DÉVELOPPEMENT ÉCONOMIQUES}

L'OCDE est un forum unique en son genre où les gouvernements œuvrent ensemble pour relever les défis économiques, sociaux et environnementaux liés à la mondialisation. À l'avant-garde des efforts engagés pour comprendre les évolutions du monde actuel et les préoccupations qu'elles suscitent, l'OCDE aide les gouvernements à y faire face en menant une réflexion sur des thèmes tels que le gouvernement d'entreprise, l'économie de l'information et la problématique du vieillissement démographique.

L'Organisation offre aux gouvernements un cadre leur permettant de confronter leurs expériences en matière d'action publique, de chercher des réponses à des problèmes communs, de recenser les bonnes pratiques et de travailler à la coordination des politiques nationales et internationales.

Les pays membres de l'OCDE sont: l'Allemagne, l'Australie, l'Autriche, la Belgique, le Canada, le Chili, la Corée, le Danemark, l'Espagne, l'Estonie, les États-Unis, la Finlande, la France, la Grèce, la Hongrie, l'Irlande, l'Islande, Israël, l'Italie, le Japon, le Luxembourg, le Mexique, la Norvège, la Nouvelle-Zélande, les Pays-Bas, la Pologne, le Portugal, la République slovaque, la République tchèque, le Royaume-Uni, la Slovénie, la Suède, la Suisse et la Turquie. L'Union européenne participe aux travaux de l'OCDE.

Les Éditions OCDE assurent une large diffusion aux travaux de l'Organisation. Ces derniers comprennent les résultats de l'activité de collecte de statistiques, les travaux de recherche menés sur des questions économiques, sociales et environnementales, ainsi que les conventions, les principes directeurs et les modèles développés par les pays membres.

\section{LA COMMISSION EUROPÉENNE}

La direction générale de l'emploi, des affaires sociales et de l'inclusion de la Commission européenne mène des initiatives politiques, législatives et financières en vue de stimuler la création d'emplois de meilleure qualité, lutter contre la pauvreté et l'exclusion sociale, promouvoir la justice et la protection sociales, favoriser la libre circulation des travailleurs, garantir la mobilité de la main-d'œuvre, faire la promotion des droits des travailleurs, encourager la solidarité entre les générations et contribuer au meilleur fonctionnement des marchés du travail, au plein emploi, au progrès social ainsi qu'à une économie sociale de marché hautement compétitive au sein de l'Union européenne dans le contexte de la stratégie Europe 2020. 


\section{Pallier la pénurie d'entrepreneurs 2014 POLITIQUES D'ENTREPRENEURIAT INCLUSIF EN EUROPE}

Cette publication se penche sur la manière dont les politiques publiques menées aux échelons national, régional et local peuvent stimuler l'emploi en encourageant la création d'entreprises et le travail indépendant au sein des groupes sociaux défavorisés ou sous-représentés dans la sphère entrepreneuriale. Elle démontre que la promotion de l'entrepreneuriat chez les femmes, les jeunes, les personnes âgées, les chômeurs et les migrants peut sensiblement contribuer à lutter contre le chômage et à favoriser l'inclusion sociale, pour autant que l'on s'attaque aux problèmes spécifiques rencontrés par ces groupes et que les politiques en faveur de l'entrepreneuriat soient ouvertes à tous. Le débat politique sur lequel porte ce rapport met l'accent sur la création d'entreprises par des chômeurs, l'entrepreneuriat des minorités ethniques, les services d'aide au développement des entreprises destinés aux start-up ainsi que sur l'interaction entre les systèmes de sécurité sociale et les politiques d'entrepreneuriat inclusif, et se veut une source d'inspiration en présentant les bonnes pratiques mises en œuvre dans l'Union européenne.

\section{Table des matières}

Préface

Guide de lecture

Chapitre 1. La politique d'entrepreneuriat inclusif de l'Union Européenne

\section{Partie I: Les activités d'entrepreneuriat inclusif en Europe}

Chapitre 2. Le travail indépendant et l'entrepreneuriat chez les femmes

Chapitre 3. Le travail indépendant et l'entrepreneuriat chez les jeunes

Chapitre 4. Le travail indépendant et l'entrepreneuriat chez les seniors

Chapitre 5. Localisation des activités entrepreneuriales

\section{Partie II: Les politiques d'entrepreneuriat inclusif}

Chapitre 6. Politiques en faveur de l'entrepreneuriat des chômeurs

Chapitre 7. Soutien politique en faveur de l'entrepreneuriat des minorités ethniques

Chapitre 8. Services d'aide au développement des start-up

Chapitre 9. Securité sociale et entrepreneuriat inclusif

\section{Partie III: Profils des pays}

Chapitre 10. Données et pratiques instructives en matière de politique d'entrepreneuriat inclusif

Veuillez consulter cet ouvrage en ligne: $\boldsymbol{h t t p : / / d x . d o i . o r g / 1 0 . 1 7 8 7 / 9 7 8 9 2 6 4 2 3 0 8 4 2 - f r ~}$

Cet ouvrage est publié sur OECD iLibrary, la bibliothèque en ligne de l'OCDE, qui regroupe tous les livres, périodiques et bases de données statistiques de l'Organisation. Rendez-vous sur le site www.oecd-ilibrary.org pour plus d'informations.

OECDpublishing www.oecd.org/publishing
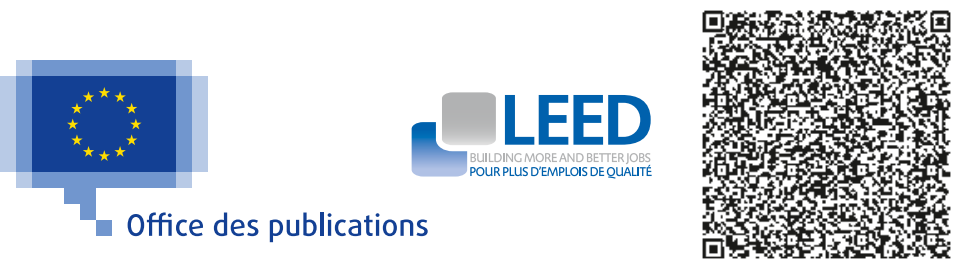

ISBN 978-92-64-23084-2 842014082 E1

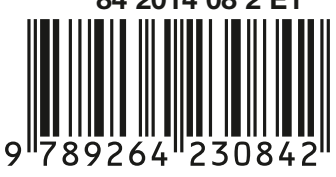

